Generalização de regras de associação utilizando conhecimento de domínio e avaliação do conhecimento generalizado

Veronica Oliveira de Carvalho 



\section{Generalização de regras de associação utilizando conhecimento de domínio e avaliação do conhecimento generalizado}

Veronica Oliveira de Carvalho

Orientadora: Prof $f^{a} \operatorname{Dr}^{a}$ Solange Oliveira Rezende

Tese apresentada ao Instituto de Ciências Matemáticas e de Computação - ICMC-USP, como parte dos requisitos para obtenção do título de Doutor em Ciências Ciências de Computação e Matemática Computacional.

USP - São Carlos

Agosto/2007 

Este documento foi preparado utilizando-se o formatador de textos $\mathrm{AT}_{\mathrm{E}} \mathrm{X}$. Sua bibliografia é gerada automaticamente pelo $\mathrm{BiBT}_{\mathrm{E}} \mathrm{X}$, utilizando o estilo Chicago.

(C) Copyright 2007 - Veronica Oliveira de Carvalho Todos os Direitos Reservados 

Aos meus pais, José e Neusa, as minhas irmãs, Vanessa e Veridiana, e ao meu amor Marcos. 



\section{Agradecimentos}

Ufa...mais uma etapa concluída. Não foi fácil chegar até aqui. Essa conquista só foi possível graças ao apoio, incentivo e contribuição de várias pessoas, às quais gostaria aqui de agradecer.

Aos meus pais, Neusa e José, as minhas irmãs, Vanessa e Veridiana, e ao meu amor Marcos, que sempre me apoiaram, incentivaram e me aturaram nos momentos mais difíceis.

À minha orientadora Solange Rezende, com a qual aprendi muito, não só profissionalmente, mas também como pessoa. Obrigada pelo tempo despendido às minhas "listas" intermináveis. Obrigada pela paciência, pelas ajudas "extras" doutorado, por aturar minhas reclamações; enfim, obrigada por tudo!

Ao meu "co-orientador" Mário de Castro, pela atenção dedicada durante o último ano. Obrigada pelas idéias, sugestões, pela paciência em responder as minhas perguntas "básicas" e "óbvias" sobre estatística, etc.

Aos meus ex-orientadores, José Pacheco (Iniciação Científica) e Orides (Mestrado), com os quais aprendi não ser tão "estressada" e que me incentivaram a continuar, de alguma forma, na área acadêmica. Aos meus ex-professores de graduação, Avelino, Formigoni, Rejane, Claudia e Gustavo, e minha ex-professora de mestrado, Maria do Carmo, por todo apoio e ensinamento.

Aos alunos e ex-alunos da professora Solange, Jaqueline, Edson, Roberta, Camila, Magaly, Giselle, Fernanda, Marcos Aurélio e Walter, pelas idéias, discussões e ajuda de sempre.

Às amigas, Lúcia e Jaqueline, que sempre estiveram ao meu lado e que nunca mediram esforços para me ajudar. Às amigas de longa data, Karina e Aline, que fizeram e fazem

parte da minha vida. À Gleice, pela prazerosa companhia durante o difícil período inicial do doutorado. 
Aos meus amigos da Uniara, Mayb, Edílson, Flávia, Dalton e Elivanete, que me escutaram sem parar durante todo esse período.

Ao Anand, por passar noites corrigindo artigos em inglês e pela revisão do abstract.

Aos funcionários do ICMC, pela atenção, respeito e dedicação.

À Universidade de São Paulo, pela oportunidade e pela qualidade do ensino e pesquisa.

A todos aqueles que, direta ou indiretamente, contribuíram para a realização desta tese.

A Deus, por ter me dado e por me dar forças para continuar lutando. 


\section{Resumo}

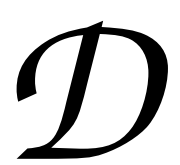

entre as técnicas de mineração de dados encontra-se a associação, a qual identifica todas as associações intrínsecas contidas na base de dados. Entretanto, essa característica, vantajosa por um lado, faz com que um grande número de padrões seja gerado, sendo que muito deles, mesmo sendo estatisticamente aceitos, são triviais, falsos, ou irrelevantes à aplicação. Além disso, a técnica de associação tradicional gera padrões compostos apenas por itens contidos na base de dados, o que leva à extração, em geral, de um conhecimento muito específico. Essa especificidade dificulta a obtenção de uma visão geral do domínio pelos usuários finais, que visam a utilização/exploração de conhecimentos úteis e compreensíveis. Assim, o pós-processamento das regras descobertas se torna um importante tópico, uma vez que há a necessidade de se validar as regras obtidas. Diante do exposto, este trabalho apresenta uma abordagem de pós-processamento de regras de associação que utiliza conhecimento de domínio, expresso via taxonomias, para obter um conjunto de regras de associação generalizadas compacto e representativo. Além disso, a fim de avaliar a representatividade de padrões generalizados, é apresentado também neste trabalho um estudo referente à utilização de medidas de interesse objetivas quando aplicadas a regras de associação generalizadas. Nesse estudo, a semântica da generalização é levada em consideração, já que cada uma delas fornece uma visão distinta do domínio. Como resultados desta tese, foi possível observar que: um conjunto de regras de associação pode ser compactado na presença de um conjunto de taxonomias; para cada uma das semânticas de generalização existe um conjunto de medidas mais apropriado para ser utilizado na avaliação de regras generalizadas. 



\section{Abstract}

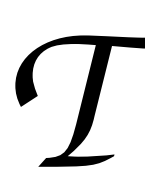

he association technique, one of the data mining techniques, identifies all the intrinsic associations in database. This characteristic, which can be advantageous on the one hand, generates a large number of patterns. Many of these patterns, even statistically accepted, are trivial, spurious, or irrelevant to the application. In addition, the association technique generates patterns composed only by items in database, which in general implies a very specific knowledge. This specificity makes it difficult to obtain a general view of the domain by the final users, who aims the utilization/exploration of useful and comprehensible knowledge. Thus, the post-processing of the discovered rules becomes an important topic, since it is necessary to validate the obtained rules. In this context, this work presents an approach for post-processing association rules that uses domain knowledge, expressed by taxonomies, to obtain a reduced and representative generalized association rule set. In addition, in order to evaluate the representativeness of generalized patterns, a study referent to the use of objective interest measures when applied to generalized association rules is presented. In this study, the generalization semantics is considered, since each semantic provides a distinct view of the domain. As results of this thesis, it was possible to observe that: an association rule set can be compacted with a taxonomy set; for each generalization semantic there is a measure set that is more appropriate to be used in the generalized rules evaluation. 



\section{Sumário}

Agradecimentos $\quad$ ix

Resumo

Abstract $\quad$ xiii

Sumário $\quad$ Xv

Lista de Figuras $\quad$ xix

Lista de Tabelas $\quad$ xxvii

Lista de Algoritmos $\quad$ xxix

1 Introdução 1

1.1 Hipóteses . . . . . . . . . . . . . . . . . . . 4

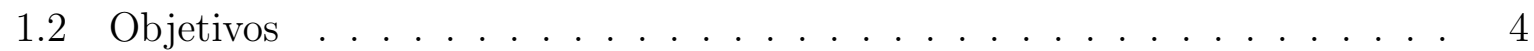

1.3 Organização . . . . . . . . . . . . . . . . . . . . . 4

2 Mineração de Dados e Regras de Associação $\quad 7$

2.1 Considerações Iniciais . . . . . . . . . . . . . . . . . . . 7

2.2 Mineração de Dados . . . . . . . . . . . . . . . . . . . . . 8

2.2.1 Identificação do Problema . . . . . . . . . . . . . . . . . 9

2.2.2 Pré-Processamento . . . . . . . . . . . . . . . . . . . . 10

2.2 .3 Extração de Padrões . . . . . . . . . . . . . . . . . . . . . . 12

2.2.4 Pós-Processamento . . . . . . . . . . . . . . . . . . . 14

2.2.5 Utilização do Conhecimento . . . . . . . . . . . . . . . . . 14

2.3 Regras de Associação . . . . . . . . . . . . . . . . . . . . . . . . 15

2.3.1 Definições e Conceitos . . . . . . . . . . . . . 16 
2.3.2 Sintaxe Padrão para Representar Regras de Associação ...... 17

2.3.3 Abordagens para Avaliação de Regras de Associação . . . . . . . . 19

2.3.4 Descrição das Medidas de Interesse Objetivas Utilizadas na Avaliação de Regras de Associação . . . . . . . . . . . . . . . . . . 23

2.4 Considerações Finais . . . . . . . . . . . . . . . . . . . . . . . 31

3 Uso de Taxonomias em Regras de Associação 33

3.1 Considerações Iniciais . . . . . . . . . . . . . . . . . . . . . . . 33

3.2 Notações e Definições . . . . . . . . . . . . . . . . . . . . . . . . . . . . . . 35

3.3 Estado da Arte . . . . . . . . . . . . . . . . . . . . . . . . . . . . . 38

3.3 .1 Pré-Processamento . . . . . . . . . . . . . . . . . 38

3.3 .2 Extração de Padrões . . . . . . . . . . . . . . . . . . . . . 39

3.3.3 Pós-Processamento . . . . . . . . . . . . . . . . . . . . 40

3.4 Considerações Finais . . . . . . . . . . . . . . . . . . . . . . . 43

4 Abordagem de Pós-Processamento de Regras de Associação ( $A P R A)$ Usando Taxonomias de Domínio $\quad 45$

4.1 Considerações Iniciais . . . . . . . . . . . . . . . . . . . . . . . 45

4.2 Especificação da Abordagem Proposta . . . . . . . . . . . . . . . 46

4.3 O Algoritmo da APRA . . . . . . . . . . . . . . . . . . . . . . 49

4.3.1 Arquivos de Entrada e Saída . . . . . . . . . . . . . . . . . . 52

4.3.2 Descrição Detalhada do Algoritmo APRA $A_{a l g} \ldots$. . . . . . . . 58

4.4 Considerações e/ou Restrições . . . . . . . . . . . . . . . . . . . . . . 62

4.5 Exemplo de Execução do $A P R A_{a l g} \ldots \ldots$. . . . . . . . . . 66

4.6 Comparação da APRA com o Estado da Arte . . . . . . . . . . . . . . 77

4.7 O Módulo de Exploração RulEE-RAG . . . . . . . . . . . . . . . . . 79

4.8 Avaliação Experimental da APRA . . . . . . . . . . . . . . . . . 82

4.8.1 Descrição dos Conjuntos de Dados . . . . . . . . . . . . . 83

4.8.2 Configuração dos Experimentos . . . . . . . . . . . . . . . . 84

4.8.3 Avaliação da Taxa de Compactação . . . . . . . . . . . . . . . . . . 86

4.9 Considerações Finais . . . . . . . . . . . . . . . . . . . . . . 89

5 Avaliação do Conhecimento Generalizado via Medidas de Interesse Ob$\begin{array}{ll}\text { jetivas } & 91\end{array}$

5.1 Considerações Iniciais . . . . . . . . . . . . . . . . . . . . . . . . . . . . . . 91

5.2 Avaliação Empírica do Conhecimento Generalizado Via Medidas de Interesse Objetivas . . . . . . . . . . . . . . . . . . . . . . 92

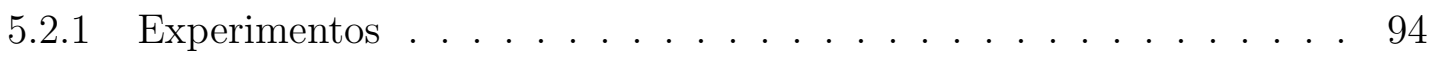


5.2.2 Comparação da Avaliação Empírica com o Estado da Arte . . . . . 103

5.3 Avaliação Analítica do Conhecimento Generalizado Via Medidas de Interesse Objetivas . . . . . . . . . . . . . . . . . . . . . 105

5.3.1 Comportamento das Medidas na Generalização do LHS . . . . . . 106

5.3.2 Comportamento das Medidas na Generalização do RHS . . . . . . 109

5.3.3 Comportamento das Medidas na Generalização do LRHS ... . 113

5.3.4 Discussão sobre o Comportamento das Medidas . . . . . . . . . . . 113

5.4 Avaliação do Conhecimento Generalizado Via Especialista do Domínio . 116

5.4.1 Metodologia de Seleção de Regras para Avaliação . . . . . . . . . . 117

5.4 .2 Avaliação do Conhecimento . . . . . . . . . . . . . . . . . . 119

5.5 Considerações Finais . . . . . . . . . . . . . . . . . 125

6 Conclusão $\quad 127$

6.1 Contribuições . . . . . . . . . . . . . . . . . . . . 128

6.2 Trabalhos Futuros . . . . . . . . . . . . . . . . . 131

A Exemplo de Execução do $A P R A_{\text {alg }}$

B Conjuntos de Taxonomias Utilizados no Cjto-Sup 147

C Conjuntos de Taxonomias Utilizados no Cjto-R 171

D Resultados Referentes à Taxa de Compactação do Cjto-Sup Agrupados por Medida $\quad 175$

E Resultados Referentes à Taxa de Compactação do Cjto-R Agrupados $\begin{array}{ll}\text { por Medida } & 187\end{array}$

F Resultados Referentes à Taxa de Compactação do Cjto-Sup Agrupados $\begin{array}{lr}\text { por Lado } & 189\end{array}$

G Resultados Referentes à Taxa de Compactação do Cjto-R Agrupados $\begin{array}{ll}\text { por Lado } & 219\end{array}$

H Histogramas do Cjto-Sup $\quad 225$

$\begin{array}{llr}\text { I Histogramas do Cjto-R } & 247\end{array}$

$\begin{array}{lr}\text { Referências Bibliográficas } & 269\end{array}$ 



\section{Lista de Figuras}

2.1 Etapas do processo de mineração de dados. . . . . . . . . . . . . . . . . . 9

3.1 Exemplo de uma taxonomia para vestuário. . . . . . . . . . . . . . . . 34

3.2 Abordagem de pós-processamento de regras proposta por Adomavicius \& Tuzhilin (2001) . . . . . . . . . . . . . . . . . . 4 41

3.3 Abordagem de pós-processamento de regras de associação proposta por Domingues \& Rezende (2005); Domingues (2004). . . . . . . . . . . . . . . 42

4.1 Visão geral da abordagem de pós-processamento de regras de associação (APRA) . . . . . . . . . . . . . . . . . . 47

4.2 Exemplo de execução do $A P R A_{\text {alg }} \ldots \ldots$. . . . . . . . . . . 50

4.3 Listagem de contribuição de itens gerada a partir dos conjuntos apresentados no exemplo da Figura 4.2 . . . . . . . . . . . . . . . . . 51

4.4 Relacionamento entre os arquivos de entrada e saída do $A P R A_{\text {alg }} \ldots$. . . . 53

4.5 Exemplo de um arquivo de dados (.apr.data). . . . . . . . . . . . . 53

4.6 Exemplo de um arquivo de regras de associação na sintaxe padrão (.apr.dcar). 54

4.7 Exemplo de um arquivo contendo uma taxonomia (.tax). . . . . . . . . . . 54

4.8 Exemplo de um arquivo contendo duas taxonomias (.tax). . . . . . . . . . 55

4.9 Exemplo de um arquivo contendo a listagem de contribuição de itens (taxonomy_elements.txt) gerado a partir dos arquivos de entrada apresentados nas Figuras 4.5, 4.6 e 4.7. . . . . . . . . . . . . . . . . . . . 55

4.10 Exemplo de um arquivo de regras de associação generalizadas (rules_gen.txt) gerado a partir dos arquivos de entrada apresentados nas Figuras 4.5, 4.6 e 4.7 . . . . . . . . . . . . . . . . . . . . . . 57

4.11 Representação gráfica da taxonomia de produtos alimentícios apresentada na Figura 4.7. . . . . . . . . . . . . . . . . . . . . . . 58

4.12 Exemplo de uma taxonomia contendo um item com mais de um pai. . . . . 63 
4.13 Arquivo de dados (correspondente ao arquivo .apr.data da Figura 4.4) utilizado no exemplo. . . . . . . . . . . . . . . 66

4.14 Arquivo de regras de associação na sintaxe padrão (correspondente ao arquivo .apr.dcar da Figura 4.4) geradas a partir do arquivo de dados da Figura 4.13, utilizado no exemplo. . . . . . . . . . . . . . . 67

4.15 Arquivo de taxonomias (correspondente ao arquivo .tax da Figura 4.4) utilizado no exemplo. . . . . . . . . . . . . . . . . . . . . 67

4.16 Listagem de contribuição de itens obtida no exemplo (correspondente ao arquivo taxonomy_elements.txt da Figura 4.4) . . . . . . . . . . . . . . . . 68

4.17 Subconjuntos iniciais obtidos no exemplo. . . . . . . . . . . . . . . . . . 69

4.18 Processo de substituição, eliminação e ordenação referente ao exemplo, utilizando o nível 1 da taxonomia. . . . . . . . . . . . . . . . . . . . . 70

4.19 Subconjuntos gerados, a partir da Figura 4.18, utilizando o nível 1 da taxonomia, referente ao exemplo. . . . . . . . . . . . . . . . . 71

4.20 Processo de substituição, eliminação e ordenação referente ao exemplo, utilizando o nível 2 da taxonomia. . . . . . . . . . . . . . . . . . . . . 72

4.21 Subconjuntos gerados, a partir da Figura 4.20, utilizando o nível 2 da taxonomia, referente ao exemplo. . . . . . . . . . . . . . . . 73

4.22 Processo de verificação da regra generalizada no exemplo: critérios de generalização e critério da medida utilizada na generalização. . . . . . . . . . 73

4.23 Remoção das regras de origem e adição da regra generalizada referente a Figura 4.22. . . . . . . . . . . . . . . . . . . . . . . 74

4.24 Arquivo parcial do conjunto final de regras de associação generalizadas referente ao exemplo. . . . . . . . . . . . . . . . . . . . . 75

4.25 Arquivo do conjunto final de regras de associação generalizadas referente ao exemplo (correspondente ao arquivo rules_gen.txt da Figura 4.4) . . . . . 76

4.26 Exemplo de exibição de um conjunto de regras generalizadas selecionado. 81

4.27 Exploração detalhada das regras generalizadas selecionadas. . . . . . . . . 81

4.28 Exploração geral das regras generalizadas selecionadas. . . . . . . . . . . . 82

4.29 Consulta SQL em um conjunto de regras de associação generalizadas. . . . 83

4.30 Exemplo de figura apresentada nos Apêndices B e C referente ao conjunto de taxonomias tax01/1N do Cjto-Sup. . . . . . . . . . . . 85

4.31 Exemplo de figura apresentada nos Apêndices D e E referente aos resultados de compactação utilizando as medidas sup e conf $(\operatorname{tax} 01 / 1 \mathrm{~N})$. . . . . . . 87

4.32 Exemplo de figura apresentada nos Apêndices F e G referente aos resultados de compactação utilizando os lados $l h s$, rhs, lrhs $(\operatorname{tax} 01 / 1 \mathrm{~N}) . \quad \ldots$. . . . 88 
5.1 Exemplo de um histograma referente à medida Added Value utilizando os conjuntos lhs-sup-0-tax07-1N, rhs-sup-0-tax07-1N e lrhs-sup-0-tax07-1N. 93

5.2 Fluxo de entrada e saída da metodologia de seleção de regras para avaliação por parte dos especialistas. . . . . . . . . . . . . . . . . . . . . 119

A.1 Arquivo de dados (correspondente ao arquivo .apr.data da Figura 4.4, página 53) utilizado nesse apêndice e no exemplo da Seção 4.5 . . . . . . . . 133

A.2 Arquivo de regras de associação na sintaxe padrão (correspondente ao arquivo .apr.dcar da Figura 4.4, página 53) geradas a partir do arquivo de dados da Figura A.1, utilizado nesse apêndice e no exemplo da Seção 4.5. 134

A.3 Arquivo de taxonomias (correspondente ao arquivo .tax da Figura 4.4, página 53) utilizado nesse apêndice e no exemplo da Seção 4.5 . . . . . . . . 134

A.4 Listagem de contribuição de itens do apêndice e do exemplo da Seção 4.5 (correspondente ao arquivo taxonomy_elements.txt da Figura 4.4, página 53).135

A.5 Processo de substituição referente ao exemplo, utilizando o nível 1 da taxonomia. . . . . . . . . . . . . . . . . 137

A.6 Processo de eliminação referente ao exemplo, utilizando o nível 1 da taxonomia. . . . . . . . . . . . . . . . . . . . . . 138

A.7 Processo de ordenação referente ao exemplo, utilizando o nível 1 da taxonomia. . . . . . . . . . . . . . . . . . . 139

A.8 Subconjuntos gerados, a partir da Figura A.7, utilizando o nível 1 da taxonomia, referente ao exemplo. . . . . . . . . . . . . . . . . . . . . 140

A.9 Processo de substituição referente ao exemplo, utilizando o nível 2 da taxonomia. . . . . . . . . . . . . . . . . . . . . 141

A.10 Processo de eliminação referente ao exemplo, utilizando o nível 2 da taxonomia. . . . . . . . . . . . . . . . . . . . 142

A.11 Processo de ordenação referente ao exemplo, utilizando o nível 2 da taxonomia. . . . . . . . . . . . . . . . . . . . . 143

A.12 Subconjuntos gerados, a partir da Figura A.11, utilizando o nível 2 da taxonomia, referente ao exemplo. . . . . . . . . . . . . . . . . . . . . 144

A.13 Processo de verificação da regra generalizada ("Subconjunto 1-4") no exemplo: critérios de generalização e critério da medida utilizada na generalização.145

A.14 Processo de verificação da regra generalizada ("Subconjunto 1-5") no exemplo: critérios de generalização e critérios de medida. . . . . . . . . . . . . . 145

A.15 Arquivo do conjunto final de regras de associação generalizadas referente ao exemplo (correspondente ao arquivo rules_gen.txt da Figura 4.4, página 53).146

B.1 Conjunto de taxonomias tax01/1N . . . . . . . . . . . . . . 148

B.2 Conjunto de taxonomias tax02/1N . . . . . . . . . . . . . . . . . . 148 
B.3 Conjunto de taxonomias tax03/1N . . . . . . . . . . . . . 149

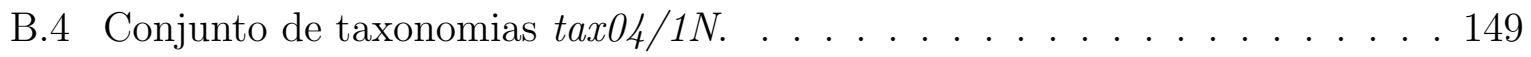

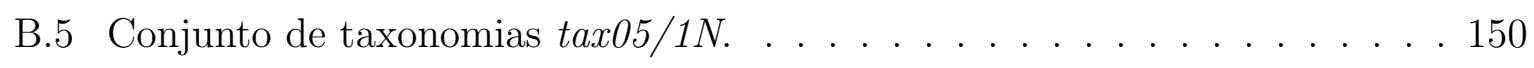

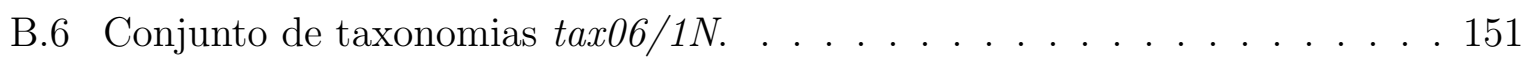

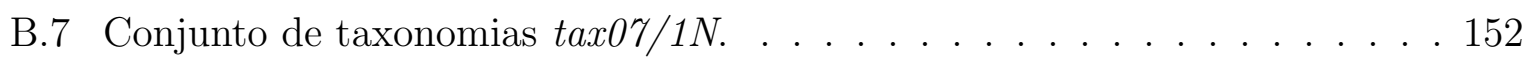

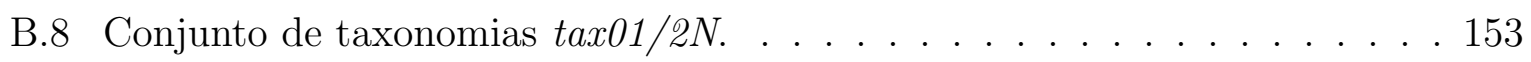

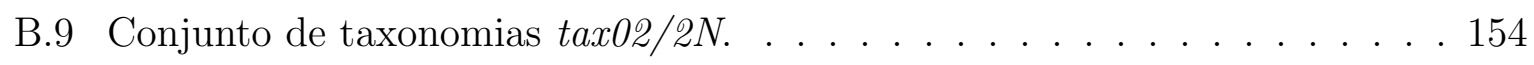

B.10 Conjunto de taxonomias tax03/2N . . . . . . . . . . . . 154

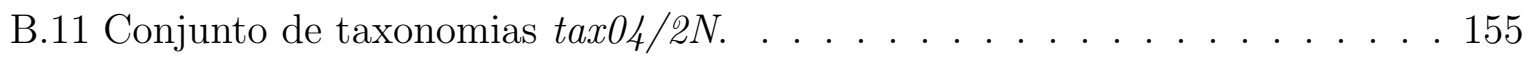

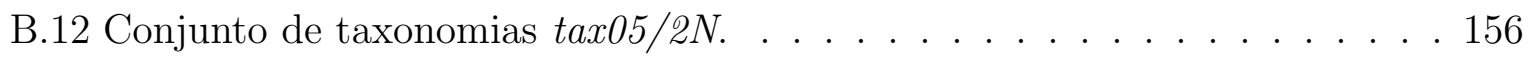

B.13 Conjunto de taxonomias tax06/2N . . . . . . . . . . . 157

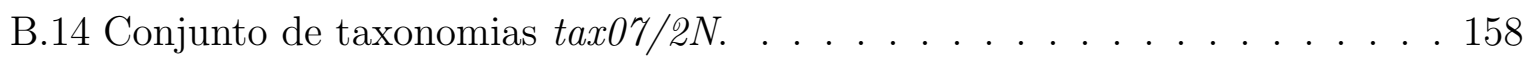

B.15 Conjunto de taxonomias tax01/3N . . . . . . . . . . . 159

B.16 Conjunto de taxonomias tax02/3N. . . . . . . . . . 160

B.17 Conjunto de taxonomias tax03/3N . . . . . . . . . . 160

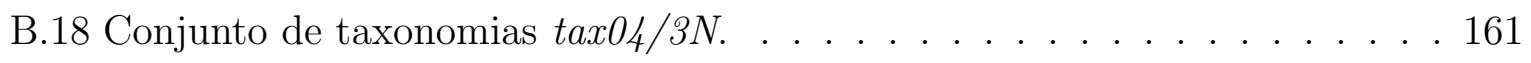

B.19 Conjunto de taxonomias tax05/3N . . . . . . . . . . . 162

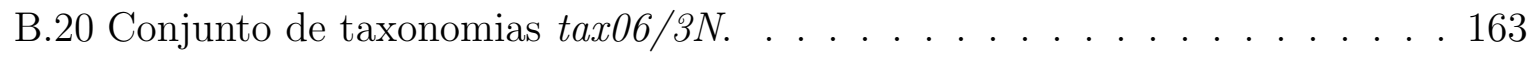

B.21 Conjunto de taxonomias tax07/3N . . . . . . . . . . . 164

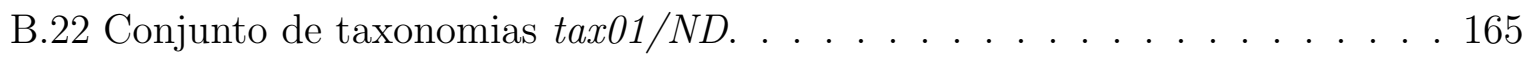

B.23 Conjunto de taxonomias tax02/ND . . . . . . . . . . . 166

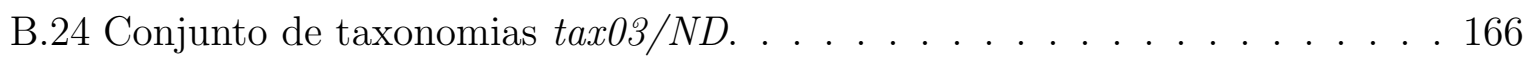

B.25 Conjunto de taxonomias tax04/ND . . . . . . . . . . 167

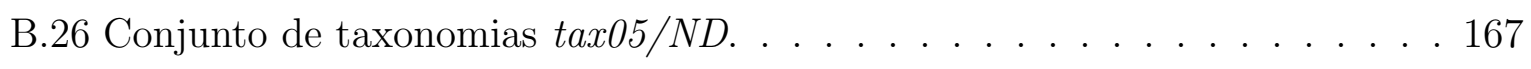

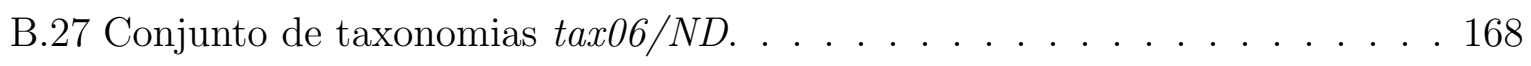

B.28 Conjunto de taxonomias tax07/ND . . . . . . . . . . . . . 169

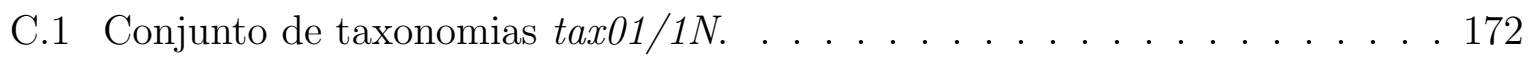

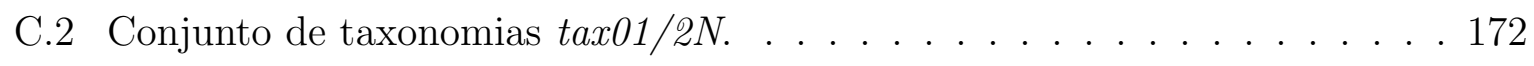

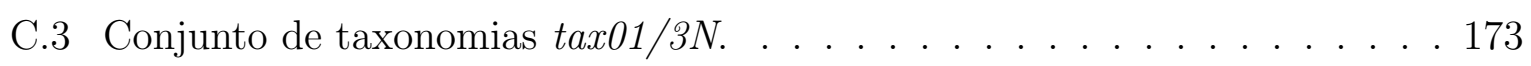

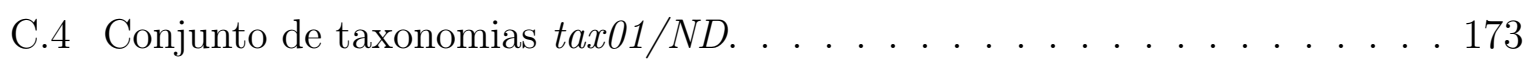

D.1 Resultados utilizando as medidas sup e conf $(\operatorname{tax} 01 / 1 \mathrm{~N}) \ldots \ldots \ldots \ldots . . \ldots 175$

D.2 Resultados utilizando as medidas sup e conf $(\operatorname{tax} 02 / 1 \mathrm{~N}) \ldots \ldots \ldots \ldots . . \ldots 176$

D.3 Resultados utilizando as medidas sup e conf $(\operatorname{tax} 03 / 1 \mathrm{~N}) \ldots \ldots \ldots \ldots . . \ldots 176$

D.4 Resultados utilizando as medidas sup e conf $(\operatorname{tax} 04 / 1 \mathrm{~N}) \ldots \ldots \ldots \ldots . . \ldots 176$

D.5 Resultados utilizando as medidas sup e conf $(\operatorname{tax} 05 / 1 \mathrm{~N}) \ldots \ldots \ldots \ldots . . \ldots 177$

D.6 Resultados utilizando as medidas sup e conf $(\operatorname{tax} 06 / 1 \mathrm{~N}) \ldots \ldots \ldots \ldots . .177$ 
D.7 Resultados utilizando as medidas sup e conf $(\operatorname{tax} 07 / 1 \mathrm{~N}) \ldots \ldots$. . . . . . 177

D.8 Resultados utilizando as medidas sup e conf $(\operatorname{tax} 01 / 2 \mathrm{~N}) \ldots \ldots$. . . . . . 178

D.9 Resultados utilizando as medidas sup e conf $(\operatorname{tax} 02 / 2 \mathrm{~N}) \ldots \ldots$. . . . . 178

D.10 Resultados utilizando as medidas sup e conf $(\operatorname{tax} 03 / 2 \mathrm{~N}) \ldots \ldots$. . . . . . 178

D.11 Resultados utilizando as medidas sup e conf $(\operatorname{tax} 04 / 2 \mathrm{~N})$. . . . . . . . . 179

D.12 Resultados utilizando as medidas sup e conf $(\operatorname{tax} 05 / 2 \mathrm{~N})$. . . . . . . . . 179

D.13 Resultados utilizando as medidas sup e conf $(\operatorname{tax} 06 / 2 \mathrm{~N})$. . . . . . . . . 179

D.14 Resultados utilizando as medidas sup e conf $(\operatorname{tax} 07 / 2 \mathrm{~N})$. . . . . . . . . . 180

D.15 Resultados utilizando as medidas sup e conf $(\operatorname{tax} 01 / 3 \mathrm{~N})$. . . . . . . . . . . 181

D.16 Resultados utilizando as medidas sup e conf $(\operatorname{tax} 02 / 3 \mathrm{~N})$. . . . . . . . . . 181

D.17 Resultados utilizando as medidas sup e conf $(\operatorname{tax} 03 / 3 \mathrm{~N})$. . . . . . . . . . . 182

D.18 Resultados utilizando as medidas sup e conf $(\operatorname{tax} 04 / 3 \mathrm{~N})$. . . . . . . . . . . 182

D.19 Resultados utilizando as medidas sup e conf $(\operatorname{tax} 05 / 3 \mathrm{~N})$. . . . . . . . . . 182

D.20 Resultados utilizando as medidas sup e conf $(\operatorname{tax} 06 / 3 \mathrm{~N}) \ldots$. . . . . . . . 183

D.21 Resultados utilizando as medidas sup e conf $(\operatorname{tax} 07 / 3 \mathrm{~N}) \ldots . . . . .183$

D.22 Resultados utilizando as medidas sup e conf (tax01/ND). . . . . . . . . . 183

D.23 Resultados utilizando as medidas sup e conf (tax02/ND). . . . . . . . . . 184

D.24 Resultados utilizando as medidas sup e conf (tax03/ND). . . . . . . . . . 184

D.25 Resultados utilizando as medidas sup e conf (tax04/ND). . . . . . . . . . 184

D.26 Resultados utilizando as medidas sup e conf (tax05/ND). . . . . . . . . . 185

D.27 Resultados utilizando as medidas sup e conf (tax06/ND). . . . . . . . . 185

D.28 Resultados utilizando as medidas sup e conf (tax07/ND). . . . . . . . . 185

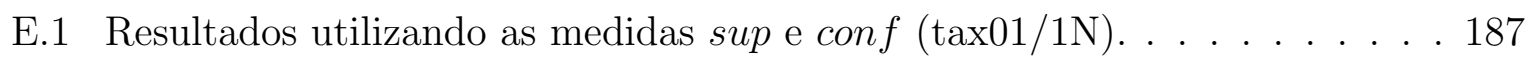

E.2 Resultados utilizando as medidas sup e conf $(\operatorname{tax} 01 / 2 \mathrm{~N}) \ldots \ldots$. . . . . . . 188

E.3 Resultados utilizando as medidas sup e conf $(\operatorname{tax} 01 / 3 \mathrm{~N}) \ldots$. . . . . . . . . 188

E.4 Resultados utilizando as medidas sup e conf (tax01/ND). . . . . . . . . 188

F.1 Resultados utilizando os lados lhs, rhs, lrhs (tax01/1N) . . . . . . . . 190

F.2 Resultados utilizando os lados lhs, rhs, lrhs (tax02/1N) . . . . . . . . . 191

F.3 Resultados utilizando os lados lhs, rhs, lrhs (tax03/1N) . . . . . . . . . 192

F.4 Resultados utilizando os lados lhs, rhs, lrhs (tax04/1N) . . . . . . . . . 193

F.5 Resultados utilizando os lados lhs, rhs, lrhs (tax05/1N) . . . . . . . . . . 194

F.6 Resultados utilizando os lados lhs, rhs, lrhs (tax06/1N) . . . . . . . . . 195

F.7 Resultados utilizando os lados lhs, rhs, lrhs (tax07/1N) . . . . . . . . 196

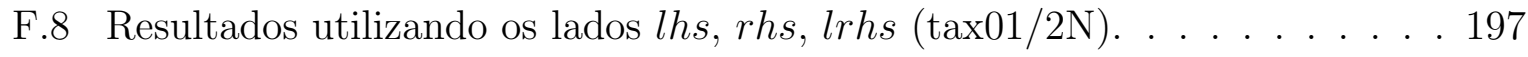

F.9 Resultados utilizando os lados lhs, rhs, lrhs (tax02/2N) . . . . . . . . 198

F.10 Resultados utilizando os lados lhs, rhs, lrhs (tax03/2N). . . . . . . . . 199 
F.11 Resultados utilizando os lados lhs, rhs, lrhs $(\operatorname{tax} 04 / 2 \mathrm{~N}) \ldots . . . .200$

F.12 Resultados utilizando os lados lhs, rhs, lrhs $(\operatorname{tax} 05 / 2 \mathrm{~N})$. . . . . . . . . 201

F.13 Resultados utilizando os lados lhs, rhs, lrhs (tax06/2N). . . . . . . . . 202

F.14 Resultados utilizando os lados lhs, rhs, lrhs $(\operatorname{tax} 07 / 2 \mathrm{~N})$. . . . . . . . 203

F.15 Resultados utilizando os lados lhs, rhs, lrhs $(\operatorname{tax} 01 / 3 \mathrm{~N})$. . . . . . . . . 204

F.16 Resultados utilizando os lados lhs, rhs, lrhs (tax02/3N) . . . . . . . . . 205

F.17 Resultados utilizando os lados lhs, rhs, lrhs (tax03/3N) . . . . . . . . 206

F.18 Resultados utilizando os lados lhs, rhs, lrhs $(\operatorname{tax} 04 / 3 \mathrm{~N})$. . . . . . . 207

F.19 Resultados utilizando os lados lhs, rhs, lrhs $(\operatorname{tax} 05 / 3 \mathrm{~N})$. . . . . . . . 208

F.20 Resultados utilizando os lados lhs, rhs, lrhs (tax06/3N) . . . . . . . . . 209

F.21 Resultados utilizando os lados lhs, rhs, lrhs $(\operatorname{tax} 07 / 3 \mathrm{~N})$. . . . . . . . . 210

F.22 Resultados utilizando os lados lhs, rhs, lrhs (tax01/ND). . . . . . . . . 211

F.23 Resultados utilizando os lados lhs, rhs, lrhs (tax02/ND). . . . . . . . . 212

F.24 Resultados utilizando os lados lhs, rhs, lrhs (tax03/ND). . . . . . . . 213

F.25 Resultados utilizando os lados lhs, rhs, lrhs (tax04/ND). . . . . . . . . 214

F.26 Resultados utilizando os lados lhs, rhs, lrhs (tax05/ND). . . . . . . . . 215

F.27 Resultados utilizando os lados lhs, rhs, lrhs (tax06/ND). . . . . . . . . 216

F.28 Resultados utilizando os lados lhs, rhs, lrhs (tax07/ND). . . . . . . . 217

G.1 Resultados utilizando os lados lhs, rhs, lrhs (tax01/1N). . . . . . . . 220

G.2 Resultados utilizando os lados lhs, rhs, lrhs $(\operatorname{tax} 01 / 2 \mathrm{~N})$. . . . . . . . 221

G.3 Resultados utilizando os lados lhs, rhs, lrhs $(\operatorname{tax} 01 / 3 \mathrm{~N})$. . . . . . . . . 222

G.4 Resultados utilizando os lados lhs, rhs, lrhs (tax01/ND). . . . . . . . 223

H.1 Histogramas referentes a medida Added Value. . . . . . . . . . . . . . 226

H.2 Histogramas referentes a medida Certainty Factor. . . . . . . . . . . . . . 227

H.3 Histogramas referentes a medida Collective Strength. . . . . . . . . . . . . 228

H.4 Histogramas referentes a medida Confiança. . . . . . . . . . . . . 229

H.5 Histogramas referentes a medida Conviction. . . . . . . . . . . . . . 230

H.6 Histogramas referentes a medida IS/Cosine. . . . . . . . . . . . . . . 231

H.7 Histogramas referentes a medida $\phi$-coefficient. . . . . . . . . . . . . . 232

H.8 Histogramas referentes a medida Gini Index. . . . . . . . . . . . . . . . . 233

H.9 Histogramas referentes a medida $J$-Measure. . . . . . . . . . . . . . . 234

H.10 Histogramas referentes a medida Jaccard. . . . . . . . . . . . . . . . 235

H.11 Histogramas referentes a medida Kappa. . . . . . . . . . . . . . . . 236

H.12 Histogramas referentes a medida Klosgen. . . . . . . . . . . . . . 237

H.13 Histogramas referentes a medida Goodman-Kruskal's $(\lambda) \ldots$. . . . . . . . 238

H.14 Histogramas referentes a medida Laplace. . . . . . . . . . . . . . . . . . 239 
H.15 Histogramas referentes a medida Interest Factor. . . . . . . . . . . . . . . . 240

H.16 Histogramas referentes a medida Mutual Information. . . . . . . . . . . . . 241

H.17 Histogramas referentes a medida Piatetsky-Shapiro's. . . . . . . . . . . . . 242

H.18 Histogramas referentes a medida Suporte. . . . . . . . . . . . . . . . . 243

H.19 Histogramas referentes a medida Odds Ratio. . . . . . . . . . . . . . . . . . 244

H.20 Histogramas referentes a medida Yule's Q. . . . . . . . . . . . . . 245

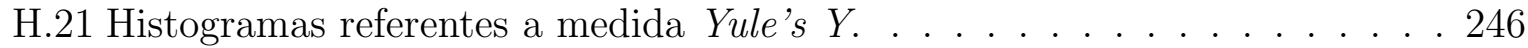

I.1 Histogramas referentes a medida Added Value. . . . . . . . . . . . . . . . . 248

I.2 Histogramas referentes a medida Certainty Factor. . . . . . . . . . . . . . . 249

I.3 Histogramas referentes a medida Collective Strength. . . . . . . . . . . . . 250

I.4 Histogramas referentes a medida Confiança. . . . . . . . . . . . . . . . . 251

I.5 Histogramas referentes a medida Conviction. . . . . . . . . . . . . . . . . . 252

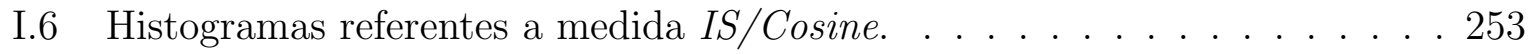

I.7 Histogramas referentes a medida $\phi$-coefficient. . . . . . . . . . . . . . . . 254

I.8 Histogramas referentes a medida Gini Index. . . . . . . . . . . . . . . . . . 255

I.9 Histogramas referentes a medida J-Measure. . . . . . . . . . . . . . . . . 256

I.10 Histogramas referentes a medida Jaccard. . . . . . . . . . . . . . . . . . . 257

I.11 Histogramas referentes a medida Kappa. . . . . . . . . . . . . . . . . . . 258

I.12 Histogramas referentes a medida Klosgen. . . . . . . . . . . . . . . . 259

I.13 Histogramas referentes a medida Goodman-Kruskal's $(\lambda) \ldots$. . . . . . . . . 260

I.14 Histogramas referentes a medida Laplace. . . . . . . . . . . . . . . . . . 261

I.15 Histogramas referentes a medida Interest Factor. . . . . . . . . . . . . . . . 262

I.16 Histogramas referentes a medida Mutual Information. . . . . . . . . . . . . 263

I.17 Histogramas referentes a medida Piatetsky-Shapiro's. . . . . . . . . . . . . 264

I.18 Histogramas referentes a medida Suporte. . . . . . . . . . . . . . . . 265

I.19 Histogramas referentes a medida Odds Ratio. . . . . . . . . . . . . . . . . . 266

I.20 Histogramas referentes a medida Yule's Q. . . . . . . . . . . . . . 267

I.21 Histogramas referentes a medida Yule's $Y$. . . . . . . . . . . . . . . 268 



\section{Lista de Tabelas}

2.1 Matriz de contingências com freqüências relativas. . . . . . . . . . . . . 18

3.1 Relação de itens comprados por transação do Exemplo 1. . . . . . . . . . . 36

5.1 Conjuntos de regras selecionados do Cjto-Sup a serem avaliados quanto ao conhecimento obtido. . . . . . . . . . . . . . . . . . . . . . . 94

5.2 Conjuntos de regras selecionados do Cjto-R a serem avaliados quanto ao conhecimento obtido. . . . . . . . . . . . . . . . . . . . . 95

5.3 Porcentagem de regras generalizadas pertencentes ao intervalo 0.9-1.0 considerando cada medida e cada conjunto generalizado. . . . . . . . . . . . . 95

5.4 Agrupamento das medidas objetivas em relação ao desempenho do lado da generalização. . . . . . . . . . . . . . . . . . . . . . 100

5.5 Estatísticas das regras generalizadas pertencentes ao intervalo 0.9-1.0 considerando cada medida e cada conjunto generalizado. . . . . . . . . . . . . 100

5.6 Grupos de medidas objetivas com propriedades similares. . . . . . . . . . . 104

5.7 Grupos de medidas objetivas com propriedades similares separadas pela propriedade de simetria. . . . . . . . . . . . . . . . . . . . . . . 104

5.8 Medidas objetivas selecionadas a avaliação analítica do conhecimento generalizado considerando o padrão de associação $A \Rightarrow B$. . . . . . . . . . 105

5.9 Relações das medidas objetivas na generalização do LHS. . . . . . . . . . . 114

5.10 Relações das medidas objetivas na generalização do RHS. . . . . . . . . . 114

5.11 Relações das medidas objetivas na generalização do LRHS. . . . . . . . . 115

5.12 Conjuntos de regras generalizadas selecionados do Cjto-Sup para avaliação dos especialistas. . . . . . . . . . . . . . . . . . 120

5.13 Conjuntos de regras generalizadas selecionados do Cjto-R para avaliação dos especialistas. . . . . . . . . . . . . . . . . . . . . 12 
5.14 Classificação dada pelos especialistas para as regras generalizadas no lhs, selecionadas do Cjto-Sup, pela metodologia descrita na Seção 5.4.1. . . . . 122

5.15 Classificação dada pelos especialistas para as regras generalizadas no $r h s$, selecionadas do Cjto-Sup, pela metodologia descrita na Seção 5.4.1. . . . . 122

5.16 Classificação dada pelos especialistas para as regras generalizadas no $l r h s$, selecionadas do Cjto-Sup, pela metodologia descrita na Seção 5.4.1. . . . . 122

5.17 Classificação dada pelos especialistas para as regras generalizadas no lhs, selecionadas do Cjto-R, pela metodologia descrita na Seção 5.4.1. .... 123

5.18 Classificação dada pelos especialistas para as regras generalizadas no $r h s$, selecionadas do Cjto-R, pela metodologia descrita na Seção 5.4.1. . . . . . 123

5.19 Classificação dada pelos especialistas para as regras generalizadas no lrhs, selecionadas do Cjto-R, pela metodologia descrita na Seção 5.4.1. . . . . . 123 


\section{Lista de Algoritmos}

1 Visão geral do APRA $A_{\text {alg }}$ - algoritmo referente à viabilização da APRA. . . 49

2 Detalhamento do APRA $A_{\text {alg }}$ - algoritmo referente à viabilização da APRA. 59 



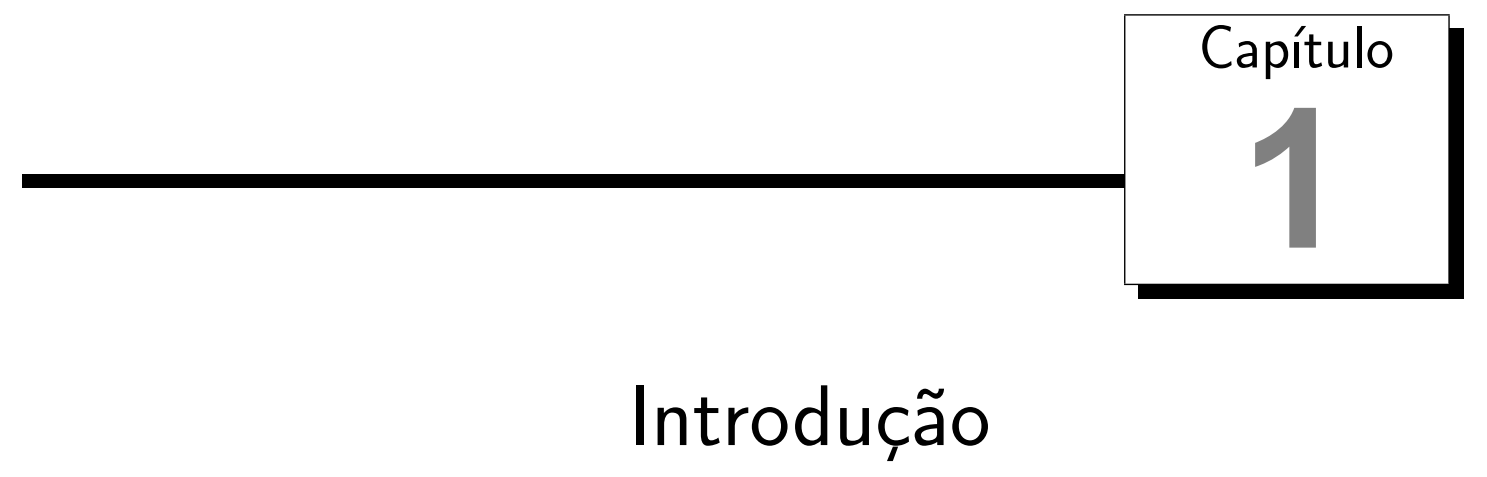

evolução da computação impulsionada pelo aumento do poder de processa-
mento dos computadores, pelo armazenamento contínuo de grandes quanti-
dades de dados a baixo custo, pela introdução de novas tecnologias de transmissão e compartilhamento de dados, entre outros fatores, tem dado às organizações a capacidade de armazenar informações detalhadas sobre cada transação que efetuam, gerando grandes bases de dados.

Durante anos, métodos predominantemente manuais têm sido utilizados para transformar dados em conhecimento. Porém, o uso desses métodos é dispendioso (em termos financeiros e de tempo), subjetivo e inviável, quando aplicados a grandes bases de dados. Devido às limitações dos métodos manuais, tornou-se necessário o desenvolvimento de processos de análise automática, como o processo de extração de conhecimento de bases de dados ou mineração de dados. Esse processo, de natureza iterativa e interativa, é bastante utilizado em diversos domínios, na extração de padrões válidos, novos, potencialmente úteis e compreensíveis embutidos nos dados (Taniar, 2007; Chen \& Liu, 2005; Apte, Liu, Pednault, \& Smyth, 2002; Lee \& Siau, 2001; Fayyad, Piatetsky-Shapiro, \& Smyth, 1996a).

Uma das técnicas de mineração de dados que vem se destacando é a associação. Em linhas gerais, uma regra de associação caracteriza o quanto a presença de um conjunto de itens nos registros de uma base de dados implica na presença de algum outro conjunto distinto de itens nos mesmos registros (Agrawal \& Srikant, 1994). Além da utilização dessa técnica nas pesquisas acadêmicas, os resultados das mesmas têm sido utilizados no 
comércio, em contratos de seguro, na saúde, no geoprocessamento, na biologia molecular, entre outras áreas (Domingues, Jorge, \& Soares, 2006; Metwally, Agrawal, \& Abbadi, 2005; Aggelis, 2004; Fonseca, Golgher, de Moura, \& Ziviani, 2003; Semenova, Hegland, Graco, \& Williams, 2001).

O aspecto de maior relevância da técnica de associação é a possibilidade da descoberta de todas as associações existentes nas transações de uma base de dados. Entretanto, essa característica determina a geração de um número surpreendentemente grande de regras, dificultando sobremaneira a interpretação do conjunto de regras pelo usuário. Segundo Hilderman \& Hamilton (2000); Ma, Wong, \& Liu (2000), interpretar o conhecimento adquirido de modo a obter um bom entendimento sobre o domínio de aplicação é uma das etapas mais importantes do processo de mineração de dados. Assim, para contornar esse problema, pesquisadores têm adotado várias abordagens, como as de avaliação por consulta, medidas de avaliação, poda, sumarização, agrupamento e visualização e exploração (Natarajan \& Shekar, 2005; Jorge, 2004; Baesens, Viaene, \& Vanthienen, 2000).

Além do problema da imensidão do número de regras, os processos tradicionais de extração de regras de associação geram todas as possíveis regras considerando somente os itens contidos na base de dados, o que leva à obtenção de um conhecimento, em geral, muito específico. Isso se deve à diversidade de itens contidos nas bases de dados. Por exemplo, em uma base de supermercado é possível encontrar diversos tipos de leite com diversas variações: leite-parmalat-integral, leite-parmalat-desnatado, leite-italac-semi-desnatado, leite-italac-omega-3, etc. Essa especificidade contida no conhecimento extraído torna difícil a obtenção de uma visão geral do domínio a ser explorado, uma vez que apenas regras do tipo "pessoas que compram leite da marca/tipo X, também compram o produto Y" são obtidas.

Para que o conhecimento expresso nas regras de associação seja descrito num nível de abstração superior ao encontrado na base de dados é necessário o uso de conhecimento de domínio. O conhecimento de domínio pode ser representado de diferentes formas, entre elas, via taxonomias. As taxonomias refletem uma caracterização coletiva ou individual de como os itens podem ser hierarquicamente classificados (Adamo, 2001). Existem diversos trabalhos na literatura que utilizam taxonomias em regras de associação, os quais diferem entre si em função da etapa do processo de mineração em que as taxonomias são utilizadas (pré-processamento: Zhou, Ruan, Zhu, Zhu, \& Shi (2001); Galindo, Coelho, \& Lachtermacher (2002); Chen, Zhou, Scherl, \& Geller (2003); Giha, Singh, \& Ewe (2006); extração de padrões: Srikant \& Agrawal (1995); Han \& Fu (1995); Hipp, Myka, Wirth, \& Güntzer (1998); Weber (1998); Baixeries, Casas, \& Balcázar (2000); Yen (2000); Yen \& Chen (2001); Rajkumar, Karthik, \& Sivanandam (2003); Pramudiono \& Kitsuregawa (2004); Sriphaew \& Theeramunkong (2004); Thakur, Jain, \& Pardasani (2006); pós-processamento: Adomavicius \& Tuzhilin (2001); Domingues (2004); Domingues \& 
Rezende (2005); Brisson, Collard, \& Pasquier (2005); Hou, Gu, Shen, \& Yan (2005)).

Nesse contexto, é proposta neste trabalho uma abordagem que utiliza conhecimento de domínio, expresso via taxonomias, para pós-processar regras de associação visando obter um conjunto de regras generalizadas que seja compacto (menor/reduzido) e representativo $(\text { geral })^{1}$. Nesse conjunto reduzido de regras podem ser encontradas regras mais gerais, chamadas de regras de associação generalizadas, as quais fornecem uma visão mais geral do conhecimento descoberto, quanto regras específicas, as quais podem ser exploradas posteriormente. É importante mencionar que com uma regra generalizada é possível se obter uma visão geral do domínio de três maneiras distintas: uma que apresenta o relacionamento entre categorias/classes de itens e itens específicos - generalização no lado esquerdo da regra; uma que apresenta o relacionamento entre itens específicos e categorias/classes de itens - generalização no lado direito da regra; e uma que apresenta o relacionamento entre categorias/classes de itens - generalização em ambos os lados da regra. Assim, uma regra generalizada pode apresentar semânticas diferentes dependendo do lado em que a abstração do domínio é realizada.

Além da preocupação referente ao número de regras obtidas e à especificidade dos padrões gerados pela técnica tradicional de associação, é importante que o conhecimento descoberto seja compreensível e interessante aos usuários finais, a fim de fornecer suporte no processo de tomada de decisão. Uma das abordagens de pós-processamento mais populares para minimizar o problema da busca por regras interessantes é o ranking de regras usando medidas de avaliação, uma vez que elas possuem um papel importante na identificação de padrões novos, relevantes, implícitos e compreensíveis contidos na imensidão de padrões descobertos (Natarajan \& Shekar, 2005). São essas medidas que auxiliam na maioria dos trabalhos de pós-processamento em mineração de dados (Natarajan \& Shekar, 2005).

Como mencionado anteriormente, a abordagem proposta neste trabalho visa obter um conjunto de regras generalizadas que seja compacto e representativo. Assim, a fim de avaliar a representatividade de padrões generalizados, neste trabalho é realizado também um estudo sobre a utilização de medidas de avaliação quando aplicadas a regras de associação generalizadas levando-se em consideração a semântica da generalização.

As hipóteses que guiaram o desenvolvimento deste trabalho são apresentadas a seguir. Logo após, são apresentados os objetivos e a organização desta tese.

\footnotetext{
${ }^{1}$ As palavras menor, reduzido e compacto serão utilizadas como sinônimos, assim como as palavras geral e representativa. A palavra representativa, no contexto deste trabalho, quando associada a um(a) modelo/padrão/conjunto/regra/etc. obtido(a) é interpretada como a representação geral de um subconjunto de elementos que contêm características semelhantes.
} 


\subsection{Hipóteses}

As hipóteses deste trabalho são:

1. É possível utilizar conhecimento de domínio, expresso via taxonomias, para pósprocessar um conjunto de regras de associação a fim de obter um conjunto de regras generalizadas que seja compacto e representativo.

2. A semântica envolvida na generalização especifica o tipo de medida de avaliação objetiva a ser utilizada para avaliar a representatividade do conhecimento generalizado.

É importante notar que as hipóteses consideradas são complementares, uma vez que a primeira se refere à obtenção de um conjunto de regras generalizadas compacto e representativo e a segunda à avaliação da representatividade do conhecimento generalizado obtido.

\subsection{Objetivos}

Tendo em vista as hipóteses apresentadas, os objetivos deste trabalho são:

1. Propor uma abordagem para reduzir um conjunto de regras de associação utilizando taxonomias de domínio a fim de obter um conjunto de regras compacto e representativo (referente à Hipótese 1 ).

2. Realizar uma investigação empírica das regras generalizadas obtidas pela abordagem proposta utilizando medidas de avaliação objetivas (referente à Hipótese 2).

3. Realizar uma investigação analítica das regras generalizadas obtidas pela abordagem proposta utilizando medidas de avaliação objetivas (referente à Hipótese 2).

4. Realizar uma investigação junto a especialistas do domínio com o objetivo de identificar a sua opinião em relação à qualidade do conhecimento obtido pela abordagem proposta (referente à Hipótese 2).

\subsection{Organização}

Para mostrar a validação das hipóteses e cumprir os objetivos especificados, esta tese está divida em seis capítulos, os quais são descritos a seguir. 


\section{Capítulo 1: Introdução}

Nesse capítulo é apresentado o contexto em que se insere este trabalho, bem como detalhadas as hipóteses que guiaram seu desenvolvimento e seus objetivos.

\section{Capítulo 2: Mineração de Dados e Regras de Associação}

Nesse capítulo é apresentado o processo de mineração de dados e descritas todas as etapas que compõem esse processo. Além disso, a técnica de associação, foco deste trabalho, também é apresentada. Para tanto, são descritos os conceitos e definições relacionados à técnica, e é feito um levantamento das abordagens de pós-processamento disponíveis na literatura, utilizadas para validar o conhecimento descoberto pela técnica.

\section{Capítulo 3: Uso de Taxonomias em Regras de Associação}

Nesse capítulo são apresentadas as regras de associação generalizadas, uma variação das regras de associação tradicionais que contêm itens de uma taxonomia de domínio. Para tanto, são descritos os conceitos/definições referentes a esse tipo de regra, assim como um levantamento bibliográfico referente à utilização de taxonomias em regras de associação nas diversas etapas do processo de mineração de dados.

\section{Capítulo 4: Abordagem de Pós-Processamento de Regras de Associação ( $A P R A)$ Usando Taxonomias de Domínio}

Nesse capítulo é apresentada uma abordagem para pós-processar regras de associação via a utilização de taxonomias de domínio, a fim de obter modelos compactos e representativos (Hipótese 1). Para tanto, a abordagem, assim como o algoritmo que a viabiliza, são descritos. Também são descritas algumas considerações/restrições utilizadas no desenvolvimento da abordagem e do algoritmo, assim como uma comparação da abordagem proposta com o estado da arte. É apresentado também o ambiente RuLEE-RAG, o qual é utilizado para explorar as regras generalizadas obtidas pela abordagem proposta. Por fim, são apresentados os experimentos utilizados para validar a Hipótese 1 acima apresentada.

\section{Capítulo 5: Avaliação do Conhecimento Generalizado via Medidas de Interesse Objetivas}

Nesse capítulo são apresentados os estudos empírico e analítico realizados a fim de verificar se uma regra generalizada é mais representativa do que as suas regras específicas em função da semântica da generalização (Hipótese 2). A representatividade da regra é avaliada via a utilização de medidas de interesse objetivas. Além disso, são apresentados alguns experimentos realizados junto a especialistas do domínio a fim de complementar os resultados obtidos nos estudos empírico e analítico.

\section{Capítulo 6: Conclusão}

Nesse capítulo são apresentadas as conclusões desta tese, as principais contribuições, e as propostas de trabalhos futuros. 



\section{Capítulo}

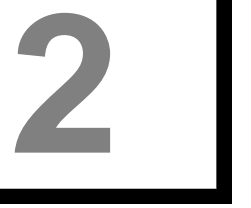

\section{Mineração de Dados e Regras de Associação}

\subsection{Considerações Iniciais}

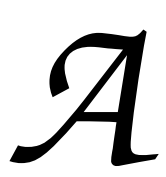

partir de 1980 a tecnologia da informação digital conquistou quase todas as atividades do mundo moderno. Hoje em dia quase tudo é digitalizado (Hipp, Güntzer, \& Nakhaeizadeh, 2002). Esse desenvolvimento não está restrito a domínios óbvios, como o da Internet, aplicações comuns de bases de dados, ou comércio eletrônico. Até mesmo os domínios mais tradicionais da vida cotidiana dependem mais e mais da tecnologia da informação digital. Conseqüentemente, armazenar dados que reflitam o mundo real tem se tornado cada vez mais fácil e barato. Embora os dados obtidos contenham informações valiosas e detalhadas que podem ser utilizadas pelas organizações (Rezende, 2004; Fayyad, Piatetsky-Shapiro, \& Smyth, 1996a), analisar essa grande quantidade de dados se torna muito mais difícil do que o esperado.

Nesse capítulo é apresentada uma visão geral do processo de mineração de dados e de uma de suas técnicas, a associação, caracterizada pela extração de regras de associação. Essa tarefa, foco deste trabalho, tem recebido grande atenção, seja na área acadêmica ou em aplicações práticas, em função de sua aplicabilidade a problemas de negócio (Aggelis, 2004; Oliveira, Zaane, \& Saygin, 2004; Besemann, Denton, Yekkirala, Hutchison, \& Anderson, 2004). São apresentadas as definições e os conceitos referentes à técnica de associação, um levantamento sobre algumas abordagens utilizadas na avaliação do conhecimento obtido pela técnica, assim como a descrição de várias medidas de interesse objetivas a serem utilizadas no desenvolvimento deste trabalho. Além disso, a sintaxe de 
regras de associação utilizada nos próximos capítulos também é apresentada.

\subsection{Mineração de Dados}

Durante os dez últimos anos, técnicas especializadas de extração automática de conhecimento têm sido desenvolvidas sob o nome de extração de conhecimento de base de dados, geralmente referenciado na literatura como knowledge discovery in database (KDD), data mining (DM) ou mineração de dados (MD). Alguns autores consideram os termos KDD e MD referentes a processos distintos (Fayyad, Piatetsky-Shapiro, \& Smyth, 1996b). Entretanto, neste trabalho, os termos KDD e MD serão tratados indistintamente referenciando o processo de extrair conhecimento a partir de dados.

A definição aceita por diversos pesquisadores de MD foi elaborada por Fayyad, PiatetskyShapiro, \& Smyth (1996a) como sendo:

Processo de identificação de padrões válidos, novos, potencialmente úteis e compreensíveis embutidos nos dados.

Existem diversas abordagens para a divisão das etapas do processo de extração de conhecimento de bases de dados. Inicialmente, foi proposto por Fayyad (1996) uma divisão do processo em nove etapas. Já Weiss \& Indurkhya (1998) dividem o processo em apenas quatro etapas. No entanto, nesse capítulo é considerada a divisão do processo em um ciclo composto de três grandes etapas: pré-processamento, extração de padrões e pós-processamento (Rezende, Pugliesi, Melanda, \& Paula, 2003). Foram incluídas nessa divisão uma fase anterior ao processo de mineração de dados, que se refere à identificação do problema e conhecimento do domínio, e uma fase posterior ao processo, que se refere à utilização do conhecimento obtido. Observa-se que normalmente esse processo é iterativo. A Figura 2.1 ilustra essas etapas.

O processo de MD é centrado na interação entre as diversas classes de usuários, e o seu sucesso depende, em parte, dessa interação. Os usuários do processo podem ser divididos em três classes:

Especialista do Domínio Usuário que deve possuir amplo conhecimento do domínio da aplicação e fornecer apoio à execução do processo.

Analista Usuário especialista no processo de mineração de dados e responsável por sua execução. Esse usuário deve conhecer profundamente as etapas que compõem esse processo, além das técnicas disponíveis para apoio ao processo. 


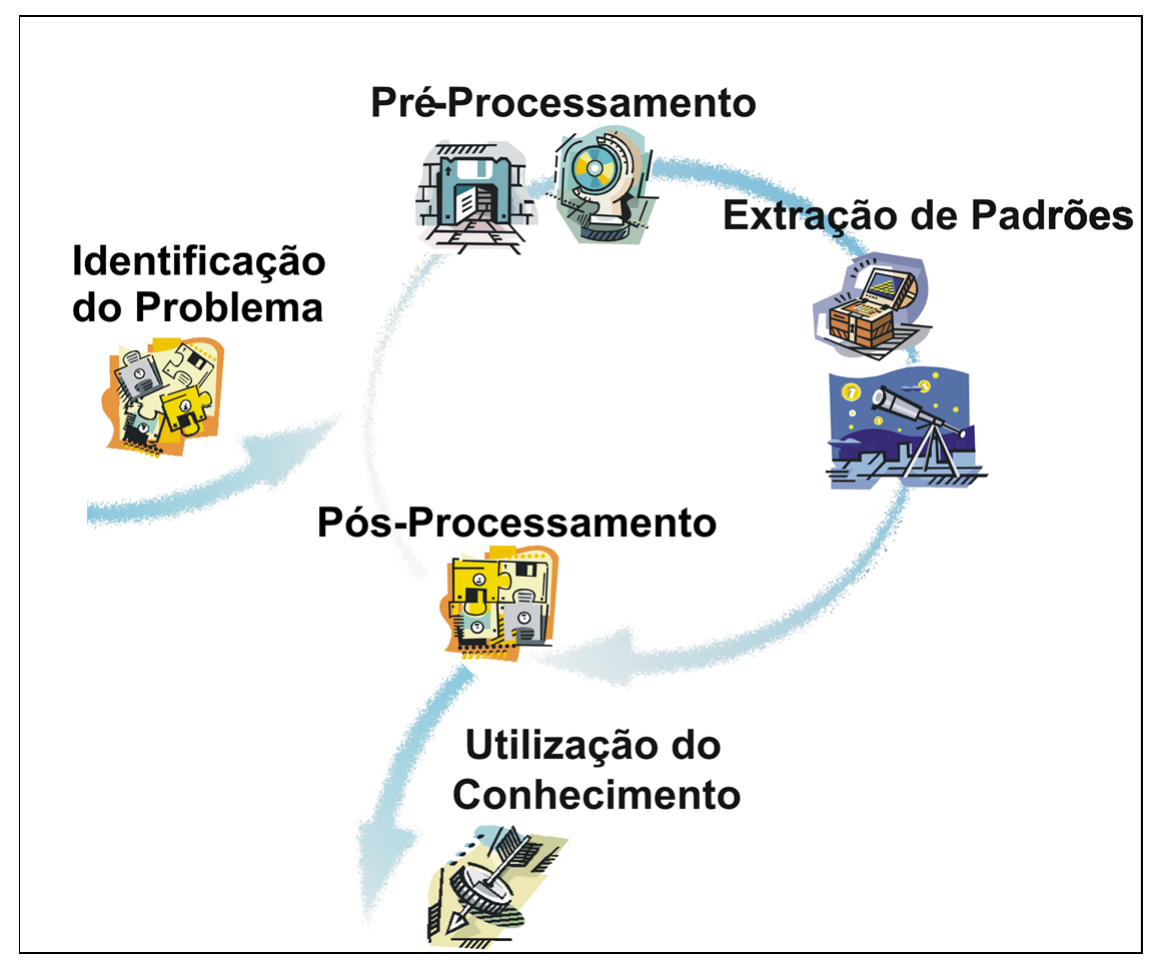

Figura 2.1: Etapas do processo de mineração de dados (Rezende, Pugliesi, Melanda, \& Paula, 2003).

Usuário Final Representa os usuários que utilizam o conhecimento extraído no processo de mineração de dados para apoiá-lo em tomadas de decisão. Não é necessário que esse usuário possua conhecimento profundo do domínio da aplicação.

A seguir, as etapas que compõem o processo de mineração de dados são descritas, sendo o pré-processamento, a extração de padrões e o pós-processamento as etapas mais detalhadas, uma vez que as mesmas compõem o núcleo do processo.

\subsubsection{Identificação do Problema}

Nessa etapa é realizado um estudo do domínio da aplicação e são definidos os objetivos e metas a serem alcançados com o processo de mineração de dados. Também são identificados e selecionados os conjuntos de dados a serem utilizados para a extração de conhecimento.

Além dessa análise inicial para definição das principais metas, objetivos e restrições, o conhecimento sobre o domínio fornece um subsídio para todas as etapas do processo de mineração de dados. Mais especificamente, na etapa de pré-processamento, esse conhecimento pode ajudar os analistas na escolha do melhor conjunto de dados para realizar a extração de padrões, e saber os valores válidos para os atributos, os critérios de preferência entre os possíveis atributos, as restrições de relacionamento ou as informações para 
geração de novos atributos.

$\mathrm{Na}$ etapa de extração de padrões, o conhecimento sobre o domínio pode ajudar os analistas na escolha de um critério de preferência entre os modelos gerados, no ajuste dos parâmetros do processo de indução, ou mesmo na geração de um conhecimento inicial a ser fornecido como entrada do algoritmo de mineração para aumentar a eficiência no aprendizado dos conceitos e melhorar a precisão ou a compreensão do modelo final.

Na etapa de pós-processamento, o conhecimento extraído pelos algoritmos de extração de padrões deve ser avaliado. Alguns critérios de avaliação utilizam o conhecimento do especialista para saber, por exemplo, se o conhecimento extraído é interessante ao usuário (Hilderman \& Hamilton, 2001; Liu \& Hsu, 1996; Piatetsky-Shapiro \& Matheus, 1994).

\subsubsection{Pré-Processamento}

Normalmente, os dados disponíveis para análise não estão em um formato adequado para a extração de conhecimento. Além disso, em razão de limitações de memória ou tempo de processamento, muitas vezes não é possível a aplicação direta dos algoritmos de extração de padrões aos dados. Dessa maneira, torna-se necessária a aplicação de métodos para tratamento, limpeza e redução do volume de dados antes de iniciar a etapa de extração de padrões. É importante salientar que a execução das transformações deve ser guiada pelos objetivos do processo de extração a fim de que o conjunto de dados gerado apresente as características necessárias para que os objetivos sejam cumpridos (Batista, 2003).

Diversas transformações nos dados podem ser executadas na etapa de pré-processamento, entre elas: obtenção e unificação, transformação, limpeza e redução de dados.

Os dados disponíveis podem estar em diferentes formatos, como arquivos-texto, arquivos no formato de planilhas, banco de dados ou data warehouse. Assim, é necessária a obtenção desses dados e sua unificação, formando uma única fonte de dados, que será utilizada como entrada para o algoritmo de extração de padrões.

Após a obtenção e unificação dos dados, esses devem ser adequados para serem utilizados nos algoritmos de extração de padrões. Algumas transformações comuns que podem ser aplicadas aos dados são: resumo, por exemplo, quando dados sobre vendas são agrupados para formar resumos diários; transformação de tipo, por exemplo, quando um atributo do tipo data é transformado em um outro tipo para que o algoritmo de extração de padrões possa utilizá-lo mais adequadamente; e normalização de atributos contínuos, mapeando seus valores em intervalos definidos, por exemplo, entre 0 e 1.

Com relação à limpeza, verifica-se que os dados disponíveis para aplicação dos algoritmos de extração de padrões podem apresentar problemas advindos do processo de 
coleta. Esses problemas podem ser erros de digitação ou de leitura dos dados por sensores. Como o resultado do processo de extração possivelmente será utilizado em um processo de tomada de decisão, a qualidade dos dados é um fator extremamente importante. Por isso, técnicas de limpeza devem ser aplicadas aos dados a fim de garantir sua qualidade.

A limpeza dos dados pode ser realizada utilizando o conhecimento do domínio. Por exemplo, pode-se encontrar registros com valor inválido em algum atributo, granularidade incorreta ou exemplos errôneos. Pode-se também efetuar alguma limpeza independente de domínio, como decisão da estratégia de tratamento de atributos incompletos, remoção de ruído e tratamento de conjunto de exemplos não balanceados (Batista, Carvalho, \& Monard, 2000).

O número de exemplos e de atributos disponíveis para análise pode inviabilizar a utilização de algoritmos de extração de padrões. Como solução para esse problema, pode ser necessária a aplicação de métodos para redução dos dados antes de iniciar a busca pelos padrões. Essa redução pode ser feita de três maneiras (Weiss \& Indurkhya, 1998):

- redução do número de exemplos: deve ser feita a fim de manter as características do conjunto de dados original, isto é, por meio da geração de amostras representativas dos dados (Glymour, Madigan, Pregibon, \& Smyth, 1997). A abordagem mais utilizada para redução do número de exemplos é a amostragem aleatória (Weiss \& Indurkhya, 1998), pois esse método tende a produzir amostras representativas. Se a amostra não for representativa, ou se a quantidade de exemplos for insuficiente para caracterizar os padrões embutidos nos dados, os modelos encontrados podem não representar a realidade, não tendo, portanto, valor.

- redução do número de atributos: pode ser uma forma de redução do espaço de busca pela solução. O objetivo é selecionar um subconjunto dos atributos existentes de forma que isto não tenha grande impacto na qualidade da solução final. Essa redução pode ser realizada com o apoio do especialista do domínio, uma vez que, ao remover um atributo potencialmente útil para o modelo final, a qualidade do conhecimento extraído pode diminuir consideravelmente. Além disso, por não se saber inicialmente quais atributos serão importantes para atingir os objetivos, deve-se remover somente aqueles atributos que, com certeza, não têm nenhuma importância para o modelo final. Para tanto, é importante identificar a relevância de cada atributo e a redundância existente entre os mesmos (Lee, 2005).

Outra maneira de reduzir o número de atributos pode ser por meio de indução construtiva, na qual um novo atributo é criado a partir do valor de outros. Caso os atributos originais utilizados na construção do novo atributo não estejam presentes em um novo modelo, eles podem ser descartados, reduzindo assim o número de atributos. A utilização de indução construtiva pode aumentar consideravelmente a 
qualidade do conhecimento extraído (Lee, 2000).

- redução do número de valores de um atributo: consiste na redução do número de valores de um atributo. Isso é feito, geralmente, por discretização ou suavização dos valores de um atributo contínuo.

Discretização de um atributo consiste na substituição de um atributo contínuo (inteiro ou real) por um atributo discreto, por meio do agrupamento de seus valores. Essencialmente, um algoritmo de discretização aceita como entrada os valores de um atributo contínuo e gera como saída uma pequena lista de intervalos ordenados. Cada intervalo é representado na forma $\left[V_{\text {inferior }}: V_{\text {superior }}\right]$, de modo que $V_{\text {inferior }} \mathrm{e}$ $V_{\text {superior }}$ são, respectivamente, os limites inferior e superior do intervalo.

Na suavização dos valores de um atributo, o objetivo é diminuir o número de valores do mesmo sem discretizá-lo. Nesse método, os valores de um determinado atributo são agrupados mas, ao contrário da discretização, cada grupo de valores é substituído por um valor numérico que o represente. Esse novo valor pode ser a média, a mediana ou mesmo os valores de borda de cada grupo (Weiss \& Indurkhya, 1998).

As transformações descritas devem ser realizadas criteriosamente e com o devido cuidado, uma vez que é fundamental garantir que as informações presentes nos dados brutos continuem presentes nas amostras geradas, para que os modelos finais representem a realidade dos dados brutos.

\subsubsection{Extração de Padrões}

A etapa de extração de padrões é direcionada ao cumprimento dos objetivos definidos na identificação do problema. Nessa etapa é realizada a escolha, a configuração e a execução de um ou mais algoritmos para extração de conhecimento. Como essa etapa é iterativa, pode ser necessário que ela seja executada diversas vezes para ajustar o conjunto de parâmetros visando a obtenção de resultados mais adequados aos objetivos preestabelecidos. Ajustes podem ser necessários, por exemplo, para a melhoria da precisão ou da compreensão do conhecimento extraído.

A etapa de extração de padrões compreende a escolha da tarefa de mineração de dados a ser empregada, a escolha do algoritmo e a extração dos padrões propriamente dita.

Com o grande número de sistemas de mineração de dados desenvolvidos para os mais diferentes domínios, a variedade de tarefas para MD vem se tornando cada vez mais diversificada. Essas tarefas podem extrair diferentes tipos de conhecimento, sendo necessário decidir já no início do processo de MD qual o tipo de conhecimento que o algoritmo deve extrair. A escolha da tarefa é feita de acordo com os objetivos desejáveis para a solução 
a ser encontrada. As possíveis tarefas de um algoritmo de extração de padrões podem ser agrupadas em atividades preditivas e descritivas.

A mineração de dados preditiva consiste na generalização de exemplos ou experiências passadas com respostas conhecidas em uma linguagem capaz de identificar a classe (atributo meta) de um novo exemplo. Os dois tipos de tarefas mais utilizadas para predição são classificação e regressão. A classificação consiste na predição de um valor categórico como predizer se o cliente é bom ou mau pagador. Na regressão, o atributo a ser predito consiste em um valor contínuo como predizer o lucro ou a perda em um empréstimo (Weiss \& Indurkhya, 1998).

Atividades de descrição, ou mineração de dados descritiva, consistem na identificação de comportamentos intrínsecos do conjunto de dados, sendo que esses dados não possuem uma classe especificada. Algumas das tarefas de descrição são clustering, sumarização e associação. As regras de associação, geradas na associação, são o foco deste trabalho.

Uma vez escolhida a tarefa a ser empregada, uma grande variedade de algoritmos pode ser utilizada para executá-la. A definição do algoritmo de extração e a configuração de seus parâmetros são realizadas nessa atividade. A escolha do algoritmo é feita de maneira subordinada à linguagem de representação dos padrões a serem encontrados. Podem-se utilizar algoritmos indutores de árvores de decisão ou regras de produção, por exemplo, se o objetivo é realizar uma predição. Entre os tipos mais freqüentes de representação de padrões destacam-se: árvores de decisão, regras de produção, modelos lineares, modelos não-lineares (redes neurais artificiais), modelos baseados em exemplos ( $k$-nearest neighbour (KNN), raciocínio baseado em casos) e modelos de dependência probabilística (redes bayesianas).

Já a extração dos padrões propriamente dita consiste na aplicação dos algoritmos selecionados para realizar a extração dos padrões contidos nos dados. É importante ressaltar que dependendo da tarefa adotada (predição ou descrição) podem ser necessárias diversas execuções dos algoritmos.

No caso da associação pode-se realizar apenas uma execução do algoritmo sem comprometer a qualidade do conhecimento extraído. Segundo Zheng, Kohavi, \& Mason (2001), os diversos algoritmos de regras de associação devem sempre gerar a mesma solução para a mesma configuração. Além disso, os parâmetros de entrada para avaliação dos resultados parciais (durante a geração das regras) são geralmente o suporte e a confiança, e a alteração desses valores irá apenas incluir ou excluir regras do conjunto de regras extraídas.

A disponibilização do conjunto de padrões extraídos nessa etapa ao usuário ou a sua incorporação a um sistema inteligente ocorre após a análise e/ou o processamento dos padrões na etapa de pós-processamento. 


\subsubsection{Pós-Processamento}

O pós-processamento é uma etapa importante do processo de mineração de dados na qual o conhecimento extraído pode ser simplificado, avaliado, visualizado ou simplesmente documentado para o usuário final.

Essa etapa consiste de vários métodos e procedimentos que podem ser agrupados nas seguintes categorias (Bruha \& Famili, 2000):

Filtragem do Conhecimento Pode ser realizada por meio de mecanismos de pós-poda, para o caso de árvores de decisão, ou de truncagem, no caso de regras de decisão. Esses mecanismos são aplicados nas situações em que os algoritmos de extração de conhecimento geram árvores de decisão com muitas folhas ou regras de decisão muito específicas, cobrindo poucos exemplos (overfitting). Outra forma de filtragem do conhecimento, especialmente útil para regras de associação, é o emprego de restrição de atributos ou ordenação de regras por meio de métricas (medidas de avaliação) (Melanda \& Rezende, 2003a,c).

Interpretação e Explanação É usualmente aplicada quando o conhecimento obtido é utilizado por um usuário final ou por um sistema inteligente. O conhecimento pode ser documentado, visualizado ou modificado de forma a torná-lo compreensível para o usuário. O conhecimento extraído pode ser comparado ao conhecimento preexistente para a verificação de conflitos ou de conformidade e pode ser sumarizado e/ou combinado com o conhecimento prévio do domínio (Domingues \& Rezende, 2005; Domingues, 2004).

Avaliação Pode ser realizada por meio dos critérios: precisão, compreensão, complexidade computacional, interesse, entre outros. Adamo (2001); Liu, Hsu, Chen, \& Ma (2000); Lavrač, Flach, \& Zupan (1999), por exemplo, apresentam algumas medidas que podem ser empregadas na avaliação do conhecimento.

Integração do Conhecimento Os sistemas tradicionais de apoio à decisão são dependentes de uma única técnica, estratégia e modelo. Já os sistemas novos e sofisticados possibilitam combinar ou refinar os resultados de vários modelos de maneira a obter uma maior precisão e um melhor desempenho. Uma das técnicas que pode ser empregada é o uso da combinação de classificadores (ensembles) (Breiman, 2000).

\subsubsection{Utilização do Conhecimento}

Essa fase sucede o processo de mineração de dados que tem como objetivo automatizar a tarefa de extrair conhecimento útil a partir de um grande volume de dados. 
O conhecimento extraído com o uso do processo, depois de ser avaliado e validado na etapa de pós-processamento, é consolidado na fase de utilização do conhecimento, podendo ser incorporado a um sistema inteligente, ou utilizado diretamente pelo usuário final para apoio a algum processo de tomada de decisão ou, simplesmente, relatado às pessoas interessadas.

Após a consolidação do conhecimento, o mesmo pode ser utilizado para resolver conflitos potenciais entre o conhecimento existente e o conhecimento obtido com o processo de mineração de dados (Rezende, 2004).

\subsection{Regras de Associação}

Desde a sua introdução por Agrawal, Imielinski, \& Swami (1993) as regras de associação têm recebido grande atenção. A associação se tornou uma técnica de mineração muito popular em função de sua aplicabilidade a problemas de negócio juntamente com sua compreensibilidade inerente - até mesmo por não especialistas em mineração de dados (Hipp, Güntzer, \& Nakhaeizadeh, 2002).

A idéia de minerar regras de associação surgiu da análise de dados de cestas de compras em que regras do tipo "um cliente que compra os produtos $x_{1}, x_{2}, \ldots, x_{n}$ também irá comprar o produto $y$ com probabilidade $c \%$ " são geradas. Entretanto, as regras de associação não estão restritas a análises de dependência no contexto de aplicações de varejo, uma vez que elas são aplicadas com sucesso a uma ampla gama de problemas.

Uma regra de associação é representada como uma implicação na forma $L H S \Rightarrow R H S$, em que LHS e RHS são, respectivamente, o lado esquerdo (Left Hand Side) e o lado direito (Right Hand Side) da regra.

As próximas seções apresentam alguns tópicos relacionados às regras de associação. Na Seção 2.3.1 são apresentadas as definições e os conceitos referentes às mesmas. Em seguida, é apresentada a sintaxe utilizada neste trabalho para representar regras de associação (Seção 2.3.2), uma vez que cada algoritmo de associação gera regras com sintaxes diferentes. Na Seção 2.3.3 são apresentadas algumas abordagens de pós-processamento que auxiliam o usuário a interpretar e explorar regras de associação, já que o volume de regras obtidas é, geralmente, muito grande. Por fim, na Seção 2.3.4 são descritas algumas medidas de interesse objetivas utilizadas na avaliação de regras de associação a serem utilizadas nos próximos capítulos. 


\subsubsection{Definições e Conceitos}

Uma regra de associação é definida da maneira descrita a seguir (definição baseada nos trabalhos de Agrawal \& Srikant (1994); Yang (2005) e adaptada para a notação utilizada neste trabalho):

Seja $D$ uma base de dados composta por um conjunto de itens $A=\left\{a_{1}, \ldots, a_{m}\right\}$, ordenados lexicograficamente, e por um conjunto de transações $T=\left\{t_{1}, \ldots, t_{n}\right\}$, na qual cada transação $t_{i} \in T$ é composta por um conjunto de itens (chamado itemset) tal que $t_{i} \subseteq A$. É dito que uma transação $t_{i}$ suporta um item $x$ se $x \in t_{i}$. É dito que uma transação $t_{i}$ suporta um itemset $X$ se $X \subseteq t_{i}$. O suporte $P(X)$ de um itemset $X$ representa a probabilidade da ocorrência do evento $X$.

A regra de associação é uma implicação na forma $L H S \Rightarrow R H S$, em que $L H S \subset A, R H S \subset A$ e $L H S \cap R H S=\varnothing$. A regra $L H S \Rightarrow R H S$ ocorre no conjunto de transações $T$ com confiança conf e suporte sup, onde $P(L H S R H S)$ representa o suporte da regra (a probabilidade da ocorrência da transação $L H S \cup R H S)$ e $P(R H S \mid L H S)$ a confiança da regra (a probabilidade condicional de $R H S$ dado $L H S$ ).

Em regras de associação, as medidas mais empregadas são o suporte e a confiança, tanto no que se refere à etapa de pós-processamento do conhecimento adquirido, como na etapa de seleção dos subconjuntos de itens durante o processo de geração das regras. É importante ressaltar então que o suporte representa a freqüência dos padrões e a confiança a força da implicação, ou seja, em pelo menos $c \%$ das vezes que o antecedente ocorrer nas transações, o conseqüente também deve ocorrer (Zhang \& Zhang, 2002).

O problema de obtenção de regras de associação é decomposto em dois passos (Agrawal, Imielinski, \& Swami, 1993):

1. Encontrar todos os $k$-itemsets (conjunto de $k$ itens) que possuam suporte maior ou igual ao suporte mínimo especificado pelo usuário (sup-min). Os itemsets com suporte igual ou superior a sup-min são definidos como itemsets freqüentes, os demais conjuntos são denominados de itemsets não-freqüentes;

2. Utilizar todos os $k$-itemsets freqüentes, com $k \geq 2$, para gerar as regras de associação. Para cada itemset freqüente $l \subseteq A$, encontrar todos os subconjuntos $\tilde{a}$ de itens não vazios e diferentes de $l$. Para cada subconjunto $\tilde{a} \subseteq l$, gerar uma regra na forma $\tilde{a} \Rightarrow(l-\tilde{a})$ se a razão de $\sup (l)$ por $\sup (\tilde{a})$ é maior ou igual à confiança mínima especificada pelo usuário (conf-min). 
Com um conjunto de itemsets freqüentes $\{a, b, c, d\}$ e um subconjunto de itemsets freqüentes $\{a, b\}$, por exemplo, pode-se gerar uma regra do tipo $a b \Rightarrow c d$, desde que $\operatorname{conf}(a b \Rightarrow c d) \geq$ conf-min, em que, $\operatorname{conf}(a b \Rightarrow c d)=\sup (\{a, b, c, d\}) / \sup (\{a, b\})$.

A obtenção de itemsets freqüentes para gerar regras de associação (passo 1) pode ser realizada utilizando diversos algoritmos, como: AIS (Agrawal, Imielinski, \& Swami, 1993), Apriori e AprioriTid (Agrawal \& Srikant, 1994), SETM (Houtsma \& Swami, 1995), Opus (Webb, 1995), Direct Hashing and Pruning (DHP) (Park, Chen, \& Yu, 1997), Dynamic Set Couting (DIC) (Brin, Motwani, Ullman, \& Tsur, 1997), Closet (Pei, Han, \& Mao, 2000) e Charm (Zaki \& Hsiao, 2002) ${ }^{1}$.

Com base nos itemsets obtidos no passo 1, o objetivo do passo 2 é gerar todas as regras de associação. É importante ressaltar que a complexidade de um sistema de mineração de regras de associação é dependente do algoritmo utilizado para gerar os itemsets freqüentes (Zhang \& Zhang, 2002).

\subsubsection{Sintaxe Padrão para Representar Regras de Associação}

Como mencionado anteriormente, a associação é uma técnica descritiva de mineração de dados que gera regras de associação como formato de representação das hipóteses geradas a partir da aplicação dos algoritmos existentes. Apesar da forma de representação das hipóteses ser semelhante, cada algoritmo gera regras com sintaxes diferentes. Os algoritmos fornecem, além das regras, as métricas suporte e confiança, geralmente acompanhadas de métricas complementares que variam de algoritmo para algoritmo.

Devido às diferentes sintaxes de representação das regras geradas por esses diversos algoritmos, qualquer medida ou estatística que necessitasse ser calculada sobre as regras teria de ser implementada várias vezes, uma para cada sintaxe. Do mesmo modo, a interpretação das regras pelo usuário tornar-se-ia mais difícil, já que esse teria que lidar com símbolos e formatos diferentes a cada conjunto de regras.

Para propiciar ao usuário um conjunto de informações padronizadas sobre cada regra e para evitar retrabalho nas implementações das métricas de avaliação, foi definida pelos pesquisadores do Laboratório de Inteligência Computacional ( LABIC $^{2}$ ) do Instituto de Ciências Matemáticas e de Computação da Universidade de São Paulo (ICMC-USP ${ }^{3}$ ) uma sintaxe padrão para representação de regras de associação (Melanda \& Rezende, 2003b). Com base nessa sintaxe, padronizam-se as saídas de alguns algoritmos de associação, convertendo-as para um formato único em que as regras são não ordenadas. Os

\footnotetext{
${ }^{1}$ Vários outros algoritmos, com suas respectivas implementações, podem ser encontrados em http: //fimi.cs.helsinki.fi/.

${ }^{2}$ http://labic.icmc.usp.br.

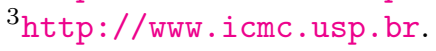


algoritmos que já possuem scripts para conversão das regras no formato original para a sintaxe padrão são: Apriori ${ }^{4}$ (Agrawal, Imielinski, \& Swami, 1993), MineSet ${ }^{T M 5}$, Weka $^{6}$ e Magnum Opus ${ }^{7}$.

Considerando que a maioria das medidas objetivas para avaliação de regras encontradas na literatura pode ser derivada da matriz de contingências, o formato padrão para regras de associação contém também as freqüências relativas $f(L H S R H S)$, $f(L H S \overline{R H S}), f(\overline{L H S} \overline{R H S})$ e $f(\overline{L H S}$ RHS) (Tabela 2.1), além do número total de transações $N^{8}$. Na Tabela 2.1, LHS denota o antecedente da regra, e $\overline{L H S}$ o complemento de $L H S$; de forma análoga para o conseqüente $R H S$ e $\overline{R H S}$. $f(L H S \quad R H S)$ denota a freqüência com que $L H S$ e RHS ocorrem juntos nas transações; de forma similar para o demais elementos. Os valores absolutos das medidas podem ser obtidos pela multiplicação das freqüências relativas por $N$. As freqüências marginais $f(L H S), f(R H S), f(\overline{L H S})$ e $f(\overline{R H S})$ também podem ser obtidas pela soma das linhas e colunas da matriz de contingências. É importante ressaltar que a freqüência relativa representa a proporção com que determinado elemento encontra-se em relação ao número total de transações $(N)$.

Tabela 2.1: Matriz de contingências com freqüências relativas.

\begin{tabular}{c|c|c|c} 
& RHS & $\overline{R H S}$ & \\
\hline$L H S$ & $f(L H S R H S)$ & $f(L H S \overline{R H S})$ & $f(L H S)$ \\
$\overline{L H S}$ & $f(\overline{L H S} R H S)$ & $f(\overline{L H S} \overline{R H S})$ & $f(\overline{L H S})$ \\
\hline & $f(R H S)$ & $f(\overline{R H S})$ & 1
\end{tabular}

Os valores de freqüência relativa e número de exemplos compõem a sintaxe padrão do seguinte modo:

$$
[f(L H S R H S), f(L H S \overline{R H S}), f(\overline{L H S} \overline{R H S}), f(\overline{L H S} R H S), N]
$$

Esse conjunto de informações é calculado a partir das métricas fornecidas pelos algoritmos de regras de associação considerados. Assim, uma regra de associação na sintaxe padrão terá o seguinte formato:

\section{[Número da Regra], Antecedente, Conseqüente, [Dados da Matriz de Contingências]}

\footnotetext{
${ }^{4} \mathrm{~A}$ implementação do Apriori considerada no processo de conversão foi a de Chistian Borgelt (http: //fuzzy.cs.uni-magdeburg.de/ borgelt/apriori.html).

${ }^{5}$ Aplicativo da Silicon Graphics.

${ }^{6} \mathrm{O}$ ambiente Weka (Waikato Environment for Knowledge Analysis) foi desenvolvido na Universidade de Waikato na Nova Zelândia (www.waikato.ac.nz) dentro da filosofia GNU de código fonte aberto.

${ }^{7} \mathrm{O}$ aplicativo Magnum Opus, comercializado pela Rule Quest (www.rulequest.com), é a implementação do algoritmo Opus proposto por Webb (1995).

${ }^{8}$ Assim como para Lavrač, Flach, \& Zupan (1999), neste trabalho a freqüência relativa é interpretada como uma probabilidade.
} 
a qual deve ser interpretada da seguinte forma:

[Número da Regra] Antecedente $\Rightarrow$ Conseqüente

[Dados da Matriz de Contingências] OU

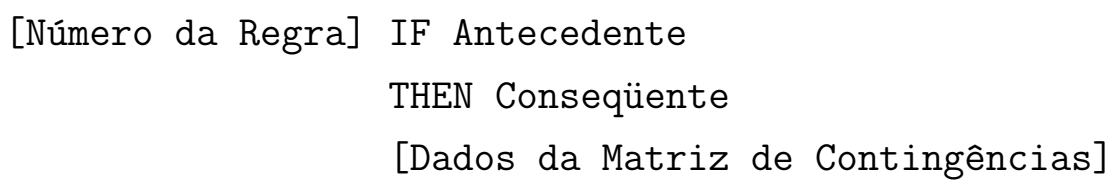

Como exemplo de uma regra de associação na sintaxe padrão, considere a regra apresentada a seguir. Nesse caso, o número da regra é "R0121", o antecedente é "temperature=hot \& outlook=overcast", o conseqüente é "humidity=high" e os valores da matriz de contingência são $f(L H S \quad R H S)=0.071429, f(L H S \quad \overline{R H S})=0.071429$, $f(\overline{L H S} \quad \overline{R H S})=0.428571, f(\overline{L H S} \quad R H S)=0.428571$ e $N=14$. A interpretação da regra segue logo após a sua definição. É importante mencionar que o símbolo \& representa o operador lógico $A N D$.

Regra Exemplo

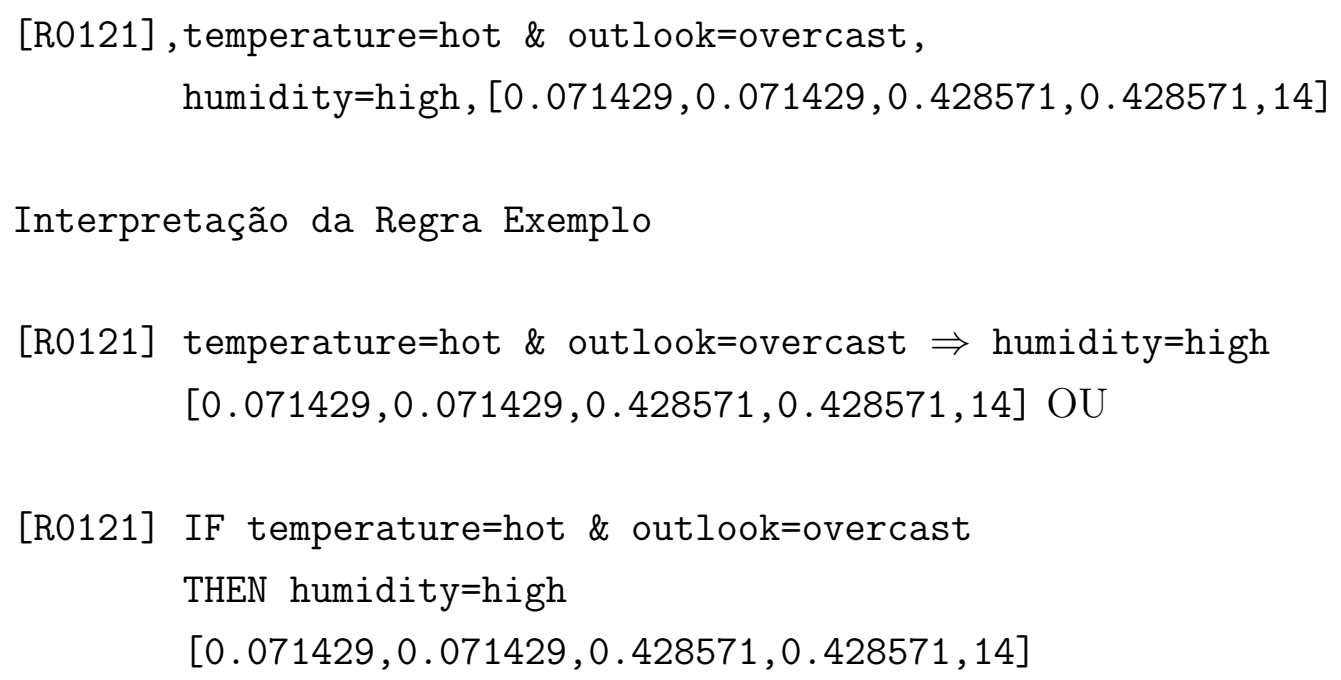

\subsubsection{Abordagens para Avaliação de Regras de Associação}

Desde o surgimento das regras de associação em 1993 (Agrawal, Imielinski, \& Swami, 1993) um grande volume de artigos tem sido publicado propondo soluções mais eficientes ao problema de geração de regras de associação, ou seja, o foco de atenção tem sido no aprimoramento do desempenho dos algoritmos existentes. Infelizmente, desempenho, embora tecnicamente importante, não é o principal problema que dificulta a grande disseminação das regras de associação. O grande volume de regras que são geradas, até mesmo utilizando bases de dados relativamente pequenas, geralmente excede o tamanho da base 
de dados em questão. Tipicamente, somente uma pequena fração desse grande volume de regras é interessante ao usuário, o qual é constantemente sobrecarregado com uma grande quantidade de regras (Jorge, 2004; Adomavicius \& Tuzhilin, 2001; Imieliński \& Virmani, 1998). Desse modo, é extremamente importante fornecer ferramentas eficientes para apoiar o usuário na análise desse grande volume de regras. A seguir, é apresentada uma visão geral de algumas abordagens existentes, reportadas na literatura, que auxiliam o usuário a interpretar e explorar as regras obtidas. A divisão apresentada foi realizada com base nos trabalhos de Natarajan \& Shekar (2005); Jorge (2004); Baesens, Viaene, \& Vanthienen (2000).

\section{Avaliação por Consulta}

Essa abordagem permite que o usuário explore o conjunto de regras por meio do uso de uma linguagem de consulta (tipicamente inspirada no SQL - Structured Query Language). Usando tal facilidade é possível obter subconjuntos das regras contendo certos itens, e/ou satisfazendo alguma restrição definida pelo usuário que envolvam, por exemplo, o suporte e a confiança (Jorge, 2004). Alguns trabalhos que fazem uso dessa abordagem são Paula (2003); Melanda \& Rezende (2003a,c); Tuzhilin \& Liu (2002); Hipp, Mangold, Guntzer, \& Nakhaeizadeh (2002); Botta, Boulicaut, Masson, \& Meo (2002); Goethals, Bussche, \& Vanhoof (1998); Imieliński \& Virmani (1998). Os templates de regras, que são "esqueletos" que descrevem, a priori, a estrutura geral das regras que se tem interesse (Baesens, Viaene, \& Vanthienen, 2000), estão inclusas, neste trabalho, nessa abordagem. Isso porque é possível se descrever um template, isto é, indicar os atributos que devem ocorrer no antecedente e no conseqüente da regra (Baesens, Viaene, \& Vanthienen, 2000), via a utilização de uma linguagem de consulta.

\section{Medidas de Avaliação}

Uma variedade de medidas para avaliação de conhecimento tem sido pesquisada com a finalidade de fornecer subsídios ao usuário no entendimento e na utilização do conhecimento adquirido. Essas medidas podem ser categorizadas quanto à forma de avaliação e quanto ao objeto de avaliação.

Quanto à forma de avaliação, as medidas podem ser objetivas ou subjetivas. As medidas objetivas dependem exclusivamente da estrutura dos padrões (regras) e dos dados utilizados no processo de extração de conhecimento. As medidas subjetivas dependem fundamentalmente dos usuários que irão interpretar o conhecimento (Silberschatz \& Tuzhilin, 1996).

Com relação ao objeto de avaliação, as medidas permitem avaliar o desempenho ou a qualidade de uma regra. O desempenho da regra está associado à fidelidade com que repre- 
senta os dados. Para a avaliação da qualidade dos padrões gerados podem ser utilizados os conceitos de compreensão e interesse. A facilidade de um ser humano interpretar um dado conjunto de regras está relacionada à compreensão desse conjunto, podendo ser estimada, por exemplo, pelo número de regras e pelo número de condições por regra. O interesse, por sua vez, é uma avaliação de natureza qualitativa realizada a partir de estimativas da quantidade de conhecimento interessante (inovador, inesperado) presente nas regras.

O interesse é uma das medidas mais utilizadas em regras de associação, a qual pode ser dividida em objetiva e subjetiva. Medidas de interesse subjetivas são baseadas em conceitos como os de utilidade e inesperabilidade. A utilidade de uma regra ou a possibilidade do usuário em obter proveito da sua utilização é indicador de interesse da mesma. A inesperabilidade indica que as regras que representam um conhecimento "inesperado" para o usuário podem ser consideradas interessantes (Silberschatz \& Tuzhilin, 1995). Alguns trabalhos que fazem uso das medidas de interesse são Tamir \& Singer (2006); Huynh, Guillet, \& Briand (2005); Tan, Kumar, \& Srivastava (2004); Melanda \& Rezende (2003a,c); Omiecinski (2003); Hussain, Liu, \& Lu (2000); Hussain, Liu, Suzuki, \& Lu (2000); Liu, Hsu, Chen, \& Ma (2000); Tan \& Kumar (2000); Hilderman \& Hamilton (1999); Lavrač, Flach, \& Zupan (1999); Dong \& Li (1998); Freitas (1998); Silberschatz \& Tuzhilin $(1996,1995)$. Na Seção 2.3.4 serão descritas várias medidas de interesse objetivas utilizadas neste trabalho.

\section{Poda}

A poda (pruning) é uma técnica utilizada para reduzir o número de regras geradas via a eliminação (exclusão) de regras redundantes (Jorge, Poças, \& Azevedo, 2002; Baesens, Viaene, \& Vanthienen, 2000) - regras que são de alguma forma dedutíveis de outras regras existentes no conjunto de regras (Baesens, Viaene, \& Vanthienen, 2000). Alguns trabalhos que fazem uso dessa abordagem são Jaroszewicz \& Simovici (2002); Zaki (2000); Liu, Hsu, \& Ma (1999); Shah, Lakshmanan, Ramamritham, \& Sudarshan (1999); Toivonen, Klemettinen, Ronkainen, Hätönen, \& Mannila (1995).

\section{Sumarização}

A abordagem de sumarização visa resumir as regras de associação descobertas em regras mais gerais ou em conceitos mais abstratos que sejam mais fáceis de serem entendidos pelo usuário. As regras em alto nível fornecem uma visão mais geral do conhecimento descoberto enquanto que as regras menos gerais podem ser exploradas posteriormente para maiores detalhes (Baesens, Viaene, \& Vanthienen, 2000).

A sumarização pode ser comparada à procura de artigos científicos. Após a leitura de alguns resumos é possível selecionar artigos que se mostrem interessantes. A partir 
desses resumos (conceitos gerais), é possível, caso haja interesse do usuário, verificar os detalhes lendo todo o artigo (conceitos menos gerais). Similarmente, o usuário deve ter a oportunidade de explorar o conjunto de regras e analisar o seu conteúdo de uma forma eficiente (por exemplo, das regras mais gerais para as mais específicas) que não apenas ordene as regras pelos seus valores de suporte e confiança (Nawarecki, Valenta, \& Zygmunt, 2003). Alguns trabalhos que fazem uso dessa abordagem são Domingues \& Rezende (2005); Domingues (2004); Jorge (2004); Nawarecki, Valenta, \& Zygmunt (2003); Adomavicius \& Tuzhilin (2001); Liu, Hu, \& Hsu (2000).

\section{Agrupamento}

O objetivo da abordagem de agrupamento (clustering) é fornecer ao usuário grupos de regras que correspondam a diferentes temas do domínio em questão (Jorge, 2004). Essa abordagem procura identificar agrupamentos que representam características específicas de determinados grupos de regras contidas no conjunto original. Com base nesse agrupamento, técnicas de sumarização podem ser utilizadas para resumir e/ou compactar as regras de cada agrupamento encontrado. Cada um desses agrupamentos pode representar particularidades da base de dados. Alguns trabalhos que fazem uso dessa abordagem são An, Khan, \& Huang (2006); Jorge (2004); Sahar (2002); Lent, Swami, \& Widom (1997); Toivonen, Klemettinen, Ronkainen, Hätönen, \& Mannila (1995).

\section{Visualização e Exploração}

Ambientes de exploração de regras de associação objetivam auxiliar o usuário na exploração de grandes conjuntos de regras. Geralmente, esses ambientes permitem que o usuário navegue interativamente no conjunto de regras, podendo inspecionar subconjuntos de interesse. Para tanto, esses ambientes fazem uso de uma ou mais abordagens descritas anteriormente, ou seja, para permitir a navegação utilizam medidas de avaliação, sumarização, etc. Além disso, esses ambientes podem fornecer mecanismos de representações gráficas para a visualização dos conjuntos e subconjuntos de regras (Jorge, 2004).

Diversos desses ambientes encontram-se disponíveis via Web, uma vez que a mesma provê uma poderosa infraestrutura para comunicação e compartilhamento de informação (Ma, Liu, \& Wong, 2000) e que os conteúdos publicados podem ser acessados de qualquer local. Além disso, a Web oferece um ambiente de interface familiar ao usuário para exploração do conhecimento descoberto (Ma, Wong, \& Liu, 2000).

Alguns trabalhos que fazem uso de ambientes de exploração, de visualização ou de exploração e visualização de regras, utilizando ou não a tecnologia Web, são Techapichetvanich \& Datta (2005); Ceglar, Roddick, Calder, \& Rainsford (2005); Yang (2005); Fule \& Roddick (2004); Chakravarthy \& Zhang (2003); Blanchard, Guillet, \& Briand (2003); 
Paula (2003); Hipp, Mangold, Guntzer, \& Nakhaeizadeh (2002); Jorge, Poças, \& Azevedo (2002); Liu, Hsu, Chen, \& Ma (2000); Ma, Wong, \& Liu (2000); Ma, Liu, \& Wong (2000); Klemettinen, Mannila, \& Verkamo (1999); Wong, Whitney, \& Thomas (1999); Klemettinen, Mannila, Ronkainen, Toivonen, \& Verkamo (1994).

\subsubsection{Descrição das Medidas de Interesse Objetivas Utilizadas na Avaliação de Regras de Associação}

Na Seção 2.3.3 foram apresentadas algumas abordagens para avaliar o conhecimento expresso pelas regras de associação. Entre as abordagens apresentadas destaca-se a de "Medidas de Avaliação", uma vez que a mesma é utilizada para selecionar e classificar os padrões de acordo com o seu potencial interesse para o usuário (Geng \& Hamilton, 2006). Assim, essa seção apresenta uma descrição das medidas objetivas utilizadas nos próximos capítulos. Embora existam muitas medidas objetivas de avaliação (Geng \& Hamilton, 2006; Ohsaki, Kitaguchi, Okamoto, Yokoi, \& Yamaguchi, 2004; Tan, Kumar, \& Srivastava, 2004; Tan \& Kumar, 2000; Lavrač, Flach, \& Zupan, 1999), as medidas aqui consideradas são as descritas em Tan \& Kumar (2000); Tan, Kumar, \& Srivastava (2004), a saber: Added Value, Certainty Factor, Collective Strength, Confidence (Confiança), Conviction, IS/Cosine, $\phi$-coefficient, Gini Index, J-Measure, Jaccard, Kappa, Klosgen, Goodman-Kruskal's ( $\lambda$ ), Laplace, Interest Factor, Mutual Information, PiatetskyShapiro's, Support (Suporte), Odds Ratio, Yule's Q e Yule's Y.

Na descrição apresentada a seguir considera-se o padrão de associação $A \Rightarrow B$. Para cada uma das medidas indica-se, além do nome, a abreviação considerada e o intervalo de variação da mesma. É importante ressaltar que as medidas aqui descritas não são utilizadas somente na avaliação de regras de associação, já que as mesmas podem ser aplicadas, por exemplo, na avaliação de regras de classificação.

Added Value (AV) [-1...0...1]. Essa medida indica o quanto a freqüência do conseqüente aumenta na presença do antecedente, ou seja, mede o ganho de $B$ na presença de $A$ (Sahar, 2003). Se $P(B \mid A)>P(B)$ tem-se que a freqüência de $B$ aumenta na presença de $A$. Se $P(B \mid A)<P(B)$ tem-se que a freqüência de $B$ diminui na presença de $A$. Se $P(B \mid A)=P(B)$ tem-se uma coincidência aleatória, ou seja, $A$ não aumenta em nada a freqüência de $B$ (independência estatística). Portanto, quanto maior for o ganho de $B$ em relação a $A$, mais relacionados estarão $A$ e $B$.

$$
A V=P(B \mid A)-P(B)=\text { Conf }-P(B)
$$

Certainty Factor $(\mathbf{C F})[-\mathbf{1} \ldots \mathbf{0 . . . 1}] . P(B)$ reflete a crença em $B$. Então $1-P(B)$ pode ser visto como uma estimativa da descrença em relação à verdade de $B$. Se $P(B \mid A)$ 
for maior que $P(B)$, significa que $A$ aumenta a crença em $B$ diminuindo a sua descrença em relação à verdade de $B$. Sendo assim, essa medida mede o aumento da crença em $B$ em conseqüência da observação de $A$ (Shortliffe \& Buchanan, 1990). Em outras palavras, mede a diminuição proporcional na descrença da hipótese $B$ como resultado da observação de $A$. Se $C F=1$ então $A$ e $B$ possuem dependência positiva. Se $C F=-1$ então $A$ e $B$ possuem dependência negativa. Se $C F=0$ significa que $A$ não confirma nem contradiz $B$, isto é, $A$ e $B$ são independentes. Observe que a medida $C F$ pode ser vista como sendo o valor adicionado (AV, Equação 2.1) em relação ao máximo ganho que $A$ pode proporcionar a $B$.

$$
C F=\frac{P(B \mid A)-P(B)}{1-P(B)}=\frac{A V}{1-P(B)}
$$

Collective Strength (CS) $[0 \ldots 1 \ldots \infty]$. Mede a correlação entre um conjunto de itens. Para tanto, utiliza os conceitos taxa de violação e violação esperada (Aggarwal \& Yu, 1998). A taxa de violação $v(I)$ é definida pela fração de transações que contêm pelo menos um item, mas não todos os itens, de um conjunto de itens $I$. Em outras palavras, dado um conjunto de itens $I, v(I)$ é igual à fração de transações que contém um subconjunto próprio não vazio de $I$. A violação esperada $E[v(I)]$ representa a fração esperada de transações nas quais alguns dos itens, mas não todos, contidos em um conjunto de itens $I$, ocorrem simultaneamente nas transações $(E[v(I)]$ corresponde a $v(I)$ supondo independência entre A e B). Com base nesses conceitos, define-se razão de violação (Equação 2.3) como a proporção entre a taxa de violação e o número de violações esperadas, e razão de concordância (Equação 2.4) como a proporção entre a taxa de não violação e o número de violações não esperadas. Assim, a medida CS é definida como a razão de concordância divida pela razão de violação (Equação 2.5) (Aggarwal \& Yu, 1998). A Equação 2.6 indica o cálculo para um conjunto de itens $I=\{A, B\}$. $C S=0$ indica uma correlação negativa perfeita entre $A$ e $B ; C S=\infty$ indica uma correlação positiva perfeita entre $A$ e $B ; C S=1$ indica independência estatística entre $A$ e $B$.

$$
\begin{gathered}
R V=\frac{v(I)}{E[v(I)]} \\
R C=\frac{1-v(I)}{1-E[v(I)]} \\
C S=\frac{R C}{R V}=\frac{1-v(I)}{1-E[v(I)]} \times \frac{E[v(I)]}{v(I)} \\
C S=\frac{1-P(A) P(B)-P(\bar{A}) P(\bar{B})}{1-P(A B)-P(\bar{A} \bar{B})} \times \frac{P(A B)+P(\bar{A} \bar{B})}{P(A) P(B)+P(\bar{A}) P(\bar{B})}
\end{gathered}
$$


Confiança (Conf) [0...1]. Definida na Seção 2.3.1 (página 16).

$$
\operatorname{Conf}=P(B \mid A)
$$

Conviction (Conv) [0...1... $)$. A medida Conviction foi desenvolvida como uma alternativa à Confiança (Equação 2.7), uma vez que a Confiança ignora a probabilidade de $P(B)$ (Brin, Motwani, Ullman, \& Tsur, 1997). A intuição por de trás dessa medida recai sobre a lógica proposicional. Se " $\Rightarrow$ " for interpretado como uma implicação lógica, tem-se que $A \Rightarrow B \equiv \neg A \vee B \equiv \neg(A \wedge \neg B)$. Portanto, medir a força de $A \Rightarrow B$ é equivalente a medir a força de $\neg(A \wedge \neg B)$. A força de $(A \wedge \neg B)$ pode ser medida em termos de quanto a ocorrência do evento $(A \wedge \neg B)$ se distancia da ocorrência conjunta dos eventos $A$ e $\neg B$, considerando que os mesmos são independentes (Adamo, 2001). Essa lógica pode ser modelada pela razão $P(A \wedge \neg B) /(P(A) P(\neg B))$; quanto maior for a razão, melhor a força da implicação. Entretanto, a razão deve ser invertida para se considerar a negação em $\neg(A \wedge \neg B)$, o que leva à Equação 2.8. Se $C o n v=1, A$ e $B$ são estatisticamente independentes. Se Conv $<1(P(B \mid A)<P(B))$, existe uma correlação negativa entre $A$ e $B$. Se Conv $>1(P(B \mid A)>P(B))$, existe uma correlação positiva entre $A$ e $B$. Quando o antecedente nunca aparece sem o conseqüente (Confiança de 100\%) Conv $=\infty$, ou seja, tem-se implicação lógica (Brin, Motwani, Ullman, \& Tsur, 1997).

Segundo Berzal, Blanco, Sánchez, \& Vila (2001), a principal desvantagem dessa medida é que seu intervalo não é limitado, dificultando a comparação do valor da medida entre as regras, uma vez que as diferenças entre elas não são significativas. Além disso, é difícil definir um threshold para a mesma.

$$
\text { Conv }=\frac{P(A) P(\bar{B})}{P(A \bar{B})}
$$

Piatetsky-Shapiro's (PS) [-0.25...0...0.25]. Também conhecida como Rule Interest, Novelty e Leverage. Essa medida calcula a porcentagem de transações adicionais cobertas por uma regra de associação que estão acima do esperado (Gonçalves \& Plastino, 2004). Em outras palavras, compara o valor observado da ocorrência de $A$ e $B$ e o valor esperado de ocorrência se $A$ e $B$ fossem independentes. Se $P S=0$, diz-se que $A$ e $B$ são independentes. Se $P S>0$ diz-se que $A$ e $B$ apresentam dependência positiva; caso contrário, dependência negativa.

$$
P S=P(A B)-P(A) P(B)
$$

$\phi$-coefficient $(\phi)[-1 \ldots 0 \ldots 1]$. Essa medida indica o grau de associação (correlação) entre duas variáveis (Tan, Kumar, \& Srivastava, 2004). Um valor de $\phi=-1$ indica uma 
correlação negativa perfeita entre $A$ e $B ; \phi=1$ uma correlação positiva perfeita entre $A$ e $B ; \phi=0$ que não há correlação entre $A$ e $B$, ou seja, $A$ e $B$ são independentes. Observe que a medida $\phi$ é uma versão padronizada da medida PS (Equação 2.9).

$$
\phi=\frac{P(A B)-P(A) P(B)}{\sqrt{P(A) P(B)(1-P(A))(1-P(B))}}
$$

Gini Index (GI) [0...1]. Essa medida é freqüentemente utilizada como critério de seleção de atributos na indução de árvores de decisão. Ela é usada para medir o decréscimo esperado na impureza ou incerteza de uma determinada classe (variável meta), condicionada ao conhecimento do valor de uma determinada variável (variável preditora) (Fisher, 1996). Sendo assim, se duas variáveis estiverem altamente associadas, então a quantidade de redução na impureza ou incerteza de uma determinada classe será grande, ou seja, quanto maior for o valor da medida, maior será a associação entre as variáveis.

$$
G I=P(A)\left[P(B \mid A)^{2}+P(\bar{B} \mid A)^{2}\right]+P(\bar{A})\left[P(B \mid \bar{A})^{2}+P(\bar{B} \mid \bar{A})^{2}\right]-P(B)^{2}-P(\bar{B})^{2}
$$

J-Measure (J) [0...1]. A medida J representa o produto de dois termos (Equação 2.12). O primeiro termo, $P(A)$, pode ser visto como uma preferência para a generalidade, ou seja, o antecedente da regra deve ocorrer freqüentemente para que uma regra seja considerada útil (Smyth \& Goodman, 1991). O segundo termo, representado entre colchetes, mede a diferença entre a probabilidade posterior $P(B \mid A)$ e a probabilidade anterior $P(B)$, ou seja, o poder discriminativo de $A$ em $B$ (Itskevitch, 2001). Portanto, maximizar o produto entre esses dois termos é equivalente a maximizar simultaneamente tanto a generalidade da hipótese $A$, quanto realizar um ajuste entre $A$ e $B$ (Smyth \& Goodman, 1991). Quanto maior for o valor de J, maior será o impacto de $A$ em $B$. A medida J atinge seu valor máximo quando $P(B \mid A)=1$ e $P(\bar{B} \mid A)=0$ (Itskevitch, 2001). O valor mínimo é atingido quando $P(B \mid A)=P(A)$ e conseqüentemente $P(\bar{B} \mid A)=P(\bar{B})$. Nesse caso, $A$ não influencia $B$. A Equação 2.13 mostra uma definição equivalente à Equação 2.12 .

$$
\begin{gathered}
J=P(A) \times\left[P(B \mid A) \log \left(\frac{P(B \mid A)}{P(B)}\right)+P(\bar{B} \mid A) \log \left(\frac{P(\bar{B} \mid A)}{P(\bar{B})}\right)\right] \\
J=P(A B) \log \left(\frac{P(B \mid A)}{P(B)}\right)+P(A \bar{B}) \log \left(\frac{P(\bar{B} \mid A)}{P(\bar{B})}\right)
\end{gathered}
$$

Jaccard $(\zeta)$ [0...1]. É um coeficiente que mede a similaridade entre conjuntos. Se $A$ e $B$ são dois conjuntos então a similaridade entre eles é medida pela razão entre o 
número de elementos em comum (intersecção) e o número de elementos diferentes (união) (Lourenço, Lobo, \& Baçäo, 2004).

Segundo van Rijsbergen (1979), a similaridade é uma medida de associação ou relação entre objetos. Sendo assim, uma medida de associação aumenta quando o número ou a proporção de elementos em comum entre os objetos aumenta. Quanto mais similares forem esses objetos, maior será a força de associação entre os mesmos (Garcia, 2005). O valor $\zeta=1$ implica em uma total correspondência entre os objetos (Borlund \& Ingwersen, 1998).

$$
\zeta=\frac{P(A B)}{P(A)+P(B)-P(A B)} \equiv \frac{P(A B)}{P(A \cup B)}
$$

Kappa $(\kappa)[-1 \ldots 0 \ldots 1]$. É um coeficiente de concordância. A medida Kappa é calculada pela razão $(P(O)-P(E)) /(1-P(E))$, onde $P(O)$ representa a concordância observada entre dois indivíduos e $P(E)$ a concordância esperada, isto é, a proporção de vezes que se espera que os indivíduos concordem por chance (Eugenio \& Glass, 2004). Se $\kappa=1$ tem-se concordância absoluta; se $\kappa=0$ tem-se coincidência puramente aleatória; se $\kappa=-1$ tem-se discordância absoluta, isto é, a propensão dos indivíduos em evitar classificações feitas por outros indivíduos. Observação: $P(O)=P(A B)+P(\bar{A} \bar{B})$ e $P(E)=P(A) P(B)+P(\bar{A}) P(\bar{B})$.

$$
\kappa=\frac{P(A B)+P(\bar{A} \bar{B})-P(A) P(B)-P(\bar{A}) P(\bar{B})}{1-P(A) P(B)-P(\bar{A}) P(\bar{B})}
$$

Goodman-Kruskal's $(\lambda)$ [0...1]. Inicialmente será discutida a medida para o caso assimétrico $\left(\lambda_{B}\right)$ e em seguida para o caso simétrico $(\lambda)^{9}$.

A medida $\lambda_{B}$ mede o decréscimo relativo da probabilidade de um erro em calcular um atributo levando-se em consideração a presença e a ausência de um outro atributo (Everitt, 1977). Em outras palavras, mede a capacidade preditiva de uma variável em relação à outra. Se a informação sobre a variável preditora não reduz a probabilidade de se cometer um erro na predição da categoria da outra variável, o índice é zero, e se conclui que não existe nenhuma associação preditiva entre as duas variáveis. Por outro lado, se o índice é um, nenhum erro é cometido dado o conhecimento da variável preditora e, conseqüentemente, existe uma associação preditiva completa.

$$
\lambda_{B}=\frac{\max (P(A B), P(A \bar{B}))+\max (P(\bar{A} B), P(\bar{A} \bar{B}))-\max (P(B), P(\bar{B}))}{1-\max (P(B), P(\bar{B}))}
$$

\footnotetext{
${ }^{9}$ Uma medida $M$ é simétrica se $M(A \Rightarrow B)=M(B \Rightarrow A)$; caso contrário é assimétrica (Tan, Steinbach, \& Kumar, 2005).
} 
A mesma abordagem de "redução no erro" pode ser usada para produzir um coeficiente para a situação simétrica (medida $\lambda$ ) onde nenhuma das variáveis é especificamente designada como a variável a ser predita (Everitt, 1977). Pelo contrário, supõe-se que algumas vezes uma variável e outras vezes a outra é fornecida a priori e pretende-se predizer a variável não fornecida. Esse coeficiente mostra a redução relativa da probabilidade de um erro em predizer a categoria de uma das variáveis conhecendo e não conhecendo a categoria da outra variável.

$$
\begin{aligned}
\lambda & =\frac{\max (P(A B), P(A \bar{B}))+\max (P(\bar{A} B), P(\bar{A} \bar{B}))+\max (P(A B), P(\bar{A} B))+\max (P(A \bar{B}), P(\bar{A} \bar{B}))}{2-\max (P(A), P(\bar{A}))-\max (P(B), P(\bar{B}))} \\
& \frac{-\max (P(A), P(\bar{A}))-\max (P(B), P(\bar{B}))}{2-\max (P(A), P(\bar{A}))-\max (P(B), P(\bar{B}))}
\end{aligned}
$$

Laplace (L) [0...1]. É uma variação da medida Confiança (Equação 2.7) e possui, portanto, uma semântica semelhante à descrita na Seção 2.3.1. Essa medida, muito utilizada nos algoritmos de indução de regras, foi desenvolvida com o objetivo de penalizar regras muito específicas (regras que cobrem poucos exemplos (transações)) a fim de evitar overfitting (Smaldon \& Freitas, 2006). Para tanto, a medida Confiança foi "corrigida" de forma a agregar essa penalidade. Suponha, por exemplo, que um determinado itemset ocorra em apenas uma transação, assim como todos os seus subconjuntos próprios não vazios. Sem a correção proposta pela medida Laplace, a Confiança desse itemset, considerando um valor de $N=10$, seria de $100 \%$ (0.1/0.1) (Equação 2.7), um valor muito otimista para uma regra extremamente específica. Sendo assim, levando-se em consideração o número de classes contidas no domínio pela medida Laplace, obtém-se um valor mais real, que no caso do exemplo anterior seria de $67 \%((10 \times 0.1+1) /(10 \times 0.1+2))$ (Equação 2.18) (Smaldon \& Freitas, 2006). O número 2 no denominador, no caso das regras de associação, indica o número de classes e representa a presença ou ausência de um item em uma transação.

$$
L=\frac{N \times P(A B)+1}{N \times P(A)+2}
$$

Interest Factor (IF) $[\mathbf{0 . . . 1 \ldots \infty ] . ~ T a m b e ́ m ~ c o n h e c i d a ~ c o m o ~ L i f t . ~ E s s a ~ m e d i d a ~ i n - ~}$ dica o quanto a freqüência do conseqüente aumenta na presença do antecedente. Em outras palavras, mede o grau de dependência entre os itens (Berzal, Blanco, Sánchez, \& Vila, 2001). Regras com $I F=1$ possuem antecedente e conseqüente independentes, ou seja, a presença do antecedente não leva ao aumento ou à diminuição da ocorrência do conseqüente. No caso de regras com $I F>1$, pode-se dizer que o antecedente influencia positivamente a freqüência do conseqüente (dependência positiva) e, no caso de IF $<1$, o antecedente e o conseqüente apresentam dependência negativa. Portanto, as 
regras interessantes devem possuir altos valores de IF. Entretanto, assim como a Conviction (Equação 2.8), seu intervalo não é limitado e, portanto, possui as mesmas limitações dessa medida (Berzal, Blanco, Sánchez, \& Vila, 2001).

$$
I F=\frac{P(A B)}{P(A) P(B)}
$$

Mutual Information (MI) [0...1]. É uma medida que indica o grau de associação entre duas variáveis. Essa medida especifica a quantidade de redução na incerteza (entropia) de uma variável $B$ quando uma segunda variável $A$ é conhecida. Se as duas variáveis forem altamente associadas, então a quantidade de redução na incerteza (entropia) será grande (Tan \& Kumar, 2000). Em outras palavras, $M I=0$ indica que $A$ e $B$ não possuem nenhuma associação, ou seja, são independentes, e $M I=1$ indica que o conhecimento de $A$ prediz completamente o valor de $B$ (Mishra \& Knowlton, 2003). Para o caso assimétrico aqui considerado, essa medida é conhecida como Theil Uncertainty Coefficient (Blanchard, Guillet, Gras, \& Briand, 2005).

$$
M I=\frac{P(A B) \log \left(\frac{P(A B)}{P(A) P(B)}\right)+P(A \bar{B}) \log \left(\frac{P(A \bar{B})}{P(A) P(\bar{B})}\right)+P(\bar{A} B) \log \left(\frac{P(\bar{A} B)}{P(\bar{A}) P(B)}\right)+P(\bar{A} \bar{B}) \log \left(\frac{P(\bar{A} \bar{B})}{P(\bar{A}) P(\bar{B})}\right)}{-P(B) \log P(B)-P(\bar{B}) \log P(\bar{B})}
$$

Suporte (Sup) [0...1]. Definida na Seção 2.3.1 (página 16).

$$
\text { Sup }=P(A B)
$$

IS/Cosine (IS) $[\mathbf{0} \ldots \sqrt{P(A B)} \ldots \mathbf{1}]$. A medida IS (Equação 2.22) representa a média geométrica entre as medidas Interest Factor (IF) (Equação 2.19) e Suporte (Sup) (Equação 2.21) (Tan, Kumar, \& Srivastava, 2004). Sendo assim, a medida IS mede tanto o interesse quanto a significância do padrão. Essa medida equivale também à média geométrica da Confiança das regras geradas a partir de um par de itens (Equação 2.23) (Tan, Kumar, \& Srivastava, 2004). A medida IS também pode ser interpretada como o cosseno do ângulo entre dois vetores (Equação 2.24).

$$
\begin{gathered}
I S=\sqrt{I F \times S u p}=\sqrt{\frac{P(A B)}{P(A) P(B)} \times P(A B)}=\frac{P(A B)}{\sqrt{P(A) P(B)}} \\
I S=\sqrt{\operatorname{Conf}(A \Rightarrow B) \times \operatorname{Conf}(B \Rightarrow A)}=\sqrt{\frac{P(A B)}{P(A)} \times \frac{P(A B)}{P(B)}}=\frac{P(A B)}{\sqrt{P(A) P(B)}}
\end{gathered}
$$




$$
I S=\frac{P(A B)}{\sqrt{P(A) P(B)}}=\frac{A \bullet B}{|A| \times|B|}=\text { Cosine }
$$

Klosgen (Kl) $\left[\left(\frac{2}{\sqrt{3}}-1\right)^{1 / 2}\left[2-\sqrt{3}-\frac{1}{\sqrt{3}}\right] \ldots \mathbf{0} \ldots \frac{2}{3 \sqrt{3}}\right]$. Representa a combinação entre as medidas Added Value (Equação 2.1) e Suporte (Equação 2.21) (Klösgen, 1996; Yao \& Zhong, 1999; Scheffer \& Wrobel, 2003). O Suporte, nesse caso, pondera o quanto $A$ e $B$ influenciam o ganho de $B$ na presença de $A$, ou seja, a proporção do ganho encontrado pela medida AV quando $A$ e $B$ ocorrem com uma determinada probabilidade.

$$
K l=\sqrt{P(A B)}(P(B \mid A)-P(B))=\sqrt{S u p} \times A V
$$

Odds Ratio (OR) $[0 \ldots 1 \ldots \infty]$. Essa medida indica o grau com que as variáveis $A$ e $B$ estão associadas uma com a outra. Se $B$ ocorre, então a probabilidade de $A$ ocorrer em uma mesma transação é $P(A B) / P(\bar{A} B)$. Por outra lado, se $B$ não ocorre, então a probabilidade de $A$ ocorrer em uma mesma transação é $P(A \bar{B}) / P(\bar{A} \bar{B})$. Se não existir nenhuma associação entre $A$ e $B$, então a probabilidade de $A$ ocorrer em uma determinada transação deve permanecer a mesma, independente de $B$ ocorrer ou não na transação $(O R=1)$. Considerando o produto cruzado dessas probabilidades (Equação 2.26) pode-se medir então a associação entre $A$ e $B$. Se $O R=1(P(A B) P(\bar{A} \bar{B})=P(\bar{A} B) P(A \bar{B}))$, $A$ e $B$ são independentes, ou seja, não existe correlação entre $A$ e $B$; se $O R<1$ $(P(A B) P(\bar{A} \bar{B})<P(\bar{A} B) P(A \bar{B}))$, existe uma correlação negativa entre $A$ e $B$; se $O R>1$ $(P(A B) P(\bar{A} \bar{B})>P(\bar{A} B) P(A \bar{B}))$, existe uma correlação positiva entre $A$ e $B$ (Adejumo, Heumann, \& Toutenburg, 2004).

$$
O R=\frac{P(A B) P(\bar{A} \bar{B})}{P(A \bar{B}) P(\bar{A} B)}
$$

Yule's Q (YQ) [-1...0...1]. Representa a medida Odds Ratio em uma escala de -1 a 1 (medida OR normalizada). Sendo assim, essa medida também mede o coeficiente de associação entre duas variáveis (Yule, 1912). Se $Y Q=1(P(A \bar{B})=0 ; P(\bar{A} B)=0$; ambos), existe uma correlação positiva perfeita entre $A$ e $B$, ou seja, a ocorrência de uma variável leva à ocorrência da outra (se $A$ acontece, $B$ sempre acontece; se $B$ acontece, $A$ sempre acontece; se $A$ não acontece, $B$ nunca acontece; se $B$ não acontece, $A$ nunca acontece) (RimRod, 2002). Se $Y Q=-1(P(A B)=0 ; P(\bar{A} \bar{B})=0$; ambos), existe uma correlação negativa perfeita entre $A$ e $B$, ou seja, a ocorrência de uma variável invariavelmente leva à não ocorrência da outra (se $A$ acontece, $B$ nunca acontece; se $B$ acontece, $A$ nunca acontece; se $A$ não acontece, $B$ sempre acontece; se $B$ não acontece, $A$ sempre acontece) (RimRod, 2002). Se $Y Q=0$ (numerador igual a zero), não existe correlação entre $A$ e $B$, ou seja, a ocorrência ou a não ocorrência de $A$ não influencia $B$ 
e vice-versa; independência estatística.

$$
Y Q=\frac{P(A B) P(\bar{A} \bar{B})-P(A \bar{B}) P(\bar{A} B)}{P(A B) P(\bar{A} \bar{B})+P(A \bar{B}) P(\bar{A} B)}=\frac{O R-1}{O R+1}
$$

Yule's Y (YY) [-1...0...1]. Essa medida, assim como a Yule's $Q$, representa a medida Odds Ratio em uma escala de -1 a 1 (medida OR normalizada). Entretanto, essa medida tende a estimar associações de uma maneira mais conservadora do que a medida Yule's $Q$ (SISA, 2007). Uma vez que a semântica dessa medida é similar à semântica de Yule's $Q$, a mesma não será descrita.

$$
Y Y=\frac{\sqrt{P(A B) P(\bar{A} \bar{B})}-\sqrt{P(A \bar{B}) P(\bar{A} B)}}{\sqrt{P(A B) P(\bar{A} \bar{B})}+\sqrt{P(A \bar{B}) P(\bar{A} B)}}=\frac{\sqrt{O R}-1}{\sqrt{O R}+1}
$$

\subsection{Considerações Finais}

Nesse capítulo foi apresentada uma visão geral do processo de mineração de dados, bem como uma descrição das etapas que compõem esse processo. O processo de MD apresenta dois tipos de atividades principais: a predição e a descrição.

Com relação aos tipos de atividades, uma vez que o foco deste trabalho é na atividade descritiva denominada associação, a mesma também foi apresentada. Para tanto, foram abordadas as definições e os conceitos dessa técnica, a sintaxe padrão a ser utilizada nos próximos capítulos para avaliação das mesmas, assim como uma revisão de algumas abordagens utilizadas no pós-processamento das regras obtidas. Além disso, uma descrição de várias medidas de interesse objetivas a serem utilizadas no desenvolvimento deste trabalho também foi apresentada.

Uma vez que o foco do processo de mineração de dados é a descoberta de padrões novos e interessantes, o pós-processamento se faz importante. Como mencionado na Seção 2.3.3, o usuário é, geralmente, sobrecarregado com um grande volume de regras, o que faz com que ele tenha dificuldades na interpretação das regras e utilização do conhecimento obtido. Uma maneira de tentar minimizar esse problema seria a utilização de conhecimento de domínio, representado via taxonomias, na etapa de pós-processamento, visando a obtenção de modelos compactos (menores/reduzidos) e representativos (gerais) do domínio e, assim, facilitar a exploração das regras pelo usuário. Para tanto, no Capítulo 4 é apresentada uma abordagem, denominada $A P R A$, que realiza o pós-processamento de regras de associação utilizando taxonomias de domínio na obtenção de modelos compactos e gerais. Assim, a APRA contribui como uma nova abordagem de sumarização (Seção 2.3.3) para avaliação de regras de associação. 
Para representar um conhecimento mais geral do domínio, uma variação das regras de associação tradicionais, denominada regras de associação generalizadas, são utilizadas. Sendo assim, no próximo capítulo são apresentados os conceitos/definições referentes a esse tipo de regra. 


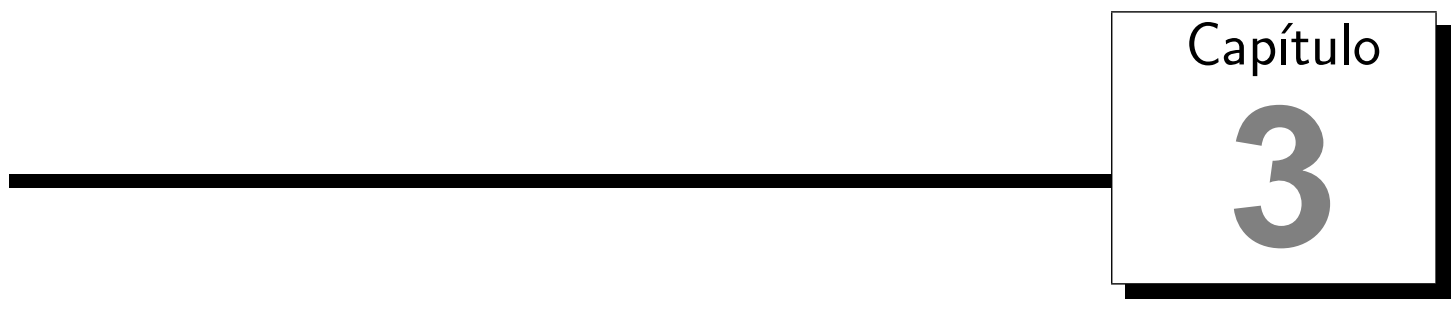

\section{Uso de Taxonomias em Regras de Associação}

\subsection{Considerações Iniciais}

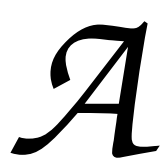

técnica tradicional de mineração de regras de associação, descrita no capítulo anterior, gera todas as possíveis regras considerando os itens contidos na base

de dados. Assim, as regras de associação tradicionais podem não fornecer um conhecimento mais representativo relacionado à base de dados. Por exemplo, a regra " $5 \%$ dos clientes que compram pão-pullman-light, também compram leite-parmalat-desnatado" é menos representativa e menos informativa do que a regra mais geral " $30 \%$ dos clientes que compram pão, também compram leite" (Sriphaew \& Theeramunkong, 2004).

Uma maneira de gerar regras mais gerais é utilizando conhecimento de domínio, o qual pode ser representado de diferentes formas, entre elas, via taxonomias. As taxonomias refletem uma caracterização coletiva ou individual de como os itens podem ser hierarquicamente classificados (Adamo, 2001). Na Figura 3.1 é apresentado um pequeno exemplo de uma taxonomia. Nesse exemplo pode-se verificar que camiseta é uma roupa leve, bermuda é uma roupa leve, roupa leve é um tipo de roupa, sandália é um tipo de calçado, etc.

Sendo assim, visando a obtenção de um conhecimento mais geral, as regras de associação generalizadas, que são regras contendo itens presentes em qualquer nível de uma dada taxonomia, foram introduzidas (Srikant \& Agrawal, 1995). Dada uma taxonomia, em que apenas os nós terminais estão presentes nos registros da base de dados, regras 


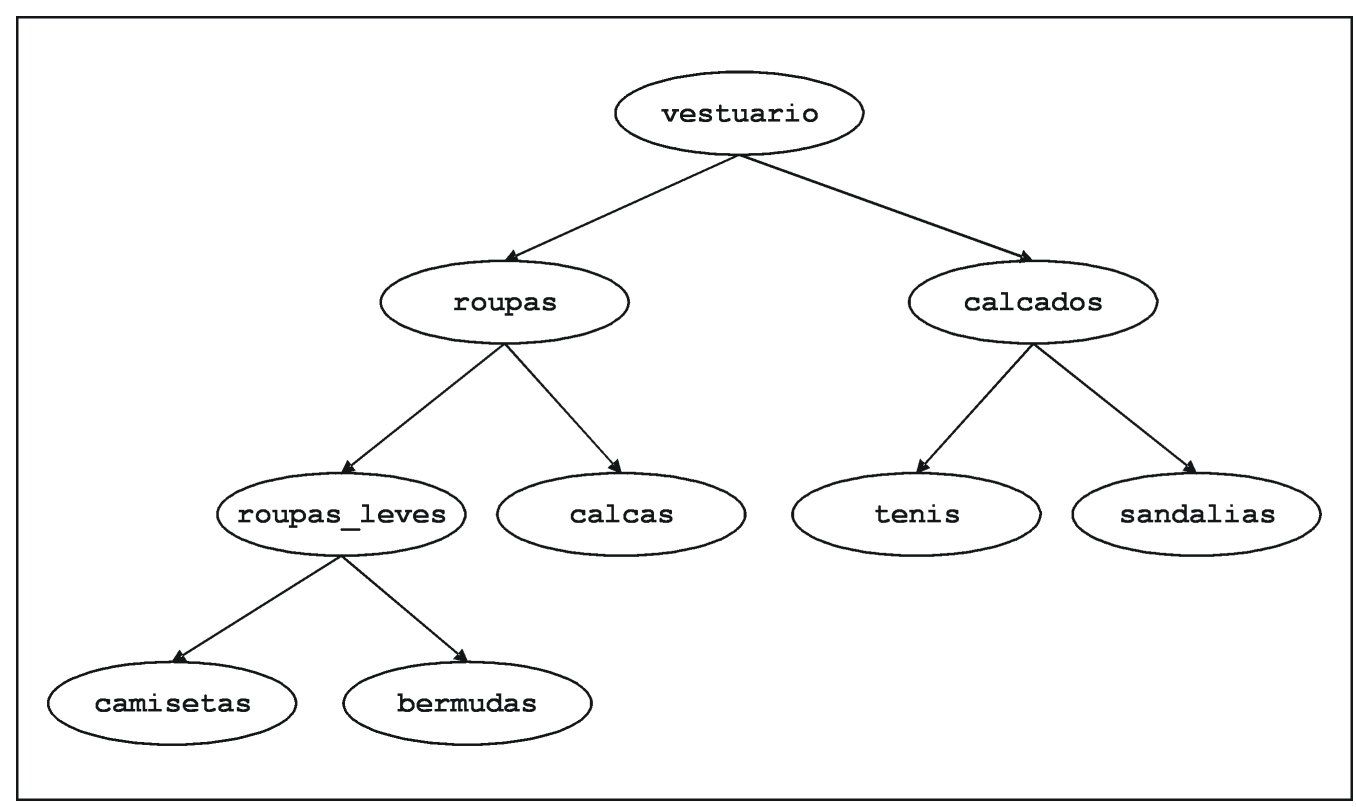

Figura 3.1: Exemplo de uma taxonomia para vestuário.

mais informativas e flexíveis podem ser obtidas (Sriphaew \& Theeramunkong, 2004).

Do ponto de vista da lógica proposicional, a introdução de taxonomias é uma maneira de se complementar a capacidade descritiva das regras de associação com disjunções. Por exemplo, "camisetas ou bermudas $\Rightarrow$ tênis ou sandálias" pode ser uma representação da regra "roupas leves $\Rightarrow$ calçados". Observa-se que essa é uma maneira restritiva de introdução de disjunções, uma vez que os argumentos de disjunção não são automaticamente descobertos, como os argumentos de conjunção ${ }^{1}$. Esses argumentos de disjunção devem ser introduzidos nas regras pelas taxonomias especificadas pelo usuário (Adamo, 2001).

Uma das razões que torna interessante a aplicação de taxonomias em regras de associação refere-se à possibilidade de obtenção de regras que utilizem itens contidos em qualquer nível de uma dada taxonomia e não apenas os itens contidos no nível inferior da mesma, como ocorre nas regras de associação tradicionais (Srikant \& Agrawal, 1997). Por exemplo, usando a taxonomia apresentada na Figura 3.1, pode-se inferir uma regra em que pessoas que compram roupas leves também compram sandálias, do fato de pessoas comprarem camisetas com sandálias e/ou bermudas com sandálias, sem necessidade de utilizar as regras: pessoas que compram camisetas também compram sandálias e pessoas que compram bermudas também compram sandálias.

Outro motivo que torna o uso de taxonomias em regras de associação interessante é que as informações contidas nas taxonomias podem ser utilizadas na avaliação subjetiva do conhecimento (gerado no formato de regras de associação), em termos de compreensão e interesse/surpresa (Liu, Hsu, Chen, \& Ma, 2000). Srikant (2001) apresenta outras razões

\footnotetext{
${ }^{1}$ As conjunções estão no antecedente e conseqüente de uma regra de associação de maneira implícita.
} 
para o emprego de taxonomias em regras de associação:

- regras específicas (cujos elementos são compostos apenas por itens terminais da taxonomia) podem não ter suporte suficiente para serem incluídas na solução, mas podem representar conhecimento interessante ao serem agrupadas segundo uma taxonomia;

- regras específicas podem ser generalizadas. De maneira similar ao item anterior, mesmo considerando as regras específicas com elevados níveis de suporte e confiança, essas podem ser agrupadas em regras mais gerais, melhorando a sua compreensão e ainda podendo aumentar os valores de suporte e confiança;

- regras interessantes podem ser identificadas com o uso de informações contidas nas taxonomias.

No restante desse capítulo são apresentados alguns conceitos necessários para se ter uma melhor compreensão do uso de taxonomias em regras de associação. Além disso, um levantamento do estado da arte referente à utilização de taxonomias nas diversas etapas do processo de mineração de regras de associação também é apresentado.

\subsection{Notações e Definições}

Uma regra de associação usando taxonomias é definida da maneira descrita a seguir (definição baseada nos trabalhos de Srikant \& Agrawal (1995); Huang \& Wu (2002); Yang (2005) e adaptada para a notação utilizada neste trabalho):

Seja $D$ uma base de dados composta por um conjunto de itens $A=\left\{a_{1}, \ldots, a_{m}\right\}$, ordenados lexicograficamente, e por um conjunto de transações $T=\left\{t_{1}, \ldots, t_{n}\right\}$, na qual cada transação $t_{i} \in T$ é composta por um conjunto de itens (chamado itemset) tal que $t_{i} \subseteq A$. Seja $\tau$ um grafo direcional acíclico sobre os itens, representando um conjunto de taxonomias. Se há uma aresta em $\tau$ de um item $\bar{x}$ para um item $x, \bar{x}$ é dito ser pai de $x$ e $x$ é dito ser filho de $\bar{x}$. Se há um caminho de $\hat{x}$ para $x$ em $\tau$, diz-se que $\hat{x}$ é ancestral de $x$ e $x$ descendente de $\hat{x}$. Um item sem nenhum descendente é chamado de terminal; caso contrário de não terminal. Diz-se que um itemset $\bar{X}$ é pai de um itemset $X$ (e $X$ filho de $\bar{X}$ ) se $\bar{X}$ é obtido pela substituição de um único item em $X$ por um de seus itens pais. Diz-se que um itemset $\hat{X}$ é ancestral de um itemset $X$ (e $X$ descendente de $\hat{X}$ ) se $\hat{X}$ é obtido pela substituição de um ou mais itens em $X$ pelos seus itens ancestrais. Formalmente, $\hat{X}$ é um itemset ancestral de $X$ se para todo $x \in X, x \in \hat{X}$ ou existe um ancestral $\hat{x}$ de $x$ tal que $\hat{x} \in \hat{X}$. É dito que uma transação $t_{i}$ suporta um item $x$ se $x$ está em $t_{i}$ ou $x$ é um ancestral de 
algum item em $t_{i}$. Uma transação $t_{i}$ suporta um itemset $X$ se $t_{i}$ suporta todo item em $X$. O suporte $P(X)$ de um itemset $X$ representa a probabilidade da ocorrência do evento $X$.

Uma regra de associação usando taxonomias é uma implicação na forma $L H S \Rightarrow R H S$, em que $L H S \subset A, R H S \subset A, L H S \cap R H S=\varnothing$ e nenhum item em RHSé um ancestral de qualquer item em $L H S$. A regra $L H S \Rightarrow R H S$ ocorre no conjunto de transações $T$ com confiança conf e suporte sup, onde $P(L H S R H S)$ representa o suporte da regra (a probabilidade da ocorrência da transação $L H S \cup R H S)$ e $P(R H S \mid L H S$ ) a confiança da regra (a probabilidade condicional de $R H S$ dado $L H S)$.

Assim como no caso tradicional (Seção 2.3, página 15), as regras de associação generalizadas também utilizam as medidas de suporte e confiança durante o processo de geração de regras. Nesse caso, embora o suporte de um item terminal $x$ na taxonomia seja definido como o apresentado na Seção 2.3.1, o suporte para um item y não terminal na taxonomia é definido como: $\sup (y)=|\cup t(\operatorname{des}(y))| / n$, em que $\operatorname{des}(y)$ representa o conjunto de descendentes de $y,|\mathrm{X}|$ a cardinalidade de $\mathrm{X}, \mathrm{t}(\mathrm{X})$ as transações em que $\mathrm{X}$ ocorre e $n$ o número de transações (Adamo, 2001). No Exemplo 1, é apresentado como é calculado o suporte de itens terminais e não terminais da taxonomia.

Exemplo 1 Considerando a taxonomia apresentada na Figura 3.1 e D uma base de dados que contém um conjunto de itens $A=\{$ bermudas, calçados, calças, camisetas, roupas, roupas leves, sandálias, tênis $\}$ e um conjunto de transações $T=\{1,2,3,4,5,6,7\}$, no qual a relação de itens comprados por cada transação ti é apresentada na Tabela 3.1.

Tabela 3.1: Relação de itens comprados por transação.

\begin{tabular}{|c|c|}
\hline Transações & Itens Comprados \\
\hline \hline 1 & camisetas, calças, tênis \\
\hline 2 & bermudas, tênis, sandálias \\
\hline 3 & camisetas, bermudas, calças, tênis, sandálias \\
\hline 4 & tênis, sandálias \\
\hline 5 & camisetas, bermudas, calças \\
\hline 6 & calças, tênis, sandálias \\
\hline 7 & bermudas, calças, sandálias \\
\hline
\end{tabular}

A partir dessas informações são calculados os suportes dos itens terminais e não terminais da taxonomia, como apresentado a seguir: 
- Itens terminais ${ }^{2}$ :

$$
\begin{aligned}
\sup (\{\text { camisetas }\})=\mid t\{\text { camisetas }\} \mid / 7 & =|\{1,3,5\}| / 7=3 / 7=42.86 \% \\
\sup (\{\text { bermudas }\})=\mid t\{\text { bermudas }\} \mid / 7 & =|\{2,3,5,7\}| / 7=4 / 7=57.14 \% \\
\sup (\{\text { calças }\})=\mid t\{\text { calças }\} \mid / 7 & =|\{1,3,5,6,7\}| / 7=5 / 7=71.43 \% \\
\sup (\{\text { tênis }\})=\mid t\{\text { tênis }\} \mid / 7 & =|\{1,2,3,4,6\}| / 7=5 / 7=71.43 \% \\
\sup (\{\text { sandálias }\})=\mid t\{\text { sandálias }\} \mid / 7 & =|\{2,3,4,6,7\}| / 7=5 / 7=71.43 \%
\end{aligned}
$$

- Itens não terminais:

$$
\begin{aligned}
\sup (\{\text { roupas leves }\}) & =\mid t\{\text { camisetas }\} \cup t\{\text { bermudas }\} \mid / 7 \\
& =|\{1,3,5\} \cup\{2,3,5,7\}| / 7 \\
& =|\{1,2,3,5,7\}| / 7=5 / 7=71.43 \% \\
\sup (\{\text { calçados }\}) & =\mid t\{\text { tênis }\} \cup t\{\text { sandálias }\} \mid / 7 \\
& =|\{1,2,3,4,6\} \cup\{2,3,4,6,7\}| \\
& =|\{1,2,3,4,6,7\}| / 7=6 / 7=85.71 \% \\
\text { sup }(\{\text { roupas }\}) & =\mid t\{\text { roupas leves }\} \cup t\{\text { calças }\} \mid / 7 \\
& =|\{1,2,3,5,7\} \cup\{1,3,5,6,7\}| / 7 \\
& =|\{1,2,3,5,6,7\}| / 7=6 / 7=85.71 \%
\end{aligned}
$$

Em relação às regras de associação generalizadas, considerando um conjunto de itens $\{x, y\}$ qualquer, é importante ressaltar que (Srikant \& Agrawal, 1995; Baixeries, Casas, \& Balcázar, 2000; Adamo, 2001):

- se $\{x, y\}$ atingir suporte mínimo, as seguintes combinações também atingirão: $\{\hat{x}, y\}$, $\{x, \hat{y}\}$ e $\{\hat{x}, \hat{y}\}$. Entretanto, se a regra $x \Rightarrow y$ possuir confiança mínima, a regra $x \Rightarrow \widehat{y}$ também possuirá, embora as regras $\widehat{x} \Rightarrow y$ e $\widehat{x} \Rightarrow \widehat{y}$ talvez não possuam;

- são válidas as seguintes propriedades:

1. $\sup (\widehat{x} \Rightarrow y) \geqslant \sup (x \Rightarrow y)$,

2. $\sup (x \Rightarrow \widehat{y}) \geqslant \sup (x \Rightarrow y)$,

3. $\sup (\widehat{x} \Rightarrow \widehat{y}) \geqslant \sup (x \Rightarrow y)$,

4. $\operatorname{conf}(x \Rightarrow \widehat{y}) \geqslant \operatorname{conf}(x \Rightarrow y)$;

\footnotetext{
${ }^{2}$ Como mencionado anteriormente, a notação $|\mathrm{X}|$ representa a cardinalidade de $\mathrm{X}$ e a notação $\mathrm{t}(\mathrm{X})$ as transações em que X ocorre.
} 
- as regras $\hat{x} \Rightarrow y, x \Rightarrow \hat{y}$ e $\hat{x} \Rightarrow \hat{y}$ representam generalizações da regra $x \Rightarrow y$; respectivamente, a regra $x \Rightarrow y$ representa especializações das regras $\hat{x} \Rightarrow y, x \Rightarrow \hat{y}$ e $\hat{x} \Rightarrow \hat{y}$.

Observe que em relação às propriedades anteriormente apresentadas (segundo item), somente as medidas de suporte e confiança são mencionadas. Isso porque não foram encontrados trabalhos na literatura que descrevem o relacionamento/comportamento de outras medidas objetivas de avaliação no contexto de regras de associação generalizadas. Sendo assim, é importante que um estudo nesse contexto seja realizado (aspecto abordado no Capítulo 5).

Assim como no caso tradicional, o problema de obtenção de regras de associação aplicando taxonomias é decomposto em dois passos:

1. Encontrar todos os k-itemsets que possuam suporte maior ou igual ao suporte mínimo especificado pelo usuário (sup-min). Entretanto, nesse caso, os itens que constituem os $k$-itemsets encontram-se presentes em qualquer nível da hierarquia (no caso tradicional os itens pertencem apenas ao nível mais baixo da hierarquia, ou seja, são considerados apenas os itens terminais da taxonomia).

2. Utilizar todos os k-itemsets freqüentes para gerar as regras de associação.

Os passos acima descritos se aplicam aos casos em que as taxonomias são utilizadas durante a etapa de extração de padrões. É importante mencionar, entretanto, que taxonomias podem ser utilizadas na obtenção de conhecimentos mais gerais em qualquer uma das etapas do processo de mineração de dados. Assim, é apresentado a seguir um levantamento bibliográfico referente à utilização de taxonomias no processo de mineração de dados.

\subsection{Estado da Arte}

Existem muitos trabalhos na literatura que utilizam taxonomias em regras de associação. O foco desses trabalhos difere em função da etapa do processo de mineração em que as taxonomias são utilizadas. Sendo assim, essa seção apresenta uma revisão desses trabalhos em função dessas etapas, dando maiores detalhes aos trabalhos relacionados à etapa de pós-processamento, que é o foco desta tese.

\subsubsection{Pré-Processamento}

A idéia dos trabalhos que utilizam taxonomias na etapa de pré-processamento é transformar a base de dados de entrada em uma base de dados generalizada. A idéia dos 
trabalhos de Zhou, Ruan, Zhu, Zhu, \& Shi (2001) e Galindo, Coelho, \& Lachtermacher (2002) é substituir os itens específicos (itens terminais) contidos na base de dados pelos itens gerais (itens não terminais) contidos na taxonomia. Na proposta de Zhou, Ruan, Zhu, Zhu, \& Shi (2001), o usuário pode definir em até que nível ele quer generalizar seus dados. A partir dessa base de dados generalizada é que a técnica de regras de associação é aplicada utilizando um algoritmo tradicional de extração de regras, por exemplo, o Apriori.

Em Giha, Singh, \& Ewe (2006) os autores trabalham com a idéia de base estendida, em que a base de dados contém tanto os itens específicos quantos os gerais, mantendo a mesma idéia utilizada no algoritmo Basic proposto por Srikant \& Agrawal (1995). A partir dessa base estendida é que o processo de extração de regras é realizado com base no algoritmo Apriori, juntamente com algumas técnicas de poda e medidas de significância.

Chen, Zhou, Scherl, \& Geller (2003) também trabalham com a idéia de base estendida. Entretanto, nesse caso, a base original já possui alguns itens gerais e a idéia é "arrumar" a base de forma que a mesma fique como a base estendida utilizada no algoritmo Basic proposto por Srikant \& Agrawal (1995). Nesse caso, essa "arrumação" também pode ser feita a partir de um determinado nível escolhido pelo usuário. Entretanto, a abordagem por eles proposta, diferentemente das abordagens anteriormente descritas, é top-down, ou seja, começa dos itens mais gerais e vai descendo para os itens mais específicos.

\subsubsection{Extração de Padrões}

Os trabalhos relacionados à etapa de extração de padrões se referem aos algoritmos para obtenção de regras de associação generalizadas. Como mencionado na Seção 3.2, o problema de obtenção de regras de associação generalizadas é semelhante ao caso tradicional. Sendo assim, a diferença existente entre os algoritmos de extração de regras generalizadas é a forma como os itemsets freqüentes são gerados.

Os primeiros trabalhos referentes à extração de regras de associação generalizadas são de Srikant \& Agrawal (1995) (Basic, Cumulate e Stratify) e Han \& Fu (1995) (família $\left.M L-T^{*}\right)$. As diferenças entre os dois trabalhos são: (1) no primeiro, as regras são obtidas considerando-se um único valor de suporte para todos os níveis e, no segundo, diferentes níveis de suporte são utilizados para cada nível da taxonomia; (2) no primeiro, uma regra pode conter itens de qualquer nível da taxonomia e, no segundo, uma regra só contém itens de um mesmo nível da taxonomia. Vários algoritmos de extração de regras de associação generalizadas surgiram após esses trabalhos, como os apresentados em Hipp, Myka, Wirth, \& Güntzer (1998) (Prutax), Weber (1998) (Genex), Baixeries, Casas, \& Balcázar (2000) (Jer e JerM), Yen (2000) (GMLAPG), Yen \& Chen (2001) (GAPG e $M L A P G$ ), Rajkumar, Karthik, \& Sivanandam (2003) (AprioriNewMulti), Pramudiono \& 
Kitsuregawa (2004) (BU-FPtax e TD-FPtax), Sriphaew \& Theeramunkong (2004) (SET e $c S E T)$ e Thakur, Jain, \& Pardasani (2006).

\subsubsection{Pós-Processamento}

Segundo Pohle (2003), a utilização de taxonomias na etapa de pré-processamento requer uma grande preparação de dados voltada especificamente ao problema, isto é, todo o processo de mineração freqüentemente deve ser reinicializado quando uma modificação, mesmo que sutil, ocorre nos objetivos da análise. Ainda segundo Pohle (2003), a utilização de taxonomias na extração de padrões não trata o problema da interpretação dos padrões descobertos, mas sim o processo em si. Sendo assim, é interessante que as taxonomias sejam utilizadas na etapa de pós-processamento, pois a utilização de algum conhecimento de fundo pode melhorar a análise dos padrões obtidos.

Adomavicius \& Tuzhilin (2001) propõem uma abordagem para realizar o agrupamento de um conjunto de regras (não apenas regras de associação) em função da similaridade existente entre as mesmas. Essa similaridade é medida por uma transformação sintática que se faz nas regras via a utilização de uma taxonomia de domínio. A Figura 3.2 ilustra o processo por eles proposto.

O processo de agrupamento ocorre em três etapas:

- Primeiramente, o usuário define em que nível de abstração deseja mapear (generalizar, transformar) os nós terminais (itens específicos) de cada ramo do nó raiz. Por exemplo, os itens $A 1$ e $A 2$ do ramo $A 6$ da taxonomia da Figura 3.2 serão mantidos durante o processo de agrupamento (destacados em cinza), enquanto que os itens $A 3, A 4$ e $A 5$ do ramo $A 7$ serão mapeados (generalizados, transformados) para o item $A 7$ (também destacado em cinza).

- Definido o nível de abstração, cada item, de cada uma das regras contidas no conjunto de entrada, é mapeado para o seu nível de abstração. Por exemplo, as regras que contêm os itens $A 3, A 4$ e $A 5$ terão seus respectivos itens mapeados para o item $A 7$, enquanto que os itens $A 1$ e $A 2$ serão mantidos. Caso uma regra, após ter seus itens mapeados, possua itens repetidos, os mesmos serão removidos. Por exemplo, a regra $A 2 \& A 3 \& A 4 \Rightarrow A 5$ seria mapeada para $A 2 \& A 7 \& A 7 \Rightarrow A 7$ e teria sua estrutura sintática final mapeada para $A 2 \& A 7 \Rightarrow A 7$.

- Após a realização do mapeamento dos itens contidos nas regras, as mesmas são agrupadas em função de sua estrutura sintática. O conjunto final será composto então por classes de regras, onde cada regra representa a estrutura sintática de um subconjunto de regras. Cada uma dessas classes poderá ser explorada posteriormente pelo usuário. 


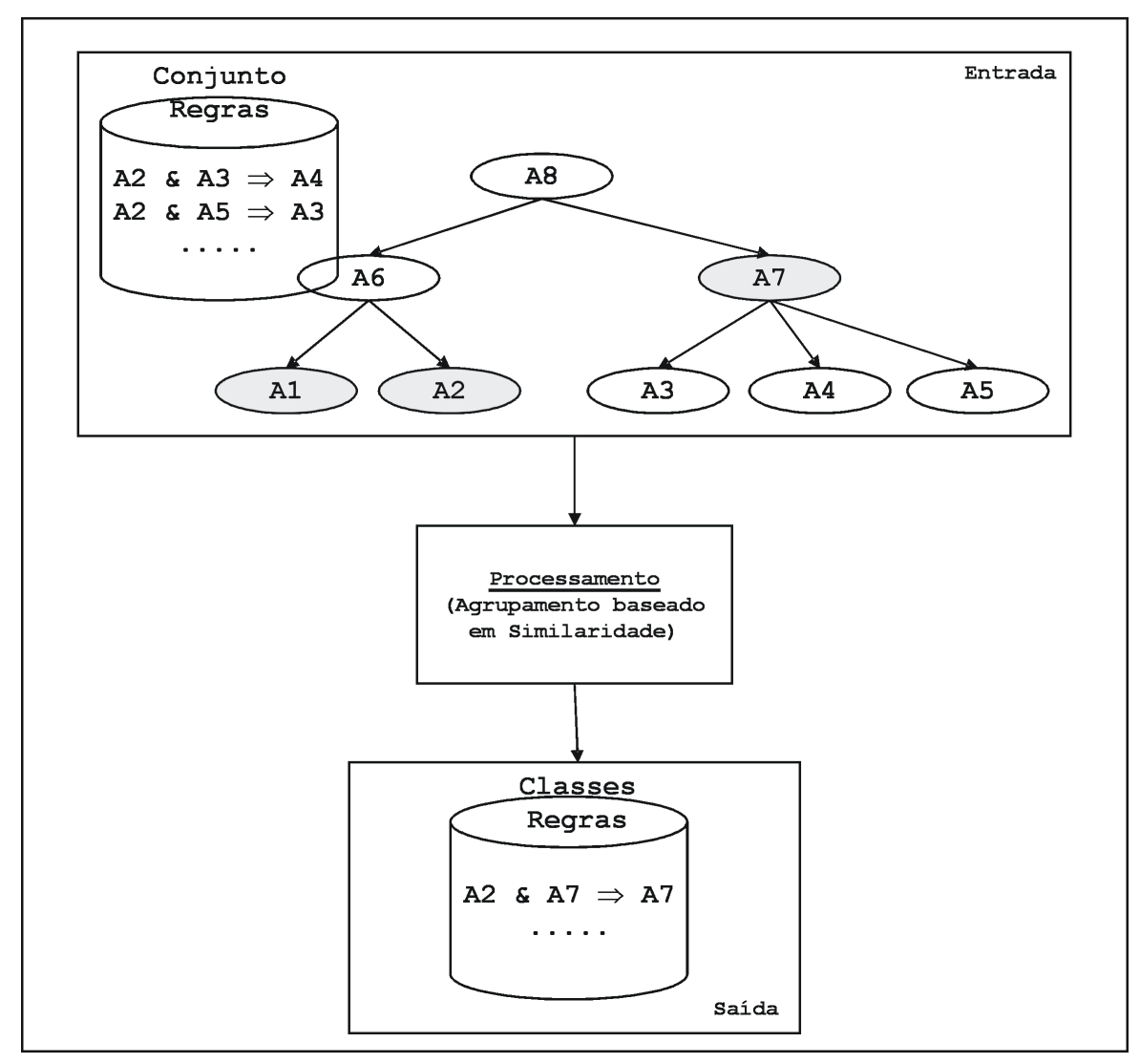

Figura 3.2: Abordagem de pós-processamento de regras proposta por Adomavicius \& Tuzhilin (2001).

O objetivo da abordagem proposta por Adomavicius \& Tuzhilin (2001) é reduzir o conjunto de regras de entrada de forma a fornecer uma visão mais geral do conhecimento extraído, facilitando, assim, a interpretação e análise do mesmo pelos usuários finais.

Domingues \& Rezende (2005); Domingues (2004) propõem uma abordagem que obtém regras de associação generalizadas a partir da união de regras específicas com base em uma taxonomia de domínio. Assim como na abordagem de Adomavicius \& Tuzhilin (2001), o objetivo é reduzir o conjunto de regras de associação geradas a partir de um algoritmo tradicional de extração. A Figura 3.3 ilustra o processo por eles proposto.

O processo de generalização ocorre em quatro etapas:

- Primeiramente, o usuário define o lado em que a generalização deverá ocorrer, isto é, antecedente $(l h s)$ ou conseqüente $(r h s)^{3}$. Com base nessa informação, agrupam-se as regras com estrutura sintática semelhante pelo lado oposto à generalização. No

\footnotetext{
${ }^{3}$ Como mencionado anteriormente, uma regra de associação é representada como uma implicação na forma $L H S \Rightarrow R H S$, em que $L H S$ e $R H S$ são, respectivamente, o lado esquerdo (Left Hand Side) e o lado direito (Right Hand Side) da regra. Assim, daqui em diante, as notações lhs, rhs e lrhs representam opções para se generalizar, respectivamente, o lado esquerdo da regra $(L H S)$, o lado direito da regra $(R H S)$ ou ambos os lados da regra $(L H S$ e $R H S)$.
} 


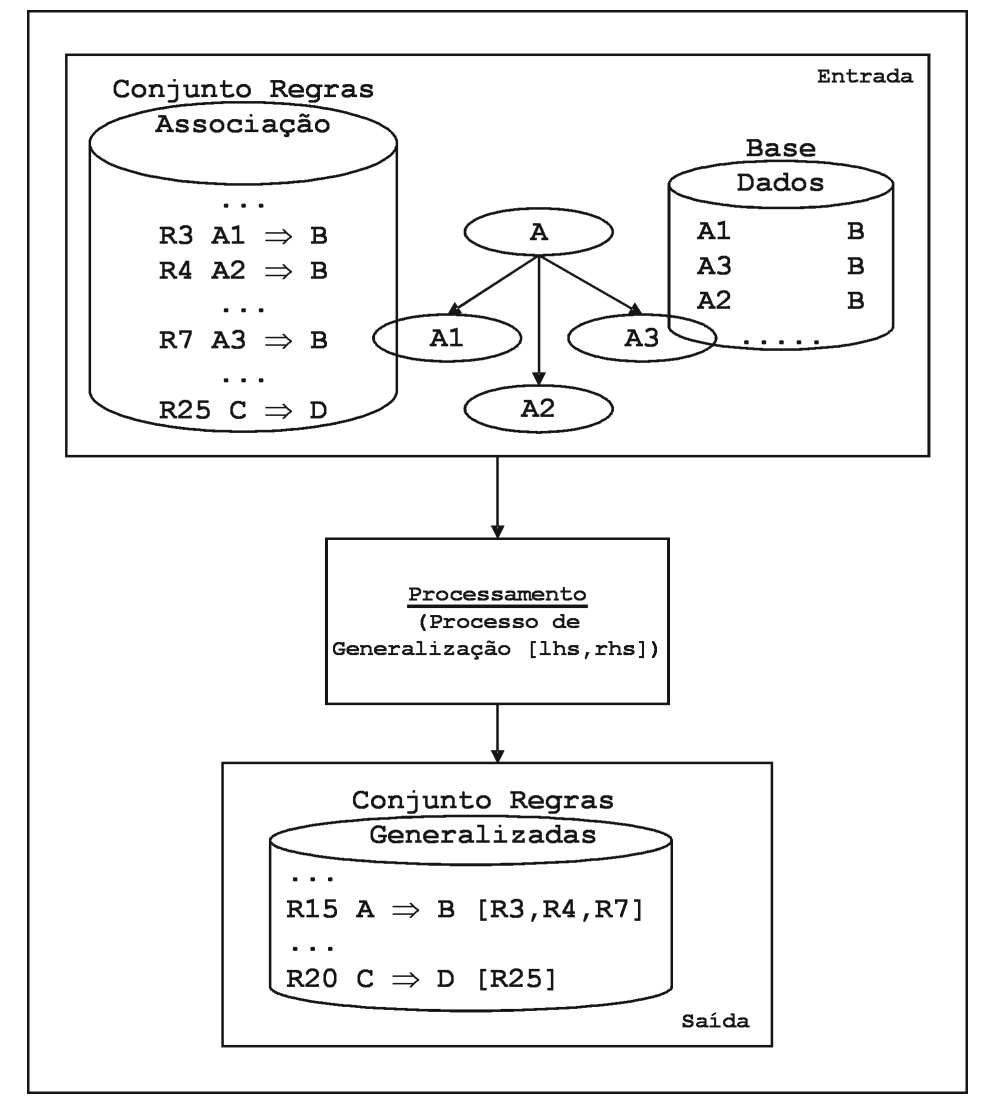

Figura 3.3: Abordagem de pós-processamento de regras de associação proposta por Domingues \& Rezende (2005); Domingues (2004).

caso do exemplo da Figura 3.3, considerando-se o processo de generalização no lhs, dois grupos seriam gerados: um para as regras com o conseqüente $B$ e um para as regras com o conseqüente $D$.

- Para cada um dos grupos gerados na etapa anterior, generalizam-se as regras de cada grupo, considerando uma abstração nível a nível. Ou seja, diferentemente da abordagem proposta por Adomavicius \& Tuzhilin (2001), em que o usuário escolhe o nível de abstração, aqui a generalização é feita nível a nível para cada regra. Entretanto, assim como no trabalho de Adomavicius \& Tuzhilin (2001), cada item, de cada uma das regras contidas em um determinado agrupamento, é mapeado para o seu nível de abstração mais próximo. Esse mapeamento é feito no lado em que se deseja realizar a generalização. No caso do exemplo da Figura 3.3, os itens $A 1$, $A 2$ e $A 3$, contidos no agrupamento do conseqüente $B$, seriam mapeados para o item A. Também diferentemente da abordagem proposta por Adomavicius \& Tuzhilin (2001), o mapeamento só é realizado se cada item de uma regra possuir mapeamentos diferentes. Por exemplo, os itens das regras $A 1 \& A 3 \Rightarrow B$ não seriam mapeados, uma vez que essa transformação implicaria na duplicação do item $A(A \& A \Rightarrow B)$. 
- Após o mapeamento, agrupam-se, pelo lado referente à generalização, as regras com estrutura sintática semelhante. Para cada um dos agrupamentos gerados verifica-se se a generalização ocorrida é válida. Uma generalização só será válida se para cada item geral contido na regra generalizada houver uma regra específica para cada item terminal relacionado ao item geral. No caso do exemplo da Figura 3.3, considerandose o agrupamento referente às regras com antecedente $A$ (após o mapeamento) e conseqüente $B$, uma vez que se tem uma regra específica para cada item terminal relacionado ao item geral $A$, é criada a regra $A \Rightarrow B$, a qual representa a união das regras $A 1 \Rightarrow B, A 2 \Rightarrow B$ e $A 3 \Rightarrow B$. Para cada regra generalizada válida, a mesma é adicionada ao conjunto final de regras, substituindo as regras específicas e reduzindo assim a quantidade de regras do conjunto original.

- Ao final do processo, para cada regra generalizada obtida calculam-se os valores de sua tabela de contingências.

Observe na Figura 3.3 que o conjunto final pode conter tanto regras generalizadas quanto regras específicas, ou seja, regras que não puderam ser generalizadas. Cada uma das regras generalizadas representa um conhecimento mais geral do domínio e engloba, de forma implícita, os conhecimentos específicos. Assim como na abordagem de Adomavicius \& Tuzhilin (2001), essas regras mais gerais também podem ser exploradas posteriormente pelo usuário. No caso dos trabalhos de Domingues \& Rezende (2005); Domingues (2004) identifica-se, para cada regra geral, quais regras específicas foram agrupadas (unidas) para se obter um conhecimento de mais alto nível (regra R15 da Figura 3.3).

Nos trabalhos de Brisson, Collard, \& Pasquier (2005) e Hou, Gu, Shen, \& Yan (2005) encontram-se apenas alguns exemplos das abordagens por eles propostas. Esses exemplos também exploram o uso de conhecimento de domínio no pós-processamento do conhecimento para a generalização de regras. Entretanto, esses trabalhos não são aqui descritos uma vez que os autores não explicam como a abordagem por eles proposta funciona.

\subsection{Considerações Finais}

Nesse capítulo foi apresentada uma visão geral da utilização de taxonomias no processo de mineração de regras de associação. Para tanto, foram introduzidas algumas notações e definições, assim como o estado da arte.

Como mencionado no Capítulo 2, Seção 2.3.3 (página 19), a quantidade de regras de associação obtidas pelos algoritmos tradicionais de extração é, geralmente, enorme, o que dificulta a interpretação das mesmas por parte dos usuários. Além disso, as regras obtidas são compostas apenas por itens que ocorrem nos próprios dados utilizados na extração. Sendo assim, para que se obtenha regras mais representativas e de fácil compreensão, é 
necessário utilizar conhecimento de domínio para generalizar algumas das regras obtidas, a fim de que o conjunto de regras se torne menor e mais claro.

Assim, diante do exposto, no próximo capítulo é apresentada uma abordagem de pósprocessamento de regras de associação, via conhecimento de domínio, denominada $A P R A$, como uma extensão dos trabalhos de Domingues \& Rezende (2005); Domingues (2004). O objetivo da $A P R A$ é obter modelos compactos e gerais do domínio, de maneira a contribuir como uma nova abordagem de sumarização para avaliação de regras de associação. 


\section{Capítulo}

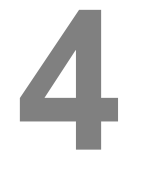

\section{Abordagem de Pós-Processamento de Regras de Associação (APRA) Usando Taxonomias de Domínio}

\subsection{Considerações Iniciais}

O pós-processamento de regras é uma importante tarefa na mineração de dados, já que a mesma melhora a eficácia dos resultados obtidos (Natarajan \& Shekar, 2005), uma vez que o número de regras descobertas, em geral, muito grande, torna a inspeção manual praticamente inviável. Sendo assim, a quantidade de regras aumenta significativamente a dificuldade de interpretar os resultados descobertos e obter uma visão do domínio (Natarajan \& Shekar, 2005).

Muitos pesquisadores têm atentado para o problema da imensidão do número de regras no caso da técnica de associação (An, Khan, \& Huang, 2006; Natarajan \& Shekar, 2005; McGarry, 2005; Yang, 2005; Shekar \& Natarajan, 2004; Tuzhilin \& Liu, 2002; Adomavicius \& Tuzhilin, 2001; Zaki, 2000; Liu, Hu, \& Hsu, 2000; Imieliński \& Virmani, 1998). Assim, para contornar esse problema, os pesquisadores têm adotado várias estratégias, como as mencionadas na Seção 2.3.3 (página 19).

Além do problema da imensidão de regras, a técnica de associação tradicional, descrita no Capítulo 2, gera todas as possíveis regras considerando somente os itens contidos na base de dados, o que leva à obtenção de um conhecimento, em geral, específico. Via a 
utilização de conhecimento de domínio é possível reduzir o conjunto de regras e obter regras mais gerais, interessantes e de fácil compreensão. As regras podem ser generalizadas utilizando conhecimento de domínio expresso via taxonomias, como descrito e apresentado no Capítulo 3. Sem generalização sabe-se apenas que, por exemplo, "leiteparmalat-desnatado" influencia a compra de pão. Com a generalização sabe-se que a categoria/classe leite influencia a compra de pão, o que facilita a interpretação da regra e uma rápida tomada de decisão (Hou, Gu, Shen, \& Yan, 2005). É importante mencionar que com um processo de generalização é possível se obter uma visão do domínio de três maneiras distintas: uma que apresenta o relacionamento entre categorias/classes de itens e itens específicos - generalização no lado esquerdo da regra; uma que apresenta o relacionamento entre itens específicos e categorias/classes de itens - generalização no lado direito da regra; uma que apresenta o relacionamento entre categorias/classes de itens generalização em ambos os lados da regra.

Assim, diante do exposto, este capítulo apresenta uma abordagem para pós-processar regras de associação, utilizando taxonomias de domínio (conhecimento de domínio), a fim de obter modelos compactos (menores/reduzidos) e representativos (gerais) ${ }^{1}$. Para tanto, na Seção 4.2 é descrita a abordagem aqui proposta, denominada APRA. Na Seção 4.3 uma descrição geral e detalhada do algoritmo, denominado $A P R A_{\text {alg }}$, que viabiliza a abordagem proposta é apresentada. Na Seção 4.4 algumas considerações e/ou restrições adotadas durante a elaboração da $A P R A$ e do $A P R A_{\text {alg }}$ são descritas. Na Seção 4.5 um exemplo de execução do algoritmo $A P R A_{\text {alg }}$ é apresentado para demonstrar a utilização da APRA. Na Seção 4.6 uma comparação da $A P R A$ com o estado da arte é realizada. Na Seção 4.7 é apresentado um módulo de exploração de regras de associação generalizadas, denominado RulEE-RAG, que auxilia o usuário na "investigação" do conhecimento obtido pela APRA. Por fim, na Seção 4.8, são apresentados os experimentos realizados a fim de verificar a viabilidade da abordagem aqui proposta.

\subsection{Especificação da Abordagem Proposta}

O objetivo da abordagem de pós-processamento de regras de associação (APRA), proposta neste trabalho, é pós-processar um conjunto de regras de associação de forma a obter um conjunto de regras reduzido (compacto) e geral (representativo). Para tanto, utiliza-se conhecimento de domínio, expresso via taxonomias, para que o conjunto de regras seja generalizado.

\footnotetext{
${ }^{1}$ Como mencionado anteriormente, as palavras menor, reduzido e compacto serão utilizadas como sinônimos, assim como as palavras geral e representativa. A palavra representativa, no contexto deste trabalho, quando associada a um(a) modelo/padrão/conjunto/regra/etc. obtido(a) é interpretada como a representação geral de um subconjunto de elementos que contêm características semelhantes.
} 


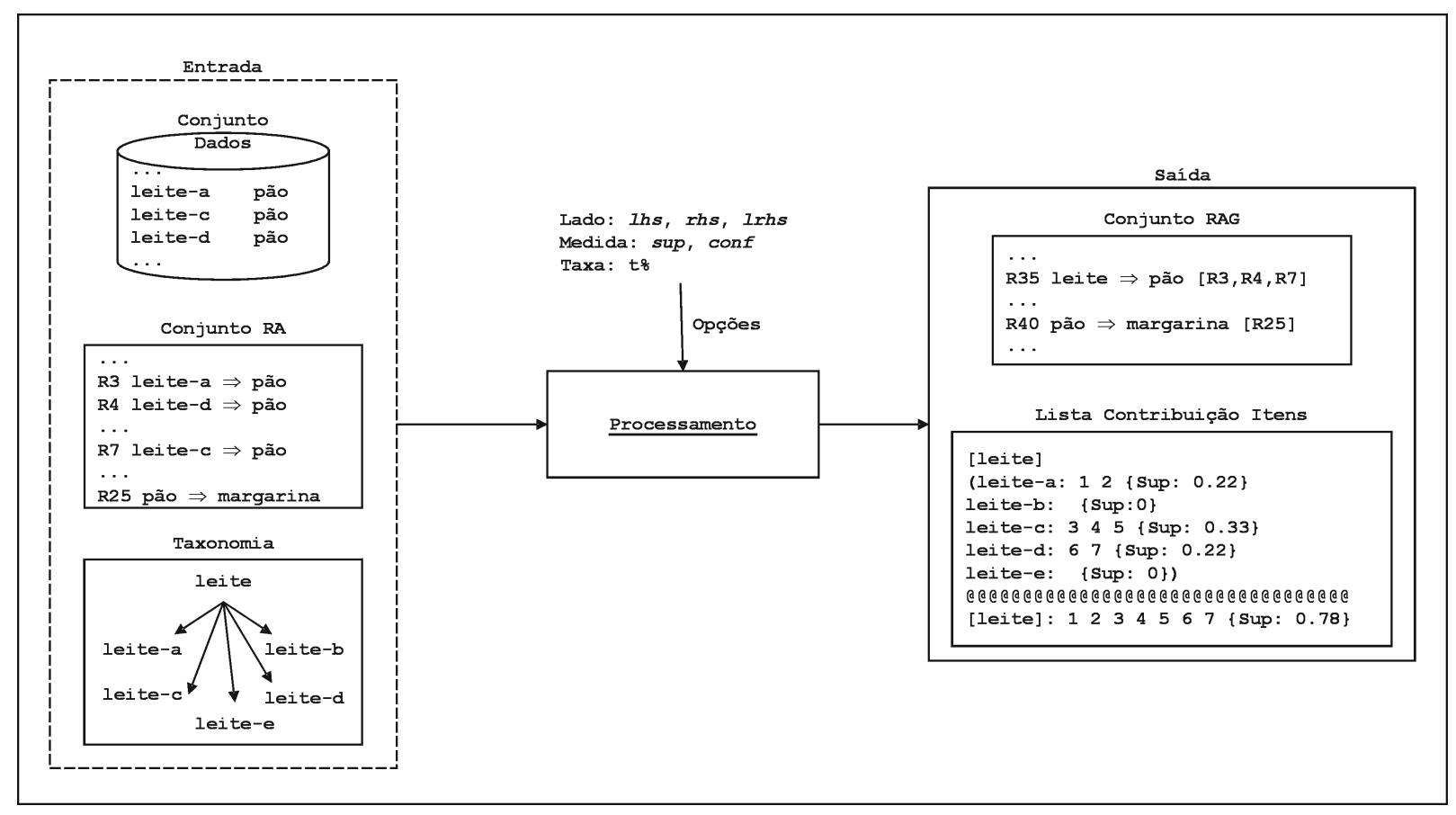

Figura 4.1: Visão geral da abordagem de pós-processamento de regras de associação (APRA).

Uma visão geral da APRA é apresentada na Figura 4.1. Considera-se que os elementos contidos no retângulo pontilhado estão disponíveis, a saber: um conjunto de regras de associação formado somente por regras específicas (regras compostas somente por itens contidos na base de dados), o conjunto de dados utilizado para gerar as regras específicas e o conhecimento de domínio expresso via taxonomias. Com base nessas entradas é possível obter com a abordagem proposta um conjunto de regras de associação generalizadas (RAG) composto por regras específicas que não puderam ser generalizadas (por exemplo, regra R40 da Figura 4.1) e por regras generalizadas obtidas pelo agrupamento de algumas regras específicas via a utilização das taxonomias fornecidas (por exemplo, regra R35 da Figura 4.1 - regra obtida pelo agrupamento das regras leite- $a \Rightarrow p \tilde{a} o(\mathrm{R} 3)$, leite- $\Rightarrow$ pão (R4) e leite-c $\Rightarrow p \tilde{a} o(\mathrm{R} 7)$ ).

De uma forma mais geral, a APRA consiste em pós-processar um conjunto de regras de associação, obtido por um algoritmo tradicional de extração de regras, nesse caso, o Apriori, por meio de um processo de generalização com base em taxonomias fornecidas pelo especialista do domínio. Essa generalização pode ser feita em apenas um dos lados da regra (antecedente $(l h s)$ ou conseqüente $(r h s)$ ) ou em ambos os lados (lrhs) (opção Lado da Figura 4.1). Enquanto a generalização lhs indica a relação entre categorias/classes de itens e itens específicos, a rhs indica a relação entre itens específicos e categorias/classes de itens. Já a generalização lrhs indica a relação entre categorias/classes de itens.

Na $A P R A$, regras generalizadas são obtidas considerando-se todos ou alguns dos itens 
contidos na taxonomia, ou seja, é possível transformar regras específicas em regras gerais mesmo que um item geral da regra generalizada não represente todos os itens específicos contidos na taxonomia. Por exemplo: suponha que a regra leite $\Rightarrow p \tilde{a} o$ represente uma regra generalizada e que leite esteja representado na taxonomia por leite-a, leite-b, leite-c, leite-d e leite-e. A regra leite $\Rightarrow$ pão irá existir mesmo que não exista uma regra específica para cada tipo de leite. Sendo assim, para orientar o usuário na compreensão da regra generalizada, é gerada uma listagem contendo a participação de cada um dos itens específicos na composição dos itens gerais. Por exemplo, a listagem apresentada na Figura 4.1 é gerada para as entradas consideradas. Para interpretar essa listagem, considere a regra acima descrita (leite $\Rightarrow p \tilde{a} o$ ). A listagem indica que se um determinado item possui $0 \%$ de suporte (caso dos itens leite-b e leite-e da Figura 4.1), ele não estava presente nas transações e, portanto, não contribuiu para o processo de generalização (a explicação detalhada dessa listagem encontra-se na Seção 4.3.1). Assim, essa listagem viabiliza a utilização de taxonomias gerais de domínio em subdomínios. Considere, por exemplo, uma taxonomia que contenha conhecimento sobre produtos alimentícios. Qualquer subdomínio que contenha informações a respeito desses produtos poderá utilizar a mesma taxonomia no processo de generalização, uma vez que identifica-se em uma listagem o suporte de cada um dos itens específicos, ou seja, os itens que contribuíram para o processo de generalização.

É importante ressaltar que a lista de contribuição de itens também favorece a identificação de regras de exceção. Como mencionado, para cada regra generalizada é possível se visualizar, por meio da listagem gerada, a contribuição de cada item específico na composição de cada um dos itens gerais contidos na regra. Assim, tem-se uma descrição mais elaborada do domínio, a partir da qual pode-se observar quais itens específicos não contribuem para uma categoria/classe de itens em uma determinada associação. Por exemplo, com base na listagem apresentada na Figura 4.1, a regra R35 pode ser interpretada como: "quem compra qualquer tipo de leite, com exceção aos leites leite-b e leite-e, também compra pão", já que o suporte desses tipos de leites é de $0 \%$.

Como uma regra generalizada pode ser gerada sem a presença de todos os itens contidos na taxonomia, para evitar que ocorra uma "sobrecarga" de generalização, um subconjunto de regras específicas só poderá ser substituído por uma regra mais geral se o suporte (sup) ou a confiança (conf) da mesma (opção Medida da Figura 4.1) for t\% maior do que o maior valor da mesma medida em suas regras específicas (opção Taxa da Figura 4.1). Esse critério pode ser visto como uma variação implícita do suporte/confiança que é explicitamente utilizado em alguns dos trabalhos mencionados na Seção 3.3 .2 (página 39).

A fim de realizar o "Processamento" apresentado na Figura 4.1, foi proposto um algoritmo denominado $A P R A_{\text {alg }}$, descrito a seguir. 


\subsection{O Algoritmo da APRA}

A fim de vialibizar a $A P R A$ foi desenvolvido o algoritmo $A P R A_{\text {alg }}$, responsável pelo processo de generalização das regras de associação. Uma visão geral do mesmo é apresentada no Algoritmo 1.

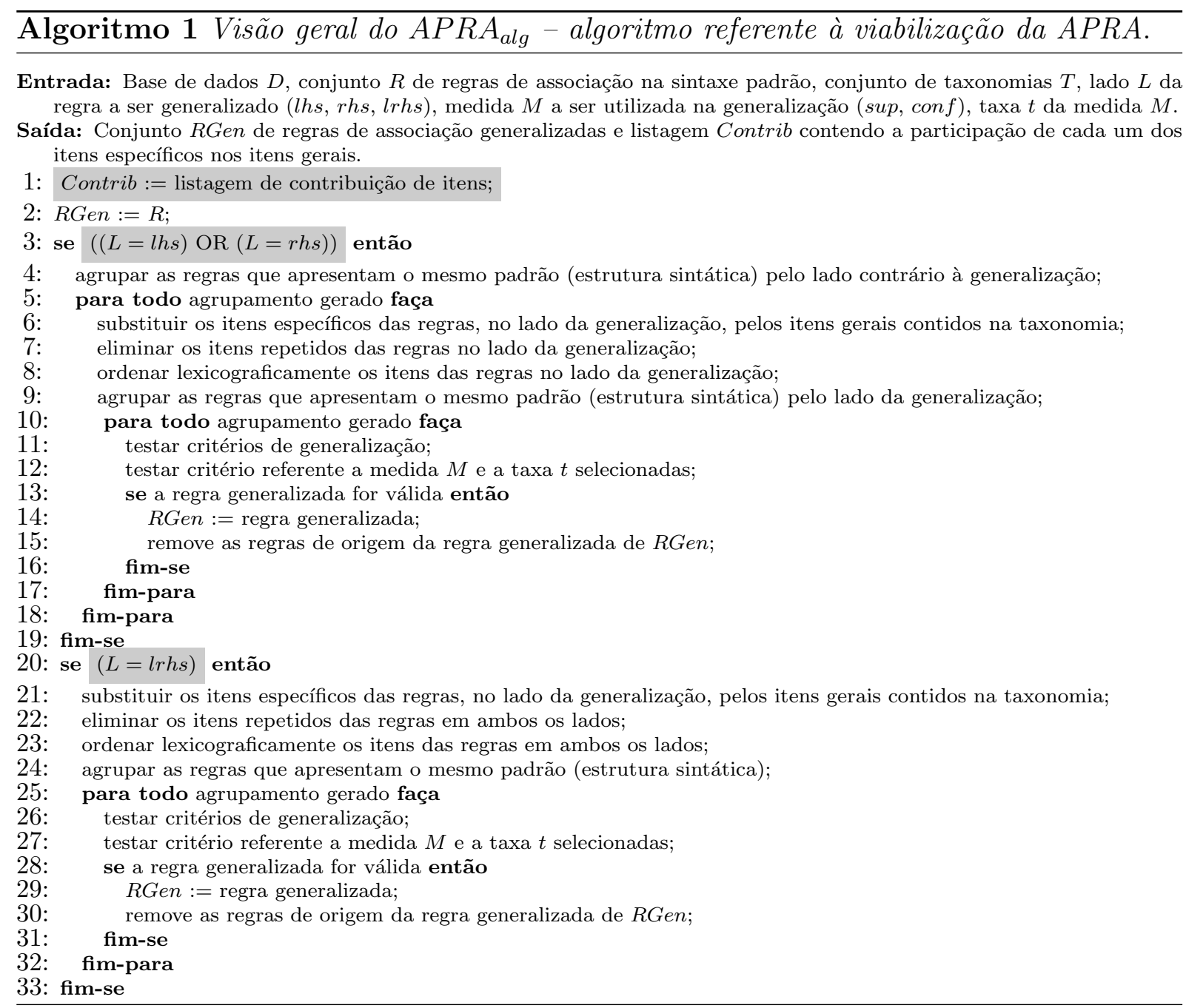

As entradas do $A P R A_{\text {alg }}$, já mostradas na Figura 4.1, se referem: a um conjunto de regras de associação na sintaxe padrão (representado por $R$ na entrada do Algoritmo 1); ao conjunto de dados utilizado para gerar o conjunto de regras de associação (representado por $D$ na entrada do Algoritmo 1); ao conhecimento de domínio expresso via taxonomias (representado por $T$ na entrada do Algoritmo 1). Além disso, as opções apresentadas na Figura 4.1 são também consideradas como entradas, a saber: lado em que a generalização será realizada (representado por $L$ na entrada do Algoritmo 1); medida a ser utilizada no processo de generalização (representada por $M$ na entrada do Algoritmo 1); valor da taxa associado à medida a ser utilizada na generalização (representado por $t$ na entrada do Algoritmo 1). Com base nessas entradas o $A P R A_{\text {alg }}$ obtém um conjunto de regras de associação generalizadas (representado por RGen na saída do Algoritmo 1) e uma listagem 
contendo a participação de cada um dos itens específicos na composição dos itens gerais (representada por Contrib na saída do Algoritmo 1).

O APRA alg é composto basicamente de duas partes, as quais encontram-se destacadas em cinza no Algoritmo 1: (a) geração da listagem de contribuição de itens (linha 1 do Algoritmo 1); (b) generalização do conjunto de regras, a qual é subdivida pelas generalizações a serem realizadas em apenas um dos lados das regras (linha 3 do Algoritmo 1) e pelas generalizações a serem realizadas em ambos os lados das regras (linha 20 do Algoritmo 1).

A fim de acompanhar a explicação do $A P R A_{a l g}$, considere o exemplo da Figura 4.2. Para toda a explicação descrita a seguir encontra-se entre parênteses a linha em que determinado processamento ocorre no Algoritmo 1. É importante mencionar que a explicação apresentada nessa seção apenas fornece uma visão geral do processo, já que os detalhes do $A P R A_{\text {alg }}$ encontram-se descritos na Seção 4.3.2.

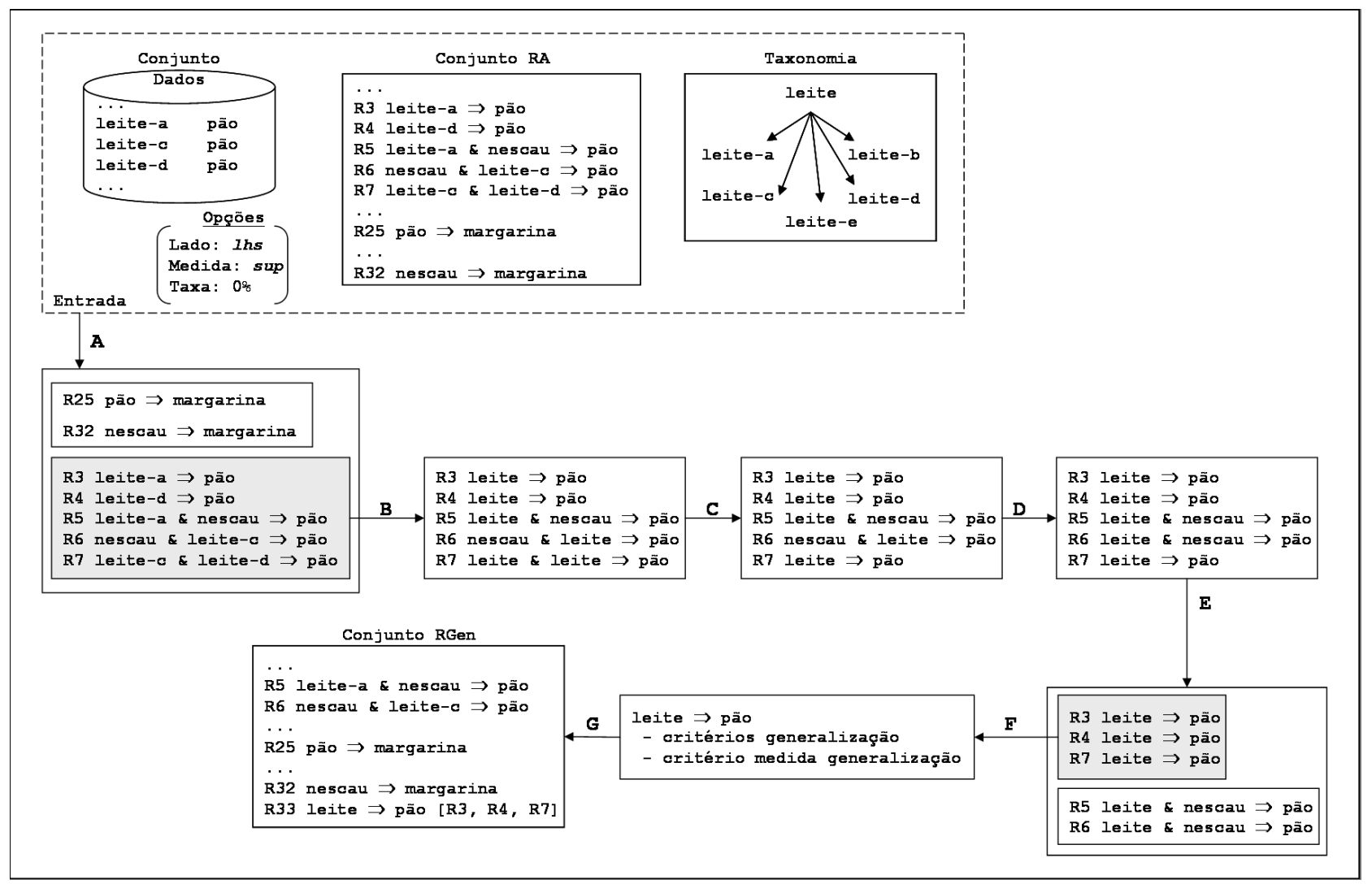

Figura 4.2: Exemplo de execução do $A P R A_{\text {alg }}$.

O primeiro processamento realizado pelo $A P R A_{a l g}$ se refere à geração da listagem de contribuição de itens (linha 1). Para gerar essa listagem considera-se somente o conjunto de dados e o conjunto de taxonomias. Com base nesses dois conjuntos percorre-se o conjunto de dados e verifica-se qual dos itens específicos (itens terminais) das taxonomias encontram-se nas transações e em quais transações os mesmos ocorrem. A partir dessas informações, identificam-se as transações em que os itens gerais (itens não terminais) 


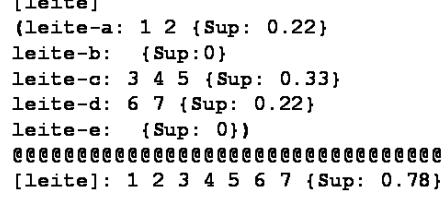

Figura 4.3: Listagem de contribuição de itens gerada a partir dos conjuntos apresentados no exemplo da Figura 4.2.

ocorrem, gerando assim a listagem de contribuição de itens. Considerando, por exemplo, as entradas apresentadas na Figura 4.2, a listagem apresentada na Figura 4.3 é gerada.

Após a geração da listagem de contribuição de itens inicia-se o processo de generalização (linhas 3 e 20 do Algoritmo 1). Para acompanhar o processo de generalização, considere as entradas apresentadas na Figura 4.2. Como nesse exemplo está se considerando uma generalização no lhs, a linha 3 do Algoritmo 1 é ativada. O primeiro passo então é agrupar as regras que apresentam o mesmo padrão (estrutura sintática) pelo lado contrário à generalização (linha 4). No caso da Figura 4.2, o resultado desse primeiro passo é apresentado após a letra A. Em seguida, para cada agrupamento gerado, três operações são realizadas: substituição de itens (linha 6), eliminação de itens (linha 7) e ordenação de itens (linha 8). No caso da Figura 4.2, esses passos são apresentados apenas para o subconjunto destacado em cinza, uma vez que o processo é o mesmo para todos os outros subconjuntos. Na operação de substituição (linha 6), substituem-se os itens específicos contidos nas regras pelos respectivos itens gerais contidos na taxonomia. O resultado dessa operação é apresentado na Figura 4.2 após a letra B. A segunda operação, referente à eliminação de itens repetidos é então realizada (linha 7), uma vez que após a operação de substituição um mesmo item pode aparecer mais de uma vez na regra. O resultado dessa operação é apresentado na Figura 4.2 após a letra C. Por fim, a operação de ordenação de itens é realizada (linha 8), uma vez que a mesma facilita a identificação de regras que apresentam o mesmo padrão (estrutura sintática). O resultado dessa operação é apresentado na Figura 4.2 após a letra D. Após a realização dessas operações, agrupam-se as regras do subconjunto selecionado pelo lado em que a generalização será realizada (linha 9). O resultado dessa operação é apresentado na Figura 4.2 após a letra E. Em seguida, dois testes são realizados: um referente aos critérios de generalização e um referente à medida $M$ e à taxa $t$ selecionadas (linhas 11 e 12 respectivamente). No caso da Figura 4.2, esses passos são apresentados apenas para o subconjunto destacado em cinza, uma vez que o processo é o mesmo para todos os outros subconjuntos. A indicação desse processamento é apresentada na Figura 4.2 após a letra F.

Em relação aos critérios de generalização (linha 11), as seguintes verificações são realizadas: $L H S \cap R H S=\emptyset$ e nenhum item em RHS é um ancestral de qualquer item de 
LHS, ou seja, item-filho $\nRightarrow$ item-pai. O critério item-pai $\nRightarrow$ item-filho também foi acrescentado (detalhes serão apresentados nas Seções 4.3.2 e 4.4). Em relação ao critério de medida (linha 12), é verificado se o valor da medida $M$ da regra generalizada é $t \%$ maior do que o maior valor da medida $M$ em suas regras de origem (regras específicas que deram origem à regra generalizada) (detalhes serão apresentados nas Seções 4.3 .2 e 4.4). Assim, supondo que a regra "IF leite THEN pão" seja válida segundo os critérios de generalização e de medida (linhas 11 e 12 respectivamente), a mesma é adicionada ao conjunto final de regras de associação generalizadas (RAG), conjunto representado por $R G e n$, e as regras de origem da regra generalizada obtida removidas do mesmo. Isso porque, o conjunto RGen é inicialmente inicializado com o conjunto de regras de associação considerado na entrada do processo (linha 2), uma vez que se nenhuma regra generalizada for gerada durante o processo, o conjunto de entrada passa a ser o conjunto final de regras. O resultado dessas operações é apresentado na Figura 4.2 após a letra G.

O processo de generalização em ambos os lados da regra é muito semelhante ao descrito para a generalização em apenas um dos lados e, portanto, não será aqui descrito. Visando uma melhor compreensão do algoritmo, as próximas seções descrevem os arquivos de entrada e saída relacionados ao mesmo, assim como uma descrição detalhada do $A P R A_{\text {alg }}$ juntamente com as funções que o compõem.

\subsubsection{Arquivos de Entrada e Saída}

Como mencionado anteriormente, o $A P R A_{\text {alg }}$ supõe a existência de um conjunto de regras de associação representadas na sintaxe padrão (arquivo de extensão ".apr.dcar" representado por $R$ na entrada do Algoritmo 1) obtido, a priori, por métodos tradicionais de extração, de um conjunto de dados utilizado para extrair o conjunto de regras (arquivo de extensão ".apr.data" - representado por $D$ na entrada do Algoritmo 1) e de um conjunto de taxonomias (arquivo de extensão ".tax" - representado por $T$ na entrada do Algoritmo 1), conforme mostra a Figura 4.4. A partir da especificação desses conjuntos, o $A P R A_{a l g}$ obtém um conjunto de regras de associação generalizadas (arquivo denominado rules_gen.txt - representado por RGen na saída do Algoritmo 1) e uma listagem de contribuição de itens (arquivo denominado taxonomy_elements.txt - representado por Contrib na saída do Algoritmo 1). Uma descrição de cada um dos arquivos é apresentada a seguir.

O arquivo de entrada .apr.data é composto por um conjunto de transações, onde cada linha representa uma transação. Na Figura 4.5, a primeira linha representa uma transação de compra, na qual os produtos leite_batavo, nescau, pao e margarina foram adquiridos.

O arquivo de entrada .apr.dcar é composto por um conjunto de regras de asso- 


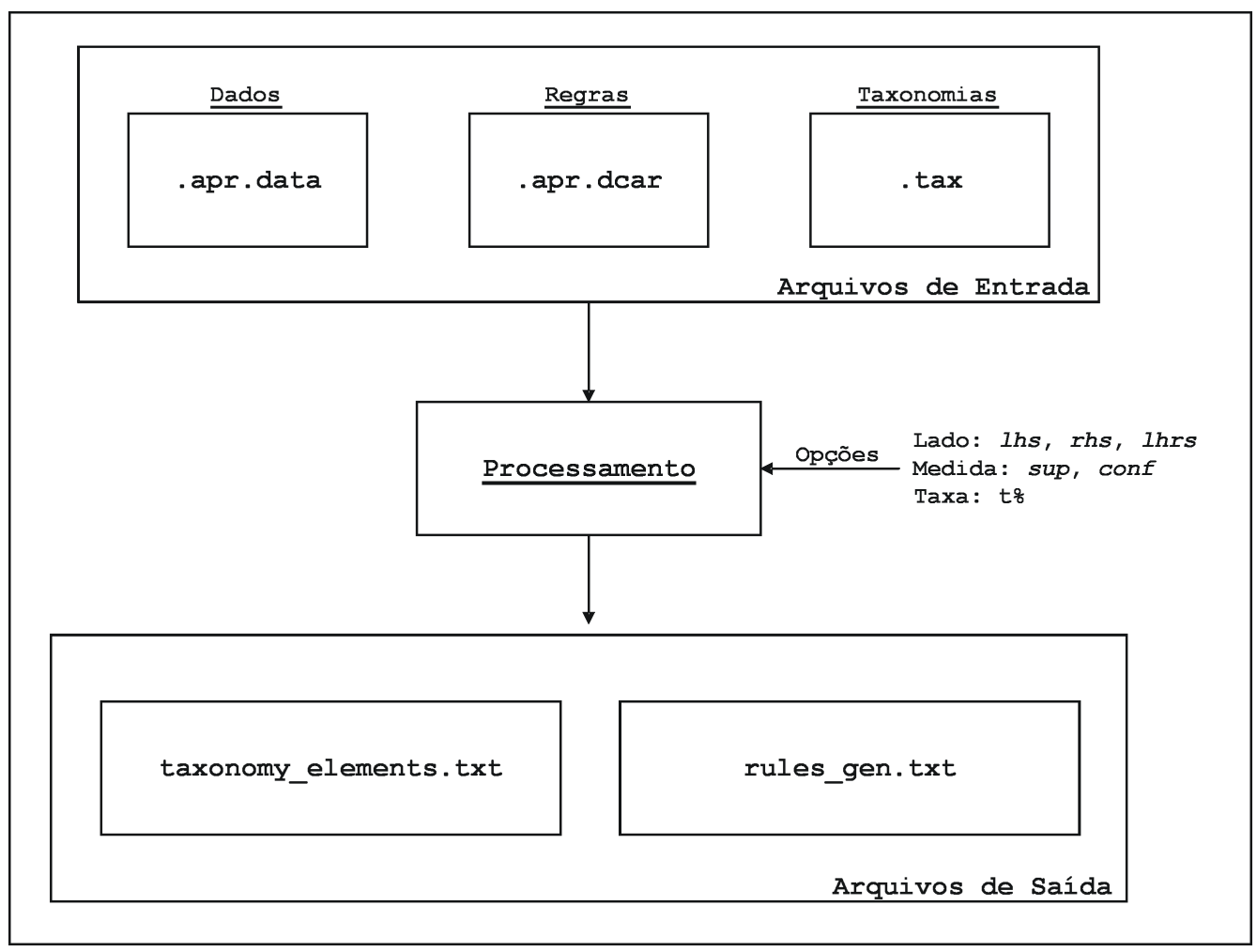

Figura 4.4: Relacionamento entre os arquivos de entrada e saída do $A P R A_{a l g}$.

\begin{tabular}{|llll|}
\hline leite_batavo & nescau pao & margarina \\
leite_batavo & nescau & pao & margarina \\
leite_nilza & nescau & pao & margarina \\
leite_nilza & nescau pao & margarina \\
leite_nilza & nescau pao & margarina \\
leite_parmalat & nescau pao & margarina \\
leite_parmalat & acucar cafe & \\
macarrao & molho_tomate cebola \\
molho_tomate & lazanha coca_cola \\
\hline
\end{tabular}

Figura 4.5: Exemplo de um arquivo de dados (.apr.data).

ciação expresso na sintaxe padrão de regras de associação (sintaxe descrita na Seção 2.3.2, página 17), o qual encontra-se exemplificado na Figura 4.6.

O arquivo de entrada .tax é composto por um conjunto de taxonomias. O conjunto de taxonomias da Figura 4.7 é formado por uma única taxonomia de dois níveis. No formato utilizado para representar as taxonomias neste trabalho, os items mais específicos das taxonomias aparecem primeiro na especificação do arquivo. Além disso, para cada nível de abstração identifica-se o nível ao qual o item pertence. Por exemplo, o item leite da Figura 4.7 representa a primeira abstração (identificador (1) no final da linha) relacionada aos tipos de leite existentes e o item produtos_matinais a segunda abstração (identificador (2)). Assim, para cada item especificado no arquivo deve-se identificar a qual nível de abstração o mesmo pertence. Como se pode observar, a taxonomia armazena as seguintes 
[R0001],TRUE, leite_nilza, [0.333333,0.666667,0.000000,0.000000,9]

[R0002] , TRUE, nescau, $[0.666667,0.333333,0.000000,0.000000,9]$

[R0003], TRUE, pao, [0.666667, 0.333333,0.000000, $0.000000,9]$

[R0004], TRUE, margarina, [0.666667,0.333333,0.000000,0.000000,9]

[R0005], leite_nilza, nescau, [0.333333,0.000000,0.333333,0.333333,9]

[R0006], nescau, leite_nilza, [0.333333,0.333333,0.333333,0.000000,9]

[R0007], leite_nilza,pao, [0.333333,0.000000,0.333333,0.333333, 9]

[R0008], pao,leite_nilza, [0.333333,0.333333,0.333333,0.000000,9]

[R0009], leite_nilza,margarina, [0.333333,0.000000,0.333333,0.333333,9]

[R0010], margarina, leite_nilza, [0.333333, 0.333333,0.333333,0.000000,9]

[R0011], nescau, pao, $[0.666667,0.000000,0.333333,0.000000,9]$

[R0012], pao, nescau, [0.666667,0.000000,0.333333,0.000000,9]

$[\mathrm{R} 0013]$, nescau, margarina, $[0.666667,0.000000,0.333333,0.000000,9]$

[R0014], margarina, nescau, $[0.666667,0.000000,0.333333,0.000000,9]$

[R0015], pao, margarina, [0.666667, 0.000000, 0.333333, 0.000000,9]

[R0016], margarina, pao, $[0.666667,0.000000,0.333333,0.000000,9]$

[R0017], leite_nilza \& nescau,pao, [0.333333,0.000000,0.333333,0.333333,9]

[R0018], leite_nilza \& pao,nescau, [0.333333,0.000000,0.333333,0.333333,9]

[R0019], nescau \& pao,leite_nilza, [0.333333,0.333333,0.333333,0.000000,9]

[R0020], leite_nilza \& nescau,margarina, [0.333333,0.000000,0.333333,0.333333,9]

[R0021], leite_nilza \& margarina,nescau, [0.333333,0.000000,0.333333,0.333333,9]

[R0022], nescau \& margarina,leite_nilza, [0.333333,0.333333,0.333333,0.000000,9]

[R0023], leite_nilza \& pao,margarina, [0.333333,0.000000,0.333333,0.333333,9]

[R0024], leite_nilza \& margarina,pao, [0.333333,0.000000,0.333333,0.333333,9]

[R0025], pao \& margarina,leite_nilza, [0.333333,0.333333,0.333333,0.000000,9]

[R0026], nescau \& pao,margarina, [0.666667,0.000000,0.333333,0.000000,9]

[R0027], nescau \& margarina,pao, [0.666667,0.000000,0.333333,0.000000,9]

[R0028], pao \& margarina, nescau, [0.666667, 0.000000,0.333333,0.000000,9]

[R0029], leite_nilza \& nescau \& pao,margarina, $[0.333333,0.000000,0.333333,0.333333,9]$

[R0030], leite_nilza \& nescau \& margarina,pao, $[0.333333,0.000000,0.333333,0.333333,9]$

[R0031], leite_nilza \& pao \& margarina,nescau, [0.333333,0.000000,0.333333,0.333333,9]

[R0032], nescau \& pao \& margarina,leite_nilza, [0.333333,0.333333,0.333333,0.000000,9]

Figura 4.6: Exemplo de um arquivo de regras de associação na sintaxe padrão (.apr.dcar).

informações: leite_batavo é um tipo de leite, leite_molico é um tipo de leite, leite_nilza é um tipo de leite, etc.; nescau é um tipo de achocolatado, tody é um tipo de achocolatado; leite e achocolatado são tipos de produtos_matinais. Caso o especialista queira especificar várias taxonomias simultaneamente no arquivo, basta informar primeiramente as abstrações de nível 1 de todas as taxonomias, depois as de nível 2 e assim sucessivamente, como mostra a Figura 4.8. Nesse caso, têm-se duas taxonomias: uma relacionada a produtos alimentícios e outra relacionada a produtos de vestuário.

leite(leite_batavo,leite_molico,leite_nilza, leite_parmalat,leite_salute)(1).

achocolatado (nescau, tody) (1).

produtos_matinais(leite, achocolatado) (2).

Figura 4.7: Exemplo de um arquivo contendo uma taxonomia (.tax).

O arquivo de saída taxonomy_elements.txt, apresentado na Figura 4.9 e gerado a partir dos arquivos de entrada apresentados nas Figuras 4.5, 4.6 e 4.7, refere-se à listagem contendo a participação de cada um dos itens específicos na composição dos itens gerais. Para cada um dos itens gerais contidos na taxonomia da Figura 4.7 são listados todos os 
leite(leite_batavo,leite_molico,leite_nilza,leite_parmalat,leite_salute)(1).

achocolatado (nescau, tody) (1).

roupas (camisetas, bermudas, calcas) (1)

calcados (tenis, sandalia, chinelo) (1).

produtos_matinais (leite, achocolatado) (2).

vestuario(roupas, calcados) (2).

Figura 4.8: Exemplo de um arquivo contendo duas taxonomias (.tax).

itens específicos que o compõem, as transações da Figura 4.5 às quais os mesmos pertencem e a freqüência (suporte) de cada um. Por exemplo, o item leite_batavo, referente aos dados apresentados na Figura 4.5, está presente nas transações 1 e 2 e possui, portanto, suporte de $22.22 \%$ (2/9). No caso dos itens leite_molico e leite_salute, que não estão presentes em nenhuma das transações da Figura 4.5, apresentam suporte de 0.0\% (0/9). Após a seqüência de @'s encontram-se as transações às quais cada um dos itens gerais pertencem, assim como suas respectivas freqüências (suporte).

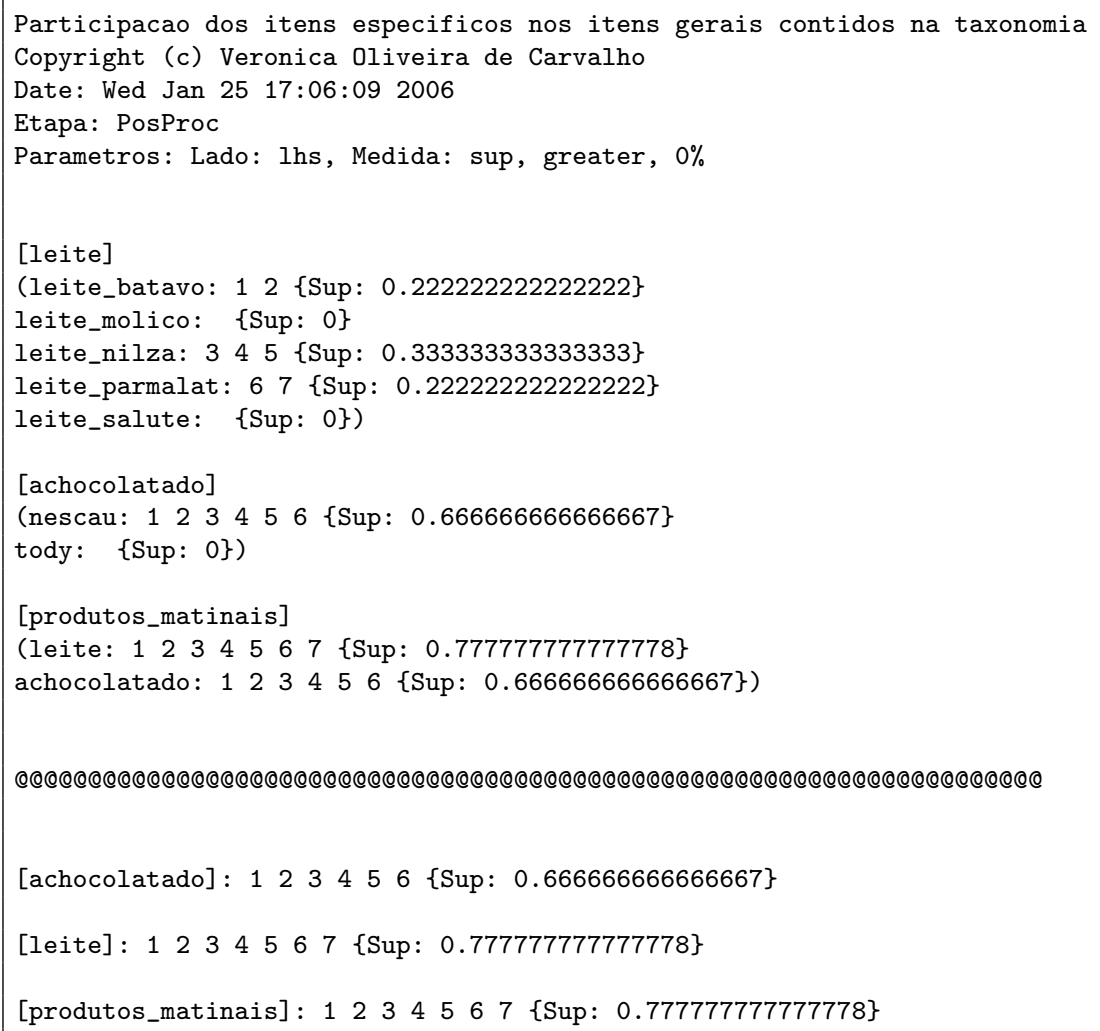

Figura 4.9: Exemplo de um arquivo contendo a listagem de contribuição de itens (taxonomy_elements.txt) gerado a partir dos arquivos de entrada apresentados nas Figu$\operatorname{ras} 4.5,4.6$ e 4.7 .

O arquivo de saída rules_gen.txt, apresentado na Figura 4.10 e gerado a partir dos 
arquivos de entrada apresentados nas Figuras 4.5, 4.6 e 4.7, refere-se ao conjunto de regras de associação generalizadas expresso na sintaxe padrão de regras de associação. Entretanto, esse conjunto possui uma diferença em relação à sintaxe padrão descrita na Seção 2.3.2 do Capítulo 2 (página 17): após os dados da matriz de contingências das regras específicas e generalizadas encontram-se os identificadores das regras que deram origem à respectiva regra, estendendo a sintaxe padrão de regras de associação para o seguinte formato:

\section{[Número da Regra], Antecedente, Conseqüente, [Dados da Matriz de Contingências], [Identificador(es) da(s) Regra(s) de Origem]}

A lista de identificadores das regras de origem deve ser interpretada de duas maneiras distintas: (a) se a lista possuir apenas um identificador, a regra representa uma regra específica (não generalizada), e o identificador indica o número da regra no conjunto de entrada - conjunto de regras utilizado para gerar o conjunto de saída (arquivo de extensão ".apr.dcar"); (b) se a lista possuir dois ou mais identificadores, a regra representa uma regra generalizada, e os identificadores indicam os números das regras no conjunto de entrada - conjunto de regras utilizado para gerar o conjunto de saída (arquivo de extensão ".apr.dcar") - que deram origem à mesma. Por exemplo, a regra [R0007] da Figura 4.10 representa uma regra específica, e o seu identificador, [R0008], o número com que a mesma encontra-se no conjunto de regras da Figura 4.6, ou seja, a regra permaneceu inalterada já que a mesma não pôde ser generalizada. Já a regra [R0022] da Figura 4.10 representa uma regra generalizada, e o seus identificadores, [R0023], [R0026] e [R0029], os números das regras específicas contidas no conjunto de regras da Figura 4.6 que deram origem à mesma. É importante mencionar que a explicação/justificativa referente a uma regra generalizada ser composta pela união de duas ou mais regras é apresentada na Seção 4.3.2. 
Regras de associacao generalizadas

Copyright (c) Veronica Oliveira de Carvalho

Date: Wed Jan 25 17:06:09 2006

Etapa: PosProc

Parametros: Lado: 1hs, Medida: sup, greater, $0 \%$

[R0001], TRUE, leite_nilza, [0.333333,0.666667,0.000000,0.000000,9], [R0001]

[R0002] , TRUE, nescau, [0.666667, 0.333333,0.000000,0.000000, 9] , [R0002]

[R0003] , TRUE, pao, $[0.666667,0.333333,0.000000,0.000000,9],[R 0003]$

[R0004], TRUE, margarina, [0.666667, 0.333333, 0.000000, 0.000000, 9] , [R0004]

[R0005], leite_nilza,nescau, [0.333333,0.000000,0.333333,0.333333, 9], [R0005]

[R0006], nescau, leite_nilza, [0.333333,0.333333,0.333333,0.000000,9], [R0006]

[R0007], pao, leite_nilza, [0.333333,0.333333, 0.333333,0.000000, 9] , [R0008]

[R0008], margarina, leite_nilza, [0.333333,0.333333,0.333333,0.000000, 9], [R0010]

[R0009], pao, nescau, [0.666667,0.000000,0.333333,0.000000,9], [R0012]

[R0010], margarina, nescau, $[0.666667,0.000000,0.333333,0.000000,9]$, [R0014]

[R0011], pao,margarina, [0.666667,0.000000,0.333333,0.000000, 9], [R0015]

[R0012] , margarina, pao, $[0.666667,0.000000,0.333333,0.000000,9]$, [R0016]

[R0013], leite_nilza \& pao,nescau, [0.333333,0.000000,0.333333,0.333333,9], [R0018]

[R0014], nescau \& pao,leite_nilza, [0.333333,0.333333,0.333333,0.000000,9], [R0019]

[R0015], leite_nilza \& margarina,nescau, [0.333333,0.000000,0.333333,0.333333,9], [R0021]

[R0016], margarina \& nescau,leite_nilza, [0.333333,0.333333,0.333333,0.000000,9], [R0022]

[R0017], margarina \& pao,leite_nilza, [0.333333,0.333333,0.333333,0.000000,9], [R0025]

[R0018], margarina \& pao,nescau, [0.666667,0.000000,0.333333,0.000000,9], [R0028]

[R0019], leite_nilza \& margarina \& pao,nescau, [0.333333,0.000000,0.333333,0.333333,9], [R0031]

[R0020], margarina \& nescau \& pao,leite_nilza, [0.333333,0.333333,0.333333,0.000000,9], [R0032]

[R0021], produtos_matinais, margarina, [0.666667,0.111111,0.222222, 0.000000,9], [R0013,R0009, R0020]

[R0022],pao \& produtos_matinais,margarina, $[0.666667,0.000000,0.333333,0.000000,9],[R 0023, R 0026, R 0029]$

[R0023], margarina \& produtos_matinais,pao, [0.666667, 0.000000,0.333333, 0.000000, 9], [R0030,R0024,R0027]

[R0024], produtos_matinais, pao, [0.666667,0.111111,0.222222,0.000000, 9], [R0011, R0007,R0017]

Figura 4.10: Exemplo de um arquivo de regras de associação generalizadas (rules_gen.txt) gerado a partir dos arquivos de entrada apresentados nas Figuras 4.5, 4.6 e 4.7 . 


\subsubsection{Descrição Detalhada do Algoritmo APRA alg}

No início da Seção 4.3 o $A P R A_{\text {alg }}$ foi apresentado e descrito em alto nível, a fim de fornecer uma visão geral do mesmo. Assim, o objetivo dessa seção é detalhar o Algoritmo 1 com o propósito de fornecer um melhor entendimento do mesmo.

O refinamento do algoritmo $A P R A_{a l g}$ é apresentado no Algoritmo 2. Uma vez que o Algoritmo 2 apresenta detalhadamente toda a lógica do $A P R A_{a l g}$, as funções que o compõem são descritas a seguir, visando facilitar a compreensão do mesmo. Para tanto, para os exemplos abaixo ilustrados considere a taxonomia apresentada na Figura 4.7, representada graficamente na Figura 4.11. É importante mencionar que para cada função apresentada a seguir é especificada, entre parênteses, a linha em que a mesma é ativada no Algoritmo 2. Além disso, algumas considerações e/ou restrições referentes ao Algoritmo 2 encontram-se na Seção 4.4.

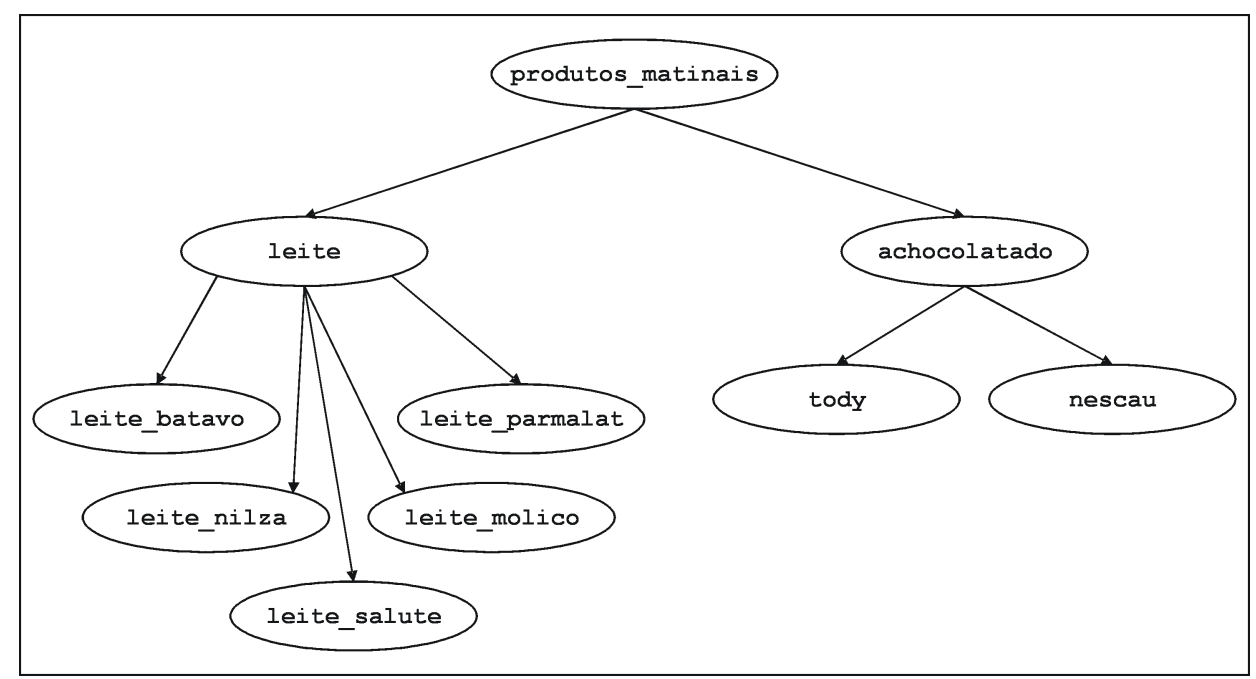

Figura 4.11: Representação gráfica da taxonomia de produtos alimentícios apresentada na Figura 4.7.

A função calcula-contribuicao-itens (linha 1) gera uma listagem contendo a participação de cada um dos itens específicos na composição dos itens gerais, ou seja, verifica o quanto a freqüência de cada um dos itens específicos contribui para a freqüência dos itens gerais. Isso é feito levando-se em consideração os arquivos de taxonomia e de dados. Observe na Figura 4.9 que os itens específicos leite_molico e leite_salute não contribuem para a freqüência final do item geral leite $(S u p=0)$, ao contrário dos itens leite_batavo, leite_nilza e leite_parmalat $($ Sup $>0)$. Essa listagem contém, além da freqüência dos itens específicos, a freqüência dos itens gerais (após a seqüência de @'s), nesse caso, os itens leite, achocolatado e produtos_matinais. Observe também que juntamente com a freqüência são apresentadas as transações a que o item pertence.

A função gera-subconjuntos-iniciais (linha 4) realiza um agrupamento inicial das 


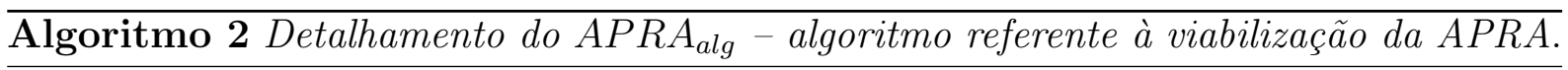

Entrada: Base de dados $D$, conjunto $R$ de regras de associação na sintaxe padrão, conjunto de taxonomias $T$, lado $L$ da regra a ser generalizado (lhs, rhs, lrhs), medida $M$ a ser utilizada na generalização (sup, conf), taxa $t$ da medida $M$.

Saída: Conjunto RGen de regras de associação generalizadas e listagem Contrib contendo a participação de cada um dos itens específicos nos itens gerais.

1: Contrib := calcula-contribuicao-itens $(D, T)$;

2: $R G e n:=R$

3: se $((L=l h s)$ OR $(L=r h s))$ então

4: $\quad S C 1:=$ gera-subconjuntos-iniciais $(R, \bar{L})$;

5: $\quad$ para todo $(\widehat{S C} 1 \geqslant 2, \widehat{S C} 1 \subseteq S C 1)$ faça

6: $\quad$ NATax $:=1$

enquanto (NATax $\leqslant N M T a x)$ faça

substitui-itens $(\widehat{S C 1}, L, N A T a x)$;

elimina-itens-repetidos $(\widehat{S C 1}, L)$;

ordena-lexicograficamente $(\widehat{S C 1}, L)$;

$S C 2:=$ gera-subconjuntos $(\widehat{S C 1}, L)$

para todo $(\widehat{S C 2} \geqslant 2, \widehat{S C 2} \subseteq S C 2)$ faça

$r:=\operatorname{regra}(\widehat{S C} 2)$

regra-valida $:=$ avalia-criterios-generalizacao $(r)$;

se regra-valida então

calcula-tabela-contingencia $(r, D)$;

regra-valida $:=$ verifica-criterio-medida $(r, M, t)$;

se regra-valida então

$R G e n:=R G e n \cup\{r\}$;

$R G e n:=$ remove-regras-origem $(r, R G e n) ;$

fim-se

fim-se

fim-para

$N A T a x:=N A T a x+1 ;$

fim-enquanto

fim-para

7: fim-se

28: se $(L=l r h s)$ então

29: $\quad$ TempRules $:=R$;

30: $\quad$ NATax $:=1$;

31: enquanto $(N A T a x \leqslant N M T a x)$ faça

substitui-itens(TempRules, L, NATax);

elimina-itens-repetidos(TempRules, $L)$;

ordena-lexicograficamente $($ TempRules,$L)$;

$S C 1:=$ gera-subconjuntos(TempRules, $L)$;

para todo $(\widehat{S C 1} \geqslant 2, \widehat{S C 1} \subseteq S C 1)$ faça

$r:=\operatorname{regra}(\widehat{S C} 1)$

regra-valida $:=$ avalia-criterios-generalizacao $(r)$;

se regra-valida então

calcula-tabela-contingencia $(r, D)$;

regra-valida := verifica-criterio-medida $(r, M, t)$;

se regra-valida então

$R G e n:=R G e n \cup\{r\} ;$

$R G e n:=$ remove-regras-origem $(r, R G e n)$;

fim-se

fim-se

fim-para

$N A T a x:=N A T a x+1 ;$

fim-enquanto

50: fim-se

51: $R G e n:=$ remove-regras-repetidas $(R G e n)$;

52: RGen $:=$ sintaxe-padrao(RGen);

regras de associação pelo lado contrário (notação $\bar{L}$ ) que se quer generalizar. Isso porque só é possível generalizar regras que possuam ou o conseqüente ou o antecedente iguais, nos casos de generalização de apenas um dos lados da regra. É importante ressaltar que os agrupamentos aqui gerados são obtidos em função da estrutura sintática das regras. Por exemplo, se as regras "IF leite_nilza THEN nescau", "IF leite_nilza THEN margarina", "IF 
pao THEN nescau" e "IF nescau THEN margarina" estivessem no conjunto de regras, e o lado considerado na generalização fosse o $l h s$, dois subconjuntos seriam gerados: um para o conseqüente "nescau" e o outro para o conseqüente "margarina".

A função substitui-itens (linhas 8 e 32) substitui os itens específicos contidos nas regras pelos respectivos itens gerais contidos na taxonomia. Essa substituição leva em consideração o nível atual da taxonomia ( NATax) em que se encontram as generalizações. Toda taxonomia é composta de níveis, onde cada nível representa a generalização de um item (e/ou conceito). A cada item ancestral de um determinado item, a partir dos itens terminais (nível 0), considera-se um nível de generalização na taxonomia. Por exemplo, os itens leite e achocolatado da Figura 4.11 encontram-se no nível 1 e o item produtos_matinais no nível 2. O total de níveis, nesse caso, é $2($ NMax $=2)$. Assim, a variável $N A T a x$ controla o nível em que a generalização está sendo realizada em determinado momento, já que na $A P R A$ as generalizações são realizadas nível a nível (a descrição sobre essa consideração/restrição é apresentada na Seção 4.4). Considerando a regra "IF leite_nilza THEN nescau" e o lado da generalização o $l h s$, se $N A T a x=1$, o item específico leite_nilza seria substituído pelo item geral leite, gerando a regra "IF leite THEN nescau". É importante notar que quando o lado a ser generalizado é o lrhs (linha 32) a substituição ocorre em ambos os lados da regra. A mesma observação se aplica às operações realizadas nas funções elimina-itens-repetidos, ordena-lexicograficamente e gera-subconjuntos, ou seja, quando $L=$ lrhs ambos os lados da regra são considerados.

A função elimina-itens-repetidos (linhas 9 e 33) elimina os itens repetidos de uma regra em decorrência das substituições realizadas. Considere a regra "IF leite_nilza \& leite_parmalat THEN nescau". Como os itens específicos leite_nilza e leite_parmalat serão substituídos pelo item geral leite (considerando $N A T a x=1$ ), a regra "IF leite \& leite THEN nescau" conterá dois itens iguais, sendo necessário excluir um dos itens a fim de obter a regra "IF leite THEN nescau". Observe que a semântica da regra foi alterada, uma vez que a regra original especifica que quem comprou dois tipos de leite comprou nescau. Entretanto, como o objetivo é reduzir o número de regras por meio de um processo de generalização, essa semântica não foi levada em consideração (a descrição sobre essa consideração/restrição é apresentada na Seção 4.4).

A função ordena-lexicograficamente (linhas 10 e 34) ordena lexicograficamente os itens de uma regra após os processos de substituição e eliminação de itens repetidos. Essa ordenação facilita a identificação de regras que apresentam o mesmo padrão (estrutura sintática). Considerando que a regra "IF leite \& achocolatado THEN margarina" foi obtida após os processos mencionados, a mesma será ordenada de forma a obter a regra "IF achocolatado \& leite THEN margarina".

A função gera-subconjuntos (linhas 11 e 35) realiza o agrupamento das regras pelo lado que se quer generalizar. Assim como na função gera-subconjuntos-iniciais, os 
agrupamentos aqui gerados são também obtidos em função da estrutura sintática das regras. Por exemplo, se as regras "IF produtos_matinais THEN margarina", "IF pao \& produtos_matinais THEN margarina", "IF produtos_matinais THEN margarina" e "IF pao \& produtos_matinais THEN margarina" estivessem no conjunto de regras, e o lado considerado na generalização fosse o $l h s$, dois subconjuntos seriam gerados: um para o antecedente "produtos_matinais" e o outro para o antecedente "pao \& produtos_matinais".

A função regra (linhas 13 e 37) retorna o padrão das regras contidas em um determinado subconjunto. Por exemplo, se um determinado subconjunto contivesse as regras "[R0015] IF leite THEN margarina", "[R0036] IF leite THEN margarina" e "[R0057] IF leite THEN margarina", a função retornaria o padrão "IF leite THEN margarina"2. Observe que nesse ponto todas as regras contidas em cada um dos subconjuntos possuirão o mesmo padrão, uma vez que os agrupamentos pelo lado da regra que se quer generalizar já foram realizados (linhas 11 e 35).

A função avalia-criterios-generalizacao (linhas 14 e 38) verifica se os critérios de definição de uma regra de associação generalizada estão sendo cumpridos. Os critérios são: $L H S \cap R H S=\emptyset$ e nenhum item em $R H S$ é um ancestral de qualquer item de $L H S$, ou seja, item-filho $\nRightarrow$ item-pai. O critério item-pai $\nRightarrow$ item-filho também foi acrescentado (a descrição sobre essa consideração/restrição é apresentada na Seção 4.4).

A função calcula-tabela-contingencia (linhas 16 e 40) calcula a tabela de contingências de uma regra generalizada, ou seja, os valores de $f(L H S R H S), f(L H S \overline{R H S})$, $f(\overline{L H S} R H S)$ e $f(\overline{L H S} \overline{R H S})$.

A função verifica-criterio-medida (linhas 17 e 41) verifica se o valor da medida $M$ da regra generalizada $r$ é $t \%$ maior do que o maior valor da medida $M$ em suas regras de origem (regras específicas que deram origem à regra generalizada). Em outras palavras, a função verifica se $\left[M_{G e n} \geqslant\left(\operatorname{maior}\left(M_{O}\right) * t \%\right)+M_{G e n}\right]$, onde $M_{G e n}$ representa o valor da medida $M$ na regra generalizada, maior $\left(M_{O}\right)$ o maior valor da medida $M$ encontrado entre as regras de origem da regra generalizada e $t \%$ a proporção do aumento desejado no valor da medida $M$ na regra generalizada em relação ao valor de $M$ em suas regras de origem. Assim, considerando as regras de origem e generalizada abaixo ilustradas e, supondo como medida $M$ o suporte (sup) e uma taxa $t$ de $0 \%$, a função irá verificar se $\left[0.666667 \geqslant\left(0.666667^{*} 0 \%\right)+0.666667\right]$.

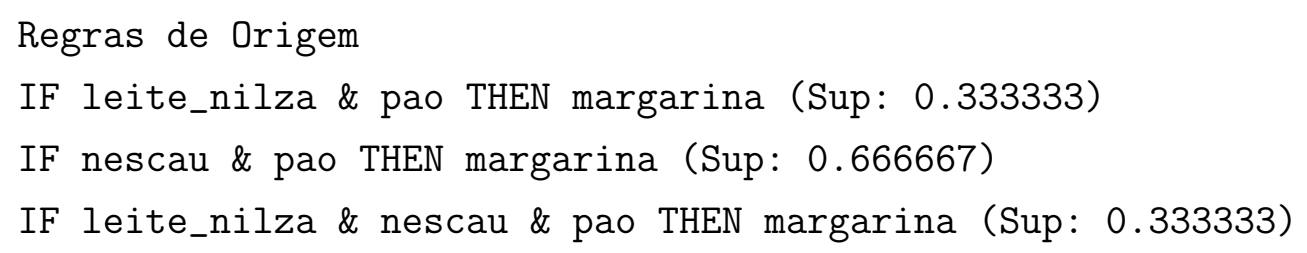

\footnotetext{
${ }^{2}$ Ao contrário dos exemplos anteriores, esse exemplo contém o número das regras. Isso porque, nesse ponto do processo, todas as regras de um determinado subconjunto possuirão a mesma estrutura sintática (padrão), embora cada uma represente uma regra distinta.
} 


\section{Regra Generalizada \\ IF pao \& produtos_matinais THEN margarina (Sup: 0.666667)}

A função remove-regras-origem (linhas 20 e 44) remove as regras de origem (regras específicas que deram origem à regra generalizada) de uma regra generalizada do conjunto final de regras.

A função remove-regras-repetidas (linha 51) remove as regras repetidas do conjunto final de regras. Essa função se torna necessária uma vez que um padrão de regra generalizada pode ser obtido a partir de diferentes padrões de regras. Suponha que o padrão generalizado "IF produtos_matinais THEN margarina" esteja presente duas vezes no conjunto final de regras generalizadas: uma com as regras de origem "[R $\left.X_{1}\right]$ IF leite_batavo THEN margarina" e "[R $\left.X_{2}\right]$ IF nescau THEN margarina" e a outra com as regras de origem "[R $\left.X_{3}\right]$ IF leite_batavo \& tody THEN margarina" e "[R $\left.X_{4}\right]$ IF leite_parmalat \& nescau THEN margarina". Note que o primeiro padrão foi obtido a partir de regras contendo apenas um item no antecedente e o segundo contendo dois itens. O objetivo dessa função então é eliminar um dos padrões do conjunto final e unir todas as regras de origem no padrão remanescente. Nesse exemplo descrito, o padrão "IF produtos_matinais THEN margarina" apareceria apenas uma vez no conjunto final de regras com as regras de origem $\mathrm{R} X_{1}, \mathrm{R} X_{2}, \mathrm{R} X_{3}$ e $\mathrm{R} X_{4}$. Esse fato ocorre em função da utilização da função elimina-itensrepetidos, a qual pode alterar, em alguns casos, a semântica da regra (a descrição sobre essa consideração/restrição é apresentada na Seção 4.4).

A função sintaxe-padrao (linha 52) retorna o conjunto final de regras de associação generalizadas na sintaxe padrão estendida apresentada na Seção 4.3.1.

\subsection{Considerações e/ou Restrições}

$\mathrm{Na}$ Seção 4.3.2 foram apresentadas as funções que compõem o $A P R A_{\text {alg }}$ (Algoritmo 2), responsável pela viabilização da abordagem de pós-processamento de regras de associação $(A P R A)$. Algumas considerações e/ou restrições foram adotadas durante a elaboração da $A P R A$ e do desenvolvimento do $A P R A_{\text {alg }}$, as quais são descritas a seguir.

1. A abordagem proposta realiza a generalização quando duas ou mais regras puderem ser agrupadas segundo uma taxonomia (linhas 12 e 36 do Algoritmo 2). Isso porque não haveria sentido generalizar uma única regra, já que a quantidade de regras não seria minimizada e a generalização estaria representando apenas um item de especialização da taxonomia. Além disso, a regra generalizada não seria tão representativa, pois a mesma seria composta pelo agrupamento de um único conhecimento 
específico. Para que esse agrupamento seja realizado corretamente nas opções lhs e rhs é necessário inicialmente agrupar as regras pelo lado contrário à generalização (linha 4 do Algoritmo 2).

2. Como se pode observar nas linhas 8-11 e 32-35 do Algoritmo 2, primeiro as substituições dos itens específicos pelos itens gerais são realizadas e só depois é que os subconjuntos são gerados. Sendo assim, mesmo quando um subconjunto contiver apenas uma regra, a mesma continuará contendo a substituição, pois em um próximo nível é possível que ela possa pertencer a um novo subconjunto. Considere, por exemplo, a taxonomia da Figura 4.11 e as regras "IF pao \& tody THEN margarina", "IF pao \& nescau THEN margarina", "IF pao \& leite_nilza THEN margarina". Realizando a substituição com o primeiro nível da taxonomia as regras "IF pao \& achocolatado THEN margarina", "IF pao \& achocolatado THEN margarina", "IF pao \& leite THEN margarina" seriam geradas, formando dois subconjuntos distintos. Embora a regra "IF pao \& leite THEN margarina" componha por si só um subconjunto, a mesma manterá a substituição realizada, uma vez que na substituição do próximo nível da taxonomia a mesma pertencerá ao mesmo subconjunto das regras anteriores, já que as seguintes regras serão obtidas: "IF pao \& produtos_matinais THEN margarina" e "IF pao \& produtos_matinais THEN margarina".

3. Uma das considerações feitas sobre as taxonomias utilizadas pela abordagem proposta é que todos os itens contidos na taxonomia contenham apenas um pai. Considere a taxonomia da Figura 4.12 e a regra "IF leite \& pao THEN margarina". Nesse caso, o item leite poderia ser substituído tanto pelo item laticinio quanto pelo item bebida. Assim, duas regras generalizadas poderiam ser geradas: "IF bebida \& pao THEN margarina" e "IF laticinio \& pao THEN margarina". Embora uma das vantagens de se considerar itens com vários pais seja as diferentes "visões" que se pode obter sobre o domínio, não é interessante que isso ocorra na abordagem proposta e descrita, uma vez que um dos objetivos da mesma é reduzir a quantidade de regras e não aumentar.

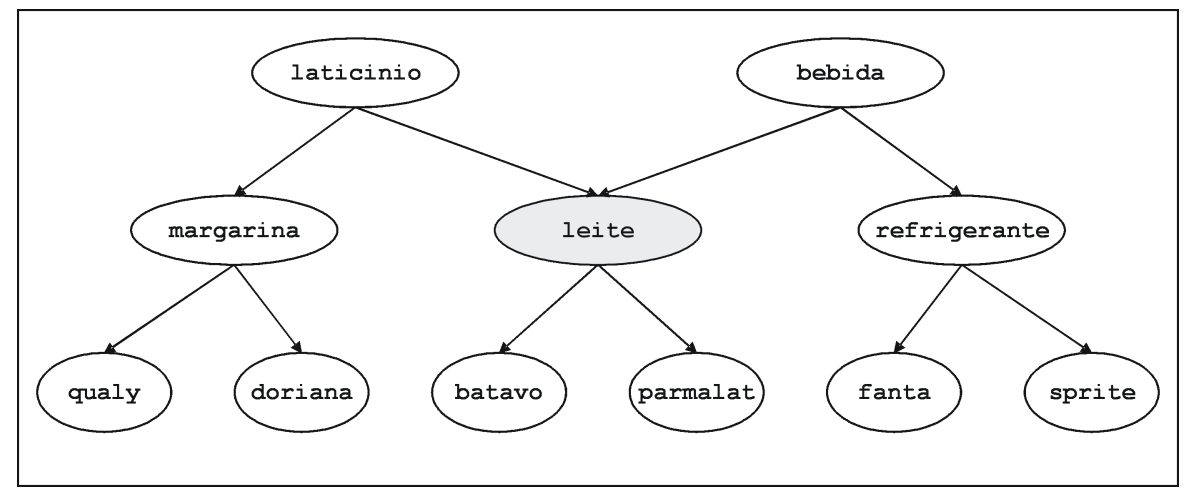

Figura 4.12: Exemplo de uma taxonomia contendo um item com mais de um pai. 
4. A generalização proposta na abordagem é considerada nível a nível. Considere a taxonomia da Figura 4.12 e a regra "IF margarina \& refrigerante THEN batavo". Se a generalização na abordagem proposta não ocorresse nível a nível, várias regras poderiam ser geradas, por exemplo, "IF laticinio \& refrigerante THEN batavo", "IF margarina \& bebida THEN batavo", "IF laticinio \& bebida THEN batavo", o que não ocorre na generalização nível a nível, na qual apenas uma regra seria gerada "IF laticinio \& bebida THEN batavo". Além disso, se a abordagem proposta não considerasse a generalização nível a nível, um processo semelhante aos utilizados nos algoritmos de extração de padrões descritos na Seção 3.3 .2 (página 39) estaria sendo realizado.

5. A abordagem proposta não considera variação de suporte nos diversos níveis da taxonomia em função da dificuldade de se definir os diferentes valores a serem utilizados em cada nível. Entretanto, como a generalização ocorre somente se o valor da medida $M$ na regra generalizada for $t \%$ maior do que o maior valor da medida $M$ em suas regras de origem, é como se o suporte/confiança já estivesse variando implicitamente. Em outras palavras, como t\% representa a proporção do aumento desejado no valor da medida $M$ na regra generalizada em relação ao valor de $M$ em suas regras de origem, o valor de $M$, a cada nível de generalização, já varia implicitamente.

6. Um dos motivos em se considerar a generalização somente se a medida $M$ da regra generalizada for $t \%$ maior do que o maior valor da medida $M$ em suas regras de origem se deve ao fato de não haver necessidade de se criar uma regra mais geral se ela não for mais representativa do que as suas regras de origem. Outro motivo considerado foi o de se evitar uma "sobrecarga" de generalização das regras, como mencionado anteriormente. Nesse caso, um outro critério que poderia ser considerado para se evitar uma "sobrecarga" seria a especificação, por parte do usuário, do nível "máximo" da taxonomia em que a generalização poderia ocorrer (como no trabalho de Adomavicius \& Tuzhilin (2001) descrito na Seção 3.3.3, página 40). Essa abordagem não foi considerada porque seria equivalente a utilizar diferentes taxonomias com diferentes níveis de abstração durante o processo de generalização.

Em relação à medida $M$, optou-se por considerar no processo de generalização tanto o suporte como a confiança, uma vez que o suporte mede a freqüência com que os itens ocorrem juntos nas transações e a confiança a relação existente entre o antecedente e o conseqüente da regra.

Em relação ao valor da taxa $t$ é importante observar o seguinte: se o objetivo do especialista for somente generalizar o conjunto de regras sem se preocupar com a "sobrecarga" do conjunto, a taxa $t$ deverá ser setada com zero, embora isso dependa da medida e do lado na qual a generalização será realizada (explicação detalhada 
na Seção 4.8). Existe, entretanto, uma diferença na redução do conjunto de regras quando essa taxa é utilizada com a medida de suporte em relação à confiança, em função das relações de generalizações explicitadas na Seção 3.2, página 35 ( $\sup (\widehat{x} \Rightarrow$ $y) \geqslant \sup (x \Rightarrow y)$, etc. $)$. Essa diferença pode ser observada com os experimentos apresentados na Seção 4.8. Sendo assim, quando a taxa $t=0 \%$, o conjunto final de regras, obtido pelo $A P R A_{\text {alg }}$, será o mais reduzido dentre todos os outros conjuntos obtidos com taxas $t>0 \%$.

7. Os critérios a serem verificados para uma regra de associação generalizada são: $L H S \cap R H S=\emptyset$ e nenhum item em RHS é um ancestral de qualquer item de $L H S$, ou seja, item-filho $\nRightarrow$ item-pai. Na abordagem proposta, o critério item-pai $\nRightarrow$ itemfilho também foi acrescentado. Isso porque, uma regra desse tipo, por exemplo, "IF leite THEN leite_batavo", indica apenas que uma porcentagem dos tipos de leite que foram comprados são leite_batavo, o que poderia ser verificado com um simples consulta SQL. Além disso, alguns algoritmos clássicos de extração de regras de associação generalizadas, como o Cumulate (Srikant \& Agrawal, 1997), excluem dos itemsets candidatos de tamanho 2 aqueles que contêm um item pai e um item filho garantindo, dessa forma, que regras do tipo item-pai $\nRightarrow$ item-filho e item-filho $\nRightarrow$ item-pai não estejam presentes no conjunto final de regras de associação.

8. Como mencionado e exemplificado anteriormente (Seção 4.3.2), a função eliminaitens-repetidos pode alterar, em alguns casos, a semântica de uma determinada regra. Na abordagem proposta, optou-se por não considerar a semântica uma vez que o objetivo da mesma é generalizar. Como generalizar é "afirmar, de forma infundada ou não, que algo é verdadeiro em grande parte de situações, ou para a maioria das pessoas" (Houaiss, 2001), excluindo-se a semântica é possível se obter um conjunto reduzido de regras composto por regras mais representativas e verificar se esse novo conhecimento obtido pelo processo de generalização é válido ou não no domínio considerado. Essa avaliação qualitativa do conhecimento pode ser realizada com o apoio do especialista do domínio ou através da avaliação com medidas objetivas (aspecto abordado no Capítulo 5). Além disso, como no trabalho de Adomavicius \& Tuzhilin (2001), descrito na Seção 3.3 .3 (página 40), a generalização nada mais é do que uma transformação sintática, onde uma regra geral representa uma classe de regras que contém uma estrutura sintática particular.

A fim de demonstrar o uso da $A P R A$, é apresentado a seguir um exemplo de execução do $A P R A_{\text {alg }}$. 


\subsection{Exemplo de Execução do $A P R A_{\text {alg }}$}

Nessa seção é apresentado um exemplo de utilização da abordagem proposta ( $A P R A)$ via a execução do $A P R A_{\text {alg }}$ (Algoritmo 2). O conjunto de dados utilizado para gerar o conjunto de regras de associação é o apresentado na Figura 4.13. Para a obtenção das regras de associação foi utilizada a implementação do algoritmo Apriori realizada por Chistian Borgelt ${ }^{3}$, com suporte mínimo e confiança mínima iguais a $30 \%$ e número máximo de 5 itens por regra. O número de regras obtidas foi 32 . O conjunto de regras obtido, apresentado na Figura 4.14, encontra-se na sintaxe padrão de regras de associação apresentada na Seção 2.3.2 (página 17). A taxonomia utilizada no processo de generalização é a apresentada na Figura 4.15, a mesma representada graficamente na Figura 4.11.

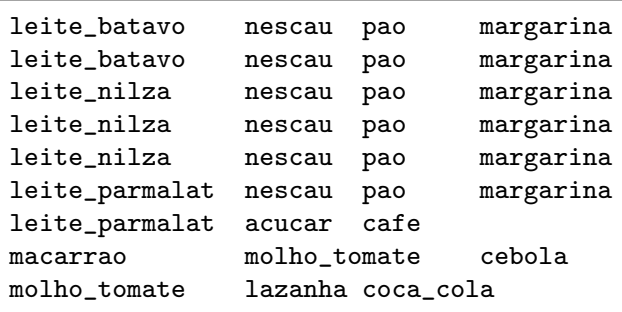

Figura 4.13: Arquivo de dados (correspondente ao arquivo .apr.data da Figura 4.4) utilizado no exemplo.

Para a apresentação do exemplo é considerado que o lado a ser generalizado é o lhs, que a medida $M$ é o suporte (sup) e que a taxa $t$ é de $0 \%$. Um exemplo assumindo que o lado a ser generalizado é o lrhs, que a medida $M$ é o suporte (sup) e que a taxa $t$ é de $0 \%$ é apresentado no Apêndice A. Para toda a explicação descrita a seguir encontra-se, entre parênteses, a linha em que a mesma é ativada no Algoritmo 2.

Com base nos arquivos de entrada apresentados nas Figuras 4.13, 4.14 e 4.15 e o $A P R A_{\text {alg }}$ (Algoritmo 2) descrito anteriormente, será gerada inicialmente (linha 1) a listagem contendo a participação de cada um dos itens específicos na composição dos itens gerais. Nesse exemplo, a listagem final gerada é a apresentada na Figura 4.16. Observe que para cada um dos itens gerais contidos na taxonomia da Figura 4.15 são listados todos os itens específicos que o compõem e a freqüência (suporte) de cada um. Em seguida, após a seqüencia de @'s, encontram-se as freqüências (suportes) de cada um dos itens gerais.

Como o lado $L$ a ser generalizado é o $l h s$, inicia-se a geração dos subconjuntos iniciais (linha 4). Os subconjuntos obtidos são apresentados na Figura 4.17. Observe que as regras foram agrupadas pelo lado contrário ao lado da generalização, nesse caso, $r h s$.

\footnotetext{
${ }^{3}$ Disponível para download no site http://fuzzy.cs . uni-magdeburg. de/ borgelt/software.html.
} 
[R0001], TRUE, leite_nilza, [0.333333,0.666667,0.000000,0.000000,9]

[R0002] , TRUE, nescau, $[0.666667,0.333333,0.000000,0.000000,9]$

[R0003], TRUE, pao, $[0.666667,0.333333,0.000000,0.000000,9]$

[R0004] , TRUE, margarina, $[0.666667,0.333333,0.000000,0.000000,9]$

[R0005], leite_nilza,nescau, [0.333333,0.000000,0.333333, 0.333333,9]

[R0006], nescau, leite_nilza, [0.333333,0.333333,0.333333,0.000000,9]

[R0007], leite_nilza,pao, [0.333333, 0.000000, 0.333333,0.333333, 9]

[R0008], pao, leite_nilza, [0.333333,0.333333,0.333333,0.000000,9]

[R0009], leite_nilza,margarina, $[0.333333,0.000000,0.333333,0.333333,9]$

[R0010], margarina, leite_nilza, [0.333333, 0.333333,0.333333,0.000000,9]

[R0011], nescau, pao, [0.666667,0.000000,0.333333,0.000000,9]

[R0012], pao, nescau, $[0.666667,0.000000,0.333333,0.000000,9]$

[R0013], nescau, margarina, $[0.666667,0.000000,0.333333,0.000000,9]$

[R0014], margarina, nescau, [0.666667,0.000000,0.333333,0.000000,9]

[R0015], pao,margarina, [0.666667, 0.000000,0.333333,0.000000,9]

[R0016], margarina, pao, $[0.666667,0.000000,0.333333,0.000000,9]$

[R0017], leite_nilza \& nescau,pao, [0.333333,0.000000,0.333333,0.333333,9]

[R0018], leite_nilza \& pao,nescau, [0.333333,0.000000,0.333333,0.333333,9]

[R0019], nescau \& pao,leite_nilza, [0.333333,0.333333,0.333333,0.000000,9]

[R0020], leite_nilza \& nescau,margarina, [0.333333,0.000000,0.333333,0.333333,9]

[R0021], leite_nilza \& margarina,nescau, [0.333333,0.000000,0.333333,0.333333,9]

[R0022], nescau \& margarina, leite_nilza, [0.333333,0.333333,0.333333,0.000000,9]

[R0023], leite_nilza \& pao,margarina, [0.333333,0.000000,0.333333,0.333333,9]

[R0024], leite_nilza \& margarina,pao, [0.333333,0.000000,0.333333,0.333333,9]

[R0025], pao \& margarina,leite_nilza, [0.333333,0.333333,0.333333,0.000000,9]

[R0026], nescau \& pao,margarina, [0.666667,0.000000,0.333333,0.000000,9]

[R0027], nescau \& margarina,pao, [0.666667,0.000000,0.333333,0.000000,9]

[R0028], pao \& margarina, nescau, [0.666667, 0.000000,0.333333,0.000000,9]

[R0029], leite_nilza \& nescau \& pao,margarina, $[0.333333,0.000000,0.333333,0.333333,9]$

[R0030], leite_nilza \& nescau \& margarina,pao, $[0.333333,0.000000,0.333333,0.333333,9]$

[R0031], leite_nilza \& pao \& margarina,nescau, $[0.333333,0.000000,0.333333,0.333333,9]$

[R0032], nescau \& pao \& margarina,leite_nilza, [0.333333,0.333333,0.333333,0.000000,9]

Figura 4.14: Arquivo de regras de associação na sintaxe padrão (correspondente ao arquivo . apr.dcar da Figura 4.4) geradas a partir do arquivo de dados da Figura 4.13, utilizado no exemplo.

leite(leite_batavo, leite_molico, leite_nilza, leite_parmalat, leite_salute) (1).

achocolatado (nescau,tody) (1).

produtos_matinais (leite, achocolatado)(2).

Figura 4.15: Arquivo de taxonomias (correspondente ao arquivo .tax da Figura 4.4) utilizado no exemplo.

Para cada um dos subconjuntos gerados que contêm duas ou mais regras (linha 5), as linhas de 8 a 11 do Algoritmo 2 serão executadas. Como o processo a ser realizado em cada um dos subconjuntos é igual, será exemplificado o processamento de apenas um dos subconjuntos. Sendo assim, considerando o "Subconjunto 1-2" da Figura 4.17, a função que realiza a substituição dos itens específicos pelos itens gerais é executada (linha 8). Como o nível atual da taxonomia é igual a $1(N A T a x=1)$, procura-se na taxonomia (Figura 4.15) pelos itens contidos no nível 1, indicados por "(1)" no final da linha, para que a substituição seja realizada. Após a substituição, é verificado se as regras possuem algum item repetido (linha 9). Caso exista, eliminam-se os itens repetidos 


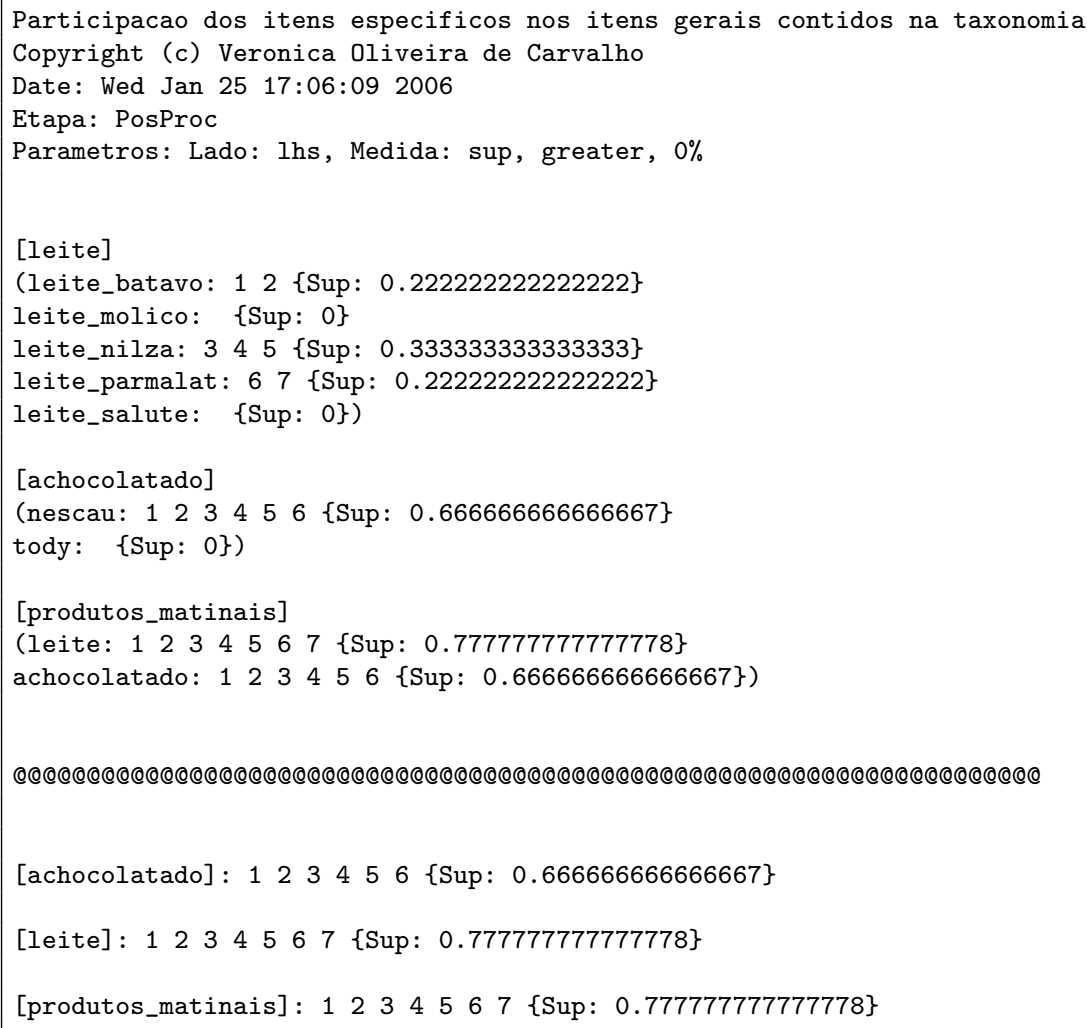

Figura 4.16: Listagem de contribuição de itens obtida no exemplo (correspondente ao arquivo taxonomy_elements.txt da Figura 4.4).

de forma que as regras contenham apenas itens distintos. Em seguida, as regras são ordenadas lexicograficamente (linha 10). Na Figura 4.18 são apresentados os três passos acima descritos. A partir do "novo" conjunto de regras obtido, geram-se os subconjuntos pelo lado que se quer generalizar (linha 11), nesse caso, lhs. Na Figura 4.19 são mostrados os subconjuntos gerados para esse "novo" conjunto.

O próximo passo do algoritmo (linha 12) é continuar a generalização em cada um dos subconjuntos obtidos que contenham duas ou mais regras. Como nenhum dos subconjuntos da Figura 4.19 atende a essa condição, o nível atual da taxonomia ( NATax) passa a ser 2 e volta-se à linha 7 do algoritmo. Como ainda existe um nível da taxonomia a ser explorado $(N A T a x=2 \leqslant N M T a x=2)$, o subconjunto apresentado na Figura 4.18 é novamente substituído pelos itens do nível atual da taxonomia (linha 8). Após a substituição, os processos para eliminar os itens repetidos (linha 9) e ordenar os itens da regra lexicograficamente (linha 10) são executados, gerando, para os três passos, os resultados apresentados na Figura 4.20. A partir do "novo" conjunto de regras obtido, geram-se os subconjuntos pelo lado que se quer generalizar (linha 11), nesse caso, lhs. Na Figura 4.21 são mostrados os subconjuntos gerados para esse "novo" conjunto. 


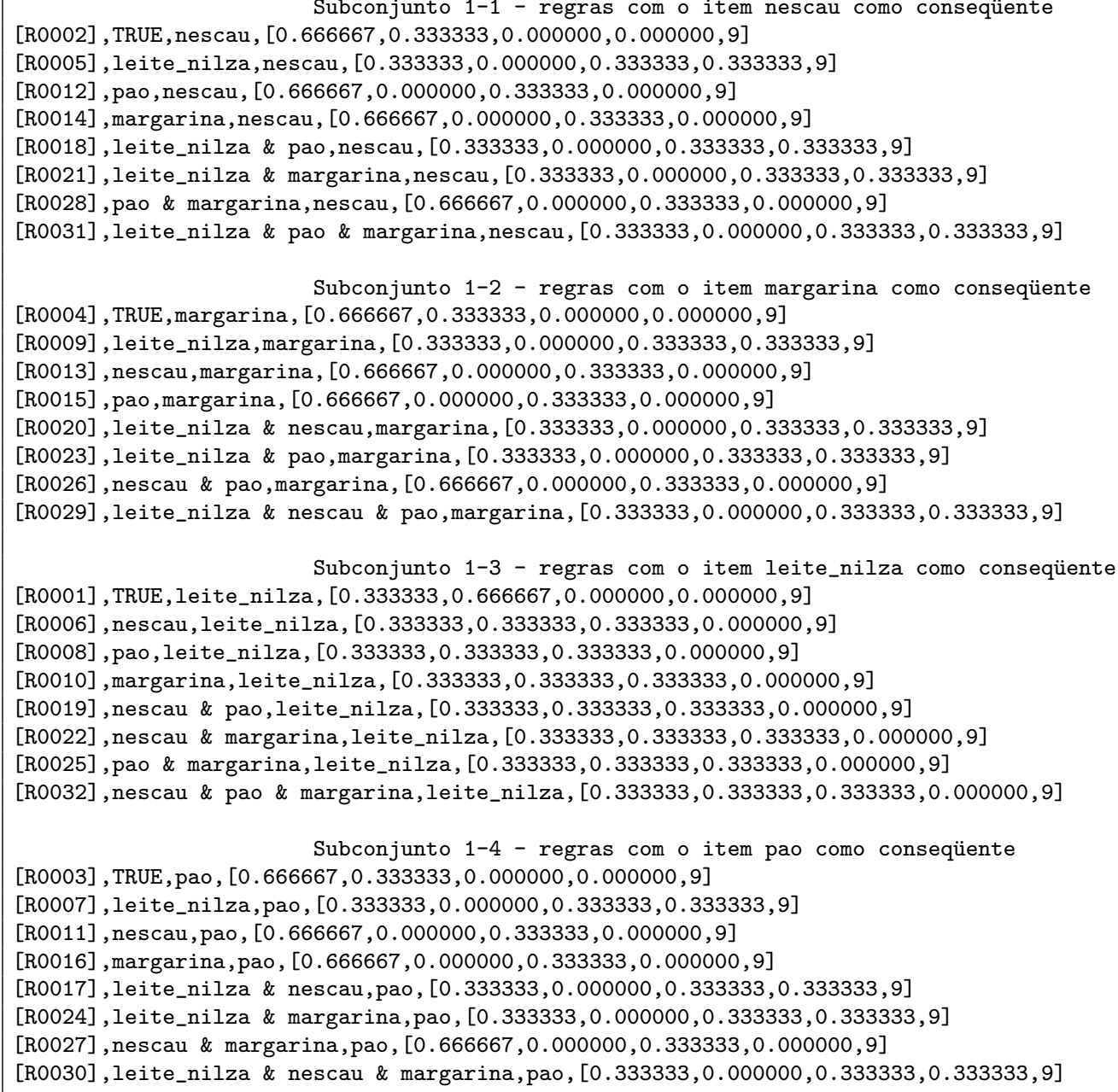

Figura 4.17: Subconjuntos iniciais obtidos no exemplo.

Para cada um dos subconjuntos obtidos (Figura 4.21) que contenham duas ou mais regras (linha 12), o processo descrito a seguir é realizado. Será exemplificado o processamento de apenas um subconjunto, nesse caso, o "Subconjunto 2-4", uma vez que o processamento dos demais é igual ao abaixo demonstrado.

Na linha 13 do algoritmo, $r$ é inicializado com o padrão da regra contida no subconjunto corrente, nesse caso, "pao \& produtos_matinais,margarina". Para o padrão corrente, é verificado se a validade dos critérios de generalização estão sendo cumpridos (linha 14): $L H S \cap R H S=\emptyset$; item-filho $\nRightarrow$ item-pai; item-pai $\nRightarrow$ item-filho. Como nesse caso todos os critérios são atendidos, o cálculo da tabela de contingências para a regra generalizada é realizado (linha 16). Em seguida, o critério de verificação da medida $M$ é realizado (linha 17). Como descrito anteriormente, esse critério verificará se as regras específicas poderão ser substituídas pela regra geral via comparação da medida $M$, dada uma taxa t, a fim de evitar uma "sobrecarga" de generalização. A função irá verificar então se o suporte da regra generalizada é $t \%$ maior do que o maior valor de suporte encontrado 


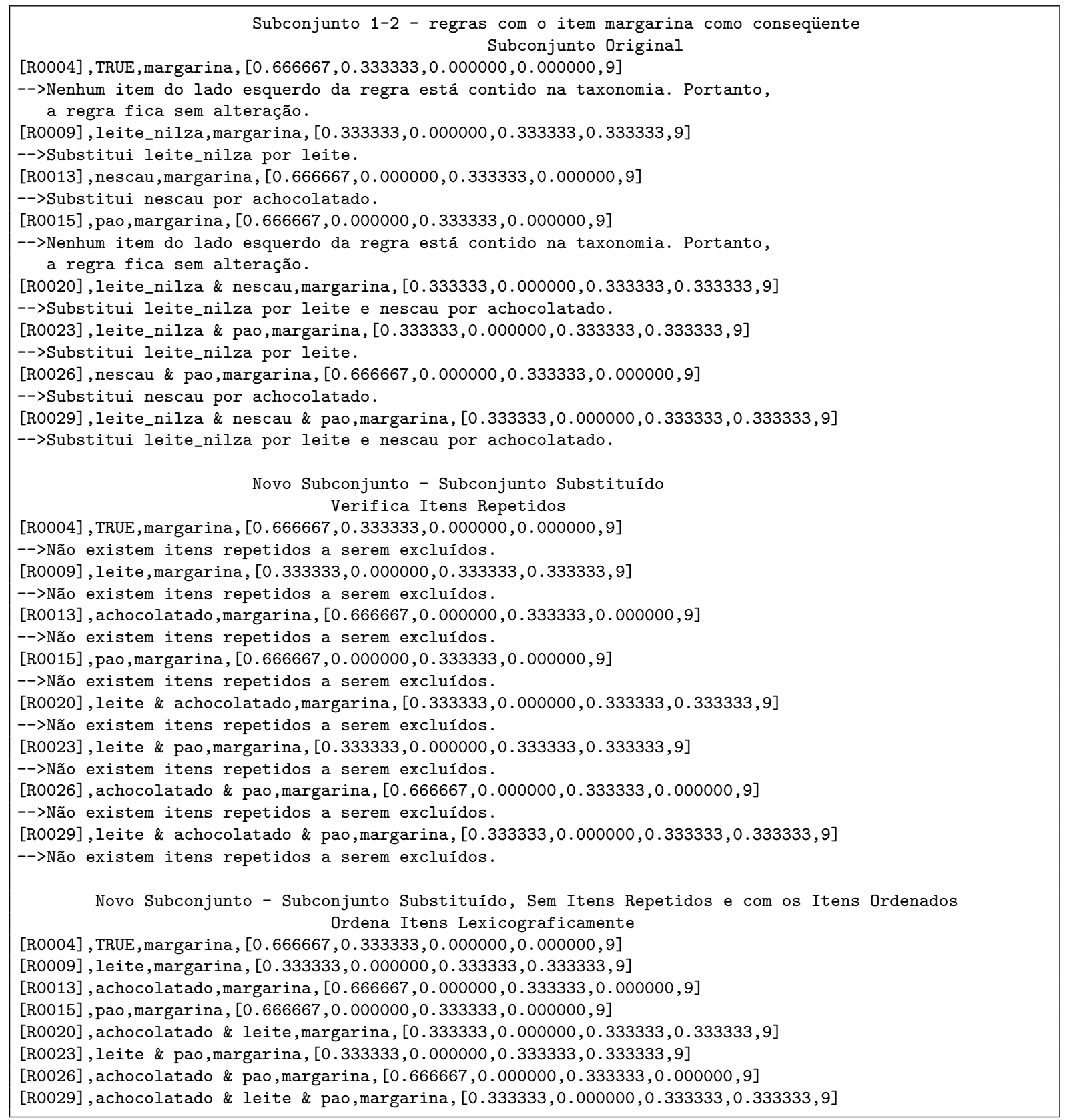

Figura 4.18: Processo de substituição, eliminação e ordenação referente ao exemplo, utilizando o nível 1 da taxonomia.

em suas regras de origem. Na Figura 4.22 é apresentado o processo descrito. Como nesse caso o suporte da regra generalizada cumpre o critério estabelecido, a mesma é considerada uma regra válida. Sendo assim, a mesma é adicionada ao conjunto final das regras generalizadas (RGen) (linha 19), e as regras de origem da mesma são removidas (linha 20), como mostrado na Figura 4.23. Nesse ponto, o arquivo RGen (correspondente ao arquivo rules_gen.txt da Figura 4.4) passa a ser o apresentado na Figura 4.24. Observe pela Figura 4.22 que o cálculo da tabela de contingências da regra generalizada só é 


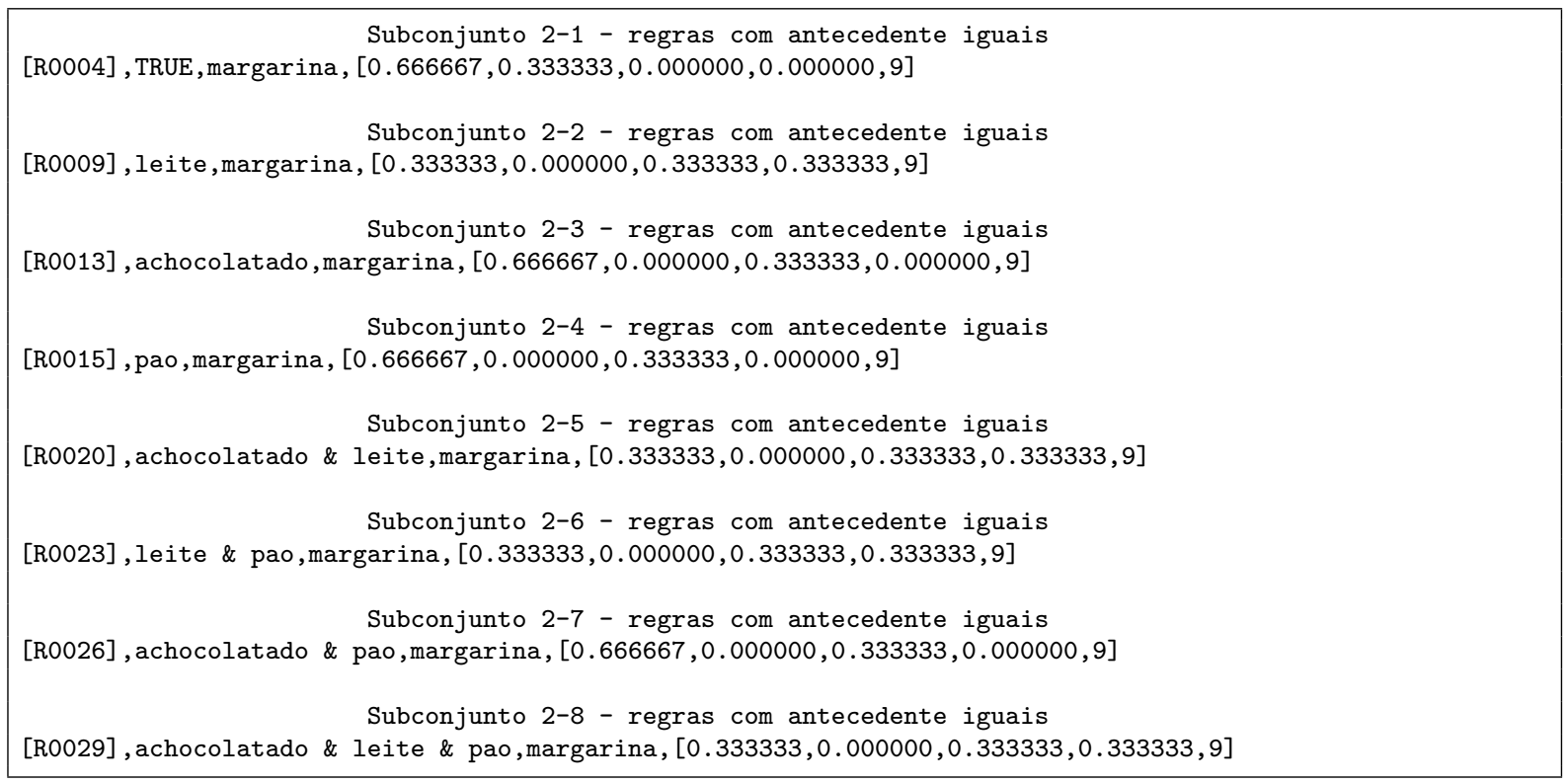

Figura 4.19: Subconjuntos gerados, a partir da Figura 4.18, utilizando o nível 1 da taxonomia, referente ao exemplo.

feito depois que a mesma for considerada uma regra generalizada válida pelos critérios de generalização. Sendo assim, apesar das regras de origem estarem representadas pelos itens gerais contidos na taxonomia, a qual representa uma substituição temporária, os valores das suas respectivas tabelas de contingências se mantêm os mesmos.

Após o processamento de todos os subconjuntos restantes, regras repetidas do arquivo RGen são removidas (linha 51) e as remanescentes formatadas na sintaxe padrão apresentada na Seção 4.3.1, página 52 (linha 52). Após todo esse processo, os arquivos de saída são os apresentados nas Figuras 4.16 e 4.25, ambos obtidos pelo $A P R A_{\text {alg }}$ considerando as opções $l$ hs-sup-0\%, ou seja, que o lado generalizado foi o $l h s$, que a medida $M$ considerada foi o suporte $($ sup) e que a taxa $t$ foi de $0 \%$. 
Subconjunto 1-2 - regras com o item margarina como conseqüente Subconjunto do Passo Anterior

[R0004], TRUE, margarina, [0.666667, 0.333333, $0.000000,0.000000,9]$

-->Nenhum item do lado esquerdo da regra está contido na taxonomia. Portanto,

a regra fica sem alteração.

[R0009], leite, margarina, [0.333333,0.000000,0.333333,0.333333,9]

-->Substitui leite por produtos_matinais.

[R0013], achocolatado, margarina, [0.666667, 0.000000,0.333333, 0.000000,9]

-->Substitui achocolatado por produtos_matinais.

[R0015], pao, margarina, [0.666667,0.000000,0.333333,0.000000,9]

->Nenhum item do lado esquerdo da regra está contido na taxonomia. Portanto,

a regra fica sem alteração.

[R0020], achocolatado \& leite, margarina, [0.333333,0.000000,0.333333,0.333333,9]

-->Substitui achocolatado e leite por produtos_matinais.

[R0023], leite \& pao,margarina, [0.333333,0.000000,0.333333,0.333333,9]

->Substitui leite por produtos_matinais.

[R0026], achocolatado \& pao,margarina, [0.666667,0.000000,0.333333,0.000000,9]

-->Substitui achocolatado por produtos_matinais.

[R0029], achocolatado \& leite \& pao,margarina, $[0.333333,0.000000,0.333333,0.333333,9]$

-->Substitui achocolatado e leite por produtos_matinais.

Novo Subconjunto - Subconjunto Substituído

Verifica Itens Repetidos

[R0004], TRUE, margarina, [0.666667, 0.333333, 0.000000,0.000000, 9]

-->Não existem itens repetidos a serem excluídos.

[R0009], produtos_matinais,margarina, [0.333333, 0.000000,0.333333, 0.333333,9]

-->Não existem itens repetidos a serem excluídos.

[R0013], produtos_matinais,margarina , [0.666667,0.000000,0.333333,0.000000,9]

-->Não existem itens repetidos a serem excluídos.

[R0015], pao,margarina, [0.666667,0.000000,0.333333,0.000000,9]

-->Não existem itens repetidos a serem excluídos.

[R0020],produtos_matinais \& produtos_matinais,margarina, [0.333333,0.000000,0.333333,0.333333,9]

-->Item a ser excluído: produtos_matinais.

[R0023],produtos_matinais \& pao,margarina, $[0.333333,0.000000,0.333333,0.333333,9]$

-->Não existem itens repetidos a serem excluídos.

[R0026],produtos_matinais \& pao,margarina, $[0.666667,0.000000,0.333333,0.000000,9]$

-->Não existem itens repetidos a serem excluídos.

[R0029],produtos_matinais \& produtos_matinais \& pao,margarina, [0.333333,0.000000,0.333333,0.333333,9]

-->Item a ser excluído: produtos_matinais.

Novo Subconjunto - Subconjunto Substituído, Sem Itens Repetidos e com os Itens Ordenados Ordena Itens Lexicograficamente

[R0004], TRUE, margarina, [0.666667,0.333333,0.000000,0.000000,9]

[R0009], produtos_matinais, margarina, [0.333333,0.000000,0.333333,0.333333,9]

[R0013], produtos_matinais, margarina, [0.666667,0.000000,0.333333,0.000000,9]

[R0015], pao, margarina, [0.666667,0.000000,0.333333,0.000000,9]

[R0020], produtos_matinais, margarina, [0.333333, 0.000000,0.333333, 0.333333,9]

[R0023], pao \& produtos_matinais,margarina, $[0.333333,0.000000,0.333333,0.333333,9]$

[R0026], pao \& produtos_matinais,margarina, $[0.666667,0.000000,0.333333,0.000000,9]$

[R0029], pao \& produtos_matinais, margarina, $[0.333333,0.000000,0.333333,0.333333,9]$

Figura 4.20: Processo de substituição, eliminação e ordenação referente ao exemplo, utilizando o nível 2 da taxonomia. 
Subconjunto 2-1 - regras com antecedente iguais

[R0004] , TRUE, margarina , [0.666667, 0.333333, 0.000000,0.000000, 9]

Subconjunto 2-2 - regras com antecedente iguais

[R0009], produtos_matinais, margarina, [0.333333,0.000000,0.333333,0.333333,9]

[R0013],produtos_matinais, margarina, $[0.666667,0.000000,0.333333,0.000000,9]$

[R0020],produtos_matinais, margarina, $[0.333333,0.000000,0.333333,0.333333,9]$

Subconjunto 2-3 - regras com antecedente iguais

[R0015], pao, margarina, $[0.666667,0.000000,0.333333,0.000000,9]$

Subconjunto 2-4 - regras com antecedente iguais

[R0023], pao \& produtos_matinais,margarina, [0.333333,0.000000,0.333333,0.333333,9]

[R0026],pao \& produtos_matinais,margarina, [0.666667,0.000000,0.333333,0.000000,9]

[R0029],pao \& produtos_matinais,margarina, $[0.333333,0.000000,0.333333,0.333333,9]$

Figura 4.21: Subconjuntos gerados, a partir da Figura 4.20, utilizando o nível 2 da taxonomia, referente ao exemplo.

Subconjunto 2-4 - regras com antecedente iguais

[R0023], pao \& produtos_matinais,margarina, $[0.333333,0.000000,0.333333,0.333333,9]$

[R0026], pao \& produtos_matinais,margarina, [0.666667,0.000000,0.333333,0.000000,9]

[R0029], pao \& produtos_matinais,margarina, $[0.333333,0.000000,0.333333,0.333333,9]$

$r:=$ pao \& produtos_matinais,margarina

Critérios de generalização:

1. Nenhum item filho de LHS implica em um item pai de RHS.

$-\rightarrow$ True.

2. Nenhum item pai de LHS implica em um item filho de RHS.

$-\rightarrow$ True.

3. A intersecção de LHS com RHS é vazia.

$\rightarrow$ True.

Como os critérios de generalização são válidos, calcula-se a tabela de contingência de $r$.

LHS de $r=\{1,2,3,4,5,6\}$.

RHS de $r=\{1,2,3,4,5,6\}$.

$f($ LHS RHS $)=(6 / 9)=0.666667 ; f($ LHS nRHS $)=(0 / 9)=0.000000$

$f(n L H S$ RHS $)=(0 / 9)=0.000000 ; f(n L H S$ nRHS $)=(3 / 9)=0.333333$.

Critério da medida de generalização:

Medida considerada: sup.

Taxa: $0 \%$.

Máximo valor de suporte das regras de origem: Max $(0.333333,0.666667,0.333333)=0.666667$.

Como $(0.666667>=((0.666667 * 0 \%)+0.666667))$ a regra $r$ é uma regra generalizada válida.

Figura 4.22: Processo de verificação da regra generalizada no exemplo: critérios de generalização e critério da medida utilizada na generalização. 


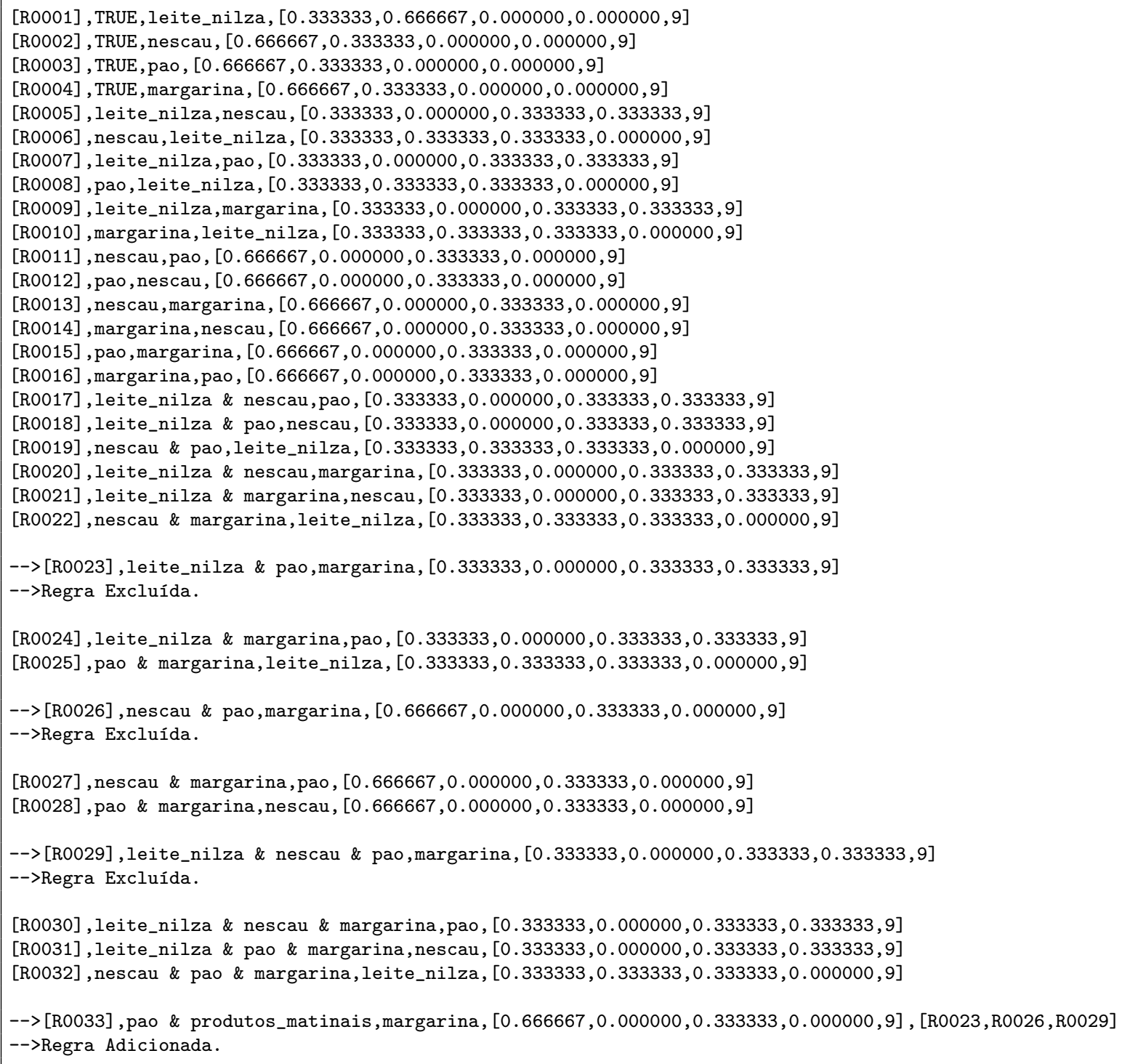

Figura 4.23: Remoção das regras de origem e adição da regra generalizada referente a Figura 4.22. 
[R0001], TRUE, leite_nilza, [0.333333,0.666667,0.000000,0.000000,9]

[R0002], TRUE, nescau, $[0.666667,0.333333,0.000000,0.000000,9]$

[R0003] , TRUE, pao, $[0.666667,0.333333,0.000000,0.000000,9]$

[R0004] , TRUE, margarina, [0.666667,0.333333,0.000000,0.000000,9]

[R0005], leite_nilza,nescau, [0.333333,0.000000,0.333333,0.333333,9]

[R0006], nescau, leite_nilza, [0.333333,0.333333,0.333333,0.000000,9]

[R0007], leite_nilza,pao, [0.333333,0.000000, 0.333333,0.333333,9]

[R0008], pao, leite_nilza, [0.333333,0.333333,0.333333,0.000000,9]

[R0009], leite_nilza, margarina, [0.333333, 0.000000, 0.333333, 0.333333, 9]

[R0010], margarina, leite_nilza, [0.333333, 0.333333,0.333333, 0.000000,9]

[R0011], nescau,pao, $[0.666667,0.000000,0.333333,0.000000,9]$

[R0012], pao, nescau, $[0.666667,0.000000,0.333333,0.000000,9]$

[R0013], nescau, margarina, [0.666667,0.000000,0.333333,0.000000,9]

[R0014], margarina, nescau, [0.666667, 0.000000,0.333333,0.000000,9]

[R0015], pao,margarina, $[0.666667,0.000000,0.333333,0.000000,9]$

[R0016], margarina, pao, [0.666667,0.000000,0.333333,0.000000,9]

[R0017], leite_nilza \& nescau,pao, [0.333333,0.000000,0.333333,0.333333,9]

[R0018], leite_nilza \& pao,nescau, [0.333333,0.000000,0.333333,0.333333,9]

[R0019], nescau \& pao,leite_nilza, [0.333333,0.333333,0.333333,0.000000,9]

[R0020], leite_nilza \& nescau,margarina, $[0.333333,0.000000,0.333333,0.333333,9]$

[R0021], leite_nilza \& margarina,nescau, [0.333333,0.000000,0.333333,0.333333,9]

[R0022], nescau \& margarina,leite_nilza, [0.333333,0.333333,0.333333,0.000000,9]

[R0024], leite_nilza \& margarina,pao, [0.333333,0.000000,0.333333,0.333333,9]

[R0025], pao \& margarina,leite_nilza, [0.333333,0.333333,0.333333,0.000000,9]

[R0027], nescau \& margarina,pao, [0.666667,0.000000,0.333333,0.000000,9]

[R0028], pao \& margarina, nescau, [0.666667,0.000000,0.333333,0.000000,9]

[R0030], leite_nilza \& nescau \& margarina,pao, $[0.333333,0.000000,0.333333,0.333333,9]$

[R0031], leite_nilza \& pao \& margarina,nescau, $[0.333333,0.000000,0.333333,0.333333,9]$

[R0032], nescau \& pao \& margarina,leite_nilza, [0.333333,0.333333,0.333333,0.000000,9]

[R0033],pao \& produtos_matinais,margarina, $[0.666667,0.000000,0.333333,0.000000,9],[R 0023, R 0026, R 0029]$

Figura 4.24: Arquivo parcial do conjunto final de regras de associação generalizadas referente ao exemplo. 


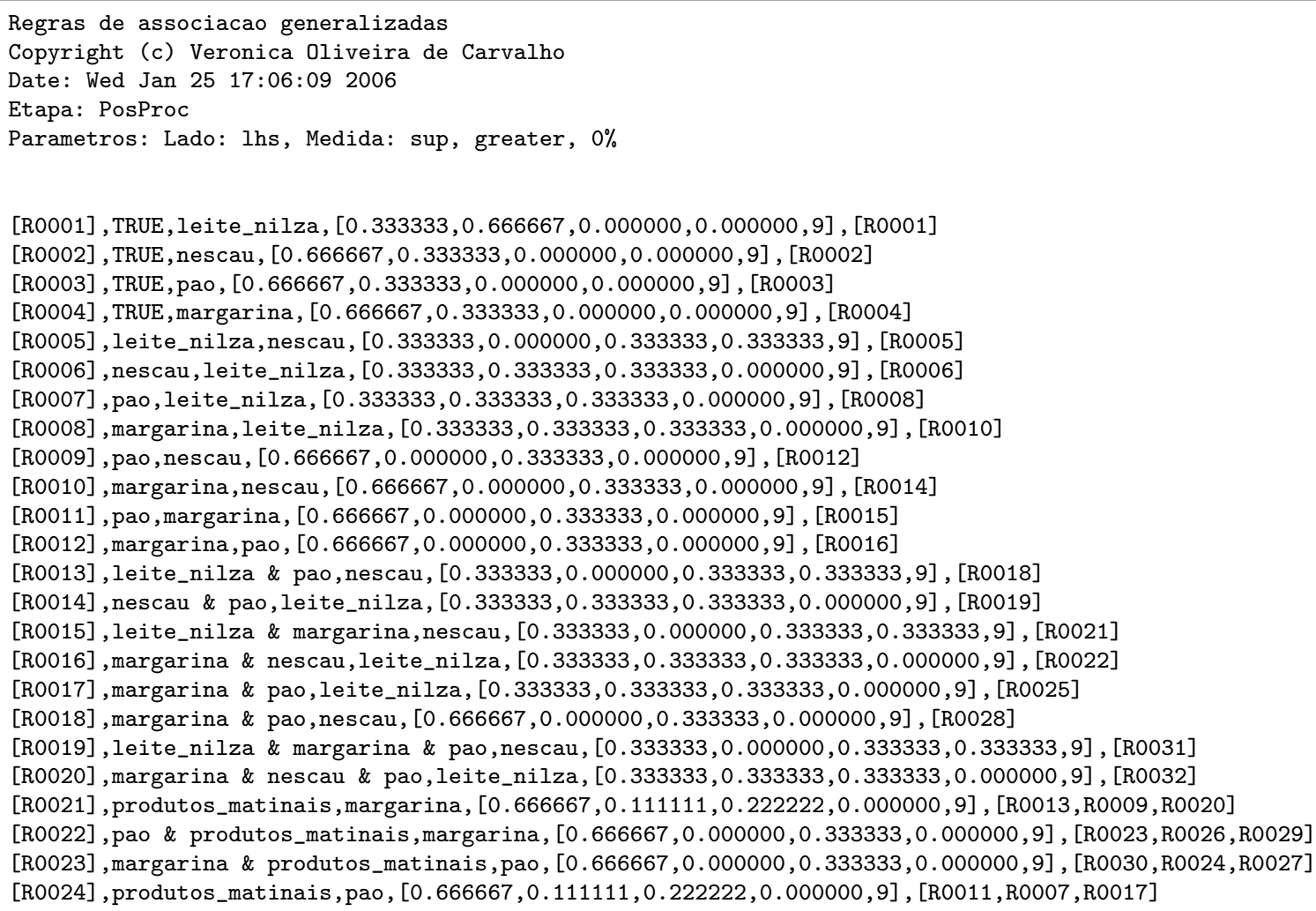

Figura 4.25: Arquivo do conjunto final de regras de associação generalizadas referente ao exemplo (correspondente ao arquivo rules_gen.txt da Figura 4.4). 


\subsection{Comparação da APRA com o Estado da Arte}

Como mencionado na Seção 3.3 do Capítulo 3 (página 38), existem diversos trabalhos na literatura que utilizam taxonomias em regras de associação, os quais variam de acordo com a etapa de aplicação das mesmas no processo de mineração de dados. Entretanto, como este trabalho se situa na etapa de pós-processamento, apresenta-se, a seguir, uma comparação da abordagem proposta com os dois trabalhos citados na Seção 3.3.3 (página 40): o de Domingues \& Rezende (2005); Domingues (2004), no qual a abordagem aqui proposta se baseia, e o de Adomavicius \& Tuzhilin (2001).

Em Domingues \& Rezende (2005); Domingues (2004) é proposta uma abordagem que, assim como a $A P R A$, também generaliza um conjunto de regras de associação específicas, obtidas, a priori, por um algoritmo de mineração tradicional, em regras mais gerais a partir de um conjunto de taxonomias fornecidas pelo especialista do domínio. Ressaltase, entretanto, que a abordagem aqui proposta possui cinco grandes diferenciais:

1. Na abordagem aqui proposta é possível se generalizar apenas um dos lados (lhs ou rhs) ou ambos os lados da regra. Em Domingues \& Rezende (2005); Domingues (2004), apenas um dos lados pode ser generalizado.

2. Na abordagem aqui proposta a generalização é realizada entre as regras e entre os itens da regra. Em Domingues \& Rezende (2005); Domingues (2004), apenas as generalizações entre as regras são realizadas. Considere a taxonomia da Figura 4.11. Se as regras "IF leite_batavo \& leite_molico THEN margarina" e "IF leite_nilza THEN margarina" estivessem contidas no conjunto de regras, a regra "IF leite THEN margarina" seria gerada pela abordagem aqui proposta, uma vez que os itens leite_batavo e leite_molico são substituídos pelo item leite (generalização entre os itens da regra), assim como o item leite_nilza. Sendo assim, após as substituições, a regra "IF leite THEN margarina" é gerada (generalização entre as regras).

3. Na abordagem aqui proposta regras generalizadas são obtidas considerando-se todos ou alguns dos itens contidos na taxonomia. Em Domingues \& Rezende (2005); Domingues (2004), todos os itens contidos na taxonomia devem ser considerados no processo de generalização, ou seja, é necessário que exista uma regra específica para cada um dos itens terminais contidos na taxonomia. Considere a taxonomia da Figura 4.11. Se apenas as regras "IF leite_batavo THEN margarina" e "IF leite_parmalat THEN margarina" estivessem contidas no conjunto de regras, a regra "IF leite THEN margarina" não seria gerada pela abordagem proposta em Domingues \& Rezende (2005); Domingues (2004), pois as regras "IF leite_nilza THEN margarina", "IF leite_salute THEN margarina" e "IF leite_molico THEN margarina", que contêm os outros itens de especialização do item leite, não foram 
geradas. Observe que essa é uma restrição muito forte, uma vez que o especialista que fornece as taxonomias não sabe precisamente quais são todos os tipos de leite que foram comprados e que estão contidos no conjunto de regras obtidas em função de um determinado valor de suporte e confiança. Sendo assim, a abordagem aqui proposta é bem mais flexível, além de possuir a vantagem de se poder utilizar taxonomias gerais de domínio em subdomínios, já que a listagem de contribuição de itens facilita a compreensão das regras generalizadas obtidas.

4. Em Domingues \& Rezende (2005); Domingues (2004) uma generalização não ocorre se uma regra possuir mais de um item com o mesmo pai. Considere a taxonomia da Figura 4.11. Se a regra "IF leite_batavo \& leite_molico THEN margarina" estivesse contida no conjunto de regras, a regra "IF leite THEN margarina" não seria gerada pela abordagem por eles proposta, uma vez que ambos os itens específicos (leite_batavo; leite_molico) possuem o mesmo item pai (leite).

5. Na abordagem aqui proposta uma regra só será generalizada se o valor de suporte/confiança da mesma for t\% maior do que o maior valor da mesma medida em suas regras específicas. Sendo assim, essa condição faz com que ocorra uma variação implícita do valor da medida de suporte/confiança nas regras generalizadas, tornando o processo mais flexível.

Em Adomavicius \& Tuzhilin (2001) é proposta uma abordagem que realiza o agrupamento de um conjunto de regras (não apenas regras de associação) em função da similaridade existente entre as mesmas, a qual é medida por uma transformação sintática que se faz nas regras via a utilização de uma taxonomia de domínio. A abordagem aqui proposta difere da apresentada por Adomavicius \& Tuzhilin (2001), uma vez que o objetivo da abordagem dos autores é criar classes de regras que representem a estrutura sintática de um subconjunto de regras. Sendo assim, no trabalho de Adomavicius \& Tuzhilin (2001):

1. A regra geral não tem como objetivo substituir as regras específicas, já que a mesma é apenas uma representação geral da estrutura sintática das regras específicas.

2. O objetivo é auxiliar a interpretação do conjunto de regras via a exploração das classes de regras geradas.

3. Regras de associação generalizadas não são obtidas, já que $L H S \cap R H S \neq \varnothing$ (essa restrição pode ser observada na Figura 3.2 da Seção 3.3.3, página 40). Isso porque a abordagem é genérica, isto é, serve para qualquer tipo de regra conjuntiva (associação, classificação, etc.), uma vez que o objetivo é realmente gerar classes de regras. Sendo assim, as medidas de suporte e confiança não são calculadas para as classes de regras. 
4. O agrupamento é realizado considerando-se toda a estrutura sintática da regra, ou seja, o agrupamento é realizado apenas em ambos os lados da regra.

5. O mapeamento sintático das regras não é realizado nível a nível, já que é o usuário que define o nível de abstração de cada ramo da taxonomia.

Ambas as abordagens mencionadas, assim como a abordagem aqui proposta, visam reduzir o conjunto de regras de entrada, de forma a fornecer uma visão mais geral do conhecimento extraído, a fim de facilitar a interpretação e análise do mesmo pelos usuários finais. Entretanto, uma diferença identificada em relação aos trabalhos de Domingues \& Rezende (2005); Domingues (2004) e Adomavicius \& Tuzhilin (2001) se refere à listagem de contribuição de itens. Na abordagem aqui proposta, para cada uma das regras generalizadas é possível se identificar, por meio da listagem gerada, qual a contribuição de cada um dos itens específicos na composição dos itens gerais que compõem a regra. Com essa informação, o especialista do domínio pode explorar com mais detalhes cada uma das regras geradas. Esse fato viabiliza a utilização de taxonomias gerais de domínio em subdomínios. Além disso, a lista de contribuição de itens também favorece a identificação de regras de exceção, já que é possível se obter uma descrição mais elaborada do domínio, a partir da qual se pode observar quais itens específicos não contribuem para uma categoria/classe de itens em uma determinada associação.

A fim de fornecer ao usuário um ambiente para explorar conjuntos de regras de associação generalizadas gerados pelo $A P R A_{a l g}$, um módulo computacional, denominado RulEE-RAG, foi criado, o qual é descrito a seguir. O objetivo desse módulo é auxiliar o usuário na visualização da contribuição de cada um dos itens específicos na composição dos itens gerais que compõem cada uma das regras generalizadas, além de auxiliar a identificação de regras de exceção.

\subsection{O Módulo de Exploração RulEE-RAG}

Dada a necessidade de se pesquisar técnicas para auxiliar o usuário na compreensão e utilização do conhecimento descoberto em um processo de mineração de dados, foi projetado e implementado no Laboratório de Inteligência Computacional (LABIC) do Instituto de Ciências Matemáticas e de Computação da Universidade de São Paulo (ICMC-USP), um sistema para exploração de regras denominado RuLEE (Rule Exploration Environment). O RulEE (Paula, 2003) viabiliza tanto a análise quanto a disponibilização de regras de classificação, regressão e associação. É um ambiente interativo no qual o usuário pode "navegar" no conjunto de regras obtido de modo a selecionar, por meio de medidas de avaliação e consultas SQL, as regras que se apresentam mais interessantes. O módulo 
RulEE-RAG (Fujimoto, Carvalho, \& Rezende, 2007), descrito a seguir, foi implementado e integrado ao ambiente RULEE utilizando a estrutura proporcionada pelo mesmo (Paula, 2003). Assim, após a autenticação do usuário no RulEE, o módulo pode ser acessado.

Como mencionado anteriormente, o objetivo do módulo RULEE-RAG é viabilizar a exploração de conjuntos de regras de associação generalizadas obtidos pelo $A P R A_{\text {alg }}$. O módulo inicialmente fornece ao usuário a opção de disponibilizar um novo conjunto de regras de associação generalizadas a ser explorado posteriormente e/ou explorar um conjunto já disponível no ambiente.

Para disponibilizar um conjunto de regras generalizadas no ambiente, o usuário deve fornecer o identificador do conjunto de regras específicas (referente ao arquivo .apr.dcar da Figura 4.4, página 53) utilizado como entrada no processo de pós-processamento (considera-se que o mesmo encontra-se disponível no ambiente), o arquivo de dados utilizado para extrair o conjunto de regras específicas (arquivo .apr.data da Figura 4.4) e o arquivo de taxonomias (arquivo .tax da Figura 4.4), além do arquivo contendo as regras generalizadas obtidas (arquivo rules_gen.txt da Figura 4.4) e o arquivo contendo a contribuição dos itens específicos na composição dos itens gerais (arquivo taxonomy_elements.txt da Figura 4.4), ambos gerados pelo $A P R A_{\text {alg }}$. Uma vez que o conjunto de regras generalizadas encontra-se disponível no ambiente, o usuário pode visualizar todas as regras do conjunto selecionado para o processo de exploração e/ou realizar consultas sobre o mesmo.

Ao selecionar a opção referente à visualização de regras, o módulo RuLEE-RAG as apresenta fazendo distinção entre as regras específicas e as generalizadas (formadas por duas ou mais regras específicas), já que as regras específicas podem apenas ser visualizadas, enquanto que as regras generalizadas podem ser exploradas (Figura 4.26). No item (a) da figura é possível observar as regras específicas e, no item (b), as regras generalizadas e suas opções de exploração (as regras generalizadas são apresentadas com um checkbox). Essas opções permitem ao usuário explorar de maneira detalhada ou geral todas as regras generalizadas ou apenas as regras generalizadas selecionadas (a seleção é feita pelo checkbox de cada regra).

Na exploração detalhada o módulo exibe: o número da regra generalizada; a regra generalizada; os valores de algumas medidas; as regras específicas que deram origem à regra generalizada, com seus respectivos valores de suporte e confiança, entre outros; a contribuição de cada item específico da taxonomia na composição de cada item geral contido na regra generalizada (Figura 4.27). É importante mencionar que é possível se identificar e recuperar as regras específicas que originaram a regra generalizada uma vez que na disponibilização do conjunto generalizado informa-se o conjunto de regras específicas utilizado no processo de generalização e que na sintaxe padrão estendida (Seção 4.3.1, página 52) utilizada para representar regras de associação generalizadas encontram-se os 


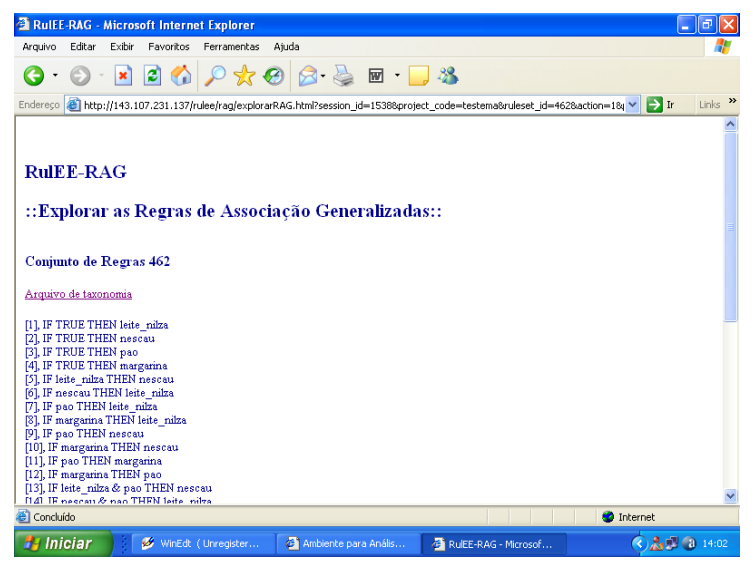

(a) Regras Específicas.

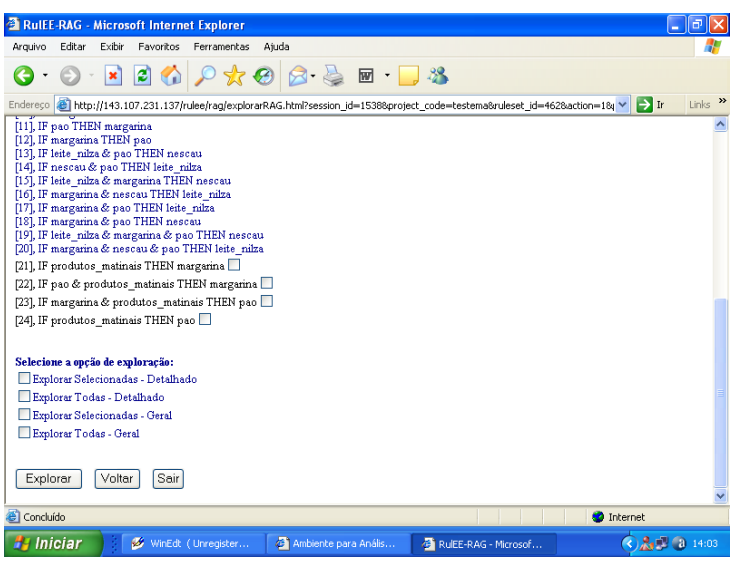

(b) Regras Generalizadas.

Figura 4.26: Exemplo de exibição de um conjunto de regras generalizadas selecionado.

números das regras específicas que deram origem à mesma.

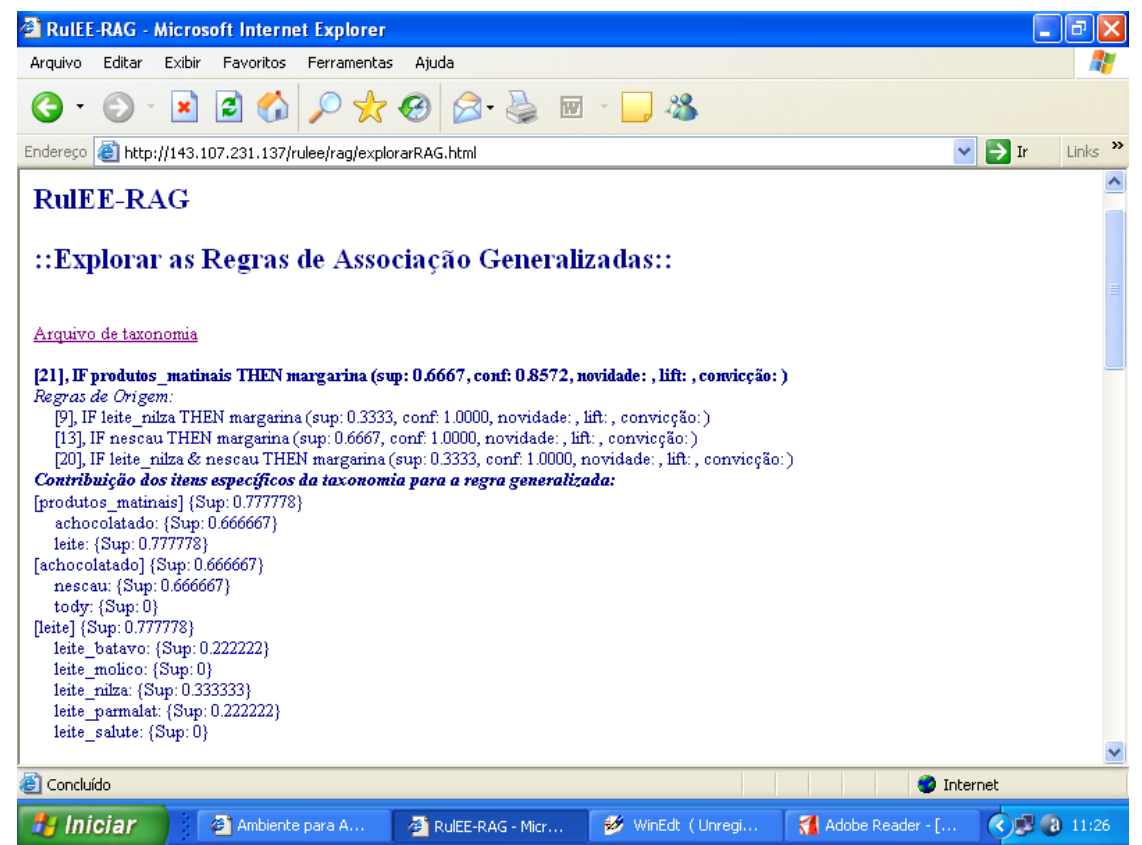

Figura 4.27: Exploração detalhada das regras generalizadas selecionadas.

A diferença entre à exploração detalhada e à geral é que na geral não é exibida a contribuição de itens para cada regra generalizada. Nesse caso, a contribuição é exibida uma única vez no final de cada página para todas as regras exploradas, exibindo os itens generalizados e os itens específicos contidos em todas as regras generalizadas exploradas (Figura 4.28).

Com a utilização da opção de exploração pode-se observar que o módulo RuLEE-RAG auxilia o usuário na visualização da contribuição de cada um dos itens específicos na composição dos itens gerais que compõem cada uma das regras generalizadas. Além disso, 


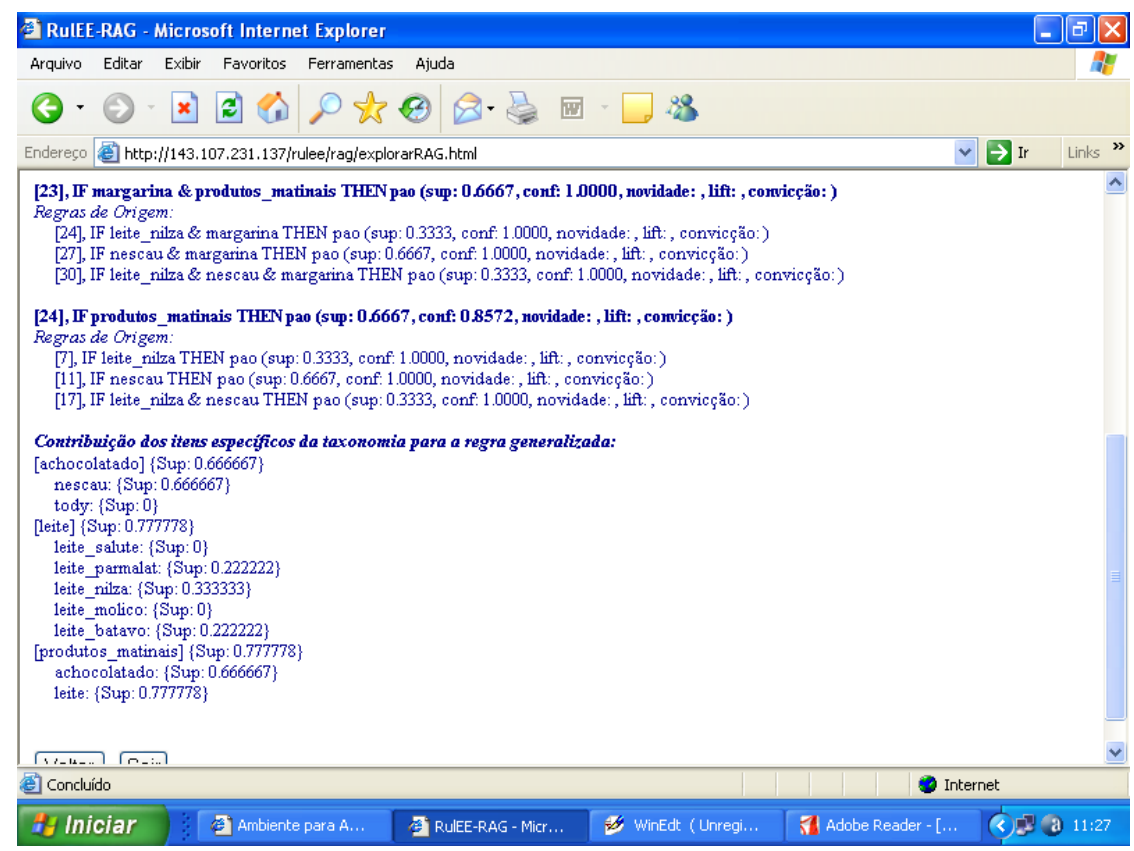

Figura 4.28: Exploração geral das regras generalizadas selecionadas.

através dessa opção, o módulo auxilia o usuário na identificação de regras de exceção. Por exemplo, visualizando a regra [21] da Figura 4.27 nota-se que os itens leite_salute, leite_molico e tody não contribuíram, respectivamente, para a composição dos itens leite e achocolatado e, portanto, representam uma exceção em relação a regra "IF produtos_matinais THEN margarina", ou seja, quem compra qualquer produto matinal, com exceção de leite_salute, leite_molico e tody, também compra margarina.

Ao selecionar a opção de consulta, o usuário cria consultas SQL de forma a selecionar subconjuntos de regras que apresentam determinada característica (Figura 4.29). Por exemplo, na consulta apresentada na Figura 4.29, o usuário tem interesse em visualizar o número da regra, o antecedente e o conseqüente de todas as regras generalizadas que contêm o item "pao" no antecedente. Assim, o módulo permite ao usuário realizar diversos tipos de consultas. Ao executar a consulta, o resultado é exibido e o usuário tem a opção de explorar detalhadamente ou de forma geral as regras resultantes, como na opção de exploração explicada anteriormente.

\subsection{Avaliação Experimental da APRA}

Como mencionado no início desse capítulo, o objetivo da abordagem de pós-processamento de regras de associação $(A P R A)$, proposta neste trabalho, é pós-processar um conjunto de regras de associação de forma a obter um conjunto de regras mais reduzido e representativo. 


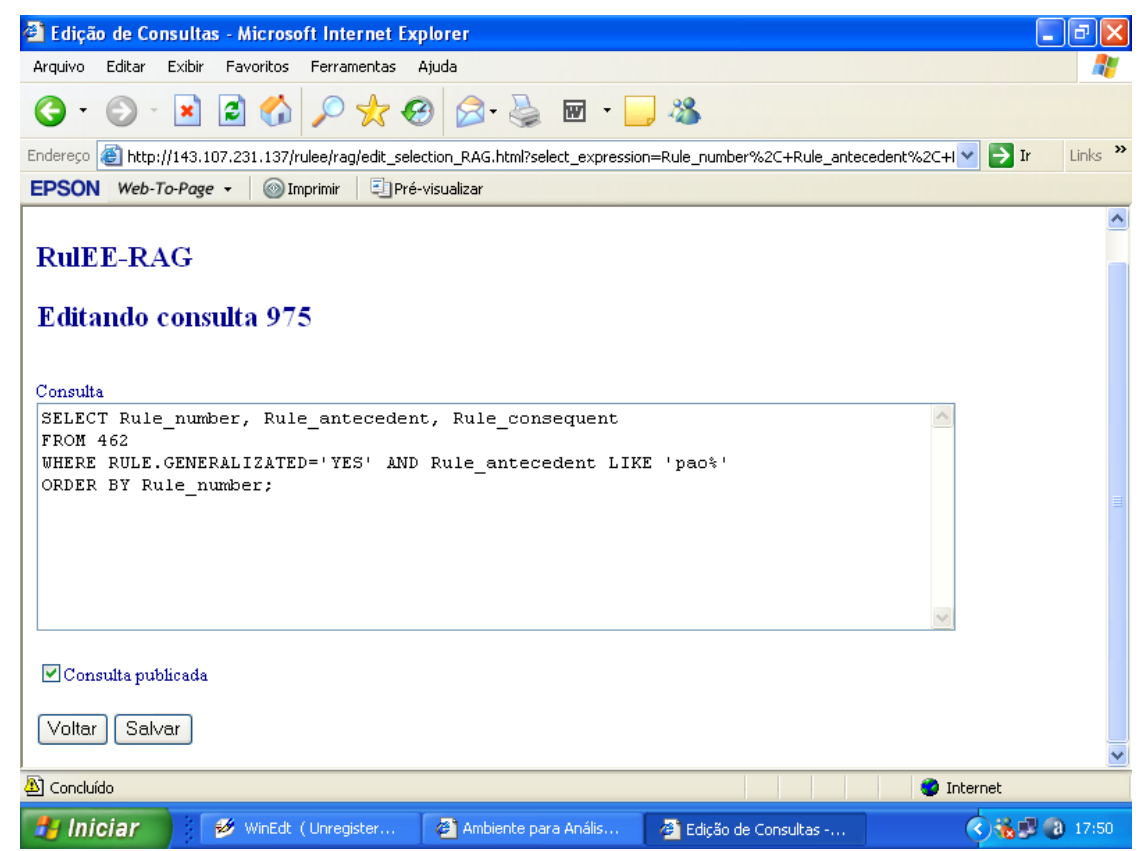

Figura 4.29: Consulta SQL em um conjunto de regras de associação generalizadas.

Para verificar se o processo de pós-processamento via generalização pode reduzir/compactar o volume de regras de um conjunto de regras de associação, comprovando a Hipótese 1 apresentada no Capítulo 1, alguns experimentos foram realizados. Assim, essa seção apresenta os experimentos realizados descrevendo, para tanto, os conjuntos de dados, as taxonomias e as configurações utilizadas no $A P R A_{\text {alg }}$. Em seguida, é feita uma discussão dos resultados obtidos.

\subsubsection{Descrição dos Conjuntos de Dados}

Dois conjuntos de dados foram utilizados na avaliação da abordagem proposta, os quais são descritos a seguir.

Cjto-Sup O primeiro conjunto de dados (Cjto-Supermercado) contém informações referentes a um dia de venda de um supermercado localizado na cidade de São Carlos (SP). O conjunto possui 1716 transações com 1939 itens distintos.

Cjto-R O segundo conjunto de dados encontra-se disponível no Projeto $R$ para Computação Estatística ${ }^{4}$. O conjunto de dados denominado groceries contém informações referentes a um mês de venda de um armazém. O conjunto possui 9835 transações com 169 itens distintos.

\footnotetext{
${ }^{4}$ Disponível para download em http://www.r-project.org/.
} 


\subsubsection{Configuração dos Experimentos}

Para que a abordagem fosse executada via a utilização do $A P R A_{\text {alg }}$, a fim de ser avaliada, era necessário, além dos conjuntos de dados, os conjuntos de regras de associação e os conjuntos de taxonomias. Assim, para ambos os conjuntos de dados, as regras de associação foram obtidas usando uma implementação do algoritmo Apriori realizada por Chistian Borgelt ${ }^{5}$, com suporte mínimo e confiança mínima igual a 0.5 e número máximo de 5 itens por regra. Com os dados do Cjto-Sup foram obtidas 32668 regras e com os dados do Cjto-R foram obtidas 2170 regras.

Em relação às taxonomias, foram construídos 28 conjuntos de taxonomias para o Cjto-Sup e 4 para o Cjto-R. Os 28 conjuntos referentes ao Cjto-Sup estão distribuídos da seguinte maneira: 7 conjuntos contendo taxonomias de apenas 1 nível $(1 \mathrm{~N})$ de generalização (ou abstração), 7 contendo 2 níveis (2N) de generalização, 7 contendo 3 níveis (3N) de generalização e 7 contendo níveis diferentes (ND) de generalização. Os 4 conjuntos referentes ao Cjto-R estão distribuídos da seguinte maneira: 1 conjunto contendo taxonomias de apenas 1 nível $(1 \mathrm{~N})$ de generalização, 1 contendo 2 níveis $(2 \mathrm{~N})$ de generalização, 1 contendo 3 níveis (3N) de generalização e 1 contendo níveis diferentes (ND) de generalização. Os conjuntos de taxonomias referentes ao Cjto-Sup encontram-se no Apêndice B (Figuras B.1 a B.28) e os conjuntos referentes ao Cjto-R no Apêndice C (Figuras C.1 a C.4). Em ambos os apêndices os conjuntos de taxonomias encontram-se no formato utilizado neste trabalho, o qual foi descrito na Seção 4.3.1, página 52. Os conjuntos de taxonomias contidos em cada um dos apêndices foram denominados "tax", adicionado a um número de identificação, seguido da informação referente a quantos níveis de abstração o mesmo possui (1N, $2 \mathrm{~N}, 3 \mathrm{~N}$ e ND), como mostra a Figura 4.30. Por exemplo, o rótulo tax01/1N da figura identifica o primeiro conjunto de taxonomias contendo generalizações de um nível de abstração. É importante mencionar que no caso do Cjto-R apenas 4 conjuntos foram construídos devido ao fato do conjunto de dados já estar "parcialmente" generalizado. Além disso, é importante ressaltar que as taxonomias tax01/2N do Cjto-R (Figura C.2, página 172) e tax01/3N do Cjto-R (Figura C.3, página 173) são consideradas taxonomias de $2 \mathrm{~N}$ e $3 \mathrm{~N}$ por realizarem, respectivamente, algumas abstrações de $1 \mathrm{~N}$ para $2 \mathrm{~N}$ e algumas abstrações de $2 \mathrm{~N}$ para $3 \mathrm{~N}$, embora não possuam todos os itens de $1 \mathrm{~N}$ contidos em algum dos itens de $2 \mathrm{~N}$, como ocorrem com as taxonomias do Cjto-Sup. Isso porque o Cjto-R já se encontrava "parcialmente" generalizado, o que dificultou a criação de generalizações mais gerais do que as já contidas no Cjto-R. Além disso, uma generalização mais detalhada do que a apresentada poderia gerar conhecimentos muitos óbvios.

Considerando então cada um dos conjuntos de taxonomias construídos, o $A P R A_{\text {alg }}$ foi executado em 18 configurações distintas para cada um dos conjuntos de dados. Essas

\footnotetext{
${ }^{5}$ Disponível para download no site http://fuzzy.cs.uni-magdeburg.de/ borgelt/software.html.
} 
CHOCOLATE (CHOCNESTLE, CHOCLACTA) (1).

CREME_DENTAL (CDSORRISO, CDCOLGATE) (1).

REFRIGERANTE (GUARANA_ANTARTICA , FANTA, COCA_COLA) (1).

BISCOITO (BISCNESTLE, BISCNABISCO, BISCPIRAQUE, BISCMARILAN) (1).

DETERGENTE (DETERGYPE, DETERGLIMPOL) (1).

PAPEL_HIGIENICO (PAPEL_HIGNEVE, PAPEL_HIGPERSONAL) (1) .

MACARRAO (NISSIM_L_AMEM, MACRENATA , MACGALO) (1).

LEITE (LEITE_PARMALAT, LEITE_NILZA) (1).

FARINHA_TRIGO (FARTRIGO_RENATA,FARTRIGO_DONA_BENTA) (1).

SABONETE (SABVINOLIA, SABLUX) (1).

AMACIANTE (AMACBABY_SOFT, AMACCOMFORT) (1).

MOLHO_TOMATE (EXTRATO_ELEFANTE_KNORRCICA,MOLHO_TOMATE_CIRIO) (1).

FEIJAO (FEIJAO_GRAO_DO_CAMPO,FEIJAO_TORRESAN , FEIJAO_BROTO_LEGAL) (1).

CALDOS (CALDO_KNORR, CALDO_MAGGI) (1).

PAES_WICKBOLD (PAO_WICKBOLD_LIGHT, PAO_WICKBOLD_FORMA) (1).

IORGUTE (IOGBATAVO, IOGNESTLE, IOGCORPUS) (1)

ACHOCOLATADO (ACHOCTODDY, ACHOCNESCAU) (1).

SUCOS (TANG, SUCO_DEL_VALLE) (1).

GUARDANAPO_PAPEL (GUARDSANTEPEL, GUARDMASCOT) (1).

ABSORVENTE (ABSCAREFREE, ABSSLIVRE) (1).

CATCHUP (CATCHUP_PIC, CATCHUP_HELLMANN_S) (1).

TOALHA_PAPEL (TOALHA_PAPEL_MASCOT, TOALHA_PAPEL_SNOB) (1).

MANTEIGA (MANTEIGA_SAO_CARLOS, MANTEIGA_BATAVO, MANTEIGA_VIGOR) (1).

ELMA_CHIPS (BATATA_RUFFLES,BATATA_PALHA_ELMA_CHIPS) (1).

ACUCAR (ACUCAR_DA_BARRA, ACUCAR_CRISTALCUCAR, ACUCAR_UNIAO) (1).

Figura 4.30: Exemplo de figura apresentada nos Apêndices B e C referente ao conjunto de taxonomias tax01/1N do Cjto-Sup.

configurações são uma variação das opções lado, medida e taxa t\%. Usando a notação lado-medida-t\%, as 18 configurações consideradas nos experimentos foram: (a) lhs-sup-0; (b) rhs-sup-0; (c) lrhs-sup-0; (d) lhs-conf-0; (e) rhs-conf-0; (f) lrhs-conf-0; (g) lhs-sup25; (h) rhs-sup-25; (i) lrhs-sup-25; (j) lhs-conf-25; (k) rhs-conf-25; (l) lrhs-conf-25; (m) lhs-sup-50; (n) rhs-sup-50; (o) lrhs-sup-50; (p) lhs-conf-50; (q) rhs-conf-50; (r) lrhs-conf50. Sendo assim, 504 experimentos foram executados na generalização do conjunto de regras de associação obtido utilizando o Cjto-Sup (18 configurações $\times 28$ conjuntos de taxonomias) e 72 utilizando o Cjto-R (18 configurações $\times 4$ conjuntos de taxonomias). É importante mencionar que os valores 0, 25 e 50, referentes à taxa $t \%$, foram selecionados para representar: $0 \%$ - a ausência de preocupação com a "sobrecarga" do conjunto de regras, uma vez que nesse caso o objetivo é apenas generalizar; $50 \%$ - tanto a preocupação com a "sobrecarga" quanto com o aumento da qualidade do conhecimento expresso na RAG com relação às regras específicas, uma vez que nesse caso o objetivo é obter regras generalizadas que possuam, no mínimo, o dobro do valor da medida $M$, selecionada no processo de generalização, em relação ao valor da medida $M$ em suas regras de origem; 25\%: apenas auxiliar na avaliação da variação da taxa de compactação entre $0 \%$ e 50\%. 


\subsubsection{Avaliação da Taxa de Compactação}

Para cada um dos experimentos realizados, a taxa de compactação foi computada. A taxa de compactação representa a porcentagem de redução no volume de regras utilizadas como entrada do processo de pós-processamento em relação ao volume de regras obtidas pela abordagem proposta. Considere, por exemplo, um dos experimentos utilizando o Cjto-Sup que com a generalização obteve 10827 regras. Como o Cjto-Sup contém 32668 regras (Seção 4.8.2) a taxa de compactação nesse caso foi de $66.86 \%$ (((3266810827)/32668)×100).

As taxas de compactação obtidas em cada uma das 18 configurações de execução realizadas para cada um dos conjuntos de taxonomias encontram-se nos Apêndices D (Figuras D.1 a D.28) e F (Figuras F.1 a F.28) para o Cjto-Sup e nos Apêndices E (Figuras E.1 a E.4) e G (Figuras G.1 a G.4) para o Cjto-R. Enquanto os Apêndices D e E apresentam os resultados obtidos agrupados pela medida utilizada na generalização ( sup e conf), como mostra a Figura 4.31, os Apêndices F e G apresentam os resultados obtidos agrupados pelo lado utilizado na generalização (lhs, rhs e $l r h s$ ), como mostra a Figura 4.32. Em todos esses apêndices os resultados encontram-se identificados pela taxonomia utilizada seguida de seu respectivo nível de abstração (por exemplo, tax01/1N das Figuras 4.31 e 4.32). Além disso, como apresentado nas figuras a seguir, os eixos $x$ de todos os gráficos são identificados pelas configurações utilizadas nos experimentos usando a notação ladomedida-t\% (por exemplo, lhs-sup-0), além do código da taxonomia. Os eixos y dos gráficos indicam a taxa de compactação obtida em uma determinada configuração. Na Figura 4.31, por exemplo, as configurações utilizando a medida sup (Figura 4.31(a)) apresentaram taxas de compactação maiores do que as da medida conf (Figura 4.31(b)); além disso, em relação às configurações da Figura 4.31(a), o lrhs é o que apresenta as melhores taxas de compactação. Na Figura 4.32, por exemplo, as taxas de compactação das configurações referentes ao lhs são maiores quando a medida sup é considerada (Figura 4.32(a)); idem para o lrhs (Figura 4.32(c)). Em relação ao rhs, as taxas de compactação apresentadas são semelhantes, independente da medida considerada (Figura 4.32(b)).

Analisando as figuras dos Apêndices D (Figuras D.1 a D.28) e E (Figuras E.1 a E.4) observou-se que quando a medida suporte (opção sup) é utilizada no processo de generalização, o lado que obtém as melhores taxas de compactação, em todos os casos, é o $l r h s$, seguido do lhs e rhs. É empiricamente lógico que quando a generalização ocorre em ambos os lados o conjunto final de regras será menor, uma vez que o processo de generalização agrupa todas as regras que apresentam o mesmo padrão (estrutura sintática) em um mesmo subconjunto (linha 35 do Algoritmo 2, página 59). Nos casos onde a generalização ocorre em apenas um lado, o lhs sempre apresenta melhores resultados em relação ao rhs com a opção sup pelas seguintes razões: quando a generalização ocorre no 


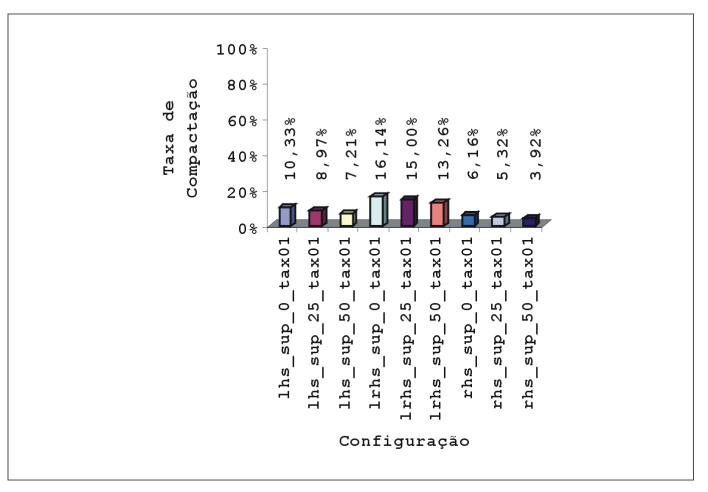

(a) $\sup$

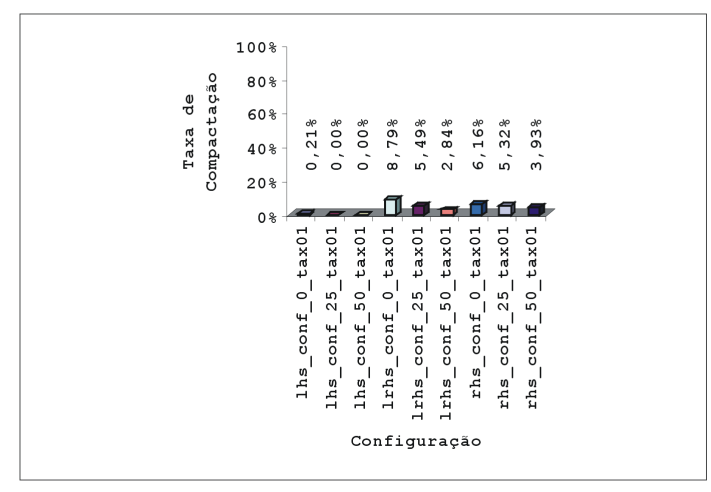

(b) $\operatorname{conf}$

Figura 4.31: Exemplo de figura apresentada nos Apêndices D e E referente aos resultados de compactação utilizando as medidas sup e conf $(\operatorname{tax} 01 / 1 \mathrm{~N})$.

lhs, como mencionado na descrição do Algoritmo 2, as regras são inicialmente agrupadas pelo rhs de forma a gerar subconjuntos compostos por regras que contenham o mesmo conseqüente. Uma vez que os conjuntos de regras de associação utilizados como entrada foram gerados pela versão do Apriori do Chistian Borgelt, as regras contidas nesses conjuntos são compostas por regras que contêm apenas um item no conseqüente. Portanto, quando as regras são inicialmente agrupadas, os subconjuntos obtidos são maiores do que os subconjuntos obtidos quando a generalização ocorre no rhs, uma vez que a probabilidade de se gerar grandes subconjuntos de regras que contenham somente um item idêntico de um lado da regra é maior do que a probabilidade de se gerar grandes subconjuntos de regras que contenham dois ou mais itens idênticos. Sendo assim, quando o processo de generalização se inicia no lhs, os subconjuntos gerados são compostos por muito mais regras, as quais podem ser agrupadas por uma determinada taxonomia de modo a obter uma regra generalizada e, conseqüentemente, obter um conjunto com menos regras.

Ainda em relação aos Apêndices D (Figuras D.1 a D.28) e E (Figuras E.1 a E.4) observou-se que quando a medida confiança (opção conf) é utilizada no processo de generalização, o lado que obtém as melhores taxas de compactação com uma taxa $t$ de $0 \%$ é o $l r h s$, seguido do $r h s$ e $l h s$. Nos casos em que a taxa $t$ de $25 \%$ é utilizada, as taxas de compactação do lrhs e do rhs começam a apresentar resultados muito próximos ou o rhs começa a apresentar taxas de compactação maiores do que o lrhs, embora também muito próximas. O mesmo acontece quando a taxa $t$ de $50 \%$ é utilizada, ou seja, os valores das taxas de compactação do lrhs e rhs ficam muito próximos, embora o rhs comece a apresentar valores maiores do que o lrhs. Nos casos em que a generalização ocorre em apenas um lado, o rhs sempre apresenta melhores resultados do que o $l h s$, ao contrário do que ocorre com a medida suporte (opção sup). Esses comportamentos ocorrem pelas seguintes razões: embora os argumentos acima descritos em relação ao tamanho dos subconjuntos sejam verdadeiros, o que ocorre nesse caso é que quando uma generalização existe, dife- 


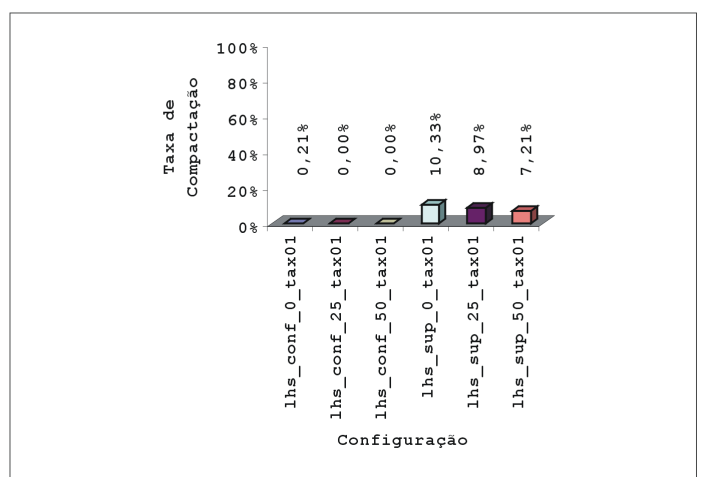

(a) lhs

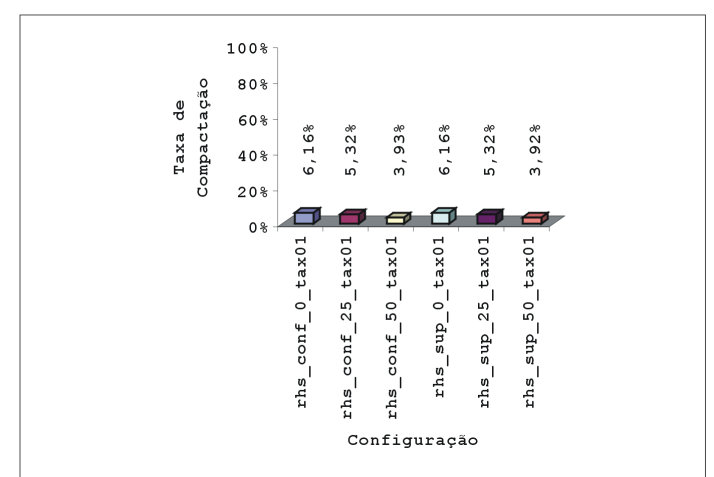

(b) rhs

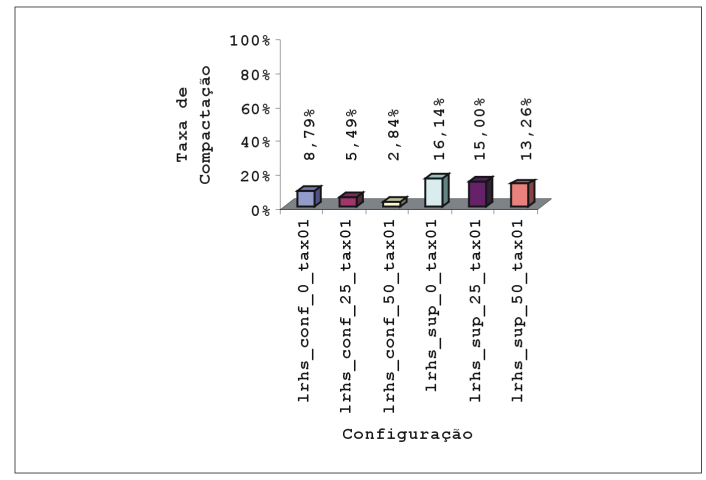

(c) lrhs

Figura 4.32: Exemplo de figura apresentada nos Apêndices F e G referente aos resultados de compactação utilizando os lados lhs, rhs, lrhs (tax01/1N).

rente da medida suporte, a única relação válida existente entre uma regra generalizada e uma regra específica é $\operatorname{conf}(A \Rightarrow \widehat{B}) \geqslant \operatorname{conf}(A \Rightarrow B)$ (Seção 3.2, página 35). Portanto, embora os subconjuntos do lhs contenham mais regras, muitas das generalizações não são realizadas, uma vez que nenhuma das outras relações de confiança pode ocorrer e, conseqüentemente, o critério taxa t\% (linhas 17 e 41 do Algoritmo 2, página 59) acaba não sendo verdadeiro e a tentativa de generalização acaba não acontecendo.

Nos Apêndices F (Figuras F.1 a F.28) e G (Figuras G.1 a G.4) observou-se que as melhores taxas de compactação obtidas para o lrhs e para o lhs foram as utilizando a medida suporte. Além disso, quanto maior é a taxa $t \%$ de generalização, menor é a taxa de compactação obtida, uma vez que o critério taxa t\% (linhas 17 e 41 do Algoritmo 2) acaba não sendo verdadeiro em alguns casos. No caso do rhs, as taxas de compactação obtidas são muito próximas ou iguais em ambas as medidas utilizadas (sup e conf) para cada uma das taxas $t \%$ consideradas $(0 \%, 25 \%$ e $50 \%)$, uma vez que tanto o suporte como a confiança de uma regra generalizada é sempre maior ou igual ao suporte de sua regra específica quando se trata de uma generalização do lado direito ( $r h s$ ) (Seção 3.2, página 35). Em relação à taxa $t \%$ de generalização, o mesmo se verifica com os outros lados mencionados, isto é, quanto maior é a taxa $t \%$ de generalização, menor é a taxa 
de compactação obtida, uma vez que o critério taxa t\% (linhas 17 e 41 do Algoritmo 2) acaba não sendo verdadeiro em alguns casos.

O que se pode observar, com base nos experimentos realizados, é que quando o processo de generalização ocorre no lhs, a medida mais indicada para a redução do conjunto de regras é o suporte; no caso do lrhs a medida mais indicada para a redução do conjunto de regras também é o suporte; no caso do rhs ambas as medidas podem ser utilizadas. Nesse último caso, a seleção da medida fica condicionada ao significado da mesma. Em relação à taxa $t \%$ de generalização, quanto maior for o seu valor, menor será a taxa de compactação. É importante mencionar também que quanto maior for a taxa de compactação, maior deverá ser o número de regras mais abstratas, o que em geral pode levar à obtenção de regras relacionadas ao senso comum.

Por fim, vale destacar que as maiores taxas de compactação obtidas, usando a notação lado-medida-t\%-tax-nível, a qual representa, respectivamente, o lado da generalização (lhs, rhs e lrhs), a medida utilizada (sup e conf), o valor da taxa $t(0 \%, 25 \%$ e $50 \%$ ), a taxonomia e seu respectivo nível de abstração, foram:

Cjto-Sup (a) lhs-sup-0-tax07-3N: taxa de 51.06\%; (b) rhs-sup-0-tax07-3N: taxa de 26.34\% e rhs-conf-0-tax07-3N: taxa de 26.34\% (empate); (c) lrhs-sup-0-tax07-3N: taxa de $66.86 \%$.

Cjto-R (a) lhs-sup-0-tax01-3N: taxa de 23.41\%; (b) rhs-sup-0-tax01-3N: taxa de 19.26\% e rhs-conf-0-tax01-3N: taxa de 19.26\% (empate); (c) lrhs-sup-0-tax01-3N: taxa de $39.03 \%$.

\subsection{Considerações Finais}

Uma das desvantagens da técnica de associação se refere à quantidade de regras e a especificidade do conhecimento gerado. Com o objetivo de se obter um número reduzido de regras que sejam mais gerais/representativas, foi apresentada nesse capítulo uma abordagem de pós-processamento de regras de associação denominada $A P R A$, que utiliza conhecimento de domínio representado via taxonomias para realizar generalizações.

A fim de viabilizar a $A P R A$ foi desenvolvido o algoritmo $A P R A_{\text {alg }}$, o qual foi apresentado de duas maneiras: geral e detalhada. Para um melhor entendimento do algoritmo foram descritos os arquivos de entrada e saída, assim como as funções que o compõem. Ainda nesse capítulo foram listadas as considerações e/ou restrições feitas durante a elaboração da $A P R A$ e do desenvolvimento do $A P R A_{\text {alg }}$ e apresentado um exemplo de execução da $A P R A$ via a utilização do $A P R A_{\text {alg. }}$ Em seguida, foi realizada uma comparação da abordagem proposta com alguns trabalhos existentes na literatura. Por fim, o módulo 
computacional RuLEE-RAG foi descrito.

Com o objetivo de verificar se a utilização de taxonomias de domínio reduz o número de regras contidas em um conjunto de regras de associação, via um processo de generalização, esse capítulo apresentou também uma discussão dos experimentos realizados a partir de dois conjuntos de dados. Para tanto, os conjuntos de dados foram descritos e as configurações utilizadas nos experimentos apresentadas. Como resultado da análise pôdese observar que um conjunto de regras de associação pode ser compactado na presença de um conjunto de taxonomias, validando assim a Hipótese 1 apresentada no Capítulo 1: "é possível utilizar conhecimento de domínio, expresso via taxonomias, para pós-processar um conjunto de regras de associação a fim de obter um conjunto de regras generalizadas que seja compacto e representativo".

A fim de complementar a hipótese acima apresentada, um outro ponto importante que deve ser discutido, além da compactação do modelo gerado, é a representatividade do conhecimento obtido por processos de generalização. Para tanto, o próximo capítulo apresenta um estudo para verificar se uma regra generalizada é mais representativa do que as suas regras específicas em função da semântica da generalização. Para tanto, a representatividade da regra é avaliada via a utilização de todas as medidas de interesse objetivas descritas na descritas na Seção 2.3.4, página 23. 


\section{Capítulo}

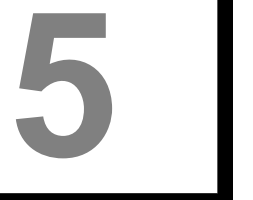

\section{Avaliação do Conhecimento Generalizado via Medidas de Interesse Objetivas}

\subsection{Considerações Iniciais}

O objetivo da $A P R A$, apresentada no Capítulo 4, é obter um conjunto de regras generalizadas que seja compacto e representativo. Como o aspecto referente à compactação do conjunto já foi abordado no Capítulo 4, esse capítulo apresenta alguns estudos referentes à representatividade do conhecimento generalizado.

Como mencionado na Seção 2.3.3 do Capítulo 2 (página 19), existem várias abordagens que auxiliam o usuário a avaliar, interpretar e explorar as regras obtidas, entre elas, as medidas de interesse. As medidas de interesse possuem um papel importante na mineração de dados, uma vez que elas são utilizadas para selecionar e classificar os padrões de acordo com o seu potencial interesse para o usuário (Geng \& Hamilton, 2006).

Diante do exposto, esse capítulo apresenta tanto um estudo empírico quanto analítico a fim de verificar se "a semântica envolvida na generalização especifica o tipo de medida a ser utilizada para avaliar a representatividade do conhecimento generalizado" (Hipótese 2 apresentada no Capítulo 1). É importante mencionar que a semântica depende do lado em que a generalização é realizada: lhs - relação entre categorias/classes de itens e itens específicos; rhs - relação entre itens específicos e categorias/classes de itens; lrhs relação entre categorias/classes de itens. Assim, esse capítulo se apresenta como um outro diferencial em relação aos trabalhos de Adomavicius \& Tuzhilin (2001) e Domingues \& 
Rezende (2005); Domingues (2004), descritos anteriormente.

É importante mencionar que não foram encontrados trabalhos que realizam qualquer tipo de análise da utilização de medidas objetivas em regras generalizadas (como mencionado na Seção 3.2 do Capítulo 3 - página 35). O que se encontrou na literatura são algumas pesquisas (Srikant \& Agrawal, 1995, 1997; Han \& Fu, 1999; Graaf, Kosters, \& Witteman, 2000; Adamo, 2001) que podam todas as regras específicas a menos que elas tenham um comportamento que difira significativamente de suas generalizações. De forma a identificar essa diferença, o usuário deve informar um valor de threshold $\beta$ para saber quantas $\beta$ vezes a regra específica deve ser diferente da regra generalizada. Como o valor de $\beta$ é subjetivo, é difícil aplicar esse tipo de poda. Observe, entretanto, que o propósito dessas metodologias é reduzir o conjunto de regras de associação obtido e não analisar o conhecimento obtido. Além disso, segundo Lui \& Chung (2000), essas metodologias de poda sempre removem as regras específicas, retendo as regras dos níveis mais gerais, o que pode levar a regras correspondentes ao conhecimento já existente.

Esse capítulo encontra-se estruturado da seguinte maneira: na Seção 5.2 são apresentados vários experimentos referentes à representatividade do conhecimento generalizado; na Seção 5.3 são apresentados alguns estudos realizados a fim de embasar os resultados apresentados na Seção 5.2; na Seção 5.4 encontram-se alguns experimentos realizados com especialistas de domínios para complementar os resultados apresentados nas Seções 5.2 e 5.3.

\subsection{Avaliação Empírica do Conhecimento Generalizado Via Medi- das de Interesse Objetivas}

Essa seção apresenta os experimentos realizados a fim de verificar se uma regra generalizada é mais representativa do que as suas regras específicas em função da semântica da generalização. A representatividade da regra é avaliada via a utilização de todas as medidas de interesse objetivas descritas na Seção 2.3.4, página 23, a saber: Added Value, Certainty Factor, Collective Strength, Confidence (Confiança), Conviction, IS/Cosine, $\phi$-coefficient, Gini Index, J-Measure, Jaccard, Kappa, Klosgen, Goodman-Kruskal's $(\lambda)$, Laplace, Interest Factor, Mutual Information, Piatetsky-Shapiro's, Support (Suporte), Odds Ratio, Yule's $Q$ e Yule's $Y$.

Para facilitar o entendimento da avaliação realizada através dos experimentos apresentados na Seção 5.2.1 considere, como exemplo, que a regra generalizada "IF pao THEN leite" tenha sido gerada pelas regras específicas "IF pao THEN leite_a", "IF pao THEN leite_b" e "IF pao THEN leite_c". Considere também que os valores de todas as medidas objetivas utilizadas neste trabalho estejam calculadas tanto para a regra generalizada 
quanto para as regras específicas. Para cada uma das medidas consideradas é feita uma contagem para identificar a proporção de vezes (porcentagem) com que uma regra generalizada obtém um valor maior ou igual ao valor das suas regras específicas. Considerando, por exemplo, as regras acima apresentadas, se a regra "IF pao THEN leite" tivesse um valor de 0.65 para uma determinada medida e as regras "IF pao THEN leite_a", "IF pao THEN leite_b" e "IF pao THEN leite_c" os valores 0.53, 0.63 e 0.77, respectivamente, para a mesma medida, a porcentagem seria de $66.67 \%$ (2/3 - num total de três regras específicas, duas delas contêm um valor menor em relação ao valor da regra generalizada).

Essa contagem é realizada para cada regra generalizada contida em conjuntos de regras obtidos pelo $A P R A_{a l g}$ e os resultados convertidos em histogramas como o da Figura 5.1 ${ }^{1}$. O eixo $x$ do histograma representa os intervalos (classes) que variam, nesse caso, de 0.0 $(0 \%)$ a $1.0(100 \%)$. Esses intervalos indicam a proporção de vezes que uma regra generalizada contém valores maiores ou iguais ao das suas regras específicas. Por exemplo, um intervalo de 0.5 a 0.6 indica que uma regra generalizada contém, em $50 \%$ a $60 \%$ dos casos, valores maiores ou iguais ao das suas regras específicas. O eixo y do histograma representa a porcentagem de regras generalizadas pertencentes a um determinado intervalo. Na Figura 5.1(b), por exemplo, 98.39\% das regras generalizadas contidas no conjunto rhs-sup-0-tax 07-1N pertencem ao intervalo 0.9-1.0, indicando que na maioria dos casos $(98.39 \%)$ as regras generalizadas mantiveram ou aumentaram seu valor em relação a quase todas as suas regras específicas (90\% a 100\%).

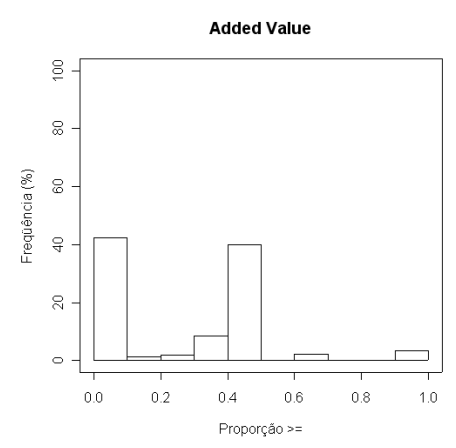

(a) lhs-sup-0-tax07-1N

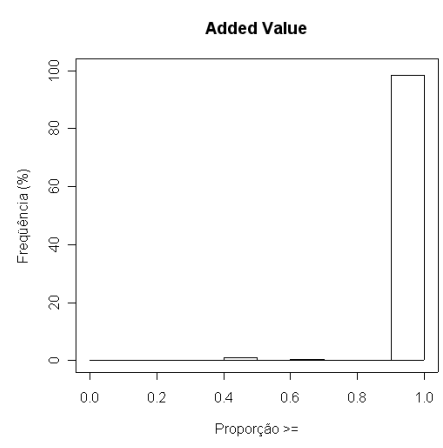

(b) rhs-sup-0-tax07-1N

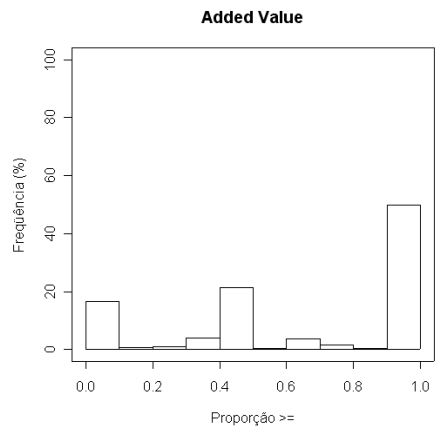

(c) lrhs-sup-0-tax07-1N

Figura 5.1: Exemplo de um histograma referente à medida Added Value utilizando os conjuntos lhs-sup-0-tax07-1N, rhs-sup-0-tax07-1N e lrhs-sup-0-tax07-1N.

Com base na descrição acima apresentada, a qual fornece uma visão geral do processo utilizado para avaliar a representatividade das regras generalizadas, experimentos foram realizados, os quais são descritos a seguir.

\footnotetext{
${ }^{1}$ Para realizar essa contagem foi desenvolvido um Script cuja saída foi utilizada no software R (http: //www.r-project.org/) para geração dos histogramas.
} 


\subsubsection{Experimentos}

Para a realização dos experimentos referentes à representatividade de regras generalizadas foram selecionados, para cada conjunto de dados, 12 conjuntos de regras. Esses conjuntos foram selecionados da seguinte maneira: para cada nível de abstração e, para cada um dos lados considerados, procurou-se qual foi a configuração que apresentou a maior taxa de compactação dos conjuntos de regras utilizados nos experimentos da Seção 4.8 (504 referentes ao Cjto-Sup e 72 referentes ao Cjto-R (dados apresentados na Seção 4.8.2, página 84). Usando a notação lado-medida-t\%-tax-nível, a qual representa, respectivamente, o lado da generalização (lhs, rhs e lrhs), a medida utilizada (sup e conf), o valor da taxa $t(0 \%, 25 \%$ e $50 \%)$, a taxonomia e seu respectivo nível de abstração, os conjuntos selecionados em cada conjunto de dados encontram-se nas Tabelas 5.1 e 5.2. Observe que ambas as tabelas apresentam tanto a configuração selecionada como a taxa de compactação obtida na configuração. É importante mencionar que para as configurações utilizando o rhs as taxas obtidas tanto pela medida suporte (sup) como pela medida confiança (conf) apresentaram as mesmas taxas de compactação (como apresentado na Seção 4.8.3, página 86). Nesse caso, optou-se por deixar a seleção pela medida suporte apenas para se ter uma padronização, já que todos os outros conjuntos selecionados usam a medida suporte. Os histogramas obtidos para os conjuntos selecionados, utilizando cada uma das medidas descritas na Seção 2.3.4, página 23, encontram-se nos Apêndices H (Figuras H.1 a H.21) e I (Figuras I.1 a I.21).

Tabela 5.1: Conjuntos de regras selecionados do Cjto-Sup a serem avaliados quanto ao conhecimento obtido.

\begin{tabular}{|c|c|}
\hline Configuração & Taxa de Compactação \\
\hline lhs-sup-0-tax07-1N & $14.63 \%$ \\
\hline rhs-sup-0-tax07-1N & $9.08 \%$ \\
\hline lrhs-sup-0-tax07-1N & $23.11 \%$ \\
\hline lhs-sup-0-tax05-2N & $36.88 \%$ \\
\hline rhs-sup-0-tax05-2N & $18.88 \%$ \\
\hline lrhs-sup-0-tax05-2N & $50.57 \%$ \\
\hline lhs-sup-0-tax07-3N & $51.06 \%$ \\
\hline rhs-sup-0-tax07-3N & $26.34 \%$ \\
\hline lrhs-sup-0-tax07-3N & $66.86 \%$ \\
\hline lhs-sup-0-tax07-ND & $41.11 \%$ \\
\hline rhs-sup-0-tax07-ND & $19.84 \%$ \\
\hline lrhs-sup-0-tax07-ND & $56.58 \%$ \\
\hline
\end{tabular}

Para sintetizar os resultados apresentados nos histogramas obtidos, a Tabela 5.3 foi gerada com base na porcentagem de regras pertencentes ao intervalo 0.9-1.0 considerando cada medida e cada um dos 12 conjuntos de regras generalizadas relacionados a cada conjunto de dados. É importante ressaltar que esse intervalo indica que uma regra generalizada contém, em $90 \%$ a 100\% dos casos, valores maiores ou iguais ao das suas regras específicas. Essa porcentagem indica que, por exemplo, em 3.33\% dos casos no Cjto-Sup, usando a opção lhs (relação entre categorias/classes de itens e itens específicos) e a me- 
Tabela 5.2: Conjuntos de regras selecionados do Cjto- $\mathrm{R}$ a serem avaliados quanto ao conhecimento obtido.

\begin{tabular}{|c|c|}
\hline Configuração & Taxa de Compactação \\
\hline lhs-sup-0-tax01-1N & $21.61 \%$ \\
\hline rhs-sup-0-tax01-1N & $17.79 \%$ \\
\hline lrhs-sup-0-tax01-1N & $36.50 \%$ \\
\hline lhs-sup-0-tax01-2N & $21.71 \%$ \\
\hline rhs-sup-0-tax01-2N & $17.74 \%$ \\
\hline lrhs-sup-0-tax01-2N & $36.45 \%$ \\
\hline lhs-sup-0-tax01-3N & $23.41 \%$ \\
\hline rhs-sup-0-tax01-3N & $19.26 \%$ \\
\hline lrhs-sup-0-tax01-3N & $39.03 \%$ \\
\hline lhs-sup-0-tax01-ND & $22.58 \%$ \\
\hline rhs-sup-0-tax01-ND & $18.62 \%$ \\
\hline lrhs-sup-0-tax01-ND & $37.79 \%$ \\
\hline
\end{tabular}

dida Added Value, as regras generalizadas obtiveram, no intervalo 0.9-1.0, um valor maior ou igual ao valor das suas regras específicas (Tabela 5.3). Observe que nessa tabela cada um dos conjuntos selecionados está identificado pelo lado utilizado na generalização e pelo nível de abstração do conjunto de taxonomias. Por exemplo, o conjunto lhs-sup-0-tax07$1 N$ do Cjto-Sup é identificado pelo nível $1 \mathrm{~N}$ e pelo lado $l h s$.

Tabela 5.3: Porcentagem de regras generalizadas pertencentes ao intervalo 0.9-1.0 considerando cada medida e cada conjunto generalizado.

\begin{tabular}{|c|c|c|c|c|c|}
\hline Medida & Conjunto Dado & Nível Taxonomia & lhs & rhs & lrhs \\
\hline \multirow[t]{4}{*}{ Added Value } & \multirow[t]{4}{*}{ Cjto-Sup } & $1 \mathrm{~N}$ & $3.33 \%$ & $98.39 \%$ & $49.84 \%$ \\
\hline & & $2 \mathrm{~N}$ & $1.22 \%$ & $97.27 \%$ & $37.63 \%$ \\
\hline & & $3 \mathrm{~N}$ & $0.77 \%$ & $82.01 \%$ & $30.59 \%$ \\
\hline & & $\mathrm{ND}$ & $2.18 \%$ & $78.49 \%$ & $29.94 \%$ \\
\hline \multirow[t]{4}{*}{ Added Value } & \multirow[t]{4}{*}{ Cjto-R } & $1 \mathrm{~N}$ & $2.07 \%$ & $77.10 \%$ & $33.33 \%$ \\
\hline & & $2 \mathrm{~N}$ & $2.02 \%$ & $84.47 \%$ & $38.11 \%$ \\
\hline & & $3 \mathrm{~N}$ & $2.12 \%$ & $83.25 \%$ & $35.95 \%$ \\
\hline & & ND & $1.99 \%$ & $84.82 \%$ & $37.12 \%$ \\
\hline \multirow[t]{4}{*}{ Certainty Factor } & \multirow[t]{4}{*}{ Cjto-Sup } & $1 \mathrm{~N}$ & $3.39 \%$ & $99.63 \%$ & $54.60 \%$ \\
\hline & & $2 \mathrm{~N}$ & $1.24 \%$ & $99.85 \%$ & $44.98 \%$ \\
\hline & & $3 \mathrm{~N}$ & $0.77 \%$ & $99.86 \%$ & $51.22 \%$ \\
\hline & & ND & $2.18 \%$ & $99.83 \%$ & $50.15 \%$ \\
\hline \multirow[t]{4}{*}{ Certainty Factor } & \multirow[t]{4}{*}{ Cjto-R } & $1 \mathrm{~N}$ & $2.07 \%$ & $92.06 \%$ & $45.37 \%$ \\
\hline & & $2 \mathrm{~N}$ & $2.02 \%$ & $93.15 \%$ & $50.61 \%$ \\
\hline & & $3 \mathrm{~N}$ & $2.12 \%$ & $94.26 \%$ & $50.65 \%$ \\
\hline & & ND & $1.99 \%$ & $93.30 \%$ & $50.00 \%$ \\
\hline \multirow[t]{4}{*}{ Collective Strength } & \multirow[t]{4}{*}{ Cjto-Sup } & $1 \mathrm{~N}$ & $89.88 \%$ & $59.08 \%$ & $89.20 \%$ \\
\hline & & $2 \mathrm{~N}$ & $81.83 \%$ & $16.36 \%$ & $64.28 \%$ \\
\hline & & $3 \mathrm{~N}$ & $75.32 \%$ & $9.76 \%$ & $55.93 \%$ \\
\hline & & ND & $80.51 \%$ & $29.44 \%$ & $65.75 \%$ \\
\hline \multirow[t]{4}{*}{ Collective Strength } & \multirow[t]{4}{*}{ Cjto-R } & $1 \mathrm{~N}$ & $72.73 \%$ & $52.80 \%$ & $68.21 \%$ \\
\hline & & $2 \mathrm{~N}$ & $73.28 \%$ & $54.79 \%$ & $73.48 \%$ \\
\hline & & $3 \mathrm{~N}$ & $72.46 \%$ & $53.11 \%$ & $72.22 \%$ \\
\hline & & ND & $73.31 \%$ & $55.36 \%$ & $73.93 \%$ \\
\hline & & & cont & na próx & a página \\
\hline
\end{tabular}




\begin{tabular}{|c|c|c|c|c|c|}
\hline \multicolumn{6}{|c|}{ continuação da página anterior } \\
\hline Medida & Conjunto Dado & Nível Taxonomia & lhs & rhs & lrhs \\
\hline \multirow{4}{*}{ Confiança } & \multirow{4}{*}{ Cjto-Sup } & $1 \mathrm{~N}$ & $3.39 \%$ & $100 \%$ & $57.82 \%$ \\
\hline & & $2 \mathrm{~N}$ & $1.24 \%$ & $100 \%$ & $47.40 \%$ \\
\hline & & $3 \mathrm{~N}$ & $0.77 \%$ & $100 \%$ & $53.56 \%$ \\
\hline & & ND & $2.18 \%$ & $100 \%$ & $52.73 \%$ \\
\hline \multirow[t]{4}{*}{ Confiança } & \multirow[t]{4}{*}{ Cjto-R } & $1 \mathrm{~N}$ & $2.07 \%$ & $100 \%$ & $59.57 \%$ \\
\hline & & $2 \mathrm{~N}$ & $2.02 \%$ & $100 \%$ & $60.06 \%$ \\
\hline & & $3 \mathrm{~N}$ & $2.12 \%$ & $100 \%$ & $59.48 \%$ \\
\hline & & ND & $1.99 \%$ & $100 \%$ & $59.20 \%$ \\
\hline \multirow[t]{4}{*}{ Conviction } & \multirow[t]{4}{*}{ Cjto-Sup } & $1 \mathrm{~N}$ & $3.39 \%$ & $99.63 \%$ & $54.60 \%$ \\
\hline & & $2 \mathrm{~N}$ & $1.24 \%$ & $99.85 \%$ & $44.98 \%$ \\
\hline & & $3 \mathrm{~N}$ & $0.77 \%$ & $99.86 \%$ & $51.22 \%$ \\
\hline & & ND & $2.18 \%$ & $99.83 \%$ & $50.15 \%$ \\
\hline \multirow[t]{4}{*}{ Conviction } & \multirow[t]{4}{*}{ Cjto-R } & $1 \mathrm{~N}$ & $2.07 \%$ & $92.06 \%$ & $45.37 \%$ \\
\hline & & $2 \mathrm{~N}$ & $2.02 \%$ & $93.15 \%$ & $50.61 \%$ \\
\hline & & $3 \mathrm{~N}$ & $2.12 \%$ & $94.26 \%$ & $50.65 \%$ \\
\hline & & ND & $1.99 \%$ & $93.30 \%$ & $50.00 \%$ \\
\hline \multirow[t]{4}{*}{ IS/Cosine } & \multirow[t]{4}{*}{ Cjto-Sup } & $1 \mathrm{~N}$ & $95.87 \%$ & $88.14 \%$ & $96.81 \%$ \\
\hline & & $2 \mathrm{~N}$ & $88.08 \%$ & $49.73 \%$ & $79.67 \%$ \\
\hline & & $3 \mathrm{~N}$ & $81.59 \%$ & $37.65 \%$ & $70.58 \%$ \\
\hline & & ND & $83.58 \%$ & $50.49 \%$ & $74.02 \%$ \\
\hline \multirow[t]{4}{*}{ IS/Cosine } & \multirow[t]{4}{*}{ Cjto-R } & $1 \mathrm{~N}$ & $98.76 \%$ & $97.20 \%$ & $99.38 \%$ \\
\hline & & $2 \mathrm{~N}$ & $99.60 \%$ & $99.09 \%$ & $99.39 \%$ \\
\hline & & $3 \mathrm{~N}$ & $100 \%$ & $99.52 \%$ & $100 \%$ \\
\hline & & ND & $99.60 \%$ & $99.11 \%$ & $99.39 \%$ \\
\hline \multirow[t]{4}{*}{$\phi$-coefficient } & \multirow[t]{4}{*}{ Cjto-Sup } & $1 \mathrm{~N}$ & $89.98 \%$ & $78.67 \%$ & $92.32 \%$ \\
\hline & & $2 \mathrm{~N}$ & $77.09 \%$ & $37.23 \%$ & $69.09 \%$ \\
\hline & & $3 \mathrm{~N}$ & $67.71 \%$ & $24.80 \%$ & $55.73 \%$ \\
\hline & & ND & $72.22 \%$ & $40.83 \%$ & $62.37 \%$ \\
\hline \multirow[t]{4}{*}{$\phi$-coefficient } & \multirow[t]{4}{*}{ Cjto-R } & $1 \mathrm{~N}$ & $71.90 \%$ & $67.76 \%$ & $62.65 \%$ \\
\hline & & $2 \mathrm{~N}$ & $73.28 \%$ & $72.60 \%$ & $72.87 \%$ \\
\hline & & $3 \mathrm{~N}$ & $72.88 \%$ & $71.29 \%$ & $71.24 \%$ \\
\hline & & ND & $72.91 \%$ & $72.32 \%$ & $72.09 \%$ \\
\hline \multirow[t]{4}{*}{ Gini Index } & \multirow[t]{4}{*}{ Cjto-Sup } & $1 \mathrm{~N}$ & $90.77 \%$ & $98.44 \%$ & $97.77 \%$ \\
\hline & & $2 \mathrm{~N}$ & $77.73 \%$ & $97.58 \%$ & $89.02 \%$ \\
\hline & & $3 \mathrm{~N}$ & $68.77 \%$ & $82.08 \%$ & $78.05 \%$ \\
\hline & & ND & $73.06 \%$ & $78.57 \%$ & $80.04 \%$ \\
\hline Gini Index & Cjto-R & $1 \mathrm{~N}$ & $73.97 \%$ & $78.97 \%$ & $72.84 \%$ \\
\hline & & $2 \mathrm{~N}$ & $75.71 \%$ & $87.21 \%$ & $82.01 \%$ \\
\hline & & $3 \mathrm{~N}$ & $75.00 \%$ & $85.65 \%$ & $79.74 \%$ \\
\hline & & ND & $75.70 \%$ & $87.50 \%$ & $81.60 \%$ \\
\hline J-Measure & Cjto-Sup & $1 \mathrm{~N}$ & $93.95 \%$ & $93.33 \%$ & $97.58 \%$ \\
\hline & & $2 \mathrm{~N}$ & $86.63 \%$ & $81.63 \%$ & $89.81 \%$ \\
\hline & & $3 \mathrm{~N}$ & $79.70 \%$ & $68.04 \%$ & $78.99 \%$ \\
\hline & & ND & $81.67 \%$ & $64.45 \%$ & $80.12 \%$ \\
\hline J-Measure & Cjto-R & $1 \mathrm{~N}$ & $71.49 \%$ & $71.96 \%$ & $64.51 \%$ \\
\hline & & $2 \mathrm{~N}$ & $72.87 \%$ & $78.08 \%$ & $73.78 \%$ \\
\hline & & $3 \mathrm{~N}$ & $71.61 \%$ & $77.03 \%$ & $72.22 \%$ \\
\hline & & ND & $72.51 \%$ & $78.13 \%$ & $73.31 \%$ \\
\hline Jaccard & Cjto-Sup & $1 \mathrm{~N}$ & $90.74 \%$ & $56.83 \%$ & $89.55 \%$ \\
\hline & & $2 \mathrm{~N}$ & $83.26 \%$ & $15.95 \%$ & $65.05 \%$ \\
\hline & & $3 \mathrm{~N}$ & $76.81 \%$ & $8.82 \%$ & $56.46 \%$ \\
\hline & & ND & $82.03 \%$ & $26.91 \%$ & $66.09 \%$ \\
\hline
\end{tabular}




\begin{tabular}{|c|c|c|c|c|c|}
\hline \multicolumn{6}{|c|}{ continuação da página anterior } \\
\hline Medida & Conjunto Dado & Nível Taxonomia & lhs & rhs & lrhs \\
\hline \multirow[t]{4}{*}{ Jaccard } & \multirow[t]{4}{*}{ Cjto-R } & $1 \mathrm{~N}$ & $83.06 \%$ & $58.41 \%$ & $80.86 \%$ \\
\hline & & $2 \mathrm{~N}$ & $83.00 \%$ & $58.90 \%$ & $83.84 \%$ \\
\hline & & $3 \mathrm{~N}$ & $82.63 \%$ & $57.42 \%$ & $82.03 \%$ \\
\hline & & ND & $83.27 \%$ & $59.82 \%$ & $83.74 \%$ \\
\hline \multirow[t]{4}{*}{ Kappa } & \multirow[t]{4}{*}{ Cjto-Sup } & $1 \mathrm{~N}$ & $86.86 \%$ & $48.60 \%$ & $84.78 \%$ \\
\hline & & $2 \mathrm{~N}$ & $78.93 \%$ & $11.97 \%$ & $58.70 \%$ \\
\hline & & $3 \mathrm{~N}$ & $71.80 \%$ & $6.36 \%$ & $48.87 \%$ \\
\hline & & ND & $77.59 \%$ & $23.24 \%$ & $59.23 \%$ \\
\hline \multirow[t]{4}{*}{ Kappa } & \multirow[t]{4}{*}{ Cjto-R } & $1 \mathrm{~N}$ & $62.40 \%$ & $33.64 \%$ & $47.84 \%$ \\
\hline & & $2 \mathrm{~N}$ & $62.35 \%$ & $32.88 \%$ & $52.74 \%$ \\
\hline & & $3 \mathrm{~N}$ & $60.59 \%$ & $29.67 \%$ & $50.65 \%$ \\
\hline & & ND & $62.15 \%$ & $33.48 \%$ & $53.37 \%$ \\
\hline \multirow[t]{4}{*}{ Klosgen } & \multirow[t]{4}{*}{ Cjto-Sup } & $1 \mathrm{~N}$ & $71.00 \%$ & $99.31 \%$ & $91.45 \%$ \\
\hline & & $2 \mathrm{~N}$ & $42.74 \%$ & $99.20 \%$ & $74.35 \%$ \\
\hline & & $3 \mathrm{~N}$ & $33.44 \%$ & $92.46 \%$ & $68.59 \%$ \\
\hline & & ND & $45.01 \%$ & $90.89 \%$ & $73.67 \%$ \\
\hline \multirow[t]{4}{*}{ Klosgen } & \multirow[t]{4}{*}{ Cjto-R } & $1 \mathrm{~N}$ & $58.68 \%$ & $85.98 \%$ & $70.68 \%$ \\
\hline & & $2 \mathrm{~N}$ & $61.13 \%$ & $91.78 \%$ & $77.44 \%$ \\
\hline & & $3 \mathrm{~N}$ & $61.02 \%$ & $90.43 \%$ & $76.47 \%$ \\
\hline & & ND & $60.56 \%$ & $91.96 \%$ & $76.69 \%$ \\
\hline \multirow[t]{4}{*}{ Goodman-Kruskal's } & \multirow[t]{4}{*}{ Cjto-Sup } & $1 \mathrm{~N}$ & $72.62 \%$ & $97.24 \%$ & $87.51 \%$ \\
\hline & & $2 \mathrm{~N}$ & $59.28 \%$ & $90.53 \%$ & $78.86 \%$ \\
\hline & & $3 \mathrm{~N}$ & $56.71 \%$ & $77.08 \%$ & $72.02 \%$ \\
\hline & & ND & $59.11 \%$ & $75.03 \%$ & $68.97 \%$ \\
\hline \multirow[t]{4}{*}{ Goodman-Kruskal's } & \multirow[t]{4}{*}{ Cjto-R } & $1 \mathrm{~N}$ & $94.21 \%$ & $99.07 \%$ & $93.52 \%$ \\
\hline & & $2 \mathrm{~N}$ & $94.33 \%$ & $100 \%$ & $99.39 \%$ \\
\hline & & $3 \mathrm{~N}$ & $94.07 \%$ & $99.52 \%$ & $99.02 \%$ \\
\hline & & ND & $94.02 \%$ & $100 \%$ & $99.08 \%$ \\
\hline \multirow[t]{4}{*}{ Laplace } & \multirow[t]{4}{*}{ Cjto-Sup } & $1 \mathrm{~N}$ & $3.76 \%$ & $100 \%$ & $58.50 \%$ \\
\hline & & $2 \mathrm{~N}$ & $1.53 \%$ & $100 \%$ & $49.23 \%$ \\
\hline & & $3 \mathrm{~N}$ & $0.86 \%$ & $100 \%$ & $54.91 \%$ \\
\hline & & ND & $2.32 \%$ & $100 \%$ & $53.87 \%$ \\
\hline \multirow[t]{4}{*}{ Laplace } & \multirow[t]{4}{*}{ Cjto-R } & $1 \mathrm{~N}$ & $1.65 \%$ & $100 \%$ & $58.95 \%$ \\
\hline & & $2 \mathrm{~N}$ & $1.62 \%$ & $100 \%$ & $59.45 \%$ \\
\hline & & $3 \mathrm{~N}$ & $1.69 \%$ & $100 \%$ & $58.82 \%$ \\
\hline & & ND & $1.59 \%$ & $100 \%$ & $58.59 \%$ \\
\hline Interest Factor & Cjto-Sup & $1 \mathrm{~N}$ & $3.33 \%$ & $3.59 \%$ & $2.30 \%$ \\
\hline & & $2 \mathrm{~N}$ & $1.22 \%$ & $0.61 \%$ & $0.49 \%$ \\
\hline & & $3 \mathrm{~N}$ & $0.77 \%$ & $0.31 \%$ & $0.50 \%$ \\
\hline & & ND & $2.18 \%$ & $2.95 \%$ & $1.69 \%$ \\
\hline Interest Factor & Cjto-R & $1 \mathrm{~N}$ & $2.07 \%$ & $1.87 \%$ & $1.23 \%$ \\
\hline & & $2 \mathrm{~N}$ & $2.02 \%$ & $1.83 \%$ & $1.22 \%$ \\
\hline & & $3 \mathrm{~N}$ & $2.12 \%$ & $1.91 \%$ & $1.31 \%$ \\
\hline & & ND & $1.99 \%$ & $1.79 \%$ & $1.23 \%$ \\
\hline Mutual Information & Cjto-Sup & $1 \mathrm{~N}$ & $96.45 \%$ & $37.43 \%$ & $82.10 \%$ \\
\hline & & $2 \mathrm{~N}$ & $92.04 \%$ & $10.00 \%$ & $66.33 \%$ \\
\hline & & $3 \mathrm{~N}$ & $87.95 \%$ & $6.46 \%$ & $58.48 \%$ \\
\hline & & ND & $88.41 \%$ & $22.10 \%$ & $64.11 \%$ \\
\hline Mutual Information & Cjto-R & $1 \mathrm{~N}$ & $75.21 \%$ & $35.51 \%$ & $53.40 \%$ \\
\hline & & $2 \mathrm{~N}$ & $76.92 \%$ & $38.81 \%$ & $63.11 \%$ \\
\hline & & $3 \mathrm{~N}$ & $76.69 \%$ & $39.23 \%$ & $62.42 \%$ \\
\hline & & ND & $76.89 \%$ & $37.95 \%$ & $62.58 \%$ \\
\hline
\end{tabular}




\begin{tabular}{|c|c|c|c|c|c|}
\hline \multicolumn{6}{|c|}{ continuação da página anterior } \\
\hline Medida & Conjunto Dado & Nível Taxonomia & lhs & rhs & lrhs \\
\hline \multirow[t]{4}{*}{ Piatetsky-Shapiro's } & \multirow[t]{4}{*}{ Cjto-Sup } & $1 \mathrm{~N}$ & $99.66 \%$ & $98.57 \%$ & $99.69 \%$ \\
\hline & & $2 \mathrm{~N}$ & $99.84 \%$ & $97.73 \%$ & $99.60 \%$ \\
\hline & & $3 \mathrm{~N}$ & $98.94 \%$ & $82.67 \%$ & $94.55 \%$ \\
\hline & & ND & $98.84 \%$ & $79.21 \%$ & $93.98 \%$ \\
\hline \multirow[t]{4}{*}{ Piatetsky-Shapiro's } & \multirow[t]{4}{*}{ Cjto-R } & $1 \mathrm{~N}$ & $84.71 \%$ & $77.10 \%$ & $80.86 \%$ \\
\hline & & $2 \mathrm{~N}$ & $87.45 \%$ & $84.93 \%$ & $87.20 \%$ \\
\hline & & $3 \mathrm{~N}$ & $86.86 \%$ & $83.73 \%$ & $85.29 \%$ \\
\hline & & ND & $87.65 \%$ & $85.27 \%$ & $87.12 \%$ \\
\hline \multirow[t]{4}{*}{ Suporte } & \multirow[t]{4}{*}{ Cjto-Sup } & $1 \mathrm{~N}$ & $100 \%$ & $100 \%$ & $100 \%$ \\
\hline & & $2 \mathrm{~N}$ & $100 \%$ & $100 \%$ & $100 \%$ \\
\hline & & $3 \mathrm{~N}$ & $100 \%$ & $100 \%$ & $100 \%$ \\
\hline & & ND & $100 \%$ & $100 \%$ & $100 \%$ \\
\hline \multirow[t]{4}{*}{ Suporte } & \multirow[t]{4}{*}{ Cjto-R } & $1 \mathrm{~N}$ & $100 \%$ & $100 \%$ & $100 \%$ \\
\hline & & $2 \mathrm{~N}$ & $100 \%$ & $100 \%$ & $100 \%$ \\
\hline & & $3 \mathrm{~N}$ & $100 \%$ & $100 \%$ & $100 \%$ \\
\hline & & ND & $100 \%$ & $100 \%$ & $100 \%$ \\
\hline \multirow[t]{4}{*}{ Odds Ratio } & \multirow[t]{4}{*}{ Cjto-Sup } & $1 \mathrm{~N}$ & $22.22 \%$ & $57.06 \%$ & $37.11 \%$ \\
\hline & & $2 \mathrm{~N}$ & $8.16 \%$ & $62.65 \%$ & $27.40 \%$ \\
\hline & & $3 \mathrm{~N}$ & $8.87 \%$ & $71.83 \%$ & $31.70 \%$ \\
\hline & & ND & $14.49 \%$ & $69.84 \%$ & $34.51 \%$ \\
\hline \multirow[t]{4}{*}{ Odds Ratio } & \multirow[t]{4}{*}{ Cjto-R } & $1 \mathrm{~N}$ & $12.81 \%$ & $35.05 \%$ & $16.36 \%$ \\
\hline & & $2 \mathrm{~N}$ & $14.98 \%$ & $39.73 \%$ & $21.95 \%$ \\
\hline & & $3 \mathrm{~N}$ & $14.83 \%$ & $40.19 \%$ & $21.90 \%$ \\
\hline & & ND & $13.94 \%$ & $38.39 \%$ & $20.86 \%$ \\
\hline \multirow[t]{4}{*}{ Yule's Q } & \multirow[t]{4}{*}{ Cjto-Sup } & $1 \mathrm{~N}$ & $22.22 \%$ & $57.15 \%$ & $37.18 \%$ \\
\hline & & $2 \mathrm{~N}$ & $8.19 \%$ & $62.65 \%$ & $27.42 \%$ \\
\hline & & $3 \mathrm{~N}$ & $8.87 \%$ & $71.83 \%$ & $31.73 \%$ \\
\hline & & ND & $14.49 \%$ & $69.84 \%$ & $34.54 \%$ \\
\hline \multirow[t]{4}{*}{ Yule's Q } & \multirow[t]{4}{*}{ Cjto-R } & $1 \mathrm{~N}$ & $12.81 \%$ & $35.05 \%$ & $16.36 \%$ \\
\hline & & $2 \mathrm{~N}$ & $14.98 \%$ & $39.73 \%$ & $21.95 \%$ \\
\hline & & $3 \mathrm{~N}$ & $14.83 \%$ & $40.19 \%$ & $21.90 \%$ \\
\hline & & ND & $13.94 \%$ & $38.39 \%$ & $20.86 \%$ \\
\hline \multirow[t]{4}{*}{ Yule's Y } & \multirow[t]{4}{*}{ Cjto-Sup } & $1 \mathrm{~N}$ & $22.25 \%$ & $57.10 \%$ & $37.18 \%$ \\
\hline & & $2 \mathrm{~N}$ & $8.19 \%$ & $62.69 \%$ & $27.40 \%$ \\
\hline & & $3 \mathrm{~N}$ & $8.87 \%$ & $71.87 \%$ & $31.70 \%$ \\
\hline & & ND & $14.49 \%$ & $69.84 \%$ & $34.51 \%$ \\
\hline \multirow[t]{4}{*}{ Yule's Y } & \multirow[t]{4}{*}{ Cjto-R } & $1 \mathrm{~N}$ & $12.81 \%$ & $35.05 \%$ & $16.36 \%$ \\
\hline & & $2 \mathrm{~N}$ & $14.98 \%$ & $39.73 \%$ & $21.95 \%$ \\
\hline & & $3 \mathrm{~N}$ & $14.83 \%$ & $40.19 \%$ & $21.90 \%$ \\
\hline & & ND & $13.94 \%$ & $38.39 \%$ & $20.86 \%$ \\
\hline
\end{tabular}

Com essa síntese é possível verificar em qual dos lados das regras cada uma das medidas obteve o melhor desempenho, para cada uma das taxonomias utilizadas, e se esse desempenho ocorreu em ambos os conjuntos de dados. Com base nessa análise gerou-se a Tabela 5.4, agrupando-se as medidas que obtiveram os melhores valores de desempenho de acordo com a semântica da generalização (os melhores valores de desempenho estão destacados em cinza na Tabela 5.3). As medidas marcadas com:

* indicam que em uma das 24 opções consideradas em cada medida (12 para cada conjunto de dado) mostradas na Tabela 5.3, o lado que obteve o melhor desempenho com a 
medida foi o $l r h s$, sendo que o lado indicado na Tabela 5.4 obteve o segundo melhor desempenho.

** indicam que em duas das 24 opções consideradas em cada medida (12 para cada conjunto de dado) mostradas na Tabela 5.3, o lado que obteve o melhor desempenho com a medida foi o lrhs, sendo que o lado indicado na Tabela 5.4 obteve o segundo melhor desempenho. Entretanto, no caso da medida Interest Factor esse desempenho foi em relação ao rhs.

**/* indicam que em duas das 24 opções consideradas em cada medida (12 para cada conjunto de dado) mostradas na Tabela 5.3, o lado que obteve o melhor desempenho com a medida foi o lrhs e em uma das opções houve um empate com o lrhs, sendo que, nesses dois casos, o lado indicado na Tabela 5.4 obteve o segundo melhor desempenho.

A única medida que não apresentou um padrão e, portanto, não se encontra na Tabela 5.4, foi a J-Measure. Observe que quase todas as medidas do rhs apresentaram o mesmo padrão $(90.91 \%$ (10/11)), ou seja, não houve nenhuma exceção em relação ao lado que obteve o melhor desempenho para uma determinada medida, diferentemente das medidas do lhs. A medida Suporte também não se encontra na Tabela 5.4, uma vez que por definição o suporte de uma regra generalizada é sempre maior ou igual ao suporte de suas regras específicas (definição apresentada na Seção 3.2, página 35), o que pode ser comprovado pelos resultados da Tabela 5.3, em que o Suporte possui desempenho de $100 \%$ em todos os lados considerados.

É importante notar na Tabela 5.3 que em 15 medidas (Added Value, Certainty Factor, Collective Strength, Confiança, Conviction, IS/Cosine, Jaccard, Kappa, Klosgen, Laplace, Mutual Information, Piatetsky-Shapiro's, Odds Ratio, Yule's Q e Yule's Y), o lado que obteve o segundo melhor desempenho foi o lrhs. Das 5 medidas restantes, excluindo o Suporte, em 4 delas ( $\phi$-coefficient, Gini Index, J-Measure e Goodman-Kruskal's) o lrhs obteve o melhor desempenho na maioria dos casos. Em relação à medida Interest Factor, o lado que obteve o segundo melhor desempenho, na maioria dos casos, foi o rhs. Assim, embora seja importante realizar generalizações no lrhs quando se deseja identificar o relacionamento entre categorias/classes de itens, essa generalização não fornece um conhecimento tão representativo quanto generalizações no lhs e no rhs já que, em geral, o conhecimento obtido com esse tipo de generalização está mais relacionado ao senso comum.

A partir da Tabela 5.3 obteve-se também a média de desempenho referente a cada um dos lados utilizados na generalização, para cada uma das medidas. Os resultados encontram-se na Tabela 5.5. Observe (Tabela 5.5) que a medida Interest Factor, embora tenha apresentado o melhor desempenho no lhs (Tabela 5.4), em todos os casos seu 
Tabela 5.4: Agrupamento das medidas objetivas em relação ao desempenho do lado da generalização.

\begin{tabular}{|l|c|c|}
\hline & \multicolumn{2}{|c|}{ Lado } \\
\hline & lhs & rhs \\
\hline Medida & Collective Strength** & Added Value \\
& IS/Cosine**/* & Certainty Factor \\
& $\phi$-coefficient* & Confiança \\
& Jaccard** & Conviction \\
& Kappa & Gini Index* \\
& Interest Factor** & Klosgen \\
& Mutual Information & Goodman-Kruskal's \\
& Piatetsky-Shapiro's* & Laplace \\
& & Odds Ratio \\
& & Yule's Q \\
& & Yule's Y \\
\hline
\end{tabular}

desempenho foi muito ruim em ambos os conjuntos de dados (média de 1.87 no Cjto-Sup e de 2.05 no Cjto-R). A maioria das outras medidas obteve um desempenho acima de $70 \%$, com exceção da medida Kappa (faixa de $60 \%$ no Cjto-R) e das medidas Odds Ratio, Yule's $Q$ e Yule's $Y$ (faixa de $60 \%$ no Cjto-Sup e faixa de $30 \%$ no Cjto-R). Os valores indicados em cinza referem-se ao desempenho do lado indicado na Tabela 5.4. Uma vez que a medida $J$-Measure não se encontra na Tabela 5.4, a mesma também não foi incluída nas estatísticas da Tabela 5.5. A medida Suporte também não foi incluída pelo exposto anteriormente, ou seja, que o suporte de uma regra generalizada é sempre maior ou igual ao suporte de suas regras específicas (definição apresentada na Seção 3.2, página 35).

Tabela 5.5: Estatísticas das regras generalizadas pertencentes ao intervalo 0.9-1.0 considerando cada medida e cada conjunto generalizado.

\begin{tabular}{|c|c|c|c|c|}
\hline Medida & Conjunto Dado & Lado & Média (\%) & Desvio Padrão (\%) \\
\hline \multirow[t]{3}{*}{ Added Value } & \multirow[t]{3}{*}{ Cjto-Sup } & lhs & 1.87 & 1.13 \\
\hline & & rhs & 89.04 & 10.26 \\
\hline & & lrhs & 37.00 & 9.24 \\
\hline \multirow[t]{3}{*}{ Added Value } & \multirow[t]{3}{*}{ Cjto-R } & lhs & 2.05 & 0.05 \\
\hline & & rhs & 82.41 & 3.60 \\
\hline & & lrhs & 36.13 & 2.06 \\
\hline \multirow[t]{3}{*}{ Certainty Factor } & \multirow[t]{3}{*}{ Cjto-Sup } & lhs & 1.90 & 1.16 \\
\hline & & rhs & 99.79 & 0.11 \\
\hline & & lrhs & 50.24 & 3.99 \\
\hline \multirow[t]{3}{*}{ Certainty Factor } & \multirow[t]{3}{*}{ Cjto-R } & lhs & 2.05 & 0.05 \\
\hline & & rhs & 93.19 & 0.90 \\
\hline & & lrhs & 49.16 & 2.54 \\
\hline \multirow[t]{3}{*}{ Collective Strength } & \multirow[t]{3}{*}{ Cjto-Sup } & lhs & 81.89 & 6.03 \\
\hline & & rhs & 28.66 & 21.87 \\
\hline & & lrhs & 68.79 & 14.27 \\
\hline \multirow[t]{3}{*}{ Collective Strength } & \multirow[t]{3}{*}{ Cjto-R } & lhs & 72.94 & 0.42 \\
\hline & & rhs & 54.02 & 1.25 \\
\hline & & lrhs & 71.96 & 2.60 \\
\hline
\end{tabular}




\begin{tabular}{|c|c|c|c|c|}
\hline \multicolumn{5}{|c|}{ continuação da página anterior } \\
\hline Medida & Conjunto Dado & Lado & Média (\%) & Desvio Padrão (\%) \\
\hline \multirow[t]{3}{*}{ Confiança } & \multirow[t]{3}{*}{ Cjto-Sup } & lhs & 1.90 & 1.16 \\
\hline & & rhs & 100 & 0.00 \\
\hline & & lrhs & 52.88 & 4.28 \\
\hline \multirow[t]{3}{*}{ Confiança } & \multirow[t]{3}{*}{ Cjto-R } & lhs & 2.05 & 0.05 \\
\hline & & rhs & 100 & 0.00 \\
\hline & & lrhs & 59.58 & 0.36 \\
\hline \multirow[t]{3}{*}{ Conviction } & \multirow[t]{3}{*}{ Cjto-Sup } & lhs & 1.90 & 1.16 \\
\hline & & rhs & 99.79 & 0.11 \\
\hline & & lrhs & 50.24 & 3.99 \\
\hline \multirow[t]{3}{*}{ Conviction } & \multirow[t]{3}{*}{ Cjto-R } & lhs & 2.05 & 0.05 \\
\hline & & rhs & 93.19 & 0.90 \\
\hline & & lrhs & 49.16 & 2.54 \\
\hline \multirow{3}{*}{ IS/Cosine } & \multirow[t]{3}{*}{ Cjto-Sup } & lhs & 87.28 & 6.34 \\
\hline & & rhs & 56.50 & 21.89 \\
\hline & & lrhs & 80.27 & 11.64 \\
\hline \multirow[t]{3}{*}{ IS/Cosine } & \multirow[t]{3}{*}{ Cjto-R } & lhs & 99.49 & 0.52 \\
\hline & & rhs & 98.73 & 1.04 \\
\hline & & lrhs & 99.54 & 0.31 \\
\hline \multirow[t]{3}{*}{$\phi$-coefficient } & \multirow[t]{3}{*}{ Cjto-Sup } & lhs & 76.75 & 9.61 \\
\hline & & rhs & 45.38 & 23.23 \\
\hline & & lrhs & 69.88 & 15.93 \\
\hline \multirow[t]{3}{*}{$\phi$-coefficient } & \multirow[t]{3}{*}{ Cjto-R } & lhs & 72.74 & 0.59 \\
\hline & & rhs & 70.99 & 2.23 \\
\hline & & lrhs & 69.71 & 4.75 \\
\hline \multirow[t]{3}{*}{ Gini Index } & \multirow[t]{3}{*}{ Cjto-Sup } & lhs & 77.58 & 9.52 \\
\hline & & rhs & 89.17 & 10.31 \\
\hline & & lrhs & 86.22 & 9.06 \\
\hline \multirow[t]{3}{*}{ Gini Index } & Cjto-R & lhs & 75.09 & 0.82 \\
\hline & & rhs & 84.83 & 3.99 \\
\hline & & lrhs & 79.05 & 4.25 \\
\hline Jaccard & Cjto-Sup & lhs & 83.21 & 5.75 \\
\hline & & rhs & 27.13 & 21.15 \\
\hline & & lrhs & 69.29 & 14.18 \\
\hline Jaccard & Cjto-R & lhs & 82.99 & 0.27 \\
\hline & & rhs & 58.64 & 1.00 \\
\hline & & lrhs & 82.62 & 1.44 \\
\hline Kappa & Cjto-Sup & lhs & 78.79 & 6.20 \\
\hline & & rhs & 22.54 & 18.74 \\
\hline & & lrhs & 62.90 & 15.35 \\
\hline Kappa & Cjto-R & lhs & 61.87 & 0.86 \\
\hline & & rhs & 32.42 & 1.86 \\
\hline & & lrhs & 51.15 & 2.50 \\
\hline Klosgen & Cjto-Sup & lhs & 48.05 & 16.10 \\
\hline & & rhs & 95.47 & 4.42 \\
\hline & & lrhs & 77.02 & 9.96 \\
\hline Klosgen & Cjto-R & lhs & 60.35 & 1.14 \\
\hline & & rhs & 90.04 & 2.79 \\
\hline & & lrhs & 75.32 & 3.12 \\
\hline Goodman-Kruskal's & Cjto-Sup & lhs & 61.93 & 7.22 \\
\hline & & rhs & 84.97 & 10.69 \\
\hline & & lrhs & 76.84 & 8.23 \\
\hline Goodman-Kruskal's & Cjto-R & lhs & 94.16 & 0.14 \\
\hline
\end{tabular}




\begin{tabular}{|c|c|c|c|c|}
\hline \multicolumn{5}{|c|}{ continuação da página anterior } \\
\hline \multirow[t]{3}{*}{ Medida } & Conjunto Dado & Lado & Média $(\%)$ & Desvio Padrão (\%) \\
\hline & & rhs & 99.65 & 0.45 \\
\hline & & lrhs & 97.75 & 2.83 \\
\hline \multirow[t]{3}{*}{ Laplace } & \multirow[t]{3}{*}{ Cjto-Sup } & lhs & 2.12 & 1.25 \\
\hline & & rhs & 100 & 0.00 \\
\hline & & lrhs & 54.13 & 3.82 \\
\hline \multirow[t]{3}{*}{ Laplace } & \multirow[t]{3}{*}{ Cjto-R } & lhs & 1.64 & 0.04 \\
\hline & & rhs & 100 & 0.00 \\
\hline & & lrhs & 58.95 & 0.36 \\
\hline \multirow[t]{3}{*}{ Interest Factor } & \multirow[t]{3}{*}{ Cjto-Sup } & lhs & 1.87 & 1.13 \\
\hline & & rhs & 1.86 & 1.65 \\
\hline & & lrhs & 1.24 & 0.90 \\
\hline \multirow[t]{3}{*}{ Interest Factor } & \multirow[t]{3}{*}{ Cjto-R } & lhs & 2.05 & 0.05 \\
\hline & & rhs & 1.85 & 0.06 \\
\hline & & lrhs & 1.25 & 0.04 \\
\hline \multirow[t]{3}{*}{ Mutual Information } & \multirow[t]{3}{*}{ Cjto-Sup } & lhs & 91.21 & 3.95 \\
\hline & & rhs & 19.00 & 13.99 \\
\hline & & lrhs & 67.76 & 10.12 \\
\hline \multirow[t]{3}{*}{ Mutual Information } & \multirow[t]{3}{*}{ Cjto-R } & lhs & 76.43 & 0.82 \\
\hline & & rhs & 37.88 & 1.66 \\
\hline & & lrhs & 60.37 & 4.66 \\
\hline \multirow[t]{3}{*}{ Piatetsky-Shapiro's } & \multirow[t]{3}{*}{ Cjto-Sup } & lhs & 99.32 & 0.51 \\
\hline & & rhs & 89.54 & 10.04 \\
\hline & & lrhs & 96.96 & 3.12 \\
\hline \multirow[t]{3}{*}{ Piatetsky-Shapiro's } & \multirow[t]{3}{*}{ Cjto-R } & lhs & 86.67 & 1.35 \\
\hline & & rhs & 82.76 & 3.83 \\
\hline & & lrhs & 85.12 & 2.97 \\
\hline \multirow[t]{3}{*}{ Odds Ratio } & \multirow[t]{3}{*}{ Cjto-Sup } & lhs & 13.44 & 6.50 \\
\hline & & rhs & 65.35 & 6.79 \\
\hline & & lrhs & 32.68 & 4.16 \\
\hline \multirow[t]{3}{*}{ Odds Ratio } & \multirow[t]{3}{*}{ Cjto-R } & lhs & 14.14 & 1.00 \\
\hline & & rhs & 38.34 & 2.32 \\
\hline & & lrhs & 20.27 & 2.65 \\
\hline \multirow[t]{3}{*}{ Yule's Q } & \multirow[t]{3}{*}{ Cjto-Sup } & lhs & 13.44 & 6.50 \\
\hline & & rhs & 65.37 & 6.75 \\
\hline & & lrhs & 32.72 & 4.17 \\
\hline Yule's Q & Cjto-R & lhs & 14.14 & 1.00 \\
\hline & & rhs & 38.34 & 2.32 \\
\hline & & lrhs & 20.27 & 2.65 \\
\hline Yule's Y & Cjto-Sup & lhs & 13.45 & 6.51 \\
\hline & & rhs & 65.38 & 6.78 \\
\hline & & lrhs & 32.70 & 4.18 \\
\hline Yule's Y & Cjto-R & lhs & 14.14 & 1.00 \\
\hline & & rhs & 38.34 & 2.32 \\
\hline & & lrhs & 20.27 & 2.65 \\
\hline
\end{tabular}

Em linhas gerais, os resultados iniciais obtidos, apresentados na Tabela 5.4, são satisfatórios, uma vez que nos direcionam para a seleção das medidas mais adequadas a serem utilizadas na avaliação do conhecimento generalizado considerando a semântica da generalização. Em outras palavras, pôde-se observar que para cada lado relacionado a uma das semânticas de generalização existe um conjunto de medidas mais apropriado para ser utilizado na seleção de regras. É importante ressaltar, entretanto, que não se pode afirmar nada em relação as medidas $J$-Measure e Interest Factor, já que a primeira não apresentou um padrão de desempenho em relação ao lado da generalização (Tabela 5.4) e 
que a segunda apresentou uma média de desempenho muito ruim em ambos os conjuntos de dados (Tabela 5.5).

\subsubsection{Comparação da Avaliação Empírica com o Estado da Arte}

Em Tan, Kumar, \& Srivastava (2004) os autores realizaram um estudo sobre algumas propriedades das medidas objetivas aqui utilizadas e as agruparam pela similaridade existente entre as suas propriedades (Tabela 5.6). Observe que as medidas Confiança, Conviction e J-Measure não estão presentes em nenhum dos grupos apresentados na Tabela 5.6. A fim de verificar o relacionamento existente entre esses grupos de medidas e os resultados obtidos na Tabela 5.4, as medidas de cada grupo foram divididas em duas categorias: simétricas e assimétricas. Uma medida $M$ é simétrica se $M(A \Rightarrow B)=M(B \Rightarrow A)$; caso contrário é assimétrica (Tan, Steinbach, \& Kumar, 2005). As medidas simétricas são geralmente usadas para avaliar itemsets, enquanto que as medidas assimétricas são mais adequadas para analisar regras de associação (Tan, Steinbach, \& Kumar, 2005). Assim, considerando a divisão entre medidas simétricas e assimétricas foi gerada a Tabela 5.7. Observe que um novo grupo (grupo 8) foi criado na Tabela 5.7 com o objetivo de se adicionar à análise duas das três medidas não consideradas na Tabela 5.6, a saber Confiança e Conviction. A medida J-Measure não foi incluída na Tabela 5.7 pelo fato de não pertencer nem à Tabela 5.6 nem à Tabela 5.4. A medida Suporte não foi considerada uma vez que por definição o suporte de uma regra generalizada é sempre maior ou igual ao suporte de suas regras específicas (Seção 3.2, página 35). Observe que em frente a cada medida da Tabela 5.7 encontra-se o lado no qual a medida obteve o melhor desempenho com base nos resultados apresentados na Tabela 5.4. Analisando os resultados da Tabela 5.7 tem-se que:

- As medidas pertencentes aos grupos 1, 3, 5 e 8 são mais adequadas para serem utilizadas na avaliação de regras que contenham itens generalizados no $r h s$, ou seja, quando a regra generalizada representa o relacionamento entre itens específicos e categorias/classes de itens.

- As medidas pertencentes aos grupos 2 e 4 são mais adequadas para serem utilizadas na avaliação de regras que contenham itens generalizados no lhs, ou seja, quando a regra generalizada representa o relacionamento entre categorias/classes de itens e itens específicos.

- Em relação ao grupo 6, quando a medida é simétrica, a mesma é mais adequada para ser utilizada na avaliação de regras que contenham itens generalizados no lhs. Entretanto, quando a medida é assimétrica, a mesma é mais adequada para generalizações realizadas no rhs. 
- O grupo 7 foi o único que não apresentou um padrão.

Assim, em linhas gerais, os resultados apresentados na Tabela 5.7 indicam que cada grupo de medidas contribui para a seleção de um subconjunto de regras quando um determinado lado é utilizado na generalização. Em outras palavras, os resultados indicam que as medidas mais adequadas para se avaliar as regras generalizadas estão associadas à semântica envolvida no processo de generalização.

Tabela 5.6: Grupos de medidas objetivas com propriedades similares (Tan, Kumar, \& Srivastava, 2004).

\begin{tabular}{|c|c|}
\hline Grupo & Medida \\
\hline 1 & $\begin{array}{c}\text { Odds Ratio } \\
\text { Yule's Q } \\
\text { Yule's Y }\end{array}$ \\
\hline 2 & $\begin{array}{c}\text { IS/Cosine } \\
\text { Jaccard }\end{array}$ \\
\hline 3 & $\begin{array}{c}\text { Suporte } \\
\text { Laplace }\end{array}$ \\
\hline 4 & $\begin{array}{c}\phi \text {-coefficient } \\
\text { Collective Strength } \\
\text { Piatetsky-Shapiro's }\end{array}$ \\
\hline 5 & $\begin{array}{c}\text { Gini Index } \\
\text { Goodman-Kruskal's }\end{array}$ \\
\hline 6 & $\begin{array}{c}\text { Interest Factor } \\
\text { Added Value } \\
\text { Klosgen }\end{array}$ \\
\hline 7 & $\begin{array}{c}\text { Mutual Information } \\
\text { Certainty Factor } \\
\text { Kappa }\end{array}$ \\
\hline
\end{tabular}

Tabela 5.7: Grupos de medidas objetivas com propriedades similares separadas pela propriedade de simetria.

\begin{tabular}{|c|c|c|}
\hline Grupo & Propriedade Simétrica & Propriedade Assimétrica \\
\hline 1 & $\begin{array}{c}\text { Odds Ratio - rhs } \\
\text { Yule's Q - rhs } \\
\text { Yule's Y - rhs }\end{array}$ & \\
\hline 2 & $\begin{array}{l}\text { IS/Cosine }- \text { lhs } \\
\text { Jaccard }- \text { lhs }\end{array}$ & \\
\hline 3 & & Laplace - rhs \\
\hline 4 & $\begin{array}{c}\quad \phi \text {-coefficient }- \text { lhs } \\
\text { Collective Strength }- \text { lhs } \\
\text { Piatetsky-Shapiro's - lhs }\end{array}$ & \\
\hline 5 & Goodman-Kruskal's - rhs & Gini Index - rhs \\
\hline 6 & Interest Factor - lhs & $\begin{array}{l}\text { Added Value - rhs } \\
\text { Klosgen - rhs }\end{array}$ \\
\hline 7 & Kappa - lhs & $\begin{array}{c}\text { Mutual Information - lhs } \\
\text { Certainty Factor - rhs }\end{array}$ \\
\hline 8 & & $\begin{array}{l}\text { Confiança - rhs } \\
\text { Conviction }- \text { rhs }\end{array}$ \\
\hline
\end{tabular}




\subsection{Avaliação Analítica do Conhecimento Generalizado Via Medi- das de Interesse Objetivas}

A fim de embasar os resultados empíricos apresentados na Seção 5.2, nessa seção é apresentada uma avaliação analítica de algumas das medidas objetivas utilizadas anteriormente. Além disso, a partir dessa avaliação analítica é possível identificar, em alguns casos, se o valor de uma medida em uma regra generalizada será maior ou menor do que o valor da mesma medida em suas regras específicas.

A fim de realizar a avaliação analítica, considera-se que um item generalizado em uma regra generalizada é composto pela união de dois ou mais itens específicos contidos na taxonomia. Para cada uma das medidas selecionadas para análise, uma relação entre a regra generalizada e suas regras específicas é demonstrada, a qual representa o relacionamento de valores de uma determinada medida entre as regras gerais e específicas (regras que deram origem à regra generalizada). Uma vez que um item generalizado pode ocorrer em ambos os lados (lrhs) ou em apenas um dos lados (lhs ou rhs) da regra, as relações apresentadas a seguir foram divididas em função do lado da generalização. É importante mencionar que as medidas objetivas utilizadas nessa avaliação, mostradas na Tabela 5.8, foram selecionadas para análise em função da simplicidade de suas estruturas. Vale lembrar que a descrição detalhada dessas medidas foi apresentada na Seção 2.3.4, página 23.

Tabela 5.8: Medidas objetivas selecionadas para o padrão de associação $A \Rightarrow B$ (Tan, Kumar, \& Srivastava, 2004).

\begin{tabular}{|l|l|c|}
\hline Medida & Definição & Simétrica \\
\hline Added Value (AV) & $P(B \mid A)-P(B)$ & Não \\
Certainty Factor (CF) & $\frac{P(B \mid A)-P(B)}{1-P(B)}$ & Não \\
Confiança (Conf) & $P(B \mid A)$ & Não \\
Conviction (Conv) & $\frac{P(A) P(\bar{B})}{P(A \cap \bar{B})}$ & Não \\
Laplace (L) & $\frac{N \times P(A \cap B)+1}{N \times P(A)+2}$ & Não \\
Interest Factor (IF) & $\frac{P(A \cap B)}{P(A) P(B)}$ & Sim \\
Jaccard ( $\zeta)$ & $\frac{P(A \cap B)}{P(A)+P(B)-P(A \cap B)}$ & Sim \\
Piatetsky-Shapiro's (PS) & $P(A \cap B)-P(A) P(B)$ & Sim \\
Suporte (Sup) & $P(A \cap B)$ & Sim \\
\hline
\end{tabular}




\subsubsection{Comportamento das Medidas na Generalização do LHS}

De forma a encontrar o comportamento das medidas em uma regra generalizada, considerando um item generalizado no lhs (relação entre categorias/classes de itens e itens específicos), a seguinte suposição foi feita. Considere a regra $G \Rightarrow A$, obtida a partir das regras $B \Rightarrow A$ e $C \Rightarrow A$, onde $G$ representa um item generalizado formado pelo agrupamento dos itens específicos $B$ e $C$. Portanto, $G$ é tal que $G=B \cup C$. Com base nessa suposição, uma relação analítica foi encontrada para cada uma das medidas consideradas e apresentadas na Tabela 5.8. É importante mencionar que a discussão sobre as relações analíticas abaixo apresentadas é realizada na Seção 5.3.4.

\section{Added Value}

Aplicando a medida Added Value à regra $G \Rightarrow A$, a seguinte relação é obtida:

$$
\begin{aligned}
A V_{G, A} & =P(A \mid G)-P(A) \\
& =P(A \mid(B \cup C))-P(A) \\
& =\frac{P[A \cap(B \cup C)]}{P(B \cup C)}-P(A) \\
& =\frac{P[(A \cap B) \cup(A \cap C)]}{P(B \cup C)}-P(A) \\
& =\frac{P(A \cap B)+P(A \cap C)-P(A \cap B \cap C)}{P(B \cup C)}-P(A) \\
& =\left[\frac{P(A \cap B)}{P(B \cup C)}-P(A)\right]+\left[\frac{P(A \cap C)}{P(B \cup C)}-P(A)\right]-\left[\frac{P(A \cap B \cap C)}{P(B \cup C)}-P(A)\right] \\
& \leqslant A V_{B, A}+A V_{C, A}-\left[\frac{P(A \cap B \cap C)}{P(B \cup C)}-P(A)\right]
\end{aligned}
$$

\section{Certainty Factor}

Aplicando a medida Certainty Factor à regra $G \Rightarrow A$, a seguinte relação é obtida:

$$
\begin{aligned}
& C F_{G, A}=\frac{P(A \mid G)-P(A)}{1-P(A)} \\
& =\frac{P(A \mid(B \cup C))-P(A)}{1-P(A)} \\
& =\frac{\frac{P[A \cap(B \cup C)]}{P(B \cup C)}-P(A)}{1-P(A)} \\
& =\frac{\frac{P(A \cap B)+P(A \cap C)-P(A \cap B \cap C)}{P(B \cup C)}-P(A)}{1-P(A)} \\
& =\left[\frac{\frac{P(A \cap B)}{P(B \cup C)}-P(A)}{1-P(A)}\right]+\left[\frac{\frac{P(A \cap C)}{P(B \cup C)}-P(A)}{1-P(A)}\right]-\left[\frac{\frac{P(A \cap B \cap C)}{P(B \cup C)}-P(A)}{1-P(A)}\right] \\
& \leqslant C F_{B, A}+C F_{C, A}-\left[\frac{P(A \cap B \cap C)}{P(B \cup C) P(\bar{A})}-\frac{P(A)}{P(\bar{A})}\right]
\end{aligned}
$$




\section{Confiança}

Aplicando a medida Confiança à regra $G \Rightarrow A$, a seguinte relação é obtida:

$$
\begin{aligned}
\operatorname{Conf}_{G, A} & =P(A \mid G) \\
& =P(A \mid(B \cup C)) \\
& =\frac{P[A \cap(B \cup C)]}{P(G)} \\
& =\frac{P(A \cap B)}{P(G)}+\frac{P(A \cap C)}{P(G)}-\frac{P(A \cap B \cap C)}{P(G)} \\
& =\frac{P(B)}{P(G)} \times \operatorname{Conf}_{B, A}+\frac{P(C)}{P(G)} \times \operatorname{Conf}_{C, A}-\frac{P(B \cap C)}{P(G)} \times \operatorname{Conf}_{B \cap C, A} \\
& \leqslant \operatorname{Conf}_{B, A}+\operatorname{Conf}_{C, A}-\frac{P(B \cap C)}{P(B \cup C)} \times \operatorname{Conf}_{B \cap C, A}
\end{aligned}
$$

\section{Conviction}

Aplicando a medida Conviction à regra $G \Rightarrow A$, a seguinte relação é obtida:

$$
\begin{aligned}
\operatorname{Conv}_{G, A} & =\frac{P(G) P(\bar{A})}{P(G \cap \bar{A})} \\
& =\frac{P(B \cup C) P(\bar{A})}{P(G \cap \bar{A})} \\
& =\frac{P(B) P(\bar{A})}{P(G \cap \bar{A})}+\frac{P(C) P(\bar{A})}{P(G \cap \bar{A})}-\frac{P(B \cap C) P(\bar{A})}{P(G \cap \bar{A})} \\
& =\frac{P(B \cap \bar{A})}{P(G \cap \bar{A})} \times \operatorname{Conv}_{B, A}+\frac{P(C \cap \bar{A})}{P(G \cap \bar{A})} \times \operatorname{Conv}_{C, A}-\frac{P(B \cap C \cap \bar{A})}{P(G \cap \bar{A})} \times \operatorname{Conv}_{B \cap C, A} \\
& \leqslant \operatorname{Conv}_{B, A}+\operatorname{Conv}_{C, A}-\frac{P(B \cap C \cap \bar{A})}{P[(B \cup C) \cap \bar{A}]} \times \operatorname{Conv}_{B \cap C, A}
\end{aligned}
$$

\section{Laplace}

Aplicando a medida Laplace à regra $G \Rightarrow A$, a seguinte relação é obtida: 


$$
\begin{aligned}
L_{G, A} & =\frac{N \times P(G \cap A)+1}{N \times P(G)+2} \\
& =\frac{N \times P[(B \cup C) \cap A]+1}{N \times P(G)+2} \\
& =\frac{N \times P(B \cap A)+1}{N \times P(G)+2}+\frac{N \times P(C \cap A)+1}{N \times P(G)+2}-\frac{N \times P(B \cap C \cap A)+1}{N \times P(G)+2} \\
& =\frac{N \times P(B)+2}{N \times P(G)+2} \times L_{B, A}+\frac{N \times P(C)+2}{N \times P(G)+2} \times L_{C, A}-\frac{N \times P(B \cap C)+2}{N \times P(G)+2} \times L_{B \cap C, A} \\
& \leqslant L_{B, A}+L_{C, A}-\frac{N \times P(B \cap C)+2}{N \times P(B \cup C)+2} \times L_{B \cap C, A}
\end{aligned}
$$

\section{Interest Factor}

Aplicando a medida Interest Factor à regra $G \Rightarrow A$, a seguinte relação é obtida:

$$
\begin{aligned}
I F_{G, A} & =\frac{P(G \cap A)}{P(G) P(A)} \\
& =\frac{P[(B \cup C) \cap A]}{P(G) P(A)} \\
& =\frac{P(B \cap A)}{P(G) P(A)}+\frac{P(C \cap A)}{P(G) P(A)}-\frac{P(B \cap C \cap A)}{P(G) P(A)} \\
& =\frac{P(B) P(A)}{P(G) P(A)} \times I F_{B, A}+\frac{P(C) P(A)}{P(G) P(A)} \times I F_{C, A}-\frac{P(B \cap C) P(A)}{P(G) P(A)} \times I F_{B \cap C, A} \\
& \leqslant I F_{B, A}+I F_{C, A}-\frac{P(B \cap C)}{P(B \cup C)} \times I F_{B \cap C, A}
\end{aligned}
$$

\section{Jaccard}

Aplicando a medida Jaccard à regra $G \Rightarrow A$, a seguinte relação é obtida:

$$
\begin{aligned}
\zeta_{G, A} & =\frac{P(G \cap A)}{P(G)+P(A)-P(G \cap A)} \\
& =\frac{P(G \cap A)}{P(G \cup A)} \\
& =\frac{P[(B \cup C) \cap A]}{P(G \cup A)} \\
& =\frac{P(B \cap A)}{P(G \cup A)}+\frac{P(C \cap A)}{P(G \cup A)}-\frac{P(B \cap C \cap A)}{P(G \cup A)} \\
& =\frac{P(B \cup A)}{P(G \cup A)} \times \zeta_{B, A}+\frac{P(C \cup A)}{P(G \cup A)} \times \zeta_{C, A}-\frac{P[(B \cap C) \cup A]}{P(G \cup A)} \times \zeta_{B \cap C, A} \\
& \leqslant \zeta_{B, A}+\zeta_{C, A}-\frac{P[(B \cap C) \cup A]}{P(B \cup C \cup A)} \times \zeta_{B \cap C, A}
\end{aligned}
$$




\section{Piatetsky-Shapiro's}

Aplicando a medida Piatetsky-Shapiro's à regra $G \Rightarrow A$, a seguinte relação é obtida:

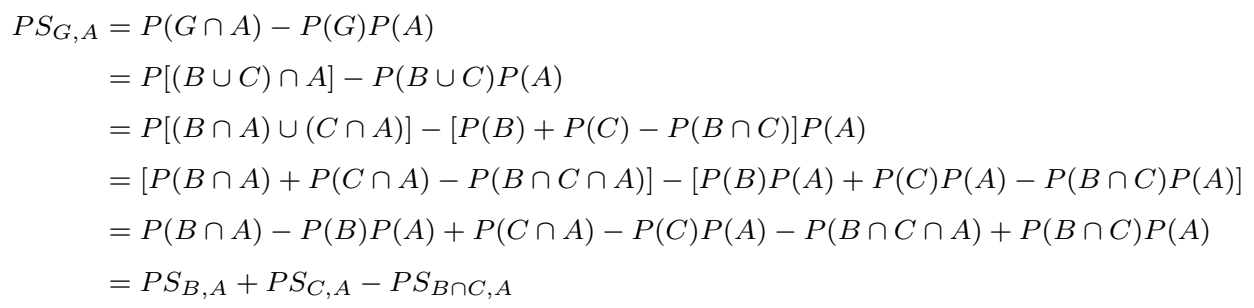

Suporte

Aplicando a medida Suporte à regra $G \Rightarrow A$, a seguinte relação é obtida:

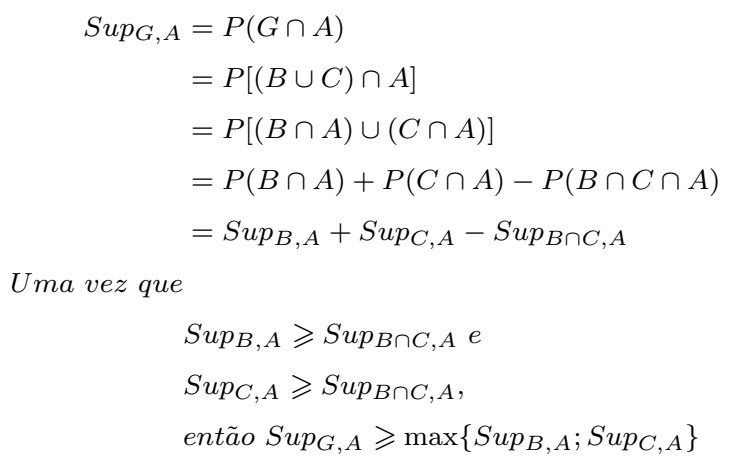

\subsubsection{Comportamento das Medidas na Generalização do RHS}

De forma a encontrar o comportamento das medidas em uma regra generalizada, considerando um item generalizado no rhs (relação entre itens específicos e categorias/classes de itens), a seguinte suposição foi feita. Considere a regra $A \Rightarrow G$, obtida a partir das regras $A \Rightarrow B$ e $A \Rightarrow C$, onde $G$ representa um item generalizado formado pelo agrupamento dos itens específicos $B$ e $C$. Portanto, $G$ é tal que $G=B \cup C$. Com base nessa suposição, uma relação analítica foi encontrada para cada uma das medidas consideradas e apresentadas na Tabela 5.8. É importante mencionar que a discussão sobre as relações analíticas abaixo apresentadas é realizada na Seção 5.3.4. 


\section{Added Value}

Aplicando a medida Added Value à regra $A \Rightarrow G$, a seguinte relação é obtida:

$$
\begin{aligned}
A V_{A, G} & =P(G \mid A)-P(G) \\
& =P((B \cup C) \mid A)-P(B \cup C) \\
& =[P(B \mid A)+P(C \mid A)-P((B \cap C) \mid A)]-[P(B)+P(C)-P(B \cap C)] \\
& =[P(B \mid A)-P(B)]+[P(C \mid A)-P(C)]-[P((B \cap C) \mid A)-P(B \cap C)] \\
& =A V_{A, B}+A V_{A, C}-A V_{A, B \cap C}
\end{aligned}
$$

\section{Certainty Factor}

Aplicando a medida Certainty Factor à regra $A \Rightarrow G$, a seguinte relação é obtida:

$$
\begin{aligned}
C F_{A, G} & =\frac{P(G \mid A)-P(G)}{1-P(G)} \\
& =\frac{P((B \cup C) \mid A)-P(B \cup C)}{1-P(G)} \\
& =\frac{P(B \mid A)}{P(\bar{G})}+\frac{P(C \mid A)}{P(\bar{G})}-\frac{P((B \cap C) \mid A)}{P(\bar{G})}-\frac{P(B)}{P(\bar{G})}-\frac{P(C)}{P(\bar{G})}+\frac{P(B \cap C)}{P(\bar{G})} \\
& =\frac{P(\bar{B})}{P(\bar{G})} \times C F_{A, B}+\frac{P(\bar{C})}{P(\bar{G})} \times C F_{A, C}-\frac{P(\bar{B} \cup \bar{C})}{P(\bar{G})} \times C F_{A, B \cap C} \\
& \geqslant C F_{A, B}+C F_{A, C}-\frac{P(\bar{B} \cup \bar{C})}{P(\bar{B} \cap \bar{C})} \times C F_{A, B \cap C}
\end{aligned}
$$

\section{Confiança}

Aplicando a medida Confiança à regra $A \Rightarrow G$, a seguinte relação é obtida:

$$
\begin{aligned}
\text { Conf }_{A, G} & =P(G \mid A) \\
& =P((B \cup C) \mid A) \\
& =P(B \mid A)+P(C \mid A)-P((B \cap C) \mid A) \\
& =\operatorname{Conf}_{A, B}+\operatorname{Conf}_{A, C}-\operatorname{Conf}_{A, B \cap C} \\
\text { Uma vez que } & \\
& \text { onf }_{A, B} \geqslant \operatorname{Conf}_{A, B \cap C} e \\
& \text { Conf } \\
& \text { ent }, C \geqslant \operatorname{Conf}_{A, B} \geqslant \operatorname{Con}, \\
&
\end{aligned}
$$




\section{Conviction}

Aplicando a medida Conviction à regra $A \Rightarrow G$, a seguinte relação é obtida:

$$
\begin{aligned}
\operatorname{Conv}_{A, G} & =\frac{P(A) P(\bar{G})}{P(A \cap \bar{G})} \\
& =\frac{P(A) P(\overline{B \cup C})}{P[A \cap(\overline{B \cup C})]} \\
& =\frac{P(A) P(\bar{B} \cap \bar{C})}{P(A \cap \bar{B} \cap \bar{C})}
\end{aligned}
$$

Uma vez que

$$
\begin{aligned}
& \frac{P(A) P(\bar{B} \cap \bar{C})}{P(A \cap \bar{B} \cap \bar{C})} \geqslant \frac{P(A) P(\bar{B} \cap \bar{C})}{P(A \cap \bar{B})} e \\
& \frac{P(A) P(\bar{B} \cap \bar{C})}{P(A \cap \bar{B} \cap \bar{C})} \geqslant \frac{P(A) P(\bar{B} \cap \bar{C})}{P(A \cap \bar{C})},
\end{aligned}
$$

tem-se que

$$
\begin{aligned}
& \operatorname{Conv}_{A, G} \geqslant \frac{P(\bar{B} \cap \bar{C})}{P(\bar{B})} \times \operatorname{Conv}_{A, B} e \\
& \operatorname{Conv}_{A, G} \geqslant \frac{P(\bar{B} \cap \bar{C})}{P(\bar{C})} \times \operatorname{Conv}_{A, C}, \\
& \text { então } \operatorname{Conv}_{A, G} \geqslant \max \left\{\frac{P(\bar{B} \cap \bar{C})}{P(\bar{B})} \times \operatorname{Conv}_{A, B} ; \frac{P(\bar{B} \cap \bar{C})}{P(\bar{C})} \times \operatorname{Conv}_{A, C}\right\}
\end{aligned}
$$

\section{Laplace}

Aplicando a medida Laplace à regra $A \Rightarrow G$, a seguinte relação é obtida:

$$
\begin{aligned}
L_{A, G} & =\frac{N \times P(A \cap G)+1}{N \times P(A)+2} \\
& =\frac{N \times P[A \cap(B \cup C)]+1}{N \times P(A)+2} \\
& =\frac{N \times P[(A \cap B) \cup(A \cap C)]+1}{N \times P(A)+2} \\
& =\frac{N \times[P(A \cap B)+P(A \cap C)-P(A \cap B \cap C)]+1}{N \times P(A)+2} \\
& =\frac{N \times P(A \cap B)+1}{N \times P(A)+2}+\frac{N \times P(A \cap C)+1}{N \times P(A)+2}-\frac{N \times P(A \cap B \cap C)+1}{N \times P(A)+2} \\
& =L_{A, B}+L_{A, C}-L_{A, B \cap C} \\
& L_{A, B} \geqslant L_{A, B \cap C} e \\
& L_{A, C} \geqslant L_{A, B \cap C}, \\
& \text { então } L_{A, G} \geqslant \max \left\{L_{A, B} ; L_{A, C}\right\}
\end{aligned}
$$

Uma vez que 


\section{Interest Factor}

Aplicando a medida Interest Factor à regra $A \Rightarrow G$, a seguinte relação é obtida:

$$
I F_{A, G} \leqslant I F_{A, B}+I F_{A, C}-\frac{P(B \cap C)}{P(B \cup C)} \times I F_{A, B \cap C}
$$

Uma vez que a medida é simétrica, a dedução matemática da mesma foi omitida por já ter sido apresentada na Seção 5.3.1.

\section{Jaccard}

Aplicando a medida Jaccard à regra $A \Rightarrow G$, a seguinte relação é obtida:

$$
\zeta_{A, G} \leqslant \zeta_{A, B}+\zeta_{A, C}-\frac{P[A \cup(B \cap C)]}{P(A \cup B \cup C)} \times \zeta_{A, B \cap C}
$$

Uma vez que a medida é simétrica, a dedução matemática da mesma foi omitida por já ter sido apresentada na Seção 5.3.1.

\section{Piatetsky-Shapiro's}

Aplicando a medida Piatetsky-Shapiro's à regra $A \Rightarrow G$, a seguinte relação é obtida:

$$
P S_{A, G}=P S_{A, B}+P S_{A, C}-P S_{A, B \cap C}
$$

Uma vez que a medida é simétrica, a dedução matemática da mesma foi omitida por já ter sido apresentada na Seção 5.3.1.

\section{Suporte}

Aplicando a medida Suporte à regra $A \Rightarrow G$, a seguinte relação é obtida:

$$
\operatorname{Sup}_{A, G} \geqslant \max \left\{\operatorname{Sup}_{A, B} ; \operatorname{Sup}_{A, C}\right\}
$$


Uma vez que a medida é simétrica, a dedução matemática da mesma foi omitida por já ter sido apresentada na Seção 5.3.1.

\subsubsection{Comportamento das Medidas na Generalização do LRHS}

De forma a encontrar o comportamento das medidas em uma regra generalizada, considerando itens generalizados em ambos os lados (lrhs - relação entre categorias/classes de itens), a seguinte suposição foi feita. Considere a regra $G_{1} \Rightarrow G_{2}$, obtida a partir das regras $A \Rightarrow C$ e $B \Rightarrow D$, onde $G_{1}$ representa um item generalizado formado pelo agrupamento dos itens específicos $A$ e $B$ e $G_{2}$ um item generalizado formado pelo agrupamento dos itens específicos $C$ e $D$. Portanto, $G_{1}$ é tal que $G_{1}=A \cup B$ e $G_{2}$ é tal que $G_{2}=C \cup D$. Com base nessa suposição, uma relação analítica foi encontrada para cada uma das medidas consideradas e apresentadas na Tabela 5.8. É importante lembrar que a discussão sobre as relações analíticas abaixo apresentadas é realizada na Seção 5.3.4.

\section{Added Value}

De forma a obter a relação analítica referente à regra $G_{1} \Rightarrow G_{2}$, para a medida Added Value, aplicou-se a regra à Equação 5.1.

$$
A V_{G_{1}, G_{2}} \leqslant A V_{A, C \cup D}+A V_{B, C \cup D}-\left[\frac{P[(C \cup D) \cap A \cap B]}{P(A \cup B)}-P(C \cup D)\right]
$$

A partir dessa relação, aplicando-se a Equação 5.10 à Equação 5.19 tem-se que:

$$
\begin{aligned}
A V_{G_{1}, G_{2}} \leqslant & A V_{A, C}+A V_{A, D}-A V_{A, C \cap D}+A V_{B, C}+A V_{B, D}-A V_{B, C \cap D} \\
& -\left[\frac{P[(C \cup D) \cap A \cap B]}{P(A \cup B)}-P(C \cup D)\right]
\end{aligned}
$$

Uma vez que a mesma idéia é usada para obter todas as outras relações referentes às outras medidas consideradas, as deduções matemáticas das mesmas foram omitidas.

\subsubsection{Discussão sobre o Comportamento das Medidas}

Nas Tabelas 5.9, 5.10 e 5.11 são apresentados os comportamentos das medidas selecionadas (Tabela 5.8) por meio das relações encontradas nas seções anteriores considerando a semântica da generalização. Essas relações representam a "conexão" existente entre o 
valor de uma medida em uma regra generalizada e os valores da mesma medida em suas regras específicas.

Tabela 5.9: Relações das medidas objetivas na generalização do $L H S$.

\begin{tabular}{|c|c|}
\hline Medida & $G \Rightarrow A(G=B \cup C)$ \\
\hline Added Value (AV) & $A V_{G, A} \leqslant A V_{B, A}+A V_{C, A}-\left[\frac{P(A \cap B \cap C)}{P(B \cup C)}-P(A)\right]$ \\
\hline Certainty Factor (CF) & $C F_{G, A} \leqslant C F_{B, A}+C F_{C, A}-\left[\frac{P(A \cap B \cap C)}{P(B \cup C) P(\bar{A})}-\frac{P(A)}{P(\bar{A})}\right]$ \\
\hline Confiança (Conf) & $\operatorname{Conf}_{G, A} \leqslant \operatorname{Conf}_{B, A}+\operatorname{Con} f_{C, A}-\frac{P(B \cap C)}{P(B \cup C)} \times \operatorname{Conf} f_{B \cap C, A}$ \\
\hline Conviction (Conv) & $\operatorname{Conv}_{G, A} \leqslant \operatorname{Conv}_{B, A}+\operatorname{Conv}_{C, A}-\frac{P(B \cap C \cap \bar{A})}{P[(B \cup C) \cap \bar{A}]} \times \operatorname{Conv}_{B \cap C, A}$ \\
\hline Laplace (L) & $L_{G, A} \leqslant L_{B, A}+L_{C, A}-\frac{N \times P(B \cap C)+2}{N \times P(B \cup C)+2} \times L_{B \cap C, A}$ \\
\hline Interest Factor (IF) & $I F_{G, A} \leqslant I F_{B, A}+I F_{C, A}-\frac{P(B \cap C)}{P(B \cup C)} \times I F_{B \cap C, A}$ \\
\hline Jaccard $(\zeta)$ & $\zeta_{G, A} \leqslant \zeta_{B, A}+\zeta_{C, A}-\frac{P[(B \cap C) \cup A]}{P(B \cup C \cup A)} \times \zeta_{B \cap C, A}$ \\
\hline Piatetsky-Shapiro's (PS) & $P S_{G, A}=P S_{B, A}+P S_{C, A}-P S_{B \cap C, A}$ \\
\hline Suporte (Sup) & $\operatorname{Sup}_{G, A} \geqslant \max \left\{\operatorname{Sup}_{B, A} ; \operatorname{Sup}_{C, A}\right\}$ \\
\hline
\end{tabular}

Tabela 5.10: Relações das medidas objetivas na generalização do $R H S$.

\begin{tabular}{|c|c|}
\hline Medida & $A \Rightarrow G(G=B \cup C)$ \\
\hline Added Value (AV) & $A V_{A, G}=A V_{A, B}+A V_{A, C}-A V_{A, B \cap C}$ \\
\hline Certainty Factor $(\mathrm{CF})$ & $C F_{A, G} \geqslant C F_{A, B}+C F_{A, C}-\frac{P(\bar{B} \cup \bar{C})}{P(\bar{B} \cap \bar{C})} \times C F_{A, B \cap C}$ \\
\hline Confiança (Conf) & $\operatorname{Conf}_{A, G} \geqslant \max \left\{\operatorname{Conf}_{A, B} ; \operatorname{Conf}_{A, C}\right\}$ \\
\hline Conviction (Conv) & $\operatorname{Conv}_{A, G} \geqslant \max \left\{\frac{P(\bar{B} \cap \bar{C})}{P(\bar{B})} \times \operatorname{Conv}_{A, B} ; \frac{P(\bar{B} \cap \bar{C})}{P(\bar{C})} \times \operatorname{Conv}_{A, C}\right\}$ \\
\hline Laplace (L) & $L_{A, G} \geqslant \max \left\{L_{A, B} ; L_{A, C}\right\}$ \\
\hline Interest Factor (IF) & $I F_{A, G} \leqslant I F_{A, B}+I F_{A, C}-\frac{P(B \cap C)}{P(B \cup C)} \times I F_{A, B \cap C}$ \\
\hline Jaccard $(\zeta)$ & $\zeta_{A, G} \leqslant \zeta_{A, B}+\zeta_{A, C}-\frac{P[A \cup(B \cap C)]}{P(A \cup B \cup C)} \times \zeta_{A, B \cap C}$ \\
\hline Piatetsky-Shapiro's (PS) & $P S_{A, G}=P S_{A, B}+P S_{A, C}-P S_{A, B \cap C}$ \\
\hline Suporte (Sup) & $\operatorname{Sup}_{A, G} \geqslant \max \left\{\operatorname{Sup}_{A, B} ; \operatorname{Sup}_{A, C}\right\}$ \\
\hline
\end{tabular}

A fim de explicar como interpretar as relações encontradas, considere a medida Suporte. Uma das relações encontradas para essa medida é $S u p_{G, A} \geqslant \max \left\{S u p_{B, A} ; S u p_{C, A}\right\}$, que significa que o valor de suporte de uma regra generalizada $\left(S u p_{G, A}\right)$, contendo um item generalizado no $l h s$, é maior ou igual ao máximo valor de suporte de suas regras específicas $\left(\operatorname{Sup}_{B, A}\right.$ e $\left.S u p_{C, A}\right)$.

Considerando outra medida, Piatetsky-Shapiro's, por exemplo, a seguinte relação foi encontrada: $P S_{A, G}=P S_{A, B}+P S_{A, C}-P S_{A, B \cap C}$, significando que o valor de $P S$ em uma regra generalizada $\left(P S_{A, G}\right)$, contendo um item generalizado no rhs, é igual à soma dos valores de $P S$ em suas regras específicas $\left(P S_{A, B}\right.$ e $\left.P S_{A, C}\right)$ menos o valor de $P S$ 
Tabela 5.11: Relações das medidas objetivas na generalização do LRHS.

\begin{tabular}{|c|c|}
\hline Medida & $G_{1} \Rightarrow G_{2}\left(G_{1}=A \cup B ; G_{2}=C \cup D\right)$ \\
\hline Added Value (AV) & $\begin{array}{l}A V_{G_{1}, G_{2}} \leqslant A V_{A, C}+A V_{A, D}-A V_{A, C \cap D}+A V_{B, C}+A V_{B, D}-A V_{B, C \cap D} \\
-\left[\frac{P[(C \cup D) \cap A \cap B]}{P(A \cup B)}-P(C \cup D)\right]\end{array}$ \\
\hline Certainty Factor (CF) & Sem Conclusão \\
\hline Confiança (Conf) & Sem Conclusão \\
\hline Conviction (Conv) & Sem Conclusão \\
\hline Laplace (L) & Sem Conclusão \\
\hline Interest Factor (IF) & $\begin{array}{l}I F_{G_{1}, G_{2}} \leqslant I F_{A, C}+I F_{A, D}-\frac{P(C \cap D)}{P(C \cup D)} \times I F_{A, C \cap D}+I F_{B, C}+I F_{B, D}-\frac{P(C \cap D)}{P(C \cup D)} \times I F_{B, C \cap D} \\
-\frac{P(A \cap B)}{P(A \cup B)}\left[I F_{A \cap B, C}+I F_{A \cap B, D}-\frac{P(C \cap D)}{P(C \cup D)} \times I F_{A \cap B, C \cap D}\right]\end{array}$ \\
\hline Jaccard $(\zeta)$ & $\begin{array}{l}\zeta_{G 1, G_{2}} \leqslant \zeta_{A, C}+\zeta_{A, D}-\frac{P[A \cup(C \cap D)]}{P(A \cup C \cup D)} \times \zeta_{A, C \cap D}+\zeta_{B, C}+\zeta_{B, D}-\frac{P[B \cup(C \cap D)]}{P(B \cup C \cup D)} \times \zeta_{B, C \cap D} \\
-\frac{P[(A \cap B) \cup C \cup D]}{P(A \cup B \cup C \cup D)}\left[\zeta_{A \cap B, C}+\zeta_{A \cap B, D}-\frac{P[(A \cap B) \cup(C \cap D)]}{P[(A \cap B) \cup C \cup D]} \times \zeta_{A \cap B, C \cap D}\right]\end{array}$ \\
\hline Piatetsky-Shapiro's (PS) & $\begin{array}{l}P S_{G_{1}, G_{2}}=P S_{A, C}+P S_{A, D}-P S_{A, C \cap D}+P S_{B, C}+P S_{B, D}-P S_{B, C \cap D} \\
-P S_{A \cap B, C}-P S_{A \cap B, D}+P S_{A \cap B, C \cap D}\end{array}$ \\
\hline Suporte (Sup) & $\operatorname{Sup}_{G_{1}, G 2} \geqslant \max \left\{\operatorname{Sup}_{A, C} ; \operatorname{Sup}_{A, D} ; \operatorname{Sup}_{B, C} ; \operatorname{Sup}_{B, D}\right\}$ \\
\hline
\end{tabular}

considerando a intersecção dos itens especializados usados para formar o item generalizado $\left(P S_{A, B \cap C}\right)$. A interpretação do restante das medidas segue a mesma idéia.

A partir das Tabelas 5.9, 5.10 e 5.11 pode-se observar que algumas das medidas são descritas por uma desigualdade para expressar o valor de uma regra generalizada. Essa desigualdade representa o comportamento da medida em relação aos itens específicos utilizados para compor o item generalizado. Desse modo, dependendo da direção da desigualdade pode-se dizer que, em alguns casos, o comportamento de uma medida em uma regra generalizada será igual ou melhor em relação ao comportamento de seus itens específicos (desigualdade $\geqslant$ ) ou que o comportamento de uma medida em uma regra generalizada será igual ou pior em relação ao comportamento de seus itens específicos (desigualdade $\leqslant$ ). Além disso, observando os resultados obtidos, pode-se dizer que é mais apropriado utilizar uma medida em uma regra generalizada que apresente uma melhora em seu comportamento em relação aos seus itens específicos. Assim, existem algumas medidas que são mais adequadas para serem utilizadas na seleção de regras quando se considera a semântica da generalização.

Considerando os argumentos apresentados e observando as Tabelas 5.9, 5.10 e 5.11 verifica-se então que as medidas Added Value, Certainty Factor, Confiança, Conviction e Laplace são mais adequadas para serem utilizadas na avaliação de regras generalizadas no rhs, como já apresentado na Tabela 5.4. Em relação à medida Interest Factor, observa-se que o seu valor em uma regra generalizada é menor ou igual ao seu valor em relação aos itens específicos, o que complementa os resultados apresentados na Tabela 5.5, em que a medida apresentou uma média de desempenho muito ruim em ambos os conjuntos de dados. Embora as medidas Interest Factor e Jaccard apresentem em uma regra generalizada um valor menor ou igual ao seu valor em relação aos itens específicos em ambos os 
lados (lhs e $r h s$ ), as mesmas apresentaram um melhor desempenho no lhs pelos resultados empíricos (Tabela 5.4). A medida Piatetsky-Shapiro's embora também apresente o mesmo comportamento em ambos os lados (lhs e rhs), também apresentou um melhor desempenho no lhs pelos resultados empíricos (Tabela 5.4). Em relação ao lrhs, observe na Tabela 5.11 que não é possível se chegar a uma conclusão para algumas das medidas (Certainty Factor, Confiança, Conviction e Laplace), uma vez que o comportamento em todas essas medidas no lhs apresentou uma relação de desigualdade " $\leqslant$ " e no rhs uma relação de desigualdade " $\geqslant "$.

A partir dos resultados obtidos pôde-se observar também que as medidas Suporte e Confiança apresentaram um comportamento esperado de acordo com as definições apresentadas na Seção 3.2 do Capítulo 3 (página 35), o que já havia sido confirmado nos experimentos empíricos (Seção 5.2, página 92). Além disso, as relações do comportamento das outras medidas, até então desconhecidas (como mencionado na Seção 3.2, página 35), quando aplicadas às regras generalizadas, foram obtidas. Sendo assim, as principais vantagens dessa avaliação analítica são:

- Ter um conhecimento a priori do comportamento de uma medida objetiva quando aplicada a uma regra generalizada.

- Calcular mais facilmente os valores das medidas objetivas para uma regra generalizada, uma vez que se pode, em alguns casos, utilizar as relações encontradas para obter esses valores.

- Fornecer uma visão geral do comportamento das medidas objetivas para as pesquisas de mineração de dados quando aplicadas a uma regra generalizada.

É importante mencionar que essa avaliação analítica é válida, independentemente da etapa de mineração em que as regras generalizadas são obtidas, para quaisquer regras generalizadas que contenham um item generalizado que possa ser visto como a união de dois ou mais itens específicos contidos em uma dada taxonomia.

\subsection{Avaliação do Conhecimento Generalizado Via Especialista do Domínio}

Nas duas últimas seções foram apresentadas avaliações em relação à utilização das medidas mais adequadas a serem utilizadas na seleção de regras de associação generalizadas. Essas avaliações levaram em consideração a semântica da generalização. Assim, um ponto importante que também deve ser avaliado é a adequação dessas medidas na semântica da generalização segundo especialistas do domínio. 
O especialista do domínio exerce um papel fundamental no processo de avaliação, já que ele irá utilizar o conhecimento obtido para apoiar suas tomadas de decisão. Em geral, quando um conhecimento é generalizado, pode ser que algumas informações sejam perdidas. Por exemplo, utilizando a APRA (Capítulo 4) a regra "IF leite_nilza \& leite_parmalat THEN nescau" pode ser generalizada para "IF leite THEN nescau" em um determinado processamento. Nesse caso, essa generalização faz com que a informação referente à quantidade de tipos de leite no antecedente da regra se perca (na específica têm-se dois tipos de leite e na generalizada somente o item leite).

Diante do exposto, essa seção apresenta alguns experimentos realizados junto a especialistas do domínio para verificar se: [1] existem conhecimentos interessantes contidos em um conjunto de regras generalizadas, assim como em conjuntos específicos; [2] os grupos de medidas encontrados na Seção 5.2 (Tabela 5.4, página 100) realmente selecionam as regras generalizadas mais interessantes em função da semântica da generalização. Para tanto, a seguir, é descrita a metodologia utilizada para selecionar as regras submetidas à análise de especialistas, assim como os resultados da avaliação do conhecimento selecionado.

\subsubsection{Metodologia de Seleção de Regras para Avaliação}

A fim de avaliar o conhecimento generalizado, visando os objetivos anteriormente citados ([1] e [2]), é descrita nessa seção a metodologia utilizada para selecionar regras gerais e específicas submetidas à avaliação de especialistas. A metodologia é composta basicamente de dois passos, os quais são descritos a seguir ${ }^{2}$.

\section{Passo 1: Classificar as regras com base nas medidas objetivas de interesse.}

Para um dado conjunto de regras, classificar todas as regras com base nos valores de $N$ medidas objetivas, como segue.

- Primeiro, para cada regra, o valor de cada uma das $N$ medidas é calculado.

- Segundo, para cada medida, todas as regras são classificadas de acordo com o valor dessa medida, isto é, à regra com o melhor valor para essa medida é associado o número de classificação 1, a segunda melhor regra é associado o número de classificação 2, e assim por diante. Isso produz $N$ classificações distintas para as regras descobertas, isto é, uma classificação para cada medida objetiva considerada. Se houver regras com valores iguais para um determinada medida, a regra que possuir menos itens no antecedente será classificada primeiro, uma vez que essa regra é, teoricamente, mais compreensível ao especialista.

\footnotetext{
${ }^{2}$ A metodologia aqui apresentada foi "inspirada" no trabalho de Carvalho, Freitas, \& Ebecken (2005).
} 
- Terceiro, é calculada uma média de classificação sobre as $N$ classificações, atribuindo a cada regra um número de classificação que representa a média dos $N$ números de classificação originalmente associados a essa regra. Esse número médio da classificação é então usado para selecionar as regras no próximo passo. Assim como descrito anteriormente, se houver regras com valores iguais de classificação, a regra que possuir menos itens no antecedente será classificada primeiro, uma vez que essa regra é, teoricamente, mais compreensível ao especialista.

As medidas aqui consideradas são as mesmas descritas na Seção 2.3.4, página 23, a saber: Added Value, Certainty Factor, Collective Strength, Confiança, Conviction, IS/Cosine, ф-coefficient, Gini Index, Jaccard, Kappa, Klosgen, Goodman-Kruskal's, Laplace, Interest Factor, Mutual Information, Piatetsky-Shapiro's, Suporte, Odds Ratio, Yule's $Q$ e Yule's Y. A medida J-Measure não é considerada por não apresentar um padrão de desempenho segundo os experimentos empíricos descritos na Seção 5.2 .

Em relação aos valores das $N$ medidas, considera-se o seguinte: (a) quando a metodologia é utilizada para selecionar regras de um conjunto específico, ou seja, de um conjunto que contém apenas regras não generalizadas, são utilizadas as 20 medidas mencionadas $(N=20)$, uma vez que, em tese, não há uma melhor medida para se avaliar uma regra específica; (b) quando a metodologia é utilizada para selecionar regras de um conjunto generalizado dois critérios são utilizados: (b.1) somente as medidas do lhs (Tabela 5.4, página 100), ou seja, $N=9$ (todas as do lhs mais o Suporte); (b.2) somente as medidas do rhs (Tabela 5.4, página 100), ou seja, $N=12$ (todas as do rhs mais o Suporte). No caso do conjunto generalizado esses dois critérios são utilizados a fim de identificar se as regras mais interessantes, segundo especialistas do domínio, são selecionadas pelo grupo de medidas referente ao lado em que a generalização ocorre (lhs/rhs/lrhs), visando verificar o objetivo [2] da Seção 5.4. É importante mencionar que no caso do conjunto generalizado são consideradas apenas as regras generalizadas, ou seja, somente aquelas obtidas pela união de duas ou mais regras específicas.

\section{Passo 2: Selecionar as regras a serem avaliadas pelo especialista. Como} se sabe, é inviável apresentar um grande número de regras ao especialista para avaliação. Sendo assim, a metodologia aqui apresentada seleciona apenas 3 regras de todas as regras contidas em um conjunto inicial de regras. O conjunto de 3 regras selecionadas consiste das 3 regras com os números mais baixos de classificação, isto é, regras com classificação 1, 2, 3, as quais foram as 3 regras mais interessantes de acordo com as medidas objetivas. A escolha do número 3 foi baseada no trabalho de Carvalho, Freitas, \& Ebecken (2005). 


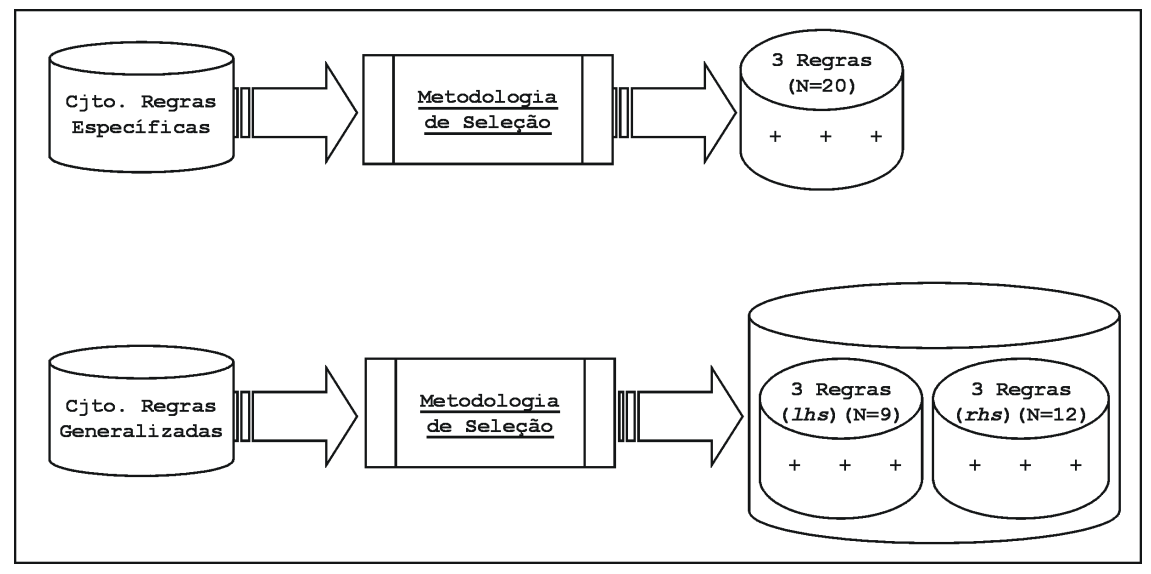

Figura 5.2: Fluxo de entrada e saída da metodologia de seleção de regras para avaliação por parte dos especialistas.

É importante destacar que quando a metodologia proposta é aplicada sobre um conjunto de regras específicas, 3 regras são selecionadas $(N=20)$; quando aplicada sobre um conjunto de regras generalizadas, 6 regras são selecionadas, sendo 3 selecionadas considerando as medidas do lhs $(N=9)$ e 3 selecionadas considerando as medidas do rhs $(N=12)$, como apresentado na Figura 5.2.

\subsubsection{Avaliação do Conhecimento}

Com base na metodologia de seleção apresentada, três experimentos foram especificados para cada um dos conjuntos de dados considerados neste trabalho (Cjto-Sup e Cjto-R), a fim de investigar os objetivos [1] e [2] enunciados na Seção 5.4. As configurações de cada experimento são descritas a seguir.

Experimento A. Considera-se um conjunto generalizado no lhs juntamente com o conjunto específico utilizado para gerá-lo. A partir desses conjuntos buscam-se as regras mais interessantes a partir da metodologia de seleção apresentada para verificar se: [E-A.1] as regras generalizadas no lhs são tão interessantes quanto as regras específicas selecionadas (objetivo [1]); [E-A.2] as regras generalizadas no lhs mais interessantes são as selecionadas pelas medidas do lhs (objetivo [2]).

Experimento B. Considera-se um conjunto generalizado no rhs juntamente com o conjunto específico utilizado para gerá-lo. A partir desses conjuntos buscam-se as regras mais interessantes a partir da metodologia de seleção apresentada para verificar se: [E-B.1] as regras generalizadas no rhs são tão interessantes quanto as regras específicas selecionadas (objetivo [1]); [E-B.2] as regras generalizadas no rhs mais interessantes são as selecionadas pelas medidas do rhs (objetivo [2]). 
Experimento C. Considera-se um conjunto generalizado no lrhs juntamente com o conjunto específico utilizado para gerá-lo. A partir desses conjuntos buscam-se as regras mais interessantes a partir da metodologia de seleção apresentada para verificar se: [E-C.1] as regras generalizadas no lrhs são tão interessantes quanto as regras específicas selecionadas (objetivo [1]); [E-C.2] as regras generalizadas no lrhs mais interessantes são as selecionadas por quais dos grupos de medidas consideradas: lhs ou rhs (objetivo [2]).

Para a execução dos experimentos foram selecionados, para cada conjunto de dado, 3 conjuntos de regras generalizadas. Esses conjuntos foram selecionados dentre os apresentados nas Tabelas 5.1 e 5.2 do Capítulo 5 (página 94). Os conjuntos de regras selecionados foram aqueles que apresentaram as maiores taxa de compactação em cada um dos lados considerados (lhs, rhs e lrhs). Usando a notação lado-medida-t\%-tax-nível, a qual representa, respectivamente, o lado da generalização (lhs, rhs e $l r h s$ ), a medida utilizada (sup e conf $)$, o valor da taxa $t(0 \%, 25 \%$ e $50 \%)$, a taxonomia e seu respectivo nível de abstração, os conjuntos selecionados em cada conjunto de dados encontram-se nas Tabelas 5.12 e 5.13. Além dos conjuntos de regras generalizadas considerou-se também os conjuntos de regras específicas utilizados para gerar as regras generalizadas de cada um dos conjuntos de dados.

Tabela 5.12: Conjuntos de regras generalizadas selecionados do Cjto-Sup para avaliação dos especialistas.

\begin{tabular}{|c|c|}
\hline Configuração & Taxa de Compactação \\
\hline lhs-sup-0-tax07-3N & $51.06 \%$ \\
\hline rhs-sup-0-tax07-3N & $26.34 \%$ \\
\hline lrhs-sup-0-tax07-3N & $66.86 \%$ \\
\hline
\end{tabular}

Tabela 5.13: Conjuntos de regras generalizadas selecionados do Cjto-R para avaliação dos especialistas.

\begin{tabular}{|c|c|}
\hline Configuração & Taxa de Compactação \\
\hline lhs-sup-0-tax01-3N & $23.41 \%$ \\
\hline rhs-sup-0-tax01-3N & $19.26 \%$ \\
\hline lrhs-sup-0-tax01-3N & $39.03 \%$ \\
\hline
\end{tabular}

Para cada um dos conjuntos selecionados, a metodologia de seleção de regras apresentada foi utilizada. Os conjuntos lhs-sup-0-tax07-3N e lhs-sup-0-tax01-3N estão associados ao Experimento A; os conjuntos rhs-sup-0-tax07-3N e rhs-sup-0-tax01-3N ao Experimento B; os conjuntos lrhs-sup-0-tax07-3N e lrhs-sup-0-tax01-3N ao Experimento C. Para cada um dos experimentos considerados foram geradas 9 regras, sendo 3 referentes ao conjunto específico utilizado para gerar o conjunto generalizado $(N=20)$, 3 ao conjunto generalizado, obtido a partir do conjunto específico em questão, utilizando apenas 
as medidas do lhs $(N=9)$ e 3 referentes ao mesmo conjunto generalizado utilizando apenas as medidas do rhs $(N=12)$.

Cada regra selecionada pela metodologia apresentada na Seção 5.4.1, referente a cada um dos experimentos, foi submetida aos especialistas do domínio. Os especialistas atribuíram então um grau subjetivo de interesse à regra. A classificação especificada pelos especialistas assume três valores, a saber: (1) regra óbvia, completamente esperada; (2) regra interessante, não tão esperada; (3) regra muito interessante, nada esperada. Foram considerados 9 especialistas para cada um dos experimentos, os quais representam consumidores de supermercados.

Os resultados das avaliações subjetivas realizadas pelos especialistas, considerando cada uma das regras selecionadas em cada um dos conjuntos de dados, encontram-se apresentados nas Tabelas 5.14 a 5.19. As Tabelas 5.14 e 5.17 se referem aos critérios do Experimento A; as Tabelas 5.15 e 5.18 aos critérios do Experimento B; as Tabelas 5.16 e 5.19 aos critérios do Experimento C. Cada uma das tabelas apresenta 4 colunas, a saber: $1^{a}$ - referente à identificação do especialista do domínio; $2^{a}$ - referente às regras selecionadas a partir de um conjunto específico utilizando as 20 medidas consideradas $(N=20) ; 3^{a}$ - referente às regras selecionadas a partir de um conjunto generalizado, obtido a partir do conjunto específico em questão, utilizando apenas as medidas do lhs $(N=9)$ e $4^{a}$ - referente às regras selecionadas a partir do mesmo conjunto generalizado utilizando apenas as medidas do rhs $(N=12)$. A cada regra foi atribuído um identificador relacionado à opção de seleção utilizada (nesse caso, opção A para $N=20$, opção B para $N=9$ e opção C para $N=12$ ) e a ordem de classificação obtida. Por exemplo, a regra "A.2" indica a segunda regra mais interessante selecionada pela metodologia descrita na Seção 5.4.1 a partir de um conjunto específico (opção A: $N=20$ ); a regra "LHS:B.3" indica a terceira regra mais interessante selecionada pela metodologia descrita na Seção 5.4.1 a partir de um conjunto generalizado no lhs utilizando apenas as medidas do lhs (opção B: $N=9$ ); etc. Como foram utilizados 9 especialistas em cada experimento, a fim de verificar a classe de interesse de cada uma das regras, na linha "Moda" de todas as tabelas encontra-se a classificação mais freqüente de uma determinada regra. Apenas a Tabela 5.19, regra "LRHS:C.2", apresentou um caso de empate entre as 3 categorias de classificação existentes. Nesse caso, considerou-se a classificação média das classes, ou seja, a categoria 2.

Analisando as classificações finais ("Moda") (Tabelas 5.14 a 5.19) tem-se que:

- em relação aos critérios [E-A.1], [E-B.1], [E-C.1], referentes aos Experimentos A, $\mathbf{B}$ e $\mathbf{C}$, verificou-se que entre as regras generalizadas há regras com classificações de interesse iguais ou melhores do que as classificações das regras específicas. Por exemplo, as regras RHS:C.1, RHS:C.2 e RHS:C.3, da Tabela 5.15, são todas classificadas como regras muito interessantes, assim como a regra A.2 da mesma tabela, 
Tabela 5.14: Classificação dada pelos especialistas para as regras generalizadas no lhs, selecionadas do Cjto-Sup, pela metodologia descrita na Seção 5.4.1.

\begin{tabular}{|c|c|c|c|c|c|c|c|c|c|}
\hline & \multicolumn{3}{|c|}{$\begin{array}{l}\text { Cjto. Específico } \\
\text { Opção A: } N=20\end{array}$} & \multicolumn{3}{|c|}{$\begin{array}{l}\text { Cjto. lhs-sup-0-tax07-3N } \\
\text { Opção B: } N=9\end{array}$} & \multicolumn{3}{|c|}{$\begin{array}{l}\text { Cjto. lhs-sup-0-tax07-3N } \\
\text { Opção C: } N=12\end{array}$} \\
\hline Especialista & A. 1 & A. 2 & A.3 & LHS:B.1 & LHS:B.2 & LHS:B.3 & LHS:C.1 & LHS:C.2 & LHS:C.3 \\
\hline 1 & 2 & 3 & 3 & 2 & 2 & 2 & 2 & 2 & 2 \\
\hline 2 & 1 & 3 & 1 & 2 & 2 & 2 & 2 & 2 & 2 \\
\hline 3 & 2 & 1 & 2 & 2 & 2 & 2 & 2 & 2 & 2 \\
\hline 4 & 3 & 2 & 2 & 3 & 2 & 3 & 3 & 3 & 3 \\
\hline 5 & 2 & 3 & 2 & 3 & 2 & 3 & 3 & 2 & 3 \\
\hline 6 & 2 & 2 & 1 & 2 & 3 & 2 & 3 & 3 & 2 \\
\hline 7 & 2 & 2 & 1 & 3 & 2 & 2 & 2 & 2 & 2 \\
\hline 8 & 2 & 3 & 1 & 3 & 3 & 2 & 3 & 3 & 2 \\
\hline 9 & 2 & 1 & 1 & 2 & 2 & 2 & 2 & 2 & 2 \\
\hline Moda & 2 & 3 & 1 & 2 & 2 & 2 & 2 & 2 & 2 \\
\hline
\end{tabular}

Tabela 5.15: Classificação dada pelos especialistas para as regras generalizadas no rhs, selecionadas do Cjto-Sup, pela metodologia descrita na Seção 5.4.1.

\begin{tabular}{|c|c|c|c|c|c|c|c|c|c|}
\hline & \multicolumn{3}{|c|}{$\begin{array}{l}\text { Cjto. Específico } \\
\text { Opção A: } N=20\end{array}$} & \multicolumn{3}{|c|}{$\begin{array}{l}\text { Cjto. rhs-sup-0-tax07-3N } \\
\text { Opção B: } N=9\end{array}$} & \multicolumn{3}{|c|}{$\begin{array}{l}\text { Cjto. rhs-sup-0-tax07-3N } \\
\text { Opção C: } N=12\end{array}$} \\
\hline Especialista & A.1 & A.2 & A.3 & RHS:B.1 & RHS:B.2 & RHS:B.3 & RHS:C.1 & RHS:C.2 & RHS:C.3 \\
\hline 1 & 2 & 3 & 3 & 1 & 1 & 1 & 2 & 2 & 3 \\
\hline 2 & 1 & 3 & 1 & 1 & 1 & 1 & 3 & 3 & 3 \\
\hline 3 & 2 & 1 & 2 & 1 & 1 & 1 & 2 & 1 & 2 \\
\hline 4 & 3 & 2 & 2 & 1 & 1 & 2 & 3 & 3 & 3 \\
\hline 5 & 2 & 3 & 2 & 1 & 1 & 1 & 3 & 3 & 3 \\
\hline 6 & 2 & 2 & 1 & 1 & 1 & 1 & 3 & 3 & 3 \\
\hline 7 & 2 & 2 & 1 & 1 & 1 & 1 & 2 & 3 & 3 \\
\hline 8 & 2 & 3 & 1 & 1 & 1 & 1 & 3 & 3 & 3 \\
\hline 9 & 2 & 1 & 1 & 1 & 1 & 1 & 2 & 2 & 2 \\
\hline
\end{tabular}

\begin{tabular}{|l|lll|lll|llll|}
\hline Moda & 2 & 3 & 1 & 1 & 1 & 1 & 3 & 3 & 3 \\
\hline
\end{tabular}

Tabela 5.16: Classificação dada pelos especialistas para as regras generalizadas no lrhs, selecionadas do Cjto-Sup, pela metodologia descrita na Seção 5.4.1.

\begin{tabular}{|c|ccc|ccc|ccc|}
\hline & \multicolumn{2}{|c|}{$\begin{array}{c}\text { Cjto. Específico } \\
\text { Opção A: } N=20\end{array}$} & \multicolumn{3}{c|}{$\begin{array}{c}\text { Cjto. lrhs-sup-0-tax07-3N } \\
\text { Opção B: } N=9\end{array}$} & \multicolumn{3}{c|}{$\begin{array}{c}\text { Cjto. lrhs-sup-0-tax07-3N } \\
\text { Opção C: } N=12\end{array}$} \\
\hline Especialista & A.1 & A.2 & A.3 & LRHS:B.1 & LRHS:B.2 & LRHS:B.3 & LRHS:C.1 & LRHS:C.2 & LRHS:C.3 \\
\hline 1 & 2 & 3 & 3 & 1 & 1 & 2 & 2 & 2 & 2 \\
\hline 2 & 1 & 3 & 1 & 2 & 2 & 2 & 3 & 2 & 2 \\
\hline 3 & 2 & 1 & 2 & 2 & 2 & 1 & 2 & 2 & 2 \\
\hline 4 & 3 & 2 & 2 & 1 & 3 & 2 & 3 & 2 & 2 \\
\hline 5 & 2 & 3 & 2 & 1 & 3 & 3 & 2 & 2 & 2 \\
\hline 6 & 2 & 2 & 1 & 1 & 2 & 3 & 2 & 3 & 3 \\
\hline 7 & 2 & 2 & 1 & 1 & 2 & 2 & 2 & 3 & 2 \\
\hline 8 & 2 & 3 & 1 & 1 & 3 & 2 & 3 & 2 \\
\hline 9 & 2 & 1 & 1 & 2 & 2 & 2 & 2 & \\
\hline
\end{tabular}

indicando que mesmo após a generalização existem regras generalizadas tão interessantes quanto as específicas;

- em relação ao critério [E-A.2] do Experimento A, Tabelas 5.14 e 5.17, verificou-se 
Tabela 5.17: Classificação dada pelos especialistas para as regras generalizadas no lhs, selecionadas do Cjto-R, pela metodologia descrita na Seção 5.4.1.

\begin{tabular}{|c|c|c|c|c|c|c|c|c|c|}
\hline \multirow[b]{2}{*}{ Especialista } & \multicolumn{3}{|c|}{$\begin{array}{c}\text { Cjto. Específico } \\
\text { Opção A: } N=20\end{array}$} & \multicolumn{3}{|c|}{$\begin{array}{c}\text { Cjto. lhs-sup-0-tax01-3N } \\
\text { Opção B: } N=9\end{array}$} & \multicolumn{3}{|c|}{$\begin{array}{l}\text { Cjto. lhs-sup-0-tax01-3N } \\
\text { Opção C: } N=12\end{array}$} \\
\hline & A.1 & A.2 & A.3 & LHS:B.1 & LHS:B.2 & LHS:B.3 & LHS:C.1 & LHS:C.2 & LHS:C.3 \\
\hline 1 & 3 & 1 & 2 & 2 & 2 & 1 & 2 & 2 & 2 \\
\hline 2 & 2 & 1 & 1 & 2 & 1 & 1 & 2 & 2 & 1 \\
\hline 3 & 2 & 2 & 1 & 3 & 1 & 1 & 3 & 1 & 3 \\
\hline 4 & 2 & 2 & 3 & 3 & 3 & 2 & 3 & 3 & 3 \\
\hline 5 & 3 & 3 & 2 & 3 & 3 & 2 & 3 & 3 & 1 \\
\hline 6 & 2 & 3 & 2 & 3 & 2 & 2 & 3 & 2 & 2 \\
\hline 7 & 2 & 2 & 1 & 2 & 1 & 1 & 2 & 2 & 1 \\
\hline 8 & 3 & 2 & 1 & 3 & 1 & 1 & 3 & 1 & 1 \\
\hline 9 & 3 & 2 & 1 & 3 & 2 & 1 & 3 & 2 & 1 \\
\hline Moda & 2 & 2 & 1 & 3 & 1 & 1 & 3 & 2 & 1 \\
\hline
\end{tabular}

Tabela 5.18: Classificação dada pelos especialistas para as regras generalizadas no rhs, selecionadas do Cjto-R, pela metodologia descrita na Seção 5.4.1.

\begin{tabular}{|c|c|c|c|c|c|c|c|c|c|}
\hline & $\begin{array}{l}\mathrm{Cjt} \\
\mathrm{Ops}\end{array}$ & $\begin{array}{l}\text { Esp } \\
\text { A: }\end{array}$ & $\begin{array}{l}\text { ífico } \\
=20\end{array}$ & Cjto. & $\begin{array}{l}\text { as-sup-0-ta } \\
\text { ção B: } N\end{array}$ & $\begin{array}{l}01-3 \mathrm{~N} \\
9\end{array}$ & Cjto. & $\begin{array}{l}\text { s-sup-0-ta } \mathrm{C}: N= \\
\text { ão }\end{array}$ & $\begin{array}{l}01-3 N \\
12\end{array}$ \\
\hline Especialista & A. 1 & A.2 & A.3 & RHS:B.1 & RHS:B.2 & RHS:B.3 & RHS:C.1 & RHS:C.2 & RHS:C.3 \\
\hline 1 & 3 & 1 & 2 & 2 & 2 & 3 & 3 & 2 & 2 \\
\hline 2 & 2 & 1 & 1 & 1 & 1 & 1 & 1 & 1 & 1 \\
\hline 3 & 2 & 2 & 1 & 2 & 2 & 1 & 1 & 3 & 2 \\
\hline 4 & 2 & 2 & 3 & 2 & 2 & 3 & 2 & 2 & 2 \\
\hline 5 & 3 & 3 & 2 & 2 & 3 & 2 & 3 & 3 & 3 \\
\hline 6 & 2 & 3 & 2 & 1 & 3 & 3 & 2 & 2 & 2 \\
\hline 7 & 2 & 2 & 1 & 2 & 1 & 1 & 1 & 1 & 3 \\
\hline 8 & 3 & 2 & 1 & 1 & 2 & 1 & 1 & 1 & 2 \\
\hline 9 & 3 & 2 & 1 & 2 & 2 & 2 & 2 & 2 & 2 \\
\hline Moda & 2 & 2 & 1 & 2 & 2 & 1 & 1 & 2 & 2 \\
\hline
\end{tabular}

Tabela 5.19: Classificação dada pelos especialistas para as regras generalizadas no lrhs, selecionadas do Cjto-R, pela metodologia descrita na Seção 5.4.1.

\begin{tabular}{|c|c|c|c|c|c|c|c|c|c|}
\hline \multirow{2}{*}{ Especialista } & \multicolumn{3}{|c|}{$\begin{array}{l}\text { Cjto. Específico } \\
\text { Opção A: } N=20\end{array}$} & \multicolumn{3}{|c|}{$\begin{array}{c}\text { Cjto. lrhs-sup-0-tax01-3N } \\
\text { Opção B: } N=9\end{array}$} & \multicolumn{3}{|c|}{$\begin{array}{l}\text { Cjto. lrhs-sup-0-tax01-3N } \\
\text { Opção C: } N=12\end{array}$} \\
\hline & A.1 & A.2 & A.3 & LRHS:B.1 & LRHS:B.2 & LRHS:B.3 & $\begin{array}{l}\text { LRHS:C.1 } \\
\end{array}$ & LRHS:C.2 & LRHS:C.3 \\
\hline 1 & 3 & 1 & 2 & 2 & 2 & 2 & 1 & 3 & 2 \\
\hline 2 & 2 & 1 & 1 & 1 & 1 & 1 & 1 & 2 & 1 \\
\hline 3 & 2 & 2 & 1 & 1 & 1 & 2 & 1 & 1 & 1 \\
\hline 4 & 2 & 2 & 3 & 2 & 2 & 2 & 1 & 3 & 1 \\
\hline 5 & 3 & 3 & 2 & 3 & 2 & 3 & 2 & 2 & 1 \\
\hline 6 & 2 & 3 & 2 & 1 & 2 & 2 & 2 & 3 & 2 \\
\hline 7 & 2 & 2 & 1 & 2 & 1 & 1 & 2 & 1 & 2 \\
\hline 8 & 3 & 2 & 1 & 1 & 1 & 1 & 1 & 1 & 2 \\
\hline 9 & 3 & 2 & 1 & 1 & 2 & 2 & 1 & 2 & 1 \\
\hline Moda & 2 & 2 & 1 & 1 & 2 & 2 & 1 & 2 & 1 \\
\hline
\end{tabular}

que as medidas do lhs no Cjto-Sup (Tabela 5.14) não selecionaram regras muito mais interessantes do que as medidas do rhs para o conjunto generalizado no lhs; para o Cjto-R (Tabela 5.17), as medidas do rhs selecionaram apenas uma regra um pouco mais interessante do que as medidas do lhs. Entretanto, ambos os grupos de 
medidas (lhs/rhs) apresentaram comportamentos (classificações) bem semelhantes em ambos os conjuntos de dados. Sendo assim, considerando os resultados iniciais apresentados referentes às classificações dos especialistas, pode-se dizer que para regras generalizadas no $l h s$, as medidas objetivas utilizadas na avaliação de regras que contêm itens generalizados no lhs (medidas $l h s$ ) não selecionam regras cuja classificação de interesse seja muito diferente do que as regras selecionadas pelas medidas do rhs;

- em relação ao critério [E-B.2] do Experimento B, Tabelas 5.15 e 5.18, verificou-se que as medidas do rhs no Cjto-Sup (Tabela 5.15) selecionaram regras muito mais interessantes do que as medidas do lhs para o conjunto generalizado no rhs; para o Cjto-R (Tabela 5.18), as medidas do rhs selecionaram regras tão interessantes quanto as medidas do lhs. Sendo assim, considerando os resultados iniciais apresentados referentes às classificações dos especialistas, pode-se dizer que para regras generalizadas no $r h s$, as medidas objetivas utilizadas na avaliação de regras que contêm itens generalizados no rhs (medidas $r h s$ ) selecionam regras cuja classificação de interesse seja muito diferente do que as regras selecionadas pelas medidas do lhs;

- em relação ao critério [E-C.2] do Experimento C, Tabelas 5.16 e 5.19, verificou-se que as medidas do rhs no Cjto-Sup (Tabela 5.16) selecionaram apenas uma regra um pouco mais interessante do que as medidas do lhs para o conjunto generalizado no lrhs; para o Cjto-R (Tabela 5.19), as medidas do lhs selecionaram apenas uma regra um pouco mais interessante do que as medidas do rhs para o conjunto generalizado no lrhs. Entretanto, ambos os grupos de medidas (lhs/rhs) apresentaram comportamentos (classificações) bem semelhantes em ambos os conjuntos de dados. Sendo assim, considerando os resultados iniciais apresentados referentes às classificações dos especialistas, pode-se dizer que para regras generalizadas no $l r h s$, tanto as medidas do lhs como as do rhs podem ser utilizadas, já que as mesmas apresentaram comportamentos semelhantes nos dois conjuntos de dados, ou seja, selecionaram regras com classificações de interesse semelhantes.

É importante notar que os resultados referentes ao Cjto-Sup apresentaram, em geral, classificações de interesse bem melhores do que as do Cjto-R. Por exemplo, o Cjto-Sup apresenta, entre as regras específicas, uma regra um pouco mais interessante do que as regras específicas do Cjto-R (categoria 3 de interesse). Isso pode ser explicado pelo seguinte fator: como mencionado na Seção 4.8 (página 82), o Cjto-R já se encontrava "parcialmente" generalizado antes da aplicação da APRA (Capítulo 4). Sendo assim, após a generalização, regras mais óbvias foram obtidas em relação ao Cjto-Sup, o qual se encontrava totalmente especializado. Além disso, observe que os resultados das classificações do Cjto-Sup são mais padronizados em relação à análise dos especialistas, para cada uma 
das regras, do que os resultados do Cjto-R. Isso pode ter ocorrido em função dos itens do Cjto-R estarem em inglês, o que pode ter levado a alguma distorção de semântica entre os especialistas, o que provavelmente não aconteceu com o Cjto-Sup.

\subsection{Considerações Finais}

Através da utilização da $A P R A$, apresentada no Capítulo 4, é possível se identificar para cada uma das regras generalizadas obtidas as regras específicas que foram agrupadas para gerar a regra generalizada. A partir dessa relação uma avaliação empírica e analítica foi realizada visando a validação da Hipótese 2 apresentada no Capítulo 1, ou seja, que "a semântica envolvida na generalização especifica o tipo de medida a ser utilizada para avaliar a representatividade do conhecimento generalizado".

Por meio da análise empírica observou-se que dependendo do lado em que a generalização ocorre, um grupo diferente de medidas deve ser utilizado para realizar a seleção de um subconjunto de regras. Em outras palavras, se uma regra apresenta um item generalizado no lhs, as medidas do lhs (Tabela 5.4, página 100) devem ser usadas, uma vez que essas medidas apresentam um melhor desempenho quando aplicadas na seleção de regras que contenham um item generalizado no lhs; a mesma idéia se aplica ao rhs.

A fim de embasar os resultados empíricos, uma avaliação analítica de algumas medidas objetivas apresentadas foi realizada. Essa avaliação encontrou as relações existentes entre os valores de uma medida objetiva em uma regra generalizada e os valores da mesma medida em suas regras específicas. Nas Tabelas 5.9, 5.10 e 5.11 (página 114) foram apresentadas todas as relações válidas encontradas para cada uma das medidas analisadas considerando itens generalizados em ambos os lados e em um lado específico de uma regra.

Além disso, na Seção 5.4 foi apresentada uma avaliação, junto a especialistas do domínio, para verificar se: [1] o processo de generalização produz conhecimentos tão interessantes quanto os específicos; [2] os grupos de medidas apresentados na Seção 5.2 (Tabela 5.4, página 100) realmente selecionam as regras mais interessantes em função da semântica envolvida na generalização.

Após vários experimentos, considerando a análise de diversos especialistas, pode-se dizer que: (a) embora se generalize conhecimentos e se perca algumas informações, ainda assim irão existir regras generalizadas tão interessantes quanto as específicas, quando as mesmas forem selecionadas pelo grupo de medidas mais adequado; (b) o grupo de medidas de avaliação do rhs tem muito mais influência sobre o interesse das regras generalizadas no rhs do que as medidas do lhs sobre regras generalizadas no lhs; (c) em relação à generalização do lrhs, ambos os grupos de medidas contribuem para a seleção de regras interessantes no lrhs. Em relação à perda de informação no processo de generalização, é 
importante mencionar que se o módulo RulEE-RAG, descrito na Seção 4.7 (página 79), for utilizado após o processo de generalização, nenhuma informação é perdida, uma vez que é possível se identificar e recuperar as regras específicas que originaram a regra generalizada. 


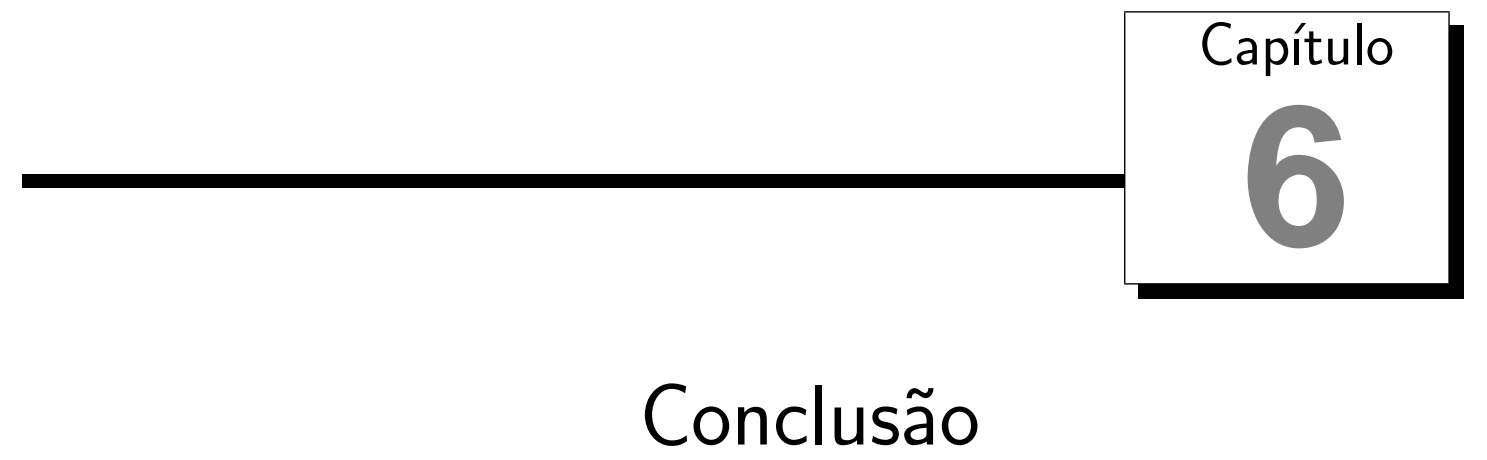

O objetivo principal da mineração de dados é que o conhecimento obtido possa ser utilizado pelos usuários finais como apoio em processos de tomada de decisão ou em um sistema inteligente. Para tanto, é importante que o conhecimento descoberto seja válido, novo, potencialmente útil e compreensível. Entretanto, um problema encontrado no final do processo é que muitos dos algoritmos utilizados geram uma grande quantidade de padrões, dificultando consideravelmente sua análise e, conseqüentemente, sua utilização. Esse problema recebe uma maior ênfase em regras de associação, uma vez que a técnica de associação procura identificar todos os padrões intrínsecos ao conjunto de dados. Além disso, os processos tradicionais de extração de regras de associação levam à obtenção de um conhecimento, em geral, muito específico.

Diante desse contexto, este trabalho objetivou pós-processar regras de associação via um processo de generalização que utiliza conhecimento de domínio expresso via taxonomias. Esse pós-processamento viabiliza a obtenção de um conjunto de regras generalizadas compacto e representativo, a fim de facilitar o entendimento do domínio pelo usuário.

Como se sabe, é importante que os padrões obtidos sejam avaliados, já que o usuário final está apenas interessado em padrões úteis e compreensíveis. Dentre as formas de avaliação existentes na literatura encontram-se as medidas de interesse objetivas, utilizadas na maioria dos trabalhos de pós-processamento em mineração de dados. Assim, foi realizado também neste trabalho um estudo sobre a utilização de algumas medidas objetivas para avaliar a representatividade do conhecimento generalizado, obtido pela abordagem proposta, em função da semântica da generalização. 


\subsection{Contribuições}

Uma das hipóteses que guiou o desenvolvimento deste trabalho afirma que é possível utilizar conhecimento de domínio, expresso via taxonomias, para pós-processar um conjunto de regras de associação a fim de obter um conjunto de regras generalizadas que seja compacto e representativo (Hipótese 1 apresentada no Capítulo 1). A fim de validar essa hipótese, foi proposta uma Abordagem de Pós-Processamento de Regras de Associação (APRA), descrita no Capítulo 4 (referente ao Objetivo 1 apresentado no Capítulo 1). Para viabilizar a utilização dessa abordagem foi proposto e implementado um algoritmo denominado $A P R A_{a l g}$, também descrito no Capítulo 4. A abordagem desenvolvida contribui para:

- fornecer uma nova abordagem para avaliação de regras de associação, mais especificamente para a abordagem de sumarização, descrita na Seção 2.3.3, página 19;

- aproveitar taxonomias gerais de domínio no processo de generalização viabilizada pela listagem de contribuição de itens descrita no Capítulo 4, a qual contém a participação de cada um dos itens específicos na composição dos itens gerais. Assim, esses tipos de taxonomias podem ser utilizadas em subdomínios, uma vez que é possível se identificar por meio da listagem os itens que contribuíram para o processo de generalização;

- ajudar na identificação das regras gerais e suas exceções, já que via a utilização da listagem de contribuição de itens se pode observar quais itens específicos não contribuem para uma categoria/classe de itens em uma determinada associação;

- associar uma regra de associação generalizada a suas regras específicas e, assim, explorar diversos aspectos de uma regra generalizada em função de suas regras específicas. Essa contribuição representa um grande ganho, uma vez que o conjunto de regras de associação se torna compacto e que esse conjunto reduzido não perde a especificidade das regras originais;

- prover ao usuário final uma visão geral do domínio via regras generalizadas, as quais podem ser exploradas posteriormente em uma análise top-down, para um melhor entendimento das mesmas;

- incorporar ao estado da arte, no que se refere ao uso de conhecimento de domínio via taxonomias em regras de associação (Seção 3.3, página 38), uma contribuição significativa para a etapa de pós-processamento.

Para apoiar a exploração top-down citada e a identificação das regras gerais e suas exceções, foi desenvolvido um módulo de exploração de regras denominado RuLEE-RAG, 
descrito na Seção 4.7, página 79. A partir desse módulo, o usuário final pode "navegar" no conhecimento generalizado descoberto de forma a explorar particularidades do domínio. Além disso, com a implementação do módulo RuLEE-RAG, foi acrescentado ao ambiente RuLEE (Seção 4.7) funcionalidades referentes à análise de regras generalizadas.

Para demonstrar que a abordagem proposta $(A P R A)$ pode compactar um conjunto de regras de associação (Hipótese 1 apresentada no Capítulo 1), foram realizados alguns experimentos utilizando o $A P R A_{\text {alg }}$, os quais encontram-se descritos na Seção 4.8, página 82. A partir dos resultados obtidos, os quais apresentam diversas taxas de redução, pôde-se observar que um conjunto de regras de associação pode ser reduzido na presença de um conjunto de taxonomias, validando assim a Hipótese 1. É importante mencionar que o resultado da compactação depende muito da qualidade das taxonomias fornecidas pelo especialista do domínio. Além disso, via a utilização da abordagem proposta é possível se compactar um conjunto de regras de associação sem perder a visão geral do domínio, assim como manter o acesso ao conhecimento específico.

A fim de complementar a hipótese acima apresentada, um outro ponto importante discutido, além da compactação do modelo gerado, foi a representatividade do conhecimento obtido por processos de generalização. Para tanto, a outra hipótese que guiou o desenvolvimento deste trabalho afirma que a semântica envolvida na generalização especifica o tipo de medida de avaliação objetiva a ser utilizada para avaliar a representatividade do conhecimento generalizado (Hipótese 2 apresentada no Capítulo 1). A fim de validar essa hipótese, um estudo empírico foi realizado para verificar se uma regra generalizada é mais representativa do que as suas regras específicas em função da semântica da generalização (Seção 5.2, página 92) (referente ao Objetivo 2 apresentado no Capítulo 1). A representatividade da regra foi avaliada via a utilização de todas as medidas de interesse objetivas descritas na Seção 2.3.4, página 23. A descrição semântica das medidas objetivas consideradas também representa uma contribuição deste trabalho, já que a obtenção de informações na literatura, referentes a algumas medidas, é relativamente difícil.

Vários experimentos foram realizados durante o estudo empírico acima mencionado. Esses experimentos levaram em consideração o comportamento de uma determinada medida em uma regra generalizada e em suas regras específicas, ou seja, nas regras que foram agrupadas a fim de gerar a regra generalizada. Como resultado, observou-se que determinadas medidas de avaliação são mais adequadas quando utilizadas em regras que possuem itens generalizados em um lado específico da regra. O agrupamento das medidas objetivas em relação ao desempenho do lado da generalização é apresentado na Tabela 5.4 da Seção 5.2 (página 92). Assim, analisando os resultados apresentados nessa tabela, observa-se que para cada lado relacionado a uma das semânticas de generalização existe um conjunto de medidas mais apropriado para ser utilizado na avaliação de regras generalizadas. 
A fim de embasar os resultados empíricos, foi realizado um estudo analítico referente à utilização de algumas das medidas apresentadas na Tabela 5.4 (Seção 5.3, página 105) (referente ao Objetivo 3 apresentado no Capítulo 1). Nesse estudo analítico foram encontradas as relações existentes entre o valor de uma medida em uma regra generalizada e os valores da mesma medida em suas regras específicas. A partir das relações obtidas pôde-se observar também que existem algumas medidas que são mais adequadas para serem utilizadas na avaliação de regras generalizadas quando se considera a semântica da generalização, complementando os resultados do estudo empírico. Como resultado dessa investigação é possível se ter um conhecimento a priori do comportamento de uma medida objetiva quando aplicada em uma regra generalizada (Seção 5.3.4, página 113).

Para finalizar o estudo referente à representatividade de regras generalizadas, foi realizada uma investigação junto a especialistas do domínio para verificar se os agrupamentos apresentados na Tabela 5.4 (Seção 5.2, página 92) realmente selecionam as regras mais interessentes/úteis aos mesmos em função da semântica da generalização (Seção 5.4, página 116) (referente ao Objetivo 4 apresentado no Capítulo 1). Como resultado tem-se que: (a) o agrupamento referente às medidas do $r h s$ realmente seleciona regras generalizadas no rhs bem mais interessantes do que as medidas do lhs; (b) no caso das medidas do lhs, o mesmo não ocorre, já que tanto o agrupamento das medidas do lhs como do rhs selecionam regras generalizadas no lhs com comportamentos de interesse bem semelhantes; (c) tanto as medidas do lhs como do rhs podem ser utilizadas na seleção de regras generalizadas no lrhs, já que ambas apresentam comportamentos de interesse bem semelhantes. Além disso, verificou-se também que apesar de algumas informações serem perdidas durante o processo de generalização, ainda irão existir regras generalizadas tão interessantes quanto as regras específicas. Entretanto, se o módulo RulEE-RAG, descrito na Seção 4.7 (página 79), for utilizado após o processo de generalização, nenhuma informação será perdida, uma vez que é possível se identificar e recuperar as regras específicas que originaram a regra generalizada. Nesse caso, embora o usuário tenha uma visão geral do domínio, ele ainda tem acesso às regras específicas, o que contribui na identificação das regras gerais e suas exceções (itens específicos relacionados aos itens gerais da regra generalizada). Assim, a partir dos resultados apresentados no Capítulo 5 a Hipótese 2 foi validada.

Algumas das contribuições citadas nesta tese podem ser encontradas nas seguintes publicações:

1. Carvalho, V. O.; Rezende, S. O.; Castro, M. Regras de Associação Generalizadas: Obtenção e Avaliação. Proceedings of the II Workshop em Algoritmos e Aplicações de Mineração de Dados (WAAMD-2006) - SBBD/SBES, 2006. pp. 81-88.

2. Carvalho, V. O.; Rezende, S. O.; Castro, M. Evaluating Generalized Association 
Rules through Objective Measures. In V. Devedžic (Eds.), Proceedings of the IASTED International Conference on Artificial Intelligence and Applications (AIA-2007), 2007. pp. 301-306.

3. Carvalho, V. O.; Rezende, S. O.; Castro, M. An Analytical Evaluation of Objective Measures Behavior for Generalized Association Rules. Proceedings of the IEEE Symposium on Computational Intelligence and Data Mining (CIDM-2007), 2007. pp. $43-50$.

4. Carvalho, V. O.; Rezende, S. O.; Castro, M. Obtaining and Evaluating Generalized Association Rules. Proceedings of the 9th International Conference on Enterprise Information Systems (ICEIS-2007), 2007.

5. Fujimoto, M. L.; Carvalho, V. O.; Rezende, S. O. Descrição do Módulo de Exploração de Regras de Associação Generalizadas RULEE-RAG. Relatório Técnico 296, Instituto de Ciências Matemáticas e de Computação - USP - São Carlos, 2007. 25p.

6. Martins, A. R.; Carvalho, V. O.; Rezende, S. O. AprioriGen: Uma Extensão do Algoritmo Apriori para Obtenção de Regras de Associação Generalizadas. Relatório Técnico 308, Instituto de Ciências Matemáticas e de Computação - USP - São Carlos, 2007. 53p.

\subsection{Trabalhos Futuros}

A seguir são apresentadas algumas propostas de trabalhos futuros que visam complementar, incrementar e dar seqüencia a esta tese:

- realizar experimentos utilizando outros conjuntos de dados;

- investigar a semântica de outras medidas de interesse objetivas não consideradas;

- realizar a dedução analítica das medidas não consideradas na Seção 5.3, página 105;

- utilizar outro algoritmo de extração de regras de associação que gere mais de um item no conseqüente e, assim, realizar mais experimentos para comparar com a generalização do lhs (Seção 4.8, página 82);

- considerar outros conjuntos de dados para explorar melhor a análise dos especialistas (Seção 5.4, página 116); considerar também mais regras a serem submetidas à análise dos especialistas; 
- desenvolver no RulEE-RAG um relatório de regras de exceção, no qual o usuário informaria uma valor de suporte mínimo que os itens específicos deveriam conter para compor um item geral de uma regra generalizada. Assim, todas as regras generalizadas que contivessem um item geral constituído por itens específicos abaixo do especificado seriam adicionadas ao relatório, juntamente com os itens específicos em questão, a fim de compor uma regra de exceção;

- realizar um estudo da aplicação de outras técnicas de pós-processamento na avaliação de regras de associação generalizadas;

- realizar uma análise comparativa das abordagens de pós-processamento de regras de associação existentes na literatura a fim de verificar a aplicação e a utilização de cada uma delas em diversos contextos. 
Apêndice

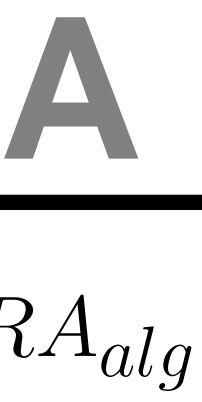

\section{Exemplo de Execução do $A P R A_{a l g}$}

Nesse apêndice é apresentado um exemplo de utilização da abordagem proposta $(A P R A)$ via a execução do $A P R A_{\text {alg }}$ (Algoritmo 2, página 59). Todos os conjuntos apresentados no exemplo da Seção 4.5 (página 66) são aqui considerados. Assim, o conjunto de dados utilizado para gerar o conjunto de regras de associação é o apresentado na Figura A.1; o conjunto de regras de associação, obtido utilizando o mesmo algoritmo e os mesmos parâmetros apresentados na Seção 4.5, é o apresentado na Figura A.2; a taxonomia utilizada no processo de generalização é a apresentada na Figura A.3.

\begin{tabular}{|llll}
\hline leite_batavo & nescau & pao & margarina \\
leite_batavo & nescau & pao & margarina \\
leite_nilza & nescau & pao & margarina \\
leite_nilza & nescau pao & margarina \\
leite_nilza & nescau pao & margarina \\
leite_parmalat & nescau pao & margarina \\
leite_parmalat & acucar cafe & \\
macarrao & molho_tomate & cebola \\
molho_tomate & lazanha coca_cola
\end{tabular}

Figura A.1: Arquivo de dados (correspondente ao arquivo .apr.data da Figura 4.4, página 53) utilizado nesse apêndice e no exemplo da Seção 4.5.

Para a apresentação do exemplo será considerado que o lado a ser generalizado é o $l r h s$, que a medida $M$ é o suporte $($ sup) e que a taxa $t$ é de $0 \%$. Para toda a explicação descrita a seguir encontra-se, entre parênteses, a linha em que a mesma é ativada no Algoritmo 2, página 59. 
[R0001],TRUE, leite_nilza, [0.333333,0.666667,0.000000,0.000000,9]

[R0002] , TRUE, nescau, $[0.666667,0.333333,0.000000,0.000000,9]$

[R0003], TRUE, pao, [0.666667, 0.333333,0.000000, $0.000000,9]$

[R0004], TRUE, margarina, [0.666667,0.333333,0.000000,0.000000,9]

[R0005], leite_nilza, nescau, [0.333333,0.000000,0.333333,0.333333,9]

[R0006], nescau, leite_nilza, [0.333333,0.333333,0.333333,0.000000,9]

[R0007], leite_nilza,pao, [0.333333,0.000000,0.333333,0.333333, 9]

[R0008], pao,leite_nilza, [0.333333,0.333333,0.333333,0.000000,9]

[R0009], leite_nilza,margarina, [0.333333,0.000000,0.333333,0.333333,9]

[R0010], margarina, leite_nilza, [0.333333, 0.333333,0.333333,0.000000,9]

[R0011], nescau, pao, $[0.666667,0.000000,0.333333,0.000000,9]$

[R0012], pao, nescau, $[0.666667,0.000000,0.333333,0.000000,9]$

$[\mathrm{R} 0013]$, nescau, margarina, $[0.666667,0.000000,0.333333,0.000000,9]$

[R0014], margarina, nescau, $[0.666667,0.000000,0.333333,0.000000,9]$

[R0015], pao, margarina, [0.666667, 0.000000, 0.333333, 0.000000,9]

[R0016], margarina, pao, $[0.666667,0.000000,0.333333,0.000000,9]$

[R0017], leite_nilza \& nescau,pao, [0.333333,0.000000,0.333333,0.333333,9]

[R0018], leite_nilza \& pao,nescau, [0.333333,0.000000,0.333333,0.333333,9]

[R0019], nescau \& pao,leite_nilza, [0.333333,0.333333,0.333333,0.000000,9]

[R0020], leite_nilza \& nescau,margarina, [0.333333,0.000000,0.333333,0.333333,9]

[R0021], leite_nilza \& margarina,nescau, [0.333333,0.000000,0.333333,0.333333,9]

[R0022], nescau \& margarina,leite_nilza, [0.333333,0.333333,0.333333,0.000000,9]

[R0023], leite_nilza \& pao,margarina, [0.333333,0.000000,0.333333,0.333333,9]

[R0024], leite_nilza \& margarina,pao, [0.333333,0.000000,0.333333,0.333333,9]

[R0025], pao \& margarina,leite_nilza, [0.333333,0.333333,0.333333,0.000000,9]

[R0026], nescau \& pao,margarina, [0.666667,0.000000,0.333333,0.000000,9]

[R0027], nescau \& margarina,pao, [0.666667,0.000000,0.333333,0.000000,9]

[R0028], pao \& margarina, nescau, [0.666667, 0.000000,0.333333,0.000000,9]

[R0029], leite_nilza \& nescau \& pao,margarina, $[0.333333,0.000000,0.333333,0.333333,9]$

[R0030], leite_nilza \& nescau \& margarina,pao, $[0.333333,0.000000,0.333333,0.333333,9]$

[R0031], leite_nilza \& pao \& margarina,nescau, [0.333333,0.000000,0.333333,0.333333,9]

[R0032], nescau \& pao \& margarina,leite_nilza, [0.333333,0.333333,0.333333,0.000000,9]

Figura A.2: Arquivo de regras de associação na sintaxe padrão (correspondente ao arquivo .apr.dcar da Figura 4.4, página 53) geradas a partir do arquivo de dados da Figura A.1, utilizado nesse apêndice e no exemplo da Seção 4.5.

leite(leite_batavo,leite_molico,leite_nilza,leite_parmalat, leite_salute)(1).

achocolatado (nescau, tody) (1).

produtos_matinais(leite, achocolatado) (2).

Figura A.3: Arquivo de taxonomias (correspondente ao arquivo .tax da Figura 4.4, página 53) utilizado nesse apêndice e no exemplo da Seção 4.5.

Assim como no exemplo apresentado na Seção 4.5, será gerada inicialmente (linha 1) a listagem contendo a participação de cada um dos itens específicos na composição dos itens gerais. A listagem nesse exemplo, apresentada na Figura A.4, será a mesma do exemplo apresentado na Seção 4.5, uma vez que a base de dados e a taxonomia consideradas são as mesmas.

Como o lado $L$ a ser generalizado é igual a $l r h s$, o processo inicia-se com a substituição dos itens específicos pelos itens gerais, a qual é realizada em ambos os lados da regra (linha 32). O processo de substituição é apresentado na Figura A.5. Após a substituição, o processo de eliminação dos itens repetidos (linha 33) e de ordenação dos itens (linha 34) 


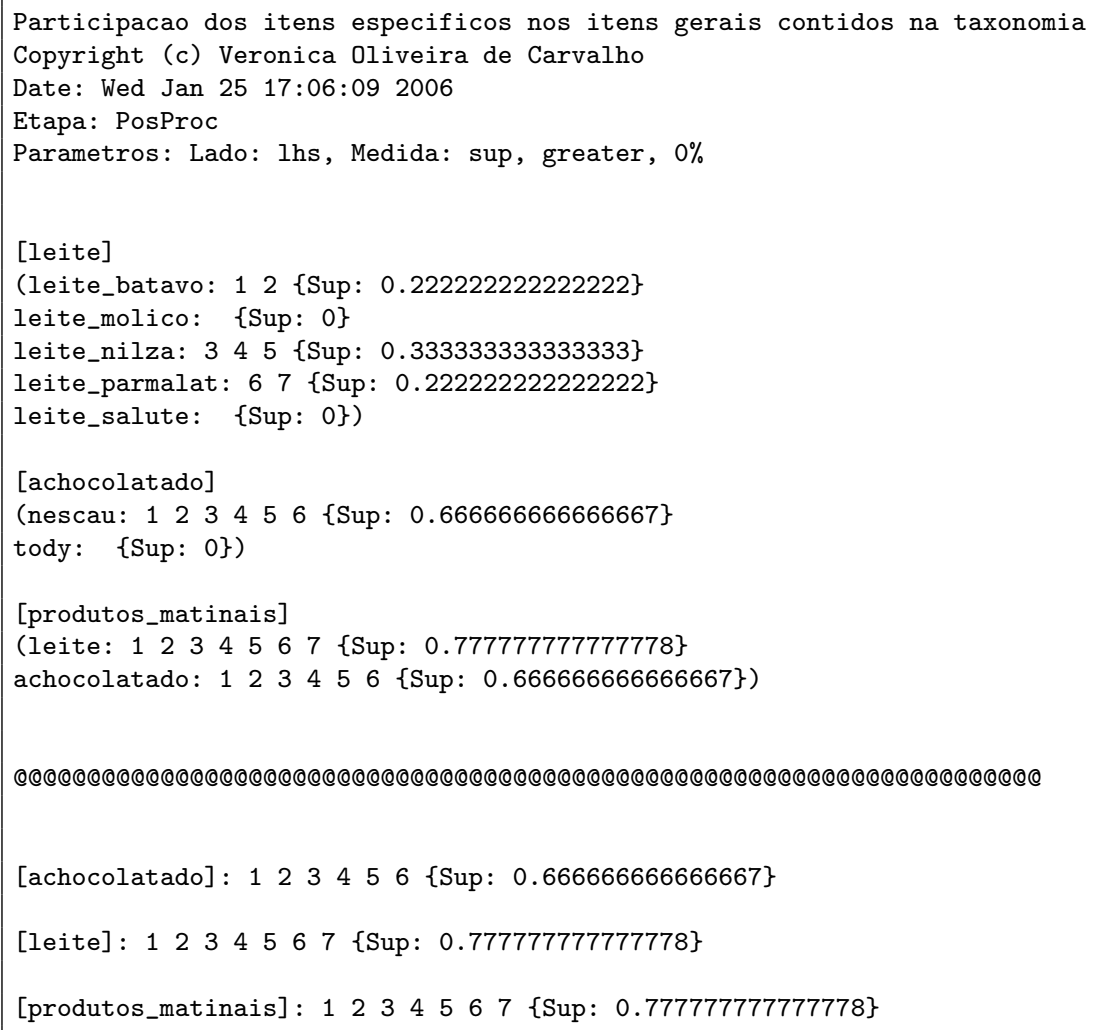

Figura A.4: Listagem de contribuição de itens do apêndice e do exemplo da Seção 4.5 (correspondente ao arquivo taxonomy_elements.txt da Figura 4.4, página 53).

é realizado, ambos mostrados nas Figuras A.6 e A.7, respectivamente. Note que no caso da opção $l h r s$, todas as funções são realizadas em ambos os lados da regra.

O próximo passo é agrupar as regras em subconjuntos que contenham regras iguais (estrutura sintática) (linha 35). Os subconjuntos gerados são apresentados na Figura A.8. Como nenhum dos subconjuntos gerados contêm duas ou mais regras (linha 36), o nível atual da taxonomia (NATax) passa a ser 2 e volta-se à linha 31 do algoritmo. Como ainda existe um nível da taxonomia a ser explorado (NATax $=2 \leqslant$ NMTax $=2$ ), as regras apresentadas na Figura A.7 são novamente substituídas pelos itens do nível atual da taxonomia (linha 32). Após a substituição, o processo para eliminar os itens repetidos (linha 33) e ordenar lexicograficamente os itens da regra (linha 34) é executado, gerando, para os 3 passos, os resultados apresentados nas Figuras A.9, A.10 e A.11. O próximo passo é agrupar as regras em subconjuntos que contenham regras iguais (estrutura sintática) (linha 35). Os subconjuntos gerados são apresentados na Figura A.12.

Como mencionado anteriormente, é importante observar que os valores da tabela de contingências das regras temporárias são calculados somente quando as mesmas se transformam em uma regra generalizada. Isso porque, é necessário que os valores das regras 
de origem sejam mantidos para se realizar a verificação do critério da medida utilizada na generalização (linha 41). Na verdade, essas regras são modificadas temporariamente, já que se elas não forem transformadas em uma regra generalizada as mesmas serão exibidas como no início do processo, uma vez que todo o processamento é realizado nos subconjuntos.

Para cada um dos subconjuntos obtidos (Figura A.12) que contêm duas ou mais regras (linha 36), o processo de verificação dos critérios é realizado. Assim como no exemplo da Seção 4.5, será exemplificado o processamento de apenas dois subconjuntos, nesse caso, o "Subconjunto 1-4" e o "Subconjunto 1-5", uma vez que o processamento dos demais é igual ao abaixo demonstrado. As Figuras A.13 e A.14 apresentam, respectivamente, o processo de verificação dos critérios nos dois subconjuntos selecionados. Observe que o primeiro subconjunto contém um exemplo de uma regra não válida, pelo fato da regra generalizada não cumprir o critério $L H S \cap R H S=\emptyset$. Portanto, a regra generalizada não é adicionada ao conjunto final de regras, o que não ocorre com o exemplo do segundo subconjunto.

Nesse ponto, considerando o "Subconjunto 1-5", a nova regra generalizada é incluída no arquivo final de regras (RGen) (correspondente ao arquivo rules_gen.txt da Figura 4.4, página 53) (linha 43) e as regras de origem da regra generalizada são excluídas (linha 44). Esse processo não é aqui demonstrado por ser igual ao exemplo apresentado na Seção 4.5.

Após o processamento de todos os subconjuntos restantes, regras repetidas do arquivo RGen são removidas (linha 51) e as restantes formatadas na sintaxe padrão apresentada na Seção 4.3.1, página 52 (linha 52). Após todo o processo, os arquivos de saída são os apresentados nas Figuras A.4 e A.15, ambos obtidos pelo APRA alg considerando as opções lrhs-sup-0\%, ou seja, que o lado generalizado foi o $l r h s$, que a medida $M$ considerada foi o suporte (sup) e que a taxa $t$ foi de $0 \%$. 


\section{Conjunto de Regras Original}

Substitui Itens

[R0001] ,TRUE, leite_nilza, [0.333333,0.666667,0.000000,0.000000,9]

-->Substitui leite_nilza por leite.

[R0002], TRUE, nescau, $[0.666667,0.333333,0.000000,0.000000,9]$

-->Substitui nescau por achocolatado.

[R0003] , TRUE, pao, [0.666667, 0.333333,0.000000,0.000000, 9]

-->Nenhum item da regra está contido na taxonomia. Portanto, a regra fica sem alteração. [R0004] , TRUE, margarina, [0.666667,0.333333,0.000000,0.000000,9]

-->Nenhum item da regra está contido na taxonomia. Portanto, a regra fica sem alteração.

[R0005], leite_nilza, nescau, [0.333333,0.000000,0.333333,0.333333,9]

-->Substitui leite_nilza por leite e nescau por achocolatado.

[R0006], nescau,leite_nilza, [0.333333,0.333333,0.333333,0.000000,9]

-->Substitui leite_nilza por leite e nescau por achocolatado.

[R0007], leite_nilza,pao, $[0.333333,0.000000,0.333333,0.333333,9]$

-->Substitui leite_nilza por leite.

[R0008], pao, leite_nilza, [0.333333,0.333333,0.333333,0.000000,9]

-->Substitui leite_nilza por leite.

[R0009], leite_nilza,margarina, [0.333333,0.000000,0.333333,0.333333,9]

-->Substitui leite_nilza por leite.

[R0010], margarina, leite_nilza, [0.333333,0.333333,0.333333,0.000000,9]

-->Substitui leite_nilza por leite.

[R0011], nescau, pao, [0.666667,0.000000,0.333333,0.000000,9]

-->Substitui nescau por achocolatado.

[R0012] , pao, nescau, [0.666667,0.000000,0.333333,0.000000,9]

-->Substitui nescau por achocolatado.

[R0013], nescau, margarina, [0.666667, 0.000000, 0.333333,0.000000,9]

-->Substitui nescau por achocolatado.

[R0014], margarina, nescau, [0.666667,0.000000,0.333333,0.000000,9]

-->Substitui nescau por achocolatado.

[R0015], pao,margarina, [0.666667, 0.000000,0.333333,0.000000,9]

-->Nenhum item da regra está contido na taxonomia. Portanto, a regra fica sem alteração. [R0016] ,margarina,pao, [0.666667,0.000000,0.333333,0.000000,9]

-->Nenhum item da regra está contido na taxonomia. Portanto, a regra fica sem alteração. [R0017], leite_nilza \& nescau,pao, [0.333333,0.000000,0.333333,0.333333,9]

->Substitui leite_nilza por leite e nescau por achocolatado.

[R0018], leite_nilza \& pao,nescau, [0.333333,0.000000,0.333333,0.333333,9]

-->Substitui leite_nilza por leite e nescau por achocolatado.

[R0019], nescau \& pao,leite_nilza, [0.333333,0.333333,0.333333,0.000000,9]

-->Substitui leite_nilza por leite e nescau por achocolatado.

[R0020], leite_nilza \& nescau,margarina, [0.333333,0.000000,0.333333,0.333333,9]

-->Substitui leite_nilza por leite e nescau por achocolatado.

[R0021], leite_nilza \& margarina,nescau, [0.333333,0.000000,0.333333,0.333333,9]

->Substitui leite_nilza por leite e nescau por achocolatado.

[R0022], nescau \& margarina,leite_nilza, [0.333333,0.333333,0.333333,0.000000,9]

-->Substitui leite_nilza por leite e nescau por achocolatado.

[R0023], leite_nilza \& pao,margarina, [0.333333,0.000000,0.333333,0.333333,9]

-->Substitui leite_nilza por leite.

[R0024], leite_nilza \& margarina,pao, [0.333333,0.000000,0.333333,0.333333,9]

-->Substitui leite_nilza por leite.

[R0025], pao \& margarina,leite_nilza, [0.333333,0.333333,0.333333,0.000000,9]

-->Substitui leite_nilza por leite.

[R0026], nescau \& pao,margarina, [0.666667,0.000000,0.333333,0.000000,9]

-->Substitui nescau por achocolatado.

[R0027], nescau \& margarina,pao, [0.666667,0.000000,0.333333,0.000000,9]

-->Substitui nescau por achocolatado.

[R0028], pao \& margarina, nescau, [0.666667,0.000000,0.333333,0.000000,9]

-->Substitui nescau por achocolatado.

[R0029], leite_nilza \& nescau \& pao,margarina, [0.333333,0.000000,0.333333,0.333333,9]

->Substitui leite_nilza por leite e nescau por achocolatado.

[R0030], leite_nilza \& nescau \& margarina,pao, $[0.333333,0.000000,0.333333,0.333333,9]$

-->Substitui leite_nilza por leite e nescau por achocolatado.

[R0031], leite_nilza \& pao \& margarina,nescau, $[0.333333,0.000000,0.333333,0.333333,9]$

-->Substitui leite_nilza por leite e nescau por achocolatado.

[R0032], nescau \& pao \& margarina,leite_nilza, [0.333333,0.333333,0.333333,0.000000,9]

-->Substitui leite_nilza por leite e nescau por achocolatado.

Figura A.5: Processo de substituição referente ao exemplo, utilizando o nível 1 da taxonomia. 
[R0001] , TRUE, leite, $[0.333333,0.666667,0.000000,0.000000,9]$

-->Não existem itens repetidos a serem excluídos.

[R0002] , TRUE, achocolatado, [0.666667, 0.333333, 0.000000, 0.000000,9]

-->Não existem itens repetidos a serem excluídos.

[R0003] , TRUE, pao, [0.666667, 0.333333, 0.000000,0.000000, 9]

-->Não existem itens repetidos a serem excluídos.

[R0004] , TRUE, margarina, [0.666667, 0.333333, $0.000000,0.000000,9]$

-->Não existem itens repetidos a serem excluídos.

[R0005], leite, achocolatado, [0.333333, 0.000000, 0.333333, 0.333333, 9]

-->Não existem itens repetidos a serem excluídos.

[R0006], achocolatado, leite, [0.333333, 0.333333, 0.333333, 0.000000,9]

-->Não existem itens repetidos a serem excluídos.

[R0007], leite, pao, [0.333333,0.000000,0.333333,0.333333,9]

-->Não existem itens repetidos a serem excluídos.

[R0008], pao, leite, [0.333333,0.333333,0.333333,0.000000,9]

-->Não existem itens repetidos a serem excluídos.

[R0009], leite, margarina, [0.333333, 0.000000,0.333333,0.333333,9]

-->Não existem itens repetidos a serem excluídos.

[R0010], margarina, leite , [0.333333, 0.333333,0.333333,0.000000,9]

-->Não existem itens repetidos a serem excluídos.

[R0011], achocolatado, pao, [0.666667, 0.000000, 0.333333, 0.000000, 9]

-->Não existem itens repetidos a serem excluídos.

[R0012], pao, achocolatado, [0.666667, 0.000000,0.333333, 0.000000,9]

-->Não existem itens repetidos a serem excluídos.

[R0013], achocolatado, margarina, [0.666667, 0.000000, 0.333333, 0.000000, 9]

->Não existem itens repetidos a serem excluídos.

[R0014] , margarina, achocolatado, [0.666667, 0.000000, 0.333333, 0.000000, 9]

-->Não existem itens repetidos a serem excluídos.

[R0015] , pao,margarina, [0.666667,0.000000,0.333333,0.000000,9]

-->Não existem itens repetidos a serem excluídos.

[R0016] , margarina, pao, [0.666667, 0.000000,0.333333,0.000000,9]

-->Não existem itens repetidos a serem excluídos.

[R0017], leite \& achocolatado,pao, [0.333333,0.000000,0.333333,0.333333,9]

-->Não existem itens repetidos a serem excluídos.

[R0018], leite \& pao, achocolatado, $[0.333333,0.000000,0.333333,0.333333,9]$

-->Não existem itens repetidos a serem excluídos.

[R0019], achocolatado \& pao,leite, [0.333333,0.333333,0.333333,0.000000,9]

-->Não existem itens repetidos a serem excluídos.

[R0020], leite \& achocolatado,margarina, [0.333333,0.000000,0.333333,0.333333,9]

-->Não existem itens repetidos a serem excluídos.

[R0021], leite \& margarina, achocolatado, [0.333333,0.000000,0.333333,0.333333,9]

-->Não existem itens repetidos a serem excluídos.

[R0022], achocolatado \& margarina, leite, [0.333333,0.333333, 0.333333, 0.000000,9]

-->Não existem itens repetidos a serem excluídos.

[R0023], leite \& pao,margarina, [0.333333,0.000000,0.333333,0.333333,9]

-->Não existem itens repetidos a serem excluídos.

[R0024], leite \& margarina,pao, [0.333333,0.000000,0.333333,0.333333,9]

-->Não existem itens repetidos a serem excluídos.

[R0025], pao \& margarina,leite, [0.333333,0.333333,0.333333,0.000000,9]

-->Não existem itens repetidos a serem excluídos.

[R0026], achocolatado \& pao, margarina, [0.666667, 0.000000,0.333333,0.000000,9]

-->Não existem itens repetidos a serem excluídos.

[R0027], achocolatado \& margarina, pao, [0.666667,0.000000,0.333333, 0.000000,9]

-->Não existem itens repetidos a serem excluídos.

[R0028], pao \& margarina, achocolatado, [0.666667,0.000000,0.333333,0.000000,9]

-->Não existem itens repetidos a serem excluídos.

[R0029], leite \& achocolatado \& pao,margarina, [0.333333,0.000000,0.333333,0.333333,9]

-->Não existem itens repetidos a serem excluídos.

[R0030], leite \& achocolatado \& margarina,pao, $[0.333333,0.000000,0.333333,0.333333,9]$

-->Não existem itens repetidos a serem excluídos.

[R0031], leite \& pao \& margarina, achocolatado, $[0.333333,0.000000,0.333333,0.333333,9]$

-->Não existem itens repetidos a serem excluídos.

[R0032], achocolatado \& pao \& margarina,leite, $[0.333333,0.333333,0.333333,0.000000,9]$

-->Não existem itens repetidos a serem excluídos.

Figura A.6: Processo de eliminação referente ao exemplo, utilizando o nível 1 da taxonomia. 
Novo Subconjunto - Subconjunto Substituído, Sem Itens Repetidos e com os Itens Ordenados Ordena Itens Lexicograficamente

[R0001] , TRUE, leite, $[0.333333,0.666667,0.000000,0.000000,9]$

[R0002], TRUE, achocolatado, $[0.666667,0.333333,0.000000,0.000000,9]$

[R0003] , TRUE, pao, $[0.666667,0.333333,0.000000,0.000000,9]$

[R0004], TRUE, margarina, [0.666667, 0.333333, 0.000000,0.000000, 9]

[R0005], leite, achocolatado, $[0.333333,0.000000,0.333333,0.333333,9]$

[R0006], achocolatado, leite, [0.333333,0.333333,0.333333,0.000000,9]

[R0007], leite, pao, [0.333333,0.000000,0.333333,0.333333,9]

[R0008], pao, leite, [0.333333,0.333333,0.333333,0.000000,9]

[R0009], leite, margarina, $[0.333333,0.000000,0.333333,0.333333,9]$

[R0010], margarina, leite, $[0.333333,0.333333,0.333333,0.000000,9]$

[R0011], achocolatado, pao, $[0.666667,0.000000,0.333333,0.000000,9]$

[R0012], pao, achocolatado, $[0.666667,0.000000,0.333333,0.000000,9]$

[R0013], achocolatado, margarina, [0.666667,0.000000,0.333333,0.000000,9]

[R0014], margarina, achocolatado, [0.666667, 0.000000, 0.333333, 0.000000,9]

[R0015], pao,margarina, [0.666667, 0.000000,0.333333,0.000000,9]

[R0016], margarina, pao, $[0.666667,0.000000,0.333333,0.000000,9]$

[R0017], achocolatado \& leite,pao, [0.333333, 0.000000,0.333333,0.333333,9]

[R0018], leite \& pao, achocolatado, [0.333333,0.000000,0.333333,0.333333,9]

[R0019], achocolatado \& pao, leite, [0.333333,0.333333,0.333333,0.000000,9]

[R0020], achocolatado \& leite, margarina, $[0.333333,0.000000,0.333333,0.333333,9]$

[R0021], leite \& margarina, achocolatado, [0.333333,0.000000,0.333333,0.333333,9]

[R0022], achocolatado \& margarina,leite, $[0.333333,0.333333,0.333333,0.000000,9]$

[R0023], leite \& pao,margarina, [0.333333,0.000000,0.333333,0.333333,9]

[R0024], leite \& margarina, pao, [0.333333,0.000000,0.333333,0.333333,9]

[R0025], margarina \& pao,leite, $[0.333333,0.333333,0.333333,0.000000,9]$

[R0026], achocolatado \& pao,margarina, [0.666667,0.000000,0.333333,0.000000,9]

[R0027], achocolatado \& margarina, pao, [0.666667,0.000000,0.333333,0.000000,9]

[R0028], margarina \& pao, achocolatado, $[0.666667,0.000000,0.333333,0.000000,9]$

[R0029], achocolatado \& leite \& pao,margarina, $[0.333333,0.000000,0.333333,0.333333,9]$

[R0030], achocolatado \& leite \& margarina,pao, $[0.333333,0.000000,0.333333,0.333333,9]$

[R0031], leite \& margarina \& pao, achocolatado, $[0.333333,0.000000,0.333333,0.333333,9]$

[R0032], achocolatado \& margarina \& pao,leite, $[0.333333,0.333333,0.333333,0.000000,9]$

Figura A.7: Processo de ordenação referente ao exemplo, utilizando o nível 1 da taxonomia. 


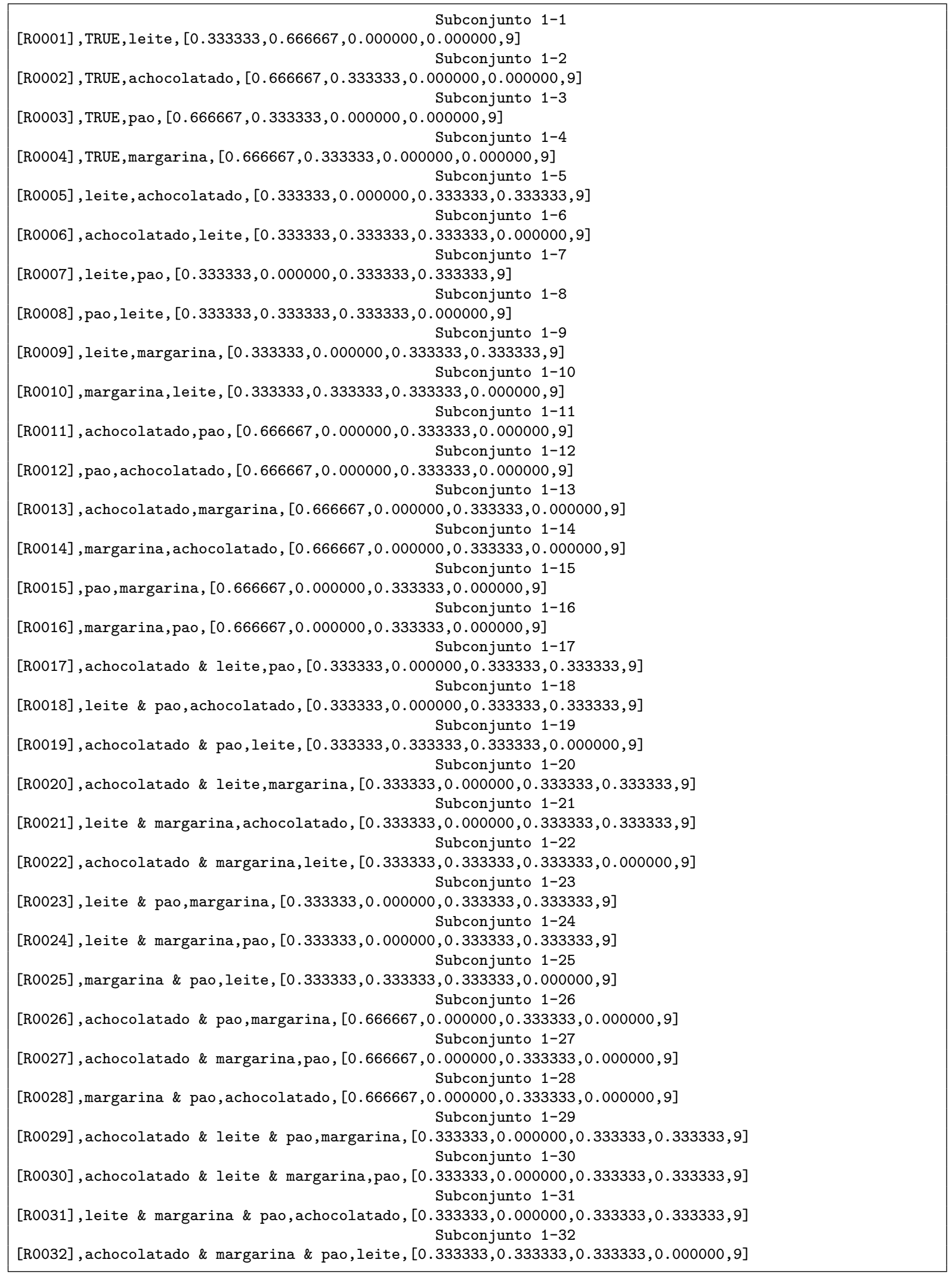

Figura A.8: Subconjuntos gerados, a partir da Figura A.7, utilizando o nível 1 da taxonomia, referente ao exemplo. 
[R0001], TRUE, leite, $[0.333333,0.666667,0.000000,0.000000,9]$

-->Substitui leite por produtos_matinais.

[R0002] , TRUE, achocolatado, $[0.666667,0.333333,0.000000,0.000000,9]$

-->Substitui achocolatado por produtos_matinais.

[R0003] , TRUE, pao, $[0.666667,0.333333,0.000000,0.000000,9]$

-->Nenhum item da regra está contido na taxonomia. Portanto, a regra fica sem alteração. [R0004] , TRUE, margarina, [0.666667, $0.333333,0.000000,0.000000,9]$

-->Nenhum item da regra está contido na taxonomia. Portanto, a regra fica sem alteração.

[R0005], leite, achocolatado, [0.333333, 0.000000, 0.333333, 0.333333, 9]

-->Substitui leite e achocolatado por produtos_matinais.

[R0006], achocolatado, leite, [0.333333,0.333333,0.333333, 0.000000,9]

->Substitui achocolatado e leite por produtos_matinais.

[R0007], leite, pao, [0.333333,0.000000,0.333333,0.333333,9]

-->Substitui leite por produtos_matinais.

[R0008], pao, leite, $[0.333333,0.333333,0.333333,0.000000,9]$

-->Substitui leite por produtos_matinais.

[R0009], leite, margarina, [0.333333,0.000000, 0.333333, 0.333333,9]

-->Substitui leite por produtos_matinais .

[R0010], margarina, leite, $[0.333333,0.333333,0.333333,0.000000,9]$

->Substitui leite por produtos_matinais.

[R0011], achocolatado, pao, $[0.666667,0.000000,0.333333,0.000000,9]$

-->Substitui achocolatado por produtos_matinais.

[R0012] , pao, achocolatado, [0.666667, 0.000000, 0.333333, 0.000000,9]

-->Substitui achocolatado por produtos_matinais.

[R0013] , achocolatado, margarina, [0.666667, $0.000000,0.333333,0.000000,9]$

-->Substitui achocolatado por produtos_matinais.

[R0014] , margarina, achocolatado, $[0.666667,0.000000,0.333333,0.000000,9]$

-> Substitui achocolatado por produtos_matinais.

[R0015] , pao, margarina, $[0.666667,0.000000,0.333333,0.000000,9]$

$-\rightarrow$ Nenhum item da regra está contido na taxonomia. Portanto, a regra fica sem alteração. [R0016] , margarina, pao, [0.666667, $0.000000,0.333333,0.000000,9]$

-->Nenhum item da regra está contido na taxonomia. Portanto, a regra fica sem alteração. [R0017], achocolatado \& leite, pao, $[0.333333,0.000000,0.333333,0.333333,9]$

-> Substitui achocolatado e leite por produtos_matinais.

[R0018], leite \& pao, achocolatado, [0.333333,0.000000, 0.333333,0.333333, 9]

-->Substitui leite e achocolatado por produtos_matinais.

[R0019], achocolatado \& pao,leite, $[0.333333,0.333333,0.333333,0.000000,9]$

-->Substitui achocolatado e leite por produtos_matinais.

[R0020], achocolatado \& leite, margarina, $[0.333333,0.000000,0.333333,0.333333,9]$

-->Substitui achocolatado e leite por produtos_matinais.

[R0021], leite \& margarina, achocolatado, [0.333333, $0.000000,0.333333,0.333333,9]$

->Substitui leite e achocolatado por produtos_matinais.

[R0022], achocolatado \& margarina, leite, $[0.333333,0.333333,0.333333,0.000000,9]$

-->Substitui achocolatado e leite por produtos_matinais.

[R0023], leite \& pao,margarina, $[0.333333,0.000000,0.333333,0.333333,9]$

-->Substitui leite por produtos_matinais.

[R0024], leite \& margarina, pao, $[0.333333,0.000000,0.333333,0.333333,9]$

->Substitui leite por produtos_matinais.

[R0025], margarina \& pao,leite, [0.333333,0.333333,0.333333,0.000000,9]

->Substitui leite por produtos_matinais.

[R0026], achocolatado \& pao, margarina, [0.666667, 0.0000000, 0.333333, 0.000000, 9]

-->Substitui achocolatado por produtos_matinais.

[R0027], achocolatado \& margarina, pao, [0.666667, 0.000000, 0.333333,0.000000, 9]

-->Substitui achocolatado por produtos_matinais.

[R0028], margarina \& pao, achocolatado, $[0.666667,0.000000,0.333333,0.000000,9]$

-->Substitui achocolatado por produtos_matinais.

[R0029], achocolatado \& leite \& pao,margarina, $[0.333333,0.000000,0.333333,0.333333,9]$

-->Substitui achocolatado e leite por produtos_matinais.

[R0030], achocolatado \& leite \& margarina,pao, $[0.333333,0.000000,0.333333,0.333333,9]$

-->Substitui achocolatado e leite por produtos_matinais.

[R0031], leite \& margarina \& pao, achocolatado, $[0.333333,0.000000,0.333333,0.333333,9]$

-->Substitui leite e achocolatado por produtos_matinais.

[R0032], achocolatado \& margarina \& pao,leite, $[0.333333,0.333333,0.333333,0.000000,9]$

-->Substitui achocolatado e leite por produtos_matinais.

Figura A.9: Processo de substituição referente ao exemplo, utilizando o nível 2 da taxonomia. 
[R0001] , TRUE, produtos_matinais, $[0.333333,0.666667,0.000000,0.000000,9]$

-->Não existem itens repetidos a serem excluídos.

[R0002] , TRUE, produtos_matinais, $[0.666667,0.333333,0.000000,0.000000,9]$

-->Não existem itens repetidos a serem excluídos.

[R0003] , TRUE, pao, $[0.666667,0.333333,0.000000,0.000000,9]$

-->Não existem itens repetidos a serem excluídos.

[R0004] , TRUE, margarina, [0.666667, 0.333333, 0.000000, 0.000000, 9]

-->Não existem itens repetidos a serem excluídos.

[R0005], produtos_matinais,produtos_matinais, $[0.333333,0.000000,0.333333,0.333333,9]$

-->Não existem itens repetidos a serem excluídos.

[R0006],produtos_matinais,produtos_matinais, $[0.333333,0.333333,0.333333,0.000000,9]$

-->Não existem itens repetidos a serem excluídos.

[R0007], produtos_matinais, pao, $[0.333333,0.000000,0.333333,0.333333,9]$

-->Não existem itens repetidos a serem excluídos.

[R0008], pao,produtos_matinais, [0.333333,0.333333,0.333333,0.000000,9]

-->Não existem itens repetidos a serem excluídos.

[R0009], produtos_matinais,margarina, [0.333333,0.000000,0.333333,0.333333,9]

-->Não existem itens repetidos a serem excluídos.

[R0010], margarina,produtos_matinais, $[0.333333,0.333333,0.333333,0.000000,9]$

-->Não existem itens repetidos a serem excluídos.

[R0011],produtos_matinais,pao, [0.666667, 0.000000,0.333333,0.000000,9]

-->Não existem itens repetidos a serem excluídos.

[R0012], pao,produtos_matinais, $[0.666667,0.000000,0.333333,0.000000,9]$

-->Não existem itens repetidos a serem excluídos.

[R0013], produtos_matinais,margarina, [0.666667, 0.000000,0.333333, 0.000000,9]

->Não existem itens repetidos a serem excluídos.

[R0014], margarina, produtos_matinais, [0.666667,0.000000,0.333333,0.000000,9]

-->Não existem itens repetidos a serem excluídos.

[R0015], pao,margarina, $[0.666667,0.000000,0.333333,0.000000,9]$

-->Não existem itens repetidos a serem excluídos.

[R0016], margarina, pao, $[0.666667,0.000000,0.333333,0.000000,9]$

-->Não existem itens repetidos a serem excluídos.

[R0017],produtos_matinais \& produtos_matinais,pao, $[0.333333,0.000000,0.333333,0.333333,9]$

-->Item a ser excluído: produtos_matinais.

[R0018],produtos_matinais \& pao,produtos_matinais, $[0.333333,0.000000,0.333333,0.333333,9]$

$-\rightarrow$ Não existem itens repetidos a serem excluídos.

[R0019],produtos_matinais \& pao,produtos_matinais, $[0.333333,0.333333,0.333333,0.000000,9]$

-->Não existem itens repetidos a serem excluídos.

[R0020],produtos_matinais \& produtos_matinais,margarina, [0.333333,0.000000,0.333333,0.333333,9]

-->Item a ser excluído: produtos_matinais.

[R0021],produtos_matinais \& margarina,produtos_matinais, [0.333333,0.000000,0.333333,0.333333,9]

-->Não existem itens repetidos a serem excluídos.

[R0022],produtos_matinais \& margarina,produtos_matinais, [0.333333,0.333333,0.333333,0.000000,9]

$->$ Não existem itens repetidos a serem excluídos.

[R0023],produtos_matinais \& pao,margarina, $[0.333333,0.000000,0.333333,0.333333,9]$

-->Não existem itens repetidos a serem excluídos.

[R0024], produtos_matinais \& margarina,pao, $[0.333333,0.000000,0.333333,0.333333,9]$

-->Não existem itens repetidos a serem excluídos.

[R0025], margarina \& pao,produtos_matinais, $[0.333333,0.333333,0.333333,0.000000,9]$

-->Não existem itens repetidos a serem excluídos.

[R0026],produtos_matinais \& pao,margarina, $[0.666667,0.000000,0.333333,0.000000,9]$

-->Não existem itens repetidos a serem excluídos.

[R0027],produtos_matinais \& margarina,pao, $[0.666667,0.000000,0.333333,0.000000,9]$

-->Não existem itens repetidos a serem excluídos.

[R0028], margarina \& pao,produtos_matinais, $[0.666667,0.000000,0.333333,0.000000,9]$

-->Não existem itens repetidos a serem excluídos.

[R0029],produtos_matinais \& produtos_matinais \& pao,margarina, [0.333333,0.000000,0.333333,0.333333,9]

-->Item a ser excluído: produtos_matinais.

[R0030],produtos_matinais \& produtos_matinais \& margarina,pao, [0.333333,0.000000,0.333333,0.333333,9]

-->Item a ser excluído: produtos_matinais.

[R0031],produtos_matinais \& margarina \& pao,produtos_matinais, [0.333333,0.000000,0.333333,0.333333,9]

-->Não existem itens repetidos a serem excluídos.

[R0032],produtos_matinais \& margarina \& pao,produtos_matinais, [0.333333,0.333333,0.333333,0.000000,9] -->Não existem itens repetidos a serem excluídos.

Figura A.10: Processo de eliminação referente ao exemplo, utilizando o nível 2 da taxonomia. 
Novo Subconjunto - Subconjunto Substituído, Sem Itens Repetidos e com os Itens Ordenados Ordena Itens Lexicograficamente

[R0001] ,TRUE, produtos_matinais, $[0.333333,0.666667,0.000000,0.000000,9]$

[R0002], TRUE, produtos_matinais, $[0.666667,0.333333,0.000000,0.000000,9]$

[R0003] , TRUE, pao, $[0.666667,0.333333,0.000000,0.000000,9]$

[R0004], TRUE, margarina, $[0.666667,0.333333,0.000000,0.000000,9]$

[R0005],produtos_matinais,produtos_matinais, $[0.333333,0.000000,0.333333,0.333333,9]$

[R0006], produtos_matinais, produtos_matinais, $[0.333333,0.333333,0.333333,0.000000,9]$

[R0007], produtos_matinais, pao, $[0.333333,0.000000,0.333333,0.333333,9]$

[R0008], pao,produtos_matinais, [0.333333,0.333333,0.333333,0.000000,9]

[R0009], produtos_matinais, margarina, [0.333333,0.000000,0.333333,0.333333,9]

[R0010], margarina, produtos_matinais, $[0.333333,0.333333,0.333333,0.000000,9]$

[R0011], produtos_matinais, pao, $[0.666667,0.000000,0.333333,0.000000,9]$

[R0012], pao,produtos_matinais, [0.666667,0.000000,0.333333,0.000000,9]

[R0013], produtos_matinais, margarina, [0.666667,0.000000,0.333333,0.000000,9]

[R0014], margarina,produtos_matinais, [0.666667,0.000000,0.333333,0.000000,9]

[R0015], pao,margarina, [0.666667,0.000000,0.333333,0.000000,9]

[R0016], margarina, pao, $[0.666667,0.000000,0.333333,0.000000,9]$

[R0017],produtos_matinais,pao, [0.333333,0.000000,0.333333,0.333333,9]

[R0018], pao \& produtos_matinais,produtos_matinais, $[0.333333,0.000000,0.333333,0.333333,9]$

[R0019], pao \& produtos_matinais,produtos_matinais, $[0.333333,0.333333,0.333333,0.000000,9]$

[R0020], produtos_matinais, margarina, [0.333333,0.000000,0.333333,0.333333,9]

[R0021],margarina \& produtos_matinais,produtos_matinais, [0.333333,0.000000,0.333333,0.333333,9]

[R0022], margarina \& produtos_matinais,produtos_matinais, [0.333333,0.333333,0.333333,0.000000,9]

[R0023], pao \& produtos_matinais,margarina, $[0.333333,0.000000,0.333333,0.333333,9]$

[R0024], margarina \& produtos_matinais,pao, $[0.333333,0.000000,0.333333,0.333333,9]$

[R0025], margarina \& pao,produtos_matinais, [0.333333,0.333333,0.333333,0.000000,9]

[R0026], pao \& produtos_matinais,margarina, [0.666667,0.000000,0.333333,0.000000,9]

[R0027], margarina \& produtos_matinais,pao, [0.666667,0.000000,0.333333,0.000000,9]

[R0028], margarina \& pao,produtos_matinais, [0.666667,0.000000,0.333333,0.000000,9]

[R0029], pao \& produtos_matinais,margarina, [0.333333,0.000000,0.333333,0.333333,9]

[R0030], margarina \& produtos_matinais,pao, $[0.333333,0.000000,0.333333,0.333333,9]$

[R0031],margarina \& pao \& produtos_matinais,produtos_matinais, [0.333333,0.000000,0.333333,0.333333,9]

[R0032], margarina \& pao \& produtos_matinais,produtos_matinais, [0.333333,0.333333,0.333333,0.000000,9]

Figura A.11: Processo de ordenação referente ao exemplo, utilizando o nível 2 da taxonomia. 
Subconjunto $1-1$

[R0001] ,TRUE,produtos_matinais, $[0.333333,0.666667,0.000000,0.000000,9]$

[R0002], TRUE, produtos_matinais, $[0.666667,0.333333,0.000000,0.000000,9]$

Subconjunto $1-2$

[R0003] , TRUE, pao, $[0.666667,0.333333,0.000000,0.000000,9]$

Subconjunto $1-3$

[R0004] ,TRUE, margarina, $[0.666667,0.333333,0.000000,0.000000,9]$

Subconjunto $1-4$

[R0005], produtos_matinais, produtos_matinais, $[0.333333,0.000000,0.333333,0.333333,9]$

[R0006], produtos_matinais, produtos_matinais, $[0.333333,0.333333,0.333333,0.000000,9]$

Subconjunto $1-5$

[R0007], produtos_matinais, pao, $[0.333333,0.000000,0.333333,0.333333,9]$

[R0011], produtos_matinais, pao, $[0.666667,0.000000,0.333333,0.000000,9]$

[R0017], produtos_matinais , pao, $[0.333333,0.000000,0.333333,0.333333,9]$

Subconjunto 1-6

[R0008], pao,produtos_matinais, $[0.333333,0.333333,0.333333,0.000000,9]$

[R0012], pao,produtos_matinais, $[0.666667,0.000000,0.333333,0.000000,9]$

Subconjunto $1-7$

[R0009], produtos_matinais, margarina, $[0.333333,0.000000,0.333333,0.333333,9]$

[R0013], produtos_matinais, margarina, $[0.666667,0.000000,0.333333,0.000000,9]$

[R0020], produtos_matinais, margarina, $[0.333333,0.000000,0.333333,0.333333,9]$

Subconjunto $1-8$

[R0010], margarina, produtos_matinais, $[0.333333,0.333333,0.333333,0.000000,9]$

[R0014], margarina, produtos_matinais, $[0.666667,0.000000,0.333333,0.000000,9]$

Subconjunto $1-9$

[R0015], pao, margarina, $[0.666667,0.000000,0.333333,0.000000,9]$

Subconjunto $1-10$

[R0016] ,margarina, pao, $[0.666667,0.000000,0.333333,0.000000,9]$

Subconjunto $1-11$

[R0018], pao \& produtos_matinais,produtos_matinais, $[0.333333,0.000000,0.333333,0.333333,9]$

[R0019], pao \& produtos_matinais,produtos_matinais, $[0.333333,0.333333,0.333333,0.000000,9]$

Subconjunto $1-12$

[R0021], margarina \& produtos_matinais, produtos_matinais, $[0.333333,0.000000,0.333333,0.333333,9]$

[R0022], margarina \& produtos_matinais, produtos_matinais, $[0.333333,0.333333,0.333333,0.000000,9]$

Subconjunto $1-13$

[R0023],pao \& produtos_matinais, margarina, $[0.333333,0.000000,0.333333,0.333333,9]$

[R0026], pao \& produtos_matinais,margarina, $[0.666667,0.000000,0.333333,0.000000,9]$

[R0029], pao \& produtos_matinais, margarina, $[0.333333,0.000000,0.333333,0.333333,9]$

Subconjunto $1-14$

[R0024],margarina \& produtos_matinais,pao, $[0.333333,0.000000,0.333333,0.333333,9]$

[R0027], margarina \& produtos_matinais,pao, $[0.666667,0.000000,0.333333,0.000000,9]$

[R0030], margarina \& produtos_matinais, pao, $[0.333333,0.000000,0.333333,0.333333,9]$

Subconjunto $1-15$

[R0025], margarina \& pao,produtos_matinais, $[0.333333,0.333333,0.333333,0.000000,9]$

[R0028], margarina \& pao,produtos_matinais, $[0.666667,0.000000,0.333333,0.000000,9]$

Subconjunto $1-16$

[R0031], margarina \& pao \& produtos_matinais,produtos_matinais, $[0.333333,0.000000,0.333333,0.333333,9]$

[R0032], margarina \& pao \& produtos_matinais,produtos_matinais, $[0.333333,0.333333,0.333333,0.000000,9]$

Figura A.12: Subconjuntos gerados, a partir da Figura A.11, utilizando o nível 2 da taxonomia, referente ao exemplo. 
Subconjunto $1-4$

[R0005], produtos_matinais, produtos_matinais, $[0.333333,0.000000,0.333333,0.333333,9]$

[R0006], produtos_matinais, produtos_matinais, $[0.333333,0.333333,0.333333,0.000000,9]$

$r:=$ produtos_matinais,produtos_matinais

Critérios de generalização:

1. Nenhum item filho de LHS implica em um item pai de RHS.

$-\rightarrow$ True.

2. Nenhum item pai de LHS implica em um item filho de RHS.

$-\rightarrow$ True.

3. A intersecção de LHS com RHS é vazia.

$-->$ False.

Como a intersecção de LHS com RHS não é vazia, a regra $r$ não é uma regra válida.

Figura A.13: Processo de verificação da regra generalizada ("Subconjunto 1-4") no exemplo: critérios de generalização e critério da medida utilizada na generalização.

Subconjunto $1-5$

[R0007] ,produtos_matinais, pao, $[0.333333,0.000000,0.333333,0.333333,9]$

[R0011],produtos_matinais, pao, $[0.666667,0.000000,0.333333,0.000000,9]$

[R0017], produtos_matinais, pao, $[0.333333,0.000000,0.333333,0.333333,9]$

$\mathrm{r}:=$ produtos_matinais, pao

Critérios de generalização:

1. Nenhum item filho de LHS implica em um item pai de RHS.

$-\rightarrow$ True.

2. Nenhum item pai de LHS implica em um item filho de RHS.

--> True.

3. A intersecção de LHS com RHS é vazia.

$-\rightarrow$ True.

Como os critérios de generalização são válidos, calcula-se a tabela de contingência de $r$.

LHS de $r=\{1,2,3,4,5,6\}$.

RHS de $r=\{1,2,3,4,5,6\}$.

$f($ LHS RHS $)=(6 / 9)=0.666667 ; f($ LHS nRHS $)=(0 / 9)=0.000000 ;$

$f(n L H S$ RHS $)=(0 / 9)=0.000000 ; f(n L H S$ nRHS $)=(3 / 9)=0.333333$.

Critério da medida de generalização:

Medida considerada: sup.

Taxa: $0 \%$

Máximo valor de suporte das regras de origem: $\operatorname{Max}(0.333333,0.666667,0.333333)=0.666667$.

Como $(0.666667>=((0.666667 * 0 \%)+0.666667))$ a regra $\mathrm{r}$ é uma regra generalizada válida.

Figura A.14: Processo de verificação da regra generalizada ("Subconjunto 1-5") no exemplo: critérios de generalização e critérios de medida. 
Regras de associacao generalizadas

Copyright (c) Veronica Oliveira de Carvalho

Date: Wed Jan 25 17:05:54 2006

Etapa: PosProc

Parametros: Lado: Irhs, Medida: sup, greater, $0 \%$

[R0001] , TRUE, pao, $[0.666667,0.333333,0.000000,0.000000,9],[R 0003]$

[R0002] , TRUE, margarina, [0.666667,0.333333, 0.000000,0.000000, 9] , [R0004]

[R0003], leite_nilza, nescau, [0.333333, 0.000000,0.333333,0.333333, 9] , [R0005]

[R0004], nescau, leite_nilza, [0.333333,0.333333,0.333333,0.000000, 9] , [R0006]

[R0005], pao,margarina, [0.666667,0.000000,0.333333,0.000000, 9] , [R0015]

[R0006], margarina, pao, $[0.666667,0.000000,0.333333,0.000000,9]$, [R0016]

[R0007], leite_nilza \& pao,nescau, [0.333333,0.000000,0.333333,0.333333,9], [R0018]

[R0008], nescau \& pao,leite_nilza, [0.333333,0.333333,0.333333,0.000000,9], [R0019]

[R0009], leite_nilza \& margarina,nescau, [0.333333,0.000000,0.333333,0.333333,9], [R0021]

[R0010], margarina \& nescau,leite_nilza, [0.333333,0.333333,0.333333,0.000000,9], [R0022]

[R0011], leite_nilza \& margarina \& pao,nescau, [0.333333,0.000000,0.333333,0.333333,9], [R0031]

[R0012], margarina \& nescau \& pao,leite_nilza, [0.333333,0.333333,0.333333,0.000000,9], [R0032]

[R0013], margarina \& produtos_matinais,pao, [0.666667,0.000000,0.333333,0.000000,9], [R0024,R0027,R0030]

[R0014], TRUE, produtos_matinais, [0.777778, 0.222222,0.000000,0.000000,9], [R0001, R0002]

[R0015], margarina \& pao,produtos_matinais, [0.666667,0.000000,0.222222,0.111111,9], [R0025,R0028]

[R0016] , pao,produtos_matinais , [0.666667,0.000000,0.222222,0.111111, 9] , [R0008, R0012]

[R0017], produtos_matinais,margarina, [0.666667,0.111111,0.222222,0.000000,9], [R0009,R0013,R0020]

[R0018], produtos_matinais, pao, [0.666667,0.111111,0.222222, 0.000000, 9] , [R0007, R0011, R0017]

[R0019], pao \& produtos_matinais,margarina, $[0.666667,0.000000,0.333333,0.000000,9],[R 0023, R 0026, R 0029]$

[R0020], margarina,produtos_matinais, [0.666667, 0.000000,0.222222, 0.111111, 9], [R0010, R0014]

Figura A.15: Arquivo do conjunto final de regras de associação generalizadas referente ao exemplo (correspondente ao arquivo rules_gen.txt da Figura 4.4, página 53). 


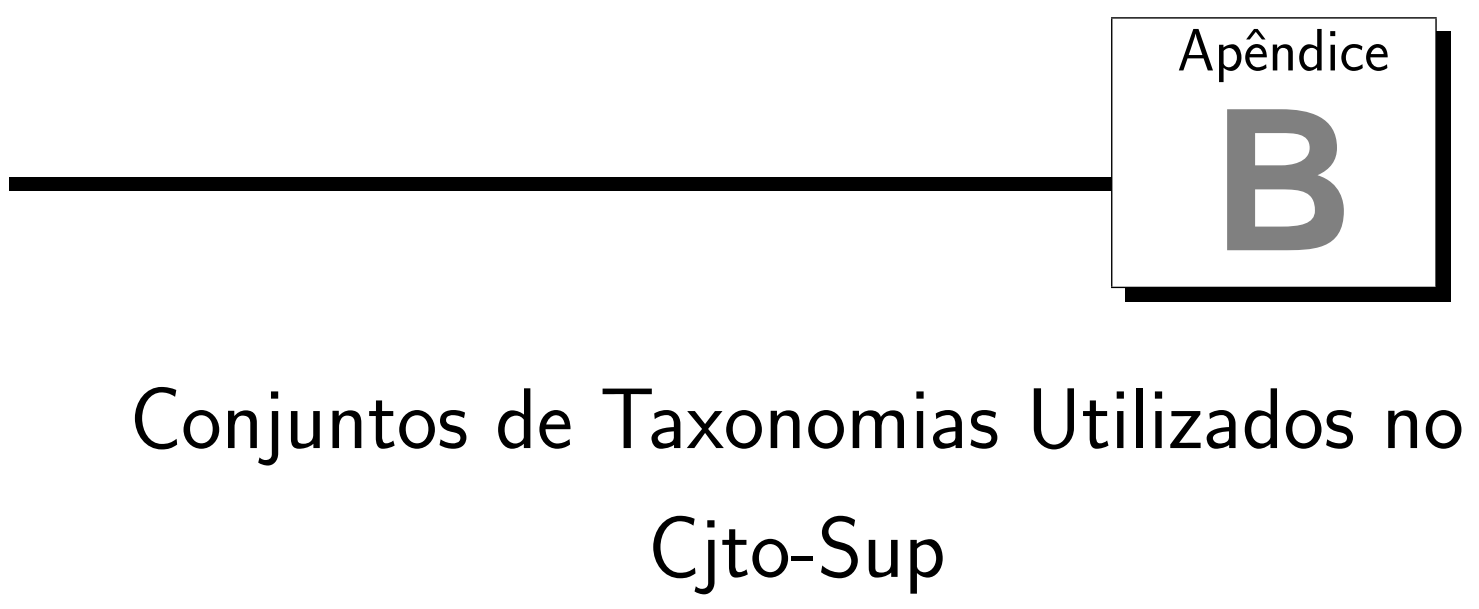

Nesse apêndice são apresentadas as taxonomias utilizadas nos experimentos descritos na Seção 4.8 (página 82) relacionados ao Cjto-Sup. Cada conjunto de taxonomias abaixo listado é identificado pelo prefixo "tax", seguido de um número de identificação seqüencial, juntamente com a informação referente a quantos níveis de abstração o mesmo possui (1N, $2 \mathrm{~N}, 3 \mathrm{~N}$ e ND). Por exemplo, no conjunto de taxonomias da Figura B.1 o rótulo tax01/1N identifica o primeiro conjunto de taxonomias contendo generalizações de um nível de abstração. 


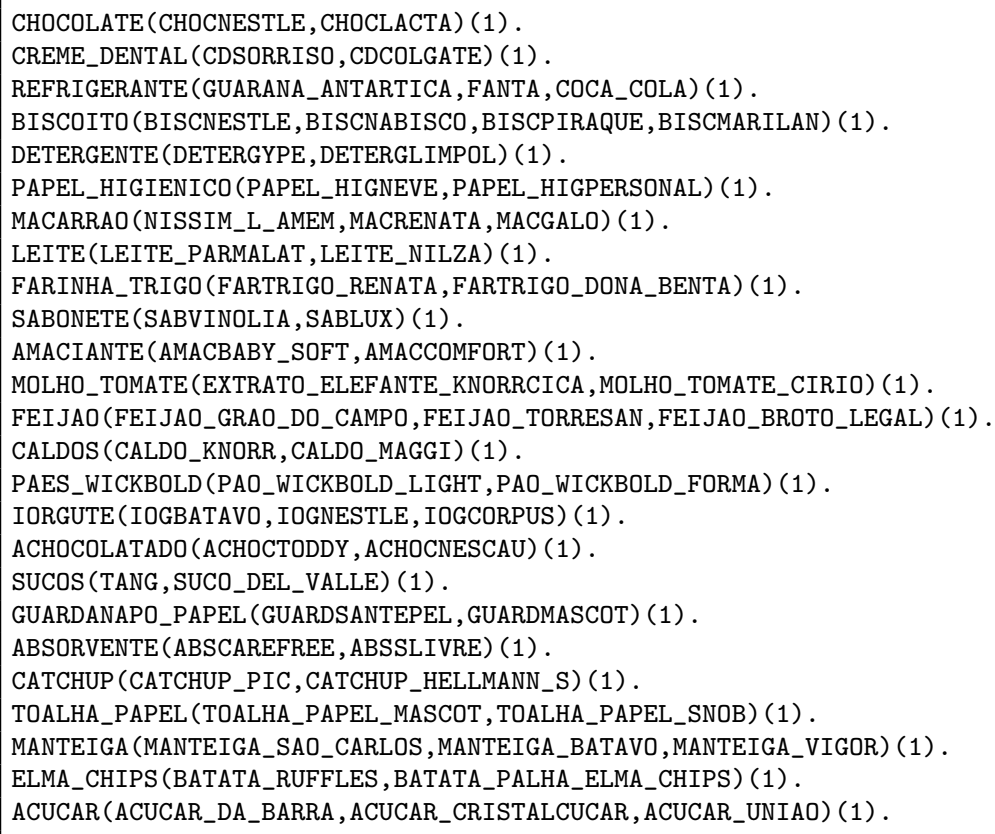

Figura B.1: Conjunto de taxonomias tax01/1N.

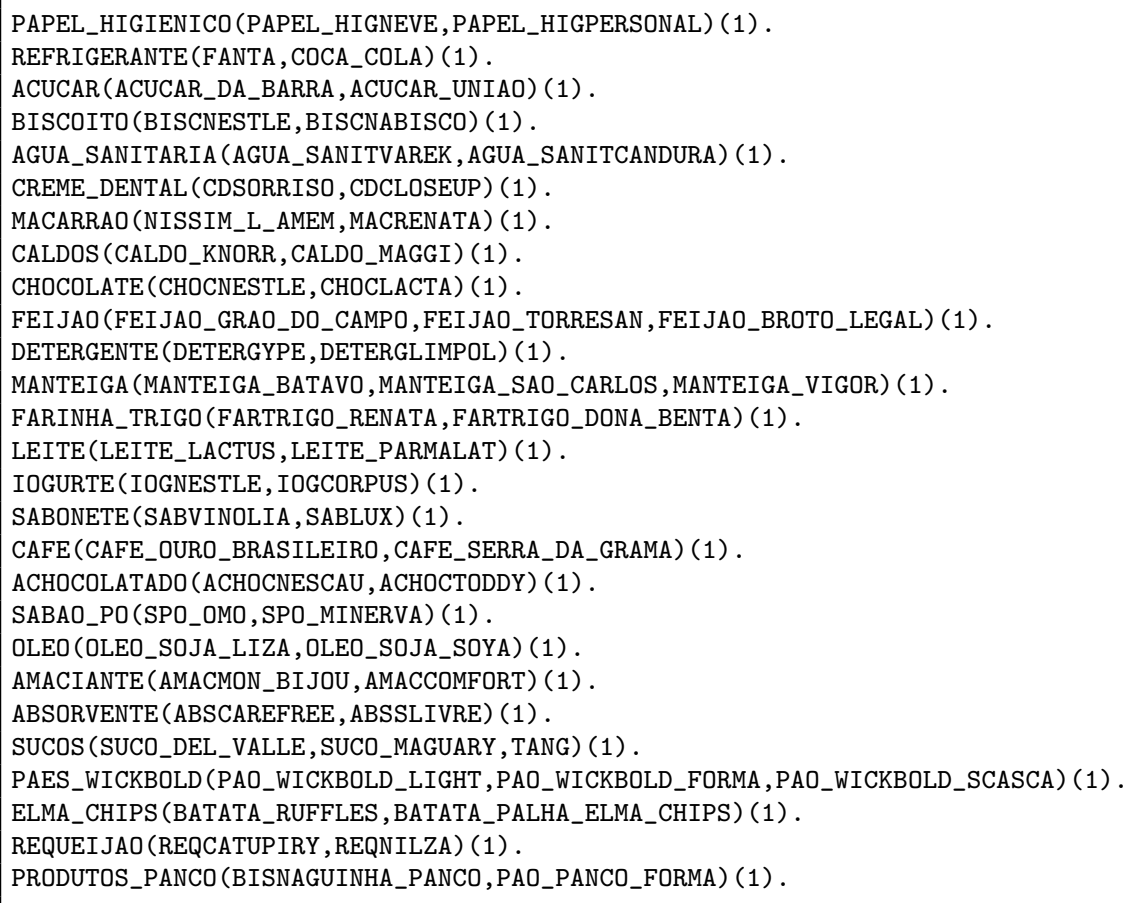

Figura B.2: Conjunto de taxonomias tax02/1N. 
ADES (ADES_ABACAXI_ALIMLIQDE_SOJA, ADES_PESSEGO, ADES_UVA) (1)

DETERGENTE (DETERGYPE, DETERGLIMPOL) (1) .

PAPEL_HIGIENICO (PAPEL_HIGNEVE, PAPEL_HIGPERSONAL) (1).

REFRIGERANTE (FANTA, SPRITE, COCA_COLA) (1).

MACARRAO (NISSIM_L_AMEM, MACRENATA) (1) .

CREME_DENTAL (CDSORRISO, CDCLOSEUP) (1).

AGUA_SANITARIA (AGUA_SANITCANDURA, AGUA_SANITVAREK) (1).

LEITE (LEITE_NILZA, LEITE_PARMALAT, LEITE_LACTUS) (1) .

BISCOITO (BISCNESTLE, BISCNABISCO, BISCTOSTINES) (1) .

IOGURTE (IOGCORPUS, IOGNESTLE, IOGMOLICO, IOGBATAVO) (1).

CHOCOLATE (CHOCNESTLE, CHOCLACTA) (1).

MOLHO_TOMATE (EXTRATO_ELEFANTE_KNORRCICA, MOLHO_TOMATE_CIRIO) (1) .

FARINHA_TRIGO (FARTRIGO_DONA_BENTA, FARTRIGO_RENATA) (1).

OLEO (OLEO_SOJA_SOYA, OLEO_SOJA_LIZA) (1).

FEIJAO (FEIJAO_TORRESAN, FEIJAO_BROTO_LEGAL, FEIJAO_GRAO_DO_CAMPO) (1).

SABONETE (SABVINOLIA , SABLUX) (1).

ACUCAR (ACUCAR_CRISTALCUCAR, ACUCAR_UNIAO) (1).

SUCOS (SUCO_DEL_VALLE, SUCO_MAGUARY) (1) .

TOALHA_PAPEL (TOALHA_PAPEL_SNOB, TOALHA_PAPEL_MASCOT) (1).

AMACIANTE (AMACBABY_SOFT, AMACCOMFORT) (1) .

ACHOCOLATADO (ACHOCTODDY, ACHOCNESCAU) (1) .

CALDOS (CALDO_KNORR, CALDO_MAGGI) (1).

PAES_WICKBOLD (PAO_WICKBOLD_FORMA, PAO_WICKBOLD_LIGHT) (1).

CEREAL (TRIO, NESTON_BARRA) (1).

ABSORVENTE (ABSCAREFREE, ABSSLIVRE) (1) .

MANTEIGA (MANTEIGA_SAO_CARLOS, MANTEIGA_LECO) (1) .

ELMA_CHIPS (BATATA_RUFFLES, BATATA_PALHA_ELMA_CHIPS) (1).

Figura B.3: Conjunto de taxonomias tax03/1N.

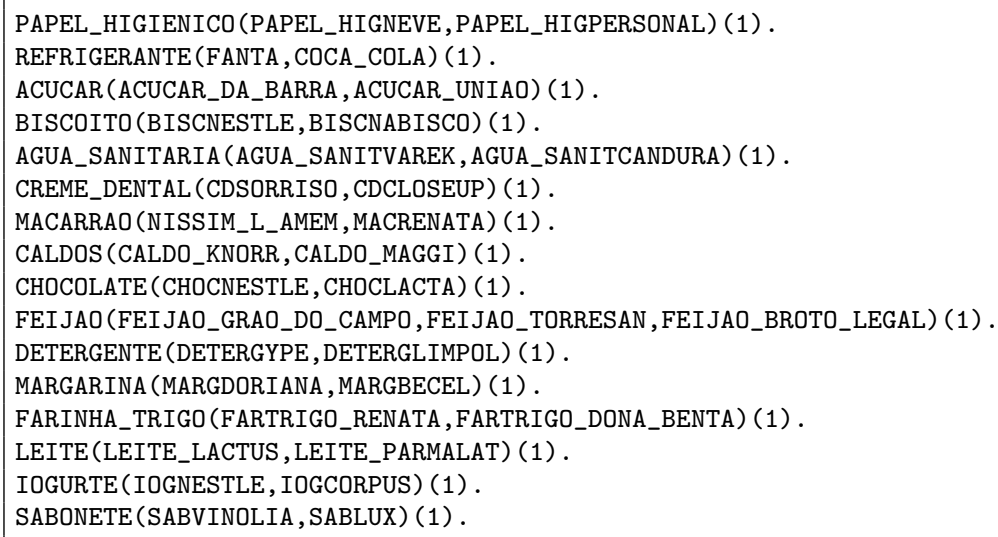

Figura B.4: Conjunto de taxonomias tax04/1N. 


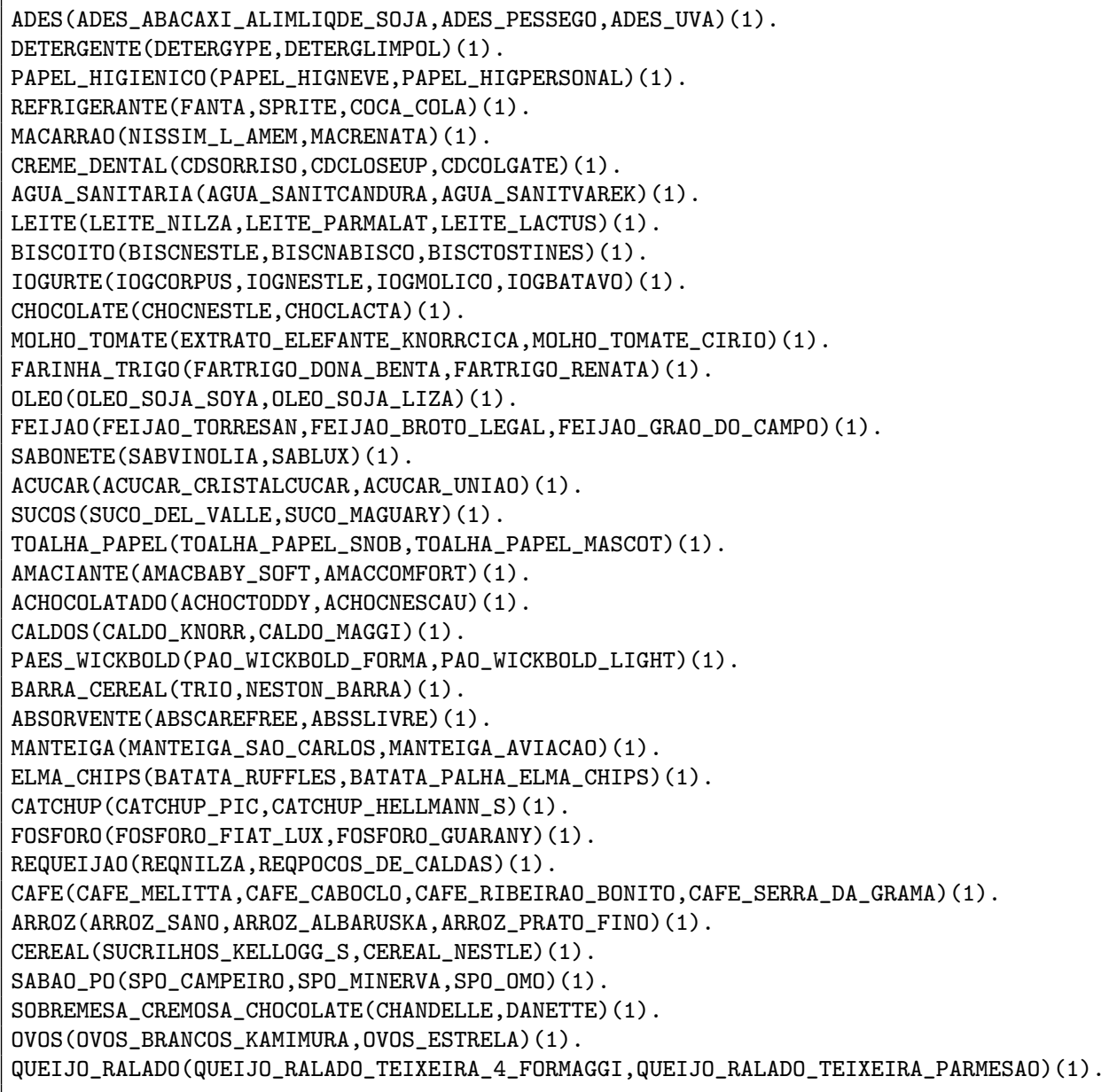

Figura B.5: Conjunto de taxonomias tax05/1N. 


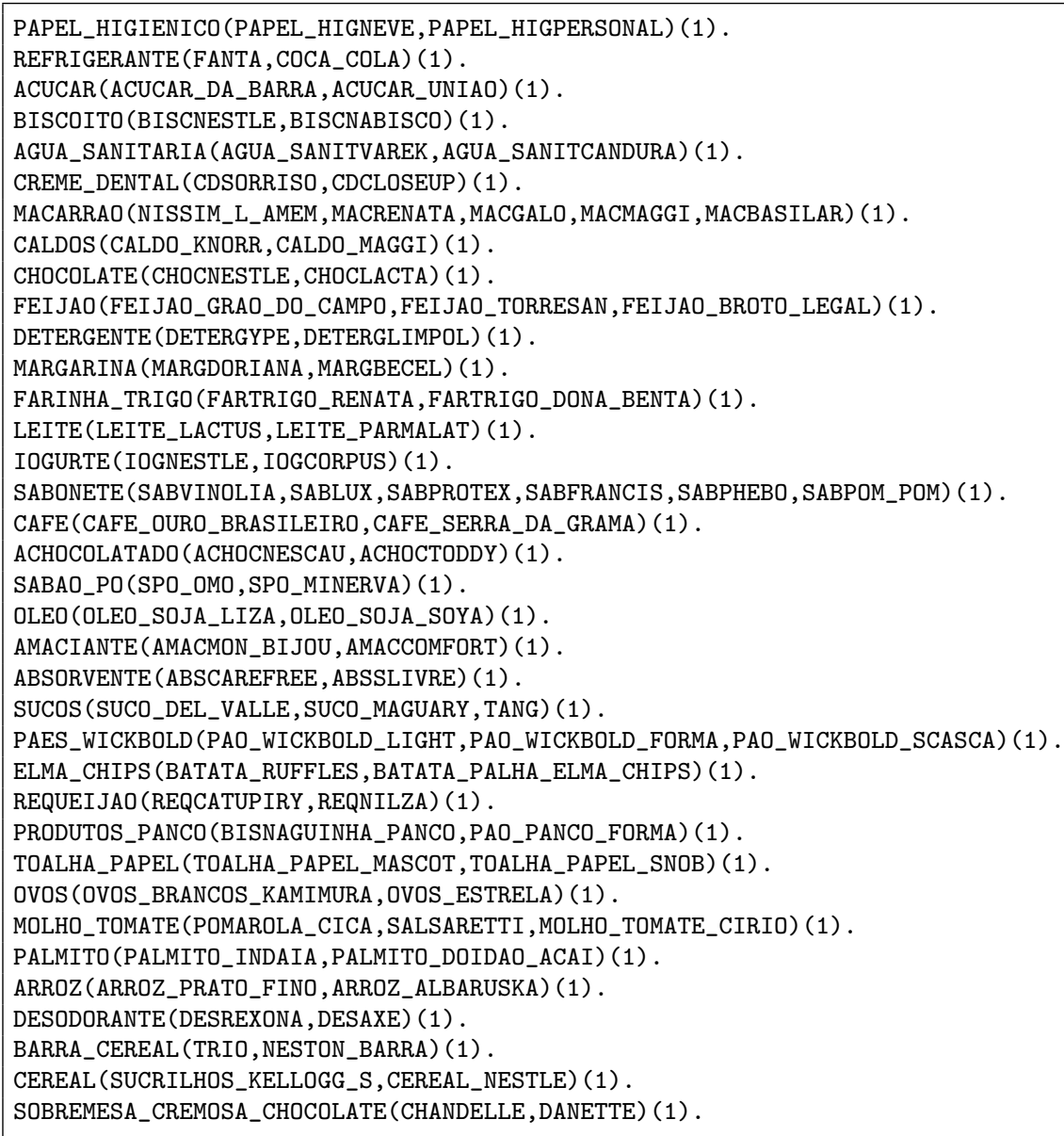

Figura B.6: Conjunto de taxonomias tax06/1N. 


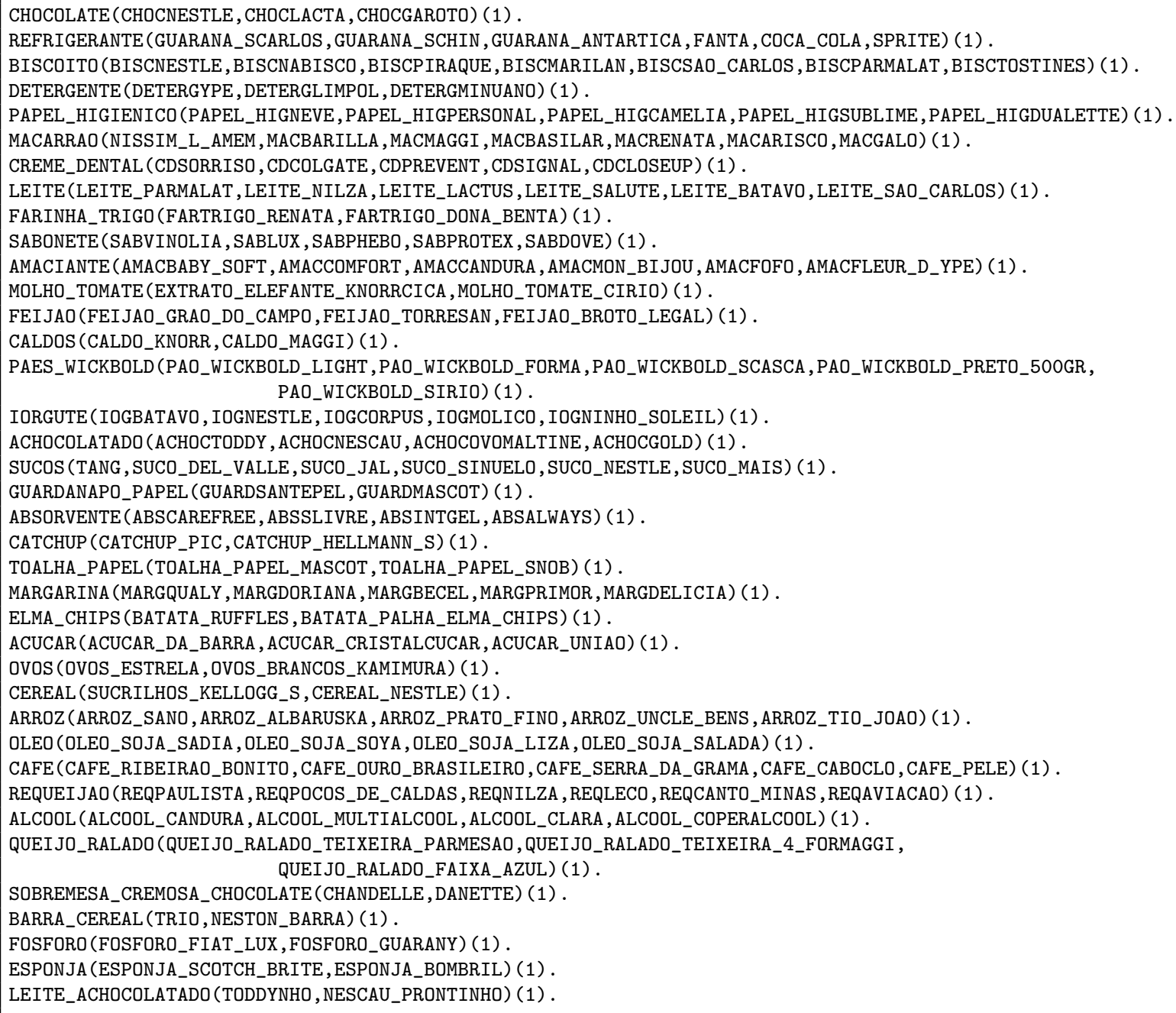

Figura B.7: Conjunto de taxonomias tax07/1N. 
CHOCOLATE (CHOCNESTLE, CHOCLACTA) (1).

CREME_DENTAL (CDSORRISO, CDCOLGATE) (1).

REFRIGERANTE (GUARANA_ANTARTICA , FANTA , COCA_COLA) (1).

BISCOITO (BISCNESTLE, BISCNABISCO, BISCPIRAQUE, BISCMARILAN) (1) .

DETERGENTE (DETERGYPE, DETERGLIMPOL) (1) .

PAPEL_HIGIENICO (PAPEL_HIGNEVE, PAPEL_HIGPERSONAL) (1).

MACARRAO_NINST (MACRENATA , MACGALO) (1) .

MACARRAO_INST (NISSIM_L_AMEM, MACESPAGUETE_MIOJO) (1) .

LEITE (LEITE_PARMALAT, LEITE_NILZA) (1).

FARINHA_TRIGO (FARTRIGO_RENATA, FARTRIGO_DONA_BENTA) (1).

SABONETE (SABVINOLIA, SABLUX) (1).

AMACIANTE (AMACBABY_SOFT, AMACCOMFORT) (1).

MOLHO_TOMATE (EXTRATO_ELEFANTE_KNORRCICA, MOLHO_TOMATE_CIRIO) (1) .

FEIJAO(FEIJAO_GRAO_DO_CAMPO, FEIJAO_TORRESAN, FEIJAO_BROTO_LEGAL) (1) .

CALDOS (CALDO_KNORR, CALDO_MAGGI) (1).

PAES_WICKBOLD (PAO_WICKBOLD_LIGHT, PAO_WICKBOLD_FORMA, PAO_WICKBOLD_SCASCA) (1).

PAES_PANCO (BISNAGUINHA_PANCO,PAO_PANCO_FORMA, PAO_PANCO_MILHO) (1).

IORGUTE (IOGBATAVO, IOGNESTLE, IOGCORPUS) (1).

ACHOCOLATADO (ACHOCTODDY, ACHOCNESCAU) (1) .

SUCOS (TANG , SUCO_DEL_VALLE) (1).

ABSORVENTE (ABSCAREFREE, ABSSLIVRE) (1).

CATCHUP (CATCHUP_PIC, CATCHUP_HELLMANN_S) (1) .

MANTEIGA (MANTEIGA_SAO_CARLOS, MANTEIGA_BATAVO, MANTEIGA_AVIACAO) (1) .

ELMA_CHIPS (BATATA_RUFFLES, BATATA_PALHA_ELMA_CHIPS) (1).

ACUCAR (ACUCAR_DA_BARRA, ACUCAR_CRISTALCUCAR, ACUCAR_UNIAO) (1).

AMENDOIM (AMENDOIM_DORI , AMENDOIM_YOKI , AMENDOIM_C_R) (1).

MARGARINA (MARGBECEL, MARGQUALY, MARGDORIANA, MARGPRIMOR) (1).

ALHO (ALHO_DA_ROCA , ALHO_BOIANI , ALHO_TOTAL, PURO_ALHO_BOIANI , PURO_ALHO_ARISCO) (1).

PRODUTOS_ENLATADOS (MOLHO_TOMATE, ACHOCOLATADO, CATCHUP) (2).

HIGIENE_PESSOAL (CREME_DENTAL, PAPEL_HIGIENICO, SABONETE, ABSORVENTE) (2) .

BEBIDA (REFRIGERANTE, LEITE, IORGUTE, SUCOS) (2).

DOCES (CHOCOLATE, BISCOITO) (2).

PRODUTOS_LIMPEZA (DETERGENTE, AMACIANTE) (2).

MACARRAO (MACARRAO_NINST, MACARRAO_INST) (2).

PRODUTOS_BASICOS (FARINHA_TRIGO, FEIJAO, ACUCAR) (2).

TEMPEROS (CALDOS, ALHO) (2).

PANIFICACAO (PAES_WICKBOLD, PAES_PANCO) (2).

LATICINIOS (MANTEIGA, MARGARINA) (2).

APERITIVOS (ELMA_CHIPS, AMENDOIM) (2).

Figura B.8: Conjunto de taxonomias tax01/2N. 
PAPEL_HIGIENICO (PAPEL_HIGNEVE, PAPEL_HIGPERSONAL) (1).

REFRIGERANTE (FANTA, COCA_COLA) (1).

ACUCAR (ACUCAR_DA_BARRA, ACUCAR_UNIAO) (1).

BISCOITO (BISCNESTLE, BISCNABISCO) (1) .

AGUA_SANITARIA (AGUA_SANITVAREK, AGUA_SANITCANDURA) (1).

CREME_DENTAL (CDSORRISO, CDCLOSEUP) (1).

CHOCOLATE (CHOCNESTLE, CHOCLACTA) (1).

FEIJAO (FEIJAO_GRAO_DO_CAMPO,FEIJAO_TORRESAN, FEIJAO_BROTO_LEGAL) (1).

DETERGENTE (DETERGYPE, DETERGLIMPOL) (1).

MANTEIGA (MANTEIGA_VIGOR, MANTEIGA_AVIACAO, MANTEIGA_LECO) (1).

FARINHA_TRIGO (FARTRIGO_RENATA,FARTRIGO_DONA_BENTA) (1).

LEITE (LEITE_LACTUS, LEITE_PARMALAT) (1).

IOGURTE (IOGNESTLE, IOGCORPUS) (1).

SABONETE (SABVINOLIA, SABLUX) (1).

CAFE (CAFE_OURO_BRASILEIRO,CAFE_SERRA_DA_GRAMA) (1).

SABAO_PO (SPO_OMO,SPO_MINERVA) (1).

OLEO (OLEO_SOJA_LIZA,OLEO_SOJA_SOYA) (1).

AMACIANTE (AMACMON_BIJOU, AMACCOMFORT) (1).

ABSORVENTE (ABSCAREFREE, ABSSLIVRE) (1).

SUCOS (SUCO_DEL_VALLE, SUCO_MAGUARY, TANG) (1).

PAES_WICKBOLD (PAO_WICKBOLD_LIGHT , PAO_WICKBOLD_FORMA, PAO_WICKBOLD_SCASCA) (1).

REQUEIJAO (REQCATUPIRY, REQNILZA) (1).

PAES_PANCO (BISNAGUINHA_PANCO,PAO_PANCO_FORMA) (1).

HIGIENE_PESSOAL (PAPEL_HIGIENICO, CREME_DENTAL, SABONETE, ABSORVENTE) (2) .

BEBIDA (REFRIGERANTE, SUCOS) (2).

PRODUTOS_BASICOS (ACUCAR, FEIJAO, FARINHA_TRIGO, CAFE, OLEO) (2).

DOCES (BISCOITO, CHOCOLATE) (2).

PRODUTOS_LIMPEZA (AGUA_SANITARIA, DETERGENTE, SABAO_PO,AMACIANTE) (2).

LATICINIOS (MANTEIGA , LEITE, IOGURTE, REQUEI JAO) (2).

PANIFICACAO (PAES_PANCO, PAES_WICKBOLD) (2).

Figura B.9: Conjunto de taxonomias tax02/2N.

ADES (ADES_ABACAXI_ALIMLIQDE_SOJA, ADES_PESSEGO,ADES_UVA) (1).

DETERGENTE (DETERGYPE, DETERGLIMPOL) (1).

PAPEL_HIGIENICO (PAPEL_HIGNEVE, PAPEL_HIGPERSONAL) (1).

REFRIGERANTE (FANTA, SPRITE, COCA_COLA) (1) .

CREME_DENTAL (CDSORRISO, CDCLOSEUP) (1).

AGUA_SANITARIA (AGUA_SANITCANDURA, AGUA_SANITVAREK) (1).

LEITE_UHT (LEITE_NILZA, LEITE_PARMALAT, LEITE_LACTUS) (1) .

LEITE_PO (LEITE_NINHO, LEITE_PO_SANCOR, LEITE_PO_SCABRA) (1).

BISCOITO (BISCNESTLE, BISCNABISCO, BISCTOSTINES) (1).

IOGURTE (IOGCORPUS, IOGNESTLE, IOGMOLICO, IOGBATAVO) (1).

CHOCOLATE (CHOCNESTLE, CHOCLACTA) (1).

MOLHO_TOMATE (EXTRATO_ELEFANTE_KNORRCICA,MOLHO_TOMATE_CIRIO) (1).

FARINHA_TRIGO (FARTRIGO_DONA_BENTA,FARTRIGO_RENATA) (1).

OLEO (OLEO_SOJA_SOYA, OLEO_SOJA_LIZA) (1).

FEIJAO (FEIJAO_TORRESAN, FEI JAO_BROTO_LEGAL, FEI JAO_GRAO_DO_CAMPO) (1).

SABONETE (SABVINOLIA, SABLUX) (1).

ACUCAR (ACUCAR_CRISTALCUCAR, ACUCAR_UNIAO) (1).

SUCOS (SUCO_DEL_VALLE,SUCO_MAGUARY) (1).

AMACIANTE (AMACBABY_SOFT, AMACCOMFORT) (1).

BARRA_CEREAL (TRIO,NESTON_BARRA, BARRA_DE_CEREAIS_UNIAO) (1).

CEREAL_MATINAL (SUCRILHOS_KELLOGG_S, CEREAL_NESTLE, CORN_FLAKES_KELLOG_S) (1) .

ABSORVENTE (ABSCAREFREE, ABSSLIVRE) (1).

LEITE (ADES , LEITE_UHT, LEITE_PO) (2).

PRODUTOS_LIMPEZA (DETERGENTE, AGUA_SANITARIA, AMACIANTE) (2).

HIGIENE_PESSOAL (PAPEL_HIGIENICO, CREME_DENTAL, SABONETE, ABSORVENTE) (2) .

BEBIDA (REFRIGERANTE, IOGURTE, SUCOS) (2).

DOCES (BISCOITO, CHOCOLATE) (2).

PRODUTOS_BASICOS (MOLHO_TOMATE, FARINHA_TRIGO, OLEO, FEIJAO, ACUCAR) (2) .

CEREAIS (BARRA_CEREAL, CEREAL_MATINAL) (2).

Figura B.10: Conjunto de taxonomias tax03/2N. 
PAPEL_HIGIENICO (PAPEL_HIGNEVE, PAPEL_HIGPERSONAL) (1).

REFRIGERANTE (FANTA, COCA_COLA) (1) .

ACUCAR (ACUCAR_DA_BARRA, ACUCAR_UNIAO) (1).

AGUA_SANITARIA (AGUA_SANITVAREK, AGUA_SANITCANDURA) (1)

CREME_DENTAL (CDSORRISO, CDCLOSEUP) (1).

MACARRAO (NISSIM_L_AMEM, MACRENATA) (1).

FEIJAO(FEIJAO_GRAO_DO_CAMPO, FEIJAO_TORRESAN, FEI JAO_BROTO_LEGAL) (1) .

DETERGENTE (DETERGYPE, DETERGLIMPOL) (1) .

FARINHA_TRIGO (FARTRIGO_RENATA, FARTRIGO_DONA_BENTA) (1).

LEITE (LEITE_LACTUS, LEITE_PARMALAT) (1) .

IOGURTE (IOGNESTLE, IOGCORPUS) (1)

SABONETE (SABVINOLIA , SABLUX) (1).

HIGIENE_PESSOAL (PAPEL_HIGIENICO, CREME_DENTAL, SABONETE) (2).

PRODUTOS_BASICOS (ACUCAR, MACARRAO, FEIJAO, FARINHA_TRIGO) (2).

BEBIDA (REFRIGERANTE, LEITE, IOGURTE) (2) .

PRODUTOS_LIMPEZA (AGUA_SANITARIA, DETERGENTE) (2).

Figura B.11: Conjunto de taxonomias tax04/2N. 


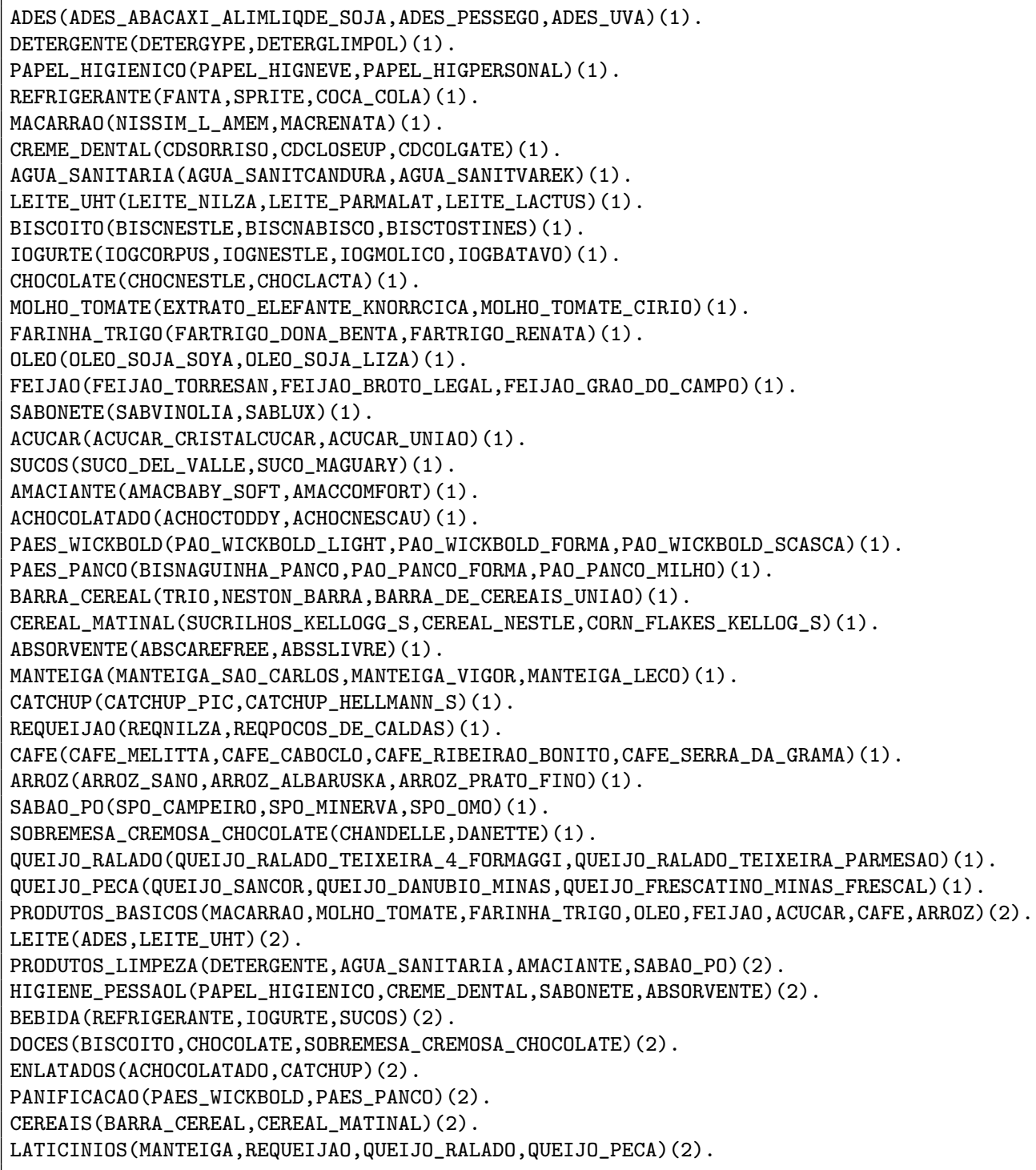

Figura B.12: Conjunto de taxonomias tax05/2N. 


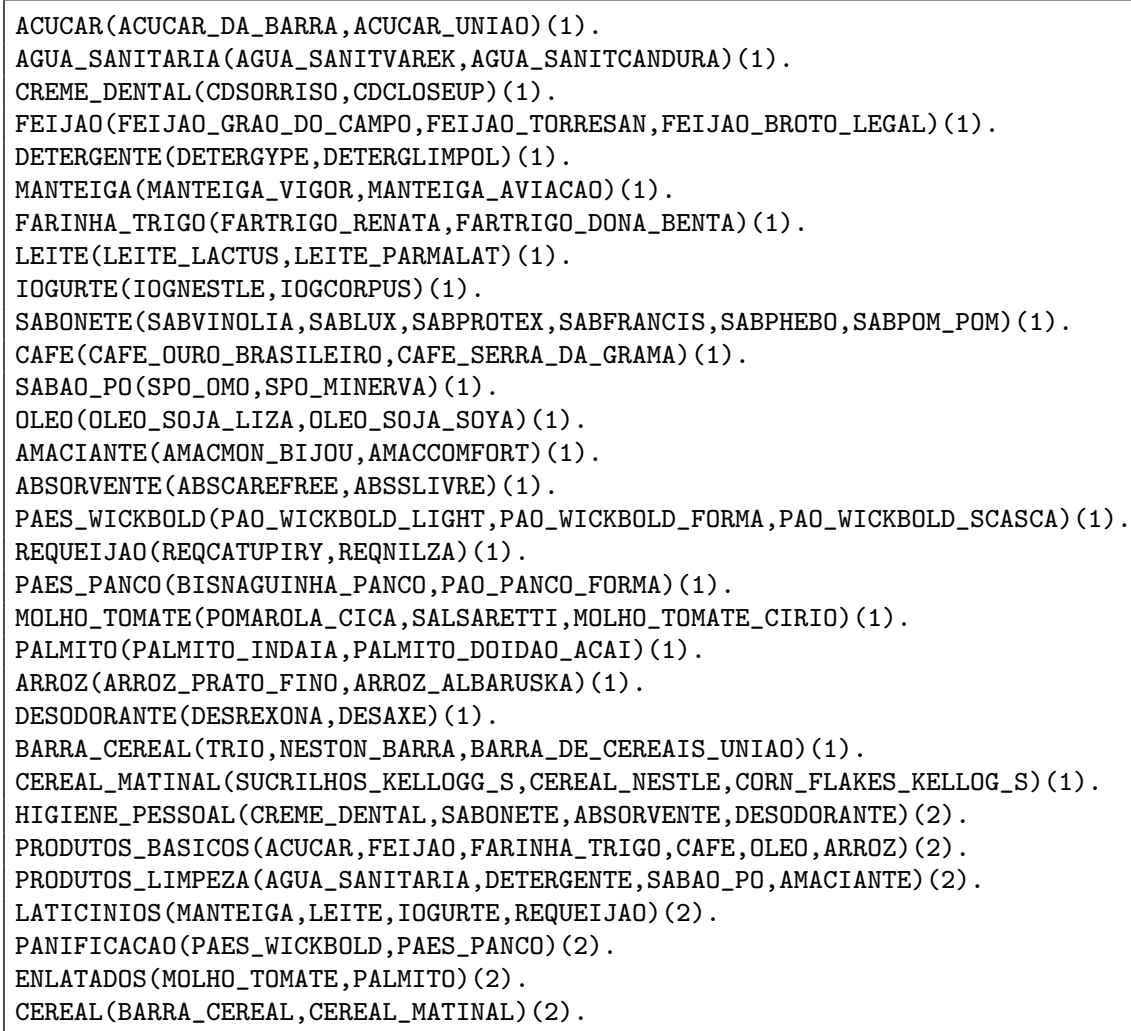

Figura B.13: Conjunto de taxonomias tax06/2N. 




Figura B.14: Conjunto de taxonomias tax07/2N. 
CHOCOLATE (CHOCNESTLE, CHOCLACTA) (1).

CREME_DENTAL (CDSORRISO, CDCOLGATE) (1).

REFRIGERANTE (GUARANA_ANTARTICA , FANTA , COCA_COLA) (1).

BISCOITO (BISCNESTLE, BISCNABISCO, BISCPIRAQUE, BISCMARILAN) (1).

DETERGENTE (DETERGYPE, DETERGLIMPOL) (1).

PAPEL_HIGIENICO (PAPEL_HIGNEVE, PAPEL_HIGPERSONAL) (1) .

MACARRAO_NINST (MACRENATA, MACGALO) (1).

MACARRAO_INST (NISSIM_L_AMEM, MACESPAGUETE_MIOJO) (1).

LEITE (LEITE_PARMALAT,LEITE_NILZA) (1).

FARINHA_TRIGO (FARTRIGO_RENATA, FARTRIGO_DONA_BENTA) (1).

SABONETE (SABVINOLIA, SABLUX) (1).

AMACIANTE (AMACBABY_SOFT, AMACCOMFORT) (1).

MOLHO_TOMATE (EXTRATO_ELEFANTE_KNORRCICA, MOLHO_TOMATE_CIRIO) (1).

FEIJAO (FEIJAO_GRAO_DO_CAMPO,FEIJAO_TORRESAN, FEIJAO_BROTO_LEGAL) (1).

CALDOS (CALDO_KNORR, CALDO_MAGGI) (1).

PAES_WICKBOLD (PAO_WICKBOLD_LIGHT ,PAO_WICKBOLD_FORMA, PAO_WICKBOLD_SCASCA) (1) .

PAES_PANCO (BISNAGUINHA_PANCO, PAO_PANCO_FORMA, PAO_PANCO_MILHO) (1).

IORGUTE (IOGBATAVO, IOGNESTLE, IOGCORPUS) (1).

ACHOCOLATADO (ACHOCTODDY, ACHOCNESCAU) (1).

SUCOS (TANG , SUCO_DEL_VALLE) (1).

ABSORVENTE (ABSCAREFREE, ABSSLIVRE) (1).

CATCHUP (CATCHUP_PIC,CATCHUP_HELLMANN_S) (1).

MANTEIGA (MANTEIGA_SAO_CARLOS, MANTEIGA_AVIACAO, MANTEIGA_LECO) (1).

ELMA_CHIPS (BATATA_RUFFLES,BATATA_PALHA_ELMA_CHIPS) (1).

ACUCAR (ACUCAR_DA_BARRA, ACUCAR_CRISTALCUCAR, ACUCAR_UNIAO) (1).

AMENDOIM (AMENDOIM_DORI , AMENDOIM_YOKI , AMENDOIM_C_R) (1) .

MARGARINA (MARGBECEL , MARGQUALY, MARGDORIANA, MARGPRIMOR) (1).

ALHO (ALHO_DA_ROCA , ALHO_BOIANI , ALHO_TOTAL ,PURO_ALHO_BOIANI , PURO_ALHO_ARISCO) (1).

FLUOR (CEPACOL, ANTI_SEPTLISTERINE) (1).

ESPONJA_ACO (BOMBRIL, ESPONJA_DE_ACO_ASSOLAN) (1).

SABAO_PO (SPO_OMO,SPO_MINERVA) (1).

CERVEJA (CERVXINGU , CERVCRYSTAL , CERVBRAHMA , CERVANTARCTICA , CERVSCHINCARIOL , CERVKAISER) (1).

VODKA (VODKA_ORLOFF, VODKA_BAIKAL, VODKA_SMIRNOFF) (1).

CHAMPAGNE (CHAMPAGNE_CHANDON,CHAMPAGNE_PETERLONGO, CHAMPAGNE_DE_GREVILLE, CHAMPAGNE_ESPDE_PRATA) (1) .

BEBIDA_ALCOOLICA (CERVEJA, VODKA, CHAMPAGNE) (2).

BEBIDA_NALCOOLICA (REFRIGERANTE, LEITE, IORGUTE, SUCOS) (2).

HIGIENE_PESSOAL (PAPEL_HIGIENICO, SABONETE, ABSORVENTE) (2).

HIGIENE_BUCAL (CREME_DENTAL, FLUOR) (2) .

PRODUTOS_LIMPEZA_LAVANDERIA (AMACIANTE,SSABAO_PO) (2).

PRODUTOS_LIMPEZA_COZINHA (DETERGENTE, ESPONJA_ACO) (2).

DOCES (CHOCOLATE, BISCOITO) (2).

PRODUTOS_ENLATADOS (MOLHO_TOMATE, ACHOCOLATADO, CATCHUP) (2) .

MACARRAO (MACARRAO_NINST, MACARRAO_INST) (2).

PRODUTOS_BASICOS (FARINHA_TRIGO, FEIJAO, ACUCAR) (2).

TEMPEROS (CALDOS, ALHO) (2).

PANIFICACAO (PAES_WICKBOLD, PAES_PANCO) (2).

LATICINIOS (MANTEIGA, MARGARINA) (2).

APERITIVOS (ELMA_CHIPS , AMENDOIM) (2).

BEBIDA (BEBIDA_ALCOOLICA, BEBIDA_NALCOOLICA) (3).

PRODUTOS_LIMPEZA (PRODUTOS_LIMPEZA_LAVANDERIA,PRODUTOS_LIMPEZA_COZINHA) (3).

PRODUTOS_HIGIENE (HIGIENE_BUCAL, HIGIENE_PESSOAL) (3).

PRODUTOS_ALIMENTICIOS (PRODUTOS_ENLATADOS, DOCES, MACARRAO, PRODUTOS_BASICOS, TEMPEROS , PANIFICACAO , LATICINIOS, APERITIVOS) (3).

Figura B.15: Conjunto de taxonomias tax01/3N. 


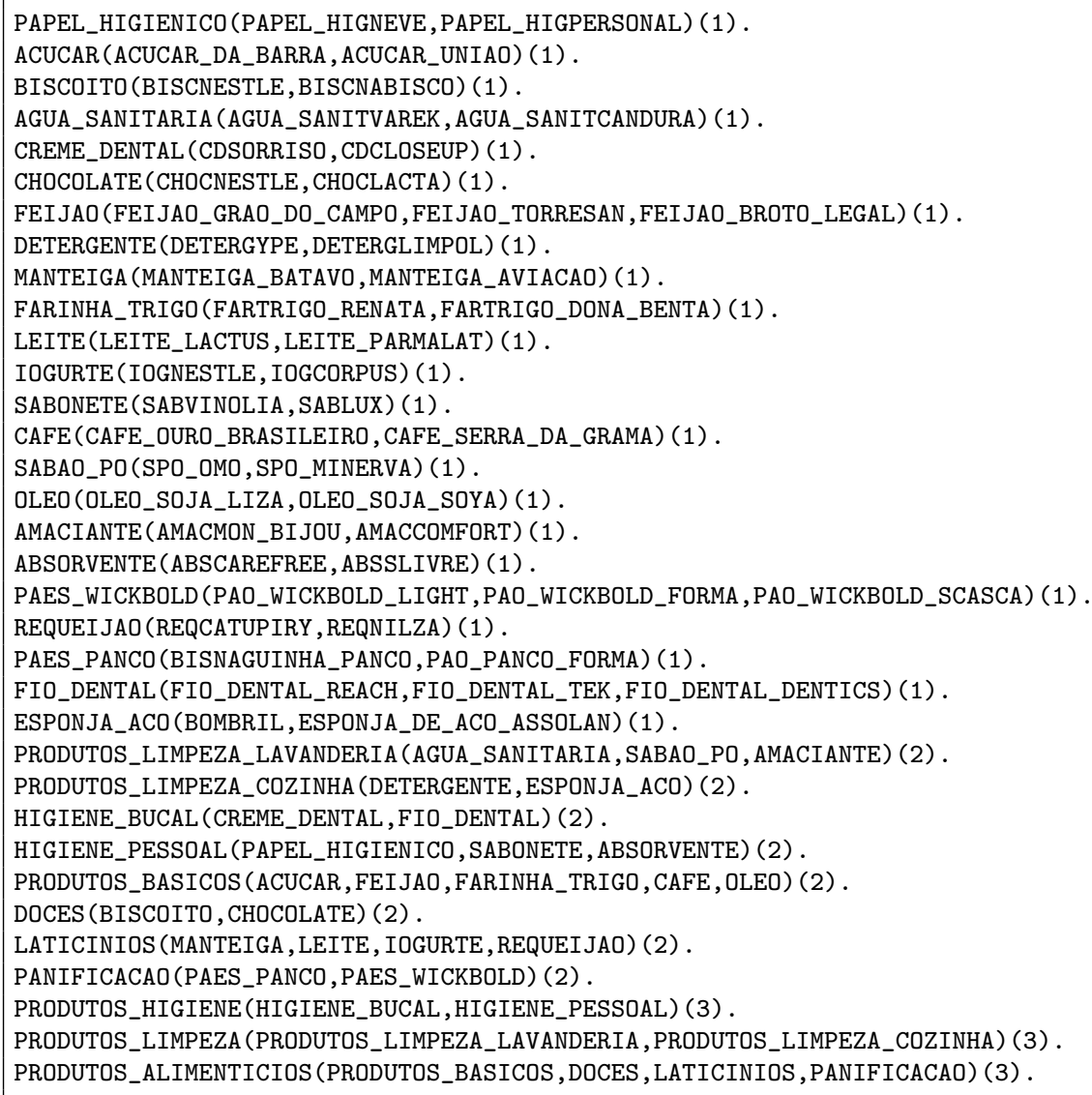

Figura B.16: Conjunto de taxonomias tax02/3N.

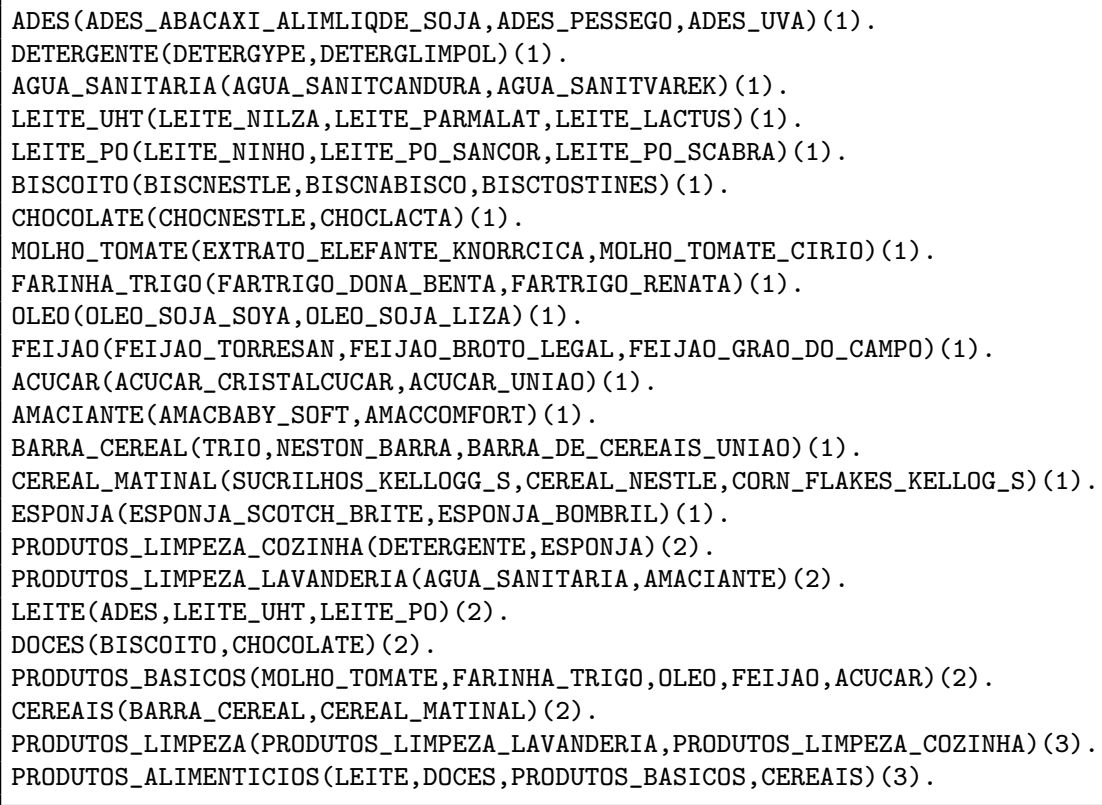

Figura B.17: Conjunto de taxonomias tax03/3N. 
PAPEL_HIGIENICO (PAPEL_HIGNEVE, PAPEL_HIGPERSONAL) (1).

ACUCAR (ACUCAR_DA_BARRA, ACUCAR_UNIAO) (1).

AGUA_SANITARIA (AGUA_SANITVAREK, AGUA_SANITCANDURA) (1).

CREME_DENTAL (CDSORRISO, CDCLOSEUP) (1).

MACARRAO (NISSIM_L_AMEM, MACRENATA) (1).

FEIJAO (FEIJAO_GRAO_DO_CAMPO, FEI JAO_TORRESAN , FEIJAO_BROTO_LEGAL) (1).

DETERGENTE (DETERGYPE, DETERGLIMPOL) (1) .

FARINHA_TRIGO (FARTRIGO_RENATA, FARTRIGO_DONA_BENTA) (1).

LEITE (LEITE_LACTUS, LEITE_PARMALAT) (1) .

IOGURTE (IOGNESTLE, IOGCORPUS) (1).

SABONETE (SABVINOLIA, SABLUX) (1)

FIO_DENTAL (FIO_DENTAL_REACH, FIO_DENTAL_TEK, FIO_DENTAL_DENTICS) (1) .

SABAO_PO (SPO_OMO,SPO_MINERVA) (1).

ESPONJA_ACO (BOMBRIL, ESPONJA_DE_ACO_ASSOLAN) (1) .

PRODUTOS_LIMPEZA_COZINHA (DETERGENTE, ESPONJA_ACO) (2) .

PRODUTOS_LIMPEZA_LAVANDERIA (AGUA_SANITARIA, SABAO_PO) (2) .

HIGIENE_BUCAL (CREME_DENTAL, FIO_DENTAL) (2) .

HIGIENE_PESSOAL (PAPEL_HIGIENICO, SABONETE) (2).

PRODUTOS_BASICOS (ACUCAR, MACARRAO, FEIJAO, FARINHA_TRIGO) (2).

LATICINIOS (LEITE, IOGURTE) (2).

PRODUTOS_ALIMENTICIOS (PRODUTOS_BASICOS, LATICINIOS) (3).

PRODUTOS_HIGIENE (HIGIENE_BUCAL, HIGIENE_PESSOAL) (3).

PRODUTOS_LIMPEZA (PRODUTOS_LIMPEZA_COZINHA, PRODUTOS_LIMPEZA_LAVANDERIA) (3).

Figura B.18: Conjunto de taxonomias tax04/3N. 


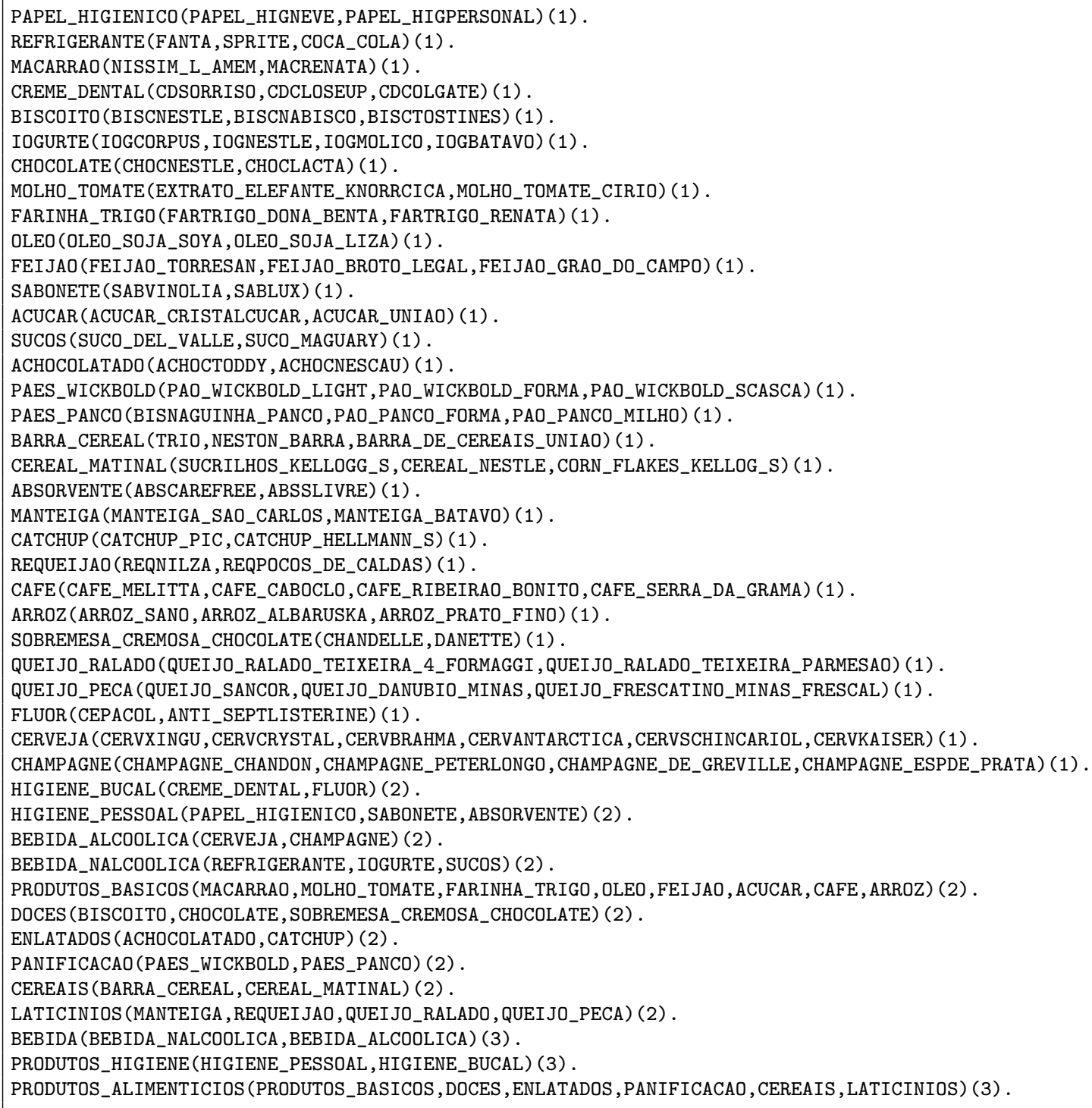

Figura B.19: Conjunto de taxonomias tax05/3N. 
ACUCAR (ACUCAR_DA_BARRA, ACUCAR_UNIAO) (1).

AGUA_SANITARIA (AGUA_SANITVAREK, AGUA_SANITCANDURA) (1).

CREME_DENTAL (CDSORRISO, CDCLOSEUP) (1).

FEIJAO (FEIJAO_GRAO_DO_CAMPO,FEIJAO_TORRESAN, FEI JAO_BROTO_LEGAL) (1).

DETERGENTE (DETERGYPE, DETERGLIMPOL) (1).

MANTEIGA (MANTEIGA_AVIACAO, MANTEIGA_LECO) (1).

FARINHA_TRIGO (FARTRIGO_RENATA,FARTRIGO_DONA_BENTA) (1).

LEITE (LEITE_LACTUS, LEITE_PARMALAT) (1).

IOGURTE (IOGNESTLE, IOGCORPUS) (1).

SABONETE (SABVINOLIA, SABLUX, SABPROTEX , SABFRANCIS, SABPHEBO, SABPOM_POM) (1).

CAFE (CAFE_OURO_BRASILEIRO, CAFE_SERRA_DA_GRAMA) (1).

SABAO_PO (SPO_OMO,SPO_MINERVA) (1).

OLEO (OLEO_SOJA_LIZA,OLEO_SOJA_SOYA) (1).

AMACIANTE (AMACMON_BIJOU, AMACCOMFORT) (1).

ABSORVENTE (ABSCAREFREE, ABSSLIVRE) (1).

PAES_WICKBOLD (PAO_WICKBOLD_LIGHT ,PAO_WICKBOLD_FORMA, PAO_WICKBOLD_SCASCA) (1) .

REQUEIJAO (REQCATUPIRY, REQNILZA) (1).

PAES_PANCO (BISNAGUINHA_PANCO,PAO_PANCO_FORMA) (1).

MOLHO_TOMATE (POMAROLA_CICA, SALSARETTI, MOLHO_TOMATE_CIRIO) (1).

PALMITO (PALMITO_INDAIA, PALMITO_DOIDAO_ACAI) (1).

ARROZ (ARROZ_PRATO_FINO, ARROZ_ALBARUSKA) (1).

DESODORANTE (DESREXONA, DESAXE) (1).

BARRA_CEREAL (TRIO, NESTON_BARRA, BARRA_DE_CEREAIS_UNIAO) (1).

CEREAL_MATINAL (SUCRILHOS_KELLOGG_S, CEREAL_NESTLE, CORN_FLAKES_KELLOG_S) (1).

ESPONJA (ESPONJA_SCOTCH_BRITE, ESPONJA_BOMBRIL) (1).

ESCOVA_DENTE (EDJ_J_REACH, EDJOHNSON___JOHNSON, EDJOHNSON_S) (1).

CENOURA (CENOURA_BABY, CENOURA_SATO, CENOURA_ORGANICA) (1).

BROCOLIS (BROCOLIS_NINJA, BROCOLIS_BONDUELLE,BROCOLIS_CAC) (1).

LEGUMES (CENOURA, BROCOLIS) (2).

HIGIENE_BUCAL (CREME_DENTAL, ESCOVA_DENTE) (2).

HIGIENE_PESSOAL (SABONETE, ABSORVENTE, DESODORANTE) (2).

PRODUTOS_LIMPEZA_LAVANDERIA (AGUA_SANITARIA, SABAO_PO, AMACIANTE) (2) .

PRODUTOS_LIMPEZA_COZINHA (DETERGENTE, ESPONJA) (2).

PRODUTOS_BASICOS (ACUCAR, FEIJAO, FARINHA_TRIGO, CAFE, OLEO, ARROZ) (2).

LATICINIOS (MANTEIGA, LEITE, IOGURTE, REQUEI JAO) (2).

PANIFICACAO (PAES_WICKBOLD, PAES_PANCO) (2).

ENLATADOS (MOLHO_TOMATE, PALMITO) (2).

CEREAL (BARRA_CEREAL, CEREAL_MATINAL) (2).

PRODUTOS_HIGIENE(HIGIENE_BUCAL,HIGIENE_PESSOAL) (3).

PRODUTOS_ALIMENTICIOS (PRODUTOS_BASICOS, LATICINIOS, PANIFICACAO, ENLATADOS , CEREAL , LEGUMES) (3) .

PRODUTOS_LIMPEZA (PRODUTOS_LIMPEZA_LAVANDERIA, PRODUTOS_LIMPEZA_COZINHA) (3).

Figura B.20: Conjunto de taxonomias tax06/3N. 
CHOCOLATE (CHOCNESTLE, CHOCLACTA, CHOCGAROTO) (1).

REFRIGERANTE (GUARANA_SCARLOS, GUARANA_SCHIN, GUARANA_ANTARTICA, FANTA , COCA_COLA, SPRITE) (1) .

BISCOITO (BISCNESTLE, BISCNABISCO, BISCPIRAQUE, BISCMARILAN, BISCSAO_CARLOS, BISCPARMALAT , BISCTOSTINES) (1) .

DETERGENTE (DETERGYPE, DETERGLIMPOL , DETERGMINUANO) (1) .

PAPEL_HIGIENICO (PAPEL_HIGNEVE, PAPEL_HIGPERSONAL, PAPEL_HIGCAMELIA, PAPEL_HIGSUBLIME, PAPEL_HIGDUALETTE) (1) .

MACARRAO_NINST (MACBARILLA , MACMAGGI , MACBASILAR, MACRENATA, MACARISCO, MACGALO) (1) .

MACARRAO_INST (NISSIM_L_AMEM, MACESPAGUETE_MIOJO) (1).

CREME_DENTAL (CDSORRISO, CDCOLGATE, CDPREVENT, CDSIGNAL , CDCLOSEUP) (1).

LEITE_UHT (LEITE_PARMALAT, LEITE_NILZA, LEITE_LACTUS, LEITE_SALUTE, LEITE_BATAVO, LEITE_SAO_CARLOS) (1) .

FARINHA_TRIGO(FARTRIGO_RENATA,FARTRIGO_DONA_BENTA) (1).

SABONETE (SABVINOLIA , SABLUX, SABPHEBO , SABPROTEX , SABDOVE) (1).

AMACIANTE (AMACBABY_SOFT, AMACCOMFORT , AMACCANDURA , AMACMON_BI JOU, AMACFOFO, AMACFLEUR_D_YPE) (1) .

MOLHO_TOMATE(EXTRATO_ELEFANTE_KNORRCICA,MOLHO_TOMATE_CIRIO) (1).

FEIJAO (FEIJAO_GRAO_DO_CAMPO, FEIJAO_TORRESAN, FEI JAO_BROTO_LEGAL) (1).

CALDOS (CALDO_KNORR, CALDO_MAGGI) (1).

IORGUTE (IOGBATAVO, IOGNESTLE, IOGCORPUS, IOGMOLICO, IOGNINHO_SOLEIL) (1) .

ACHOCOLATADO (ACHOCTODDY, ACHOCNESCAU, ACHOCOVOMALTINE, ACHOCGOLD) (1).

SUCOS (TANG, SUCO_DEL_VALLE, SUCO_JAL, SUCO_SINUELO, SUCO_NESTLE, SUCO_MAIS) (1) .

ABSORVENTE (ABSCAREFREE , ABSSLIVRE, ABSINTGEL , ABSALWAYS) (1).

CATCHUP (CATCHUP_PIC,CATCHUP_HELLMANN_S) (1).

ELMA_CHIPS (BATATA_RUFFLES, BATATA_PALHA_ELMA_CHIPS) (1).

AMENDOIM (AMENDOIM_DORI , AMENDOIM_YOKI , AMENDOIM_C_R) (1).

ACUCAR (ACUCAR_DA_BARRA, ACUCAR_CRISTALCUCAR, ACUCAR_UNIAO) (1).

ARROZ (ARROZ_SANO, ARROZ_ALBARUSKA , ARROZ_PRATO_FINO, ARROZ_UNCLE_BENS, ARROZ_TIO_JOAO) (1).

OLEO (OLEO_SOJA_SADIA, OLEO_SOJA_SOYA, OLEO_SOJA_LIZA, OLEO_SOJA_SALADA) (1) .

CAFE (CAFE_RIBEIRAO_BONITO,CAFE_OURO_BRASILEIRO,CAFE_SERRA_DA_GRAMA,CAFE_CABOCLO, CAFE_PELE) (1).

ALCOOL (ALCOOL_CANDURA, ALCOOL_MULTIALCOOL, ALCOOL_CLARA, ALCOOL_COPERALCOOL) (1).

QUEIJO_RALADO (QUEIJO_RALADO_TEIXEIRA_PARMESAO, QUEIJO_RALADO_TEIXEIRA_4_FORMAGGI, QUEIJO_RALADO_FAIXA_AZUL) (1).

QUEIJO_PECA (QUEIJO_SANCOR, QUEIJO_DANUBIO_MINAS, QUEIJO_FRESCATINO_MINAS_FRESCAL) (1).

SOBREMESA_CREMOSA_CHOCOLATE (CHANDELLE, DANETTE) (1).

ESPONJA (ESPONJA_SCOTCH_BRITE,ESPONJA_BOMBRIL) (1).

LEITE_ACHOCOLATADO (TODDYNHO,NESCAU_PRONTINHO) (1).

ALHO (ALHO_DA_ROCA , ALHO_BOIANI , ALHO_TOTAL , PURO_ALHO_BOIANI , PURO_ALHO_ARISCO) (1) .

SABAO_PO (SPO_OMO,SPO_MINERVA, SPO_BRILHANTE, SPO_ACE, SPO_CAMPEIRO) (1) .

ESPONJA_ACO (BOMBRIL , ESPONJA_DE_ACO_ASSOLAN) (1).

FLUOR (CEPACOL, ANTI_SEPTLISTERINE) (1).

FIO_DENTAL (FIO_DENTAL_REACH, FIO_DENTAL_TEK, FIO_DENTAL_DENTICS) (1).

ESCOVA_DENTE(EDJ_J_REACH,EDJOHNSON___JOHNSON,EDJOHNSON_S) (1) .

CERVEJA (CERVXINGU, CERVCRYSTAL , CERVBRAHMA, CERVANTARCTICA , CERVSCHINCARIOL , CERVKAISER) (1).

VODKA (VODKA_ORLOFF, VODKA_BAIKAL, VODKA_SMIRNOFF) (1).

CHAMPAGNE (CHAMPAGNE_CHANDON, CHAMPAGNE_PETERLONGO, CHAMPAGNE_DE_GREVILLE, CHAMPAGNE_ESPDE_PRATA) (1).

ALFACE (ALFACE_CRESPA, ALFACE_AMERICANA,ALFACE_LISA) (1) .

RUCULA (RUCULA_BIO_TERRA, RUCULA_SATO) (1).

COUVE (COUVE_MANTEIGA_ORGANICA, COUVE_MANTEIGA) (1).

VERDURAS (ALFACE, RUCULA, COUVE) (2).

HIGIENE_BUCAL (CREME_DENTAL, FLUOR, FIO_DENTAL, ESCOVA_DENTE) (2).

HIGIENE_PESSOAL (PAPEL_HIGIENICO, SABONETE, ABSORVENTE) (2).

BEBIDA_ALCOOLICA (CERVEJA, VODKA, CHAMPAGNE) (2)

BEBIDA_NALCOOLICA (REFRIGERANTE, IORGUTE, SUCOS, LEITE_UHT, LEITE_ACHOCOLATADO) (2).

PRODUTOS_LIMPEZA_COZINHA (DETERGENTE, ALCOOL , ESPONJA , ESPONJA_ACO) (2).

PRODUTOS_LIMPEZA_LAVANDERIA (AMACIANTE, SABAO_PO) (2).

DOCES (CHOCOLATE, BISCOITO, SOBREMESA_CREMOSA_CHOCOLATE) (2) .

ENLATADOS (MOLHO_TOMATE, ACHOCOLATADO, CATCHUP) (2).

QUEIJO (QUEIJO_RALADO, QUEIJO_PECA) (2) .

APERITIVOS (ELMA_CHIPS, AMENDOIM) (2).

MACARRAO (MACARRAO_NINST, MACARRAO_INST) (2)

PRODUTOS_BASICOS (FARINHA_TRIGO, FEIJAO, ACUCAR, ARROZ, OLEO, CAFE) (2) .

TEMPEROS (CALDOS , ALHO) (2).

PRODUTOS_LIMPEZA (PRODUTOS_LIMPEZA_LAVANDERIA,PRODUTOS_LIMPEZA_COZINHA) (3).

PRODUTOS_ALIMENTICIOS (DOCES, ENLATADOS, QUEIJO, APERITIVOS, MACARRAO, PRODUTOS_BASICOS , TEMPEROS, VERDURAS) (3) .

PRODUTOS_HIGIENE(HIGIENE_BUCAL, HIGIENE_PESSOAL) (3).

BEBIDA (BEBIDA_ALCOOLICA, BEBIDA_NALCOOLICA) (3).

Figura B.21: Conjunto de taxonomias $\operatorname{tax} 0 \% / 3 N$. 
CHOCOLATE (CHOCNESTLE, CHOCLACTA) (1).

CREME_DENTAL (CDSORRISO, CDCOLGATE) (1).

REFRIGERANTE (GUARANA_ANTARTICA ,FANTA, COCA_COLA) (1).

BISCOITO (BISCNESTLE, BISCNABISCO, BISCPIRAQUE, BISCMARILAN) (1).

DETERGENTE (DETERGYPE, DETERGLIMPOL) (1).

PAPEL_HIGIENICO (PAPEL_HIGNEVE, PAPEL_HIGPERSONAL) (1) .

MACARRAO_NINST (MACRENATA, MACGALO) (1).

MACARRAO_INST (NISSIM_L_AMEM, MACESPAGUETE_MIOJO) (1).

LEITE (LEITE_PARMALAT , LEITE_NILZA) (1).

FARINHA_TRIGO (FARTRIGO_RENATA, FARTRIGO_DONA_BENTA) (1).

SABONETE (SABVINOLIA, SABLUX) (1).

AMACIANTE (AMACBABY_SOFT, AMACCOMFORT) (1).

MOLHO_TOMATE (EXTRATO_ELEFANTE_KNORRCICA, MOLHO_TOMATE_CIRIO) (1).

FEIJAO (FEIJAO_GRAO_DO_CAMPO, FEIJAO_TORRESAN , FEIJAO_BROTO_LEGAL) (1) .

CALDOS (CALDO_KNORR, CALDO_MAGGI) (1).

PAES_WICKBOLD (PAO_WICKBOLD_LIGHT , PAO_WICKBOLD_FORMA, PAO_WICKBOLD_SCASCA) (1).

PAES_PANCO (BISNAGUINHA_PANCO, PAO_PANCO_FORMA ,PAO_PANCO_MILHO) (1) .

IORGUTE (IOGBATAVO, IOGNESTLE, IOGCORPUS) (1).

ACHOCOLATADO (ACHOCTODDY, ACHOCNESCAU) (1).

SUCOS (TANG, SUCO_DEL_VALLE) (1).

ABSORVENTE (ABSCAREFREE, ABSSLIVRE) (1) .

CATCHUP (CATCHUP_PIC, CATCHUP_HELLMANN_S) (1).

MANTEIGA (MANTEIGA_SAO_CARLOS, MANTEIGA_AVIACAO, MANTEIGA_LECO) (1).

ELMA_CHIPS (BATATA_RUFFLES, BATATA_PALHA_ELMA_CHIPS) (1).

ACUCAR (ACUCAR_DA_BARRA, ACUCAR_CRISTALCUCAR, ACUCAR_UNIAO) (1).

AMENDOIM (AMENDOIM_DORI , AMENDOIM_YOKI , AMENDOIM_C_R) (1) .

MARGARINA (MARGBECEL, MARGQUALY, MARGDORIANA , MARGPRIMOR) (1).

ALHO (ALHO_DA_ROCA , ALHO_BOIANI , ALHO_TOTAL, PURO_ALHO_BOIANI , PURO_ALHO_ARISCO) (1).

FLUOR (CEPACOL , ANTI_SEPTLISTERINE) (1).

ESPONJA_ACO (BOMBRIL, ESPONJA_DE_ACO_ASSOLAN) (1).

SABAO_PO (SPO_OMO,SPO_MINERVA) (1).

CERVEJA (CERVXINGU, CERVCRYSTAL , CERVBRAHMA , CERVANTARCTICA , CERVSCHINCARIOL , CERVKAISER) (1).

VODKA (VODKA_ORLOFF, VODKA_BAIKAL, VODKA_SMIRNOFF) (1).

CHAMPAGNE (CHAMPAGNE_CHANDON, CHAMPAGNE_PETERLONGO, CHAMPAGNE_DE_GREVILLE, CHAMPAGNE_ESPDE_PRATA) (1) .

HIGIENE_PESSOAL (PAPEL_HIGIENICO, SABONETE, ABSORVENTE) (2) .

HIGIENE_BUCAL (CREME_DENTAL, FLUOR) (2).

PRODUTOS_LIMPEZA_LAVANDERIA (AMACIANTE, SABAO_PO) (2).

PRODUTOS_LIMPEZA_COZINHA (DETERGENTE, ESPONJA_ACO) (2).

PRODUTOS_ENLATADOS (MOLHO_TOMATE, ACHOCOLATADO, CATCHUP) (2) .

MACARRAO (MACARRAO_NINST , MACARRAO_INST) (2) .

PRODUTOS_BASICOS (FARINHA_TRIGO, FEIJAO, ACUCAR) (2).

PANIFICACAO (PAES_WICKBOLD, PAES_PANCO) (2).

LATICINIOS (MANTEIGA, MARGARINA) (2) .

APERITIVOS (ELMA_CHIPS, AMENDOIM) (2).

PRODUTOS_LIMPEZA (PRODUTOS_LIMPEZA_LAVANDERIA , PRODUTOS_LIMPEZA_COZINHA) (3).

PRODUTOS_HIGIENE (HIGIENE_BUCAL, HIGIENE_PESSOAL) (3).

PRODUTOS_ALIMENTICIOS (PRODUTOS_ENLATADOS, MACARRAO, PRODUTOS_BASICOS , PANIFICACAO, LATICINIOS , APERITIVOS) (3).

Figura B.22: Conjunto de taxonomias tax01/ND. 


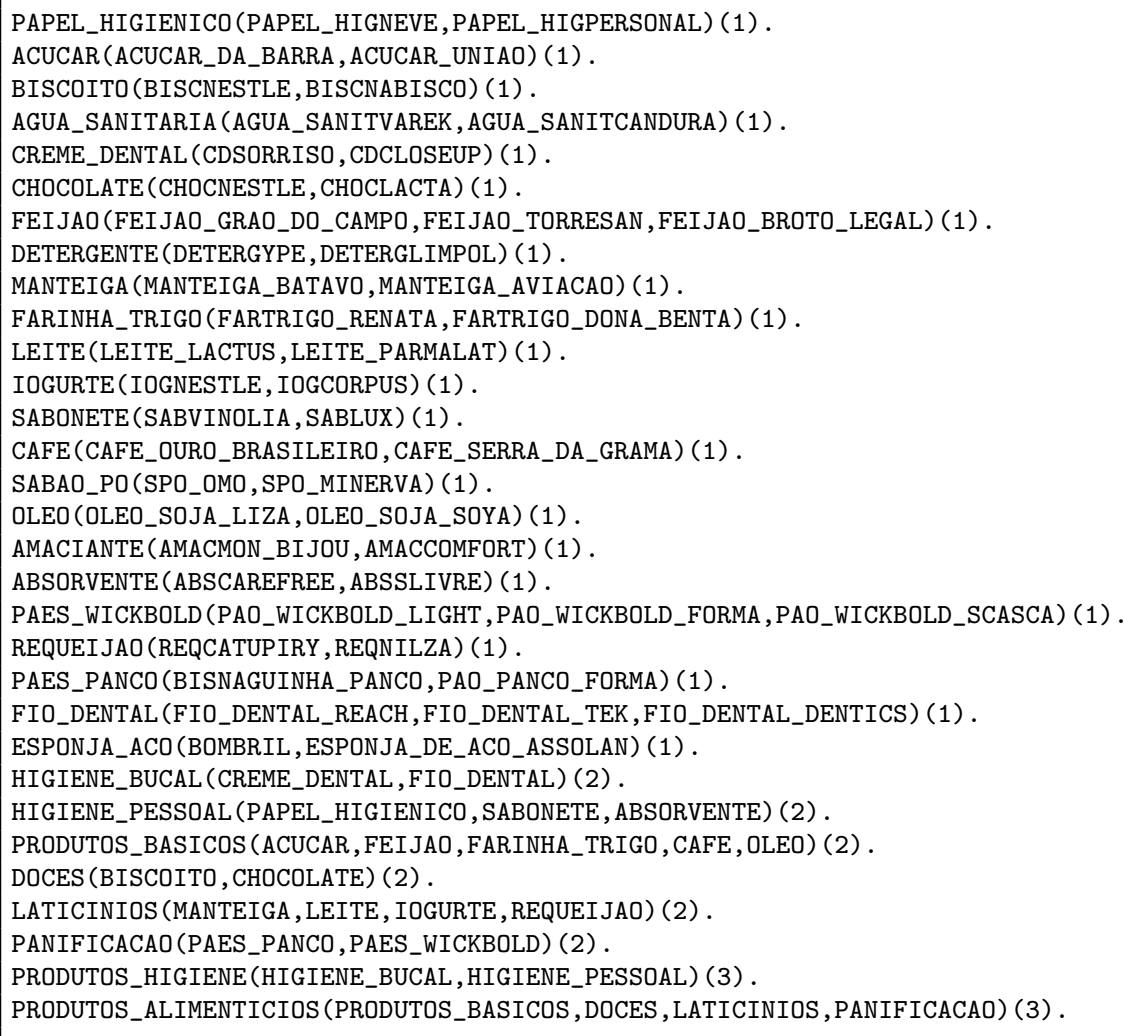

Figura B.23: Conjunto de taxonomias tax02/ND.

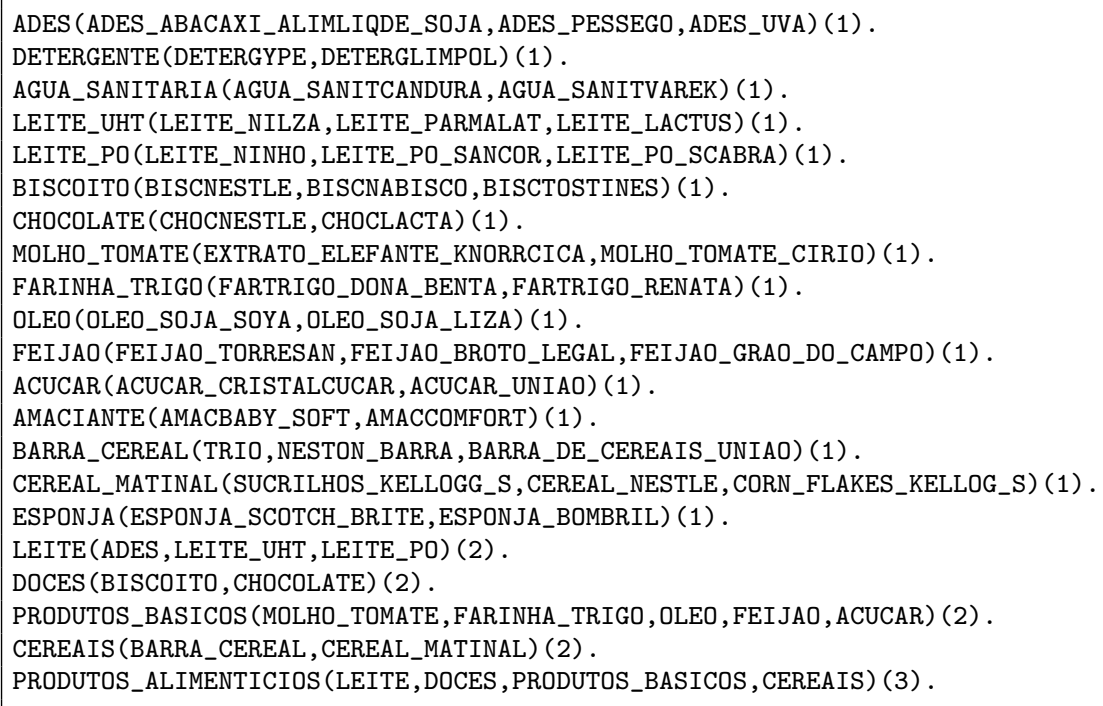

Figura B.24: Conjunto de taxonomias tax03/ND. 
PAPEL_HIGIENICO (PAPEL_HIGNEVE, PAPEL_HIGPERSONAL) (1).

ACUCAR (ACUCAR_DA_BARRA, ACUCAR_UNIAO) (1).

AGUA_SANITARIA (AGUA_SANITVAREK, AGUA_SANITCANDURA) (1)

CREME_DENTAL (CDSORRISO, CDCLOSEUP) (1).

MACARRAO (NISSIM_L_AMEM, MACRENATA) (1).

FEIJAO (FEIJAO_GRAO_DO_CAMPO, FEIJAO_TORRESAN, FEIJAO_BROTO_LEGAL) (1).

DETERGENTE (DETERGYPE, DETERGLIMPOL) (1).

FARINHA_TRIGO (FARTRIGO_RENATA, FARTRIGO_DONA_BENTA) (1).

LEITE (LEITE_LACTUS, LEITE_PARMALAT) (1) .

IOGURTE (IOGNESTLE, IOGCORPUS) (1).

SABONETE (SABVINOLIA , SABLUX) (1).

FIO_DENTAL (FIO_DENTAL_REACH,FIO_DENTAL_TEK, FIO_DENTAL_DENTICS) (1) .

SABAO_PO (SPO_OMO, SPO_MINERVA) (1).

ESPONJA_ACO (BOMBRIL, ESPONJA_DE_ACO_ASSOLAN) (1).

PRODUTOS_LIMPEZA_COZINHA (DETERGENTE, ESPONJA_ACO) (2).

PRODUTOS_LIMPEZA_LAVANDERIA (AGUA_SANITARIA, SABAO_PO) (2) .

PRODUTOS_BASICOS (ACUCAR, MACARRAO, FEIJAO, FARINHA_TRIGO) (2).

LATICINIOS (LEITE, IOGURTE) (2).

PRODUTOS_ALIMENTICIOS (PRODUTOS_BASICOS, LATICINIOS) (3).

PRODUTOS_LIMPEZA (PRODUTOS_LIMPEZA_COZINHA , PRODUTOS_LIMPEZA_LAVANDERIA) (3).

Figura B.25: Conjunto de taxonomias tax04/ND.

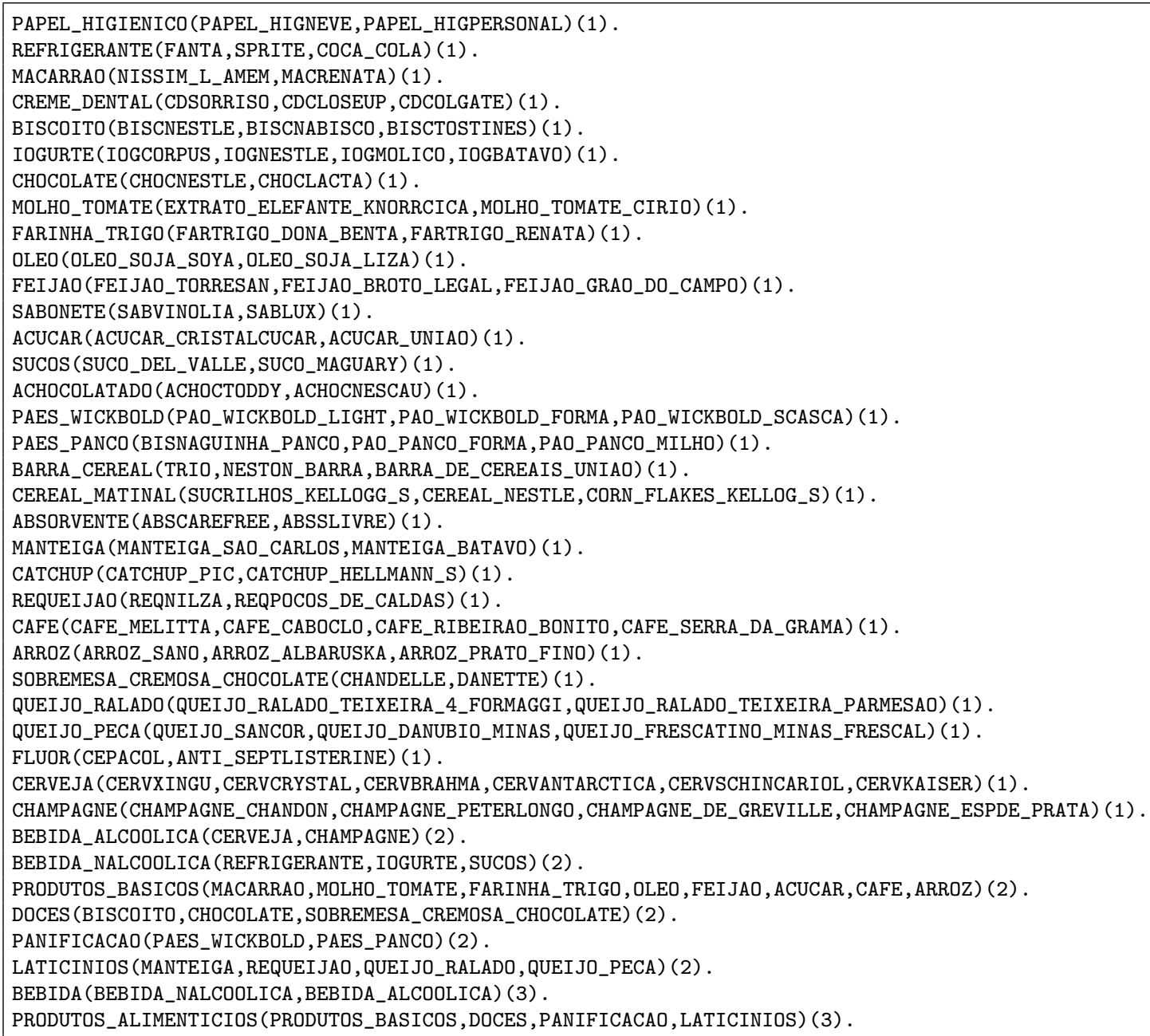

Figura B.26: Conjunto de taxonomias tax05/ND. 
ACUCAR (ACUCAR_DA_BARRA, ACUCAR_UNIAO) (1).

AGUA_SANITARIA (AGUA_SANITVAREK, AGUA_SANITCANDURA) (1).

CREME_DENTAL (CDSORRISO, CDCLOSEUP) (1).

FEIJAO (FEIJAO_GRAO_DO_CAMPO,FEIJAO_TORRESAN,FEIJAO_BROTO_LEGAL) (1).

DETERGENTE (DETERGYPE, DETERGLIMPOL) (1).

MANTEIGA (MANTEIGA_AVIACAO, MANTEIGA_LECO) (1).

FARINHA_TRIGO (FARTRIGO_RENATA, FARTRIGO_DONA_BENTA) (1).

LEITE (LEITE_LACTUS, LEITE_PARMALAT) (1) .

IOGURTE (IOGNESTLE, IOGCORPUS) (1).

SABONETE (SABVINOLIA, SABLUX, SABPROTEX , SABFRANCIS , SABPHEBO , SABPOM_POM) (1).

CAFE (CAFE_OURO_BRASILEIRO,CAFE_SERRA_DA_GRAMA) (1).

SABAO_PO (SPO_OMO,SPO_MINERVA) (1).

OLEO (OLEO_SOJA_LIZA,OLEO_SOJA_SOYA) (1).

AMACIANTE (AMACMON_BIJOU, AMACCOMFORT) (1).

ABSORVENTE (ABSCAREFREE, ABSSLIVRE) (1).

PAES_WICKBOLD (PAO_WICKBOLD_LIGHT , PAO_WICKBOLD_FORMA ,PAO_WICKBOLD_SCASCA) (1).

REQUEIJAO (REQCATUPIRY, REQNILZA) (1).

PAES_PANCO (BISNAGUINHA_PANCO,PAO_PANCO_FORMA) (1).

MOLHO_TOMATE(POMAROLA_CICA, SALSARETTI , MOLHO_TOMATE_CIRIO) (1).

PALMITO(PALMITO_INDAIA,PALMITO_DOIDAO_ACAI) (1).

ARROZ (ARROZ_PRATO_FINO, ARROZ_ALBARUSKA) (1).

DESODORANTE (DESREXONA, DESAXE) (1).

BARRA_CEREAL (TRIO, NESTON_BARRA, BARRA_DE_CEREAIS_UNIAO) (1).

CEREAL_MATINAL (SUCRILHOS_KELLOGG_S, CEREAL_NESTLE, CORN_FLAKES_KELLOG_S) (1).

ESPONJA (ESPONJA_SCOTCH_BRITE,ESPONJA_BOMBRIL) (1).

ESCOVA_DENTE (EDJ_J_REACH, EDJOHNSON___JOHNSON, EDJOHNSON_S) (1).

CENOURA (CENOURA_BABY, CENOURA_SATO, CENOURA_ORGANICA) (1).

BROCOLIS (BROCOLIS_NINJA, BROCOLIS_BONDUELLE, BROCOLIS_CAC) (1).

LEGUMES (CENOURA , BROCOLIS) (2).

HIGIENE_BUCAL (CREME_DENTAL, ESCOVA_DENTE) (2).

HIGIENE_PESSOAL (SABONETE, ABSORVENTE, DESODORANTE) (2).

PRODUTOS_BASICOS (ACUCAR, FEIJAO, FARINHA_TRIGO, CAFE, OLEO, ARROZ) (2).

LATICINIOS (MANTEIGA, LEITE, IOGURTE, REQUEIJAO) (2).

PANIFICACAO (PAES_WICKBOLD, PAES_PANCO) (2).

ENLATADOS (MOLHO_TOMATE, PALMITO) (2).

CEREAL (BARRA_CEREAL, CEREAL_MATINAL) (2).

PRODUTOS_HIGIENE(HIGIENE_BUCAL, HIGIENE_PESSOAL) (3).

PRODUTOS_ALIMENTICIOS (PRODUTOS_BASICOS, LATICINIOS, PANIFICACAO, ENLATADOS, CEREAL , LEGUMES) (3) .

Figura B.27: Conjunto de taxonomias tax06/ND. 
CHOCOLATE (CHOCNESTLE, CHOCLACTA, CHOCGAROTO) (1).

REFRIGERANTE (GUARANA_SCARLOS, GUARANA_SCHIN, GUARANA_ANTARTICA , FANTA , COCA_COLA , SPRITE) (1) .

BISCOITO (BISCNESTLE, BISCNABISCO , BISCPIRAQUE, BISCMARILAN, BISCSAO_CARLOS, BISCPARMALAT , BISCTOSTINES) (1).

DETERGENTE (DETERGYPE, DETERGLIMPOL , DETERGMINUANO) (1).

PAPEL_HIGIENICO (PAPEL_HIGNEVE, PAPEL_HIGPERSONAL, PAPEL_HIGCAMELIA, PAPEL_HIGSUBLIME, PAPEL_HIGDUALETTE) (1).

MACARRAO_NINST (MACBARILLA , MACMAGGI , MACBASILAR, MACRENATA , MACARISCO, MACGALO) (1) .

MACARRAO_INST (NISSIM_L_AMEM, MACESPAGUETE_MIOJO) (1) .

CREME_DENTAL (CDSORRISO, CDCOLGATE, CDPREVENT , CDSIGNAL , CDCLOSEUP) (1) .

LEITE_UHT (LEITE_PARMALAT, LEITE_NILZA, LEITE_LACTUS, LEITE_SALUTE, LEITE_BATAVO, LEITE_SAO_CARLOS) (1) .

FARINHA_TRIGO (FARTRIGO_RENATA, FARTRIGO_DONA_BENTA) (1).

SABONETE (SABVINOLIA , SABLUX, SABPHEBO, SABPROTEX, SABDOVE) (1).

AMACI ANTE (AMACBABY_SOFT , AMACCOMFORT, AMACCANDURA, AMACMON_BIJOU, AMACFOFO, AMACFLEUR_D_YPE) (1) .

MOLHO_TOMATE (EXTRATO_ELEFANTE_KNORRCICA, MOLHO_TOMATE_CIRIO) (1) .

FEIJAO (FEIJAO_GRAO_DO_CAMPO, FEIJAO_TORRESAN, FEIJAO_BROTO_LEGAL) (1).

CALDOS (CALDO_KNORR, CALDO_MAGGI) (1).

IORGUTE (IOGBATAVO, IOGNESTLE, IOGCORPUS, IOGMOLICO, IOGNINHO_SOLEIL) (1).

ACHOCOLATADO (ACHOCTODDY , ACHOCNESCAU, ACHOCOVOMALTINE, ACHOCGOLD) (1) .

SUCOS (TANG, SUCO_DEL_VALLE, SUCO_JAL, SUCO_SINUELO, SUCO_NESTLE, SUCO_MAIS) (1) .

ABSORVENTE (ABSCAREFREE, ABSSLIVRE, ABSINTGEL , ABSALWAYS) (1) .

CATCHUP (CATCHUP_PIC, CATCHUP_HELLMANN_S) (1).

ELMA_CHIPS (BATATA_RUFFLES, BATATA_PALHA_ELMA_CHIPS) (1) .

AMENDOIM (AMENDOIM_DORI , AMENDOIM_YOKI, AMENDOIM_C_R) (1).

ACUCAR (ACUCAR_DA_BARRA, ACUCAR_CRISTALCUCAR, ACUCAR_UNIAO) (1).

ARROZ (ARROZ_SANO, ARROZ_ALBARUSKA , ARROZ_PRATO_FINO, ARROZ_UNCLE_BENS , ARROZ_TIO_JOAO) (1) .

OLEO (OLEO_SOJA_SADIA , OLEO_SOJA_SOYA, OLEO_SOJA_LIZA , OLEO_SOJA_SALADA) (1) .

CAFE (CAFE_RIBEIRAO_BONITO,CAFE_OURO_BRASILEIRO,CAFE_SERRA_DA_GRAMA, CAFE_CABOCLO, CAFE_PELE) (1).

ALCOOL (ALCOOL_CANDURA, ALCOOL_MULTIALCOOL , ALCOOL_CLARA , ALCOOL_COPERALCOOL) (1) .

QUEI JO_RALADO (QUEIJO_RALADO_TEIXEIRA_PARMESAO, QUEIJO_RALADO_TEIXEIRA_4_FORMAGGI , QUEIJO_RALADO_FAIXA_AZUL) (1).

QUEIJO_PECA (QUEIJO_SANCOR, QUEIJO_DANUBIO_MINAS, QUEIJO_FRESCATINO_MINAS_FRESCAL) (1) .

SOBREMESA_CREMOSA_CHOCOLATE (CHANDELLE, DANETTE) (1).

ESPONJA (ESPONJA_SCOTCH_BRITE, ESPONJA_BOMBRIL) (1).

LEITE_ACHOCOLATADO (TODDYNHO, NESCAU_PRONTINHO) (1).

ALHO (ALHO_DA_ROCA , ALHO_BOIANI , ALHO_TOTAL , PURO_ALHO_BOIANI , PURO_ALHO_ARISCO) (1) .

SABAO_PO (SPO_OMO, SPO_MINERVA, SPO_BRILHANTE, SPO_ACE, SPO_CAMPEIRO) (1).

ESPONJA_ACO (BOMBRIL, ESPONJA_DE_ACO_ASSOLAN) (1).

FLUOR (CEPACOL, ANTI_SEPTLISTERINE) (1).

FIO_DENTAL (FIO_DENTAL_REACH, FIO_DENTAL_TEK, FIO_DENTAL_DENTICS) (1) .

ESCOVA_DENTE (EDJ_J_REACH, ED JOHNSON__-_JOHNSON, EDJOHNSON_S) (1) .

CERVEJA (CERVXINGU , CERVCRYSTAL , CERVBRAHMA , CERVANTARCTICA , CERVSCHINCARIOL , CERVKAISER) (1) .

VODKA (VODKA_ORLOFF, VODKA_BAIKAL, VODKA_SMIRNOFF) (1).

CHAMPAGNE (CHAMPAGNE_CHANDON, CHAMPAGNE_PETERLONGO, CHAMPAGNE_DE_GREVILLE, CHAMPAGNE_ESPDE_PRATA) (1).

ALFACE (ALFACE_CRESPA , ALFACE_AMERICANA , ALFACE_LISA) (1).

RUCULA (RUCULA_BIO_TERRA, RUCULA_SATO) (1).

COUVE (COUVE_MANTEIGA_ORGANICA , COUVE_MANTEIGA) (1) .

VERDURAS (ALFACE , RUCULA, COUVE) (2) .

BEBIDA_ALCOOLICA (CERVEJA, VODKA, CHAMPAGNE) (2) .

BEBIDA_NALCOOLICA (REFRIGERANTE, IORGUTE, SUCOS, LEITE_UHT, LEITE_ACHOCOLATADO) (2).

DOCES (CHOCOLATE, BISCOITO, SOBREMESA_CREMOSA_CHOCOLATE) (2) .

ENLATADOS (MOLHO_TOMATE, ACHOCOLATADO, CATCHUP) (2) .

QUEIJO (QUEIJO_RALADO, QUEIJO_PECA) (2) .

APERITIVOS (ELMA_CHIPS, AMENDOIM) (2) .

MACARRAO (MACARRAO_NINST , MACARRAO_INST) (2).

PRODUTOS_BASICOS (FARINHA_TRIGO, FEIJAO, ACUCAR, ARROZ, OLEO , CAFE) (2).

TEMPEROS (CALDOS, ALHO) (2).

PRODUTOS_ALIMENTICIOS (DOCES , ENLATADOS, QUEIJO, APERITIVOS , MACARRAO, PRODUTOS_BASICOS , TEMPEROS , VERDURAS) (3) . BEBIDA (BEBIDA_ALCOOLICA, BEBIDA_NALCOOLICA) (3).

Figura B.28: Conjunto de taxonomias tax07/ND. 



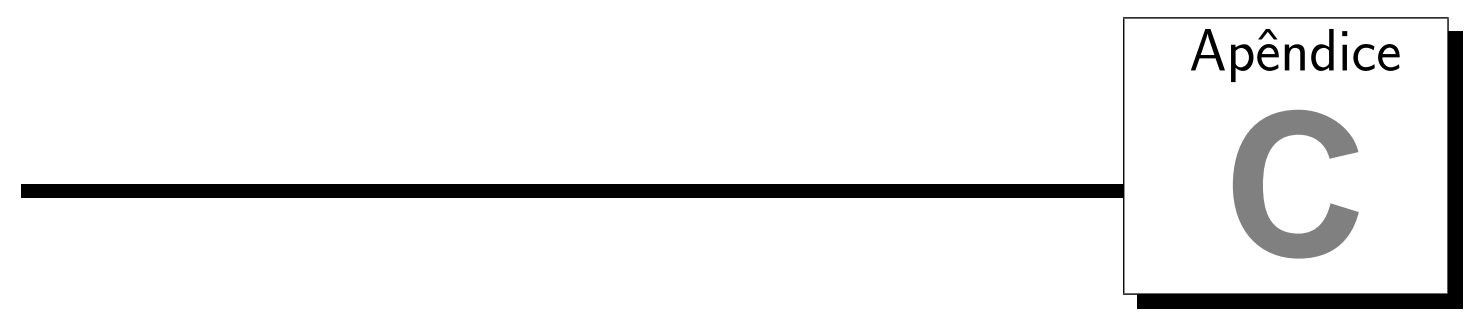

\section{Conjuntos de Taxonomias Utilizados no Cjto-R}

Nesse apêndice são apresentadas as taxonomias utilizadas nos experimentos descritos na Seção 4.8 (página 82) relacionados ao Cjto-R. Cada conjunto de taxonomias abaixo listado é identificado pelo prefixo "tax", seguido de um número de identificação seqüencial, juntamente com a informação referente a quantos níveis de abstração o mesmo possui (1N, $2 \mathrm{~N}, 3 \mathrm{~N}$ e ND). Por exemplo, no conjunto de taxonomias da Figura C.1 o rótulo tax01/1N identifica o primeiro conjunto de taxonomias contendo generalizações de um nível de abstração. 
desserts (ice_cream, dessert)(1).

curd_products (curd_cheese, curd) (1).

organics (organic_sausage, organic_products) (1).

cheeses (specialty_cheese, spread_cheese,hard_cheese, soft_cheese,processed_cheese,sliced_cheese) (1).

cosmetics (baby_cosmetics, male_cosmetics) (1).

frozens (frozen_dessert,frozen_fruits,frozen_vegetables,frozen_potato_products,frozen_meals,frozen_fish, frozen_chicken) (1).

meats (meat_spreads, fish, chicken, hamburger_meat,meat) (1).

bag(cling_film_bags, shopping_bags, bags)(1).

vegetable (specialty_vegetables, root_vegetables,pickled_vegetables, other_vegetables) (1).

breads (white_bread, brown_bread, semi_finished_bread) (1).

beverages_all (beverages, coffee, whole_milk, UHT_milk, butter_milk, white_wine, bottled_beer,misc_beverages, instant_coffee,red_blush_wine, bottled_water,fruit_vegetable_juice,canned_beer, liquor_appetizer, liquor, sparkling_wine)(1).

chocolate_products (chocolate, chocolate_marshmallow, cooking_chocolate, specialty_chocolate)(1).

snacks (nut_snack, snack_products, salty_snack) (1).

soup (ready_soups, soups) (1).

cream_products (whipped_sour_cream, cream, cream_cheese) (1).

canned_products (canned_fruit, canned_fish, canned_vegetables) (1).

care_products (pet_care, skin_care, dental_care) (1).

clean_products (abrasive_cleaner,dish_cleaner,toilet_cleaner,cleaner, bathroom_cleaner) (1).

fruits (citrus_fruit,tropical_fruit,packaged_fruit_vegetables,pip_fruit) (1).

Figura C.1: Conjunto de taxonomias tax01/1N.

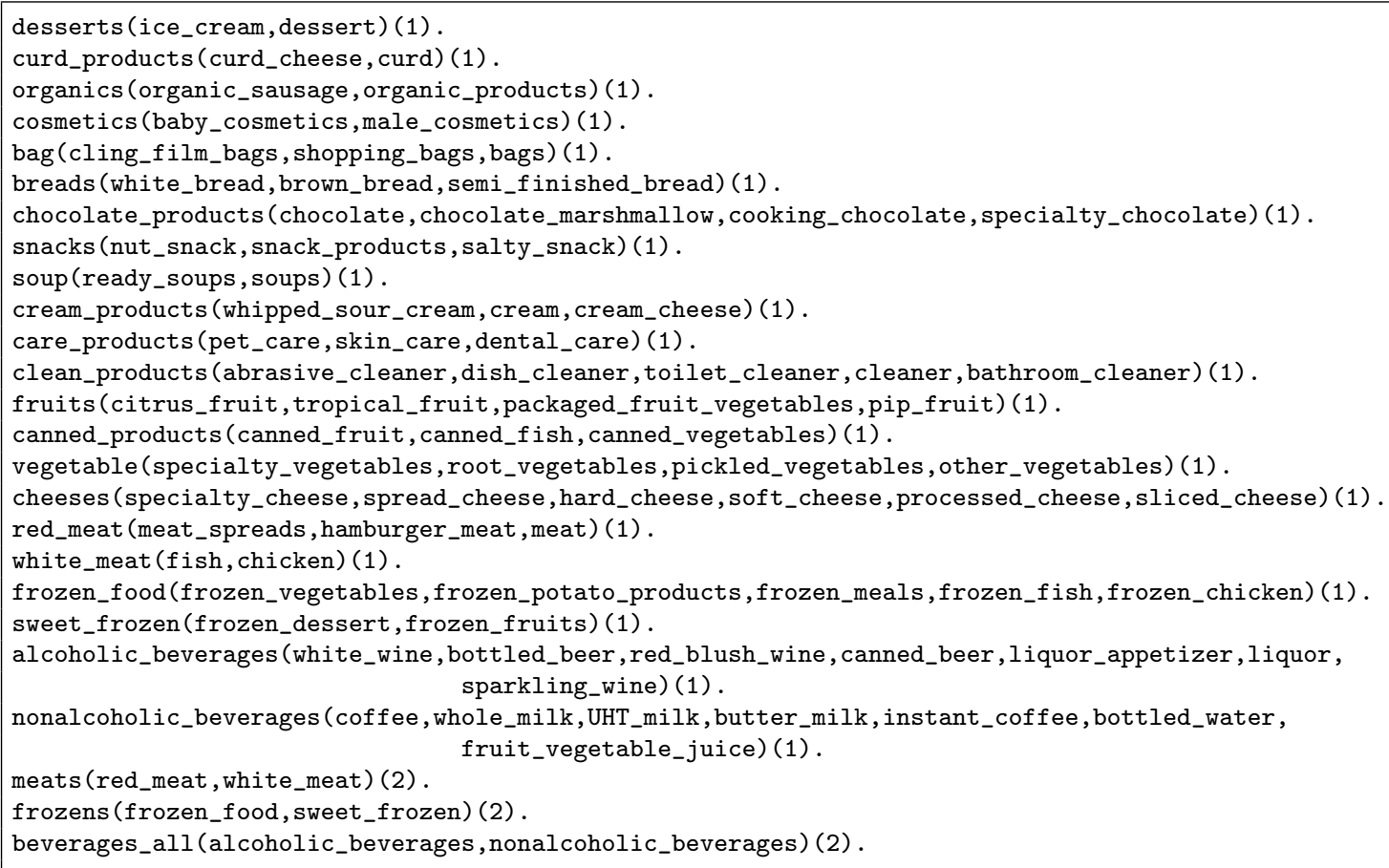

Figura C.2: Conjunto de taxonomias tax01/2N. 
desserts (ice_cream, dessert) (1).

curd_products (curd_cheese, curd) (1).

organics (organic_sausage, organic_products) (1).

cosmetics (baby_cosmetics, male_cosmetics) (1).

bag (cling_film_bags, shopping_bags, bags) (1).

breads (white_bread, brown_bread, semi_finished_bread) (1).

chocolate_products (chocolate, chocolate_marshmallow, cooking_chocolate, specialty_chocolate) (1).

snacks (nut_snack, snack_products, salty_snack) (1).

soup (ready_soups, soups) (1).

cream_products (whipped_sour_cream, cream, cream_cheese) (1).

care_products (pet_care, skin_care, dental_care) (1).

clean_products (abrasive_cleaner,dish_cleaner,toilet_cleaner,cleaner, bathroom_cleaner) (1).

fruits (citrus_fruit,tropical_fruit,packaged_fruit_vegetables,pip_fruit)(1).

canned_products (canned_fruit, canned_fish, canned_vegetables) (1).

vegetable (specialty_vegetables, root_vegetables,pickled_vegetables, other_vegetables) (1).

cheeses (specialty_cheese, spread_cheese, hard_cheese, soft_cheese,processed_cheese, sliced_cheese) (1).

red_meat (meat_spreads, hamburger_meat,meat) (1).

white_meat (fish, chicken) (1).

frozen_food (frozen_vegetables,frozen_potato_products,frozen_meals,frozen_fish,frozen_chicken) (1).

sweet_frozen (frozen_dessert,frozen_fruits) (1).

alcoholic_beverages (white_wine, bottled_beer,red_blush_wine, canned_beer, liquor_appetizer, liquor, sparkling_wine)(1).

nonalcoholic_beverages (coffee,whole_milk,UHT_milk, butter_milk, instant_coffee, bottled_water, fruit_vegetable_juice)(1).

meats (red_meat, white_meat) (2).

frozens (frozen_food, sweet_frozen) (2).

beverages_all (alcoholic_beverages, nonalcoholic_beverages) (2) .

supermarket_products (meats, frozens, beverages_all) (3).

Figura C.3: Conjunto de taxonomias tax01/3N.

desserts (ice_cream, dessert)(1).

curd_products (curd_cheese, curd) (1).

organics (organic_sausage, organic_products) (1).

cosmetics (baby_cosmetics, male_cosmetics) (1).

bag(cling_film_bags, shopping_bags, bags) (1).

breads (white_bread, brown_bread,semi_finished_bread) (1) .

chocolate_products (chocolate, chocolate_marshmallow, cooking_chocolate, specialty_chocolate) (1).

snacks (nut_snack, snack_products, salty_snack) (1).

soup (ready_soups, soups) (1).

cream_products (whipped_sour_cream, cream, cream_cheese) (1).

care_products (pet_care,skin_care,dental_care) (1).

clean_products (abrasive_cleaner, dish_cleaner, toilet_cleaner, cleaner, bathroom_cleaner) (1).

fruits (citrus_fruit,tropical_fruit,packaged_fruit_vegetables,pip_fruit)(1).

canned_products (canned_fruit, canned_fish, canned_vegetables) (1).

vegetable (specialty_vegetables, root_vegetables,pickled_vegetables, other_vegetables) (1).

cheeses (specialty_cheese, spread_cheese, hard_cheese, soft_cheese,processed_cheese, sliced_cheese) (1).

red_meat (meat_spreads, hamburger_meat,meat) (1).

white_meat (fish, chicken) (1).

frozen_food (frozen_vegetables,frozen_potato_products,frozen_meals,frozen_fish,frozen_chicken) (1).

sweet_frozen(frozen_dessert,frozen_fruits) (1).

alcoholic_beverages (white_wine, bottled_beer,red_blush_wine, canned_beer, liquor_appetizer, liquor, sparkling_wine) (1).

nonalcoholic_beverages (coffee, whole_milk, UHT_milk, butter_milk, instant_coffee, bottled_water, fruit_vegetable_juice)(1).

meats (red_meat, white_meat) (2).

frozens (frozen_food, sweet_frozen) (2).

beverages_all (alcoholic_beverages, nonalcoholic_beverages) (2).

food (meats, frozens) (3).

Figura C.4: Conjunto de taxonomias tax01/ND. 

Apêndice

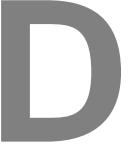

\section{Resultados Referentes à Taxa de Compactação do Cjto-Sup Agrupados por Medida}

Nesse apêndice são apresentados os resultados descritos na Seção 4.8 (página 82) referentes à taxa de compactação do Cjto-Sup agrupados pela medida utilizada na generalização (sup e conf) (Figuras D.1 a D.28). Os resultados foram plotados em gráficos, os quais são apresentados a seguir. Os rótulos das figuras são identificados pela taxonomia utilizada seguida de seu respectivo nível de abstração (por exemplo, tax01/1N). Os eixos $x$ dos gráficos são identificados pelas configurações utilizadas nos experimentos usando a notação lado-medida-t\% (por exemplo, lhs-sup-0), além do código da taxonomia. Os eixos $y$ dos gráficos indicam a taxa de compactação obtida em uma determinada configuração.

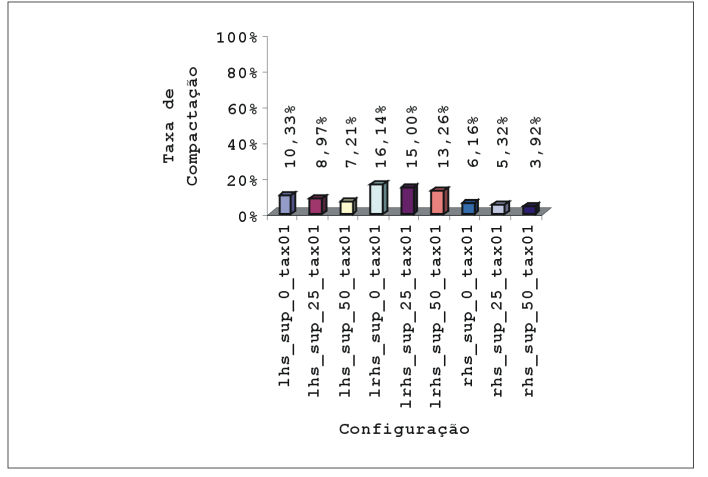

(a) sup

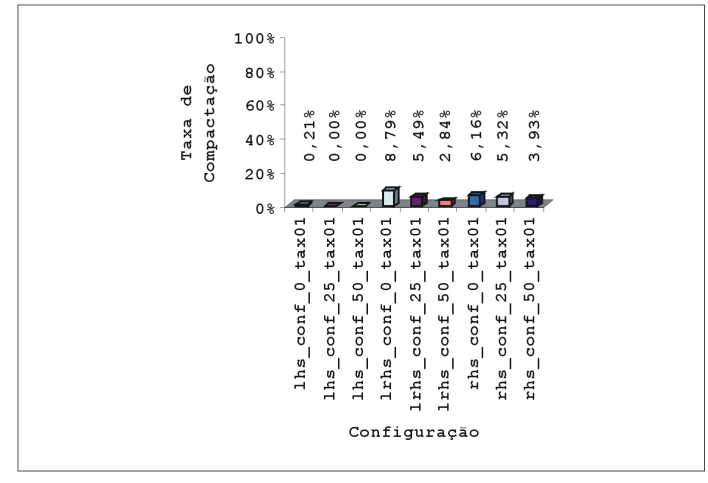

(b) conf

Figura D.1: Resultados utilizando as medidas sup e conf $(\operatorname{tax} 01 / 1 \mathrm{~N})$. 


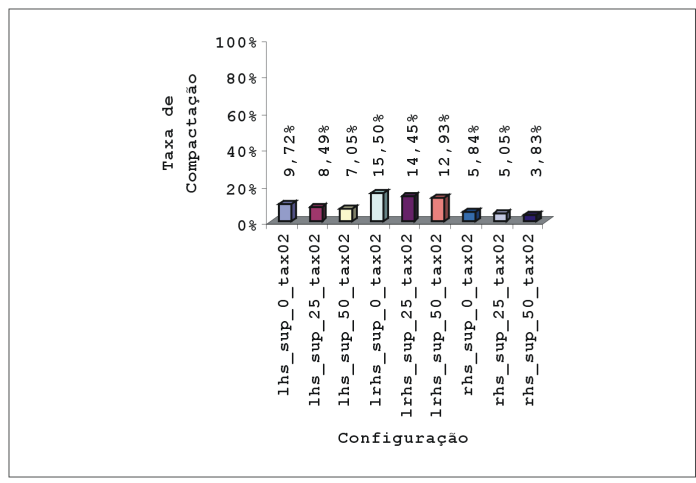

(a) sup

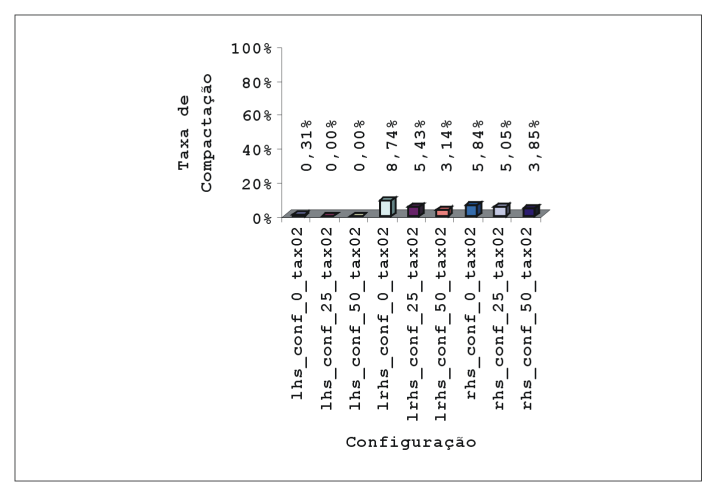

(b) conf

Figura D.2: Resultados utilizando as medidas sup e conf $(\operatorname{tax} 02 / 1 \mathrm{~N})$.

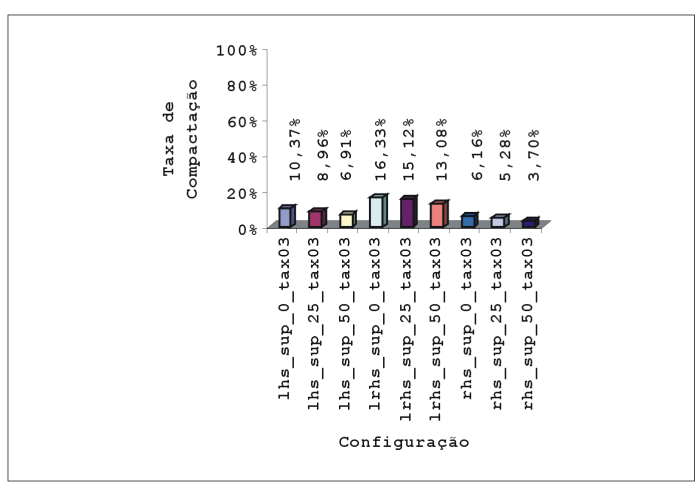

(a) sup

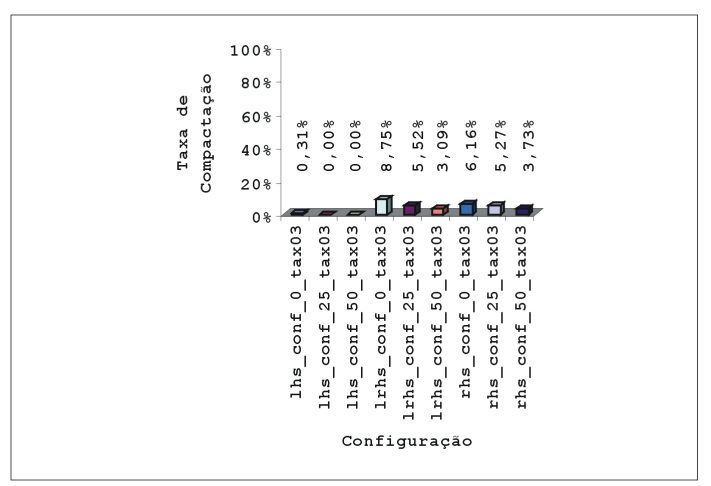

(b) conf

Figura D.3: Resultados utilizando as medidas sup e conf $(\operatorname{tax} 03 / 1 \mathrm{~N})$.

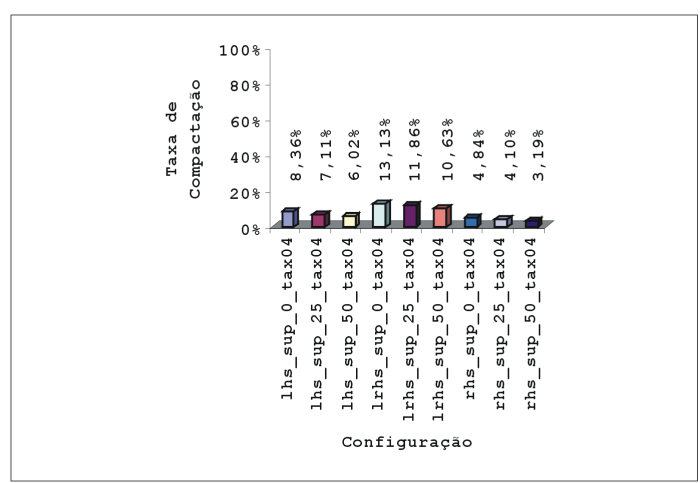

(a) sup

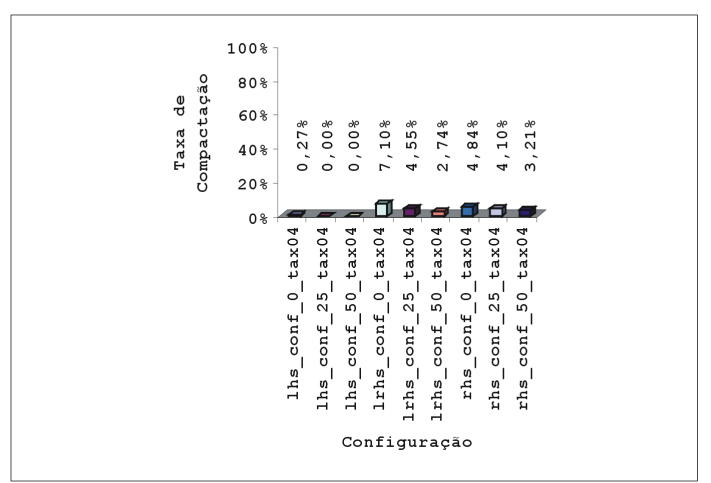

(b) conf

Figura D.4: Resultados utilizando as medidas sup e conf (tax04/1N). 


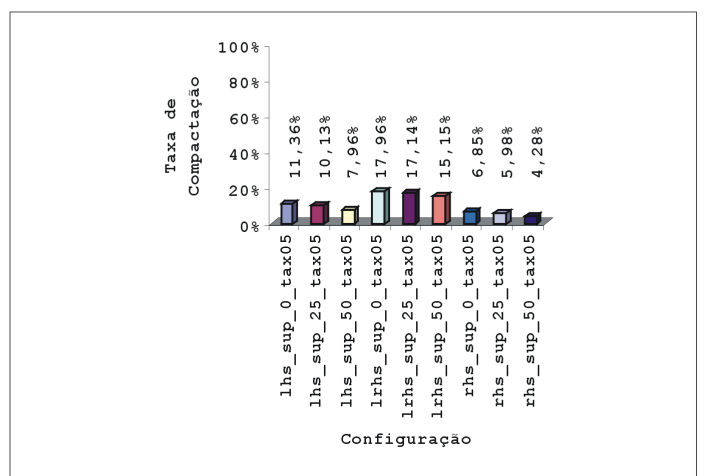

(a) sup

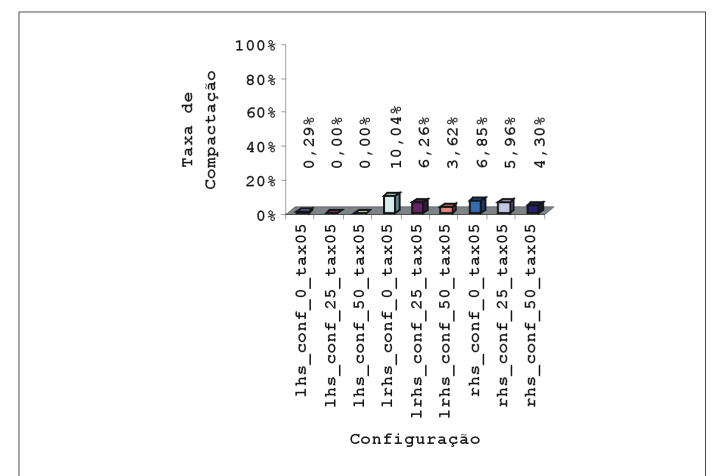

(b) conf

Figura D.5: Resultados utilizando as medidas sup e conf $(\operatorname{tax} 05 / 1 \mathrm{~N})$.

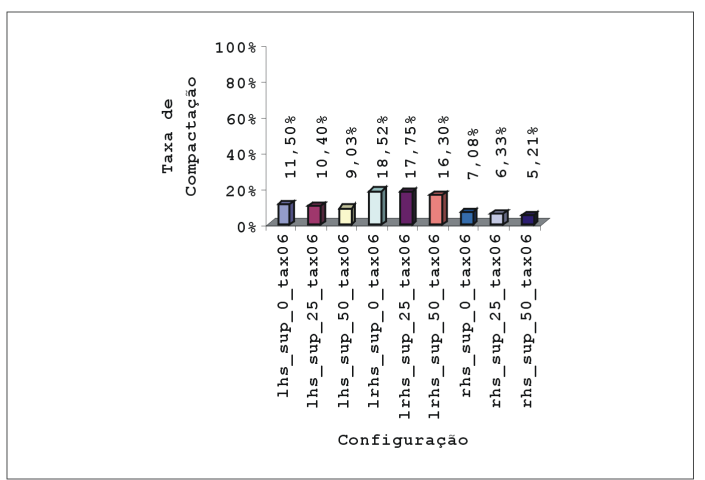

(a) sup

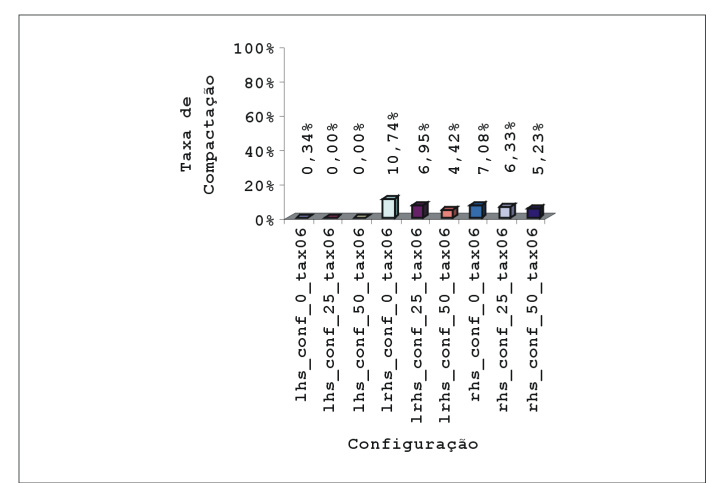

(b) $\operatorname{conf}$

Figura D.6: Resultados utilizando as medidas sup e conf $(\operatorname{tax} 06 / 1 \mathrm{~N})$.

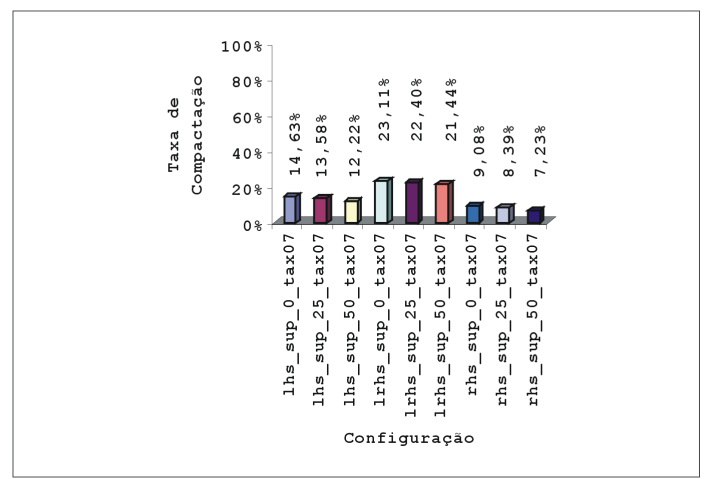

(a) sup

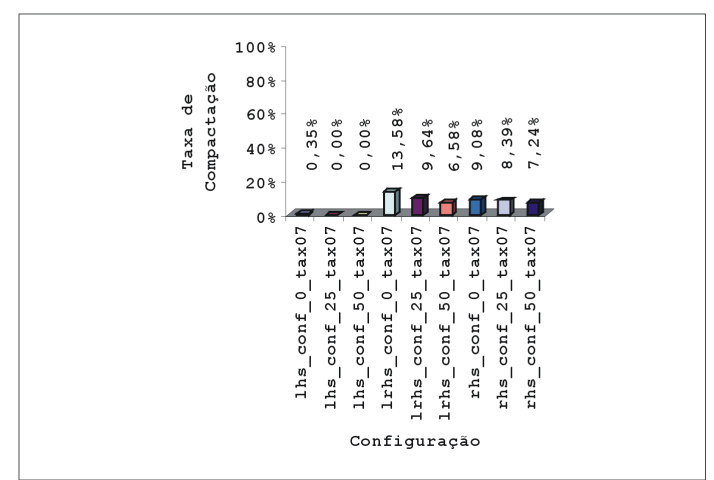

(b) $\operatorname{conf}$

Figura D.7: Resultados utilizando as medidas sup e conf $(\operatorname{tax} 07 / 1 \mathrm{~N})$. 


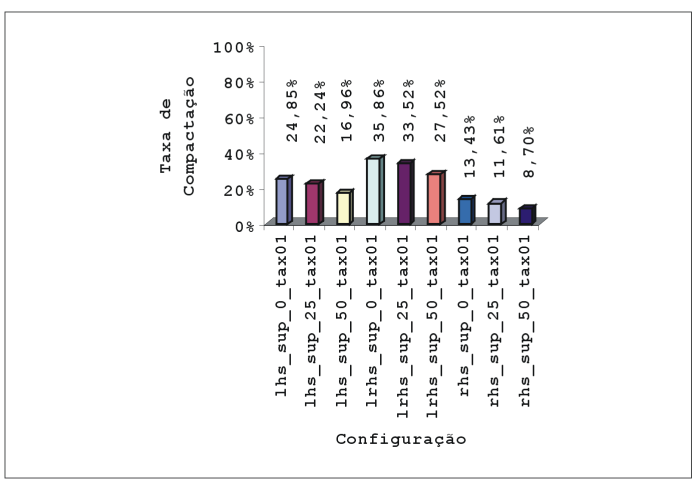

(a) sup

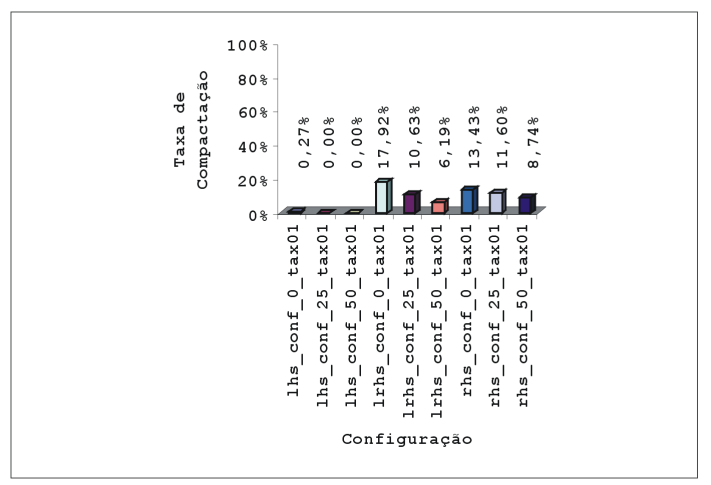

(b) $\operatorname{conf}$

Figura D.8: Resultados utilizando as medidas sup e conf $(\operatorname{tax} 01 / 2 \mathrm{~N})$.

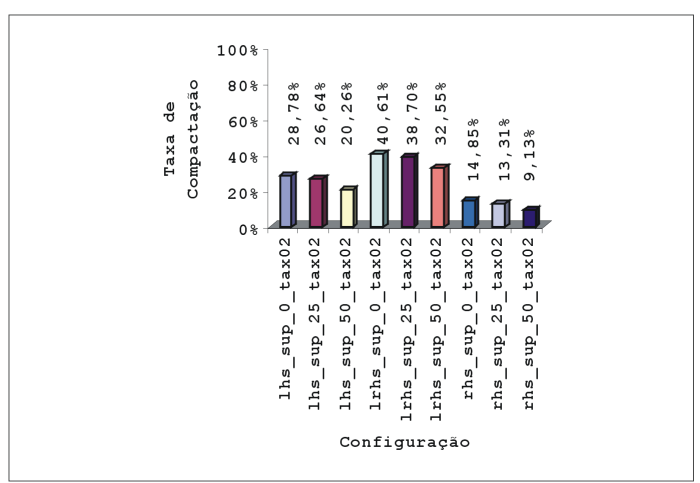

(a) sup

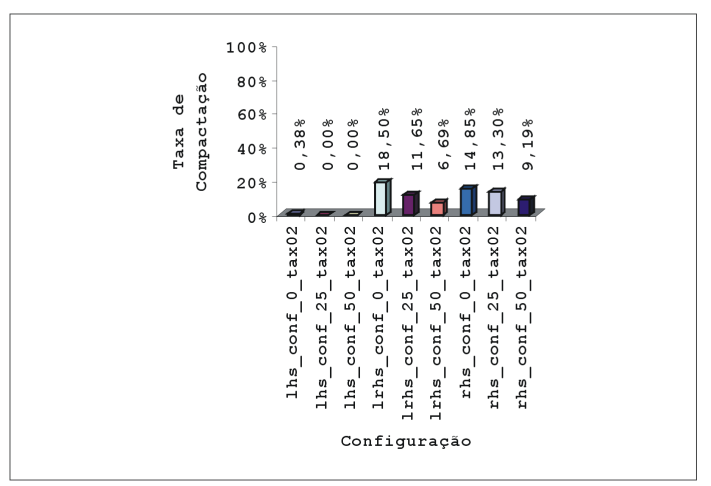

(b) conf

Figura D.9: Resultados utilizando as medidas sup e conf $(\operatorname{tax} 02 / 2 \mathrm{~N})$.

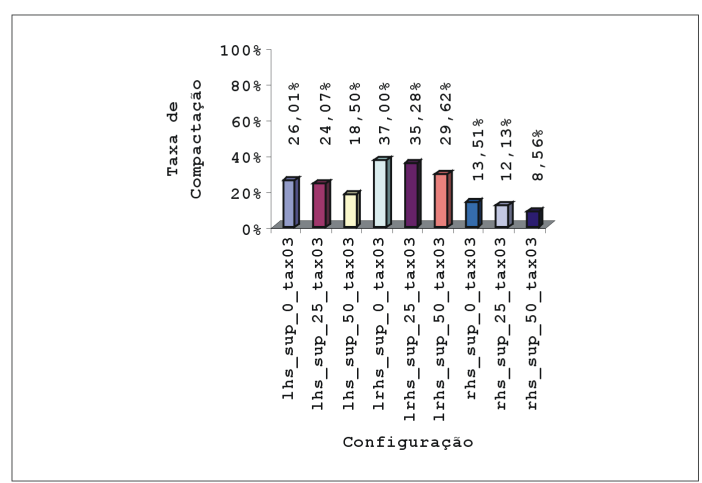

(a) sup

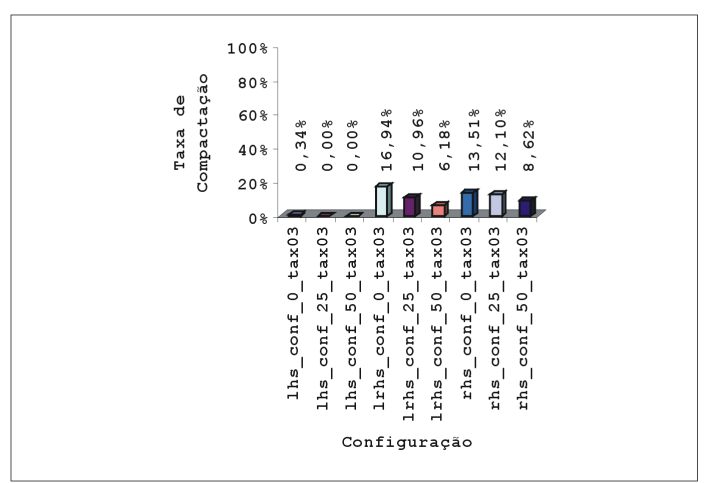

(b) conf

Figura D.10: Resultados utilizando as medidas sup e conf $(\operatorname{tax} 03 / 2 \mathrm{~N})$. 


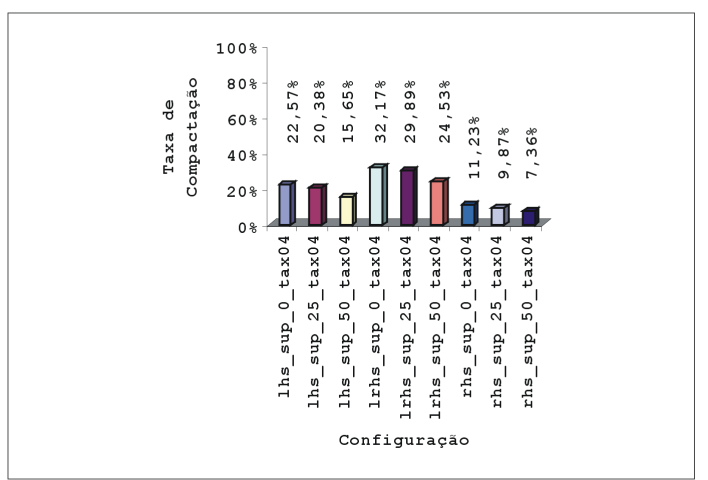

(a) sup

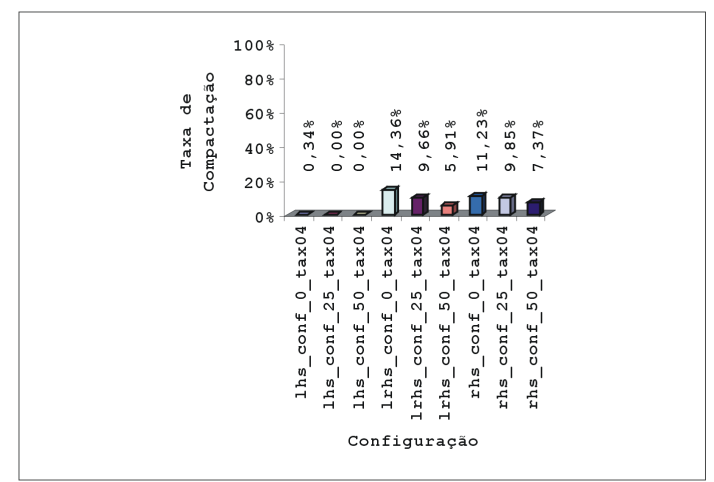

(b) conf

Figura D.11: Resultados utilizando as medidas sup e conf $(\operatorname{tax} 04 / 2 \mathrm{~N})$.

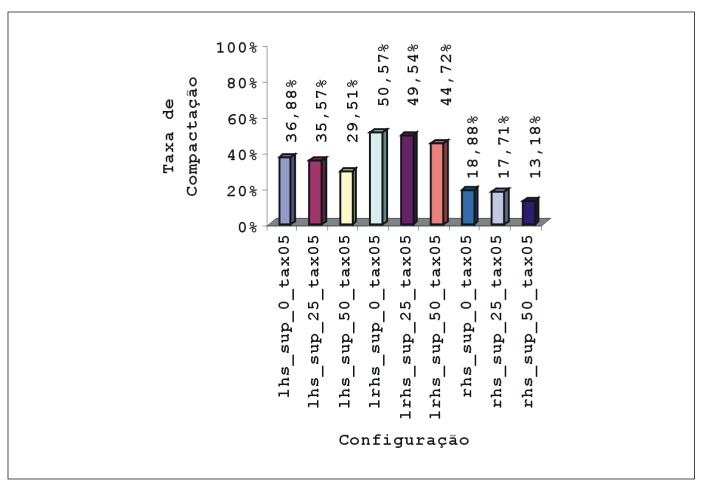

(a) sup

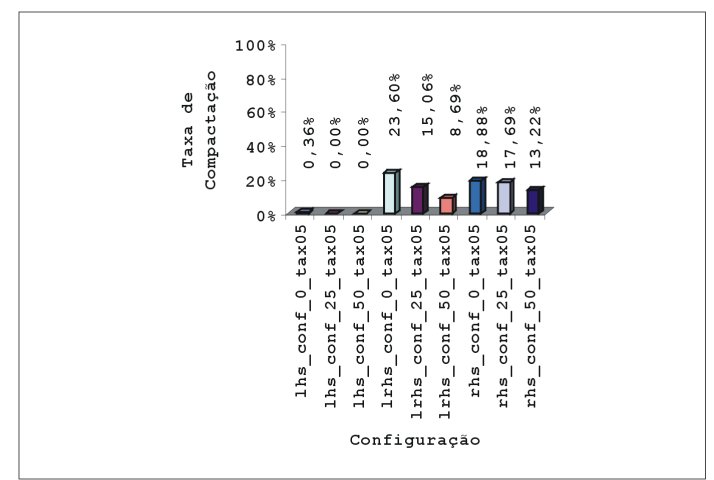

(b) $\operatorname{conf}$

Figura D.12: Resultados utilizando as medidas sup e conf (tax05/2N).

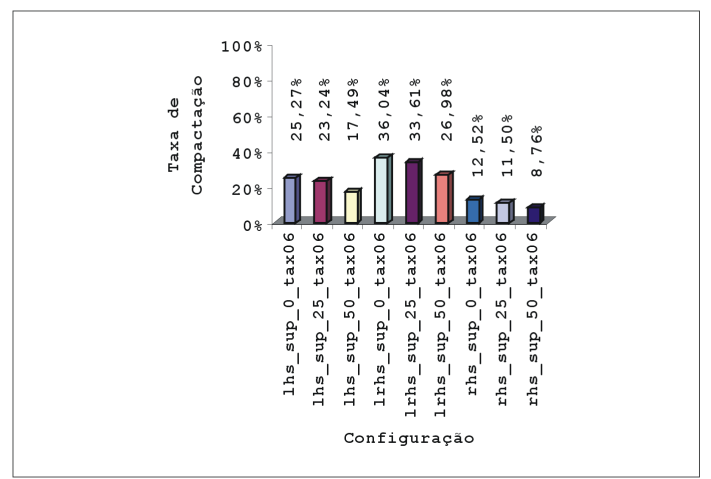

(a) sup

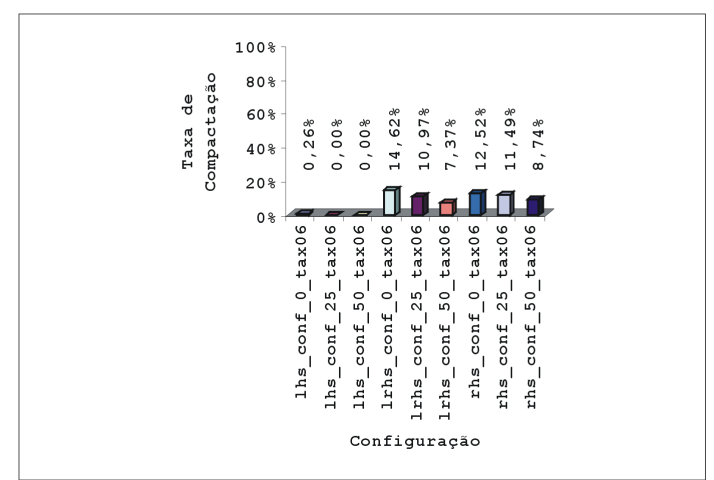

(b) conf

Figura D.13: Resultados utilizando as medidas sup e conf $(\operatorname{tax} 06 / 2 \mathrm{~N})$. 


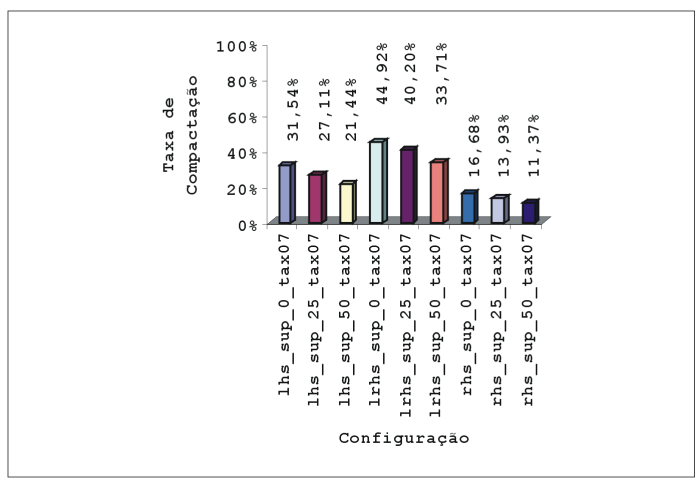

(a) sup

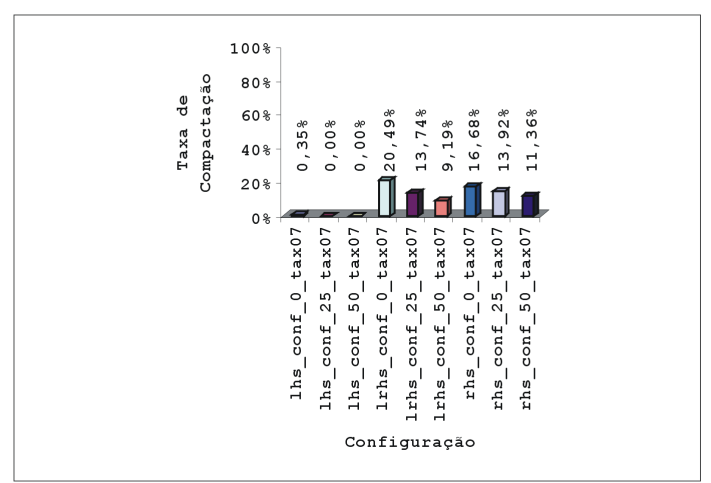

(b) conf

Figura D.14: Resultados utilizando as medidas sup e conf $(\operatorname{tax} 07 / 2 \mathrm{~N})$. 


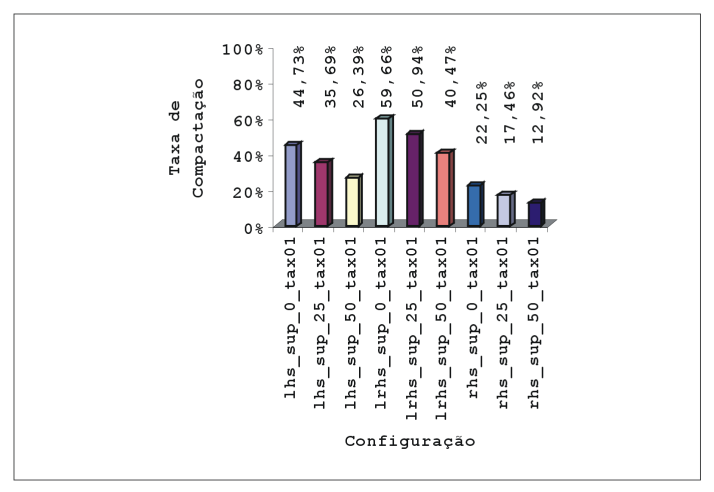

(a) sup

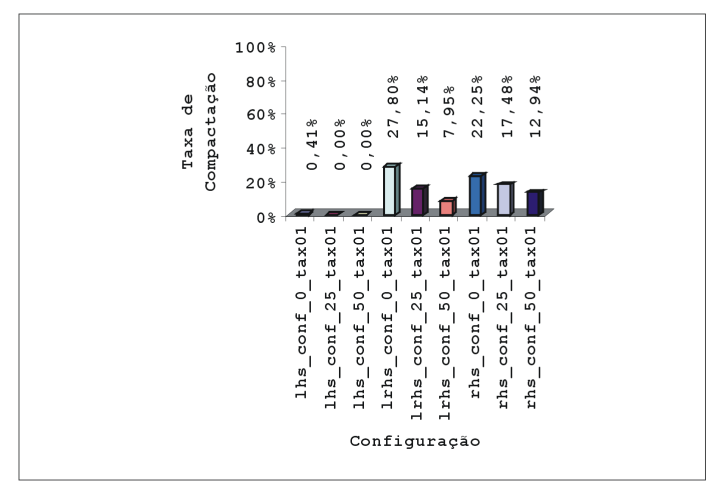

(b) conf

Figura D.15: Resultados utilizando as medidas sup e conf (tax01/3N).

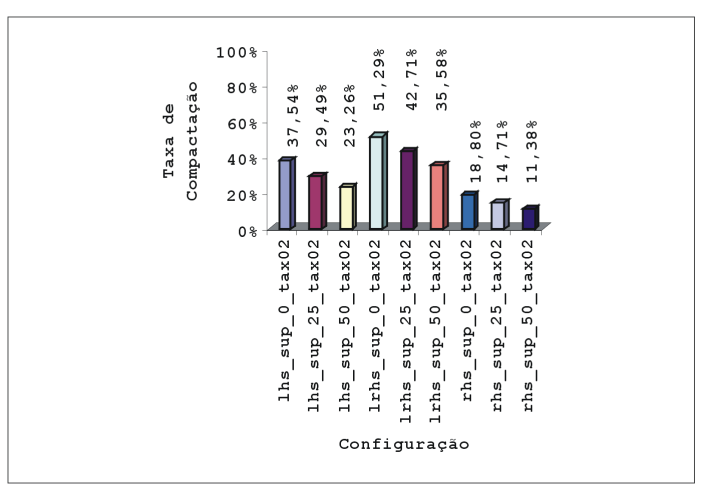

(a) sup

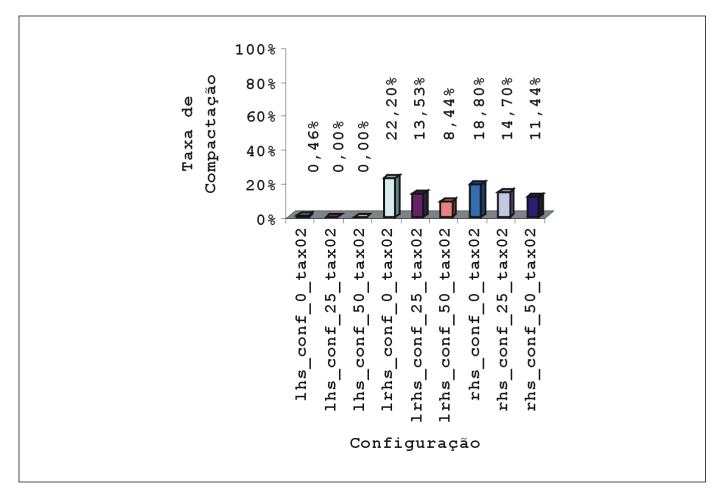

(b) conf

Figura D.16: Resultados utilizando as medidas sup e conf $(\operatorname{tax} 02 / 3 \mathrm{~N})$. 


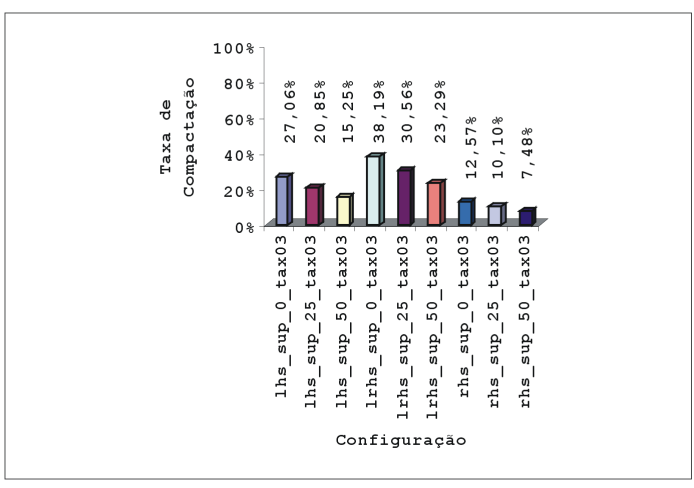

(a) sup

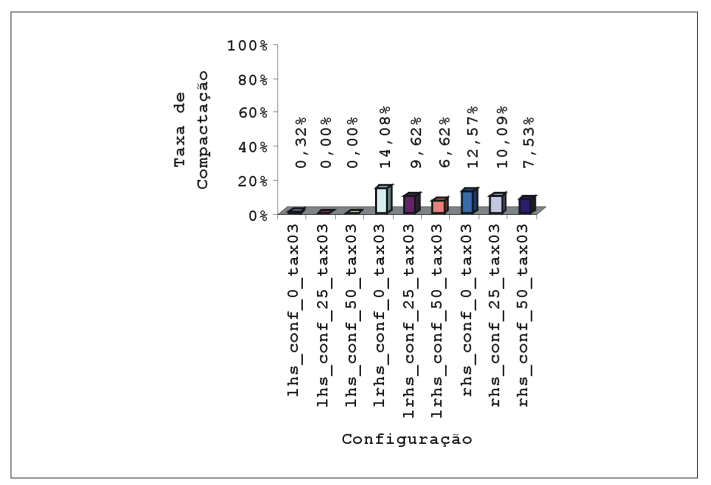

(b) $\operatorname{conf}$

Figura D.17: Resultados utilizando as medidas sup e conf (tax03/3N).

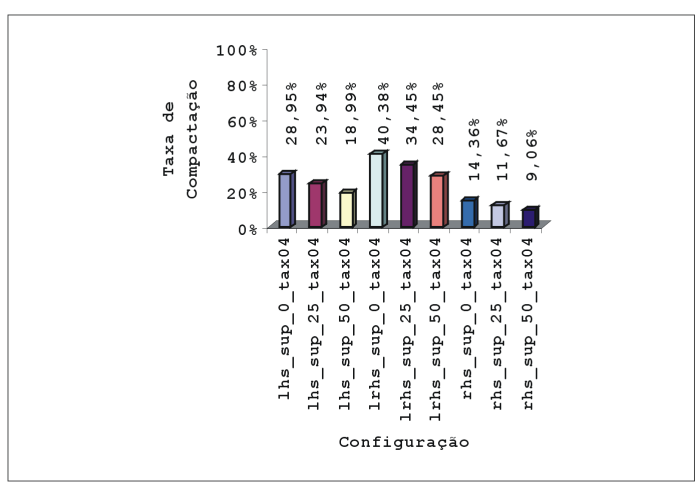

(a) sup

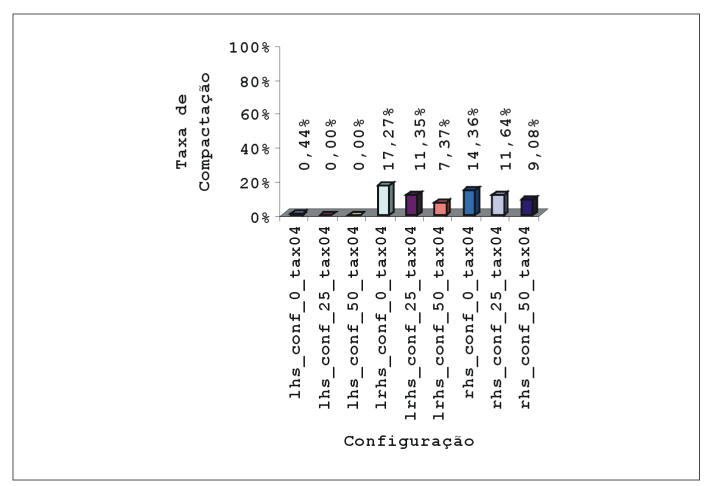

(b) conf

Figura D.18: Resultados utilizando as medidas sup e conf (tax04/3N).

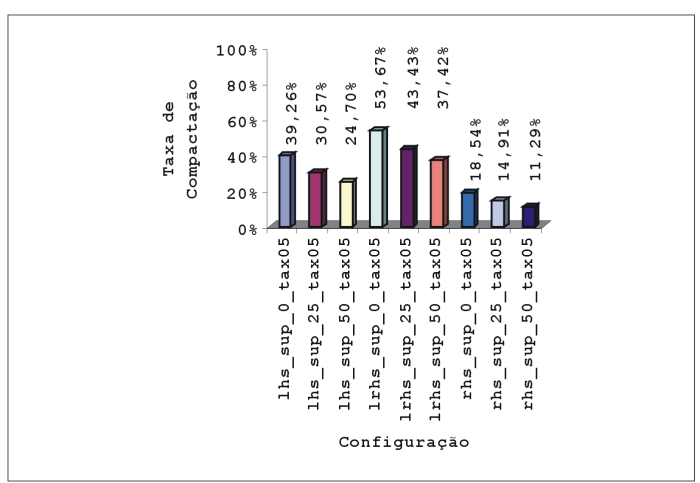

(a) sup

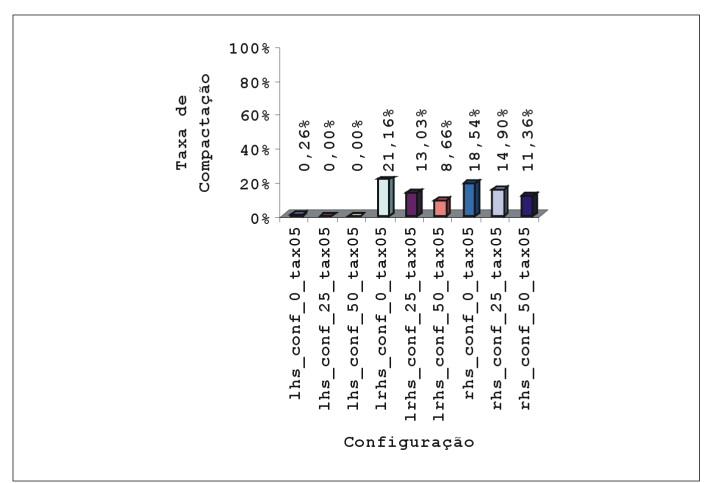

(b) conf

Figura D.19: Resultados utilizando as medidas sup e conf (tax05/3N). 


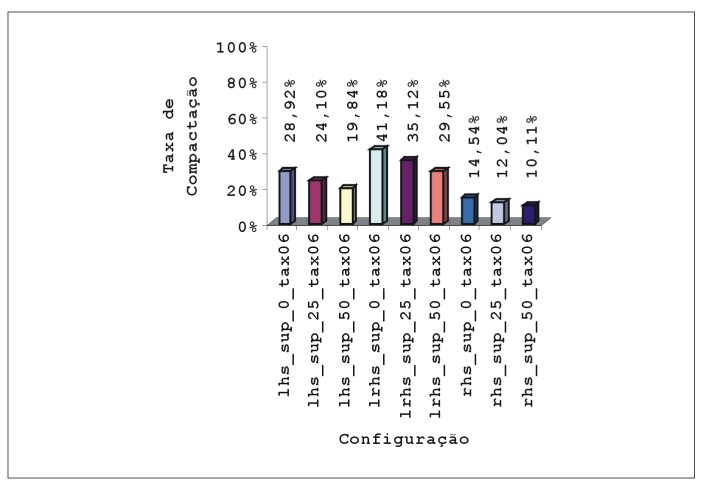

(a) sup

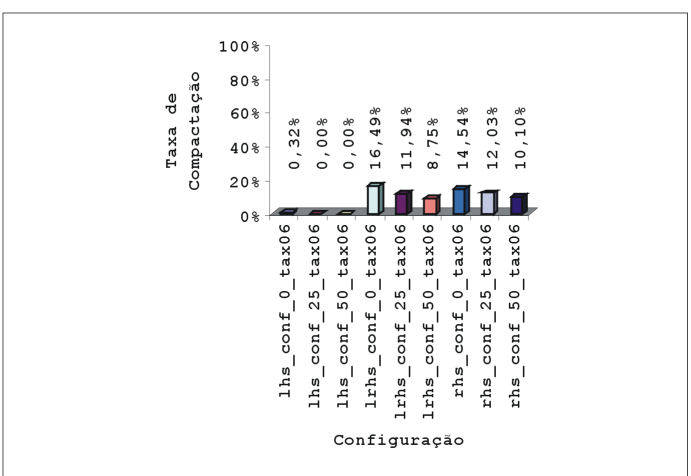

(b) conf

Figura D.20: Resultados utilizando as medidas sup e conf $(\operatorname{tax} 06 / 3 \mathrm{~N})$.

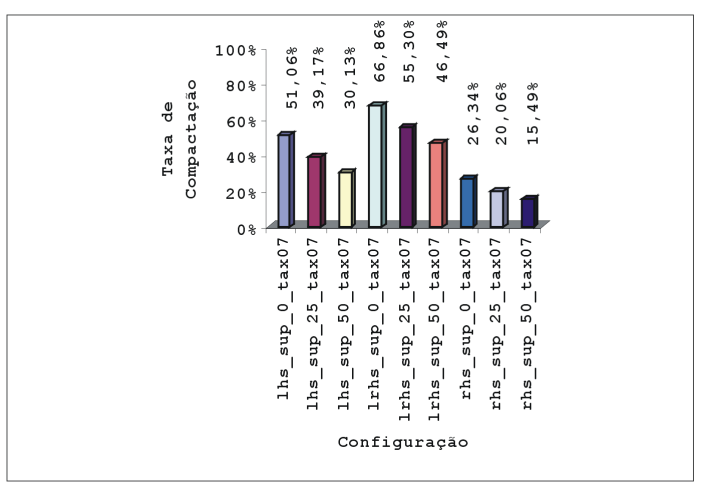

(a) sup

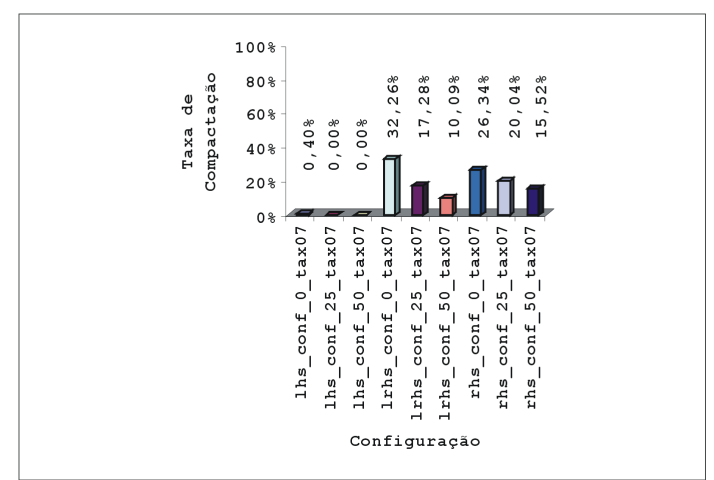

(b) conf

Figura D.21: Resultados utilizando as medidas sup e conf $(\operatorname{tax} 07 / 3 \mathrm{~N})$.

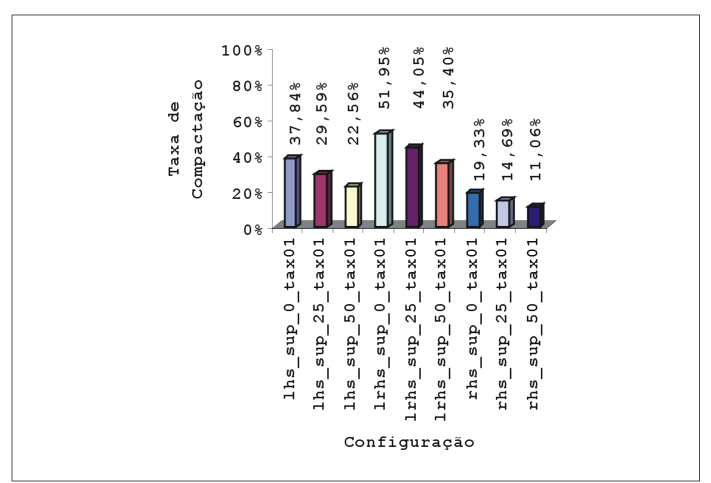

(a) sup

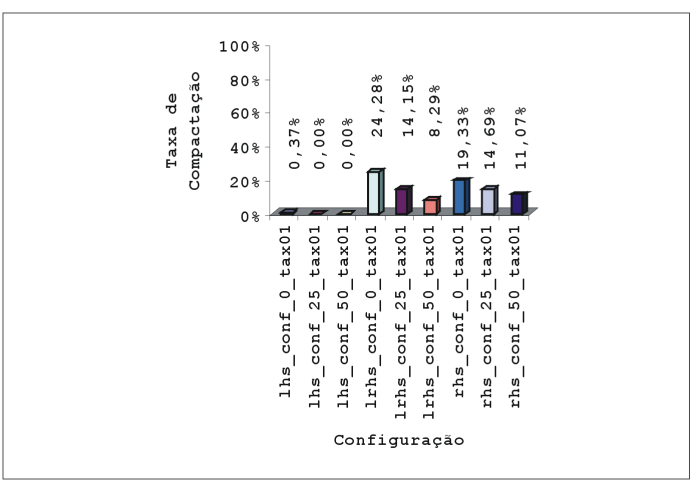

(b) conf

Figura D.22: Resultados utilizando as medidas sup e conf (tax01/ND). 


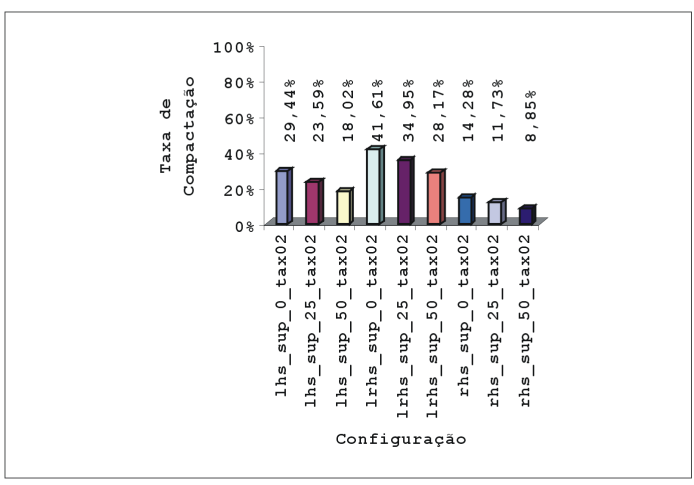

(a) sup

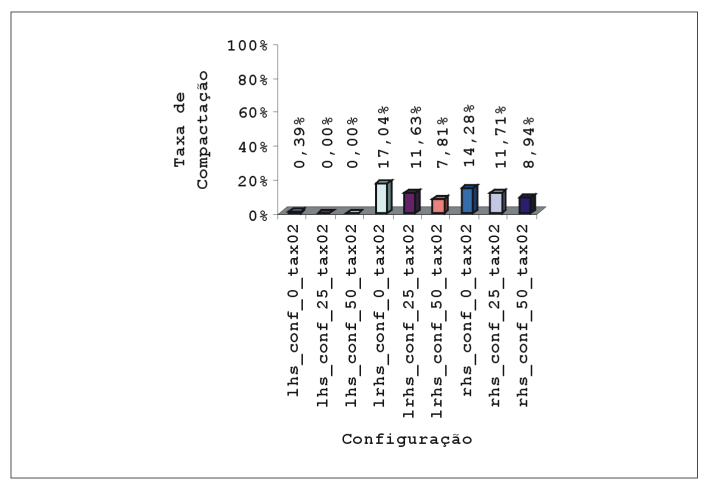

(b) $\operatorname{conf}$

Figura D.23: Resultados utilizando as medidas sup e conf (tax02/ND).

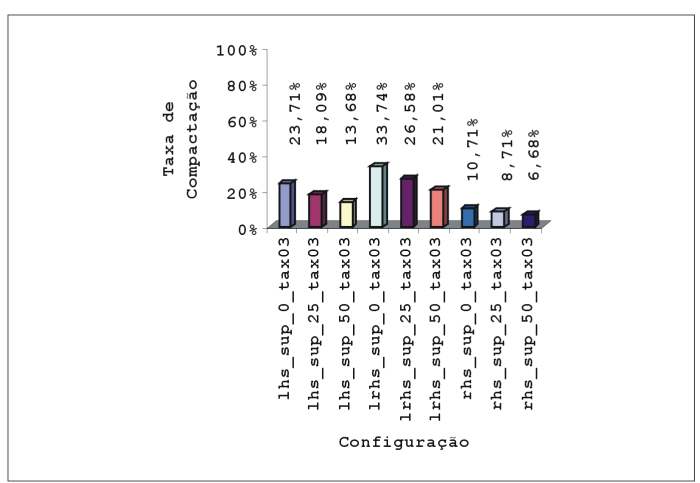

(a) sup

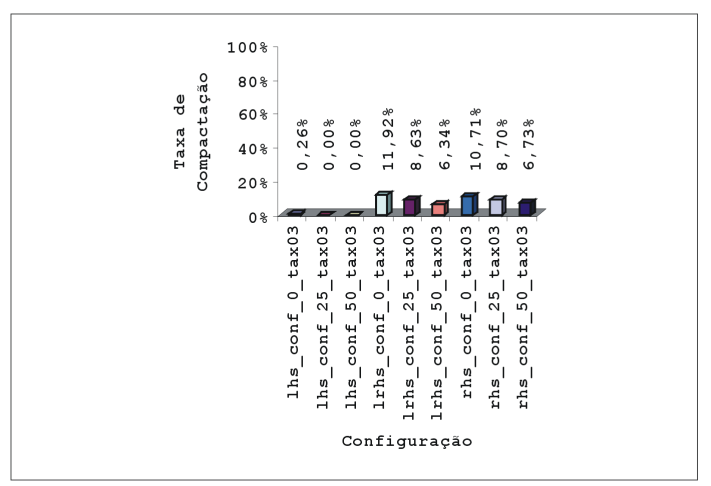

(b) conf

Figura D.24: Resultados utilizando as medidas sup e conf (tax03/ND).

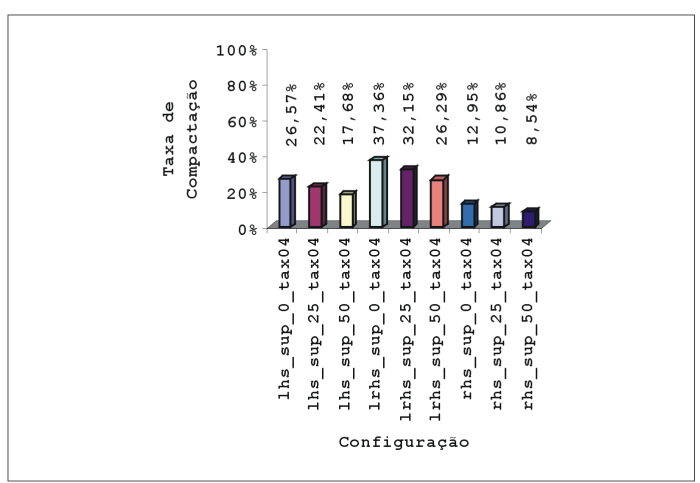

(a) sup

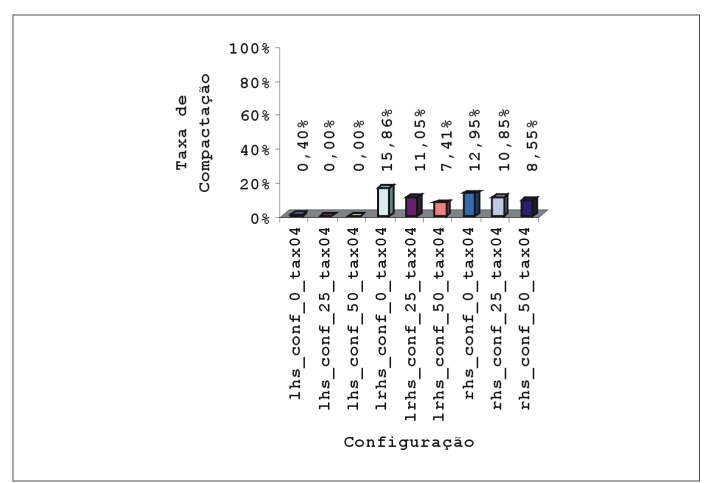

(b) conf

Figura D.25: Resultados utilizando as medidas sup e conf (tax04/ND). 


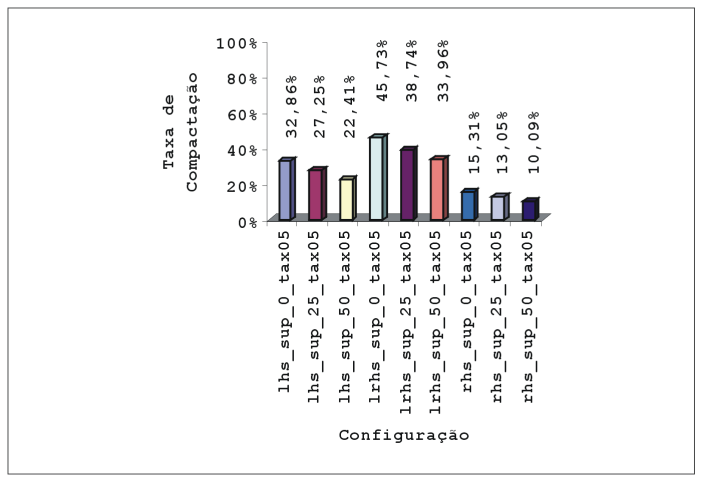

(a) sup

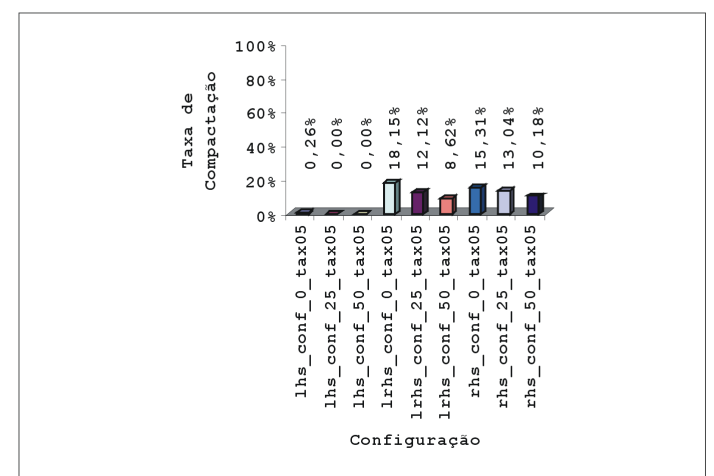

(b) conf

Figura D.26: Resultados utilizando as medidas sup e conf (tax05/ND).

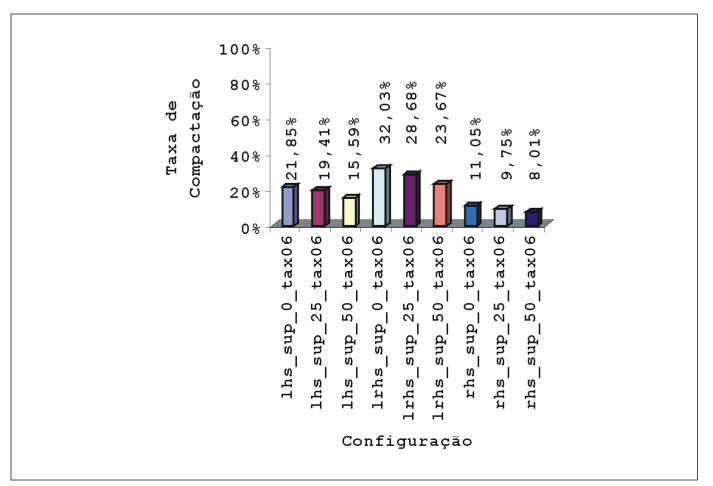

(a) sup

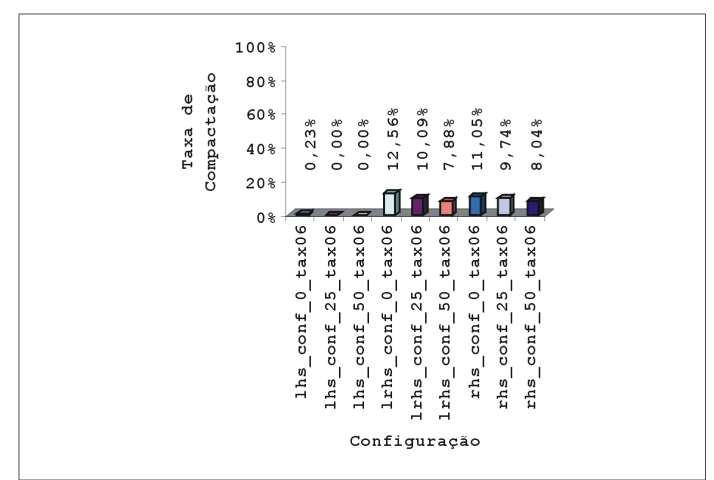

(b) $\operatorname{conf}$

Figura D.27: Resultados utilizando as medidas sup e conf (tax06/ND).

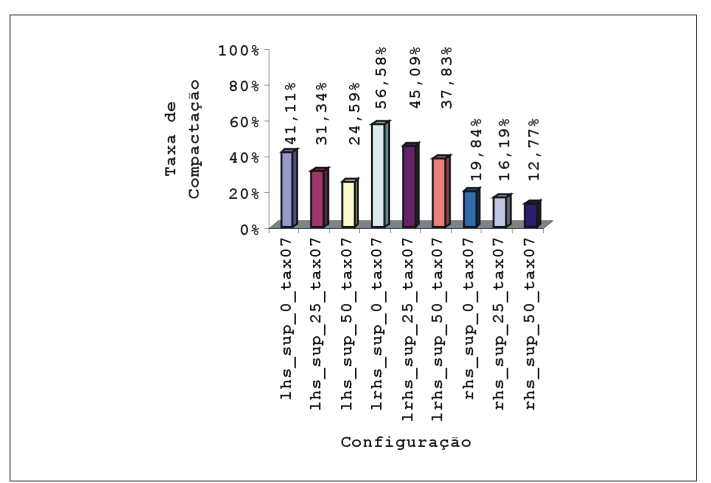

(a) sup

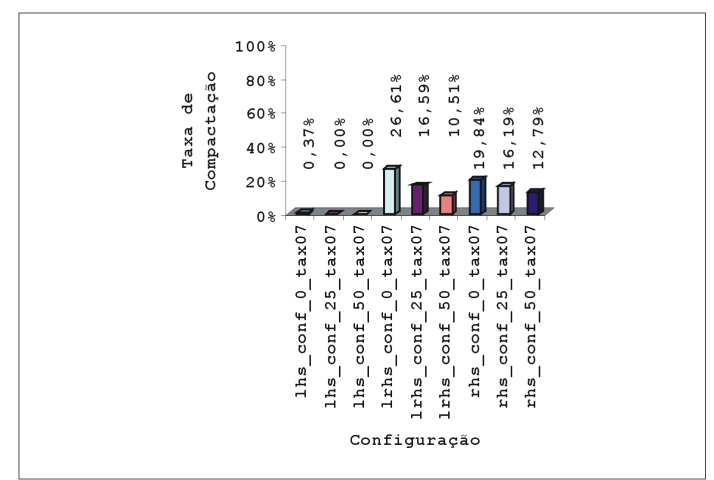

(b) conf

Figura D.28: Resultados utilizando as medidas sup e conf (tax07/ND). 

Apêndice

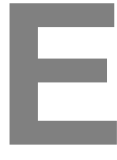

\section{Resultados Referentes à Taxa de Compactação do Cjto-R Agrupados por Medida}

Nesse apêndice são apresentados os resultados descritos na Seção 4.8 (página 82) referentes à taxa de compactação do Cjto-R agrupados pela medida utilizada na generalização (sup e conf) (Figuras E.1 a E.4). Os resultados foram plotados em gráficos, os quais são apresentados a seguir. Os rótulos das figuras são identificados pela taxonomia utilizada seguida de seu respectivo nível de abstração (por exemplo, tax01/1N). Os eixos $x$ dos gráficos são identificados pelas configurações utilizadas nos experimentos usando a notação lado-medida-t\% (por exemplo, lhs-sup-0), além do código da taxonomia. Os eixos y dos gráficos indicam a taxa de compactação obtida em uma determinada configuração.

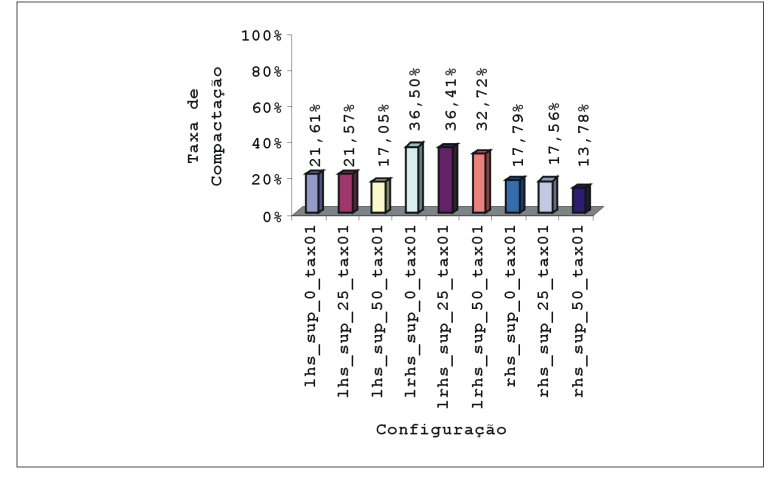

(a) sup

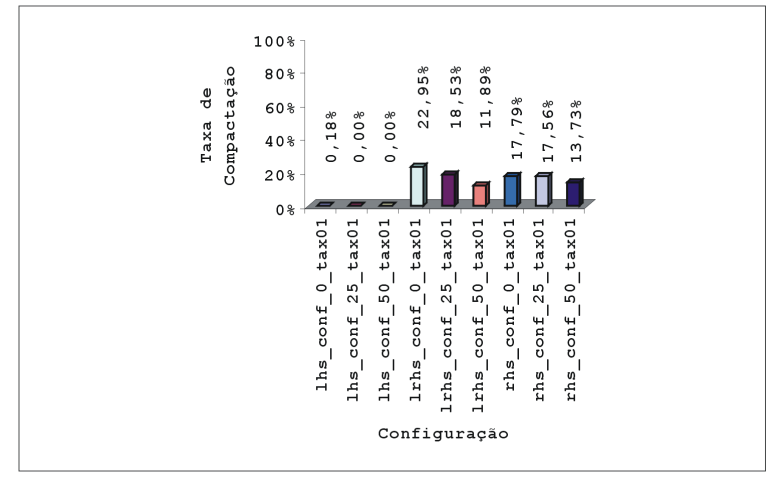

(b) $\operatorname{conf}$

Figura E.1: Resultados utilizando as medidas sup e conf $(\operatorname{tax} 01 / 1 \mathrm{~N})$. 


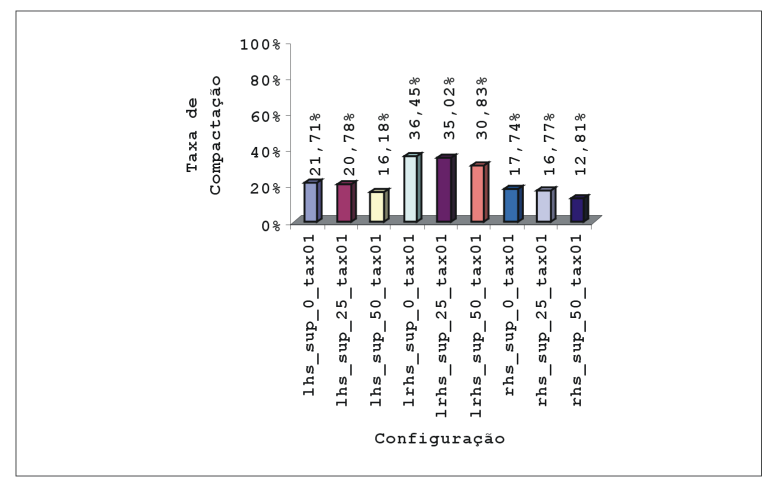

(a) sup

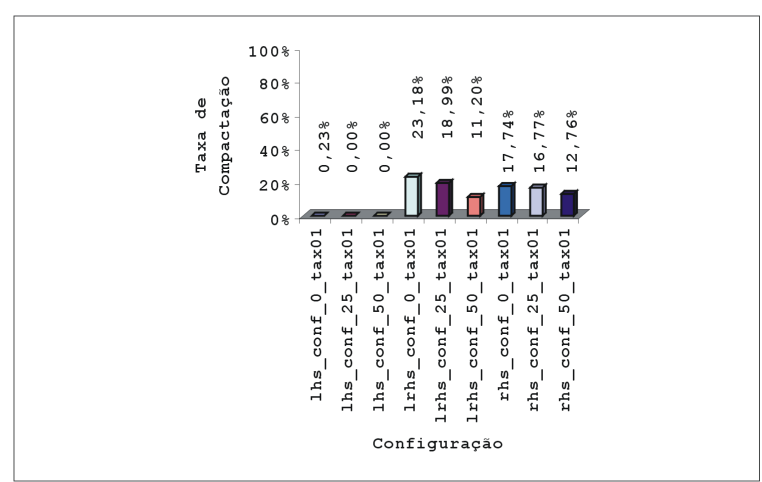

(b) conf

Figura E.2: Resultados utilizando as medidas sup e conf $(\operatorname{tax} 01 / 2 \mathrm{~N})$.

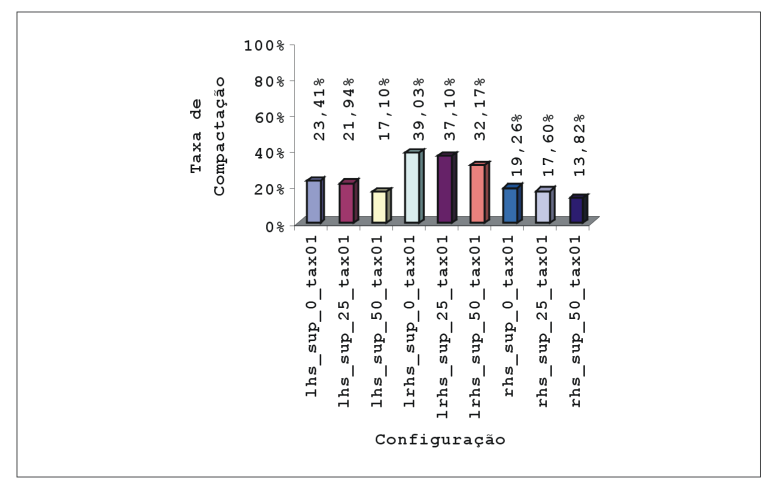

(a) sup

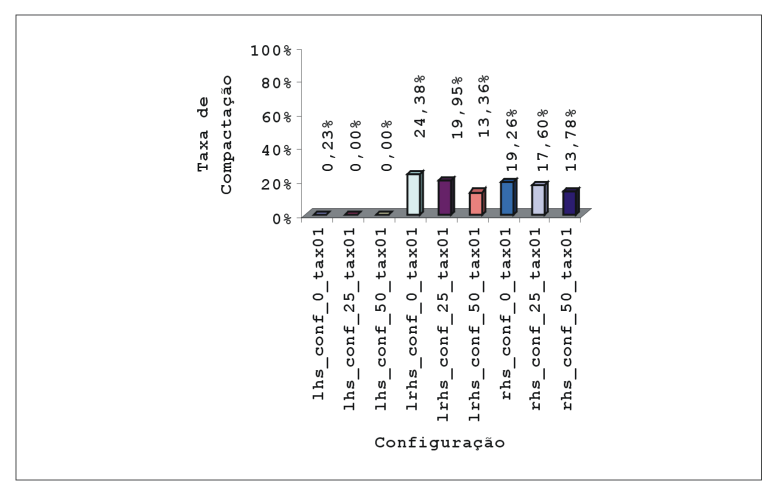

(b) conf

Figura E.3: Resultados utilizando as medidas sup e conf (tax01/3N).

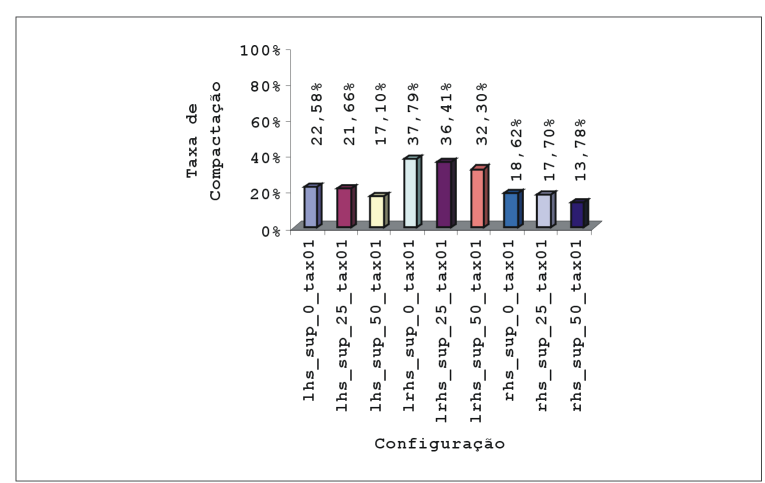

(a) sup

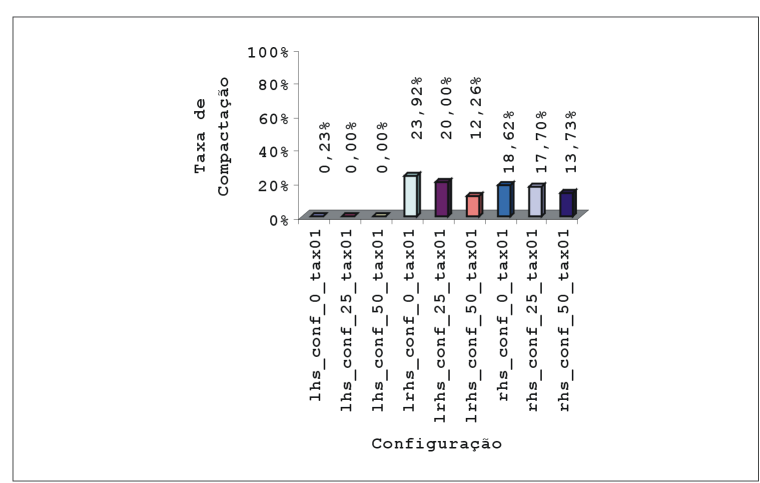

(b) conf

Figura E.4: Resultados utilizando as medidas sup e conf (tax01/ND). 
Apêndice

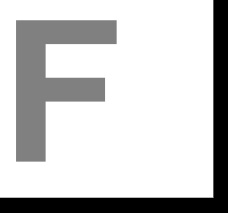

\section{Resultados Referentes à Taxa de Compactação do Cjto-Sup Agrupados por Lado}

Nesse apêndice são apresentados os resultados descritos na Seção 4.8 (página 82) referentes à taxa de compactação do Cjto-Sup agrupados pelo lado utilizado na generalização (lhs, rhs e lrhs) (Figuras F.1 a F.28). Os resultados foram plotados em gráficos, os quais são apresentados a seguir. Os rótulos das figuras são identificados pela taxonomia utilizada seguida de seu respectivo nível de abstração (por exemplo, tax01/1N). Os eixos $x$ dos gráficos são identificados pelas configurações utilizadas nos experimentos usando a notação lado-medida-t\% (por exemplo, lhs-sup-0), além do código da taxonomia. Os eixos $y$ dos gráficos indicam a taxa de compactação obtida em uma determinada configuração. 


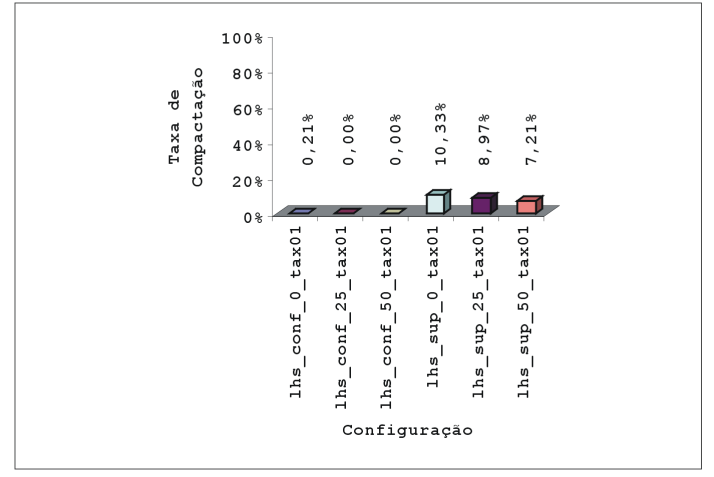

(a) lhs

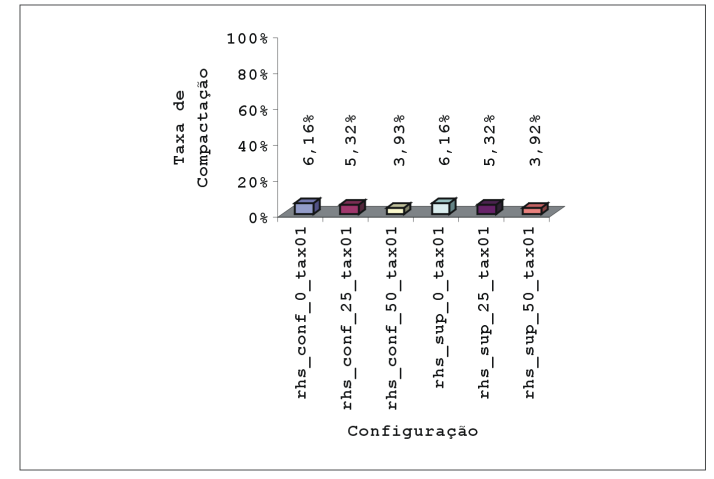

(b) rhs

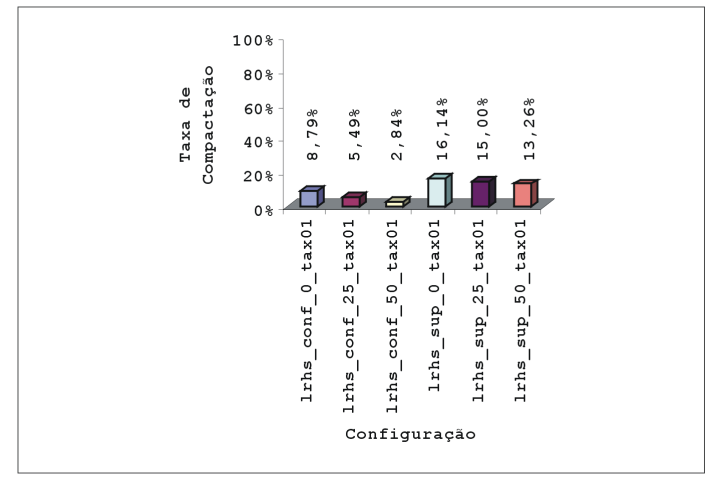

(c) lrhs

Figura F.1: Resultados utilizando os lados lhs, rhs, lrhs (tax01/1N). 


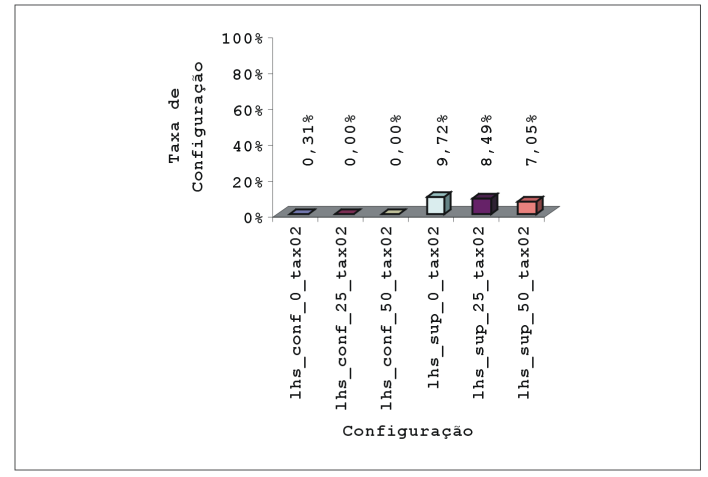

(a) lhs

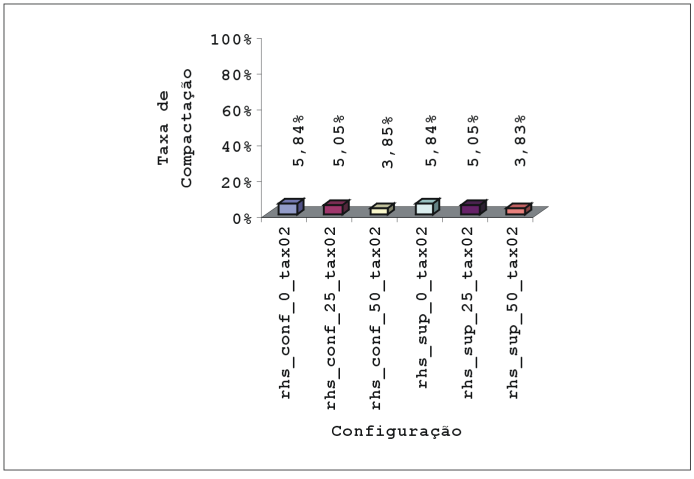

(b) rhs

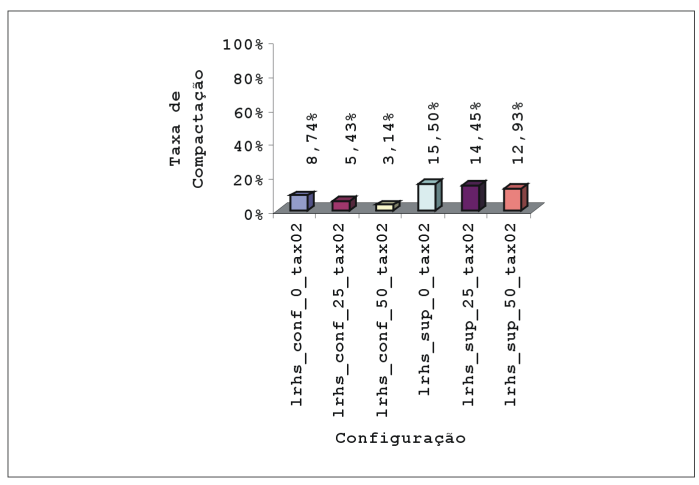

(c) lrhs

Figura F.2: Resultados utilizando os lados lhs, rhs, lrhs (tax02/1N). 


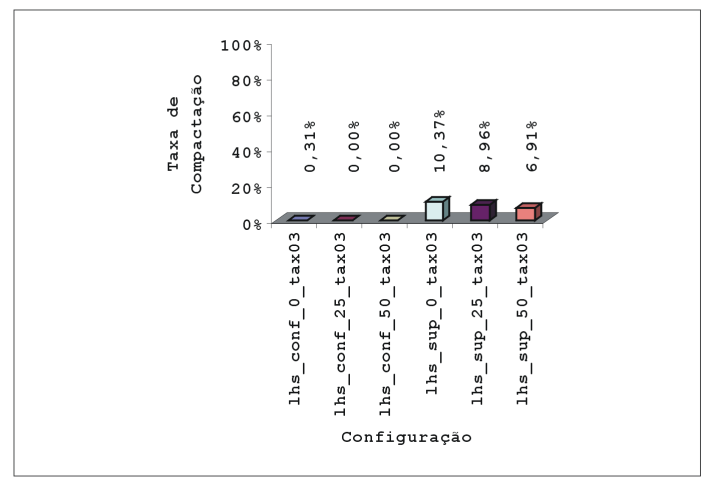

(a) lhs

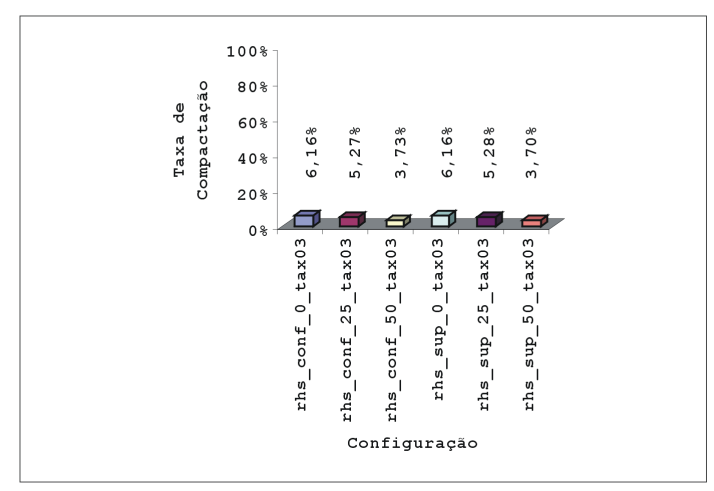

(b) rhs

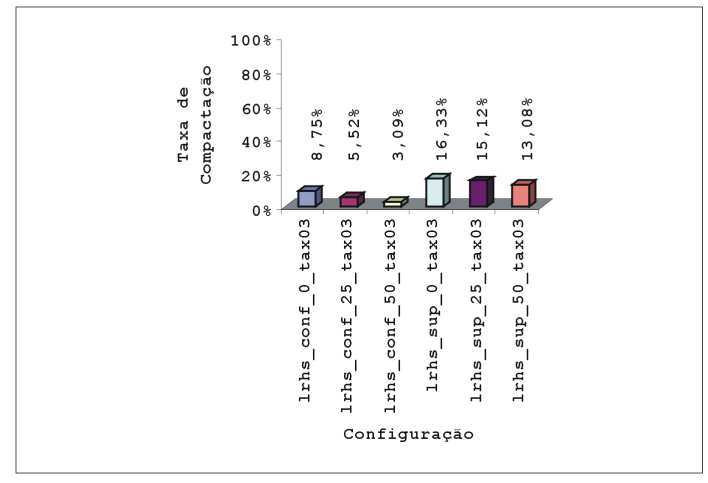

(c) lrhs

Figura F.3: Resultados utilizando os lados lhs, rhs, lrhs (tax03/1N). 


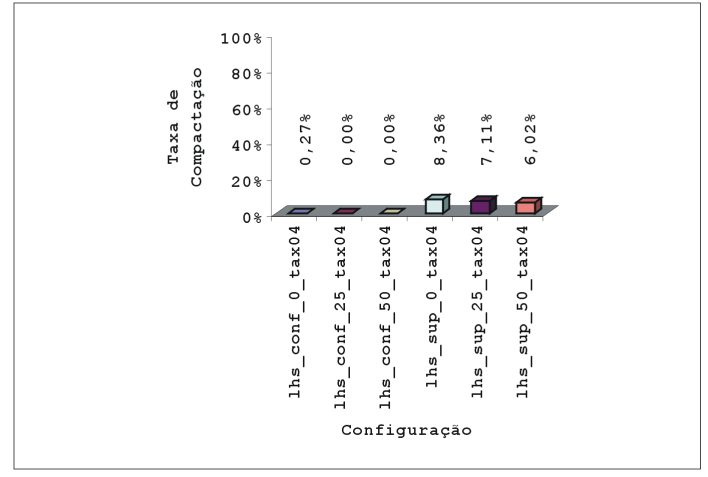

(a) $l h s$

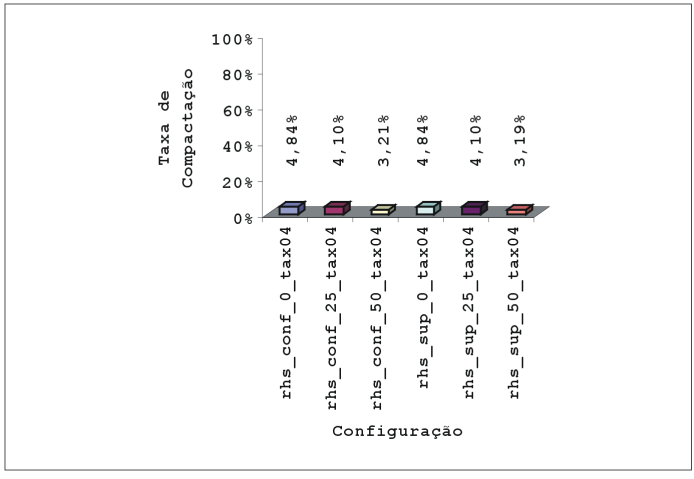

(b) $r h s$

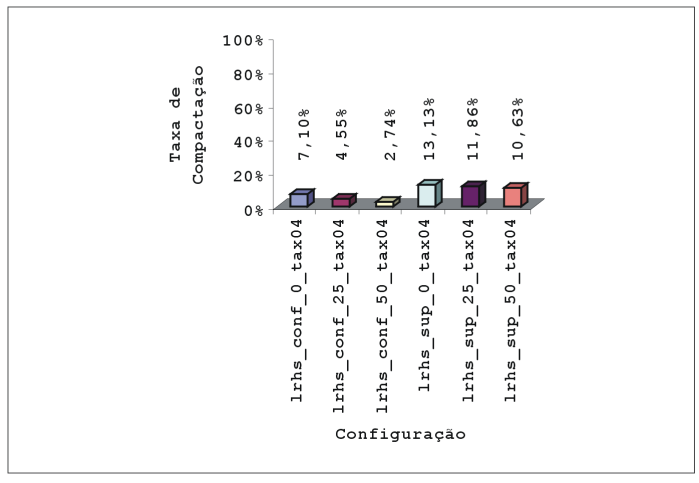

(c) $l r h s$

Figura F.4: Resultados utilizando os lados lhs, rhs, lrhs (tax04/1N). 


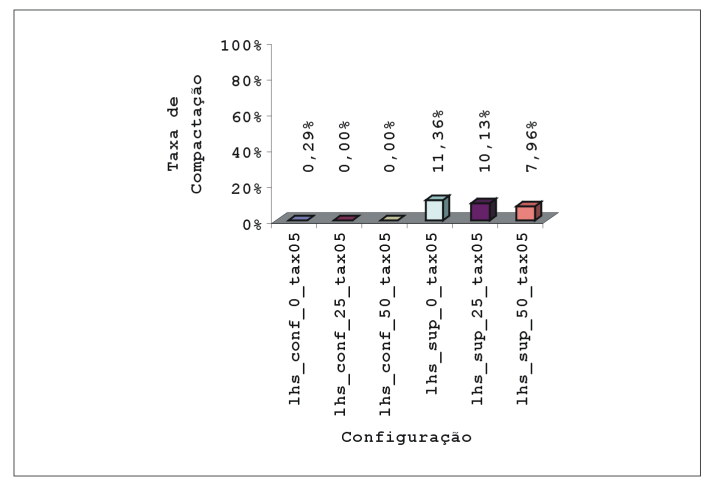

(a) $l \mathrm{hs}$

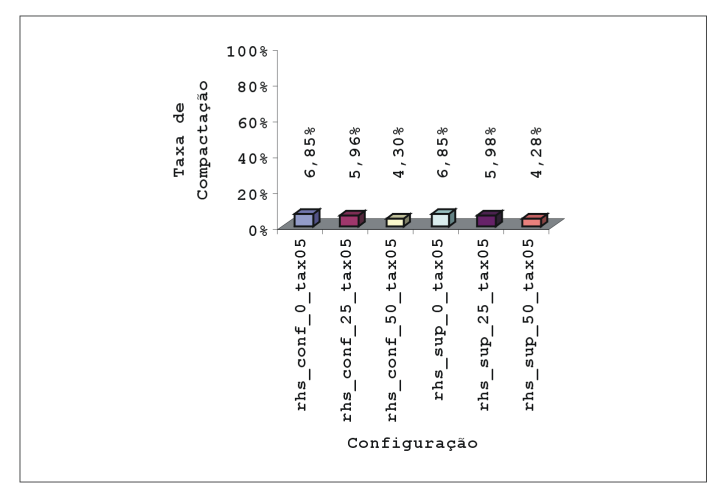

(b) rhs

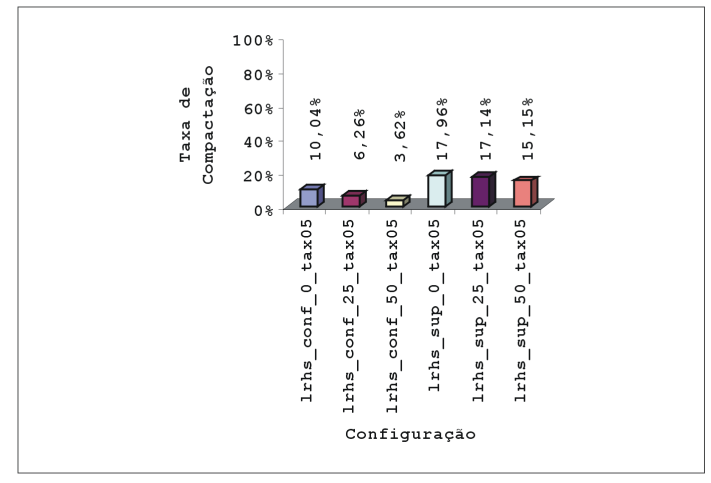

(c) lrhs

Figura F.5: Resultados utilizando os lados lhs, rhs, lrhs (tax05/1N). 


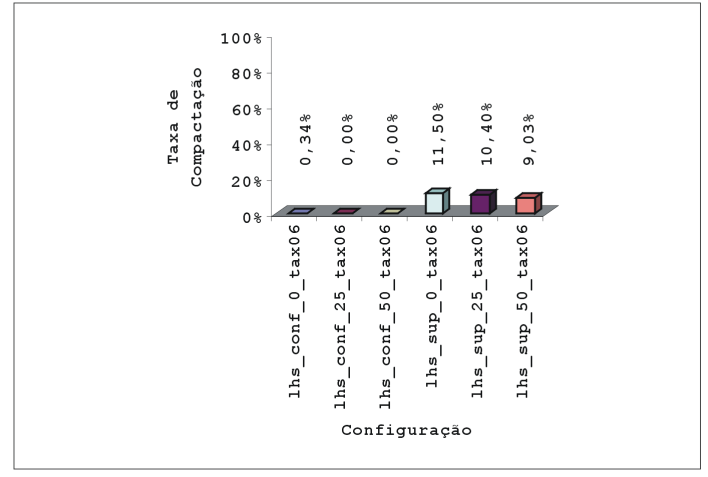

(a) $l h s$

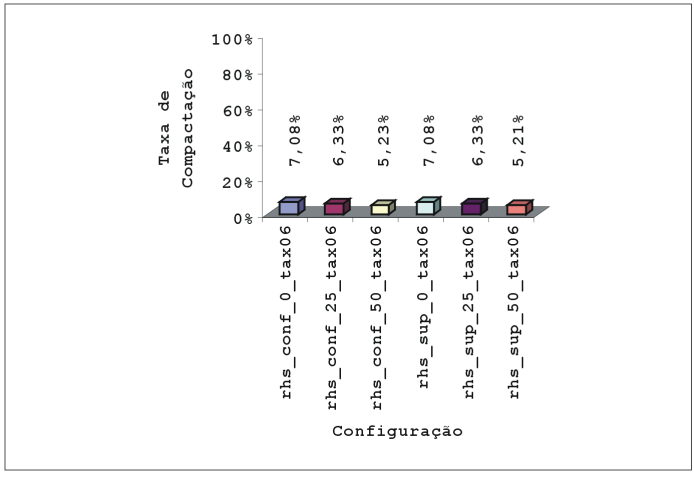

(b) $r h s$

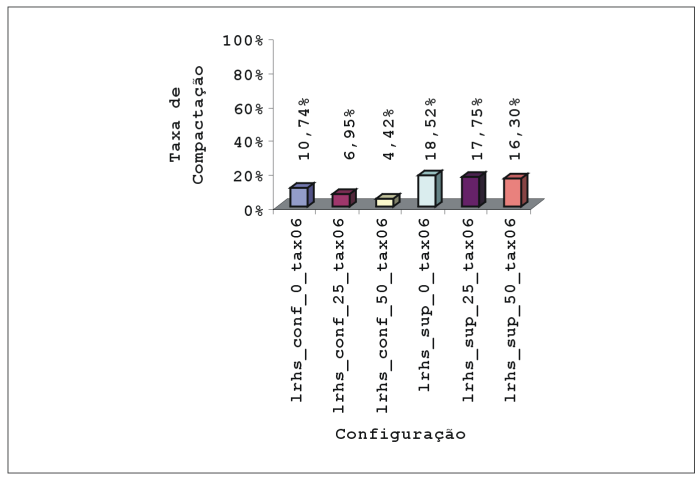

(c) $l r h s$

Figura F.6: Resultados utilizando os lados lhs, rhs, lrhs (tax06/1N). 


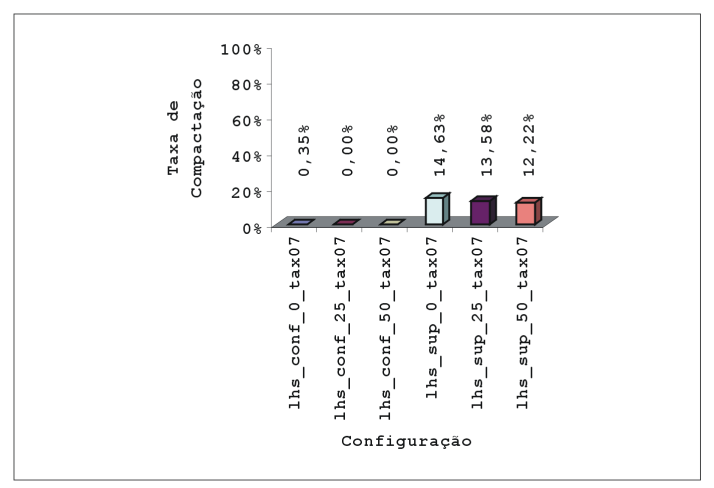

(a) $l \mathrm{hs}$

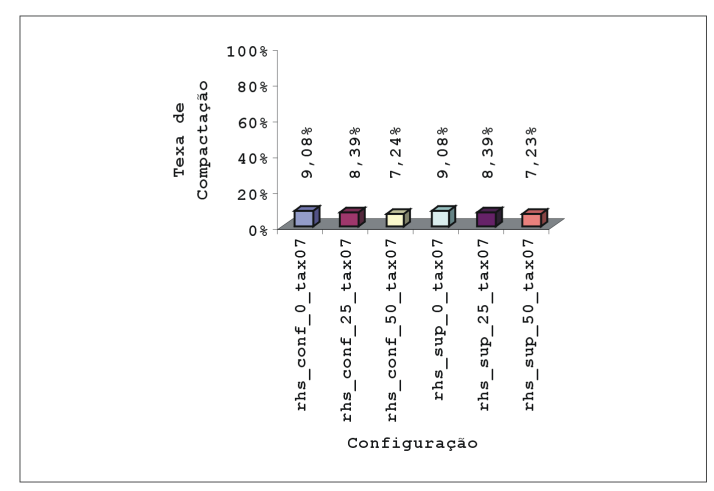

(b) rhs

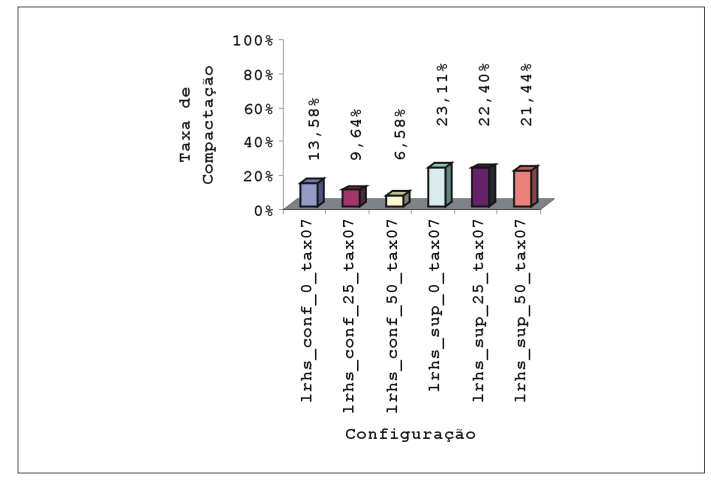

(c) lrhs

Figura F.7: Resultados utilizando os lados lhs, rhs, lrhs $(\operatorname{tax} 07 / 1 \mathrm{~N})$. 


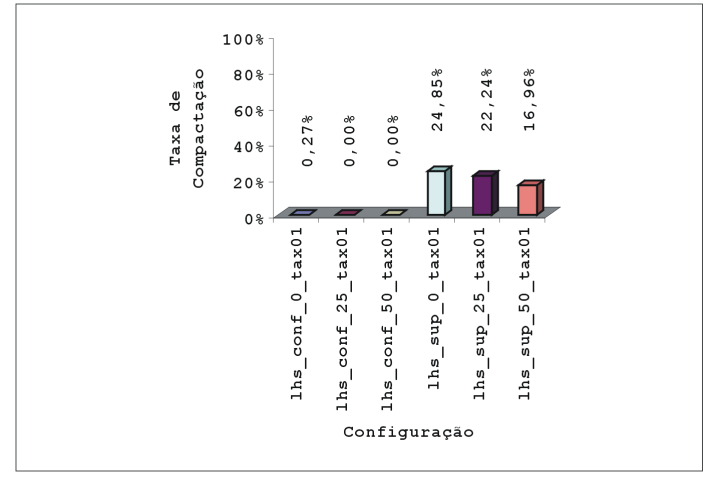

(a) $l h s$

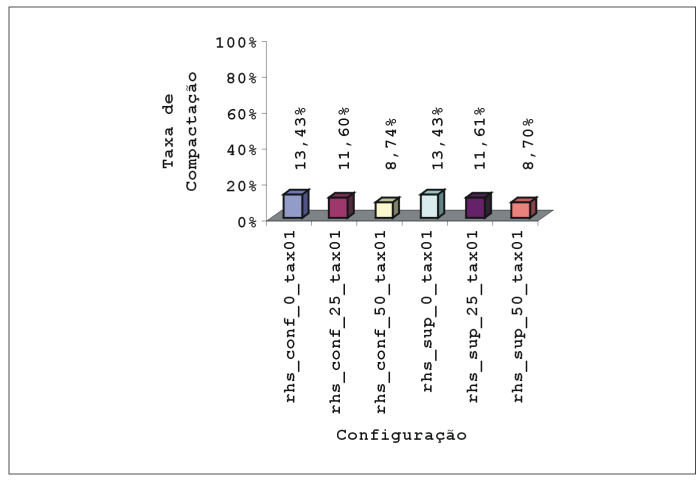

(b) $r h s$

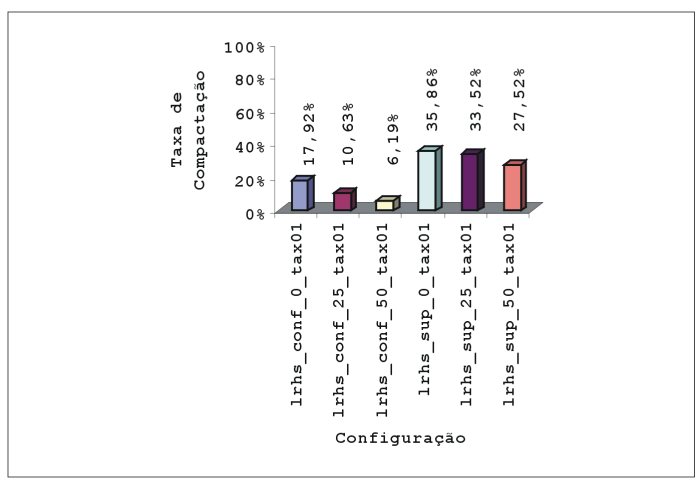

(c) $l r h s$

Figura F.8: Resultados utilizando os lados lhs, rhs, lrhs (tax01/2N). 


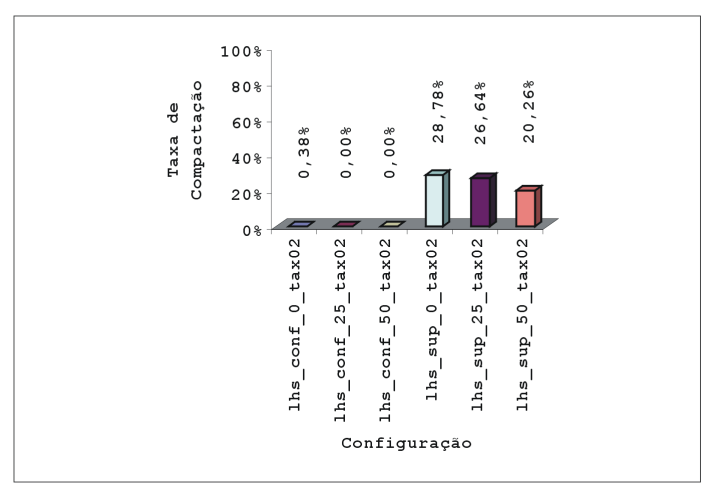

(a) $l h s$

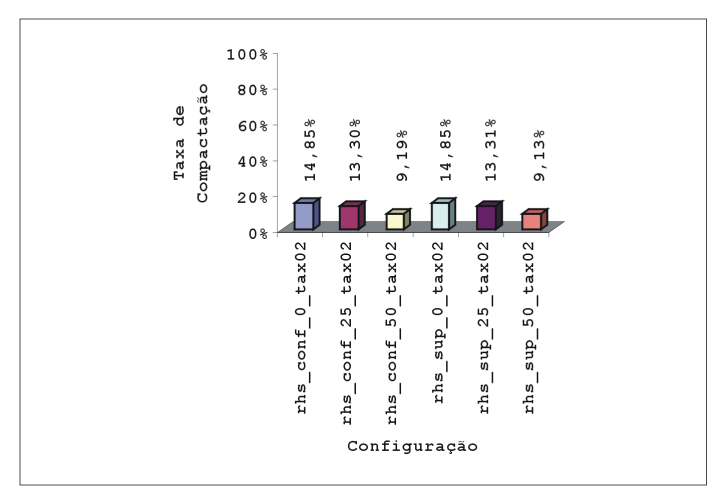

(b) rhs

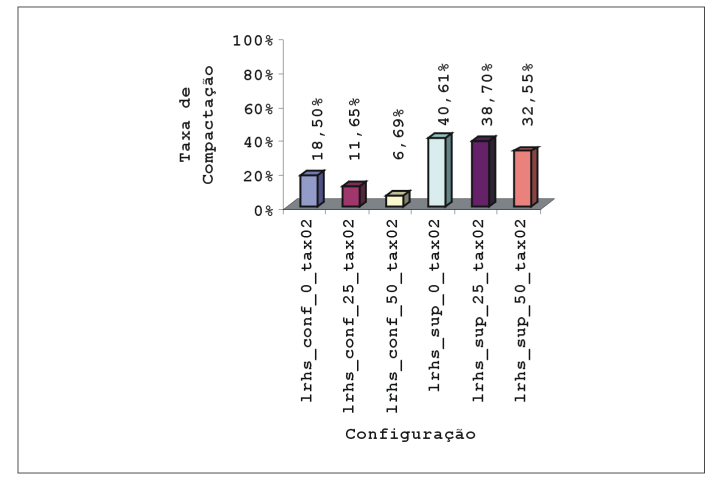

(c) lrhs

Figura F.9: Resultados utilizando os lados $l h s, r h s$, lrhs $(\operatorname{tax} 02 / 2 \mathrm{~N})$. 


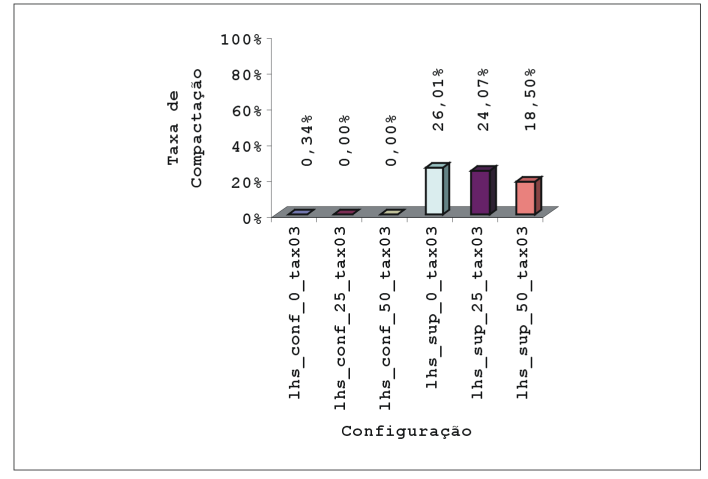

(a) $l h s$

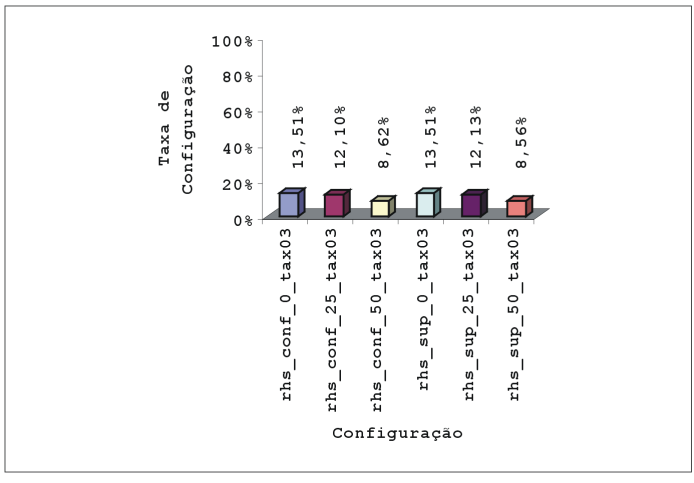

(b) $r h s$

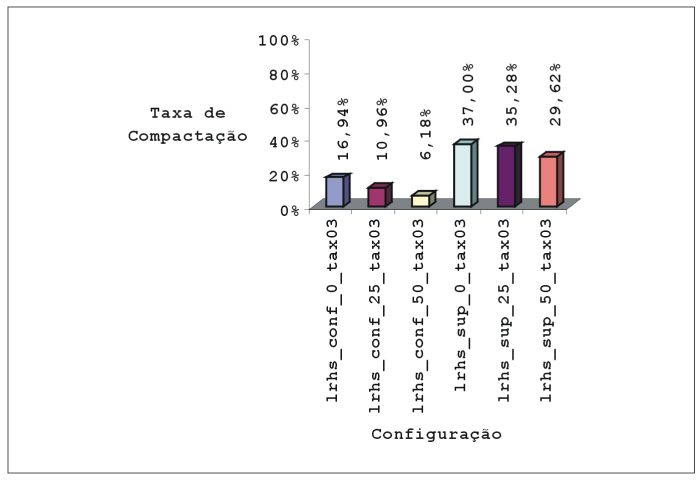

(c) $l r h s$

Figura F.10: Resultados utilizando os lados lhs, rhs, lrhs (tax03/2N). 


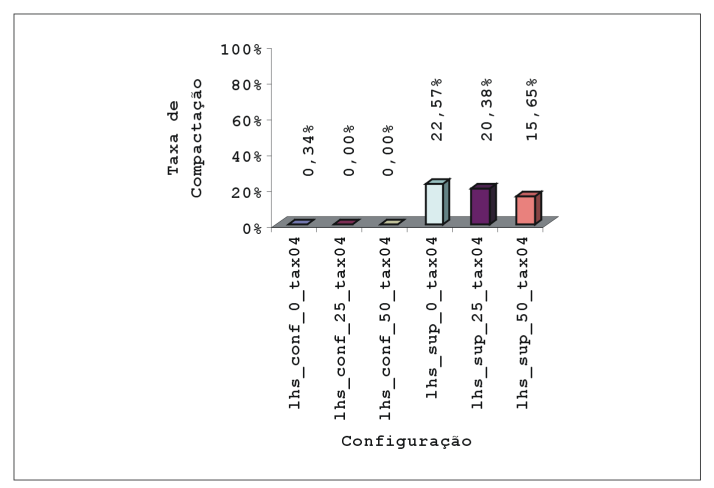

(a) $l \mathrm{hs}$

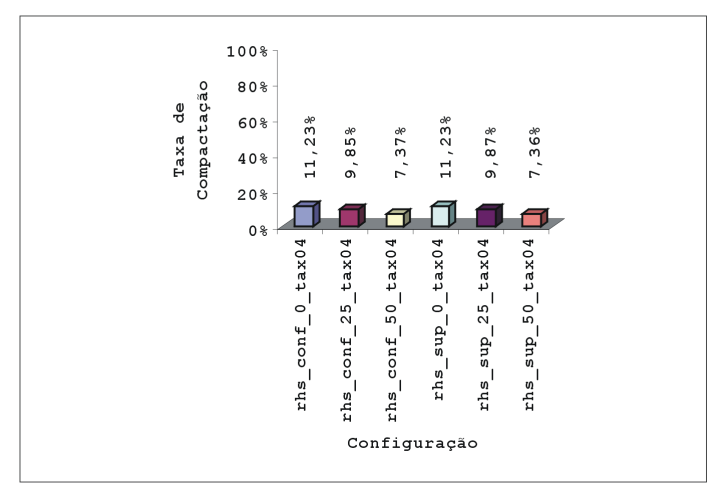

(b) rhs

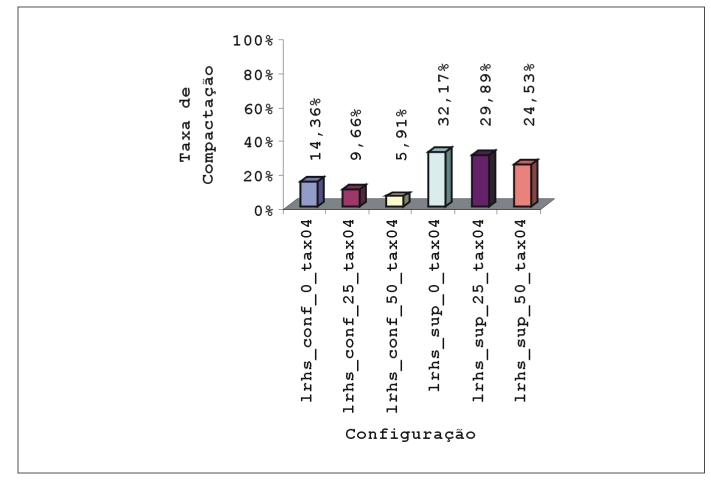

(c) lrhs

Figura F.11: Resultados utilizando os lados lhs, rhs, lrhs (tax04/2N). 


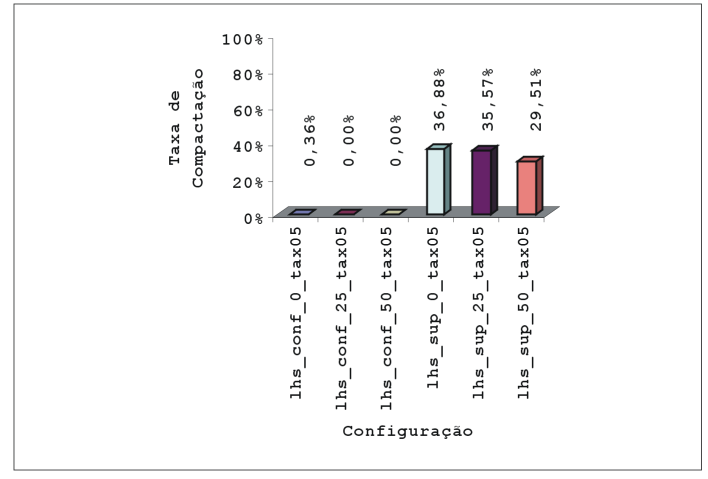

(a) $l h s$

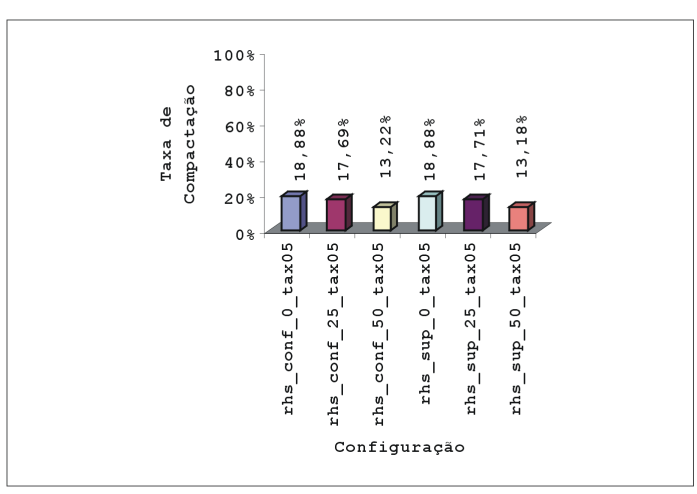

(b) $r h s$

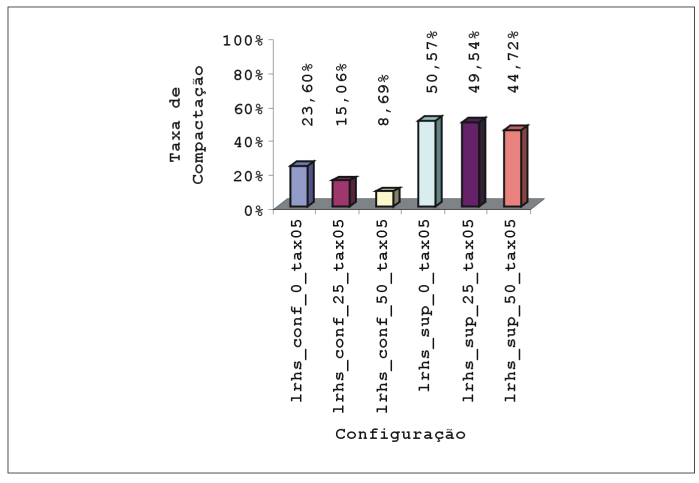

(c) lrhs

Figura F.12: Resultados utilizando os lados lhs, rhs, lrhs (tax05/2N). 


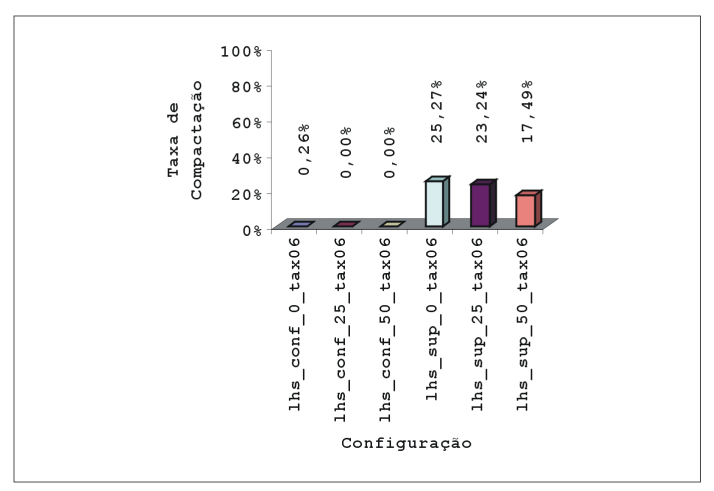

(a) $l h s$

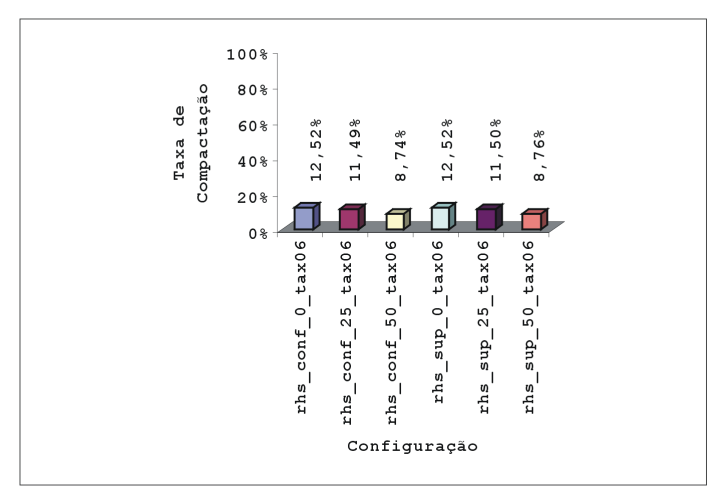

(b) rhs

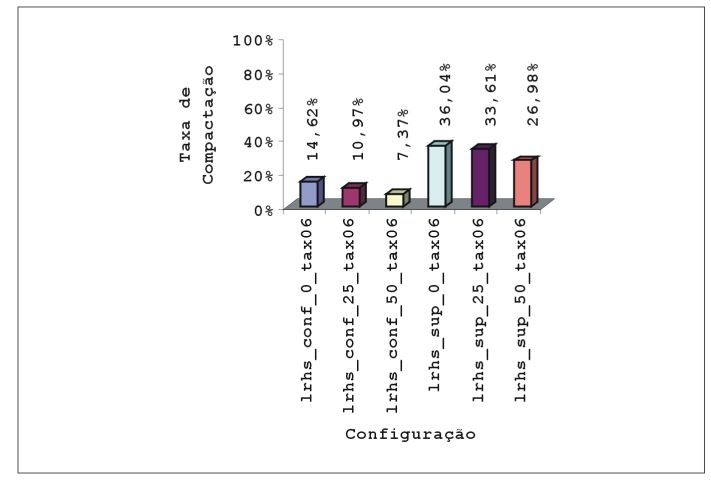

(c) lrhs

Figura F.13: Resultados utilizando os lados lhs, rhs, lrhs (tax06/2N). 


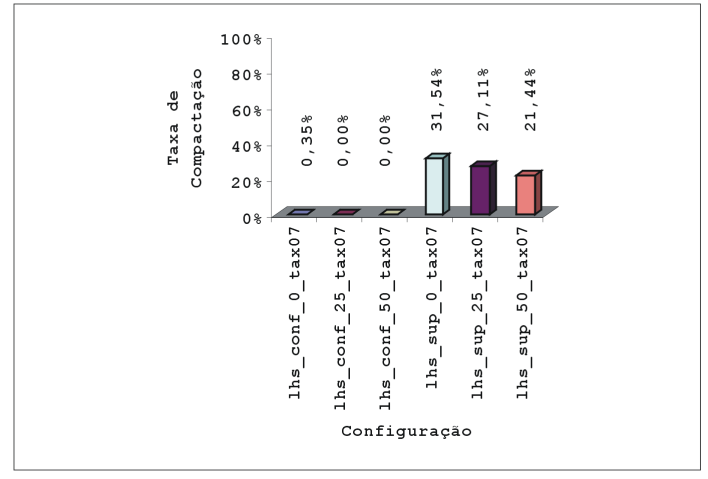

(a) $l h s$

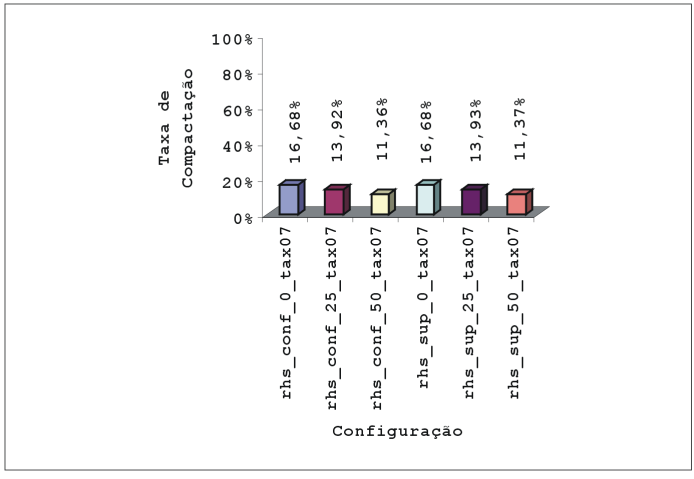

(b) $r h s$

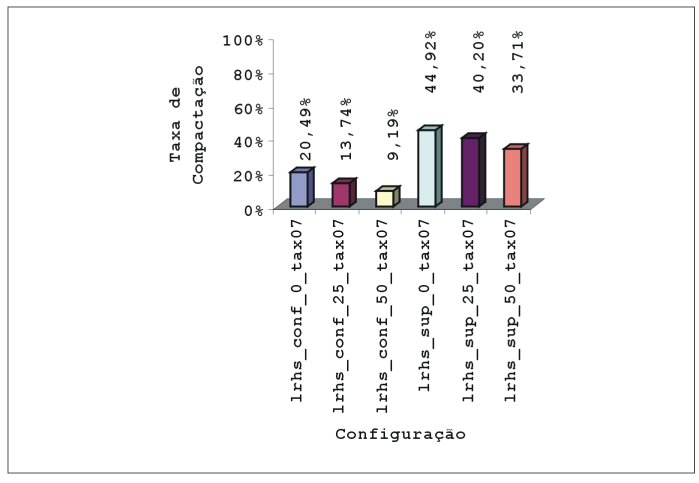

(c) $l r h s$

Figura F.14: Resultados utilizando os lados lhs, rhs, lrhs (tax07/2N). 


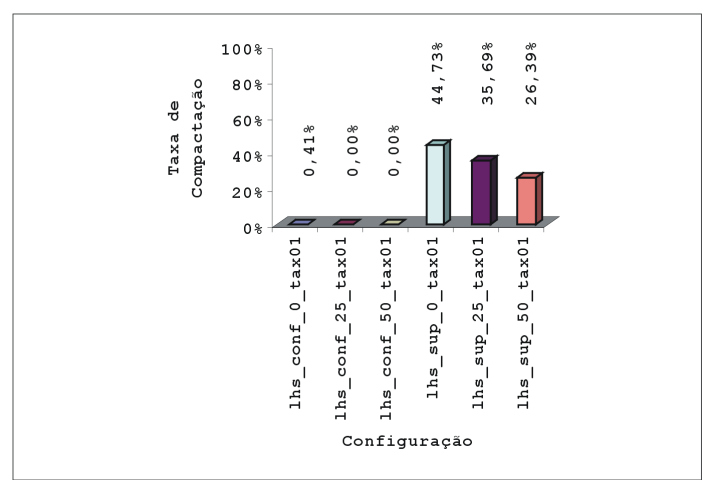

(a) lhs

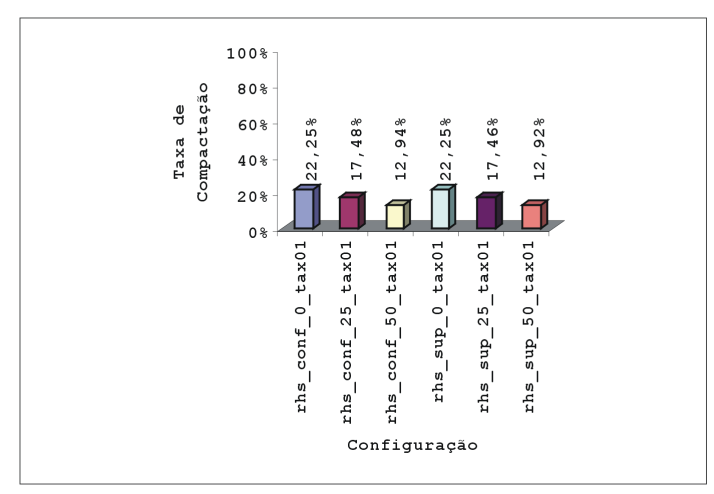

(b) rhs

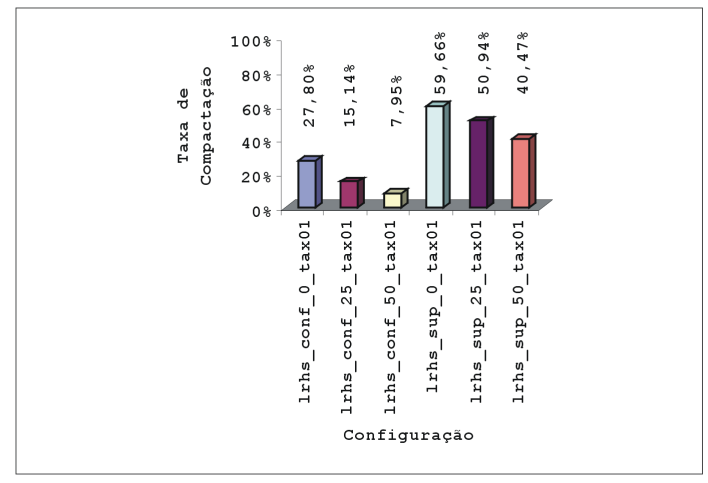

(c) lrhs

Figura F.15: Resultados utilizando os lados lhs, rhs, lrhs (tax01/3N). 


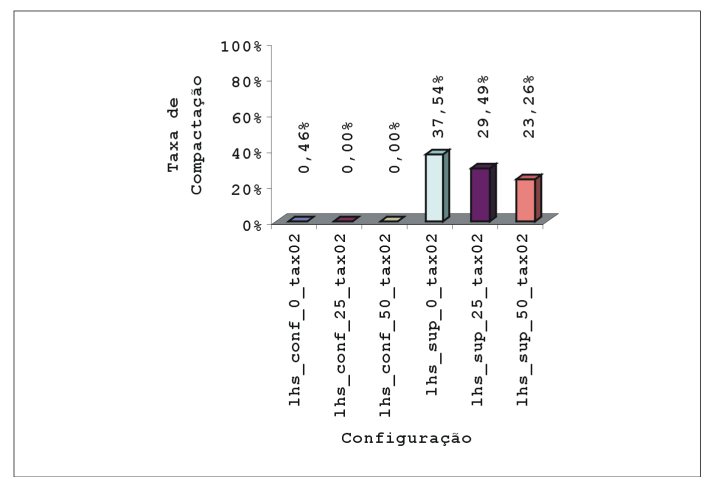

(a) lhs

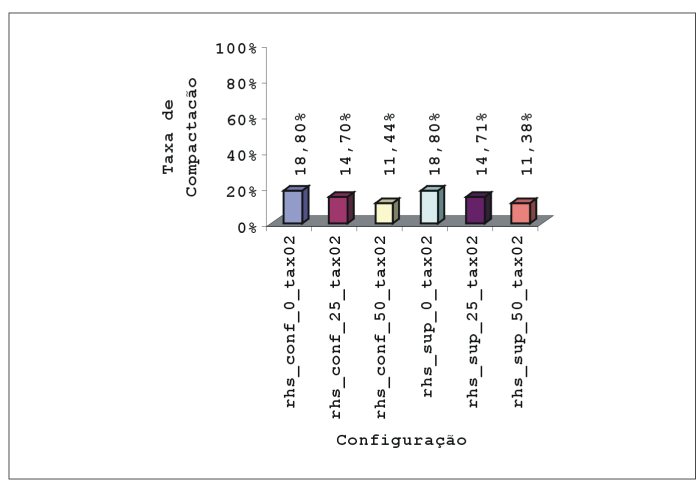

(b) rhs

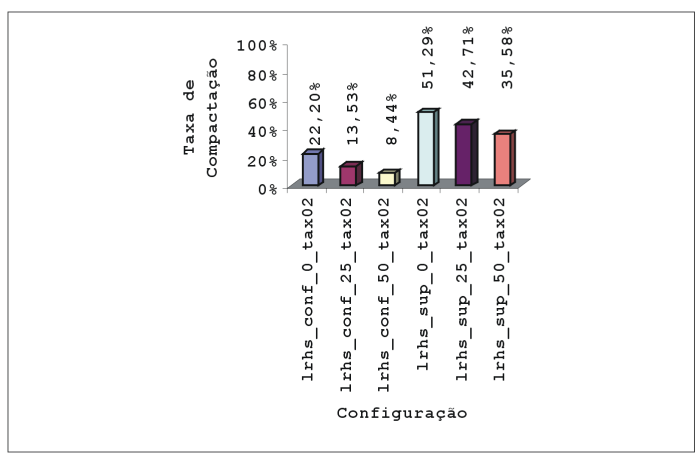

(c) lrhs

Figura F.16: Resultados utilizando os lados lhs, rhs, lrhs (tax02/3N). 


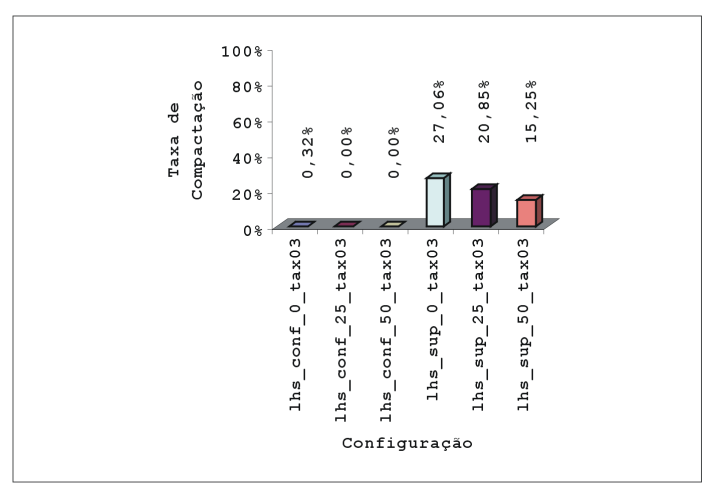

(a) $l \mathrm{hs}$

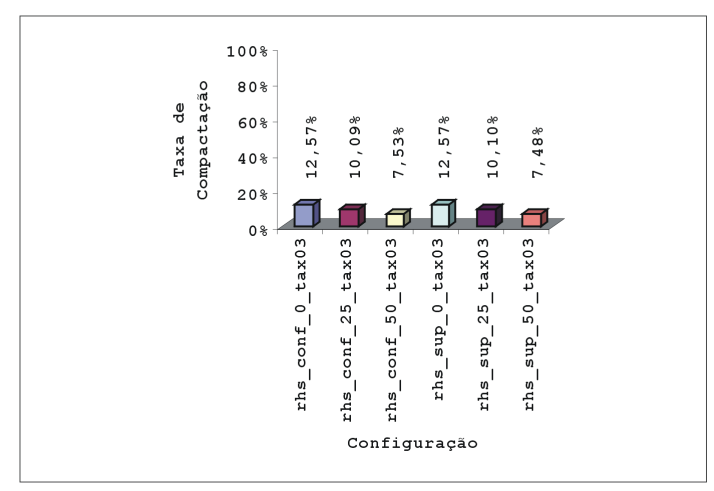

(b) rhs

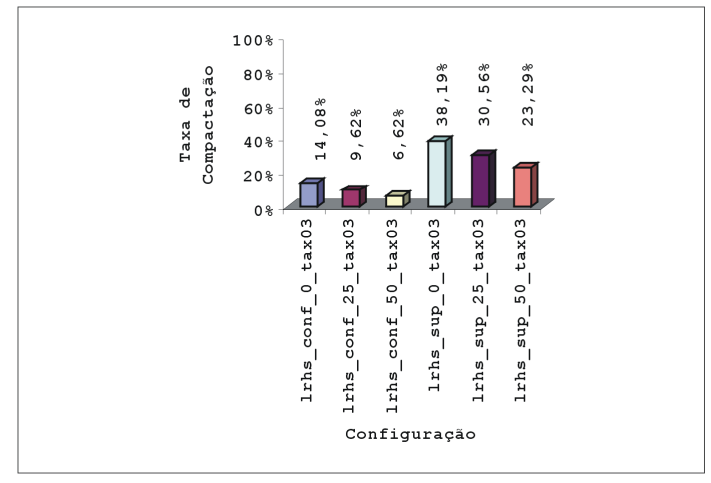

(c) lrhs

Figura F.17: Resultados utilizando os lados lhs, rhs, lrhs (tax03/3N). 


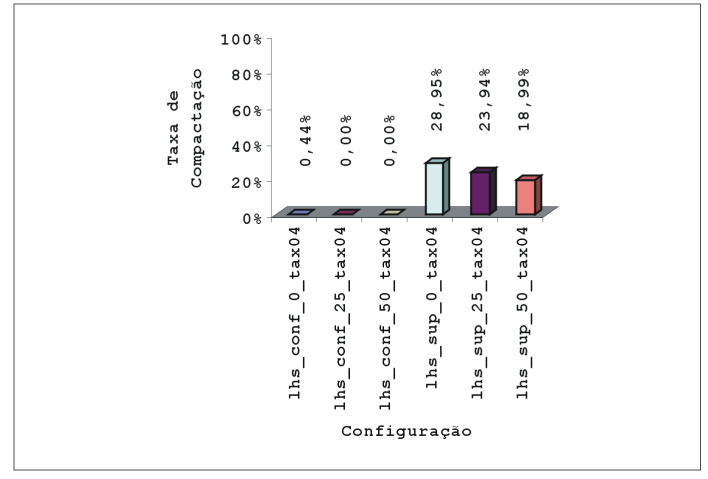

(a) $l h s$

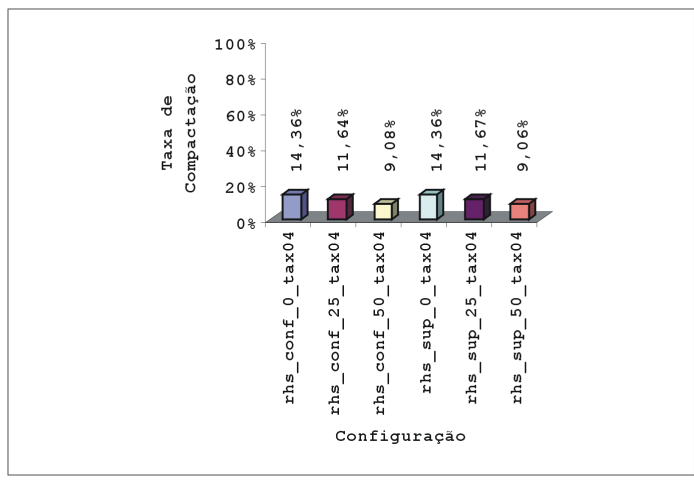

(b) $r h s$

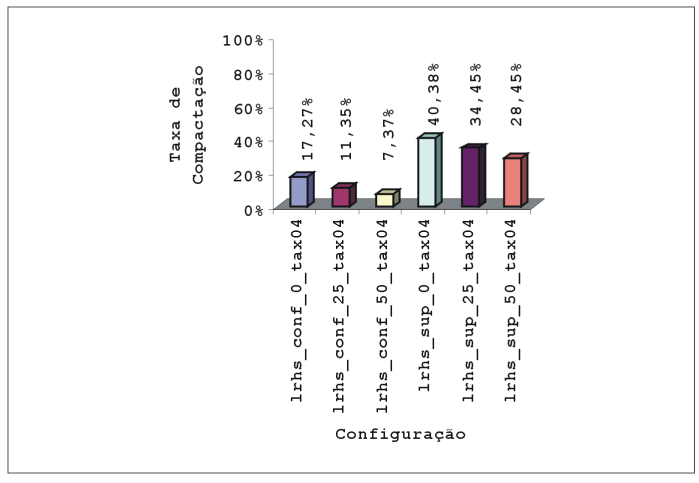

(c) $l r h s$

Figura F.18: Resultados utilizando os lados lhs, rhs, lrhs (tax04/3N). 


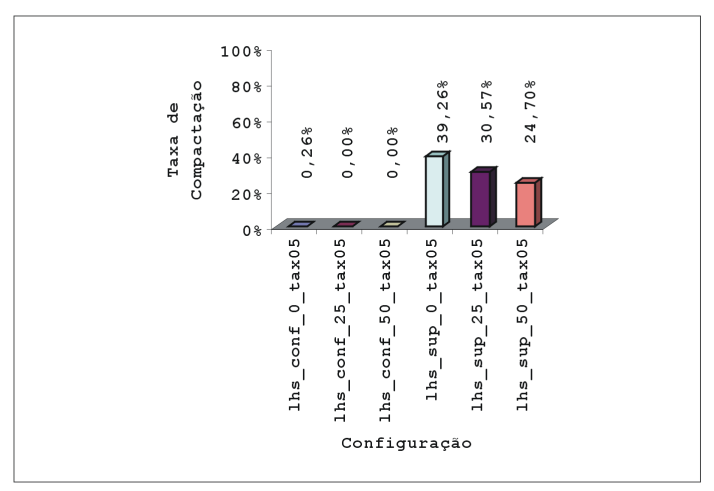

(a) $l \mathrm{hs}$

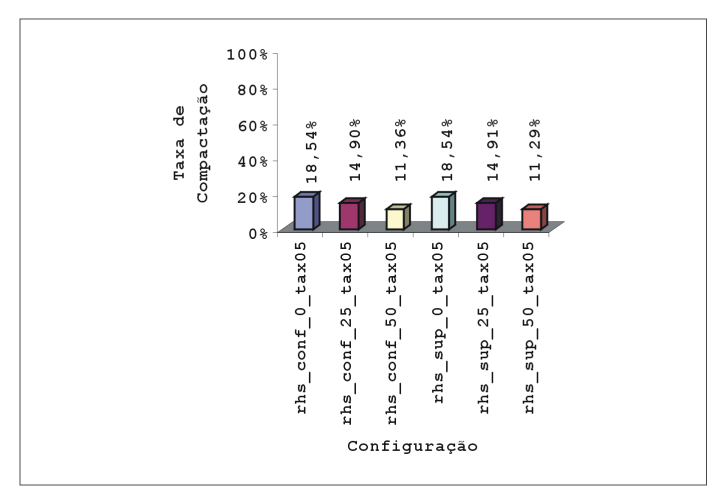

(b) rhs

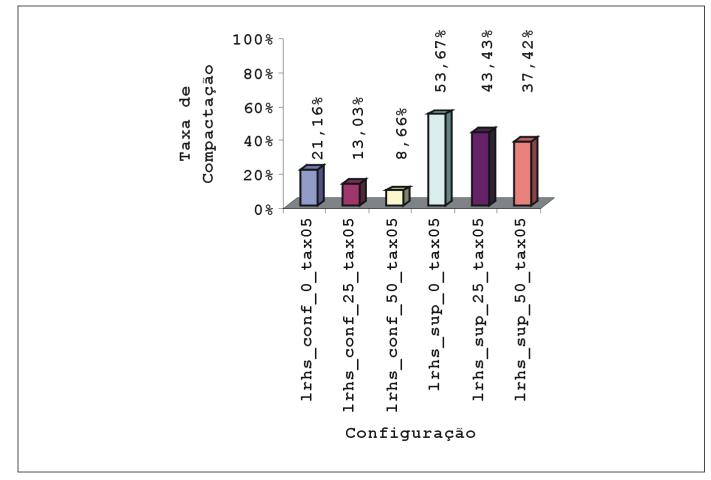

(c) lrhs

Figura F.19: Resultados utilizando os lados lhs, rhs, lrhs (tax05/3N). 


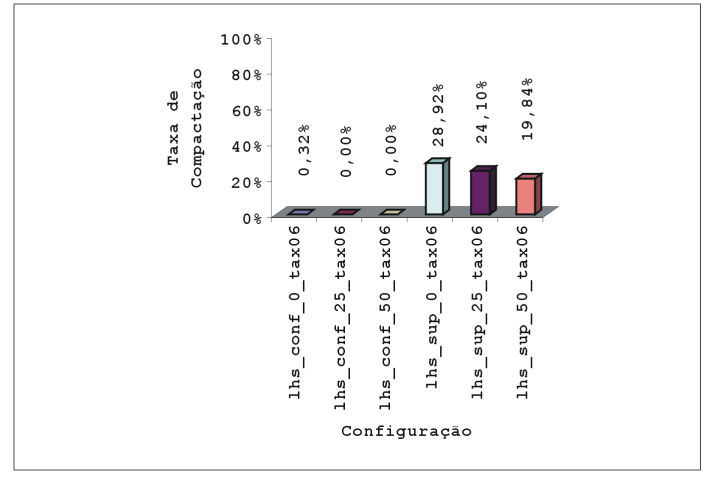

(a) $l h s$

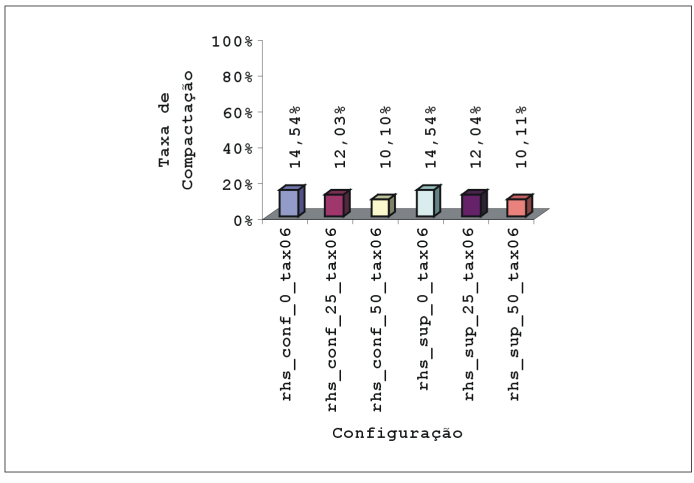

(b) $r h s$

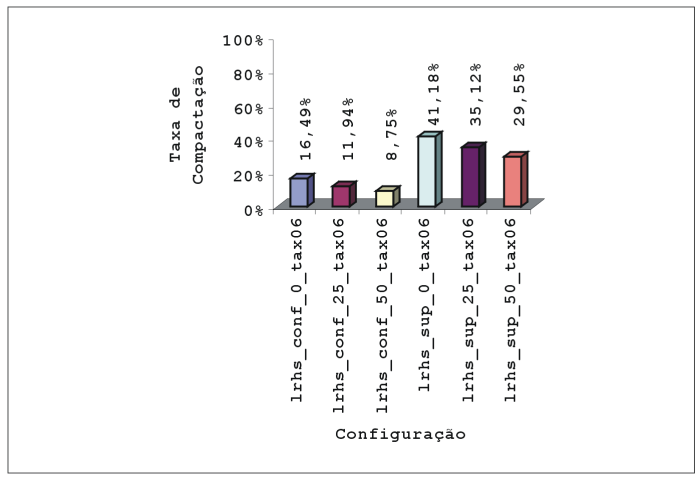

(c) $l r h s$

Figura F.20: Resultados utilizando os lados lhs, rhs, lrhs (tax06/3N). 


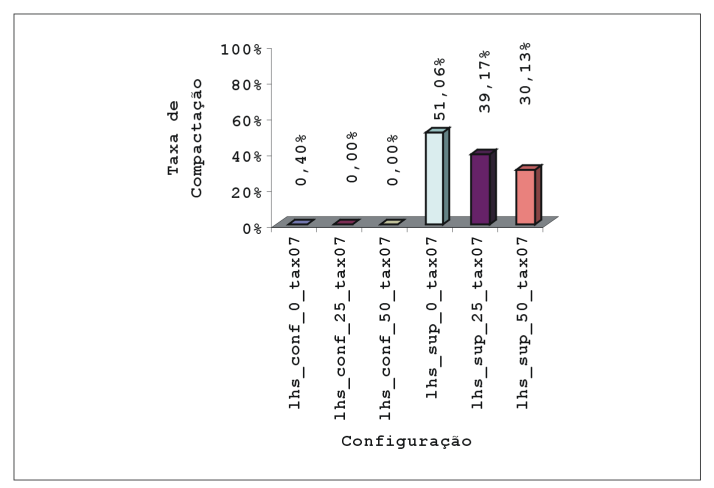

(a) $l \mathrm{hs}$

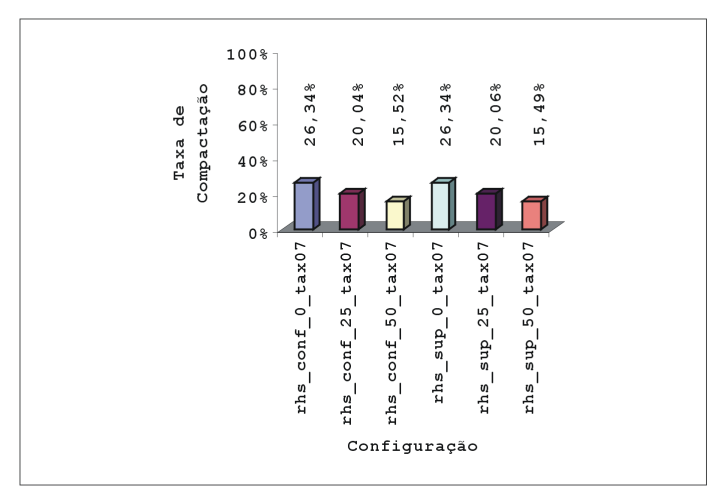

(b) rhs

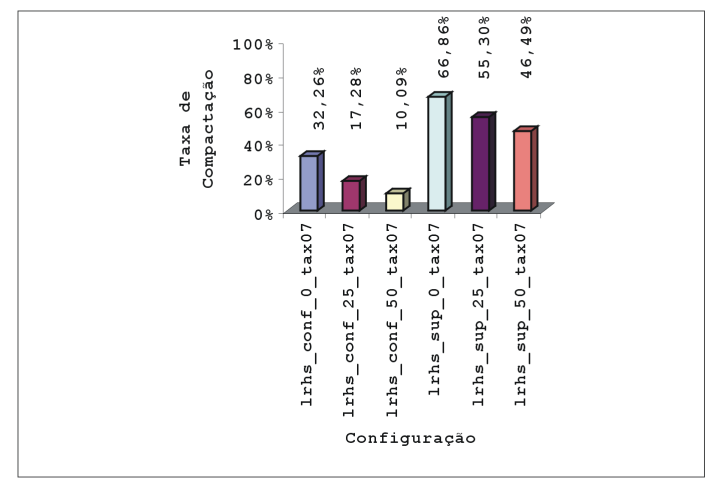

(c) lrhs

Figura F.21: Resultados utilizando os lados lhs, rhs, lrhs (tax07/3N). 


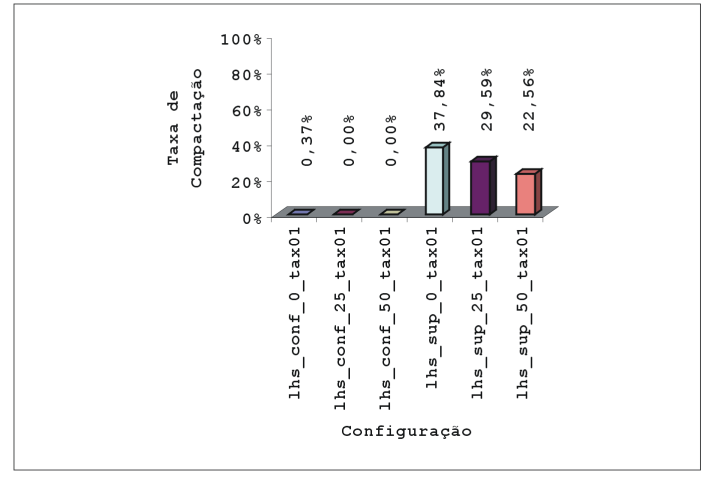

(a) $l h s$

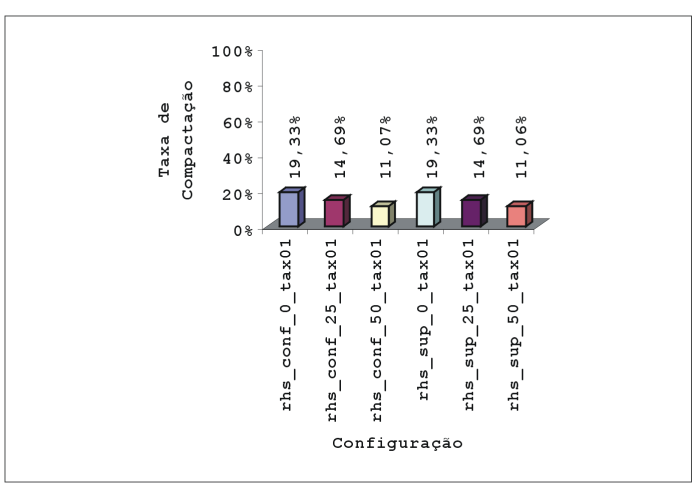

(b) rhs

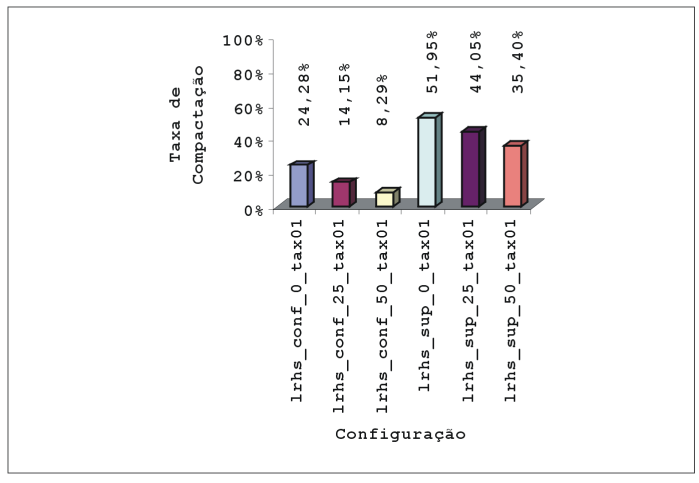

(c) lrhs

Figura F.22: Resultados utilizando os lados lhs, rhs, lrhs (tax01/ND). 


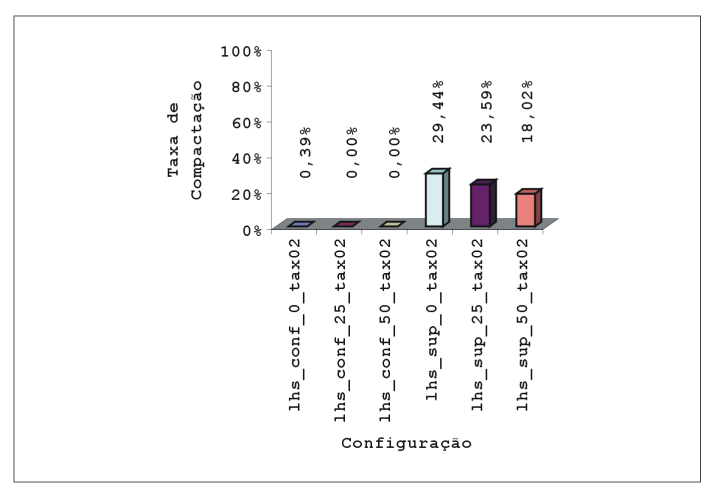

(a) lhs

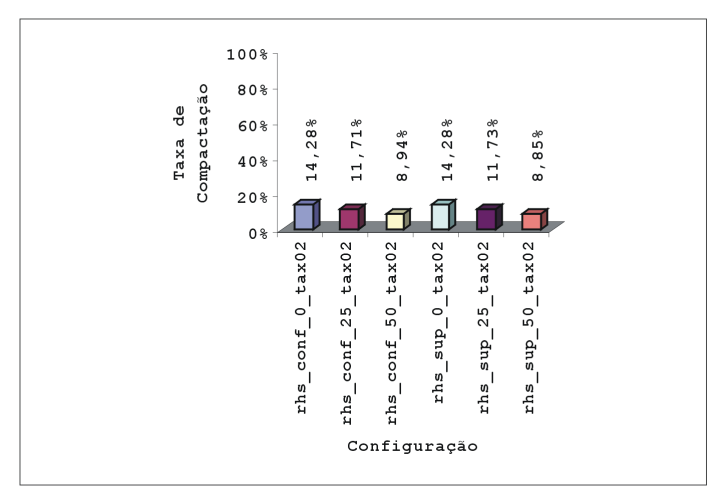

(b) rhs

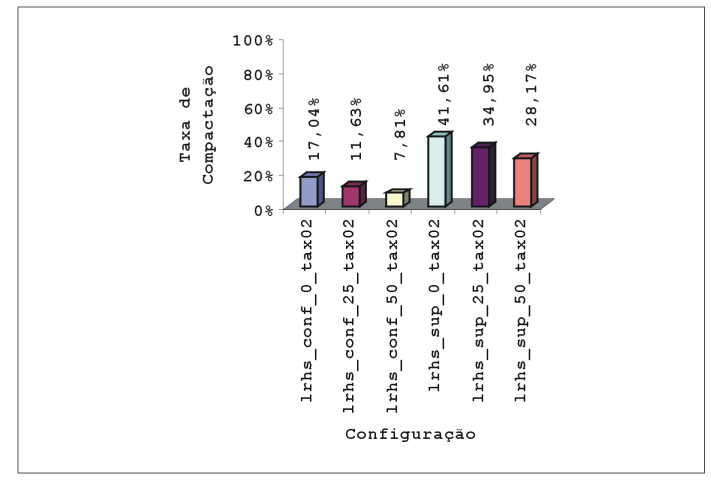

(c) lrhs

Figura F.23: Resultados utilizando os lados $l h s, r h s$, lrhs (tax02/ND). 


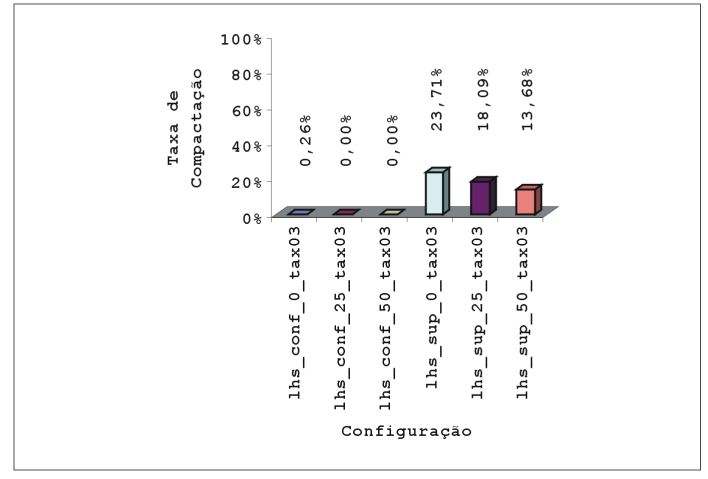

(a) $l h s$

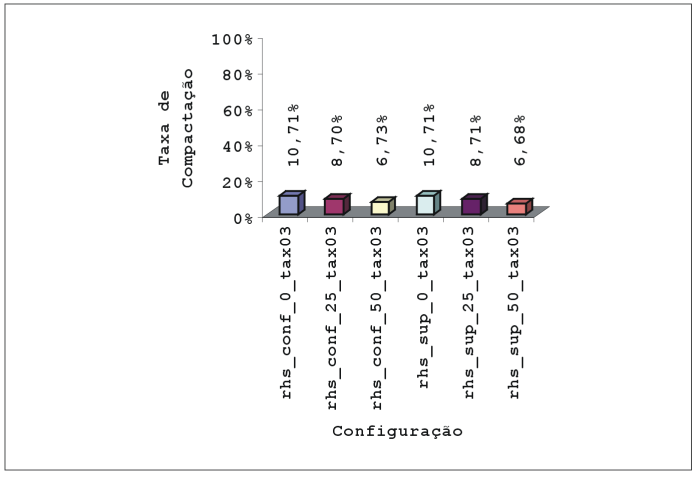

(b) $r h s$

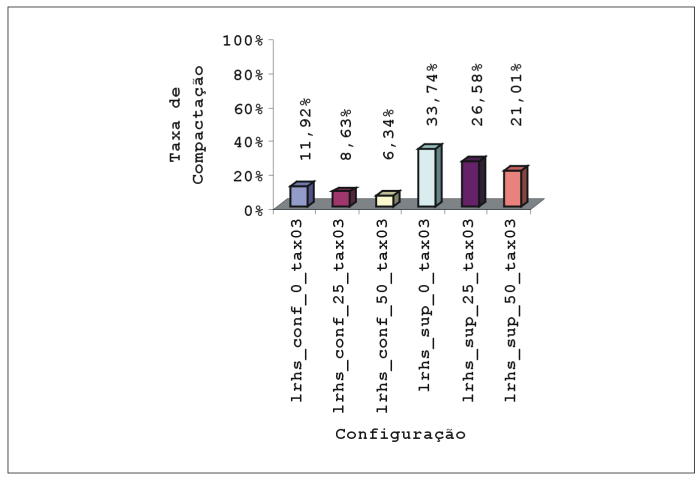

(c) $l r h s$

Figura F.24: Resultados utilizando os lados $l h s, r h s$, lrhs (tax03/ND). 


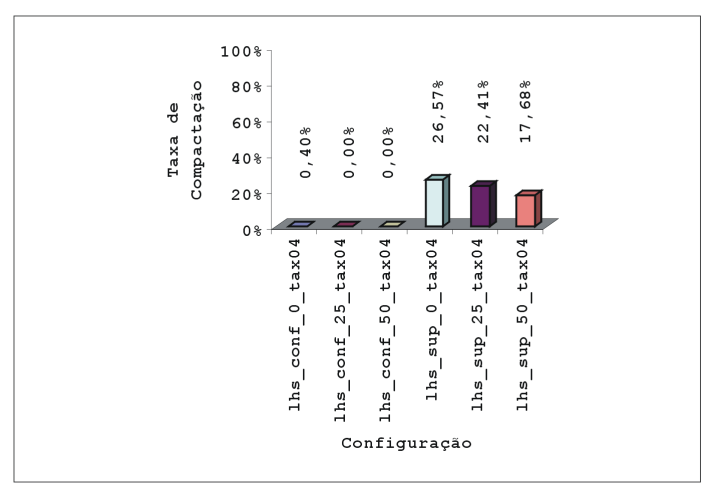

(a) lhs

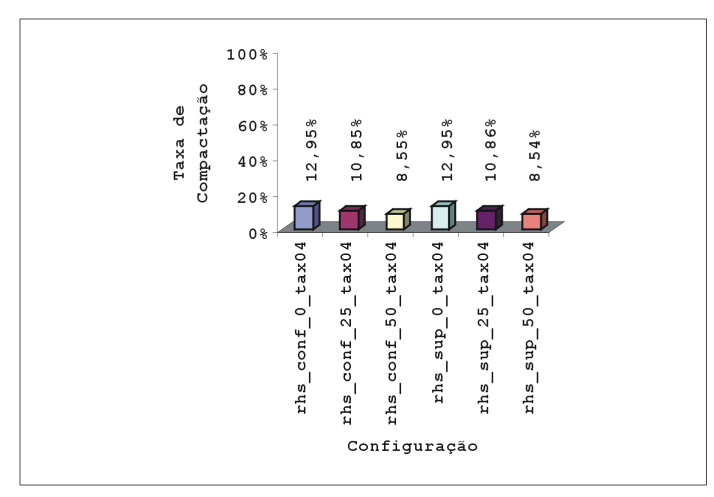

(b) rhs

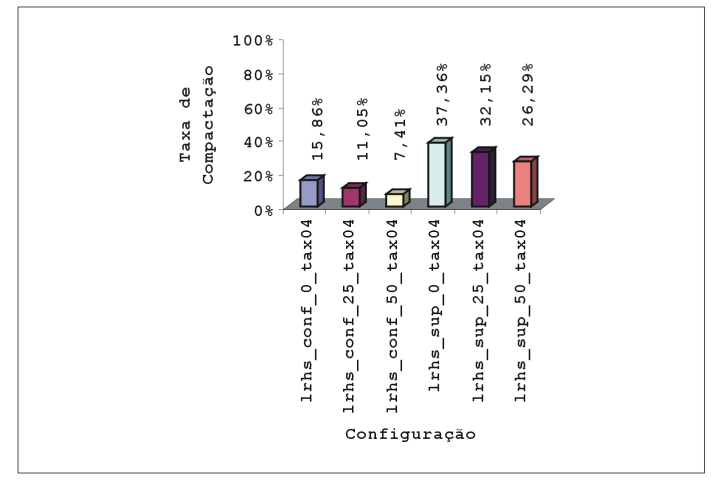

(c) lrhs

Figura F.25: Resultados utilizando os lados lhs, rhs, lrhs (tax04/ND). 


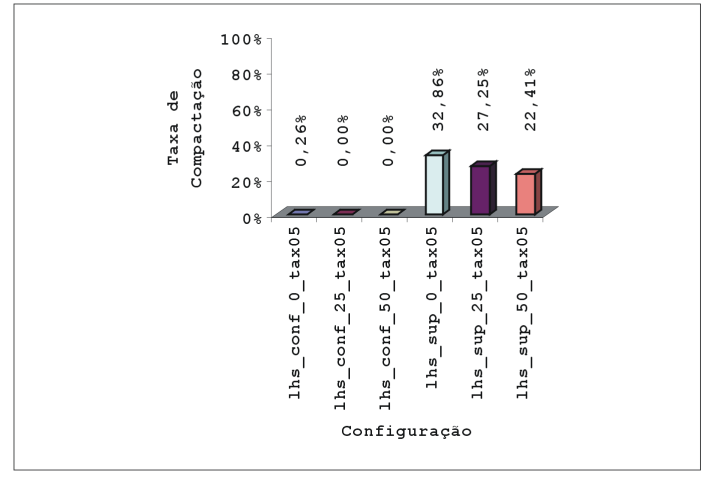

(a) $l h s$

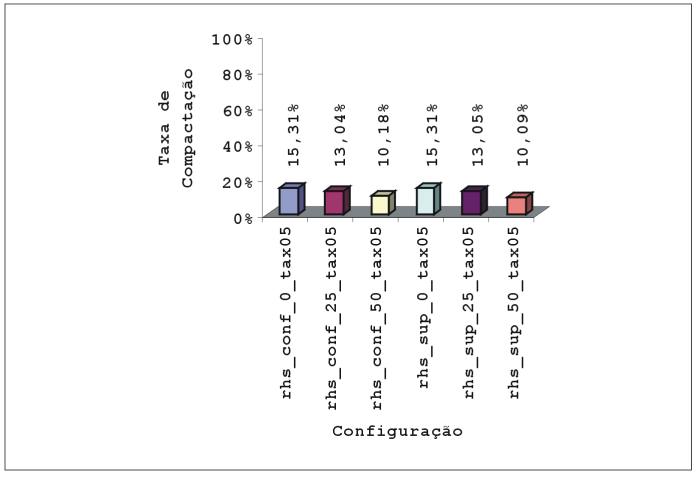

(b) $r h s$

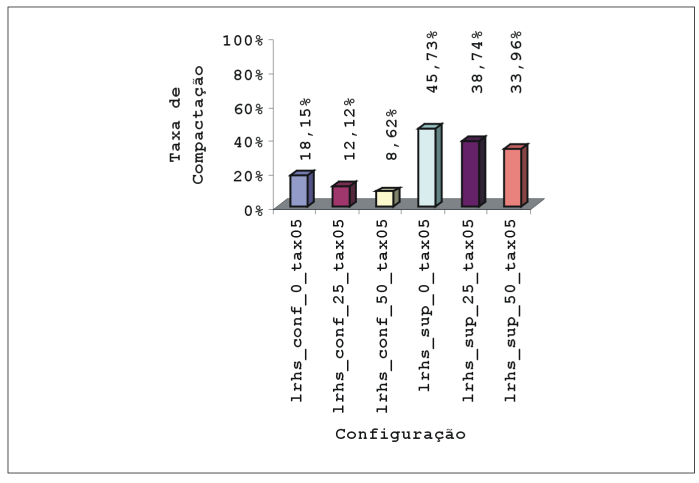

(c) $l r h s$

Figura F.26: Resultados utilizando os lados $l h s, r h s$, lrhs (tax05/ND). 


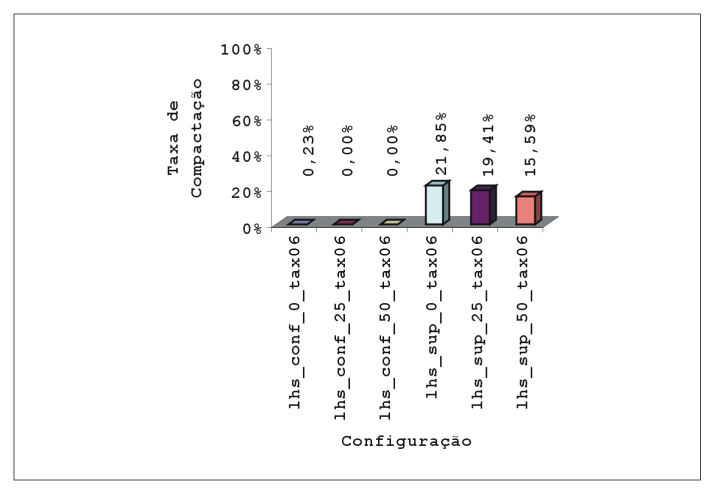

(a) lhs

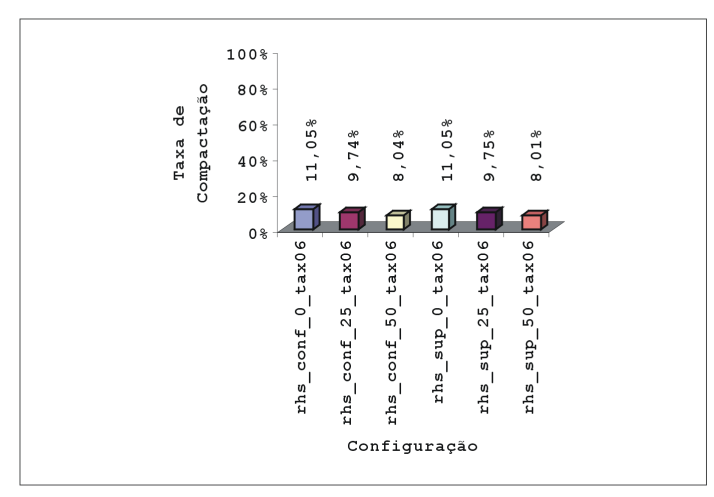

(b) rhs

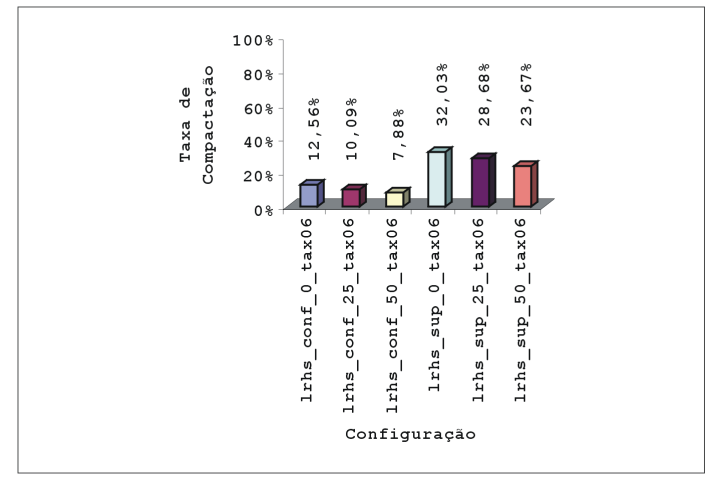

(c) lrhs

Figura F.27: Resultados utilizando os lados $l h s, r h s$, lrhs (tax06/ND). 


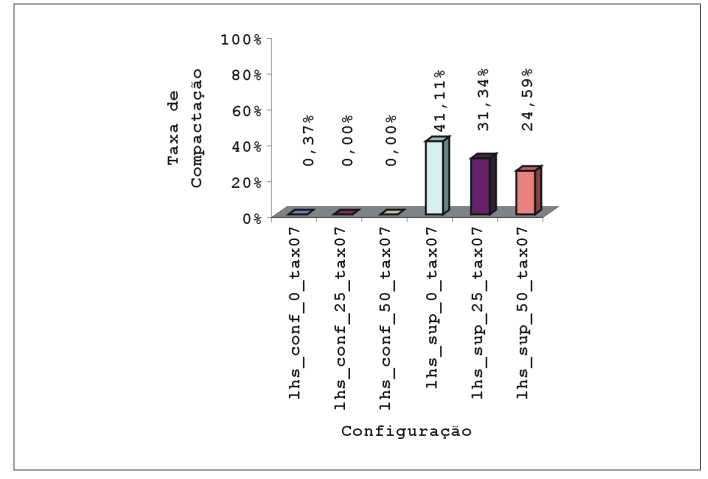

(a) $l h s$

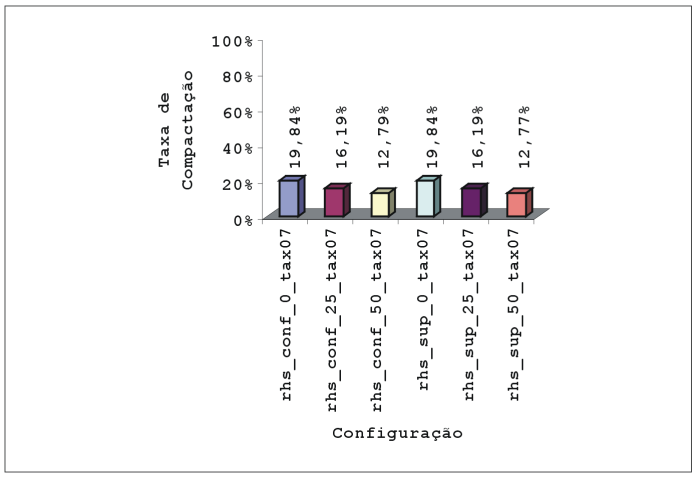

(b) $r h s$

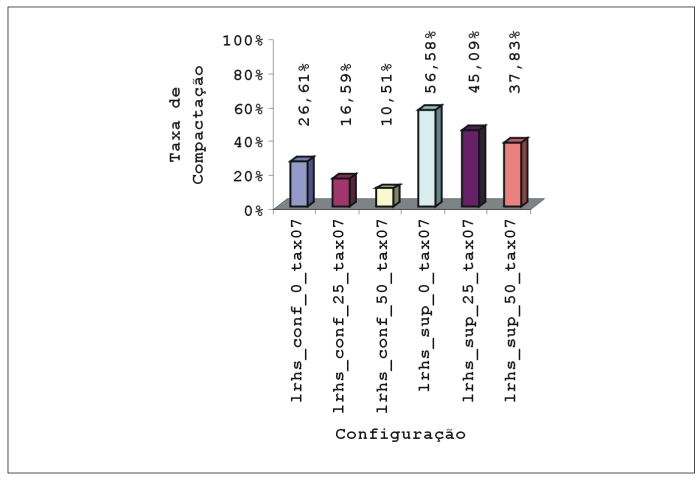

(c) $\operatorname{lrhs}$

Figura F.28: Resultados utilizando os lados lhs, rhs, lrhs (tax07/ND). 



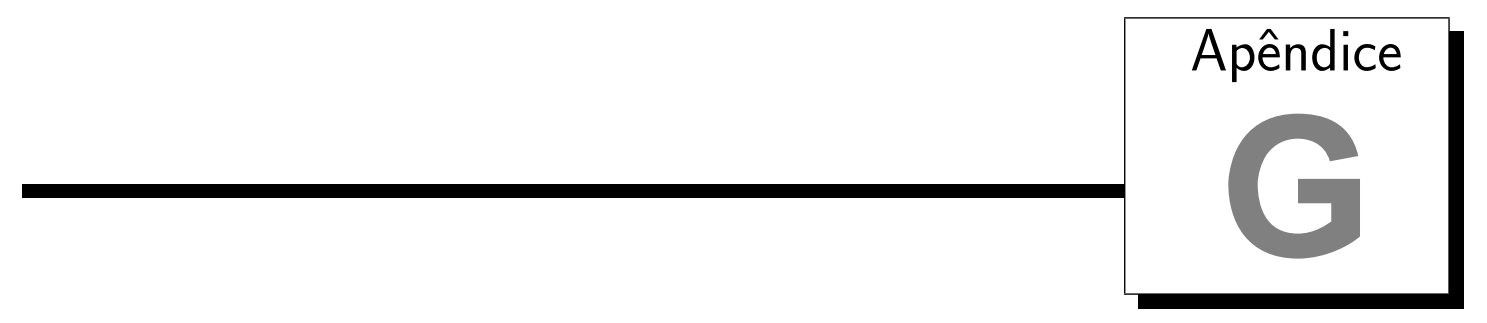

\section{Resultados Referentes à Taxa de Compactação do Cjto-R Agrupados por Lado}

Nesse apêndice são apresentados os resultados descritos na Seção 4.8 (página 82) referentes à taxa de compactação do Cjto-R agrupados pelo lado utilizado na generalização (lhs, rhs e lrhs) (Figuras G.1 a G.4). Os resultados foram plotados em gráficos, os quais são apresentados a seguir. Os rótulos das figuras são identificados pela taxonomia utilizada seguida de seu respectivo nível de abstração (por exemplo, tax01/1N). Os eixos $x$ dos gráficos são identificados pelas configurações utilizadas nos experimentos usando a notação lado-medida-t\% (por exemplo, lhs-sup-0), além do código da taxonomia. Os eixos $y$ dos gráficos indicam a taxa de compactação obtida em uma determinada configuração. 


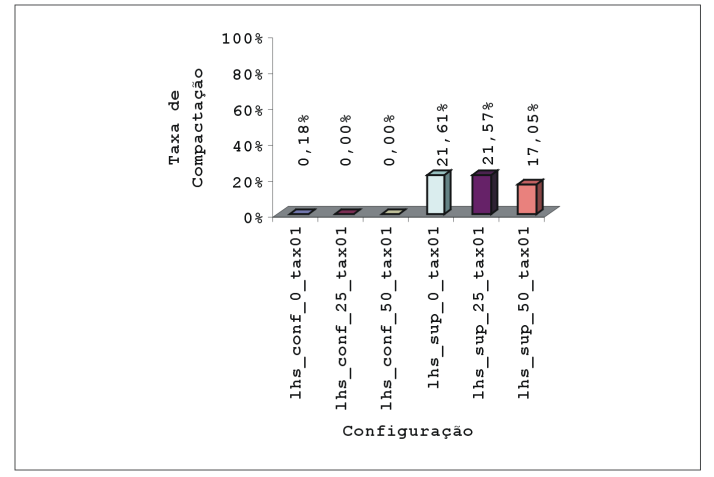

(a) $l h s$

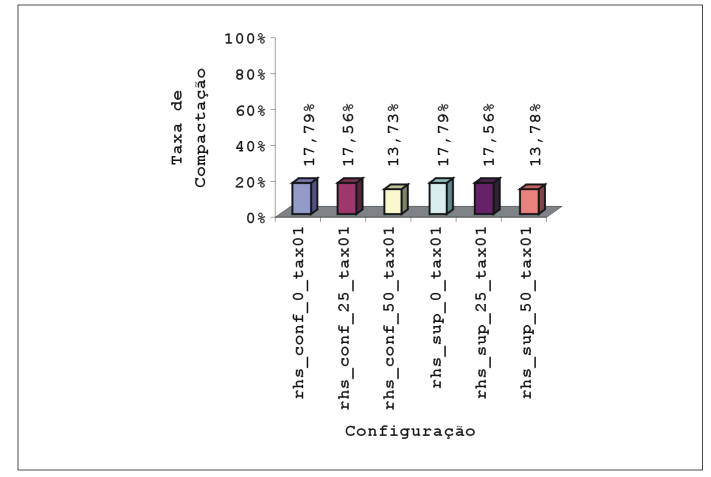

(b) rhs

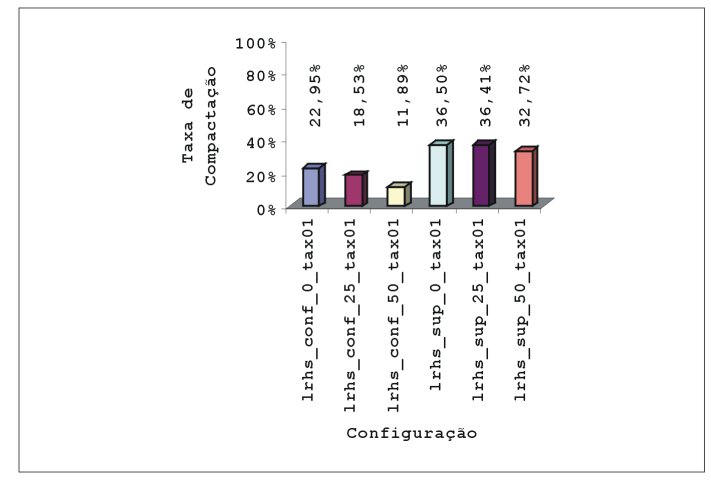

(c) lrhs

Figura G.1: Resultados utilizando os lados lhs, rhs, lrhs (tax01/1N). 


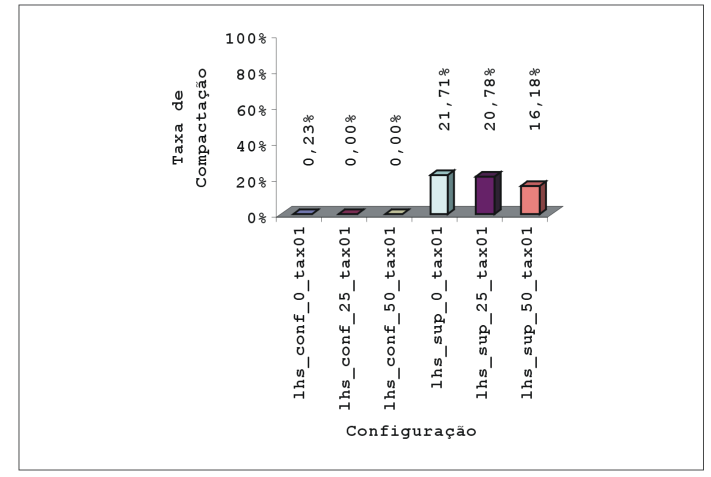

(a) $l h s$

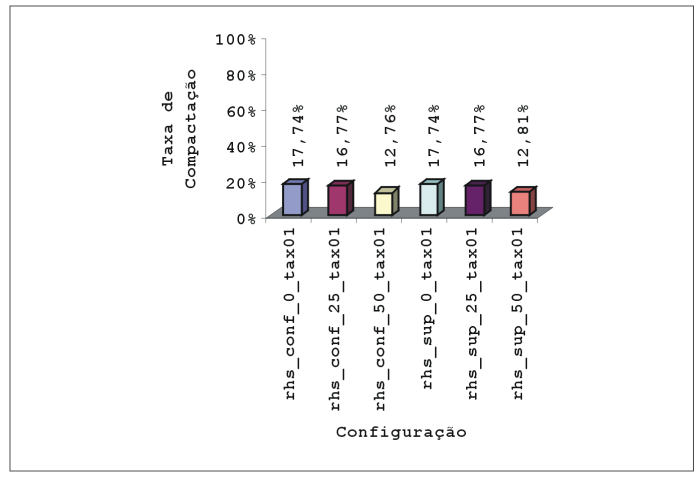

(b) rhs

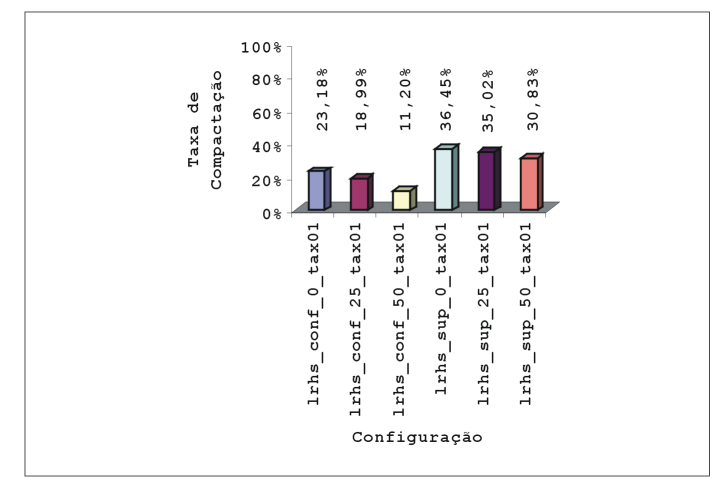

(c) lrhs

Figura G.2: Resultados utilizando os lados lhs, rhs, lrhs (tax01/2N). 


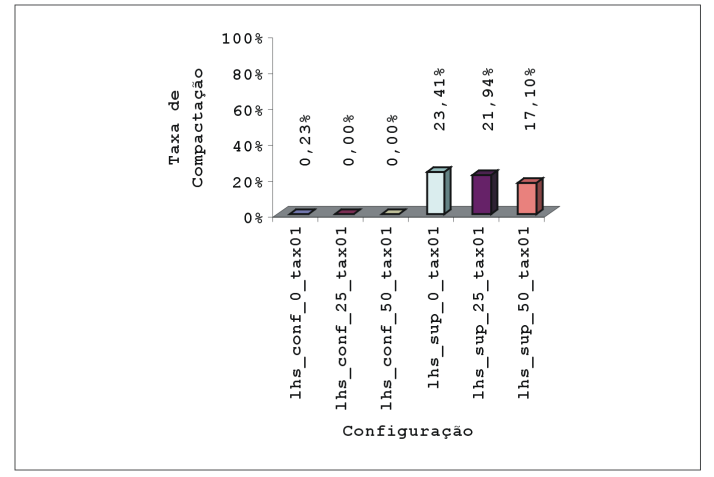

(a) lhs

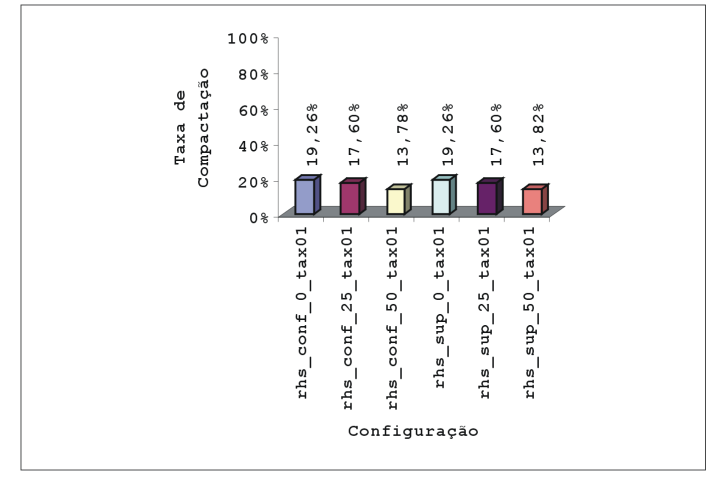

(b) rhs

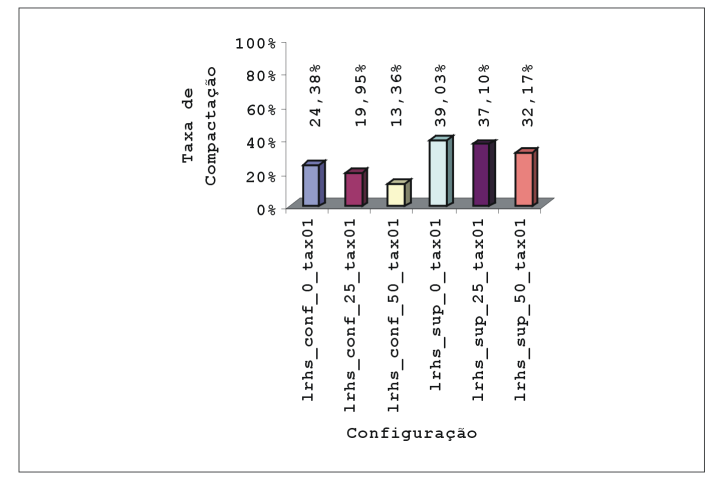

(c) lrhs

Figura G.3: Resultados utilizando os lados lhs, rhs, lrhs (tax01/3N). 


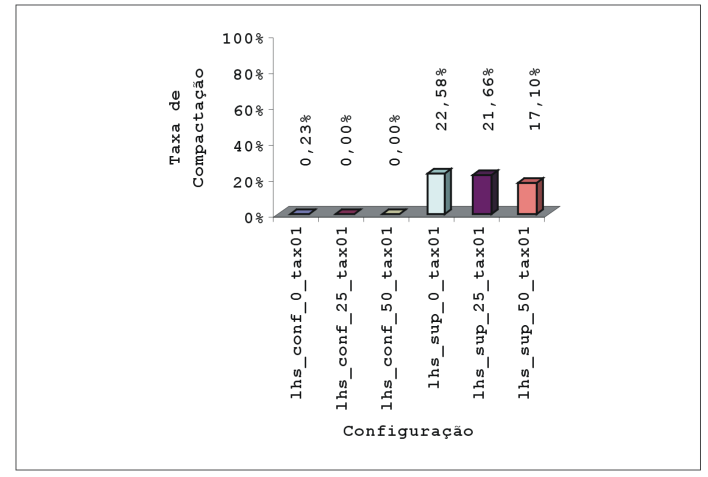

(a) $l h s$

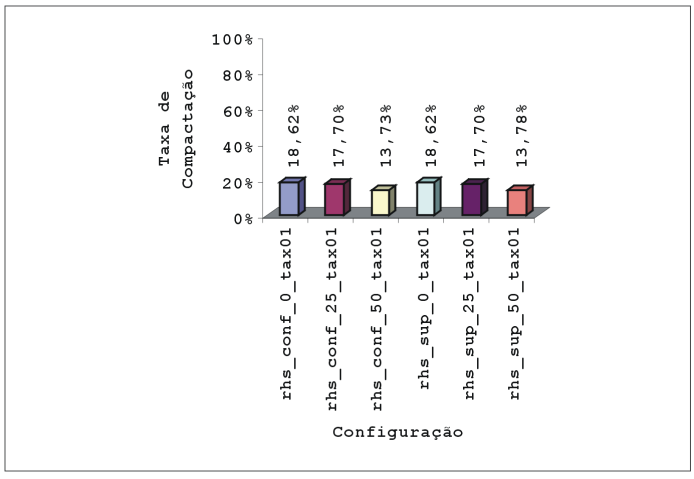

(b) rhs

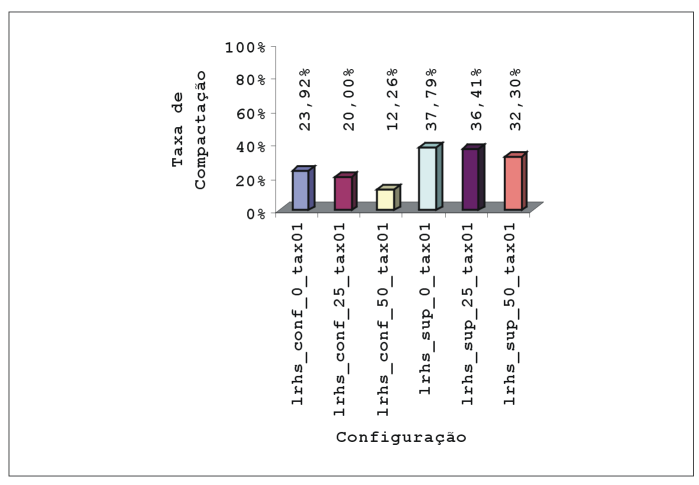

(c) lrhs

Figura G.4: Resultados utilizando os lados lhs, rhs, lrhs (tax01/ND). 



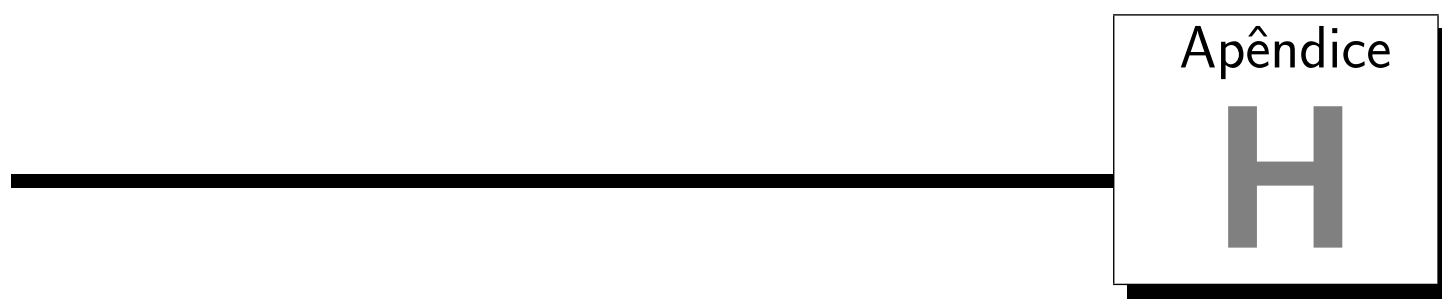

\section{Histogramas do Cjto-Sup}

Nesse apêndice são apresentados os histogramas obtidos para cada uma das medidas consideradas na Seção 5.2 (página 92) utilizando cada um dos conjuntos selecionados e apresentados na Tabela 5.1 (página 94) referentes ao Cjto-Sup. Os eixos $x$ dos histogramas representam os intervalos (classes) que variam, nesse caso, de 0.0 (0\%) a 1.0 (100\%). Esses intervalos indicam a proporção de vezes que uma regra generalizada contém valores maiores ou iguais aos das suas regras específicas. Os eixos y dos histogramas representam a porcentagem de regras generalizadas pertencentes a um determinado intervalo. 


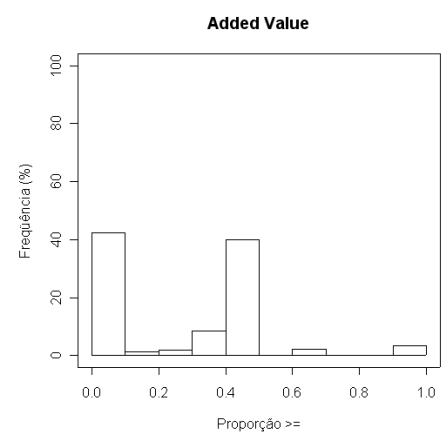

(a) lhs-sup-0-tax $07-1 \mathrm{~N}$

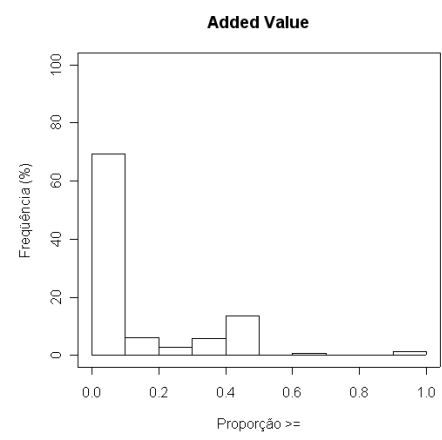

(d) lhs-sup-0-tax05-2N

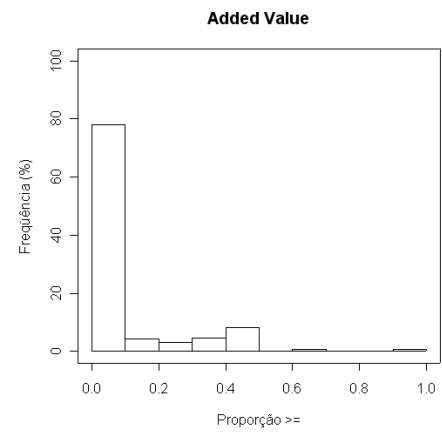

(g) lhs-sup-0-tax07-3N

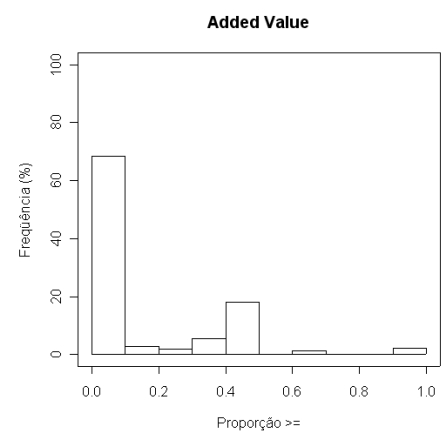

(j) lhs-sup-0-tax07-ND

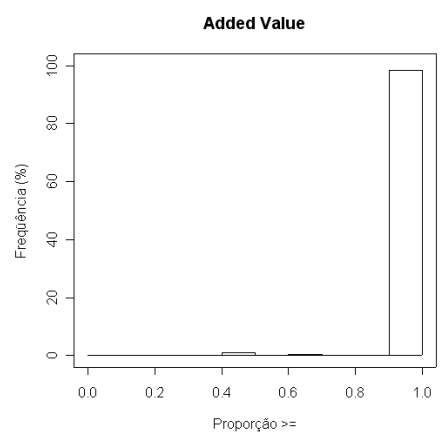

(b) rhs-sup-0-tax07-1N

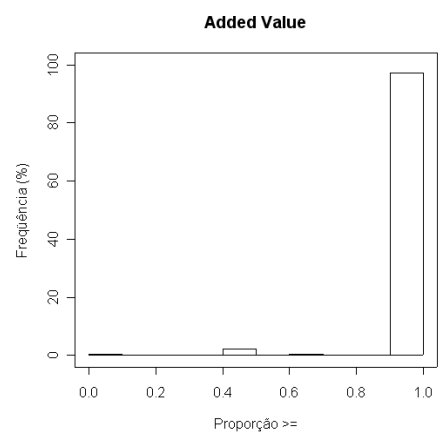

(e) rhs-sup-0-tax05-2N

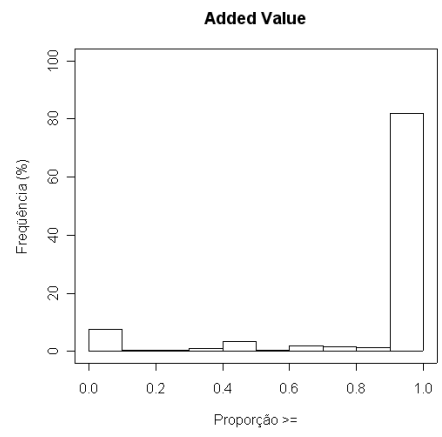

(h) rhs-sup-0-tax07-3N

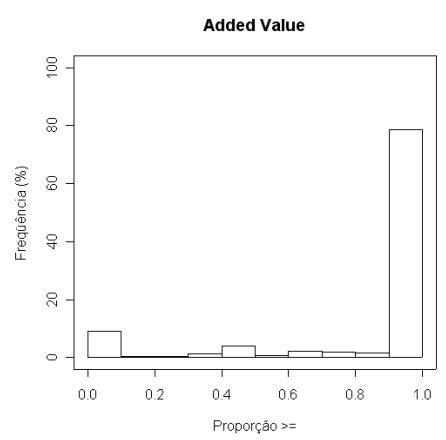

(k) rhs-sup-0-tax07-ND

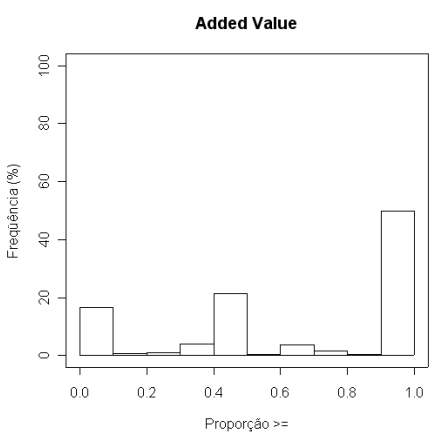

(c) lrhs-sup-0-tax07-1N

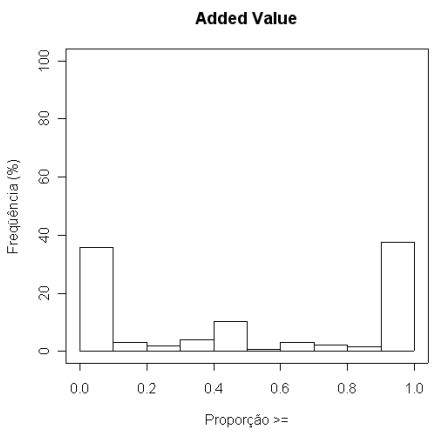

(f) lrhs-sup-0-tax05-2N

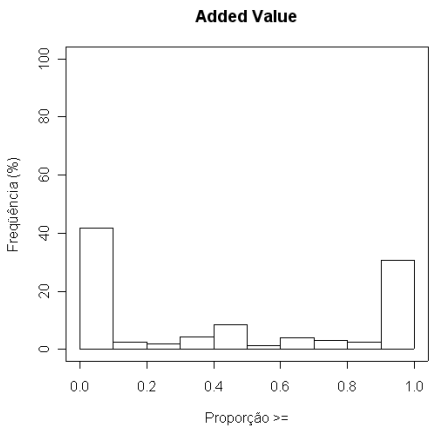

(i) lrhs-sup-0-tax07-3N

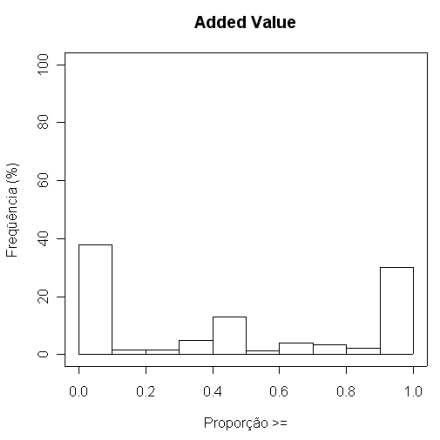

(l) lrhs-sup-0-tax07-ND

Figura H.1: Histogramas referentes a medida Added Value. 


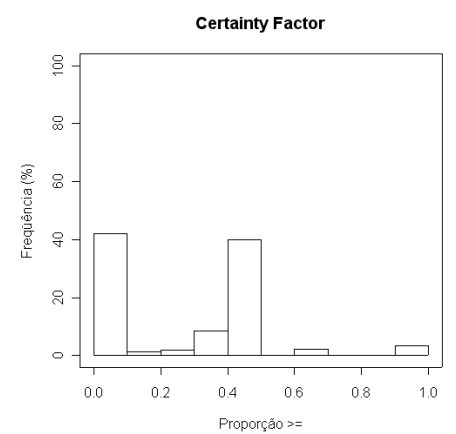

(a) lhs-sup-0-tax07-1N

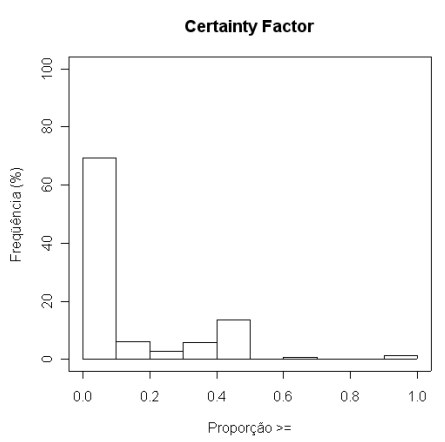

(d) lhs-sup-0-tax05-2N

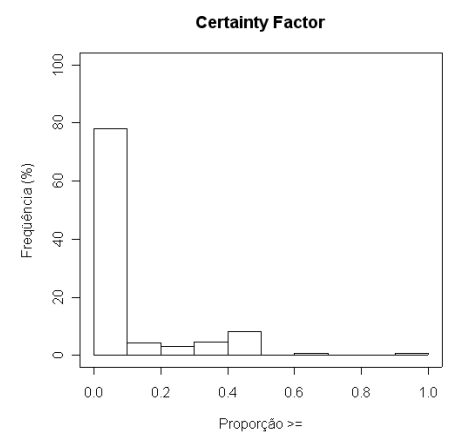

(g) lhs-sup-0-tax07-3N

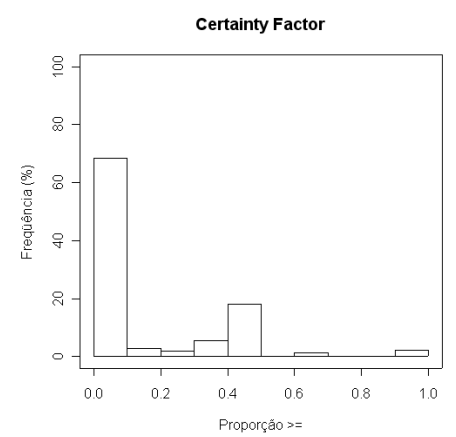

(j) lhs-sup-0-tax07-ND

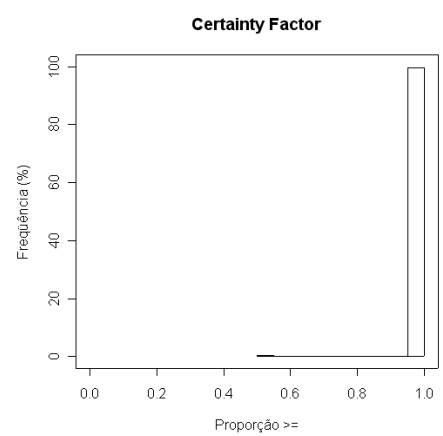

(b) rhs-sup-0-tax07-1N

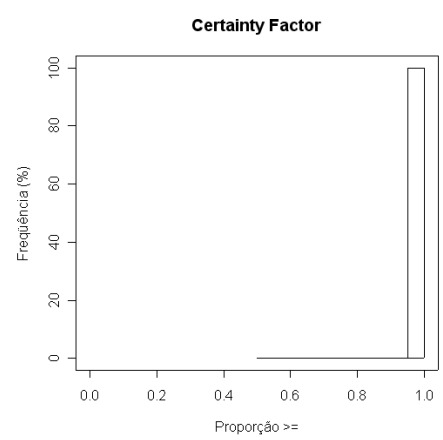

(e) rhs-sup-0-tax05-2N

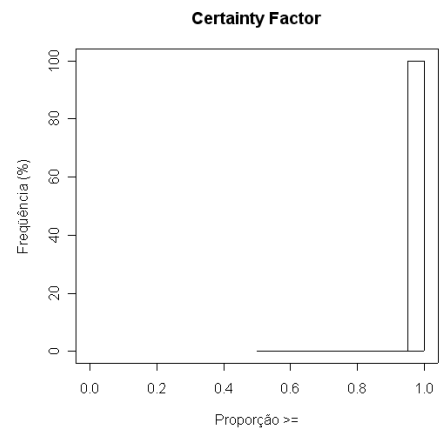

(h) rhs-sup-0-tax07-3N

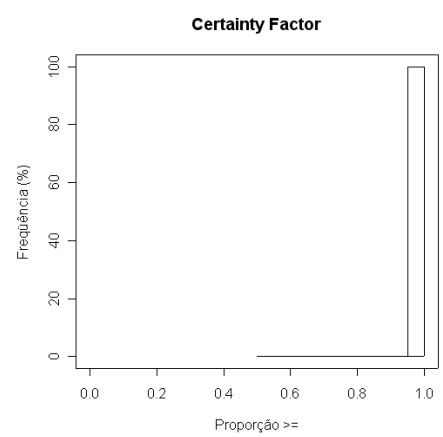

(k) rhs-sup-0-tax07-ND

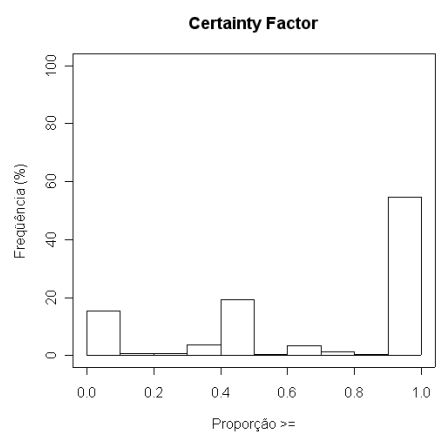

(c) lrhs-sup-0-tax07-1N

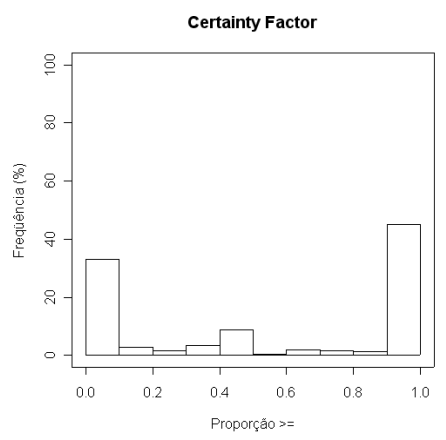

(f) lrhs-sup-0-tax05-2N

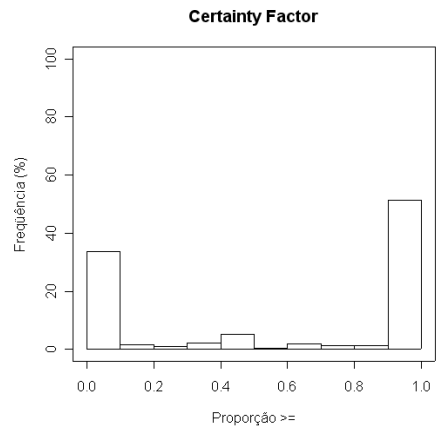

(i) lrhs-sup-0-tax07-3N

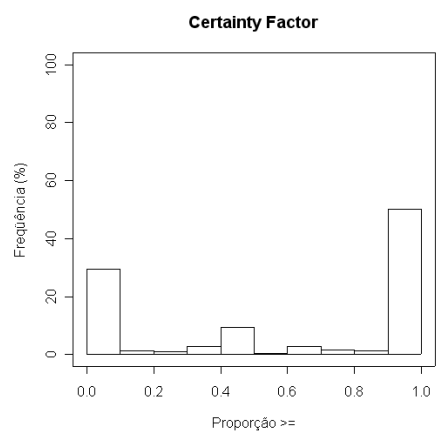

(1) lrhs-sup-0-tax07-ND

Figura H.2: Histogramas referentes a medida Certainty Factor. 


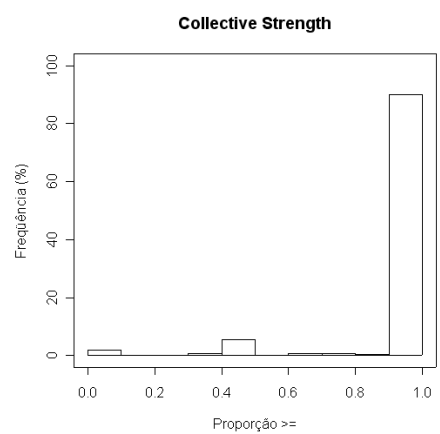

(a) lhs-sup-0-tax07-1N

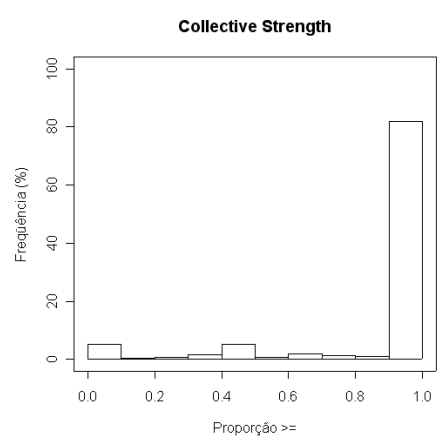

(d) lhs-sup-0-tax05-2N

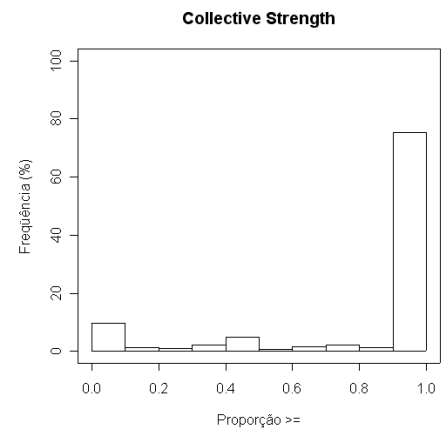

(g) lhs-sup-0-tax07-3N

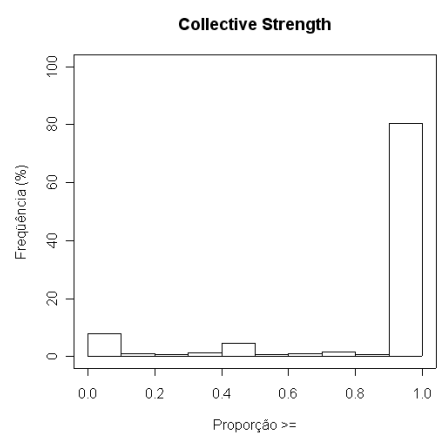

(j) lhs-sup-0-tax07-ND

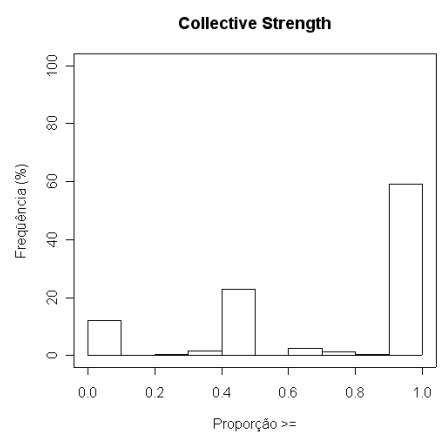

(b) rhs-sup-0-tax $07-1 \mathrm{~N}$

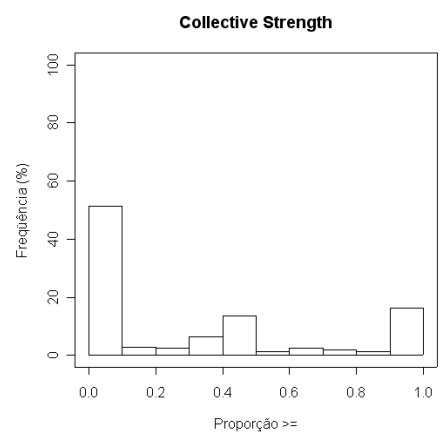

(e) rhs-sup-0-tax05-2N

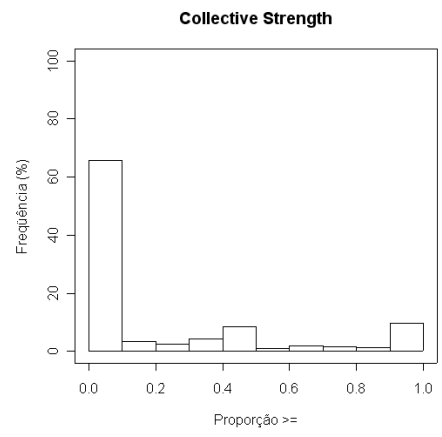

(h) rhs-sup-0-tax07-3N

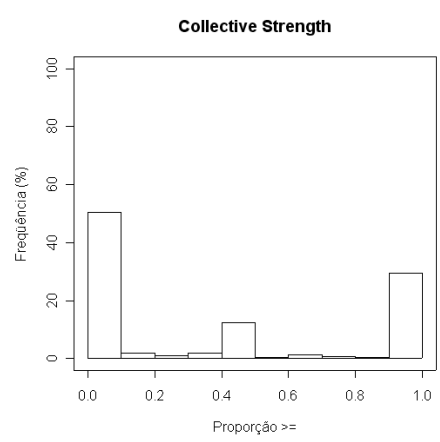

(k) rhs-sup-0-tax07-ND

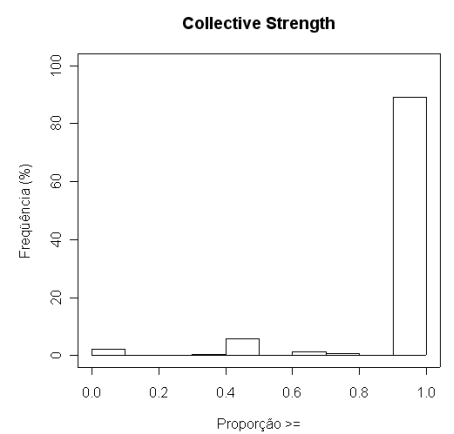

(c) lrhs-sup-0-tax07-1N

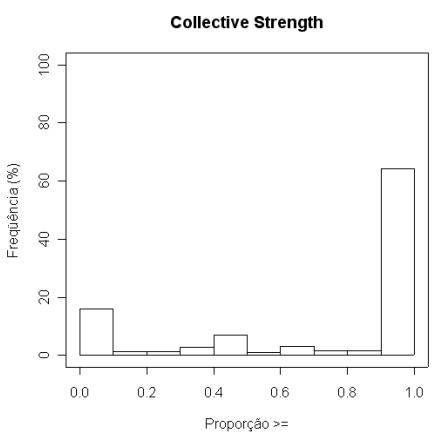

(f) lrhs-sup-0-tax05-2N

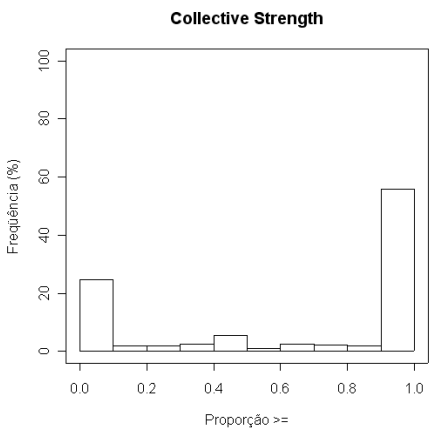

(i) lrhs-sup-0-tax07-3N

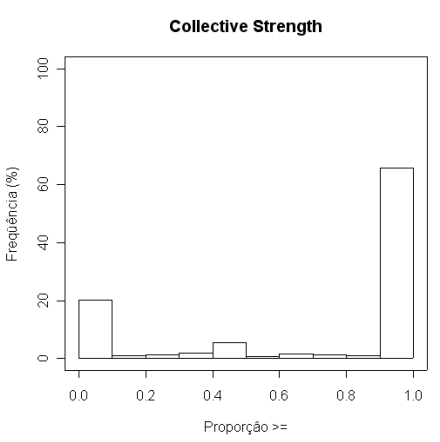

(l) lrhs-sup-0-tax07-ND

Figura H.3: Histogramas referentes a medida Collective Strength. 


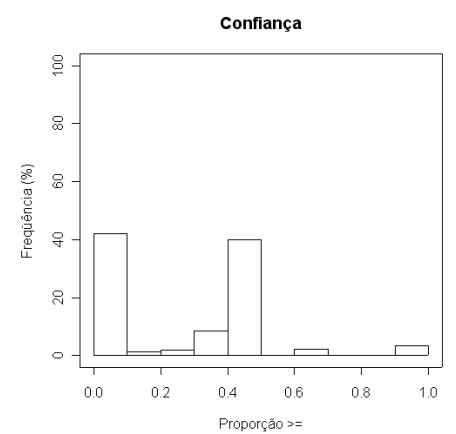

(a) lhs-sup-0-tax $07-1 \mathrm{~N}$

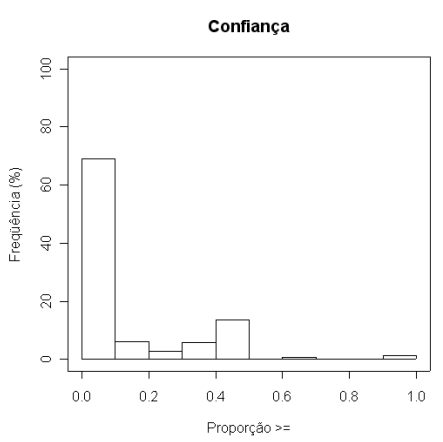

(d) lhs-sup-0-tax05-2N

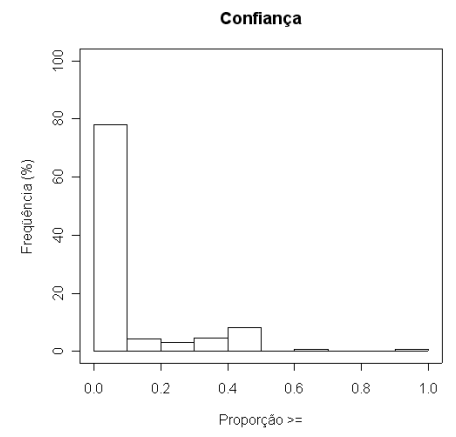

(g) lhs-sup-0-tax07-3N

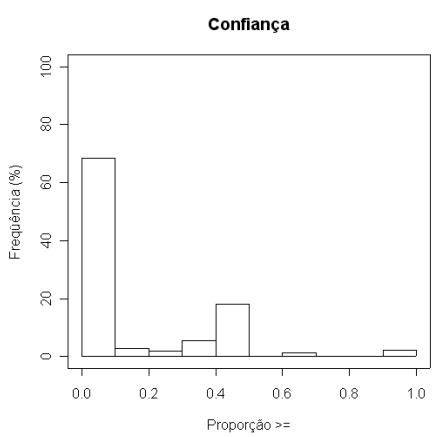

(j) lhs-sup-0-tax07-ND

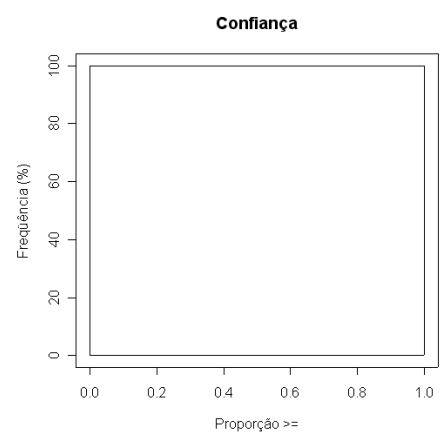

(b) rhs-sup-0-tax07-1N

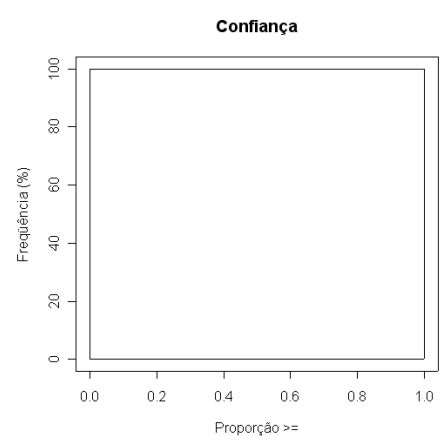

(e) rhs-sup-0-tax05-2N

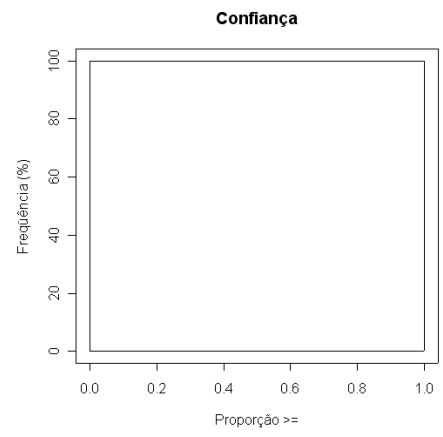

(h) rhs-sup-0-tax07-3N

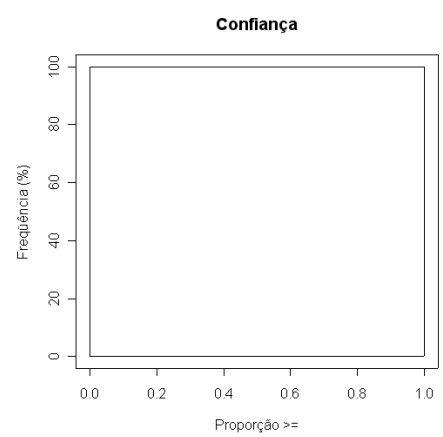

(k) rhs-sup-0-tax07-ND

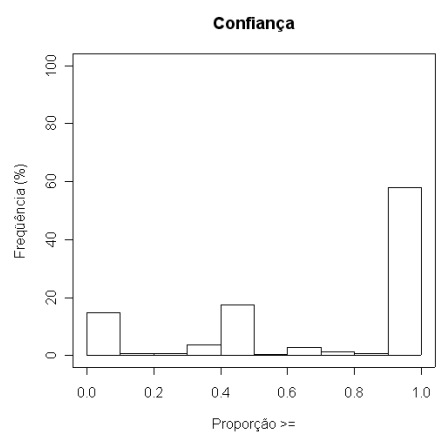

(c) lrhs-sup-0-tax07-1N

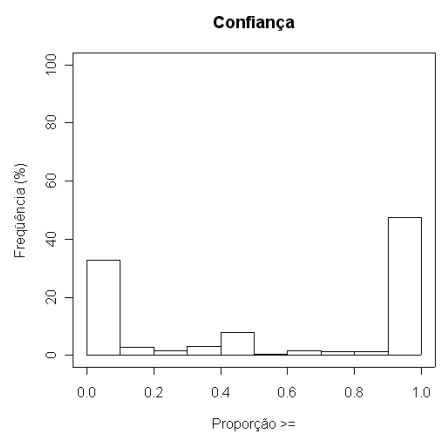

(f) lrhs-sup-0-tax05-2N

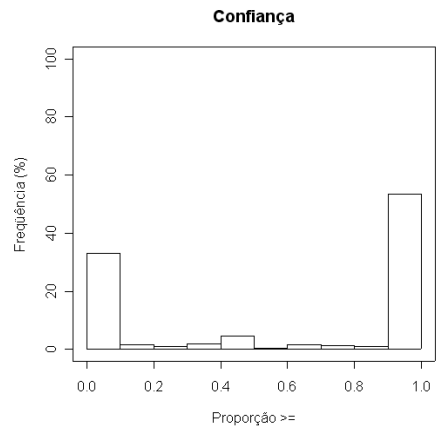

(i) lrhs-sup-0-tax07-3N

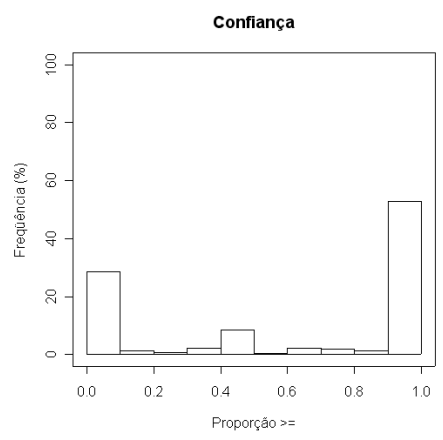

(1) lrhs-sup-0-tax07-ND

Figura H.4: Histogramas referentes a medida Confiança. 


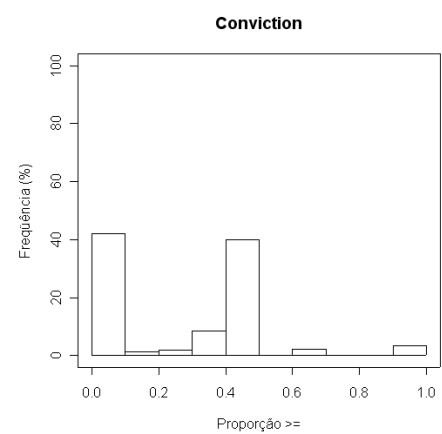

(a) lhs-sup-0-tax $07-1 \mathrm{~N}$

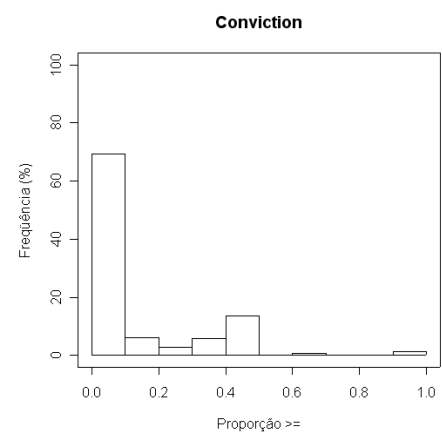

(d) lhs-sup-0-tax05-2N

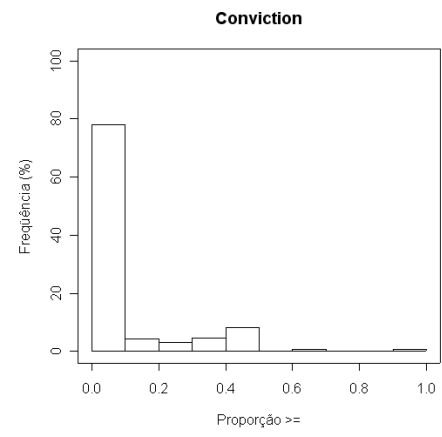

(g) lhs-sup-0-tax07-3N

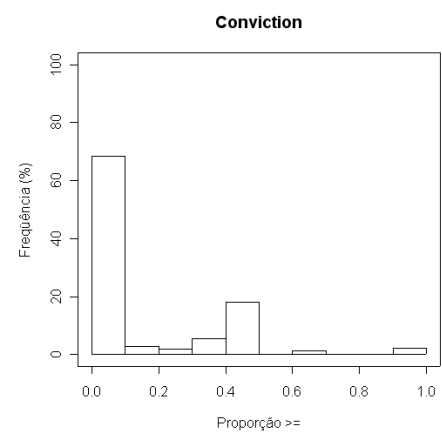

(j) lhs-sup-0-tax07-ND

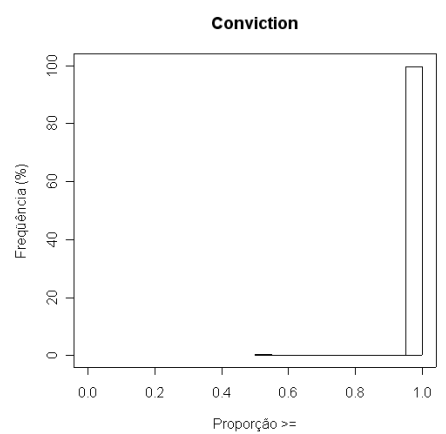

(b) rhs-sup-0-tax07-1N

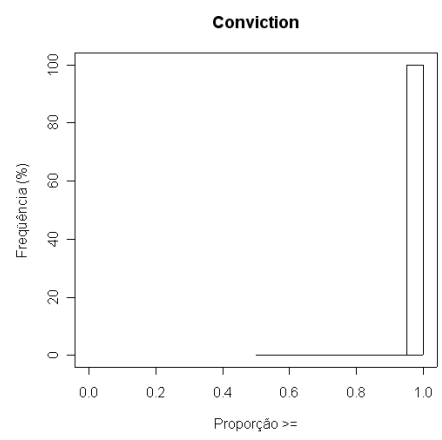

(e) rhs-sup-0-tax05-2N

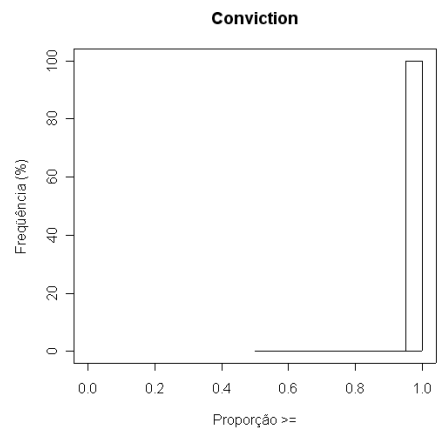

(h) rhs-sup-0-tax07-3N

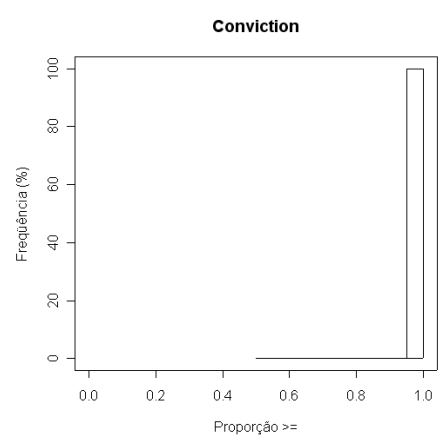

(k) rhs-sup-0-tax07-ND

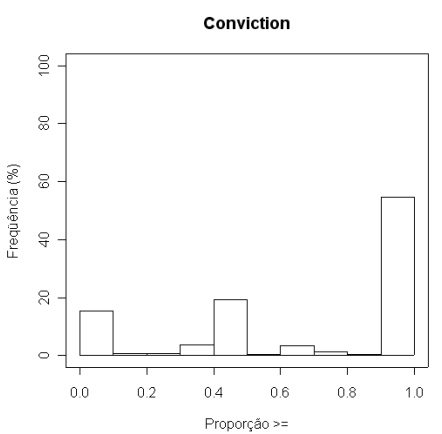

(c) lrhs-sup-0-tax07-1N

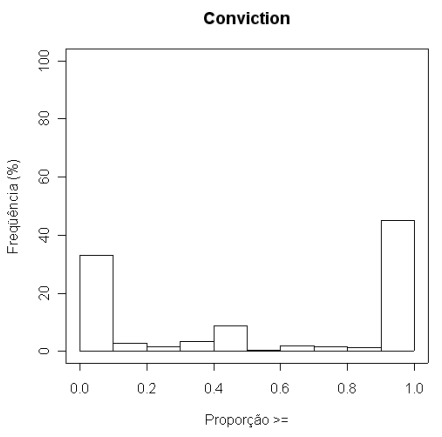

(f) lrhs-sup-0-tax05-2N

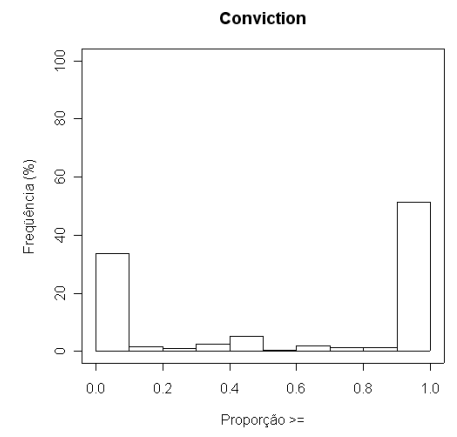

(i) lrhs-sup-0-tax07-3N

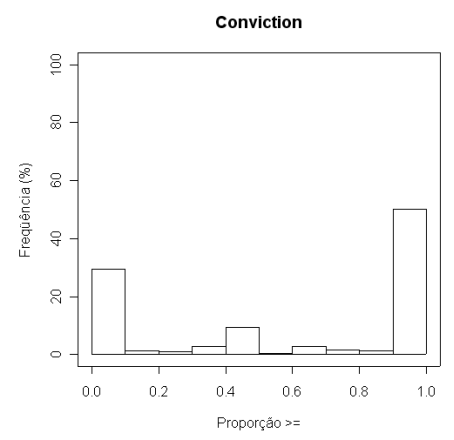

(l) lrhs-sup-0-tax07-ND

Figura H.5: Histogramas referentes a medida Conviction. 


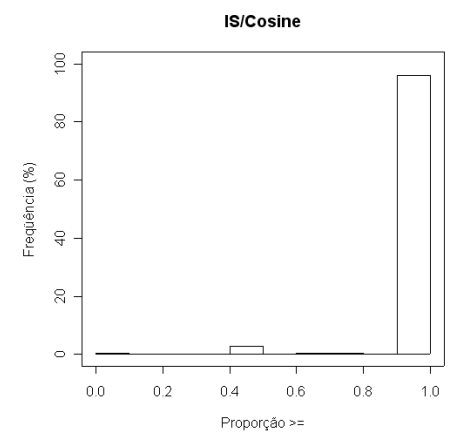

(a) lhs-sup-0-tax $07-1 \mathrm{~N}$

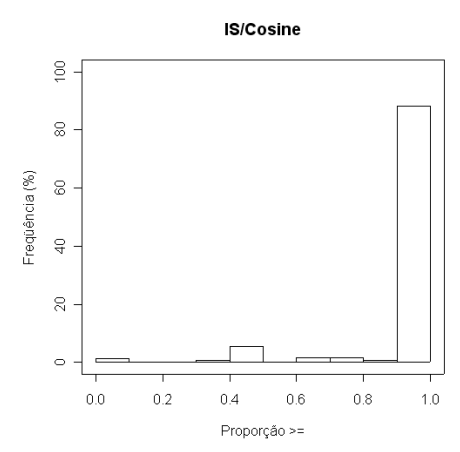

(d) lhs-sup-0-tax05-2N

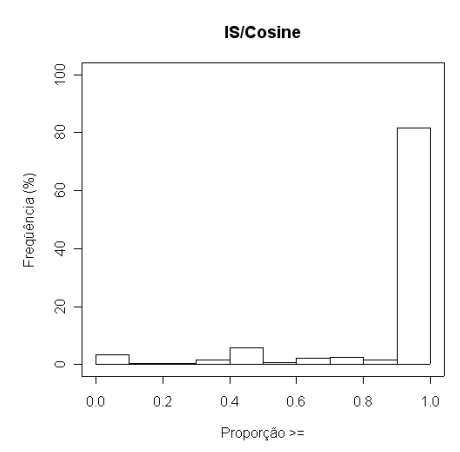

(g) lhs-sup-0-tax07-3N

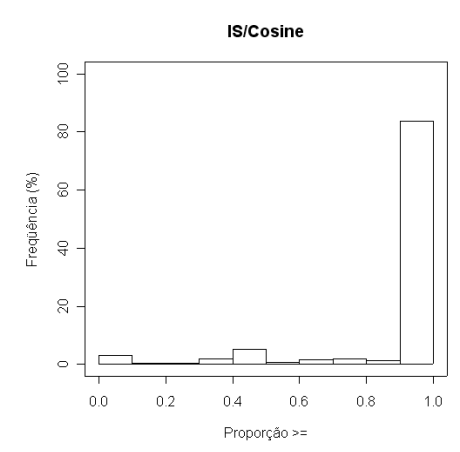

(j) lhs-sup-0-tax07-ND

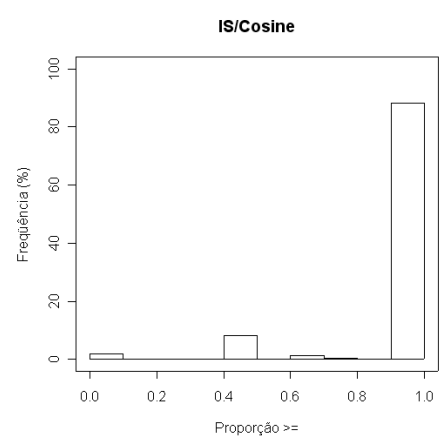

(b) rhs-sup-0-tax07-1N

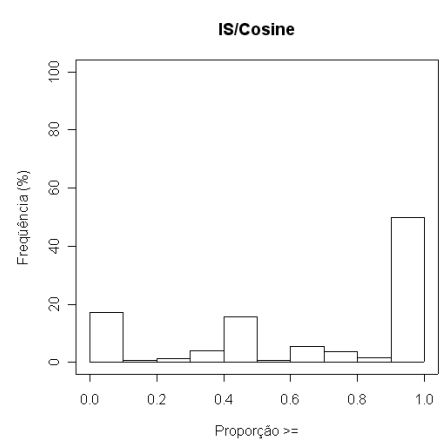

(e) rhs-sup-0-tax05-2N

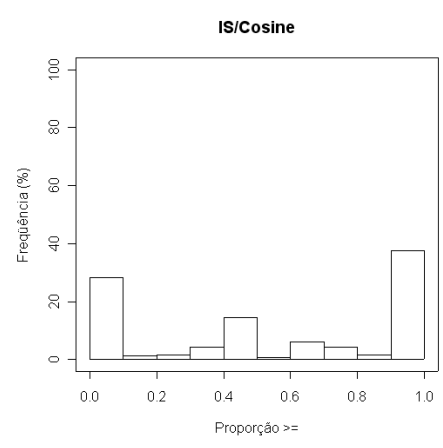

(h) rhs-sup-0-tax07-3N

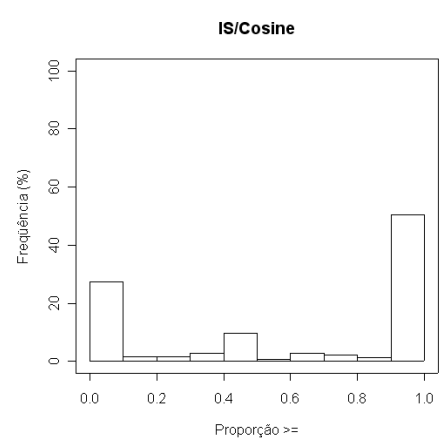

(k) rhs-sup-0-tax07-ND

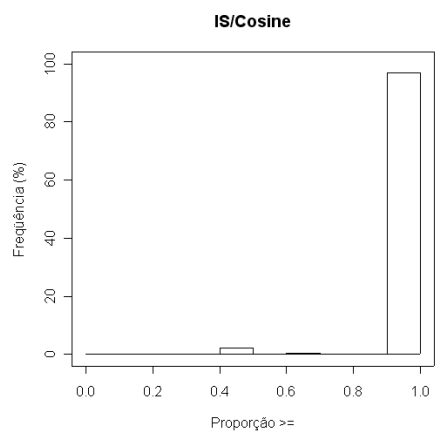

(c) lrhs-sup-0-tax07-1N

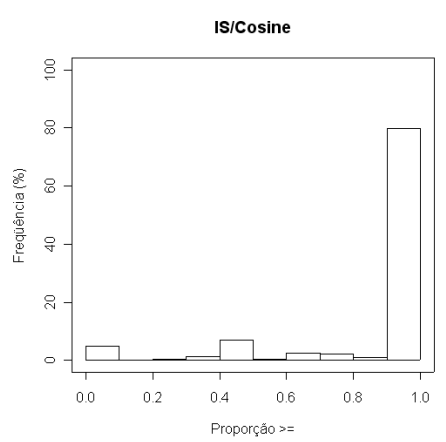

(f) lrhs-sup-0-tax05-2N

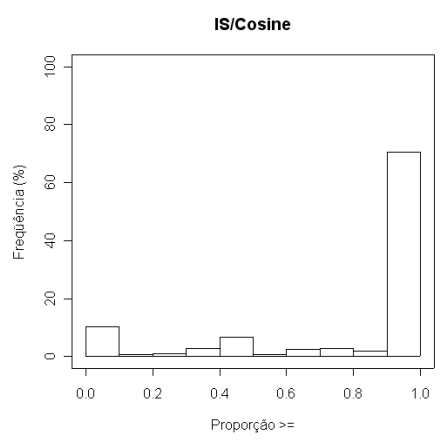

(i) lrhs-sup-0-tax07-3N

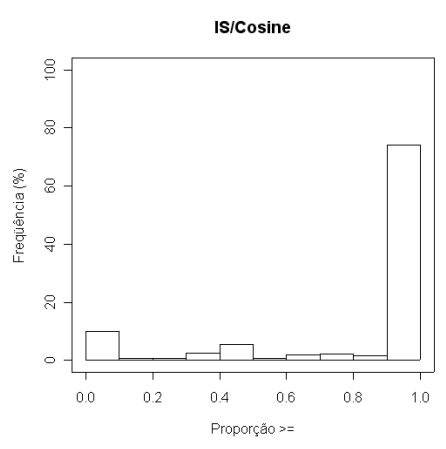

(l) lrhs-sup-0-tax07-ND

Figura H.6: Histogramas referentes a medida IS/Cosine. 


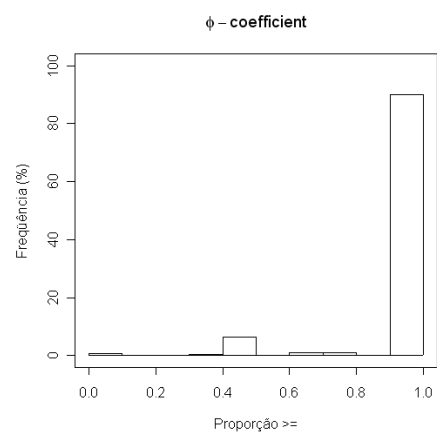

(a) lhs-sup-0-tax07-1N

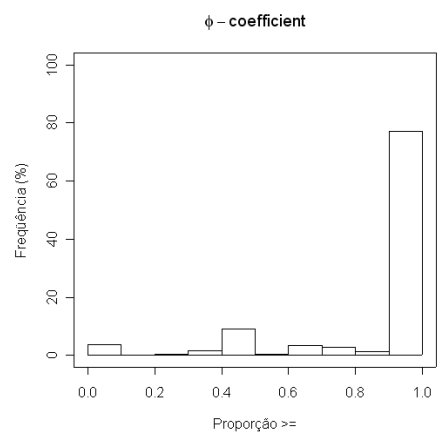

(d) lhs-sup-0-tax05-2N

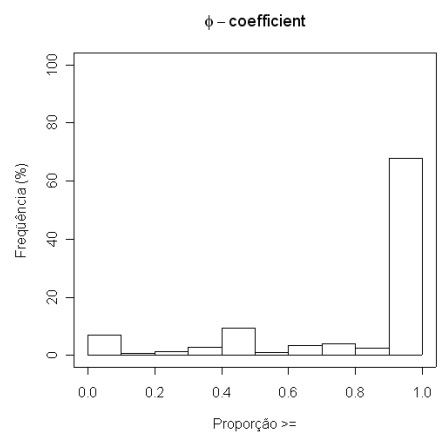

(g) lhs-sup-0-tax07-3N

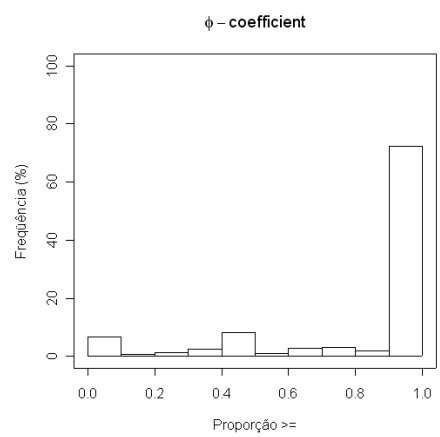

(j) lhs-sup-0-tax07-ND

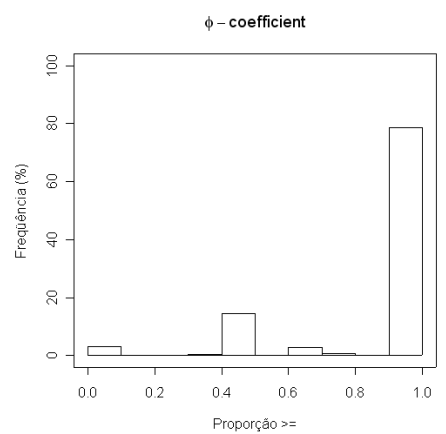

(b) rhs-sup-0-tax $07-1 \mathrm{~N}$

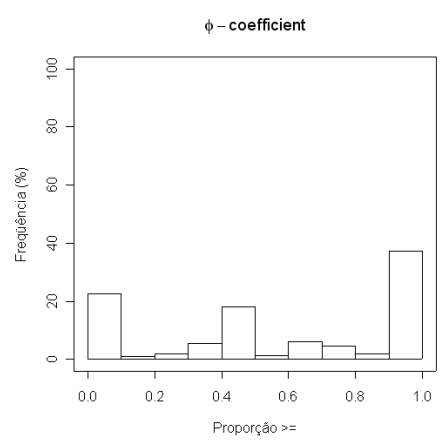

(e) rhs-sup-0-tax05-2N

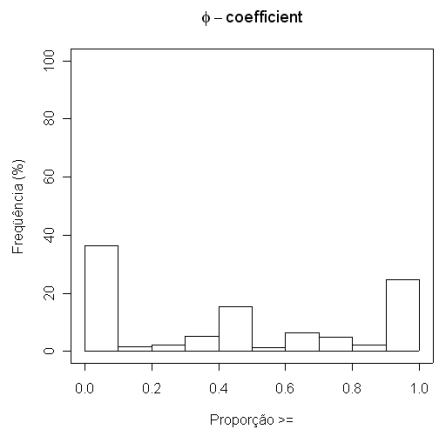

(h) rhs-sup-0-tax07-3N

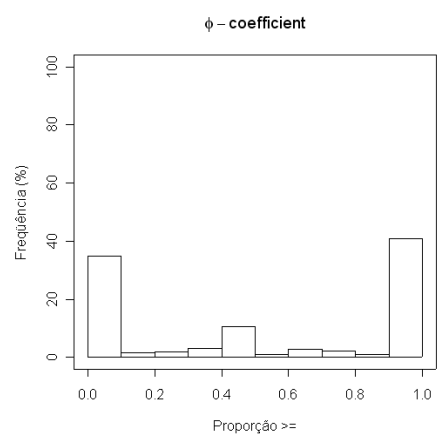

(k) rhs-sup-0-tax07-ND

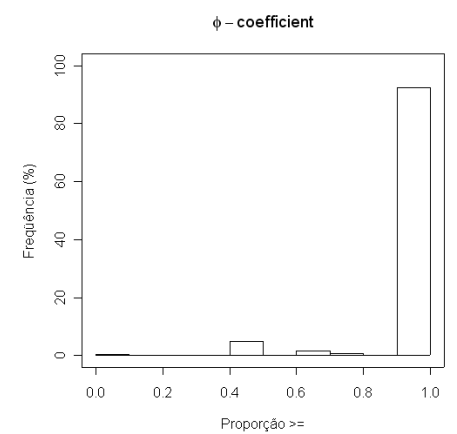

(c) lrhs-sup-0-tax07-1N

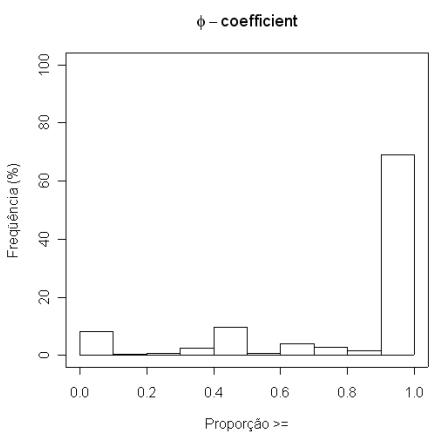

(f) lrhs-sup-0-tax05-2N

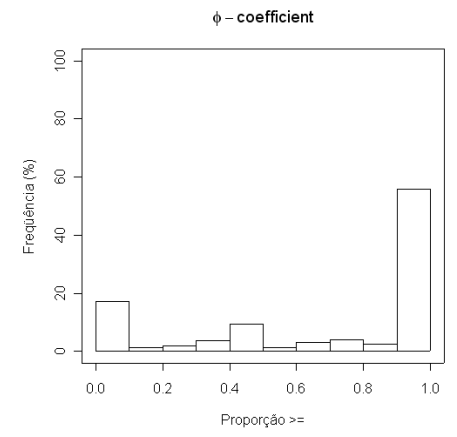

(i) lrhs-sup-0-tax07-3N

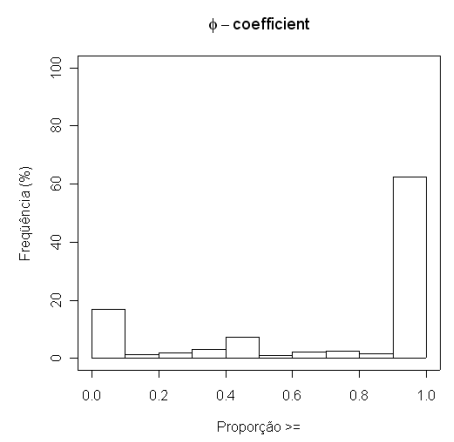

(l) lrhs-sup-0-tax07-ND

Figura H.7: Histogramas referentes a medida $\phi$-coefficient. 


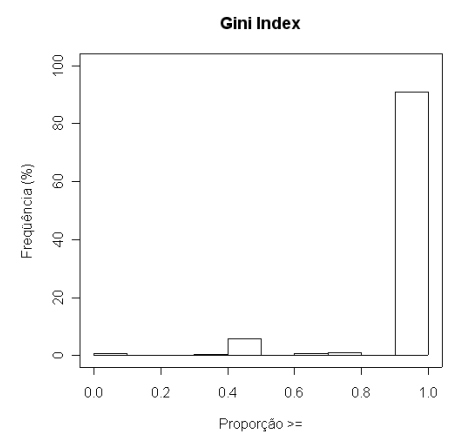

(a) lhs-sup-0-tax $07-1 \mathrm{~N}$

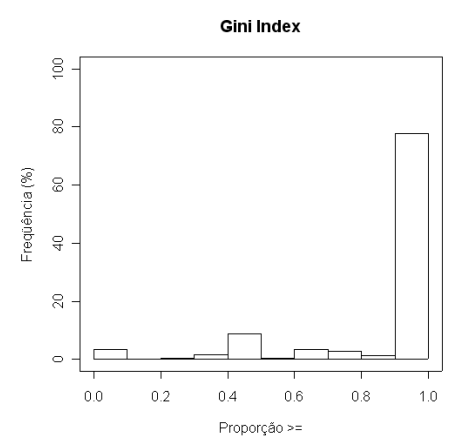

(d) lhs-sup-0-tax05-2N

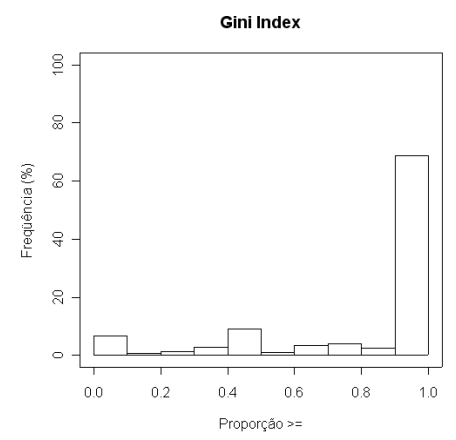

(g) lhs-sup-0-tax07-3N

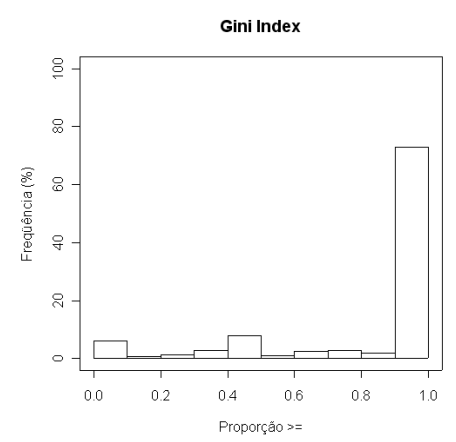

(j) lhs-sup-0-tax07-ND

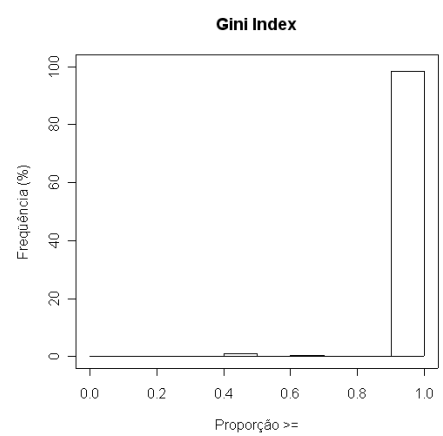

(b) rhs-sup-0-tax $07-1 \mathrm{~N}$

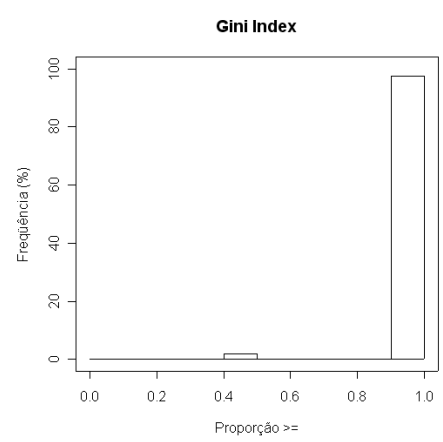

(e) rhs-sup-0-tax05-2N

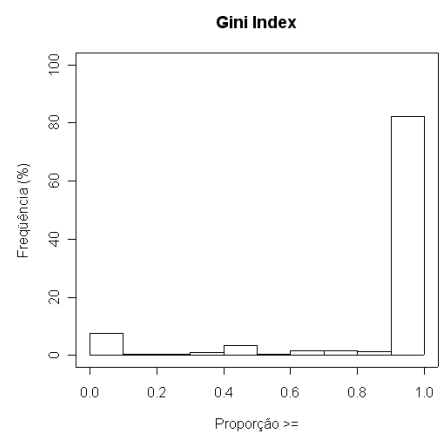

(h) rhs-sup-0-tax07-3N

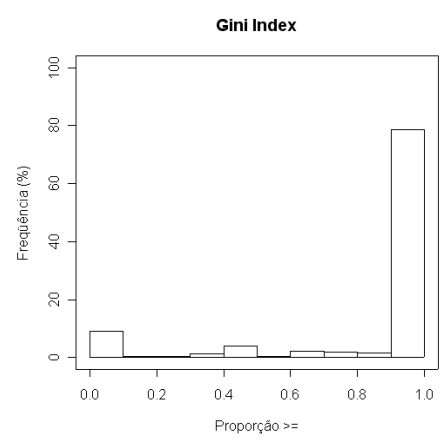

(k) rhs-sup-0-tax07-ND

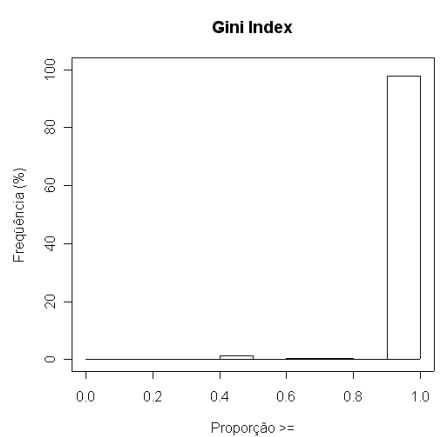

(c) lrhs-sup-0-tax $07-1 \mathrm{~N}$

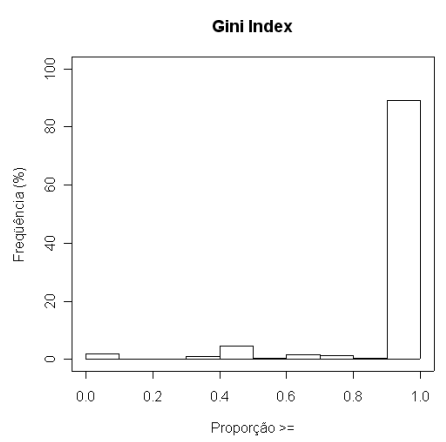

(f) lrhs-sup-0-tax05-2N

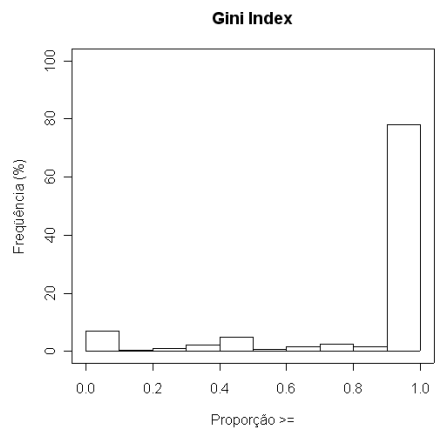

(i) lrhs-sup-0-tax07-3N

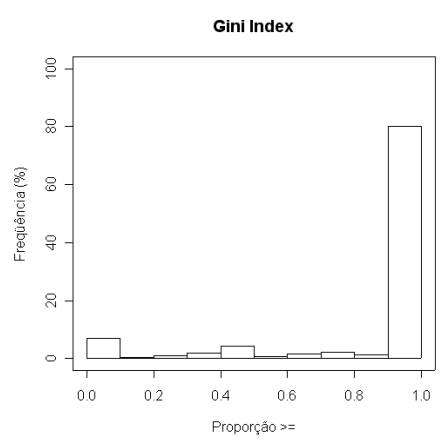

(l) lrhs-sup-0-tax07-ND

Figura H.8: Histogramas referentes a medida Gini Index. 


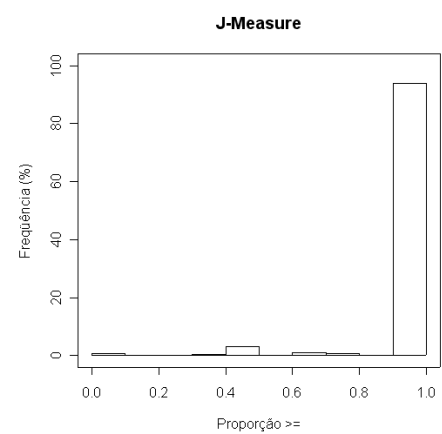

(a) lhs-sup-0-tax07-1N

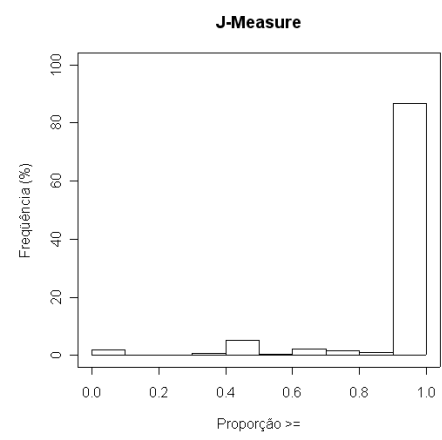

(d) lhs-sup-0-tax05-2N

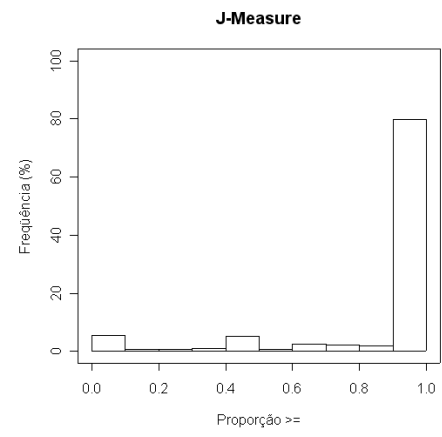

(g) lhs-sup-0-tax07-3N

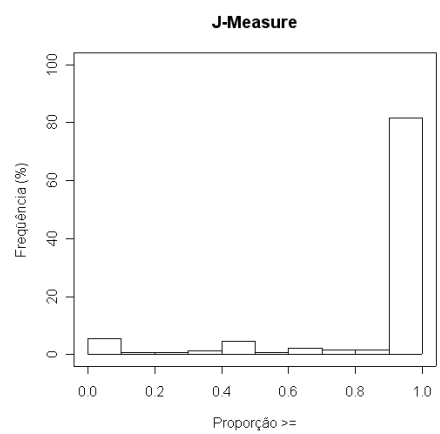

(j) lhs-sup-0-tax07-ND

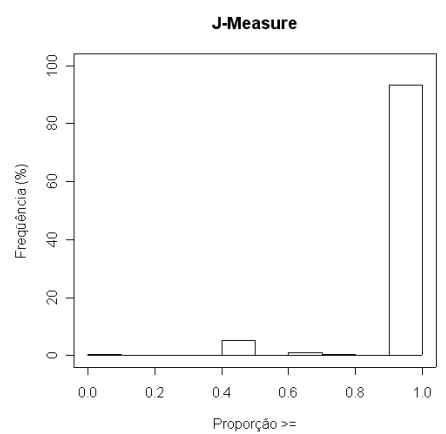

(b) rhs-sup-0-tax $07-1 \mathrm{~N}$

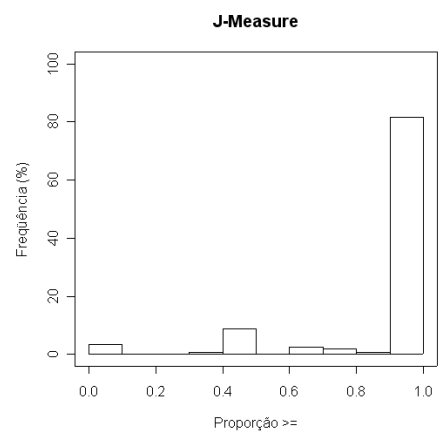

(e) rhs-sup-0-tax05-2N

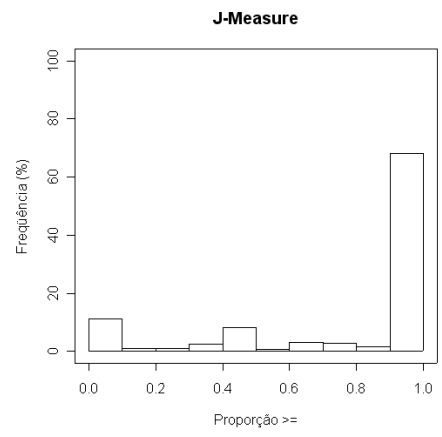

(h) rhs-sup-0-tax07-3N

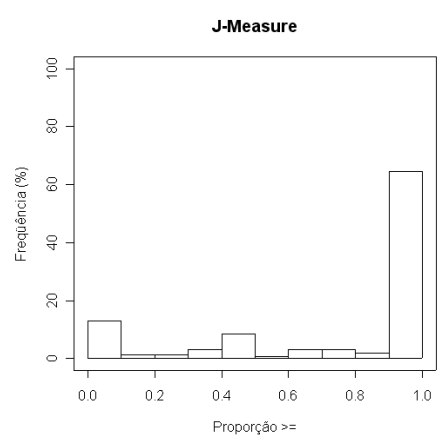

(k) rhs-sup-0-tax07-ND

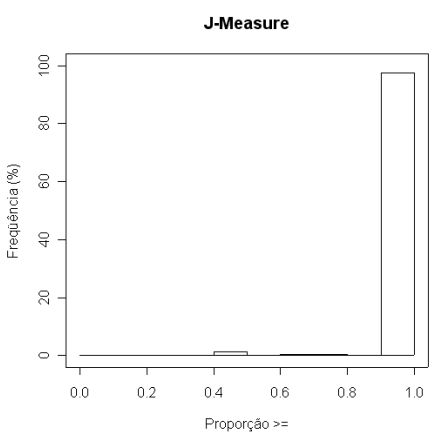

(c) lrhs-sup-0-tax07-1N

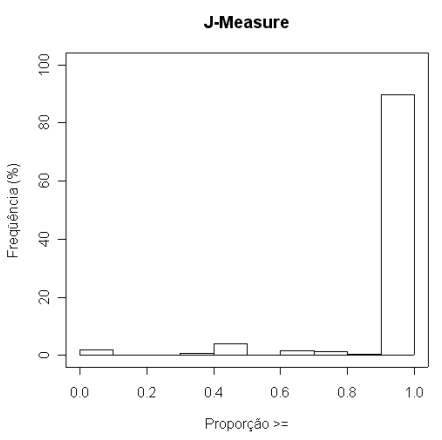

(f) lrhs-sup-0-tax05-2N

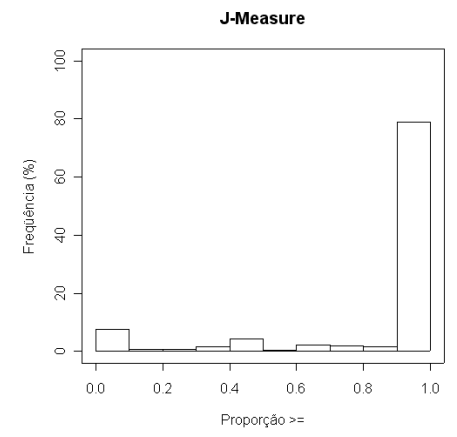

(i) lrhs-sup-0-tax07-3N

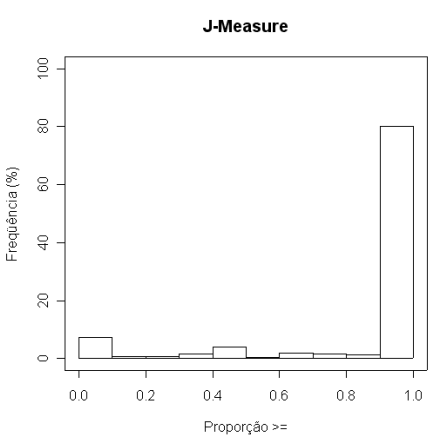

(l) lrhs-sup-0-tax07-ND

Figura H.9: Histogramas referentes a medida J-Measure. 


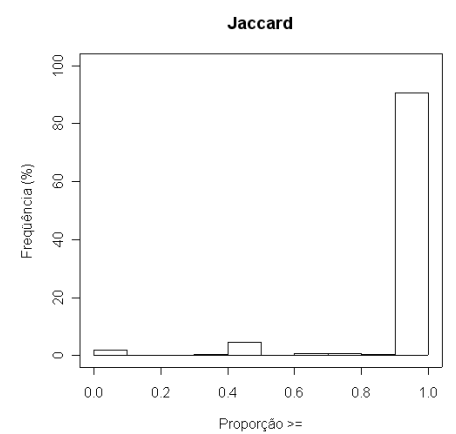

(a) lhs-sup-0-tax $07-1 \mathrm{~N}$

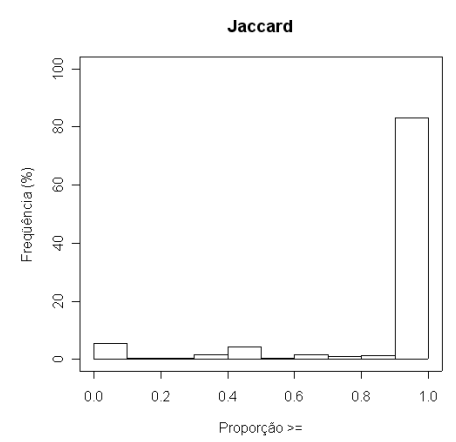

(d) lhs-sup-0-tax05-2N

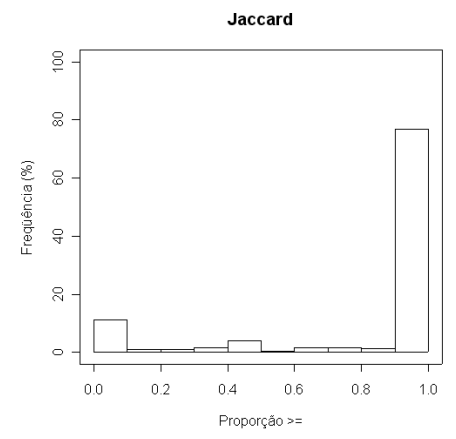

(g) lhs-sup-0-tax07-3N

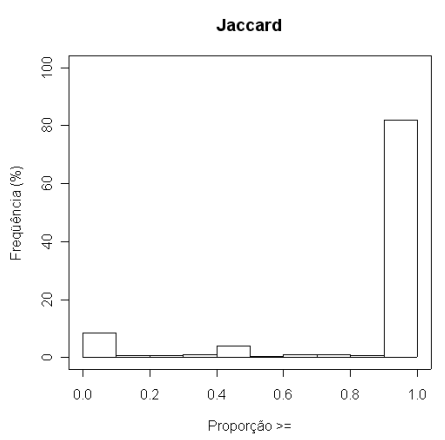

(j) lhs-sup-0-tax07-ND

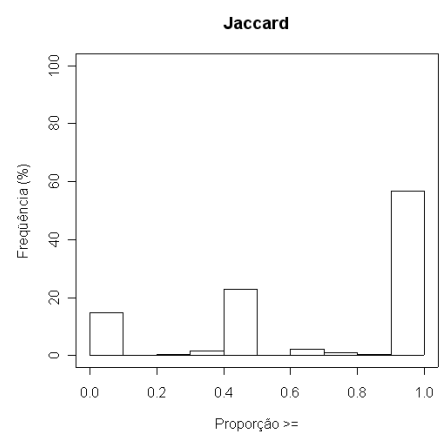

(b) rhs-sup-0-tax $07-1 \mathrm{~N}$

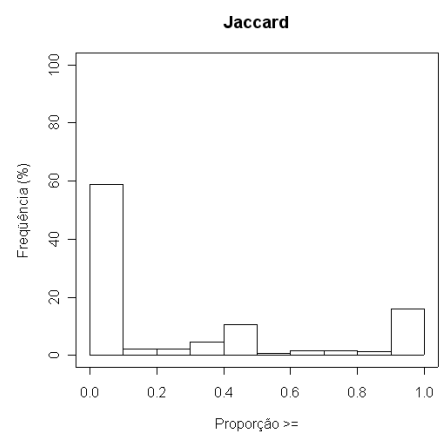

(e) rhs-sup-0-tax05-2N

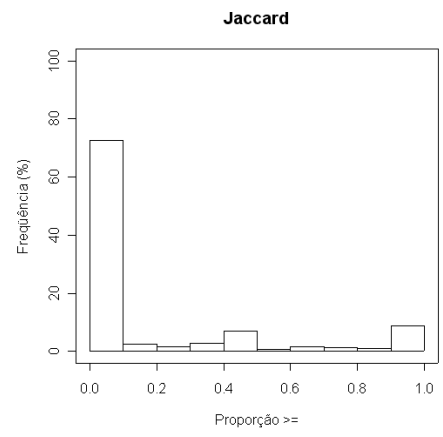

(h) rhs-sup-0-tax07-3N

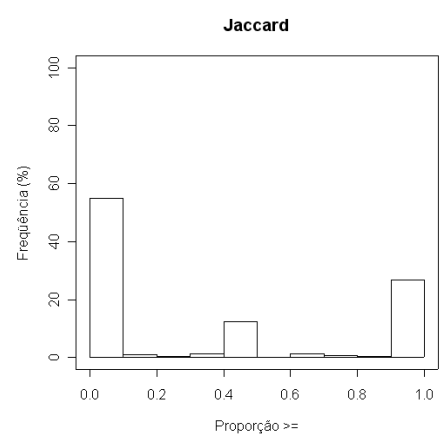

(k) rhs-sup-0-tax07-ND

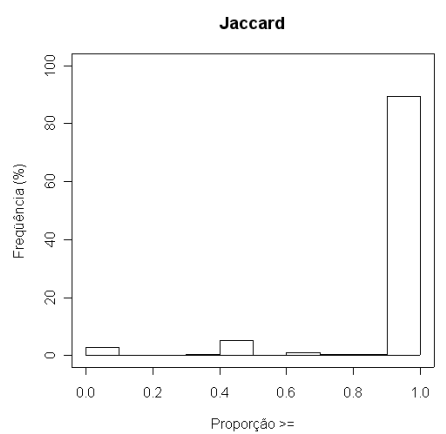

(c) lrhs-sup-0-tax $07-1 \mathrm{~N}$

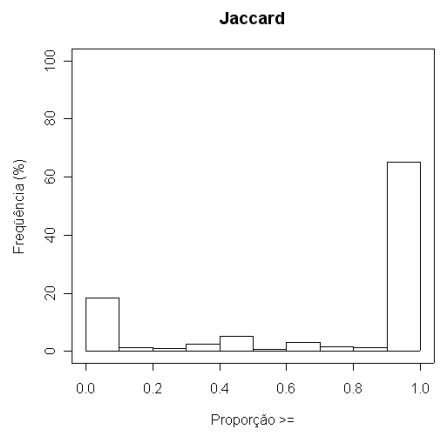

(f) lrhs-sup-0-tax05-2N

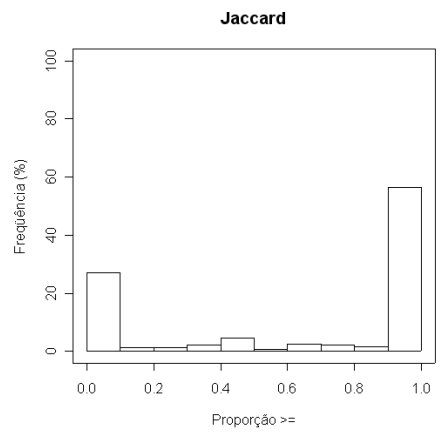

(i) lrhs-sup-0-tax07-3N

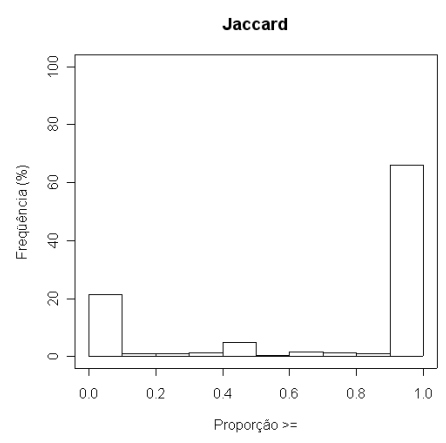

(l) lrhs-sup-0-tax07-ND

Figura H.10: Histogramas referentes a medida Jaccard. 


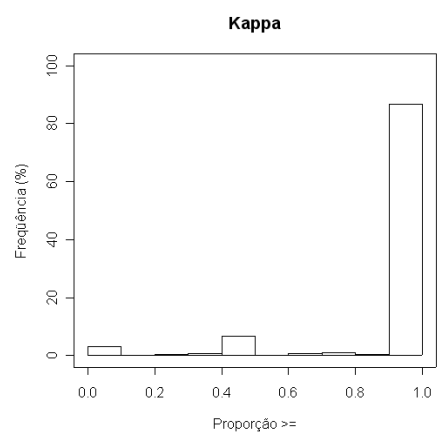

(a) lhs-sup-0-tax07-1N

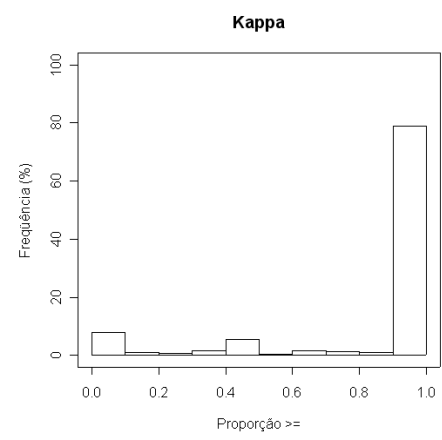

(d) lhs-sup-0-tax05-2N

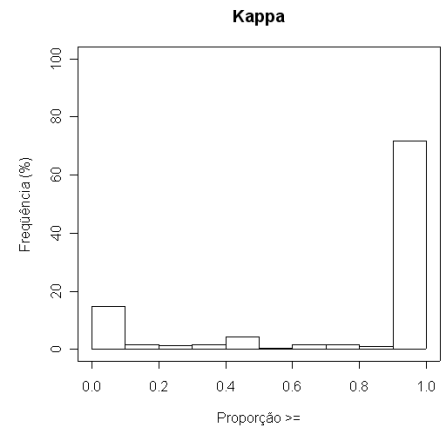

(g) lhs-sup-0-tax07-3N

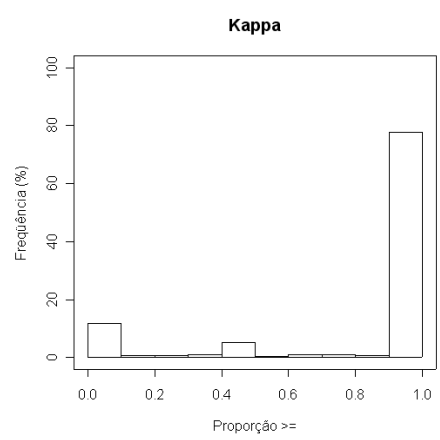

(j) lhs-sup-0-tax07-ND

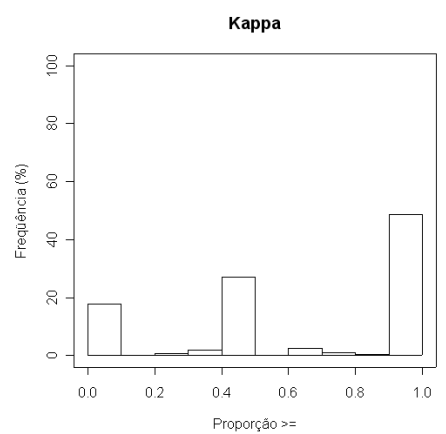

(b) rhs-sup-0-tax $07-1 \mathrm{~N}$

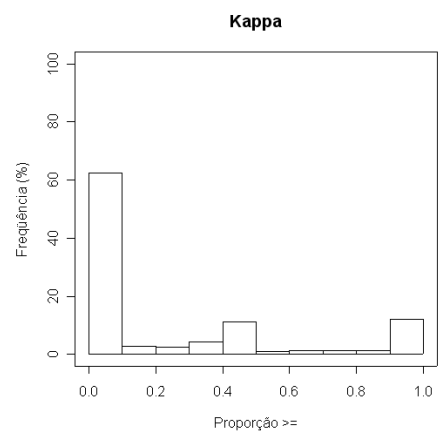

(e) rhs-sup-0-tax05-2N

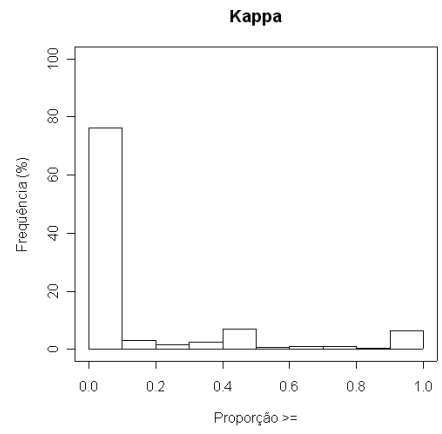

(h) rhs-sup-0-tax07-3N

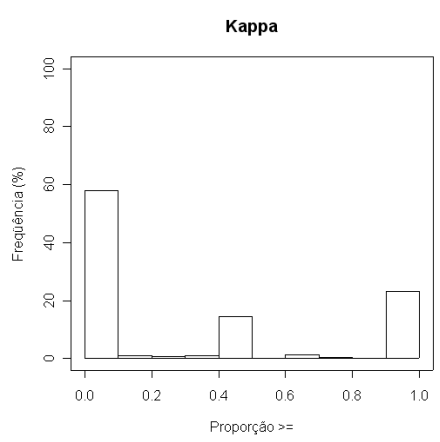

(k) rhs-sup-0-tax07-ND

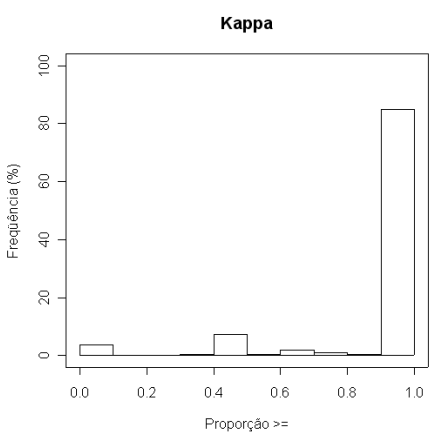

(c) lrhs-sup-0-tax07-1N

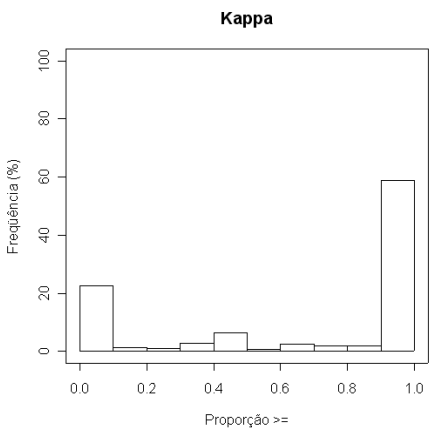

(f) lrhs-sup-0-tax05-2N

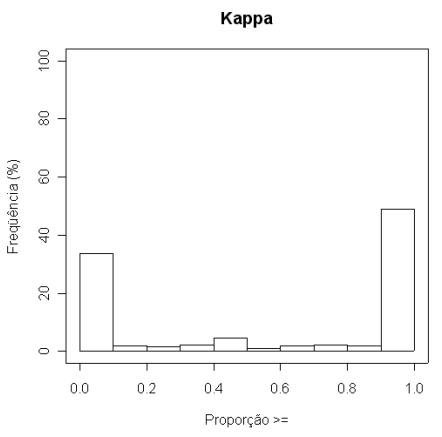

(i) lrhs-sup-0-tax07-3N

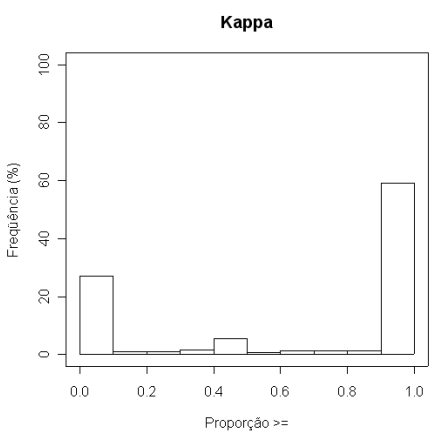

(l) lrhs-sup-0-tax07-ND

Figura H.11: Histogramas referentes a medida Kappa. 


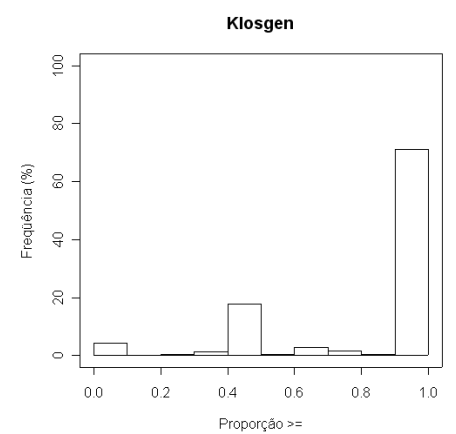

(a) lhs-sup-0-tax07-1N

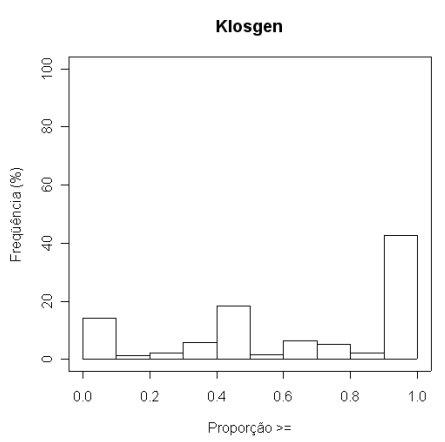

(d) lhs-sup-0-tax05-2N

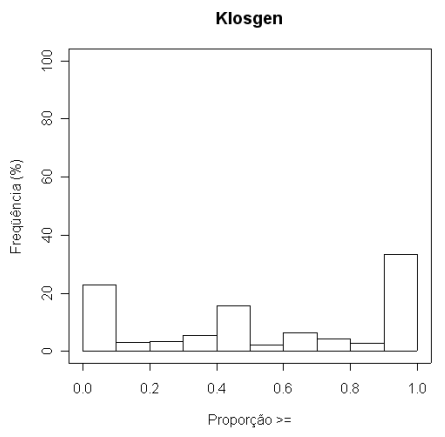

(g) lhs-sup-0-tax07-3N

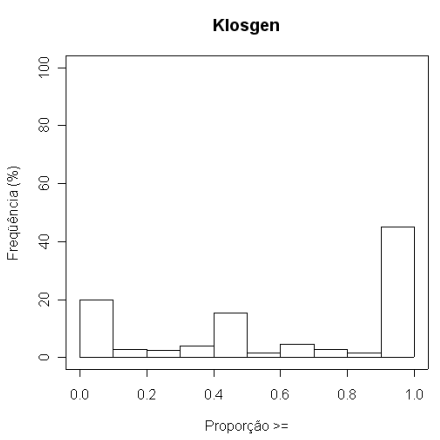

(j) lhs-sup-0-tax07-ND

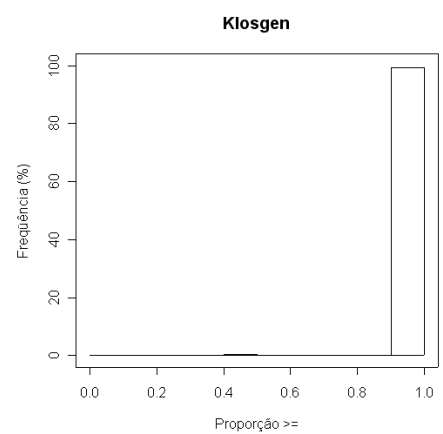

(b) rhs-sup-0-tax $07-1 \mathrm{~N}$

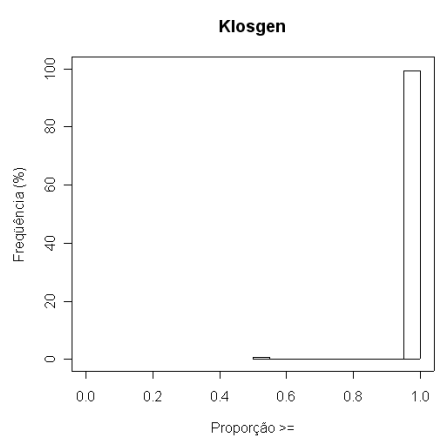

(e) rhs-sup-0-tax05- $2 \mathrm{~N}$

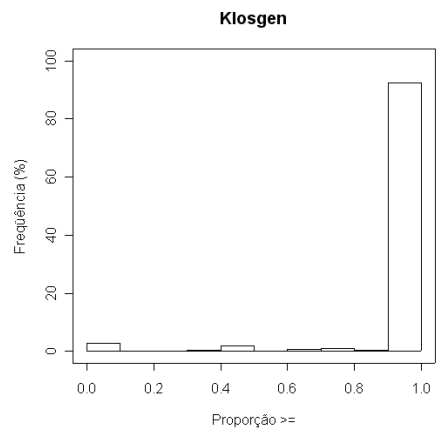

(h) rhs-sup-0-tax07-3N

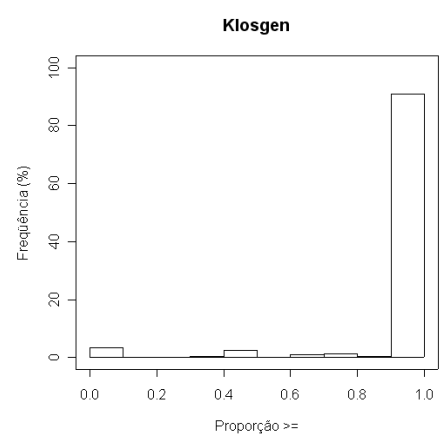

(k) rhs-sup-0-tax07-ND

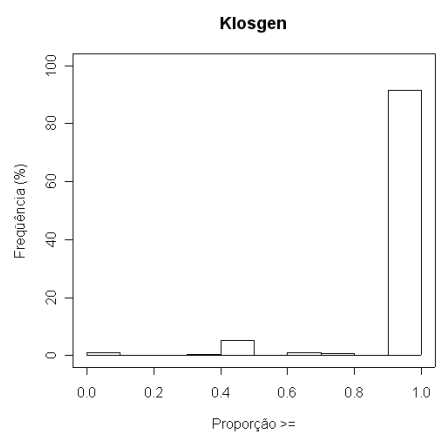

(c) lrhs-sup-0-tax $07-1 \mathrm{~N}$

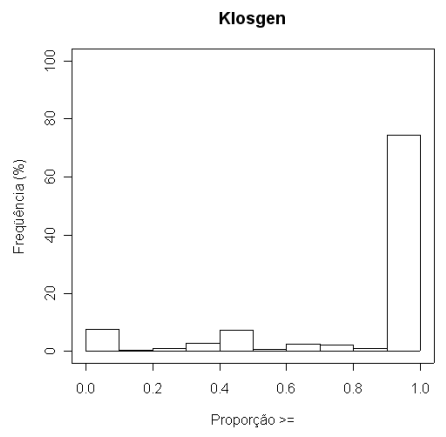

(f) lrhs-sup-0-tax05-2N

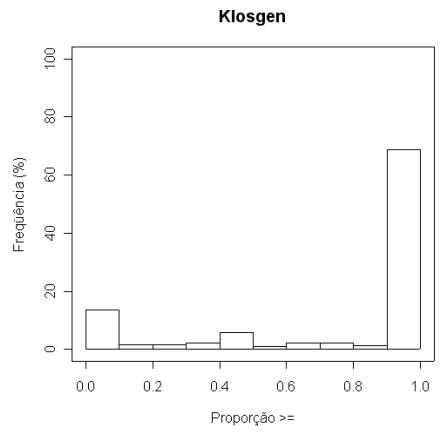

(i) lrhs-sup-0-tax07-3N

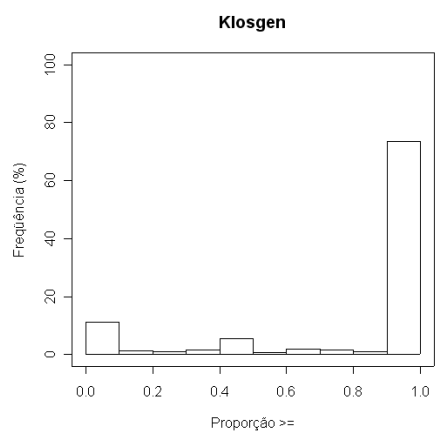

(l) lrhs-sup-0-tax07-ND

Figura H.12: Histogramas referentes a medida Klosgen. 


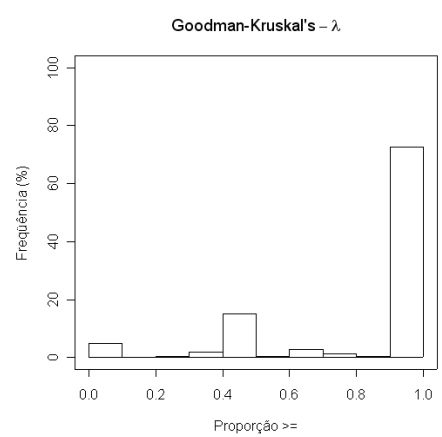

(a) lhs-sup-0-tax07-1N

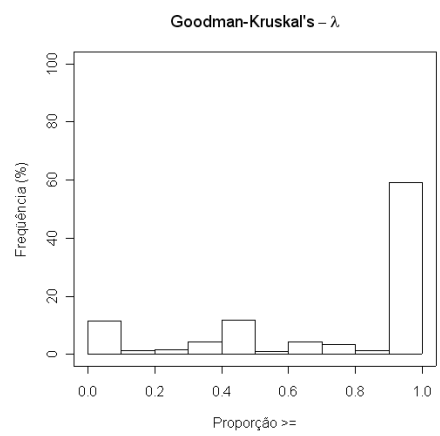

(d) lhs-sup-0-tax05-2N

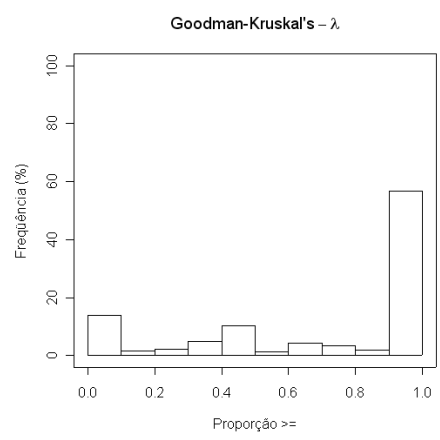

(g) lhs-sup-0-tax07-3N

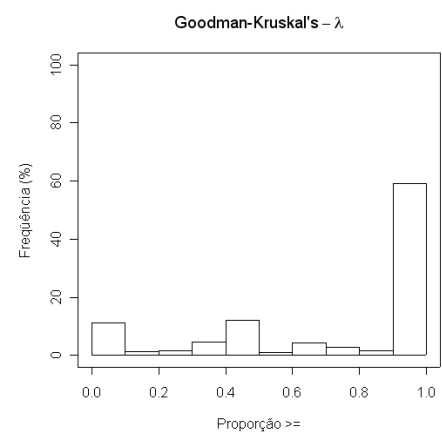

(j) lhs-sup-0-tax07-ND

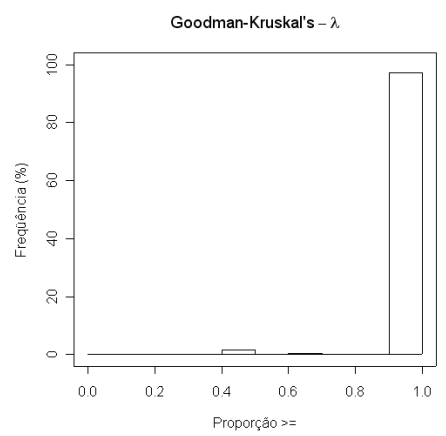

(b) rhs-sup-0-tax $07-1 \mathrm{~N}$

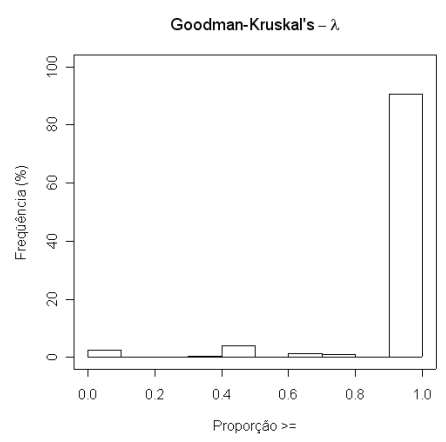

(e) rhs-sup-0-tax $05-2 \mathrm{~N}$

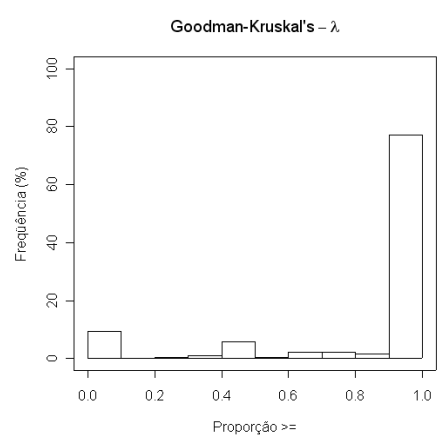

(h) rhs-sup-0-tax07-3N

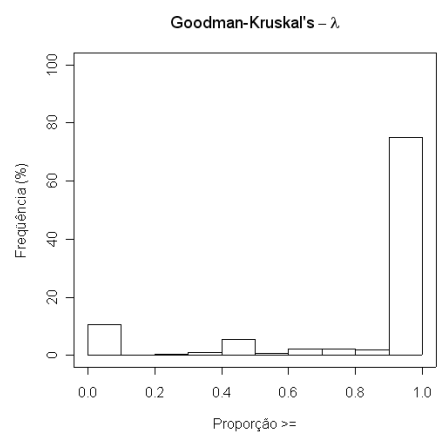

(k) rhs-sup-0-tax07-ND

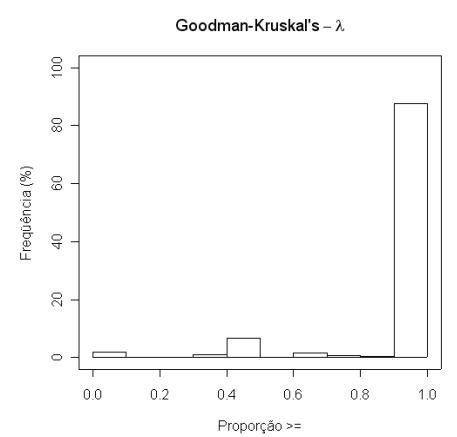

(c) lrhs-sup-0-tax $07-1 \mathrm{~N}$

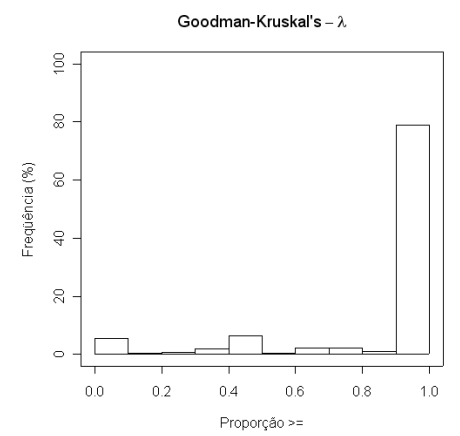

(f) lrhs-sup-0-tax05-2N

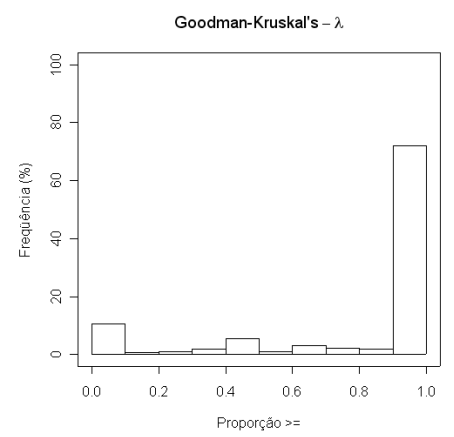

(i) lrhs-sup-0-tax07-3N

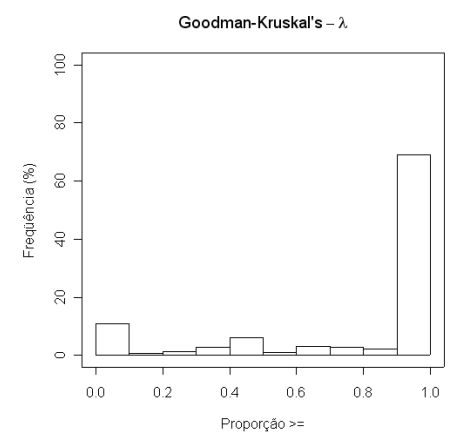

(l) lrhs-sup-0-tax07-ND

Figura H.13: Histogramas referentes a medida Goodman-Kruskal's $(\lambda)$. 


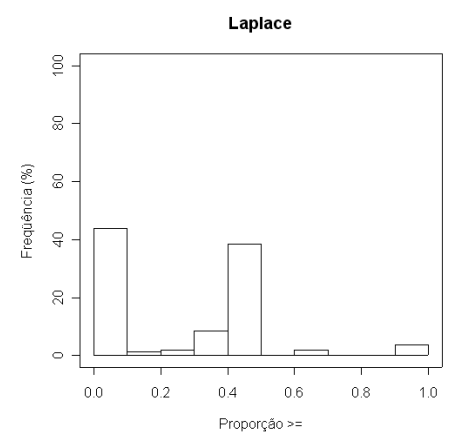

(a) lhs-sup-0-tax $07-1 \mathrm{~N}$

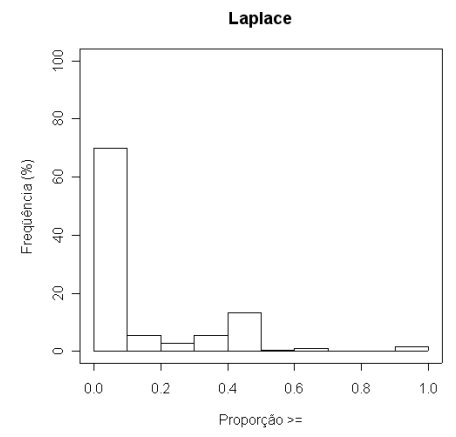

(d) lhs-sup-0-tax05-2N

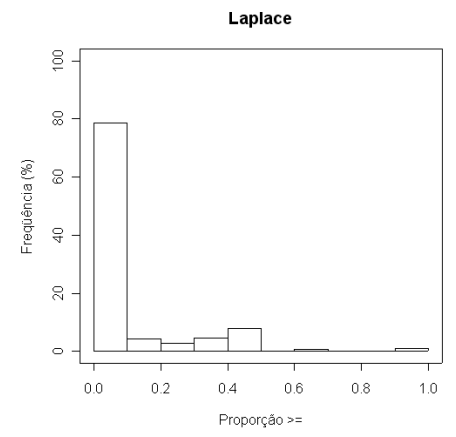

(g) lhs-sup-0-tax07-3N

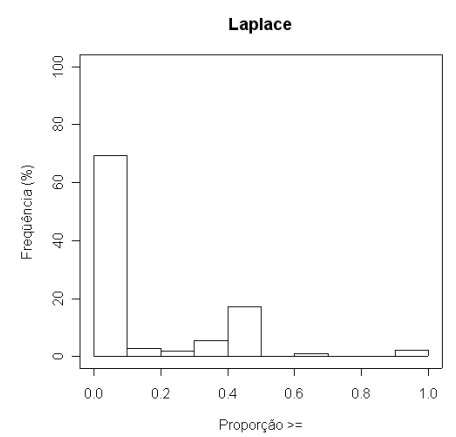

(j) lhs-sup-0-tax07-ND

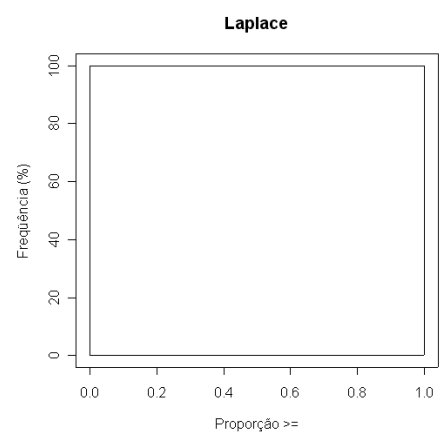

(b) rhs-sup-0-tax $07-1 \mathrm{~N}$

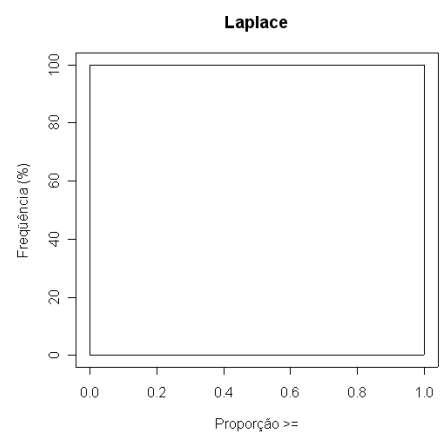

(e) rhs-sup-0-tax05- $2 \mathrm{~N}$

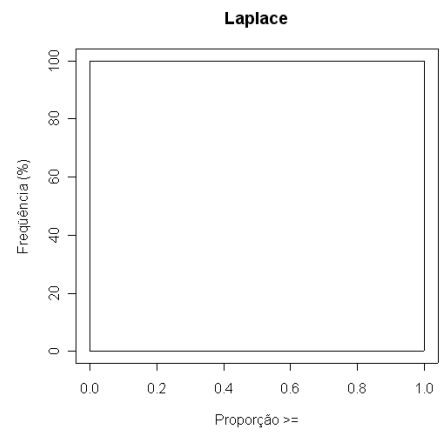

(h) rhs-sup-0-tax07-3N

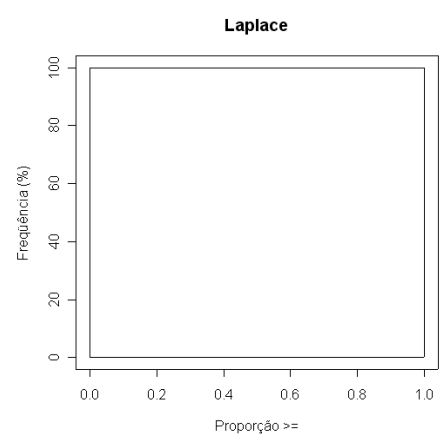

(k) rhs-sup-0-tax07-ND

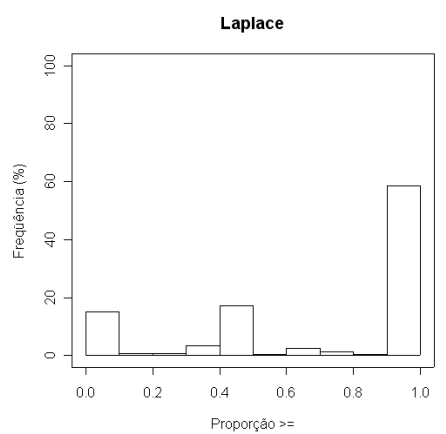

(c) lrhs-sup-0-tax $07-1 \mathrm{~N}$

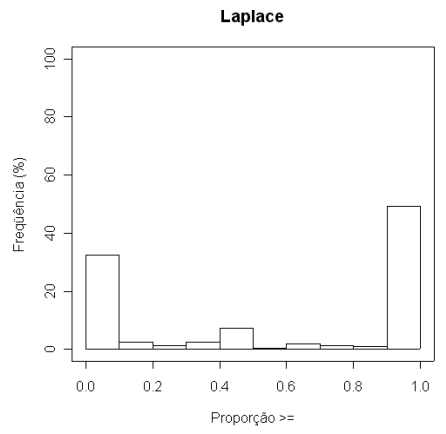

(f) lrhs-sup-0-tax05-2N

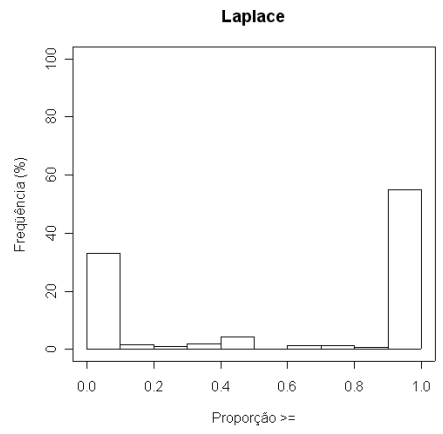

(i) lrhs-sup-0-tax07-3N

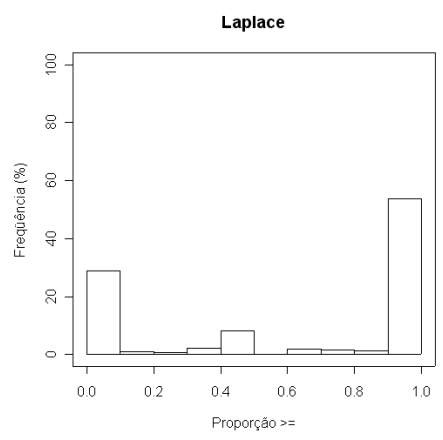

(l) lrhs-sup-0-tax07-ND

Figura H.14: Histogramas referentes a medida Laplace. 


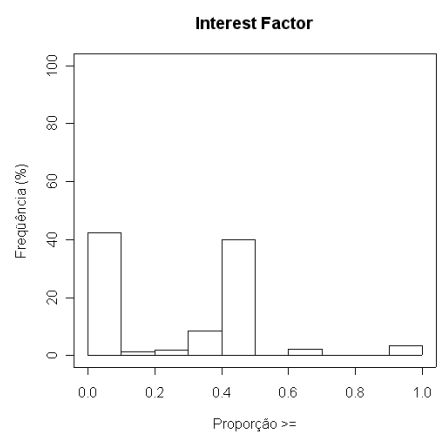

(a) lhs-sup-0-tax $07-1 \mathrm{~N}$

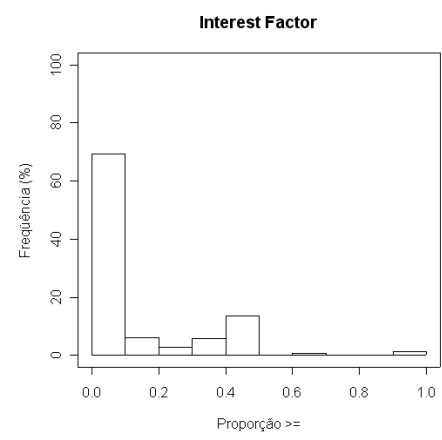

(d) lhs-sup-0-tax05-2N

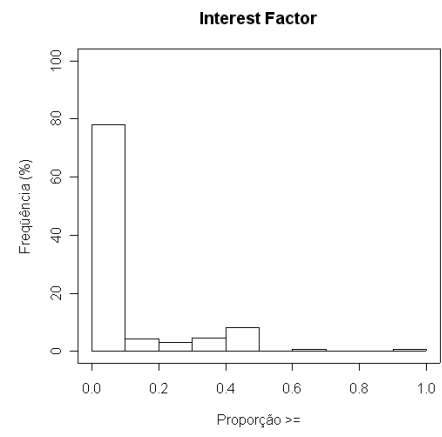

(g) lhs-sup-0-tax07-3N

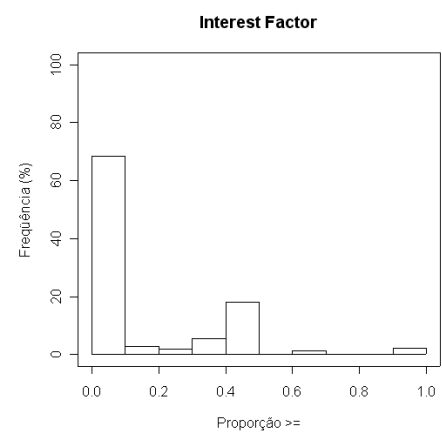

(j) lhs-sup-0-tax07-ND

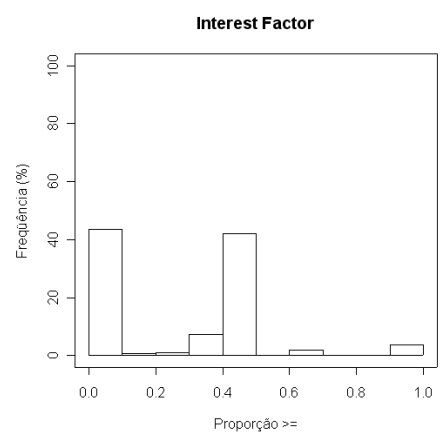

(b) rhs-sup-0-tax07-1N

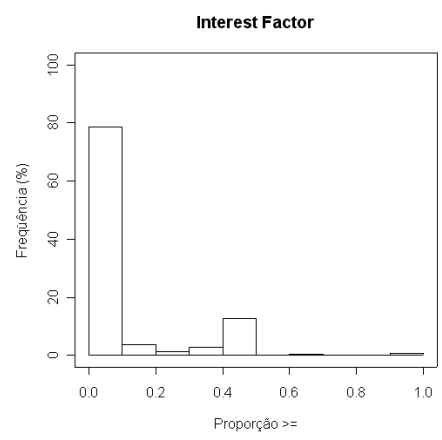

(e) rhs-sup-0-tax05-2N

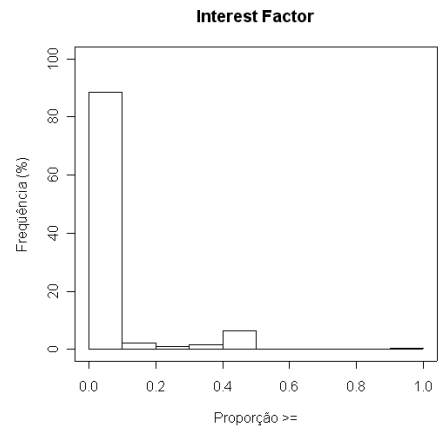

(h) rhs-sup-0-tax07-3N

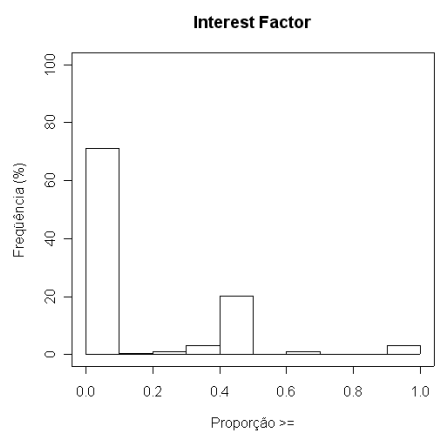

(k) rhs-sup-0-tax07-ND

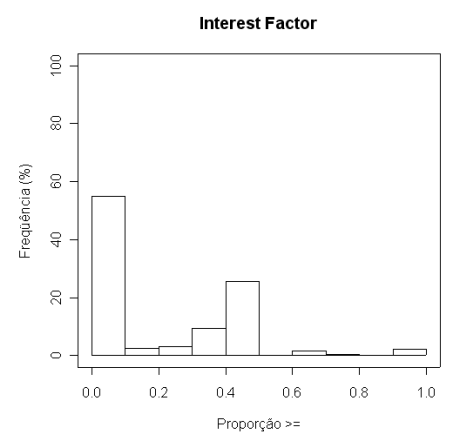

(c) lrhs-sup-0-tax07-1N

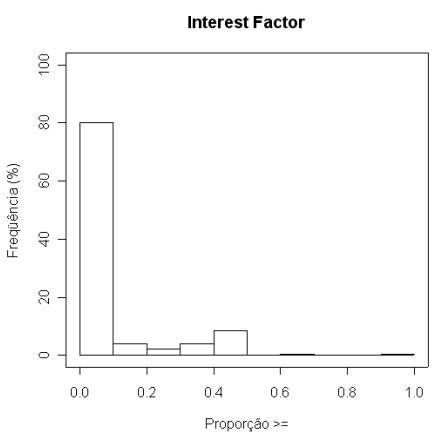

(f) lrhs-sup-0-tax05-2N

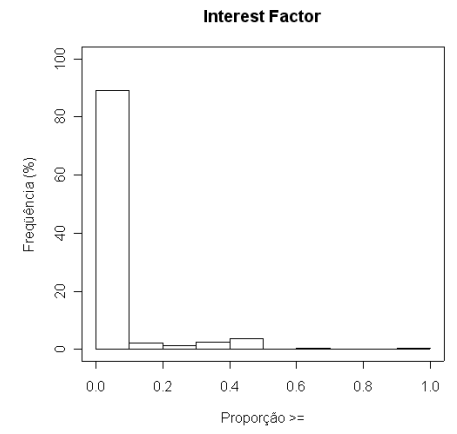

(i) lrhs-sup-0-tax07-3N

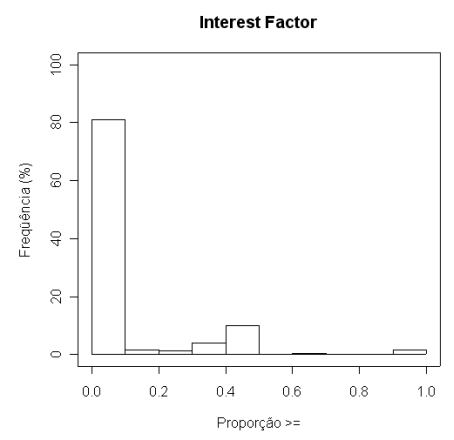

(l) lrhs-sup-0-tax07-ND

Figura H.15: Histogramas referentes a medida Interest Factor. 


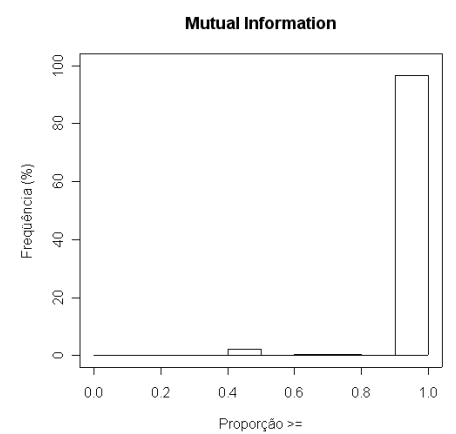

(a) lhs-sup-0-tax07-1N

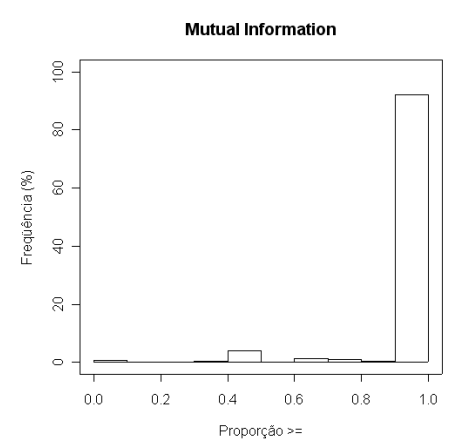

(d) lhs-sup-0-tax05-2N

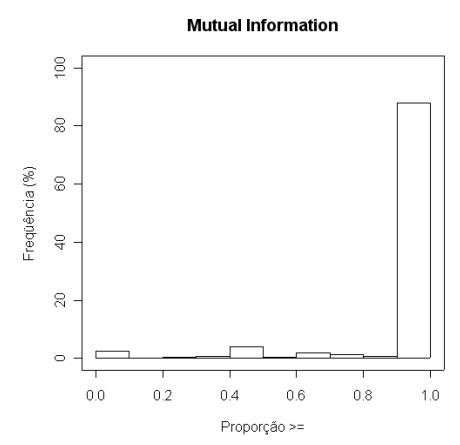

(g) lhs-sup-0-tax07-3N

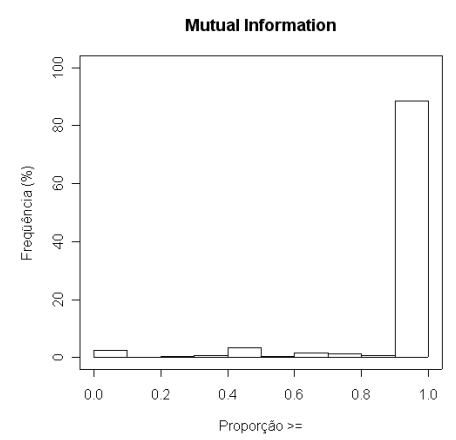

(j) lhs-sup-0-tax07-ND

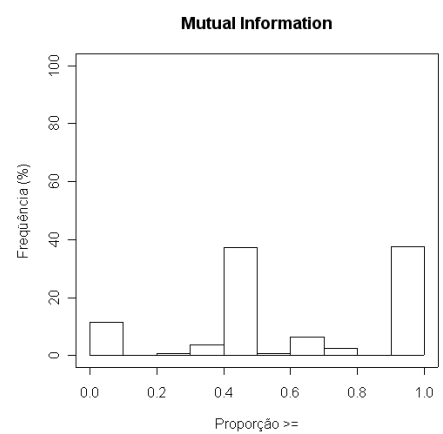

(b) rhs-sup-0-tax07-1N

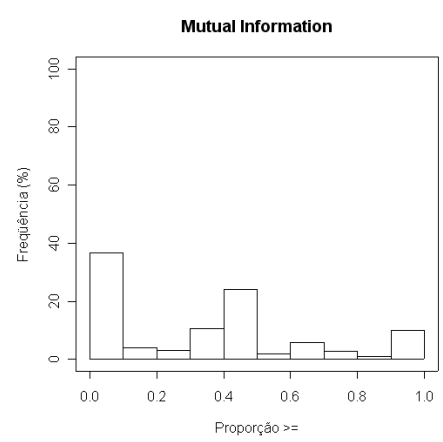

(e) rhs-sup-0-tax05-2N

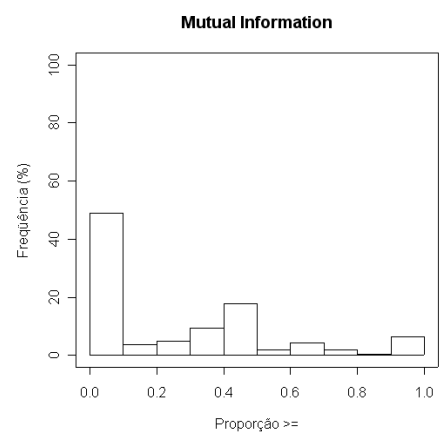

(h) rhs-sup-0-tax07-3N

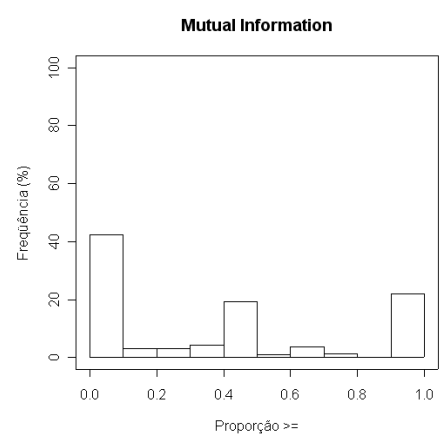

(k) rhs-sup-0-tax07-ND

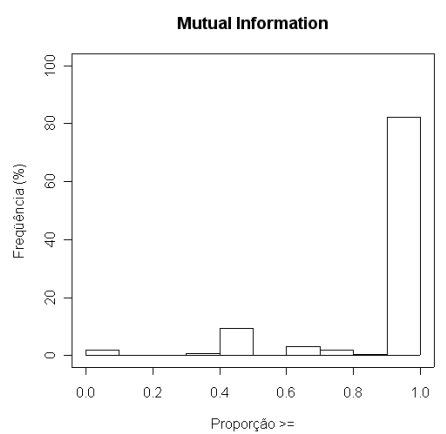

(c) lrhs-sup-0-tax07-1N

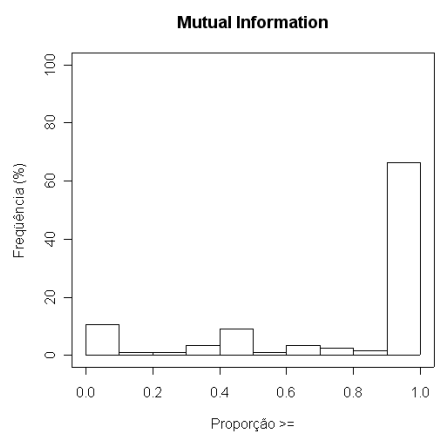

(f) lrhs-sup-0-tax05-2N

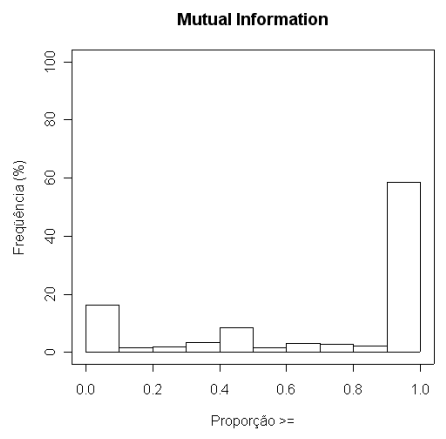

(i) lrhs-sup-0-tax07-3N

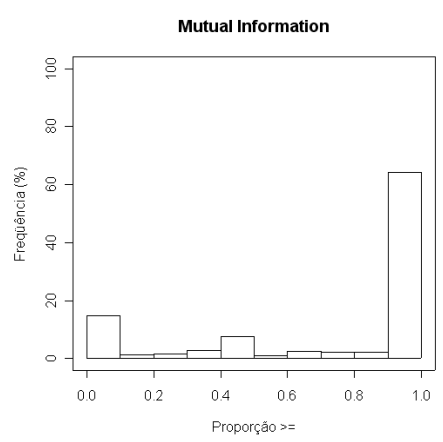

(1) lrhs-sup-0-tax07-ND

Figura H.16: Histogramas referentes a medida Mutual Information. 


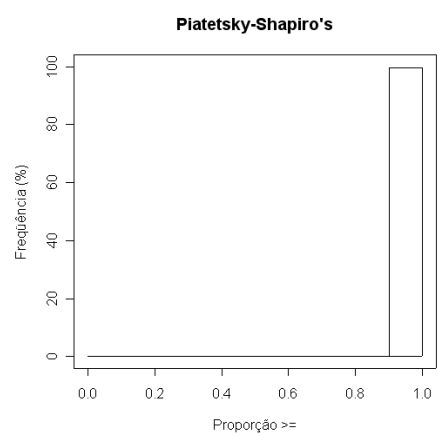

(a) lhs-sup-0-tax07-1N

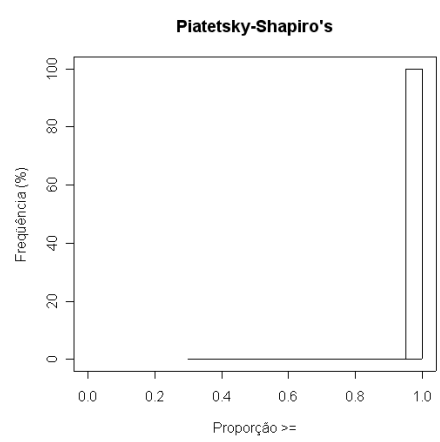

(d) lhs-sup-0-tax05-2N

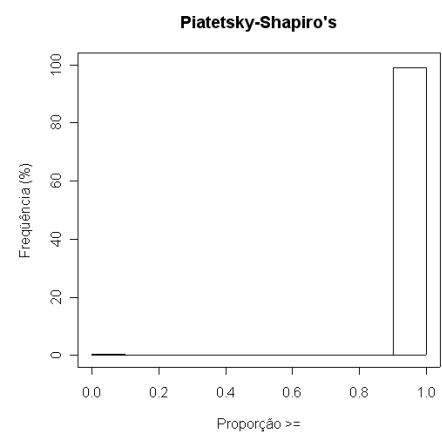

(g) lhs-sup-0-tax07-3N

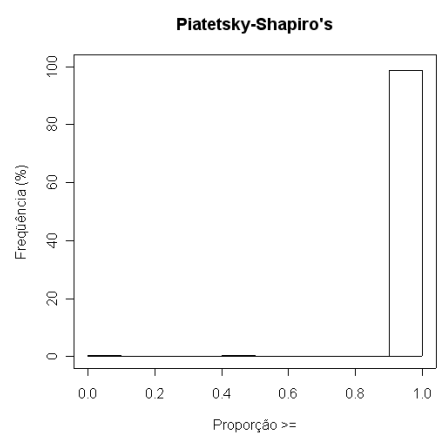

(j) lhs-sup-0-tax07-ND

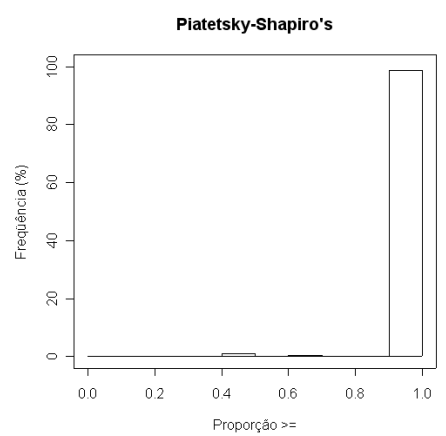

(b) rhs-sup-0-tax $07-1 \mathrm{~N}$

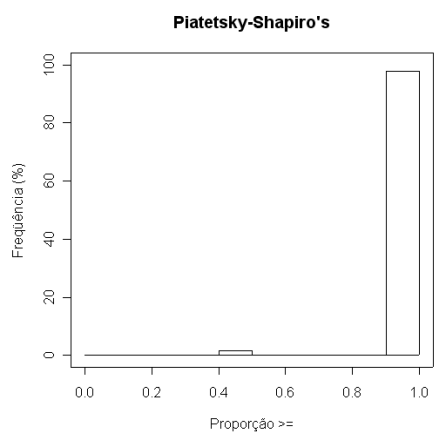

(e) rhs-sup-0-tax05-2N

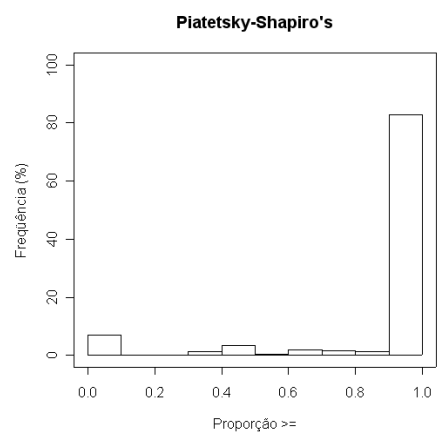

(h) rhs-sup-0-tax07-3N

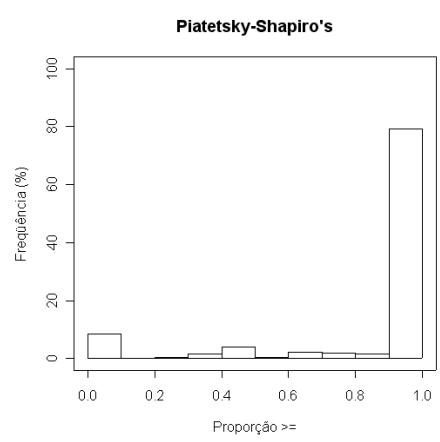

(k) rhs-sup-0-tax07-ND

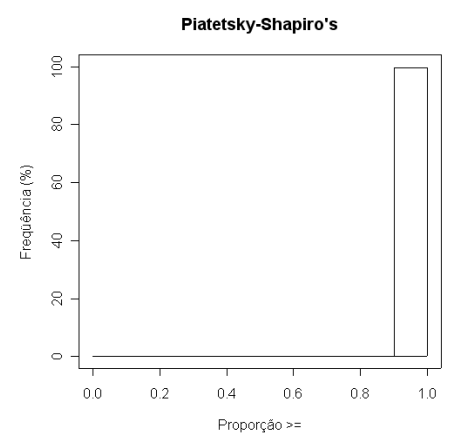

(c) lrhs-sup-0-tax07-1N

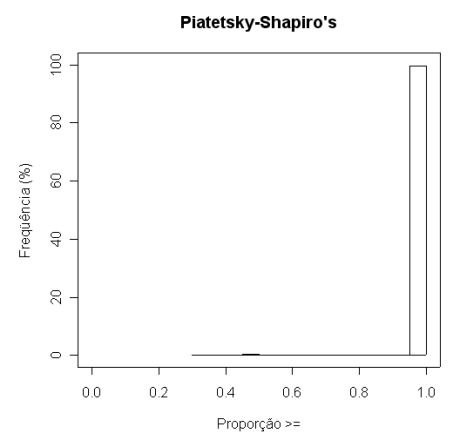

(f) lrhs-sup-0-tax05-2N

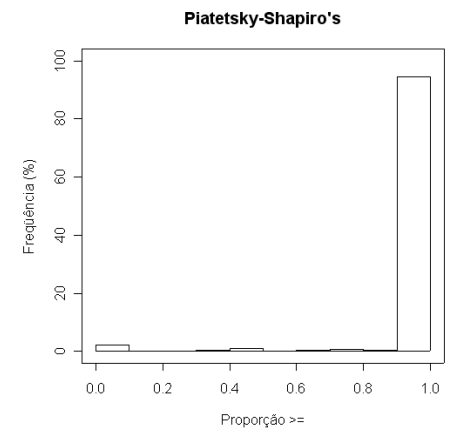

(i) lrhs-sup-0-tax07-3N

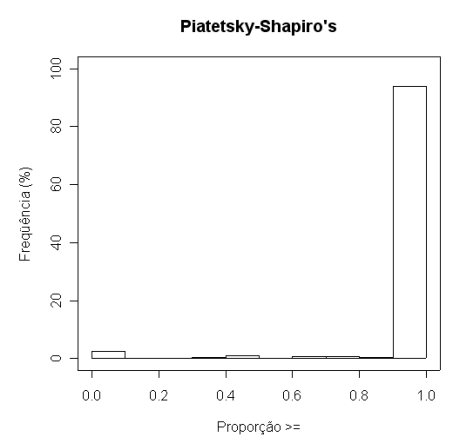

(l) lrhs-sup-0-tax07-ND

Figura H.17: Histogramas referentes a medida Piatetsky-Shapiro's. 


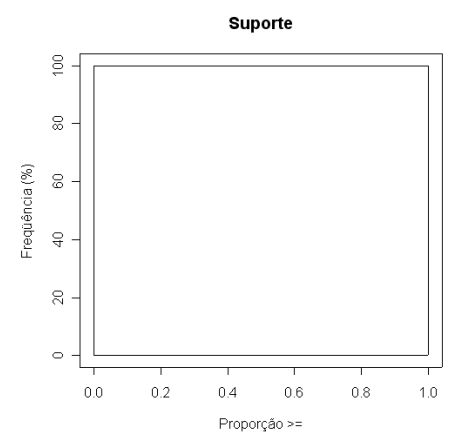

(a) lhs-sup-0-tax $07-1 \mathrm{~N}$

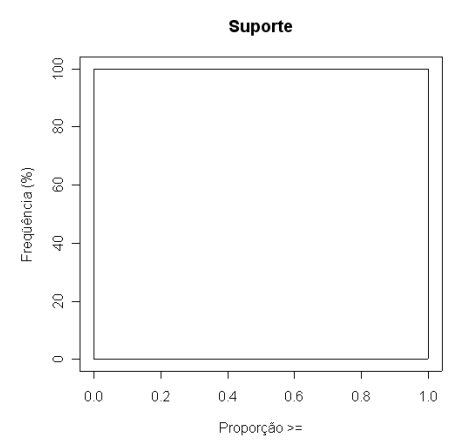

(d) lhs-sup-0-tax05-2N

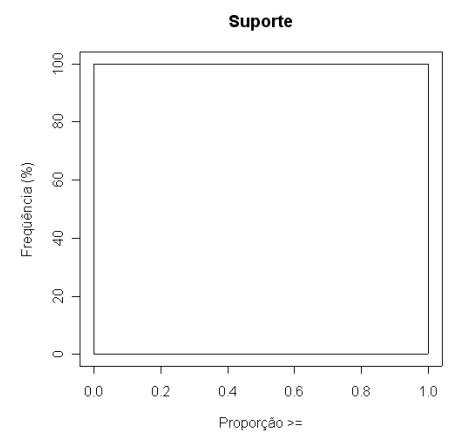

(g) lhs-sup-0-tax07-3N

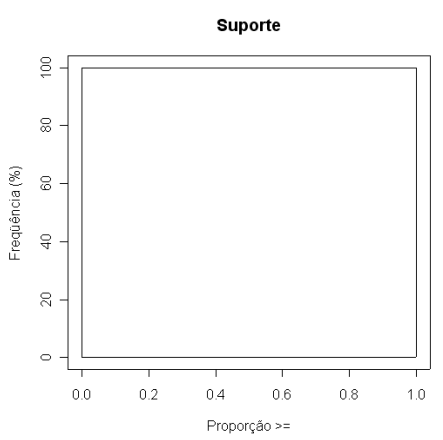

(j) lhs-sup-0-tax07-ND

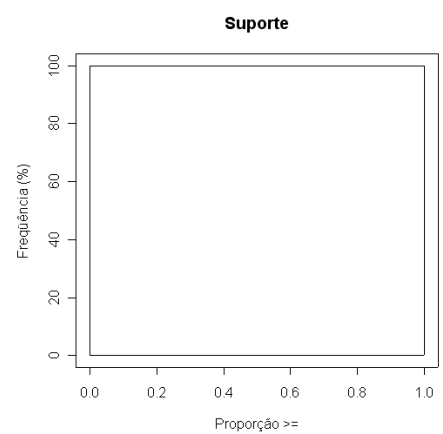

(b) rhs-sup-0-tax $07-1 \mathrm{~N}$

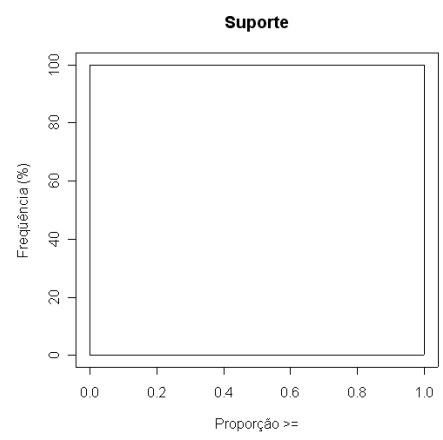

(e) rhs-sup-0-tax05-2N

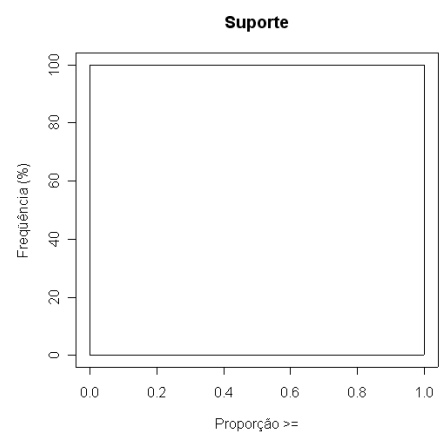

(h) rhs-sup-0-tax07-3N

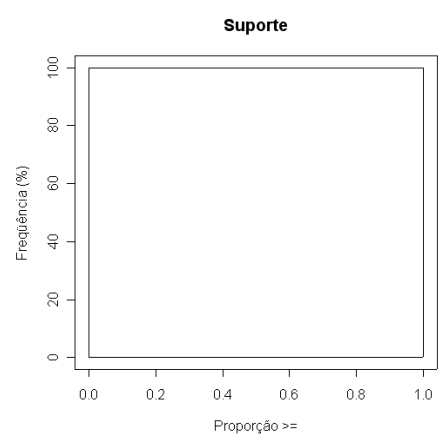

(k) rhs-sup-0-tax07-ND

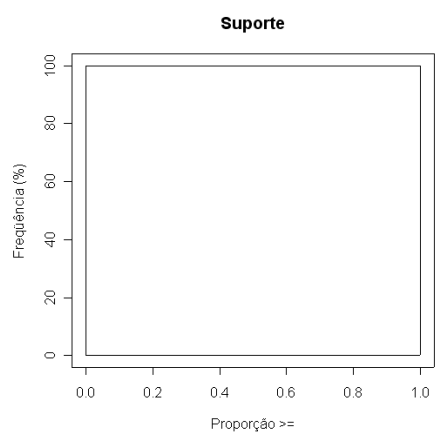

(c) lrhs-sup-0-tax $07-1 \mathrm{~N}$

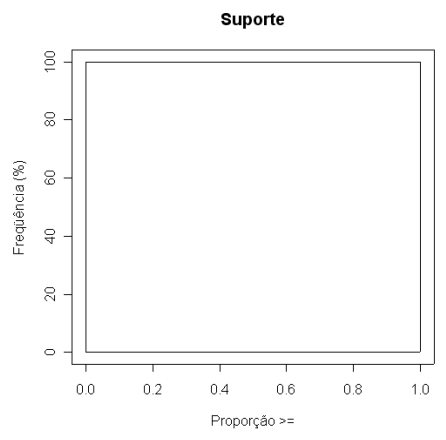

(f) lrhs-sup-0-tax05-2N

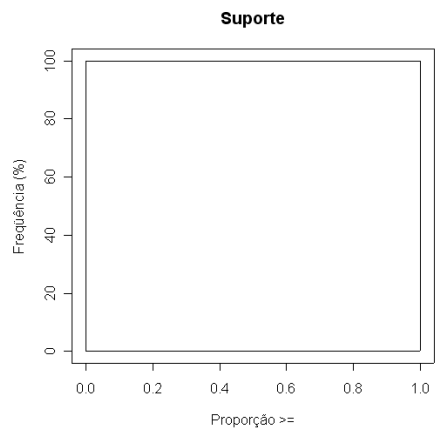

(i) lrhs-sup-0-tax07-3N

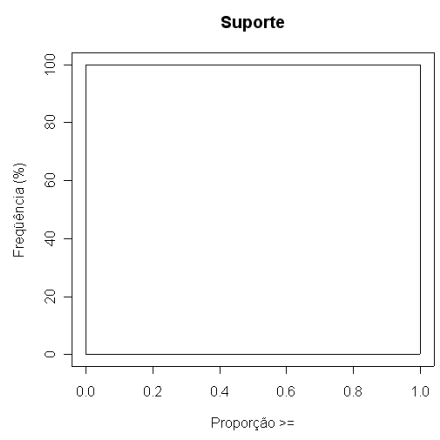

(l) lrhs-sup-0-tax07-ND

Figura H.18: Histogramas referentes a medida Suporte. 


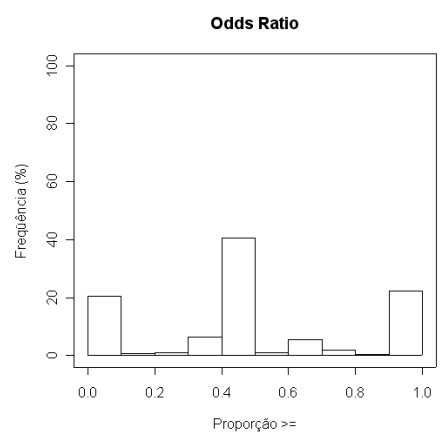

(a) lhs-sup-0-tax $07-1 \mathrm{~N}$

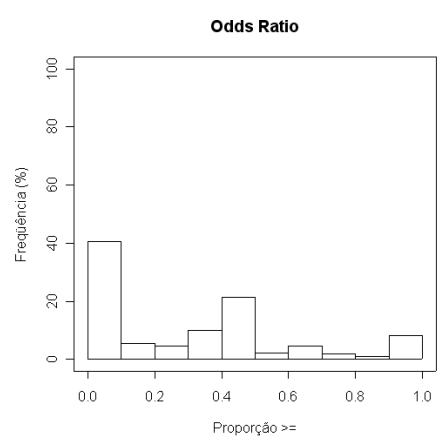

(d) lhs-sup-0-tax05-2N

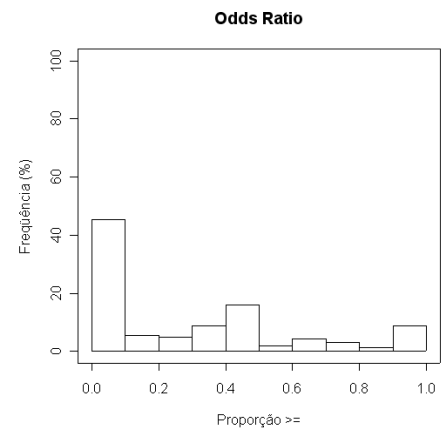

(g) lhs-sup-0-tax07-3N

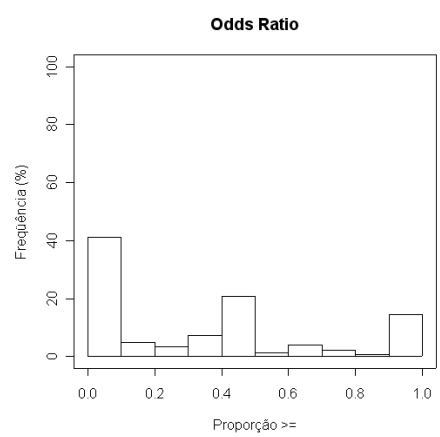

(j) lhs-sup-0-tax07-ND

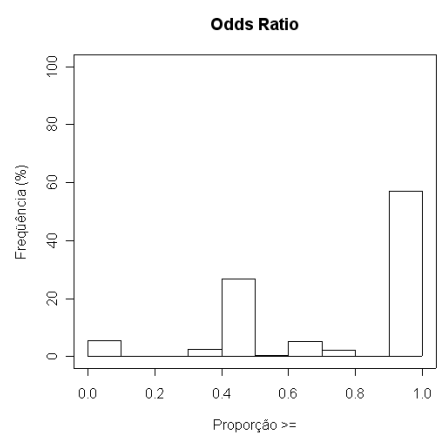

(b) rhs-sup-0-tax07-1N

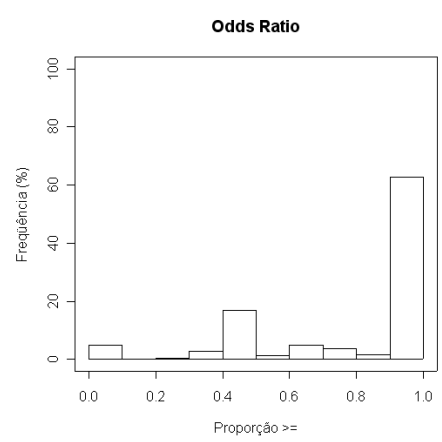

(e) rhs-sup-0-tax05-2N

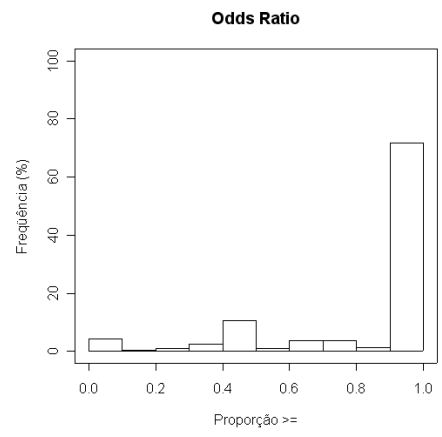

(h) rhs-sup-0-tax07-3N

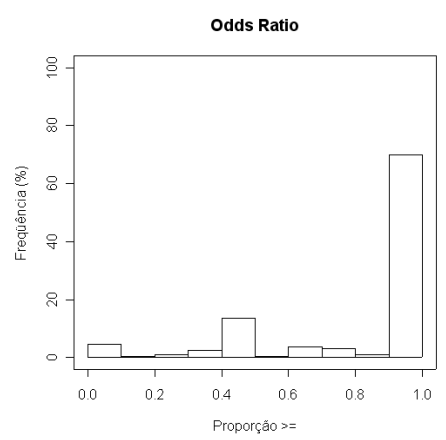

(k) rhs-sup-0-tax07-ND

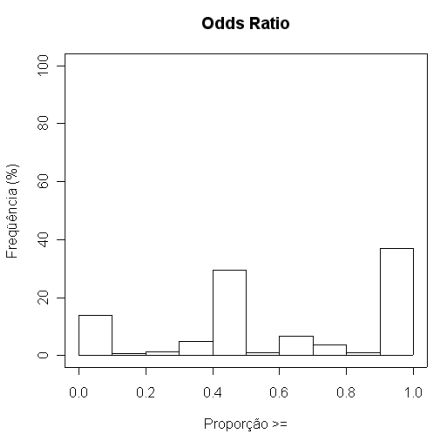

(c) lrhs-sup-0-tax07-1N

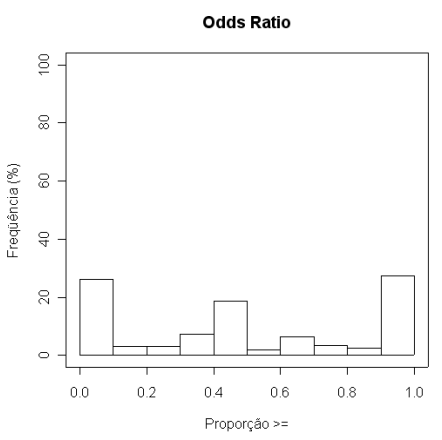

(f) lrhs-sup-0-tax05-2N

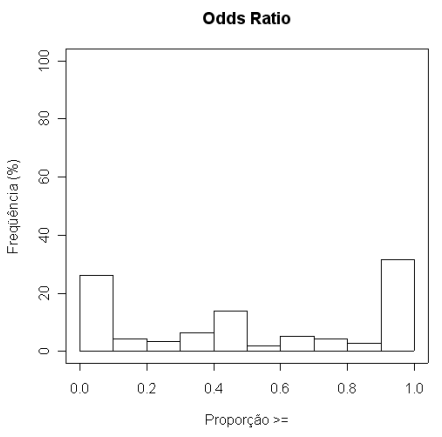

(i) lrhs-sup-0-tax07-3N

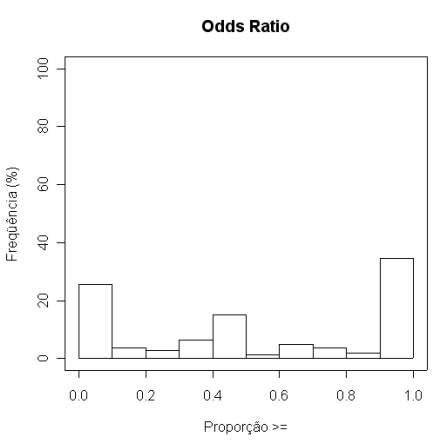

(l) lrhs-sup-0-tax07-ND

Figura H.19: Histogramas referentes a medida Odds Ratio. 


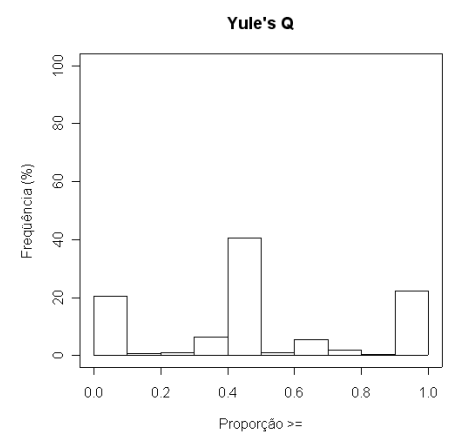

(a) lhs-sup-0-tax $07-1 \mathrm{~N}$

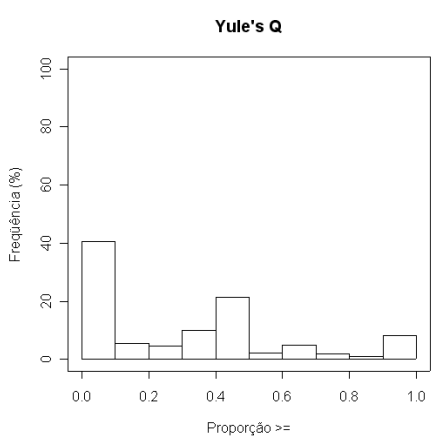

(d) lhs-sup-0-tax05-2N

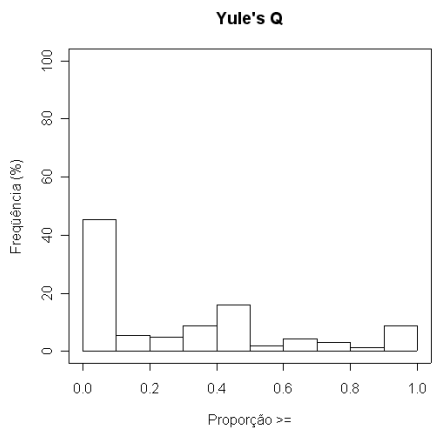

(g) lhs-sup-0-tax07-3N

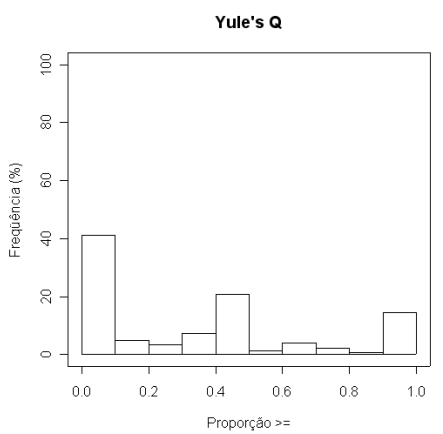

(j) lhs-sup-0-tax07-ND

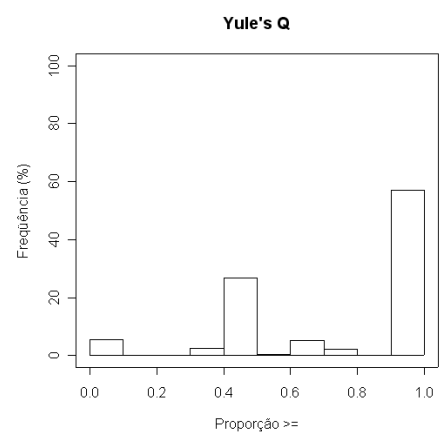

(b) rhs-sup-0-tax07-1N

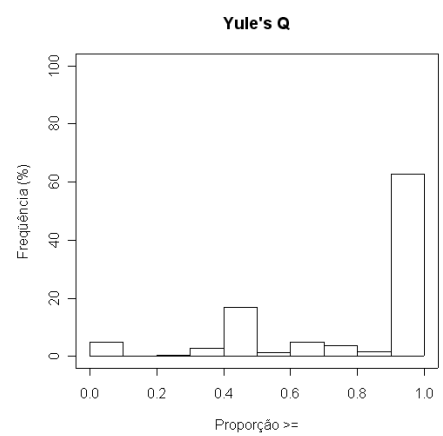

(e) rhs-sup-0-tax05-2N

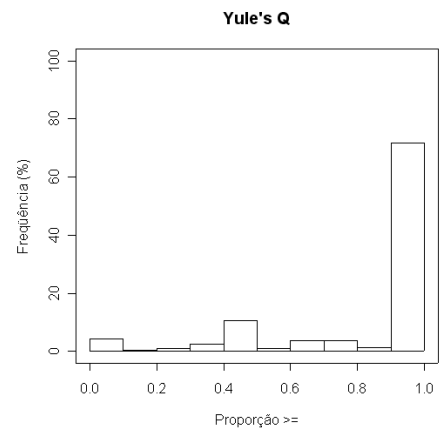

(h) rhs-sup-0-tax07-3N

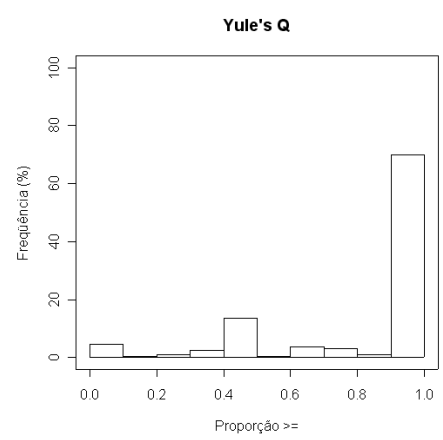

(k) rhs-sup-0-tax07-ND

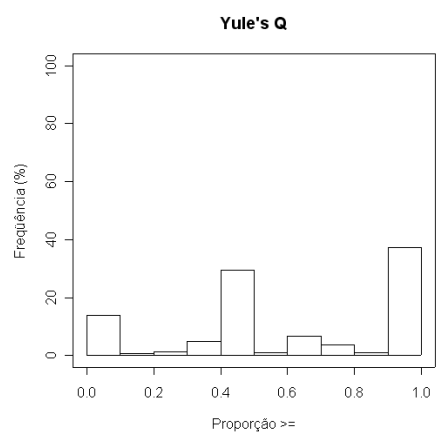

(c) lrhs-sup-0-tax07-1N

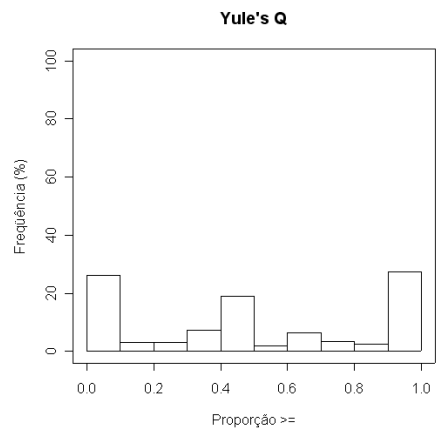

(f) lrhs-sup-0-tax05-2N

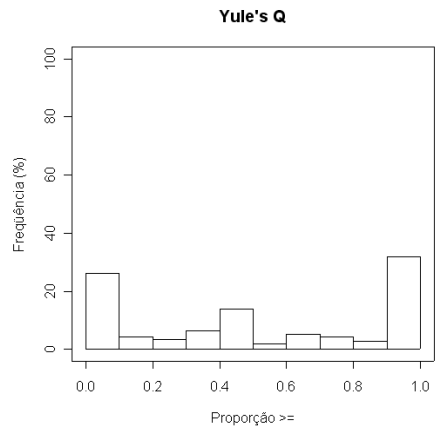

(i) lrhs-sup-0-tax07-3N

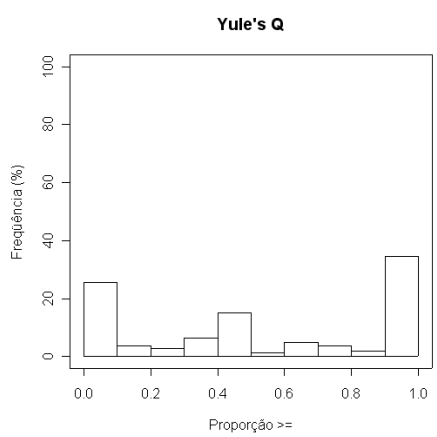

(1) lrhs-sup-0-tax07-ND

Figura H.20: Histogramas referentes a medida Yule's $Q$. 


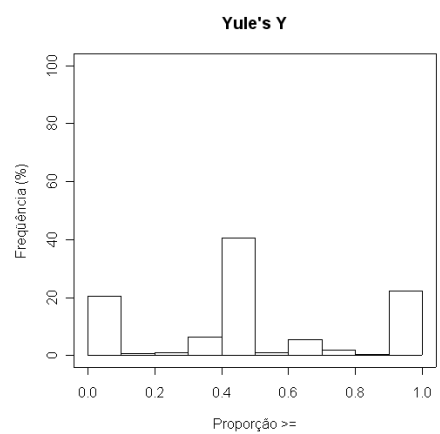

(a) lhs-sup-0-tax $07-1 \mathrm{~N}$

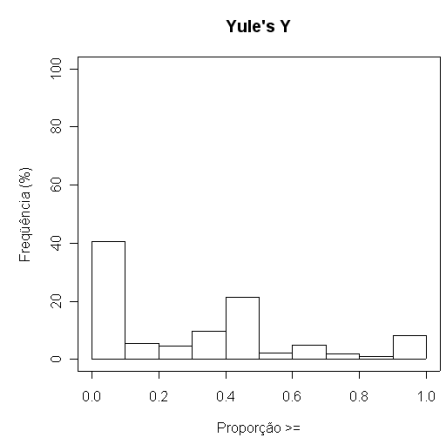

(d) lhs-sup-0-tax05-2N

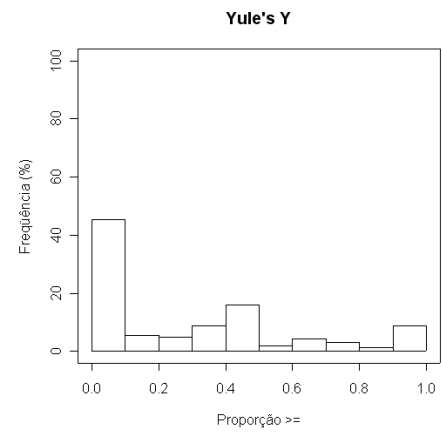

(g) lhs-sup-0-tax07-3N

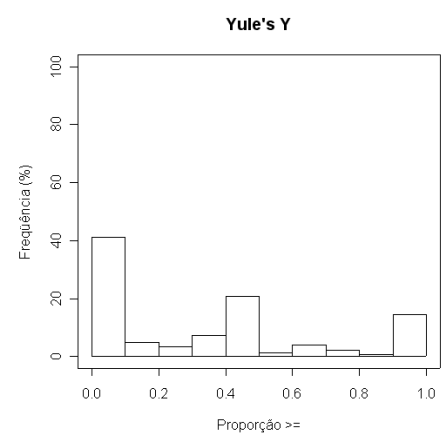

(j) lhs-sup-0-tax07-ND

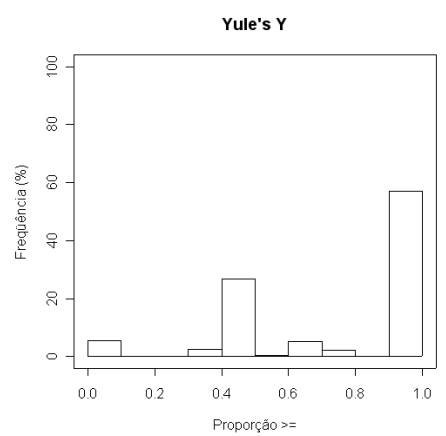

(b) rhs-sup-0-tax07-1N

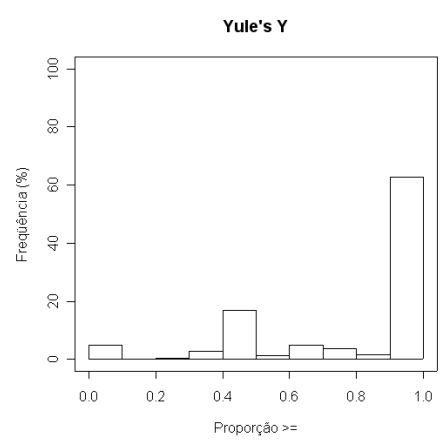

(e) rhs-sup-0-tax05-2N

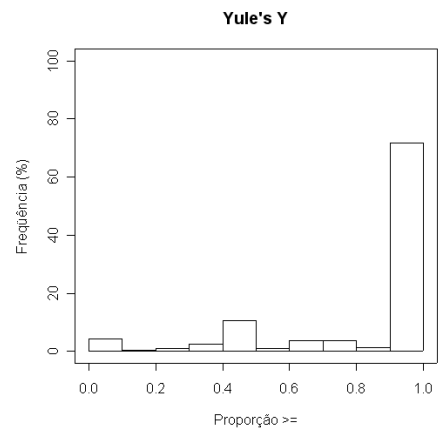

(h) rhs-sup-0-tax07-3N

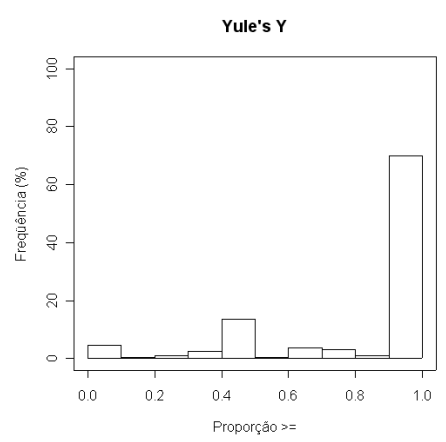

(k) rhs-sup-0-tax07-ND

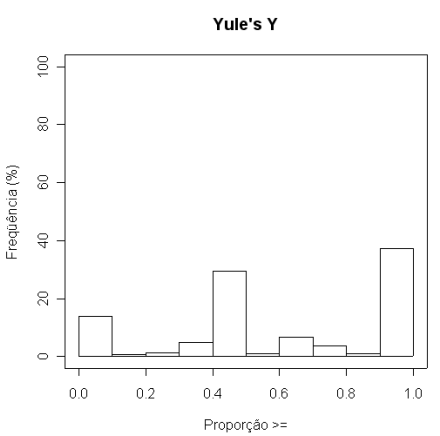

(c) lrhs-sup-0-tax07-1N

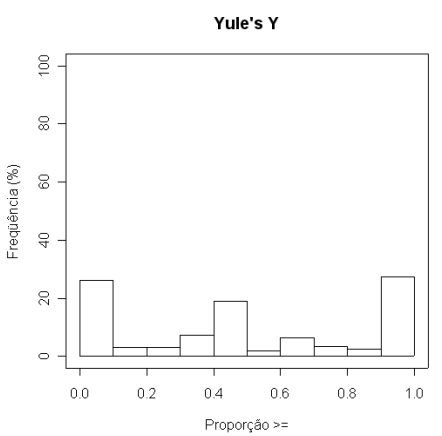

(f) lrhs-sup-0-tax05-2N

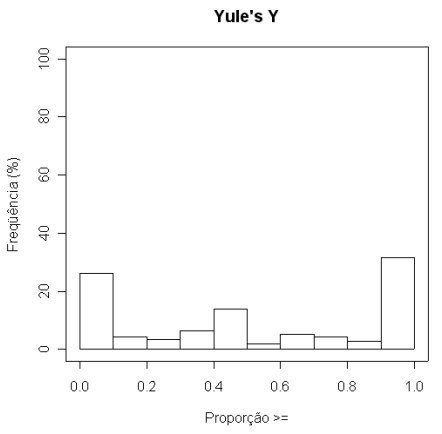

(i) lrhs-sup-0-tax07-3N

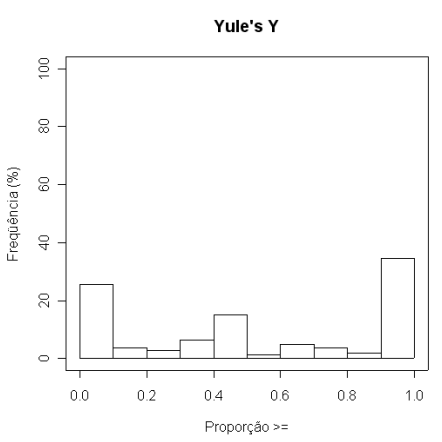

(l) lrhs-sup-0-tax07-ND

Figura H.21: Histogramas referentes a medida Yule's Y. 


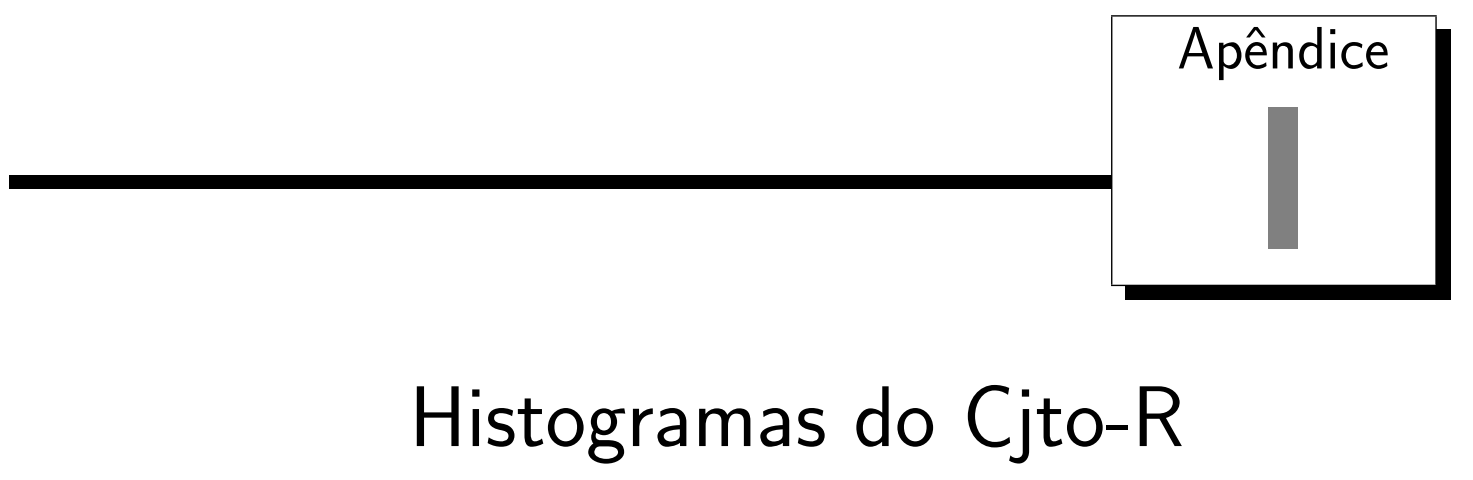

Nesse apêndice são apresentados os histogramas obtidos para cada uma das medidas consideradas na Seção 5.2 (página 92) utilizando cada um dos conjuntos selecionados e apresentados na Tabela 5.2 (página 95) referentes ao Cjto-R. Os eixos $x$ dos histogramas representam os intervalos (classes) que variam, nesse caso, de $0.0(0 \%)$ a $1.0(100 \%)$. Esses intervalos indicam a proporção de vezes que uma regra generalizada contém valores maiores ou iguais aos das suas regras específicas. Os eixos y dos histogramas representam a porcentagem de regras generalizadas pertencentes a um determinado intervalo. 


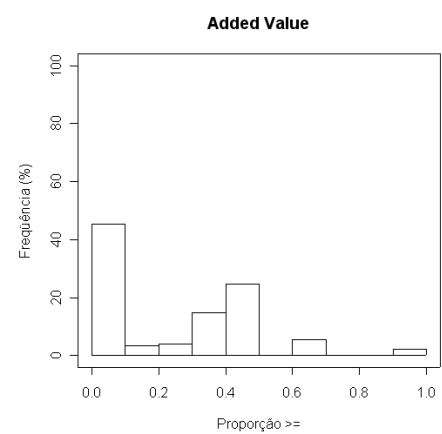

(a) lhs-sup-0-tax $01-1 \mathrm{~N}$

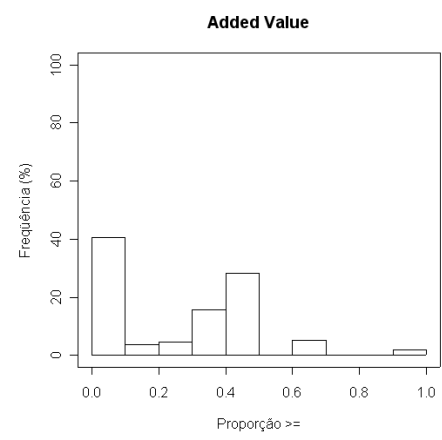

(d) lhs-sup-0-tax01-2N

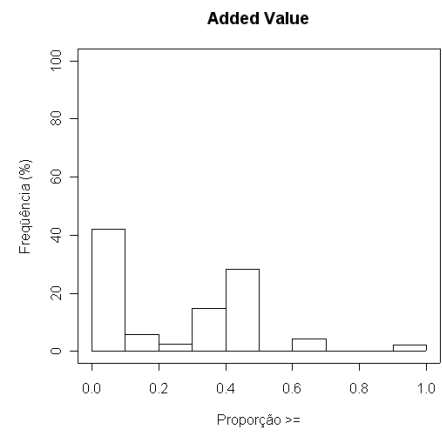

(g) lhs-sup-0-tax01-3N

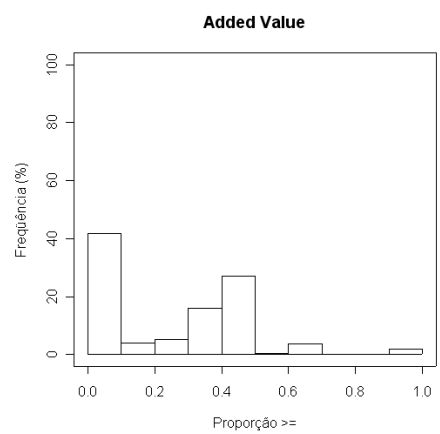

(j) lhs-sup-0-tax01-ND

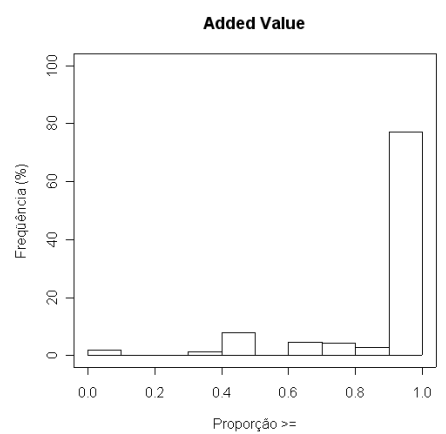

(b) rhs-sup-0-tax01-1N

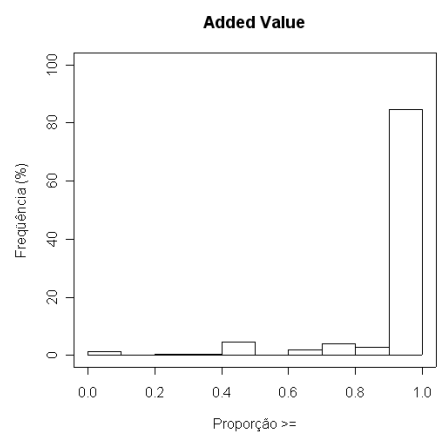

(e) rhs-sup-0-tax01-2N

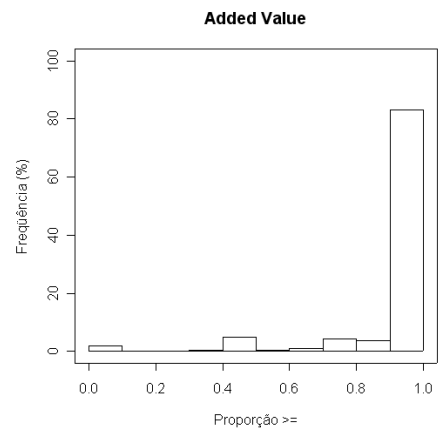

(h) rhs-sup-0-tax01-3N

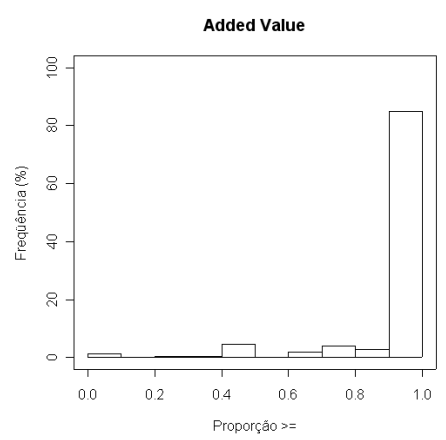

(k) rhs-sup-0-tax01-ND

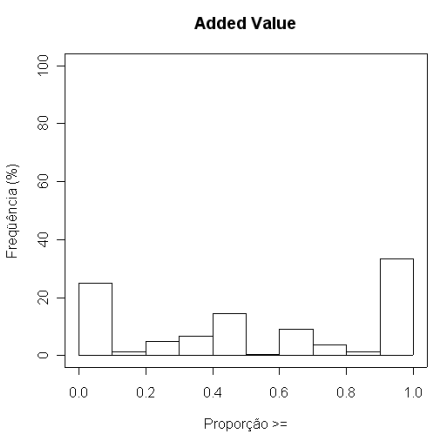

(c) lrhs-sup-0-tax01-1N

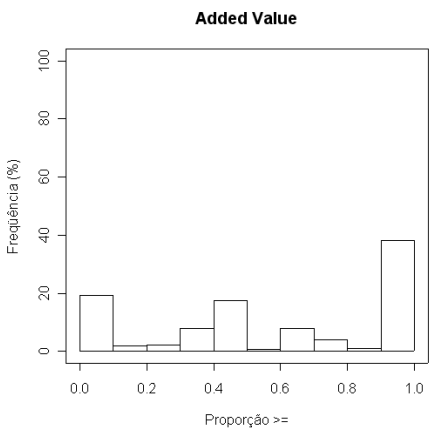

(f) lrhs-sup-0-tax01-2N

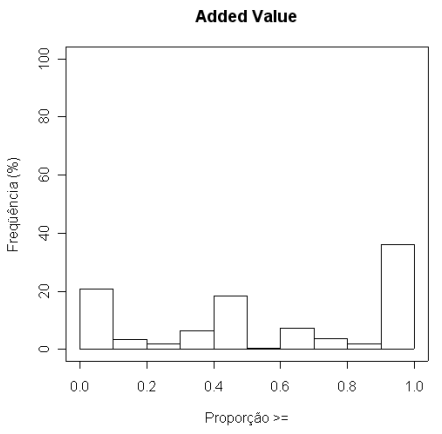

(i) lrhs-sup-0-tax01-3N

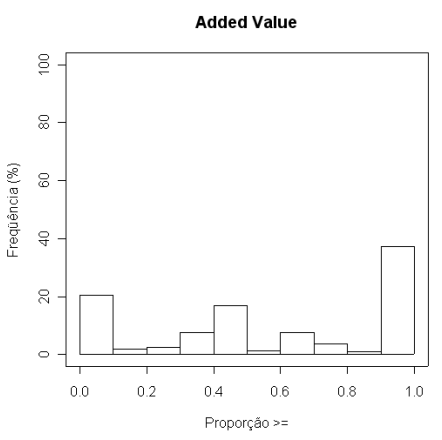

(l) lrhs-sup-0-tax01-ND

Figura I.1: Histogramas referentes a medida Added Value. 


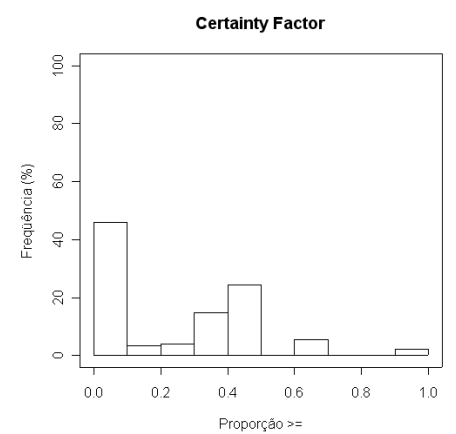

(a) lhs-sup-0-tax01-1N

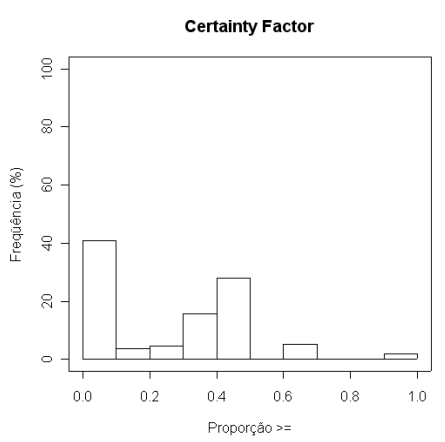

(d) lhs-sup-0-tax01-2N

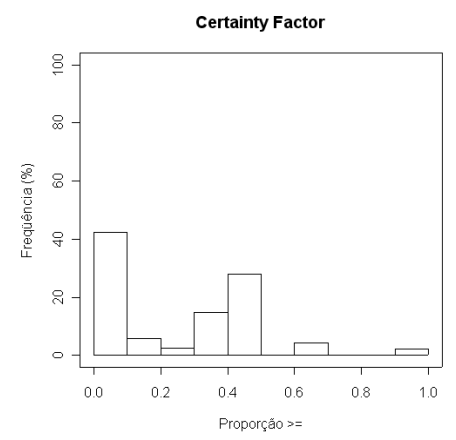

(g) lhs-sup-0-tax01-3N

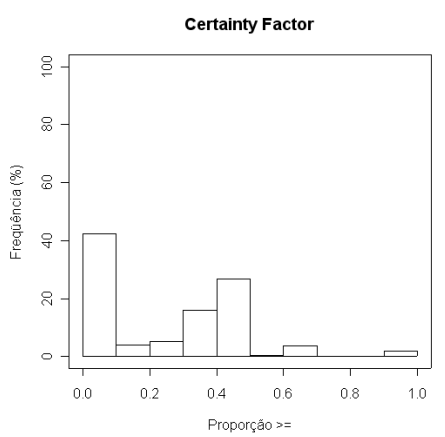

(j) lhs-sup-0-tax01-ND

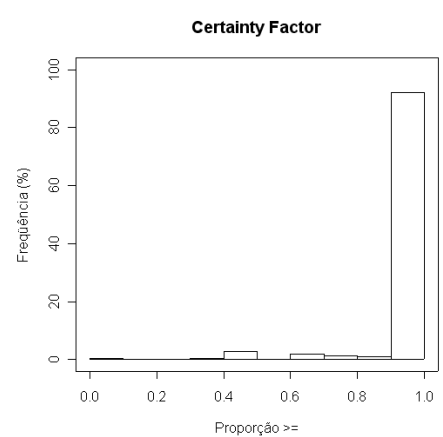

(b) rhs-sup-0-tax $01-1 \mathrm{~N}$

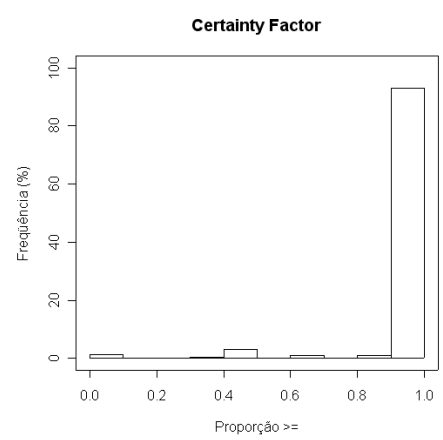

(e) rhs-sup-0-tax01-2N

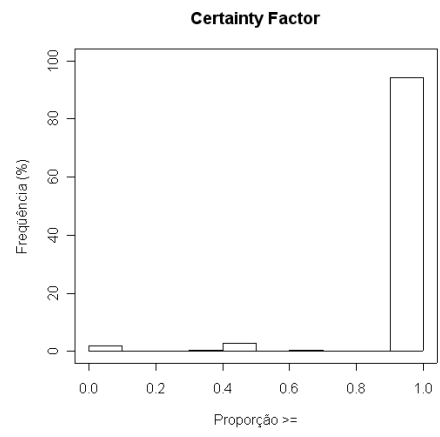

(h) rhs-sup-0-tax01-3N

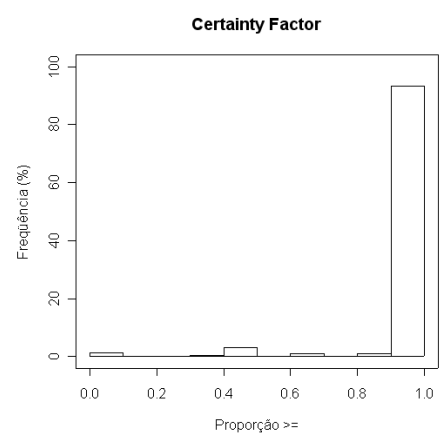

(k) rhs-sup-0-tax01-ND

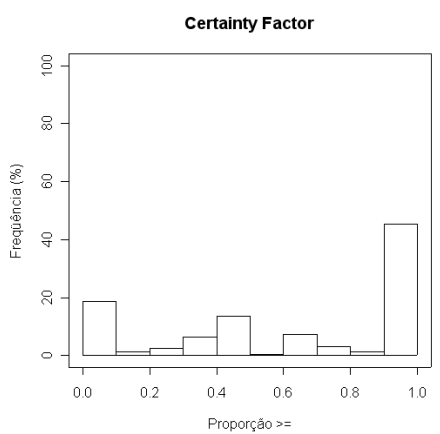

(c) lrhs-sup-0-tax01-1N

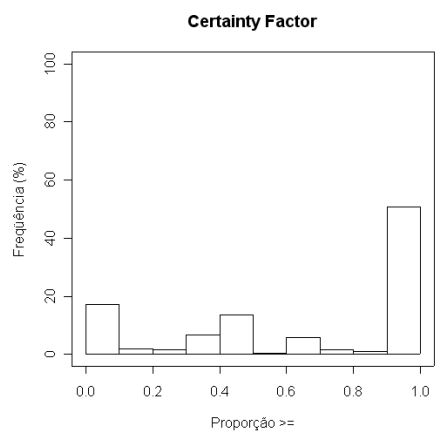

(f) lrhs-sup-0-tax01-2N

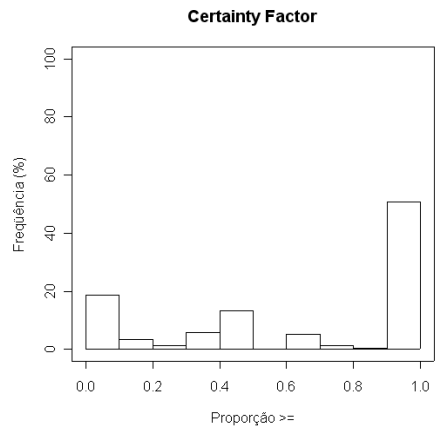

(i) lrhs-sup-0-tax01-3N

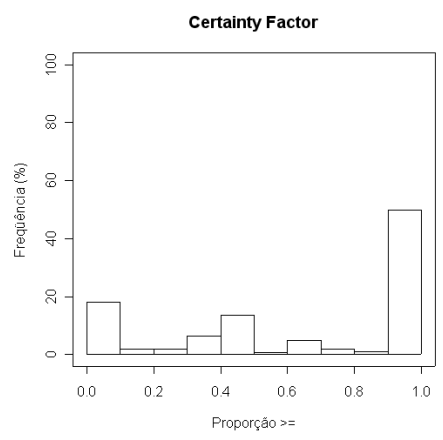

(1) lrhs-sup-0-tax01-ND

Figura I.2: Histogramas referentes a medida Certainty Factor. 


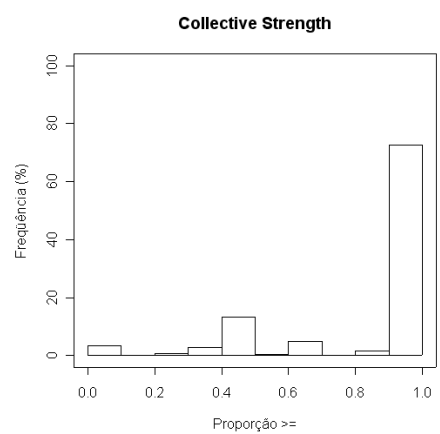

(a) lhs-sup-0-tax01-1N

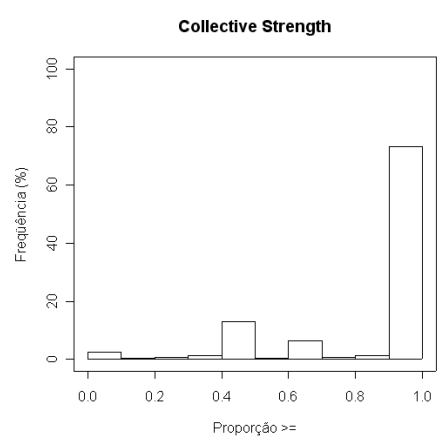

(d) lhs-sup-0-tax01-2N

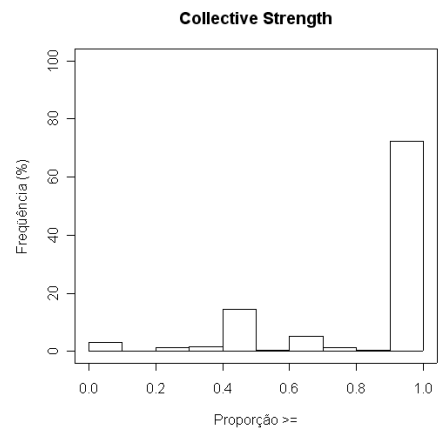

(g) lhs-sup-0-tax01-3N

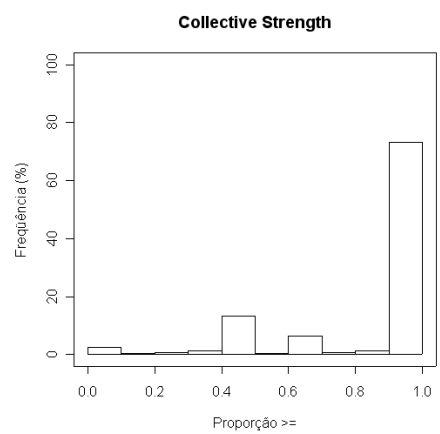

(j) lhs-sup-0-tax01-ND

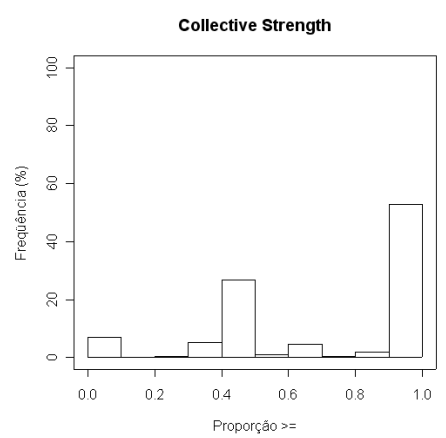

(b) rhs-sup-0-tax01-1N

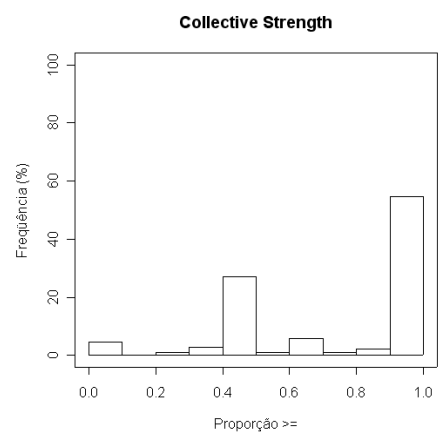

(e) rhs-sup-0-tax01-2N

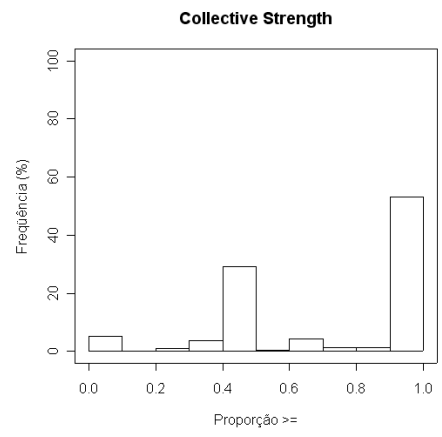

(h) rhs-sup-0-tax01-3N

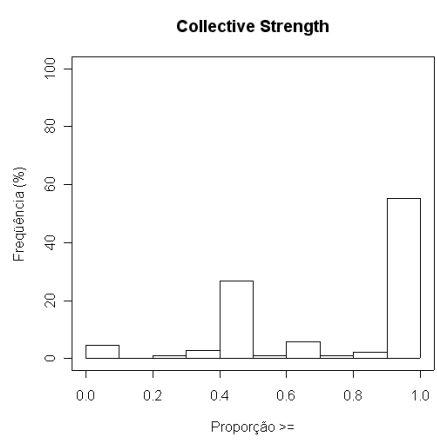

(k) rhs-sup-0-tax01-ND

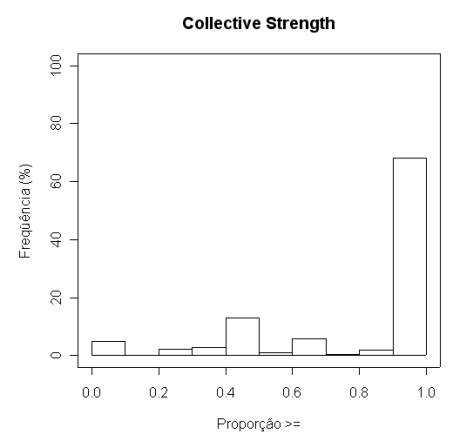

(c) lrhs-sup-0-tax01-1N

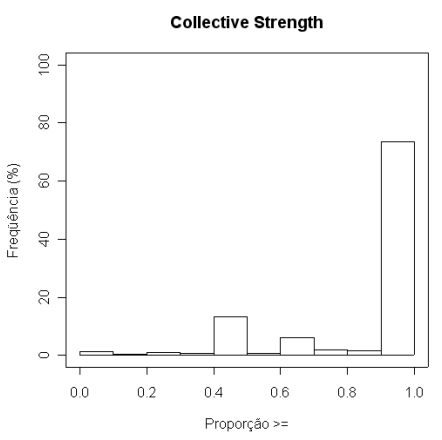

(f) lrhs-sup-0-tax01-2N

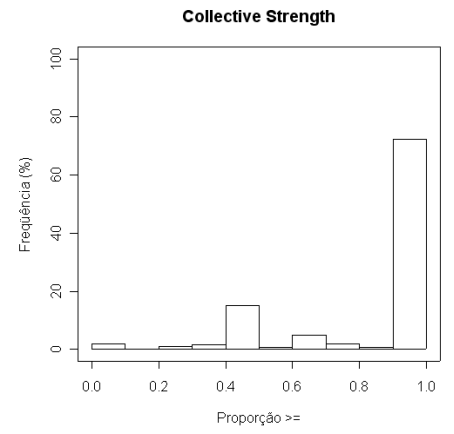

(i) lrhs-sup-0-tax01-3N

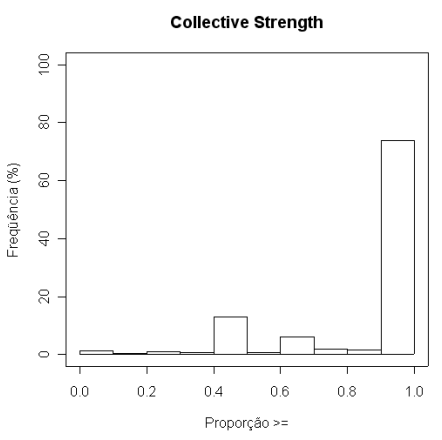

(l) lrhs-sup-0-tax01-ND

Figura I.3: Histogramas referentes a medida Collective Strength. 


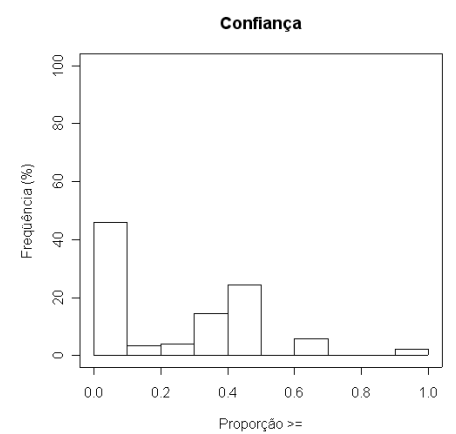

(a) lhs-sup-0-tax01-1N

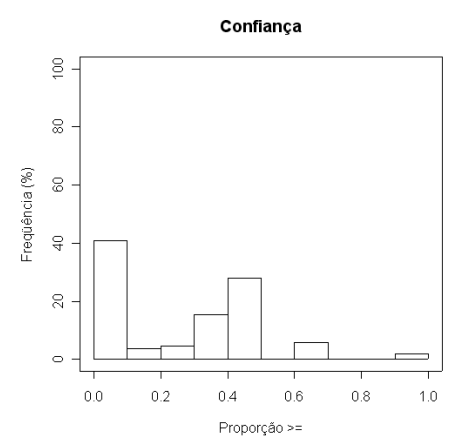

(d) lhs-sup-0-tax01-2N

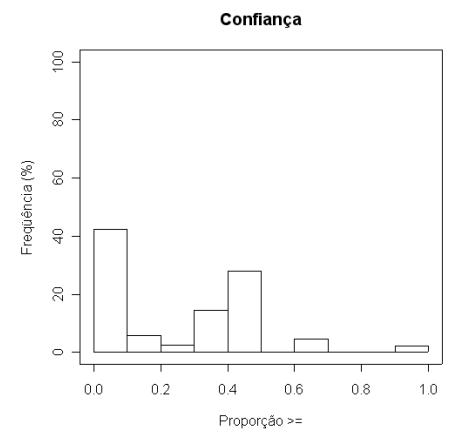

(g) lhs-sup-0-tax01-3N

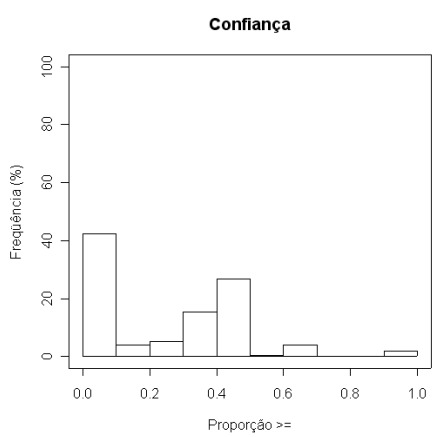

(j) lhs-sup-0-tax01-ND

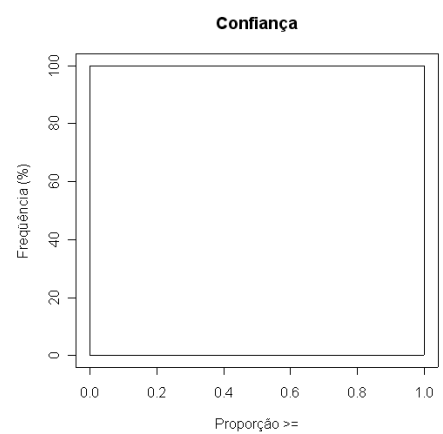

(b) rhs-sup-0-tax $01-1 \mathrm{~N}$

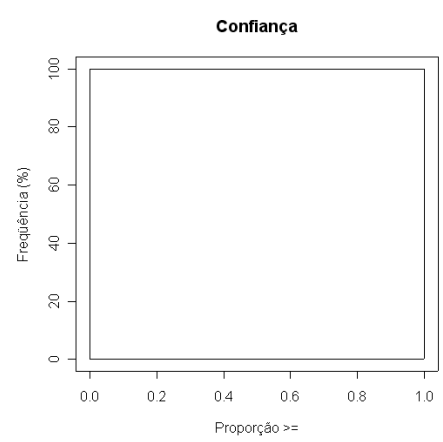

(e) rhs-sup-0-tax01-2N

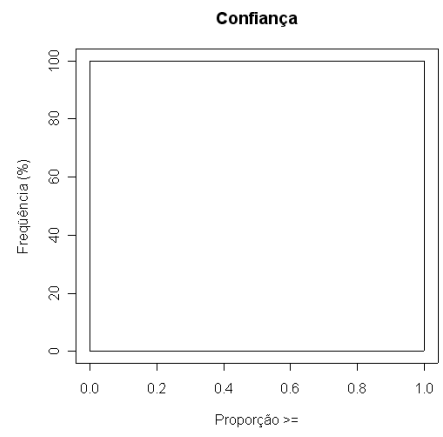

(h) rhs-sup-0-tax01-3N

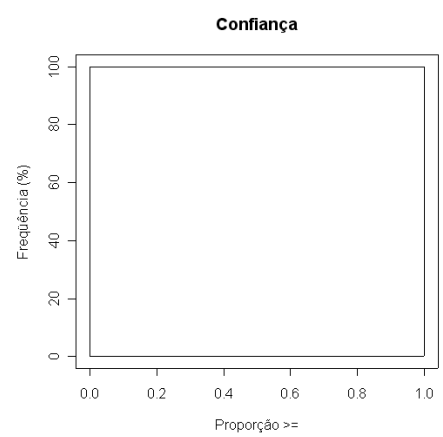

(k) rhs-sup-0-tax01-ND

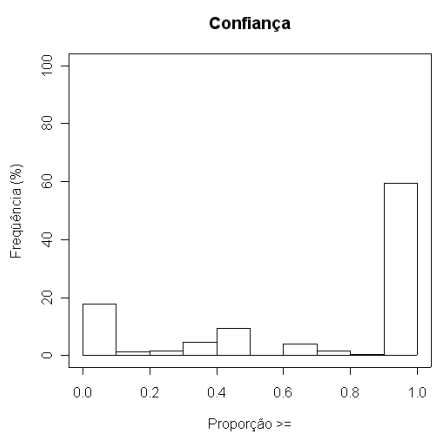

(c) lrhs-sup-0-tax01-1N

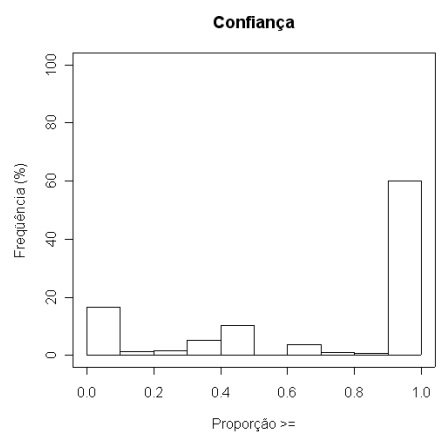

(f) lrhs-sup-0-tax01-2N

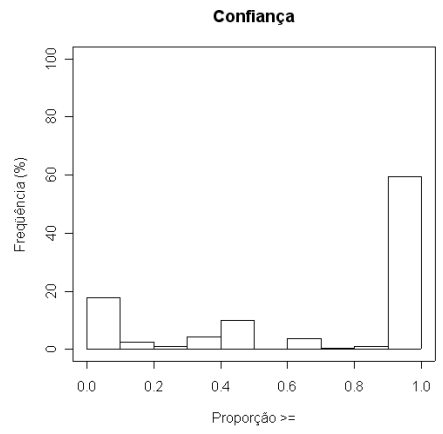

(i) lrhs-sup-0-tax01-3N

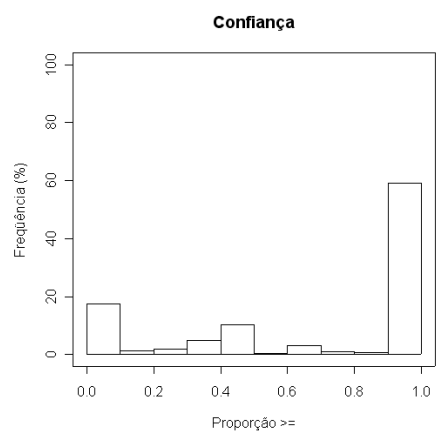

(l) lrhs-sup-0-tax01-ND

Figura I.4: Histogramas referentes a medida Confiança. 


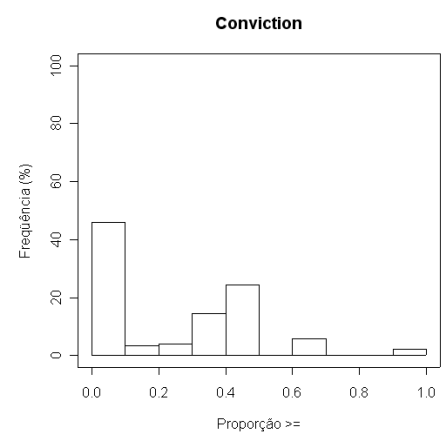

(a) lhs-sup-0-tax $01-1 \mathrm{~N}$

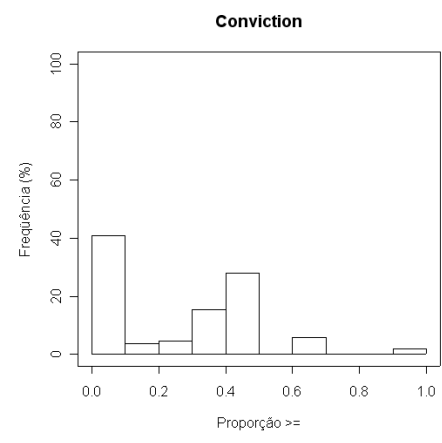

(d) lhs-sup-0-tax01-2N

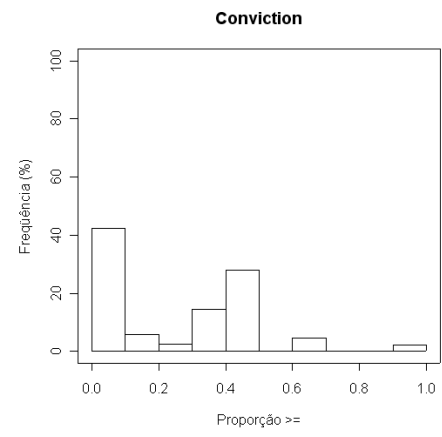

(g) lhs-sup-0-tax01-3N

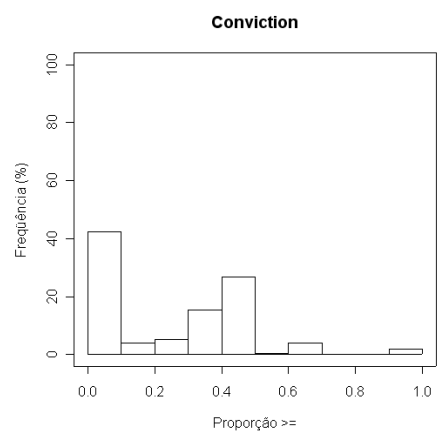

(j) lhs-sup-0-tax01-ND

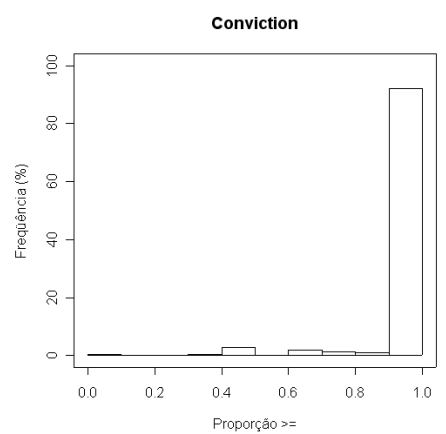

(b) rhs-sup-0-tax01-1N

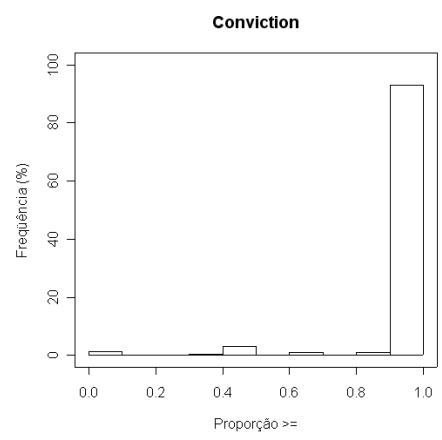

(e) rhs-sup-0-tax01-2N

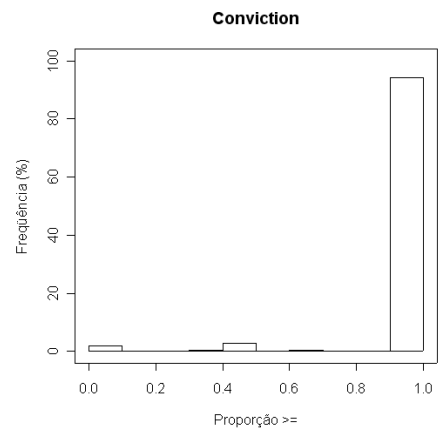

(h) rhs-sup-0-tax01-3N

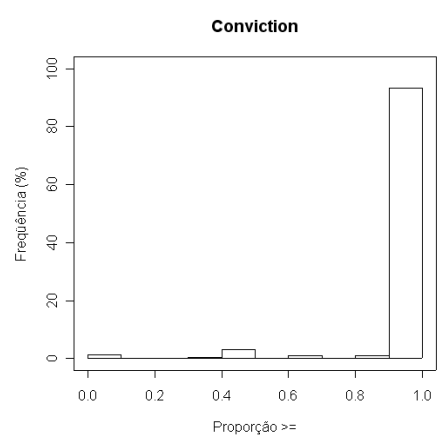

(k) rhs-sup-0-tax01-ND

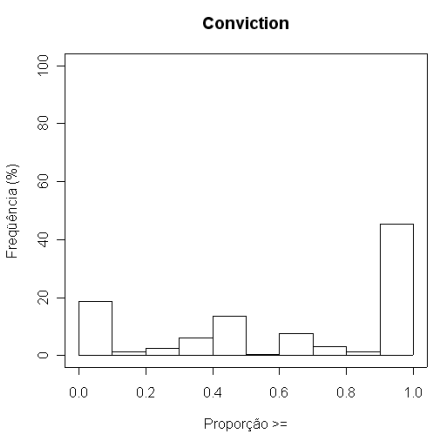

(c) lrhs-sup-0-tax01-1N

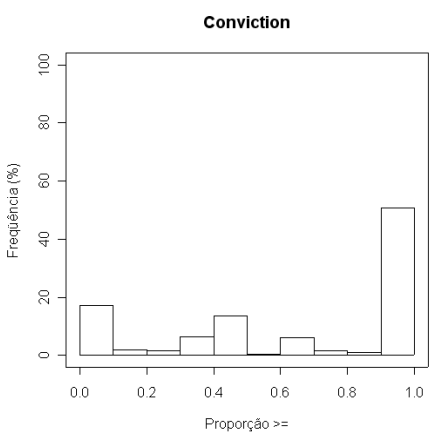

(f) lrhs-sup-0-tax01-2N

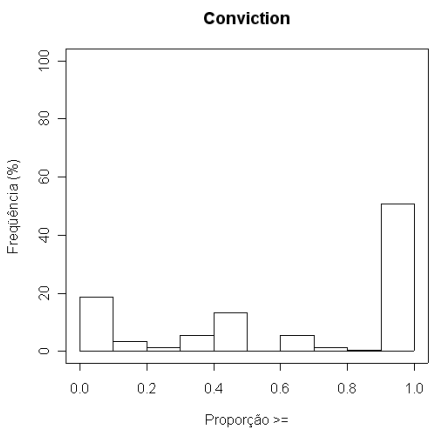

(i) lrhs-sup-0-tax01-3N

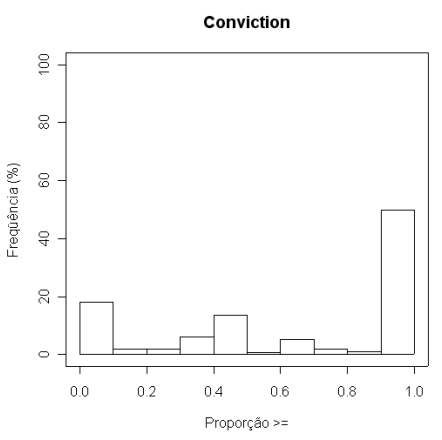

(l) lrhs-sup-0-tax01-ND

Figura I.5: Histogramas referentes a medida Conviction. 


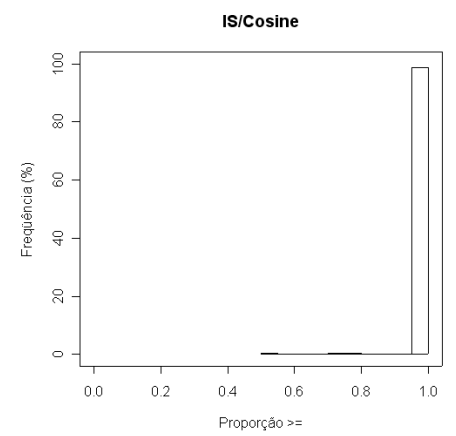

(a) lhs-sup-0-tax $01-1 \mathrm{~N}$

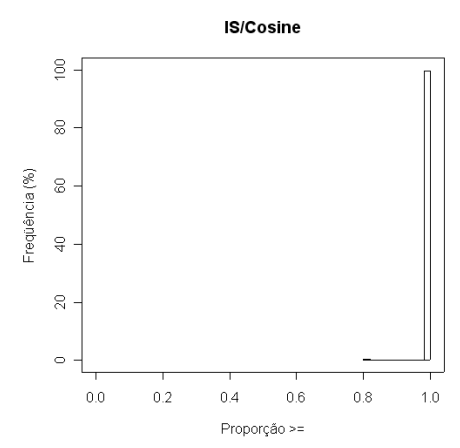

(d) lhs-sup-0-tax01-2N

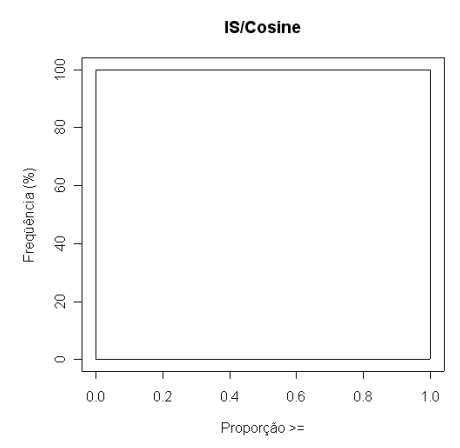

(g) lhs-sup-0-tax01-3N

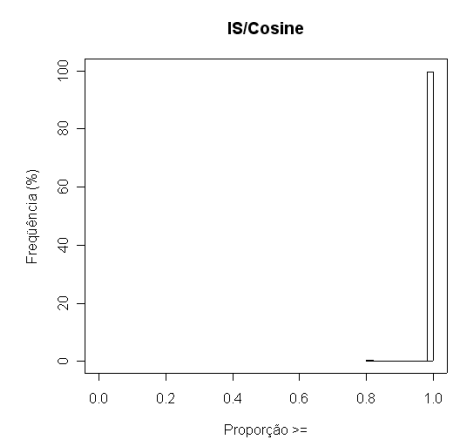

(j) lhs-sup-0-tax01-ND

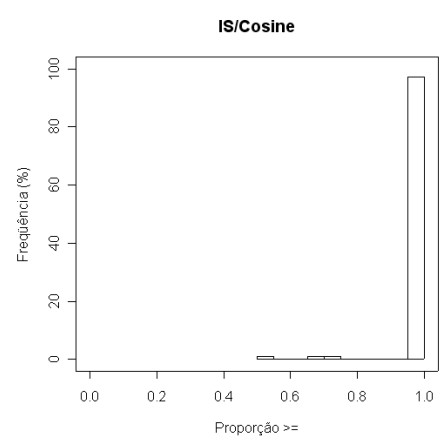

(b) rhs-sup-0-tax01-1N

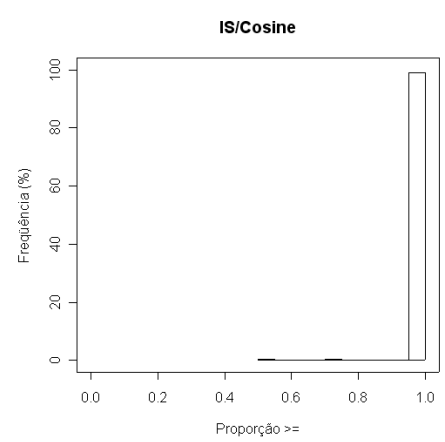

(e) rhs-sup-0-tax01-2N

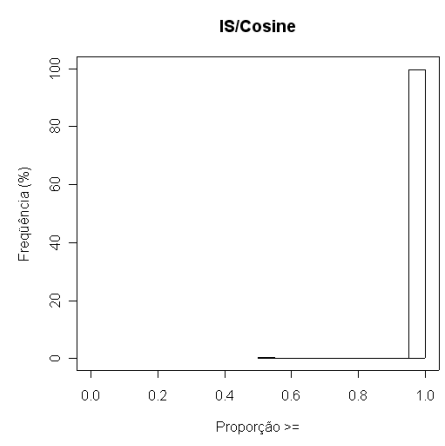

(h) rhs-sup-0-tax01-3N

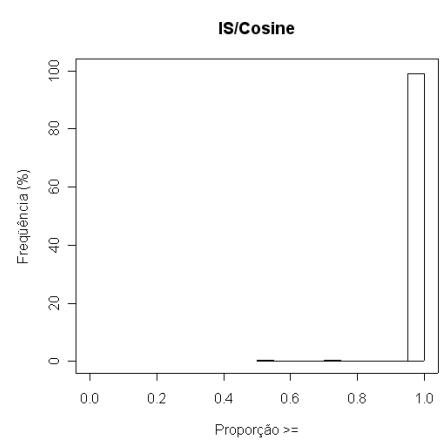

(k) rhs-sup-0-tax01-ND

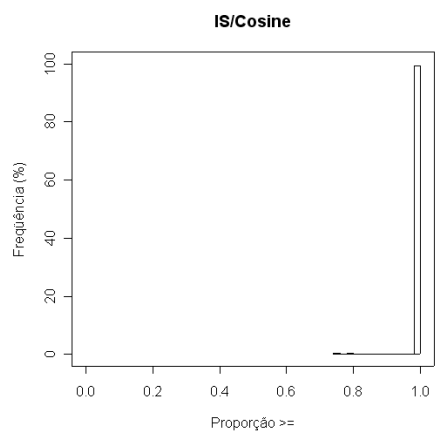

(c) lrhs-sup-0-tax01-1N

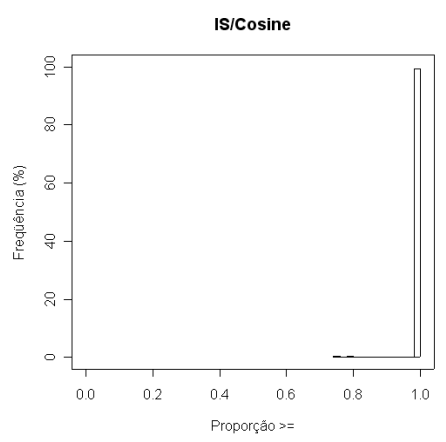

(f) lrhs-sup-0-tax01-2N

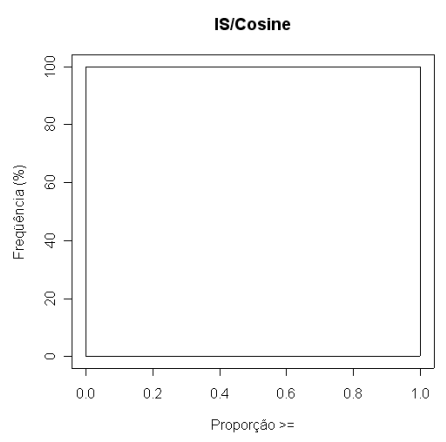

(i) lrhs-sup-0-tax01-3N

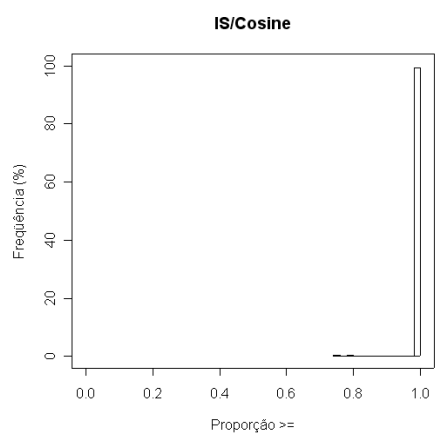

(1) lrhs-sup-0-tax01-ND

Figura I.6: Histogramas referentes a medida IS/Cosine. 


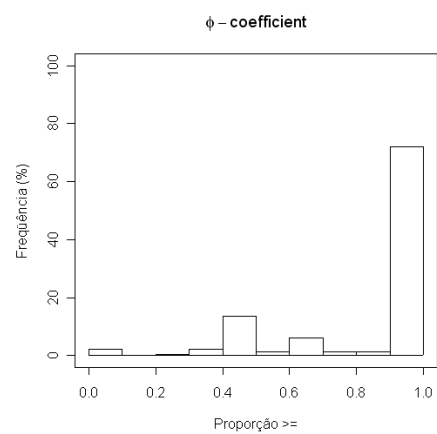

(a) lhs-sup-0-tax $01-1 \mathrm{~N}$

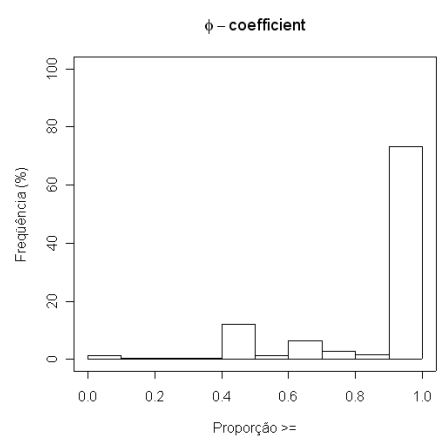

(d) lhs-sup-0-tax01-2N

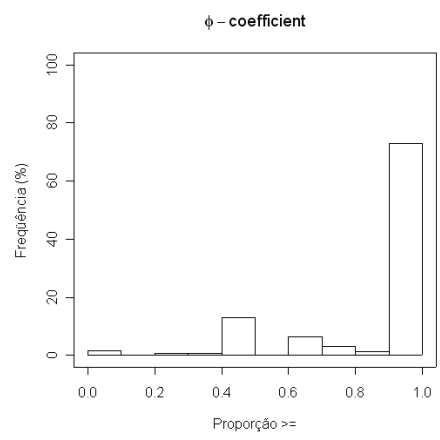

(g) lhs-sup-0-tax01-3N

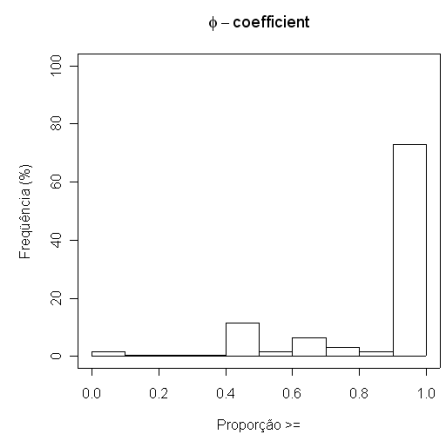

(j) lhs-sup-0-tax01-ND

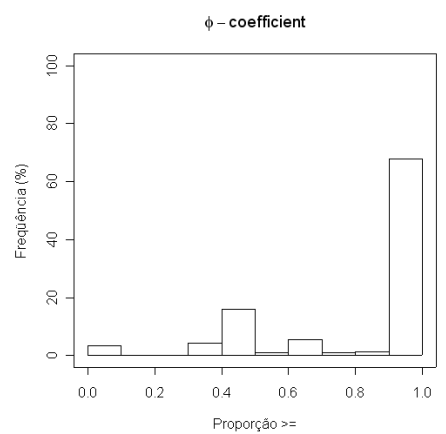

(b) rhs-sup-0-tax01-1N

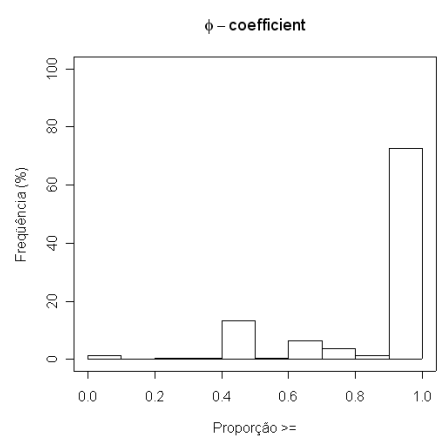

(e) rhs-sup-0-tax01-2N

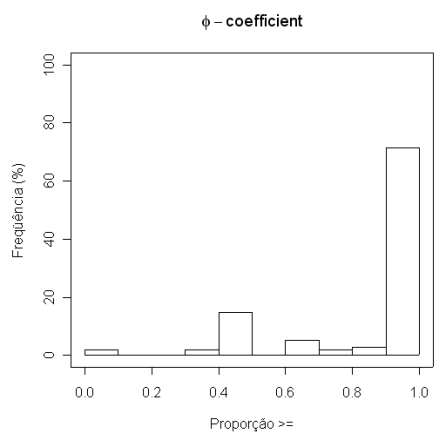

(h) rhs-sup-0-tax01-3N

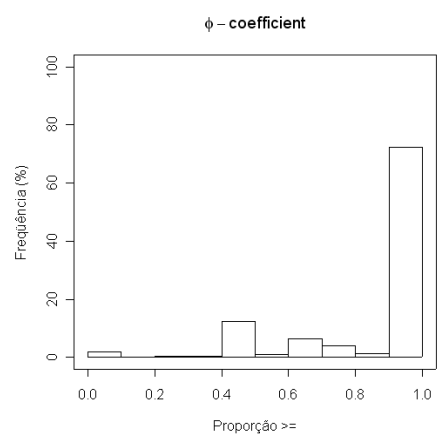

(k) rhs-sup-0-tax01-ND

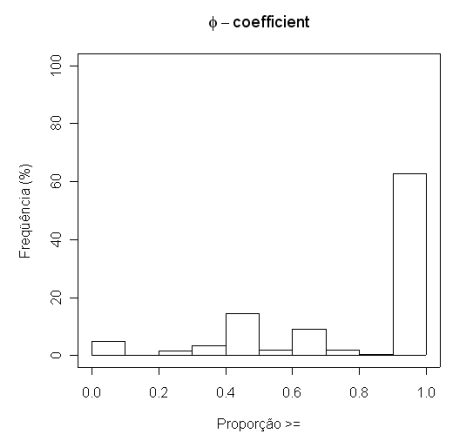

(c) lrhs-sup-0-tax01-1N

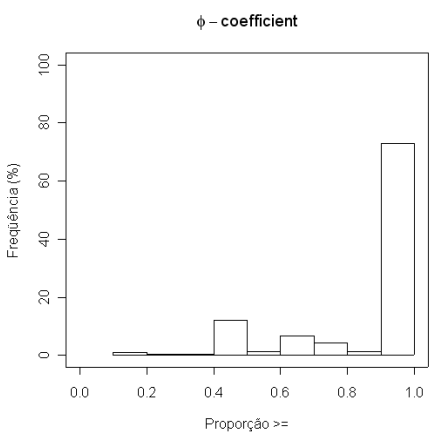

(f) lrhs-sup-0-tax01-2N

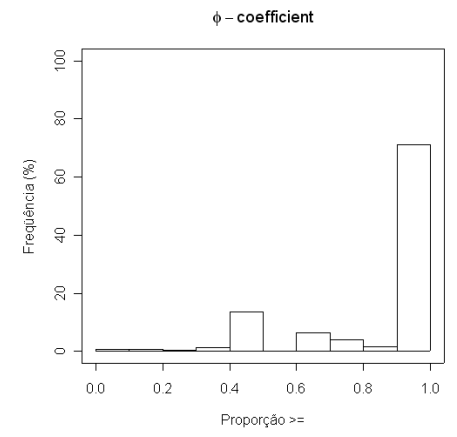

(i) lrhs-sup-0-tax01-3N

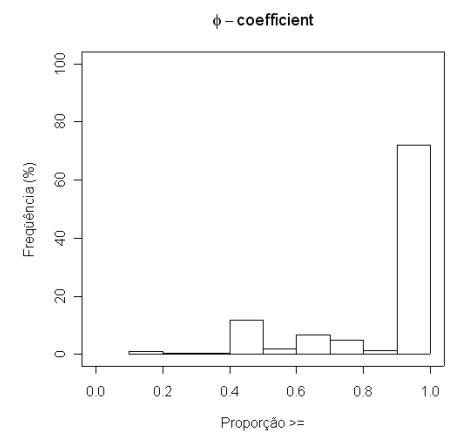

(l) lrhs-sup-0-tax01-ND

Figura I.7: Histogramas referentes a medida $\phi$-coefficient. 


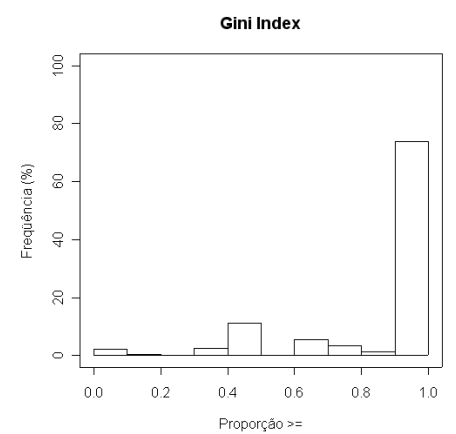

(a) lhs-sup-0-tax01-1N

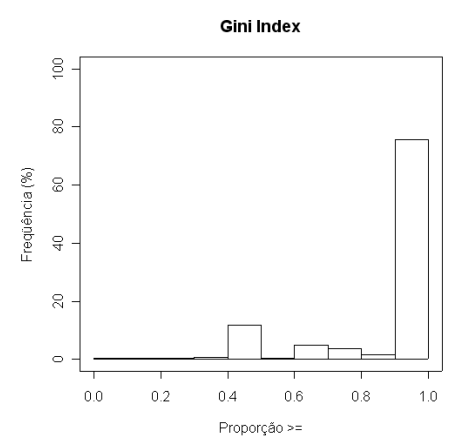

(d) lhs-sup-0-tax01-2N

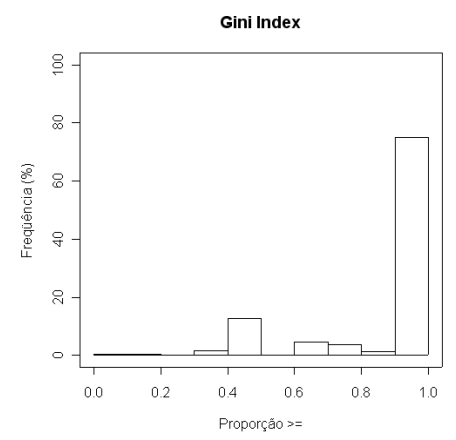

(g) lhs-sup-0-tax01-3N

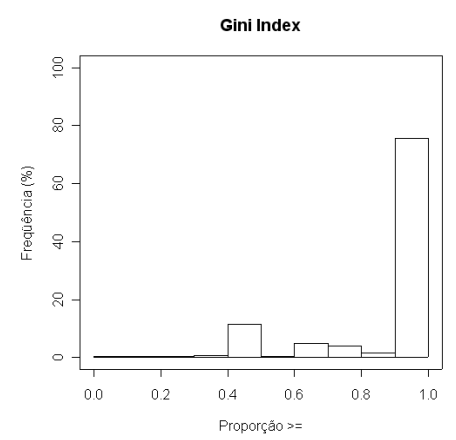

(j) lhs-sup-0-tax01-ND

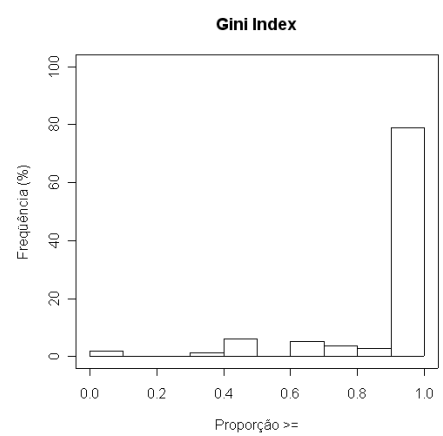

(b) rhs-sup-0-tax $01-1 \mathrm{~N}$

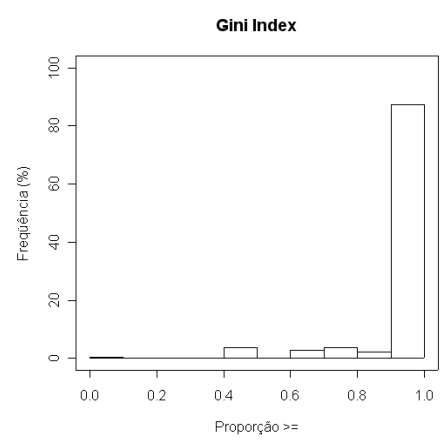

(e) rhs-sup-0-tax01-2N

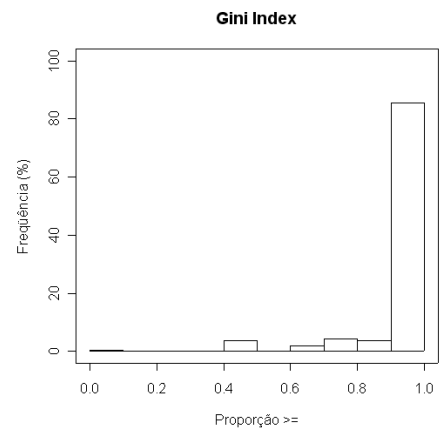

(h) rhs-sup-0-tax01-3N

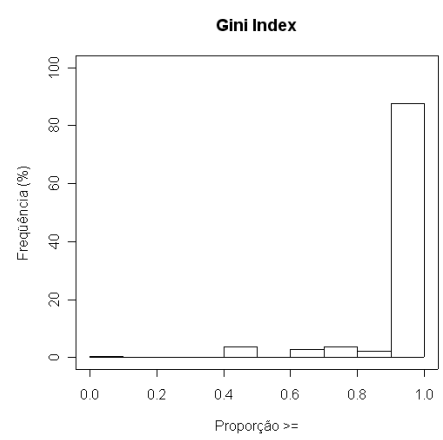

(k) rhs-sup-0-tax01-ND

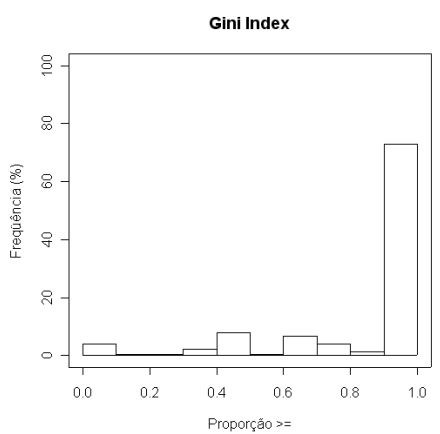

(c) lrhs-sup-0-tax01-1N

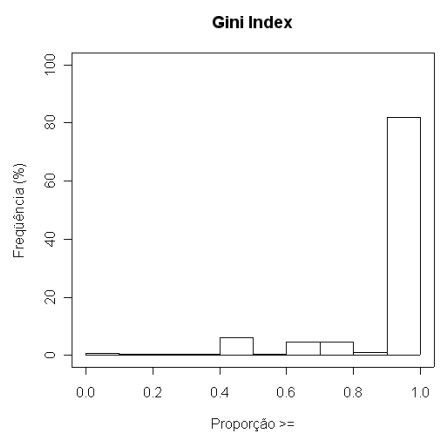

(f) lrhs-sup-0-tax01-2N

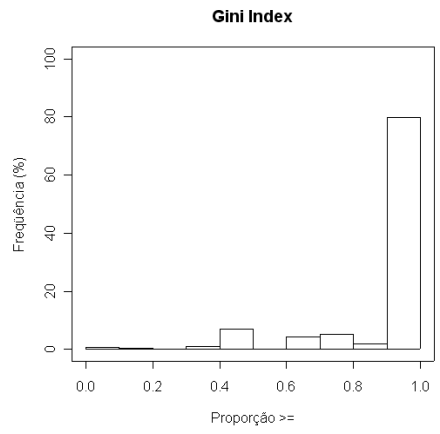

(i) lrhs-sup-0-tax01-3N

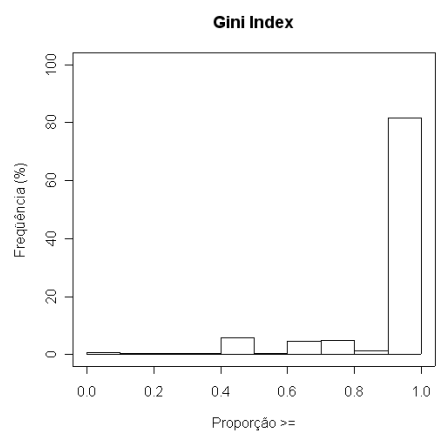

(1) lrhs-sup-0-tax01-ND

Figura I.8: Histogramas referentes a medida Gini Index. 


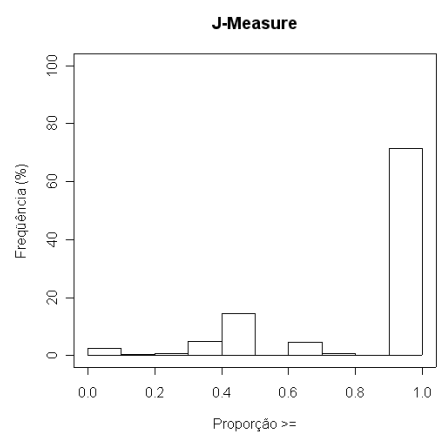

(a) lhs-sup-0-tax01-1N

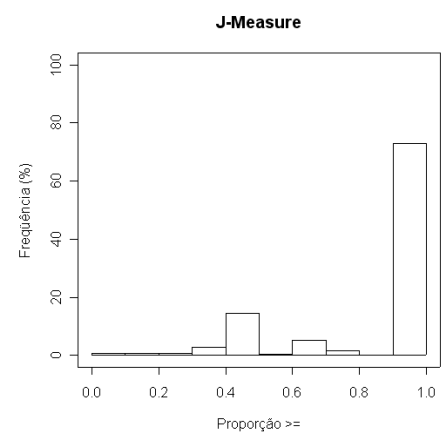

(d) lhs-sup-0-tax01-2N

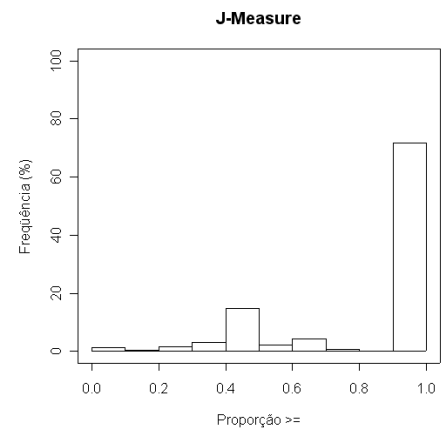

(g) lhs-sup-0-tax01-3N

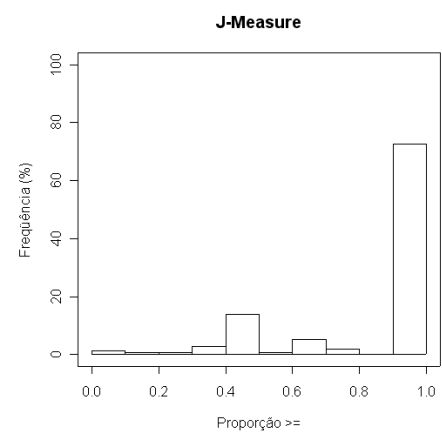

(j) lhs-sup-0-tax01-ND

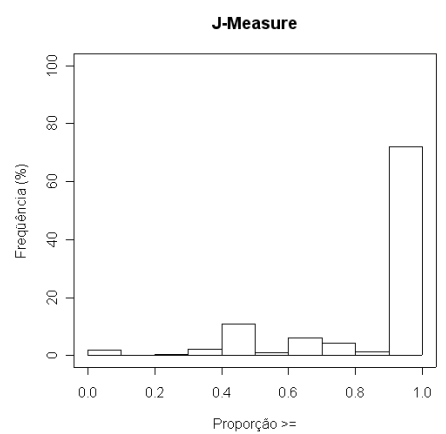

(b) rhs-sup-0-tax $01-1 \mathrm{~N}$

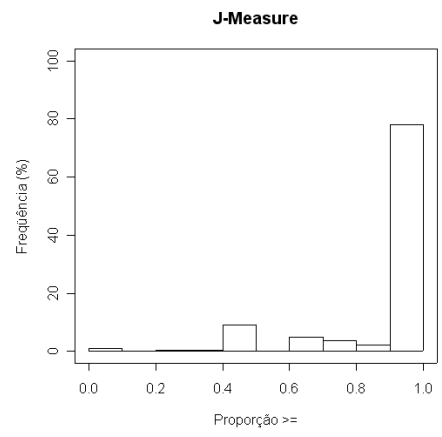

(e) rhs-sup-0-tax01-2N

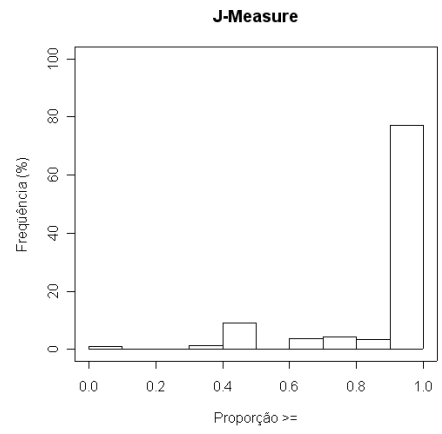

(h) rhs-sup-0-tax01-3N

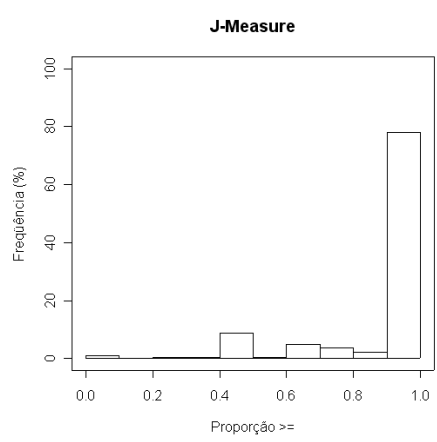

(k) rhs-sup-0-tax01-ND

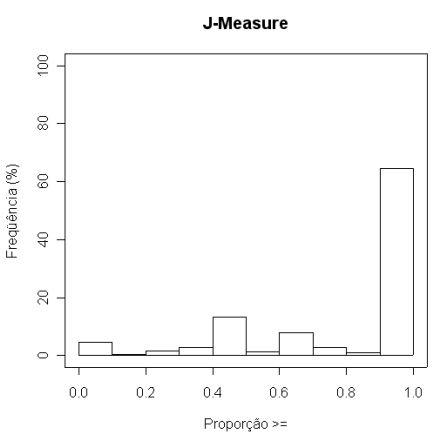

(c) lrhs-sup-0-tax01-1N

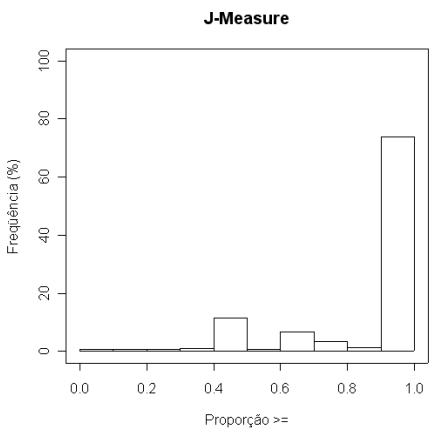

(f) lrhs-sup-0-tax01-2N

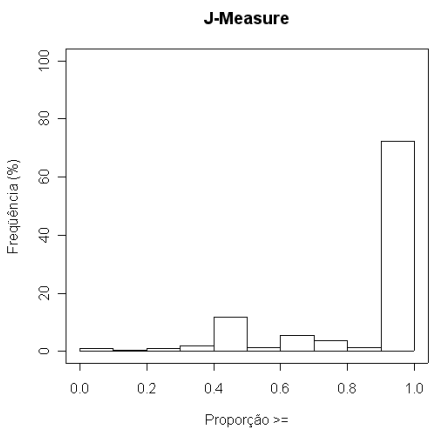

(i) lrhs-sup-0-tax01-3N

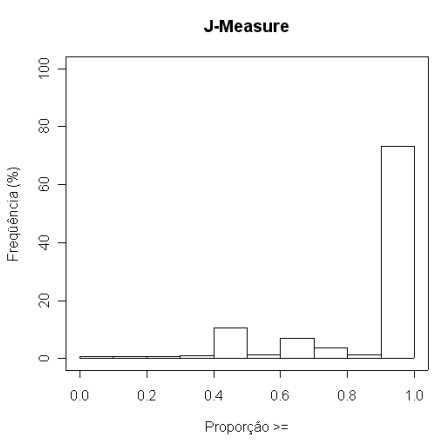

(l) lrhs-sup-0-tax01-ND

Figura I.9: Histogramas referentes a medida $J$-Measure. 


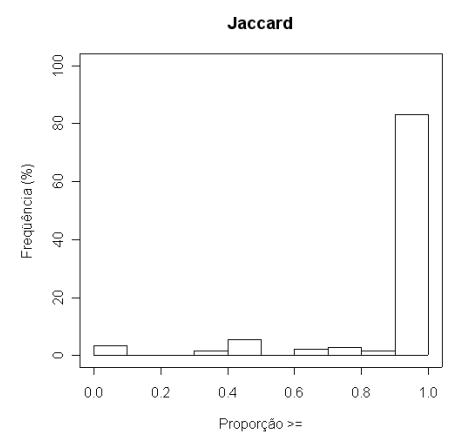

(a) lhs-sup-0-tax $01-1 \mathrm{~N}$

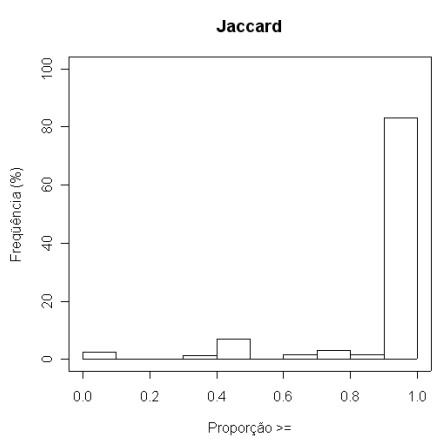

(d) lhs-sup-0-tax01-2N

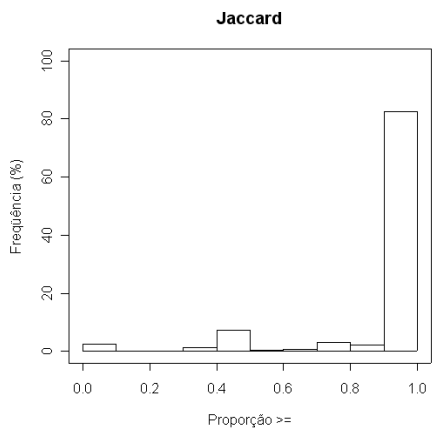

(g) lhs-sup-0-tax01-3N

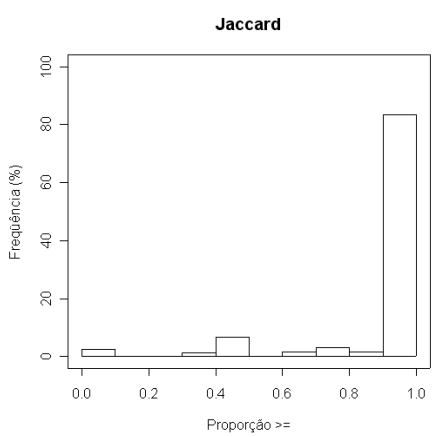

(j) lhs-sup-0-tax01-ND

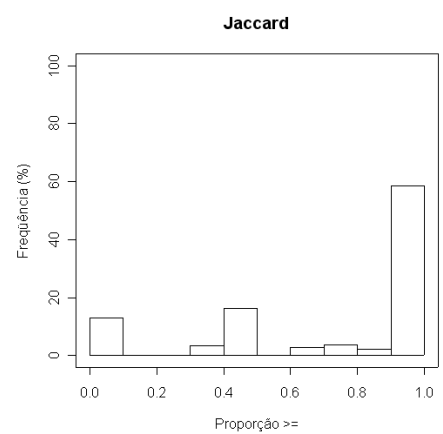

(b) rhs-sup-0-tax $01-1 \mathrm{~N}$

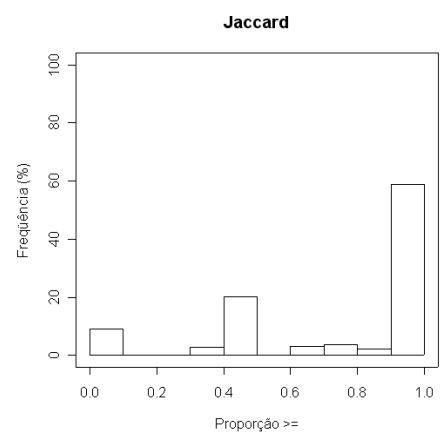

(e) rhs-sup-0-tax01-2N

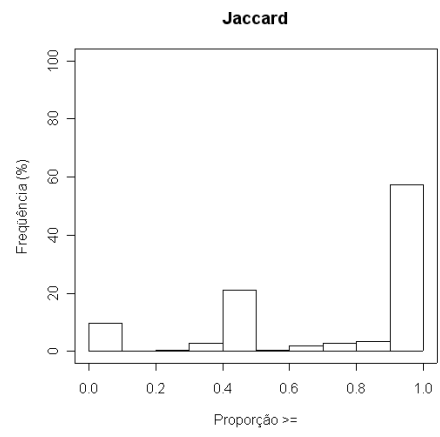

(h) rhs-sup-0-tax01-3N

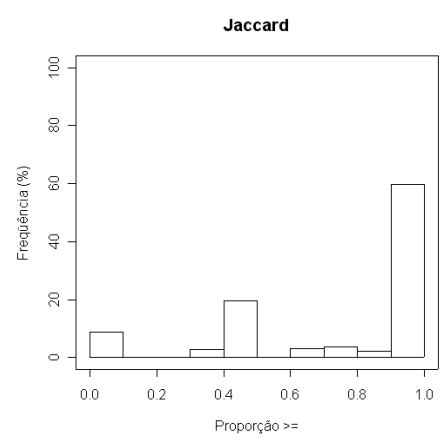

(k) rhs-sup-0-tax01-ND

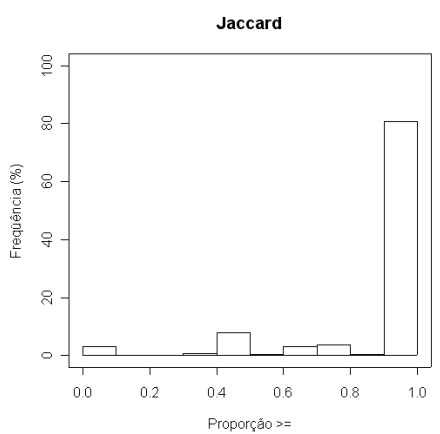

(c) lrhs-sup-0-tax $01-1 \mathrm{~N}$

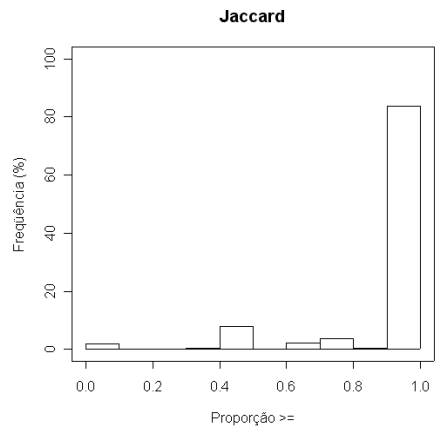

(f) lrhs-sup-0-tax01-2N

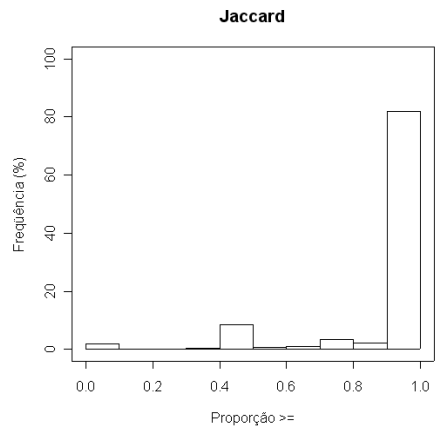

(i) lrhs-sup-0-tax01-3N

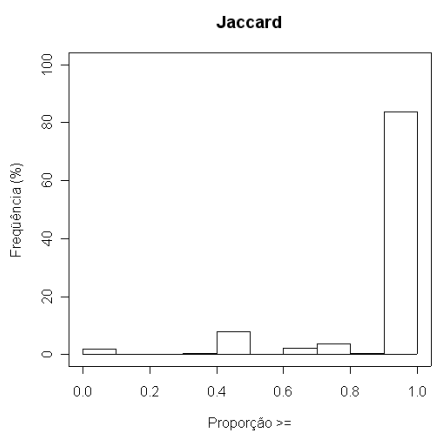

(l) lrhs-sup-0-tax01-ND

Figura I.10: Histogramas referentes a medida Jaccard. 


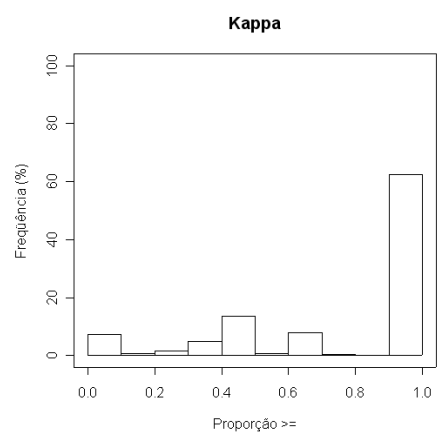

(a) lhs-sup-0-tax01-1N

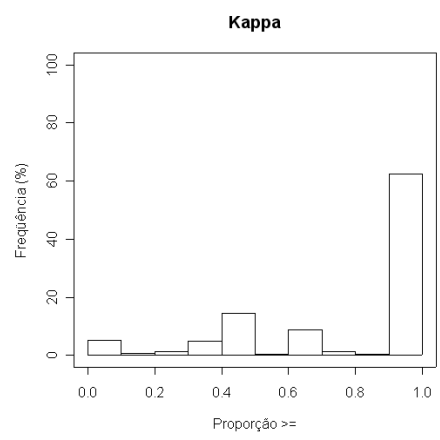

(d) lhs-sup-0-tax01-2N

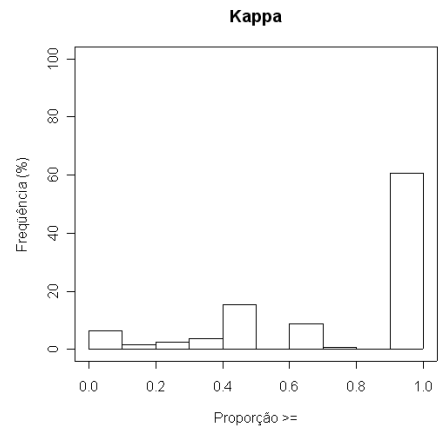

(g) lhs-sup-0-tax01-3N

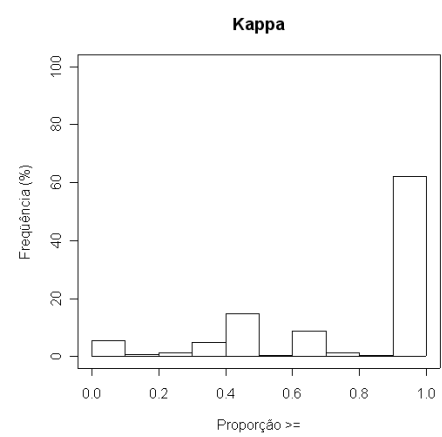

(j) lhs-sup-0-tax01-ND

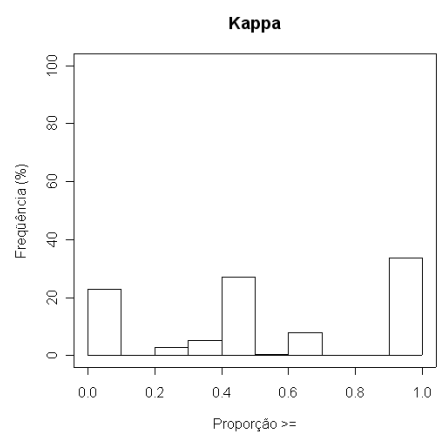

(b) rhs-sup-0-tax $01-1 \mathrm{~N}$

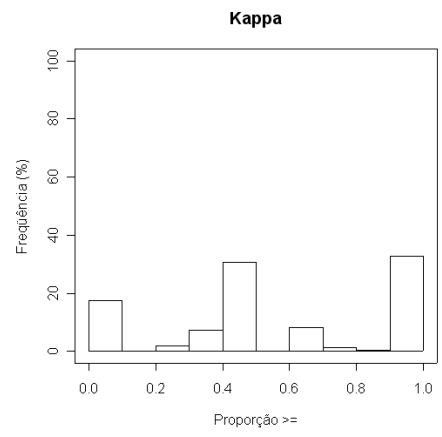

(e) rhs-sup-0-tax01-2N

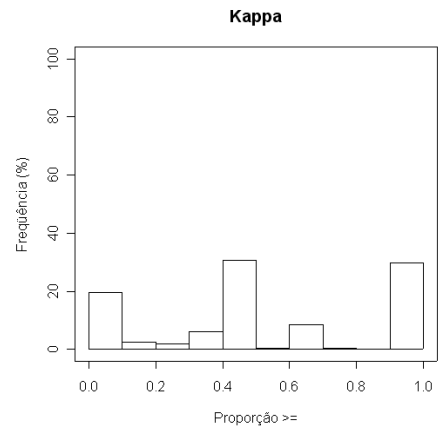

(h) rhs-sup-0-tax01-3N

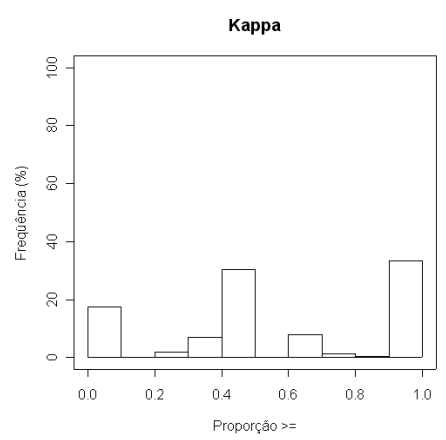

(k) rhs-sup-0-tax01-ND

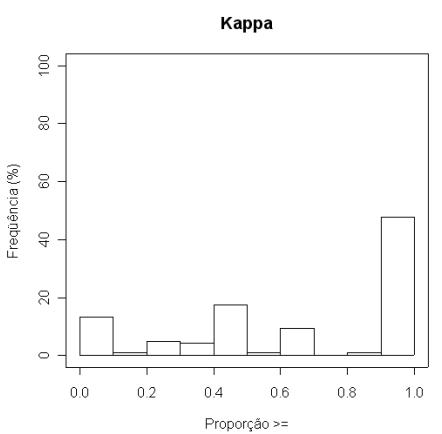

(c) lrhs-sup-0-tax01-1N

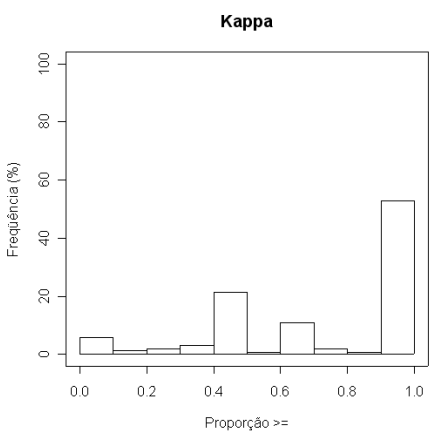

(f) lrhs-sup-0-tax01-2N

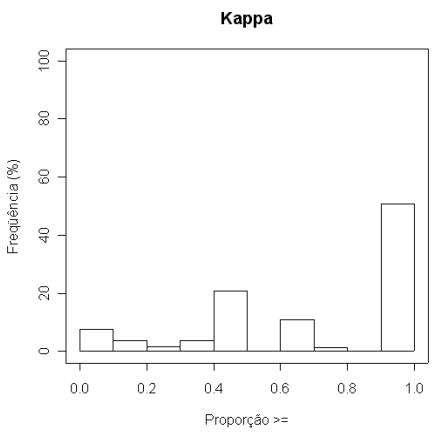

(i) lrhs-sup-0-tax01-3N

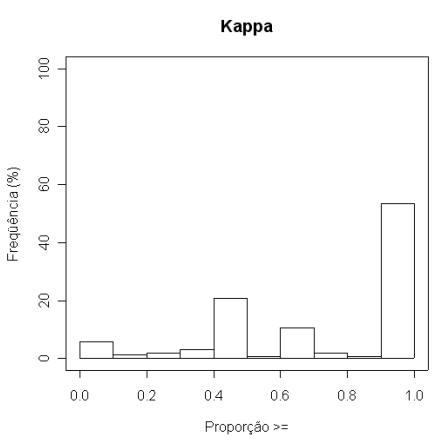

(l) lrhs-sup-0-tax01-ND

Figura I.11: Histogramas referentes a medida Kappa. 


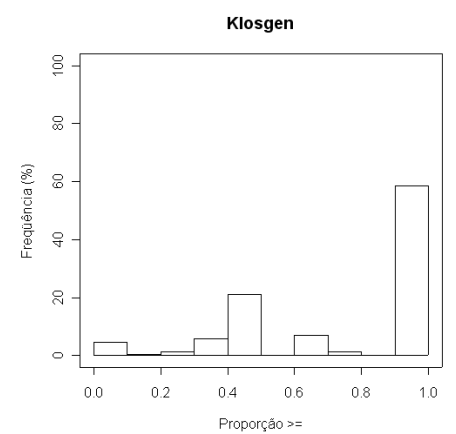

(a) lhs-sup-0-tax01-1N

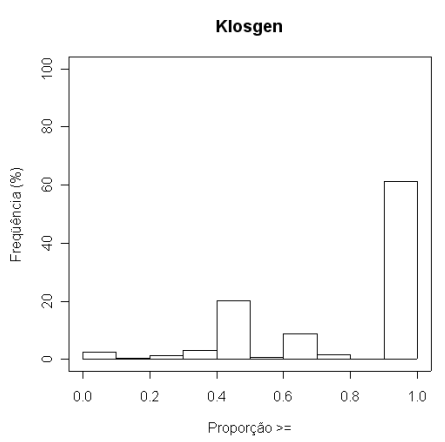

(d) lhs-sup-0-tax01-2N

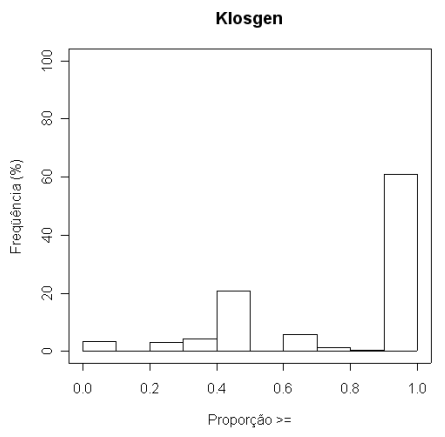

(g) lhs-sup-0-tax01-3N

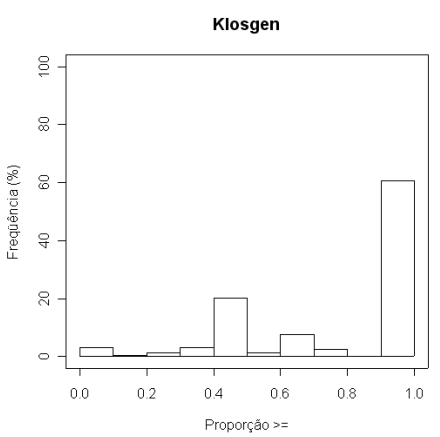

(j) lhs-sup-0-tax01-ND

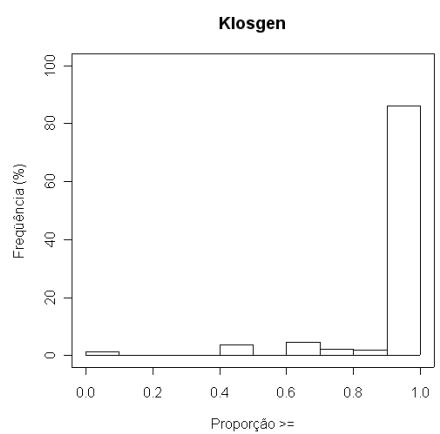

(b) rhs-sup-0-tax $01-1 \mathrm{~N}$

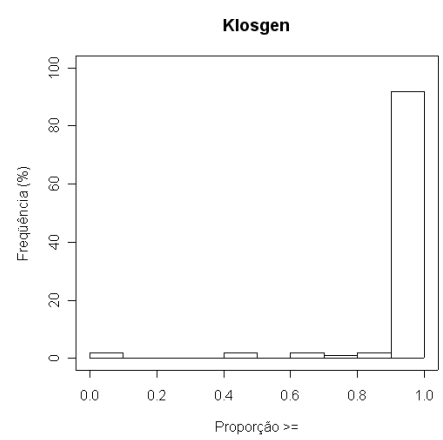

(e) rhs-sup-0-tax01-2N

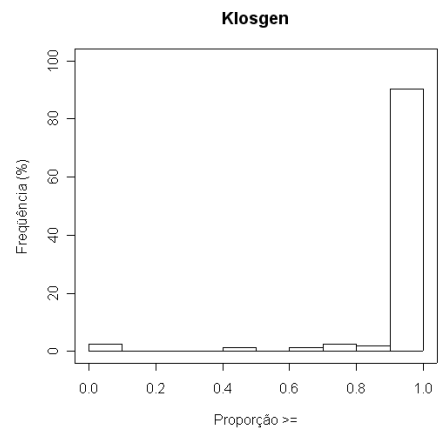

(h) rhs-sup-0-tax01-3N

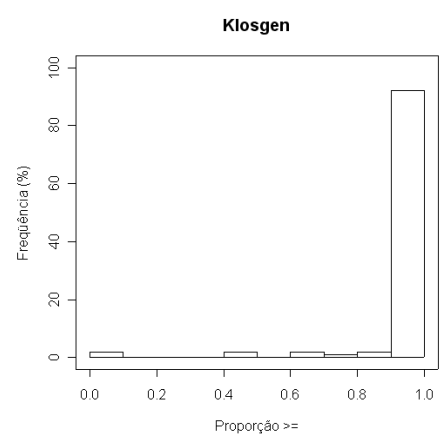

(k) rhs-sup-0-tax01-ND

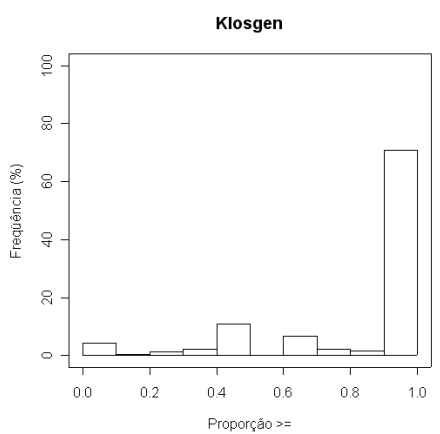

(c) lrhs-sup-0-tax01-1N

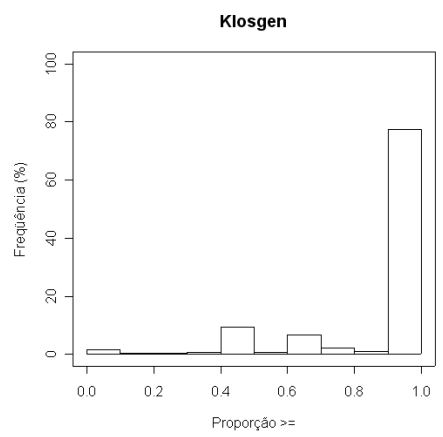

(f) lrhs-sup-0-tax01-2N

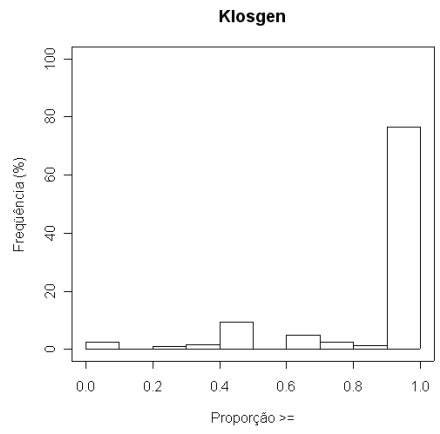

(i) lrhs-sup-0-tax01-3N

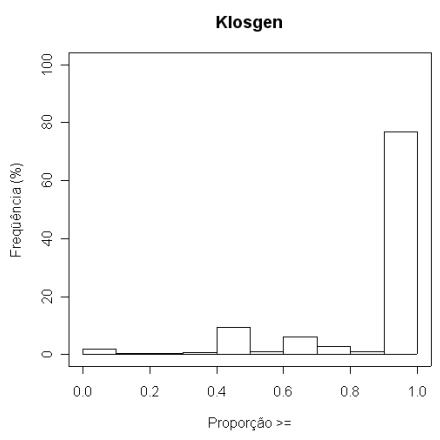

(1) lrhs-sup-0-tax01-ND

Figura I.12: Histogramas referentes a medida Klosgen. 


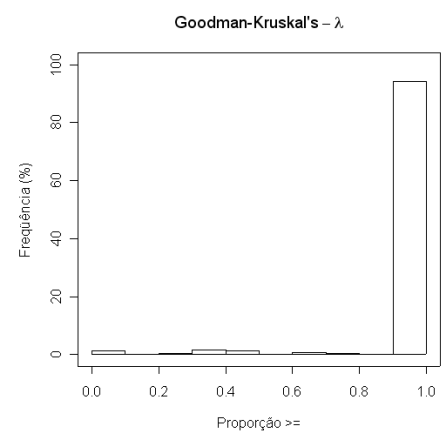

(a) lhs-sup-0-tax01-1N

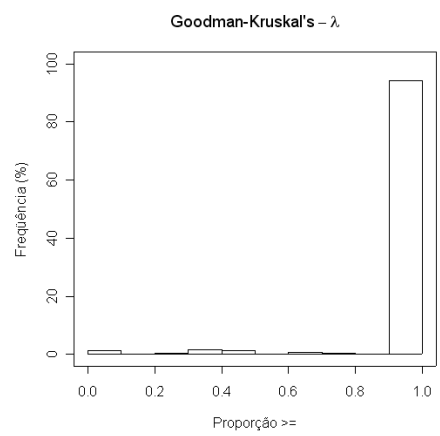

(d) lhs-sup-0-tax01-2N

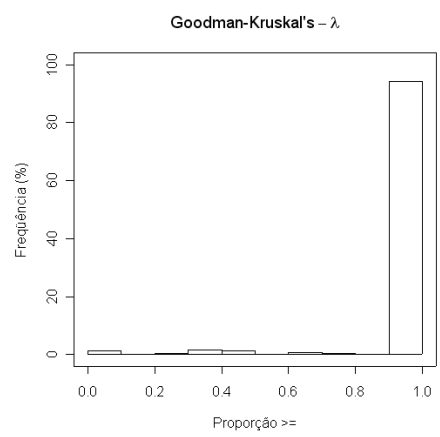

(g) lhs-sup-0-tax01-3N

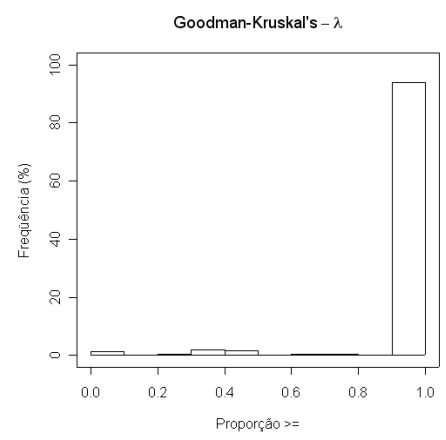

(j) lhs-sup-0-tax01-ND

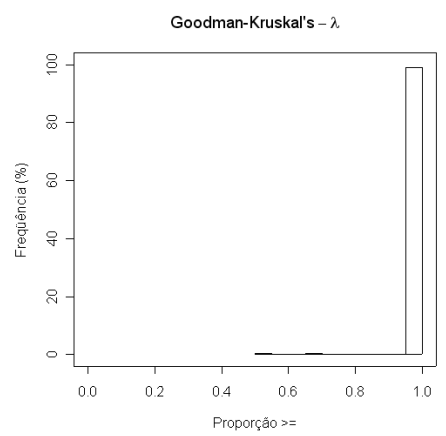

(b) rhs-sup-0-tax $01-1 \mathrm{~N}$

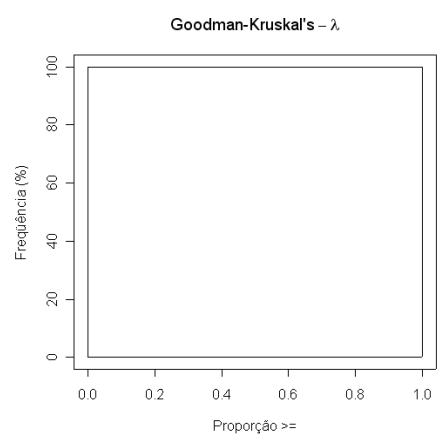

(e) rhs-sup-0-tax $01-2 \mathrm{~N}$

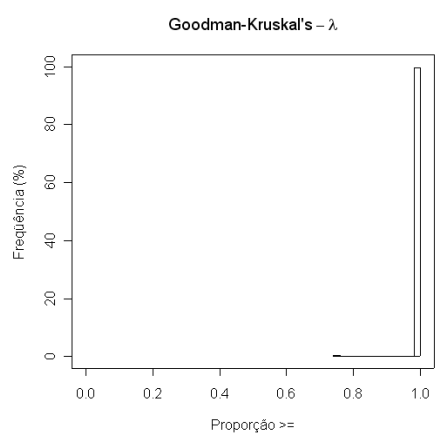

(h) rhs-sup-0-tax01-3N

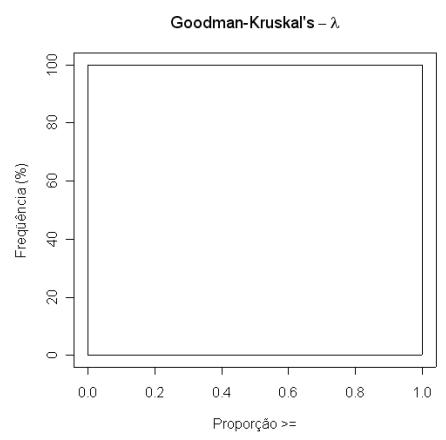

(k) rhs-sup-0-tax01-ND

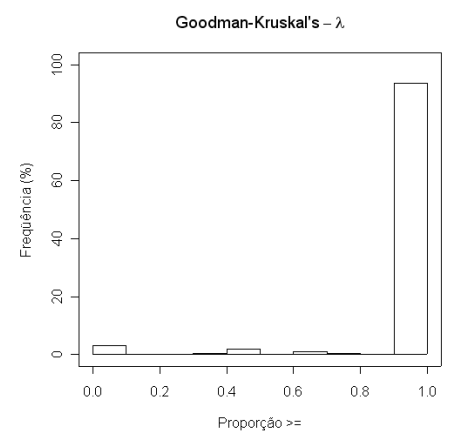

(c) lrhs-sup-0-tax01-1N

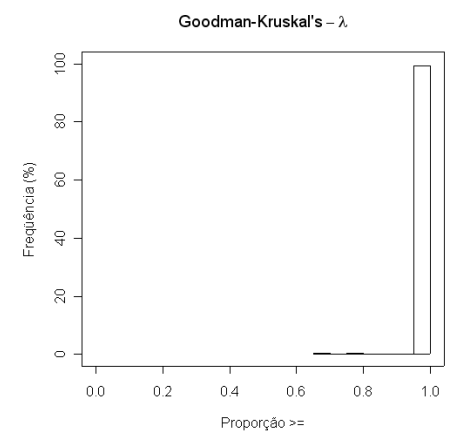

(f) lrhs-sup-0-tax01-2N

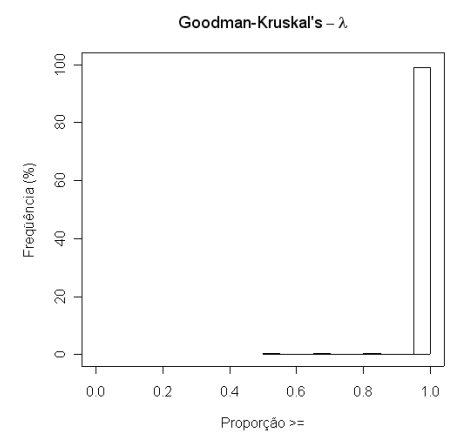

(i) lrhs-sup-0-tax01-3N

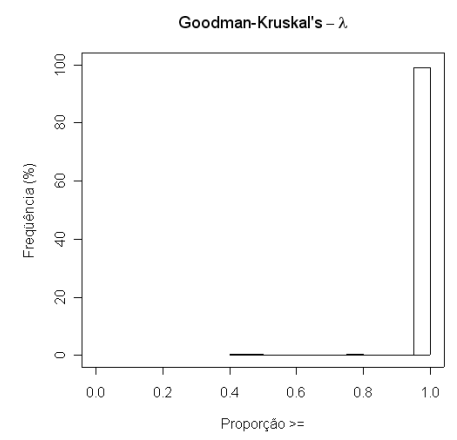

(l) lrhs-sup-0-tax01-ND

Figura I.13: Histogramas referentes a medida Goodman-Kruskal's $(\lambda)$. 


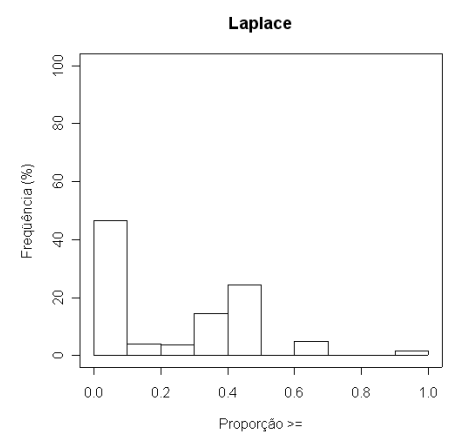

(a) lhs-sup-0-tax $01-1 \mathrm{~N}$

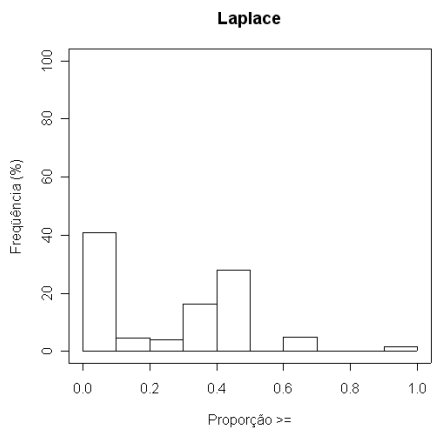

(d) lhs-sup-0-tax01-2N

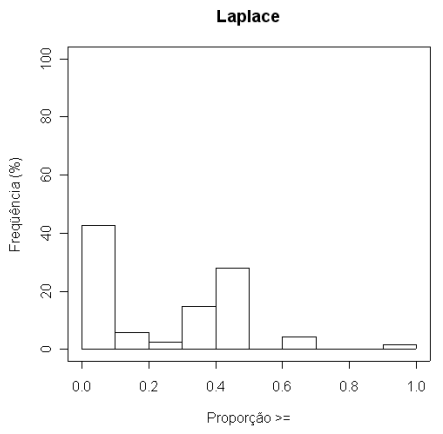

(g) lhs-sup-0-tax01-3N

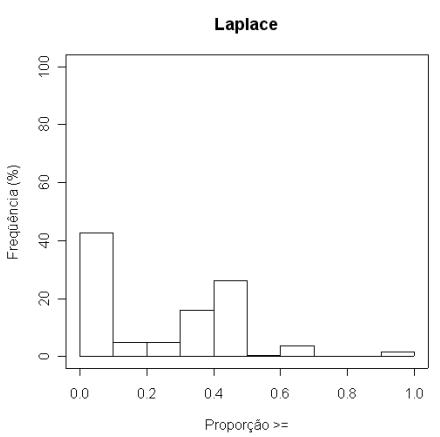

(j) lhs-sup-0-tax01-ND

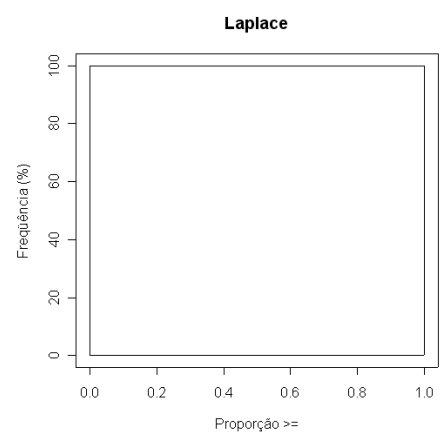

(b) rhs-sup-0-tax $01-1 \mathrm{~N}$

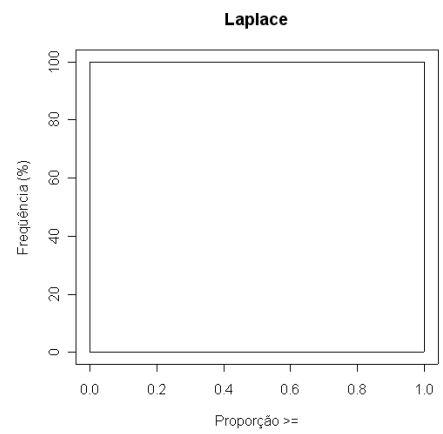

(e) rhs-sup-0-tax01-2N

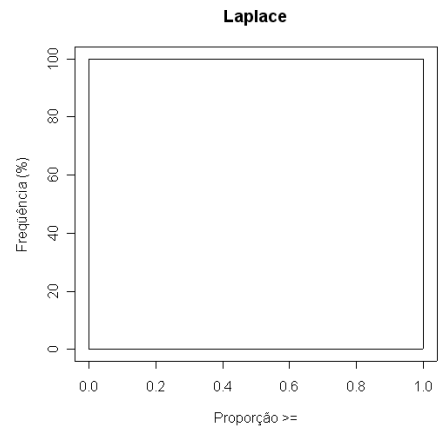

(h) rhs-sup-0-tax01-3N

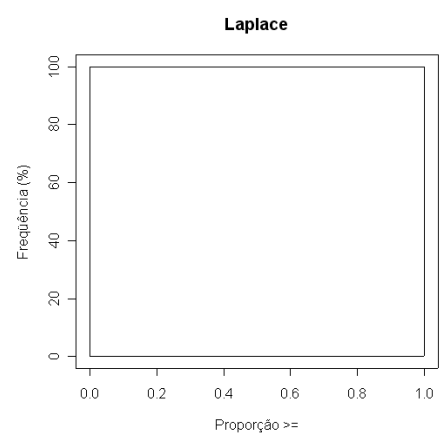

(k) rhs-sup-0-tax01-ND

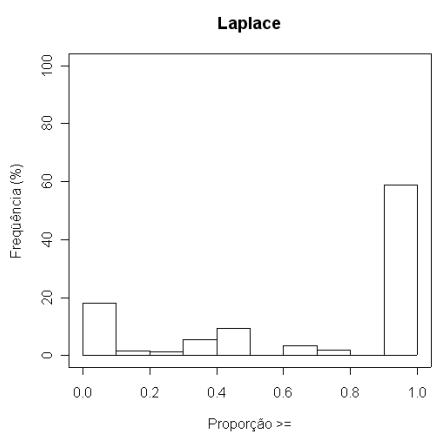

(c) lrhs-sup-0-tax $01-1 \mathrm{~N}$

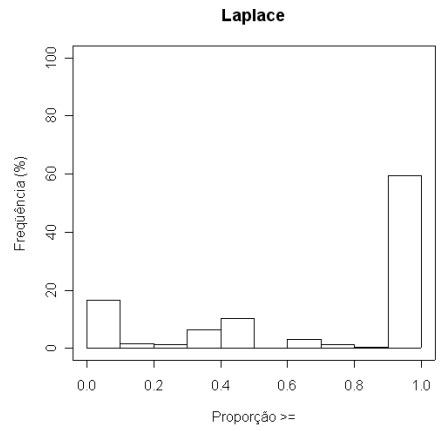

(f) lrhs-sup-0-tax01-2N

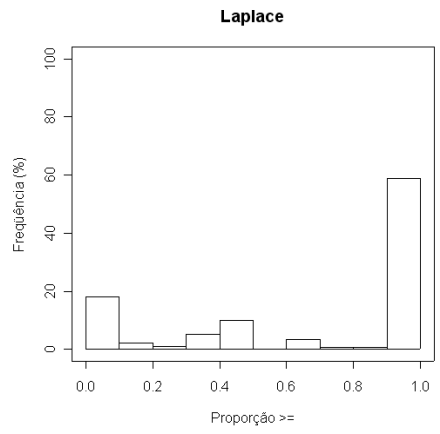

(i) lrhs-sup-0-tax01-3N

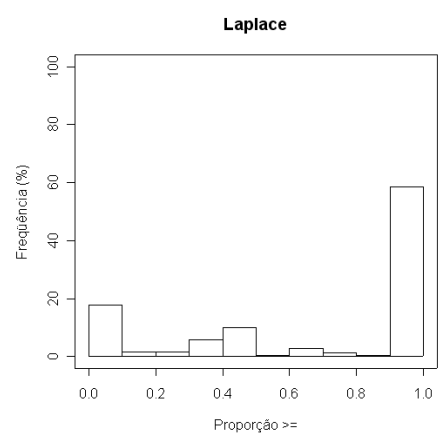

(l) lrhs-sup-0-tax01-ND

Figura I.14: Histogramas referentes a medida Laplace. 


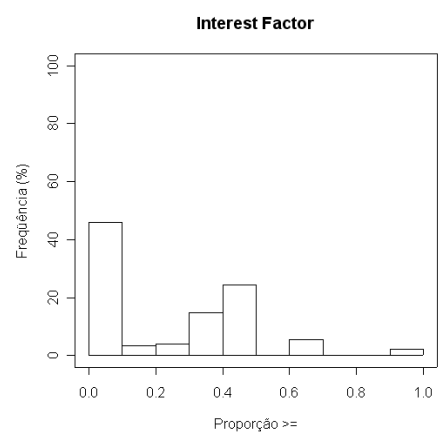

(a) lhs-sup-0-tax01-1N

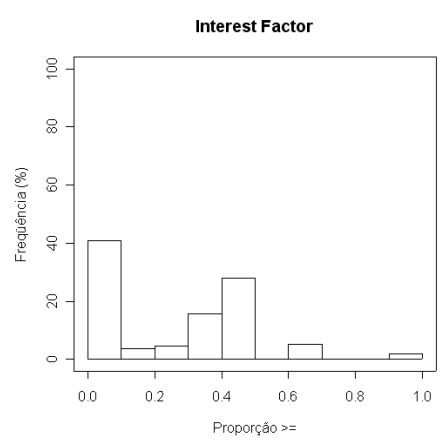

(d) lhs-sup-0-tax01-2N

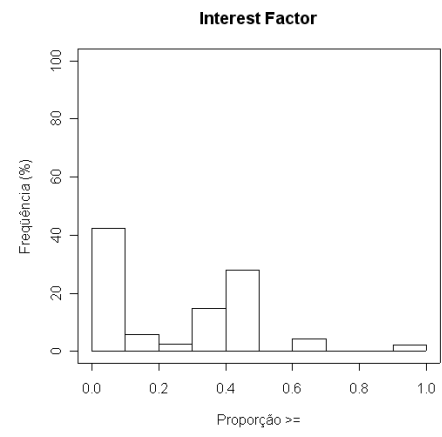

(g) lhs-sup-0-tax01-3N

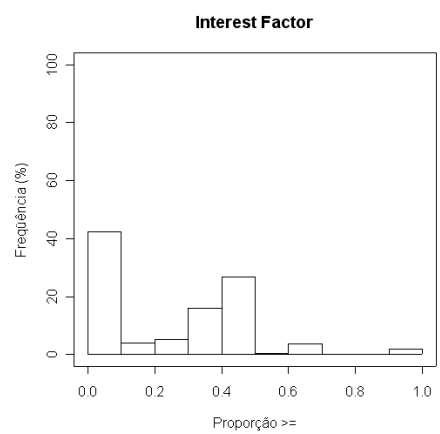

(j) lhs-sup-0-tax01-ND

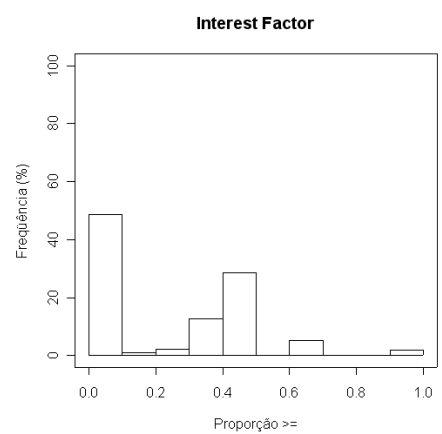

(b) rhs-sup-0-tax01-1N

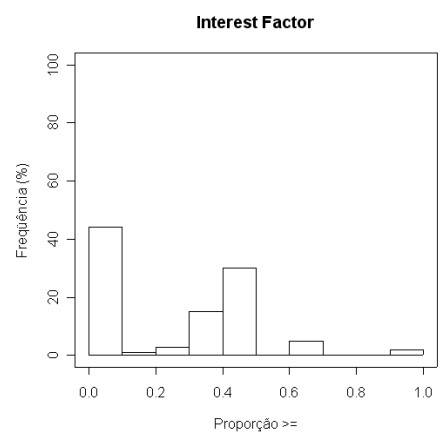

(e) rhs-sup-0-tax01-2N

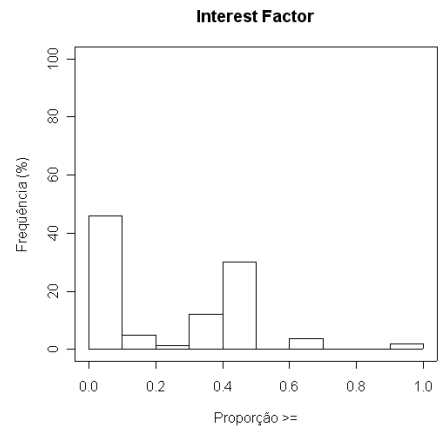

(h) rhs-sup-0-tax01-3N

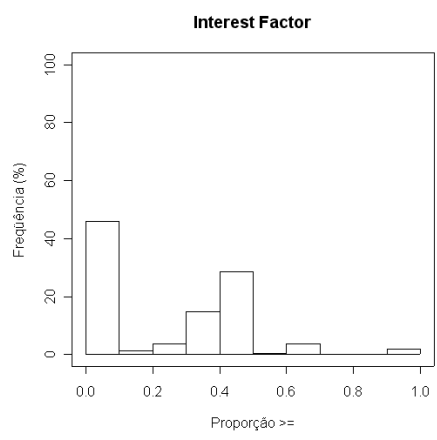

(k) rhs-sup-0-tax01-ND

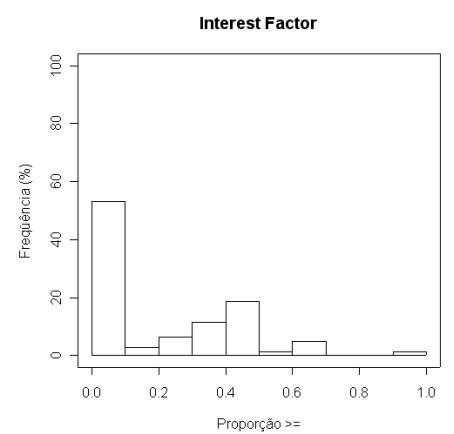

(c) lrhs-sup-0-tax01-1N

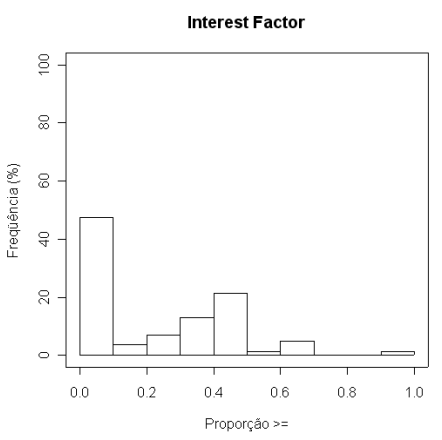

(f) lrhs-sup-0-tax01-2N

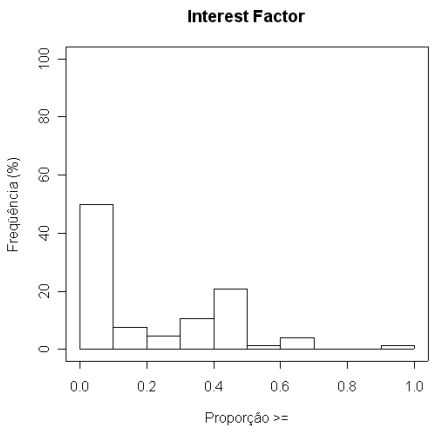

(i) lrhs-sup-0-tax01-3N

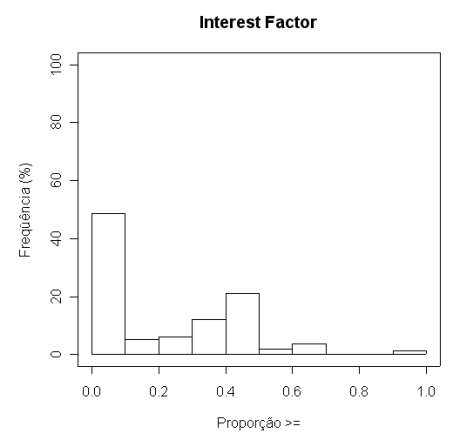

(l) lrhs-sup-0-tax01-ND

Figura I.15: Histogramas referentes a medida Interest Factor. 


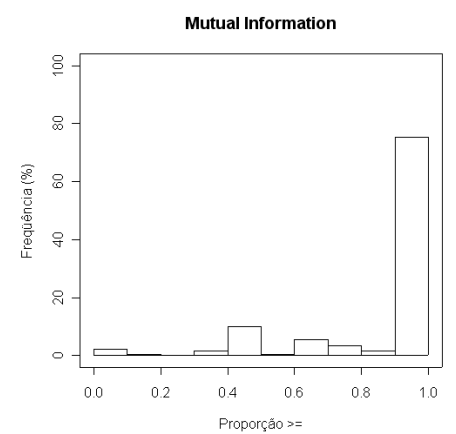

(a) lhs-sup-0-tax01-1N

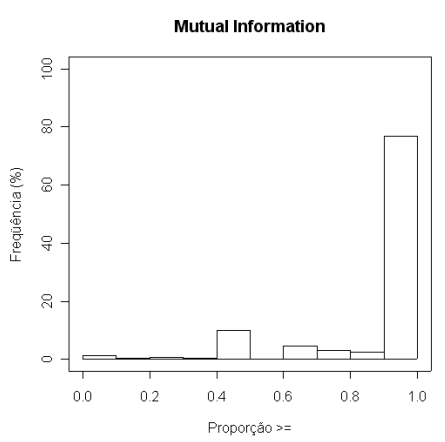

(d) lhs-sup-0-tax01-2N

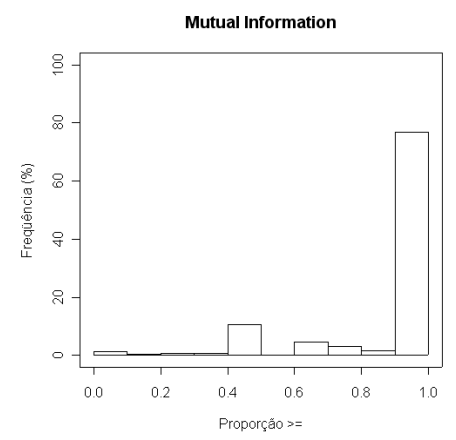

(g) lhs-sup-0-tax01-3N

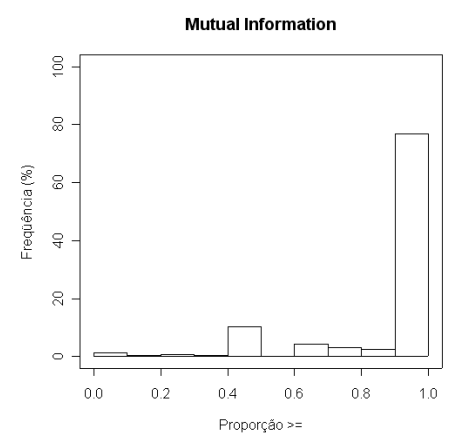

(j) lhs-sup-0-tax01-ND

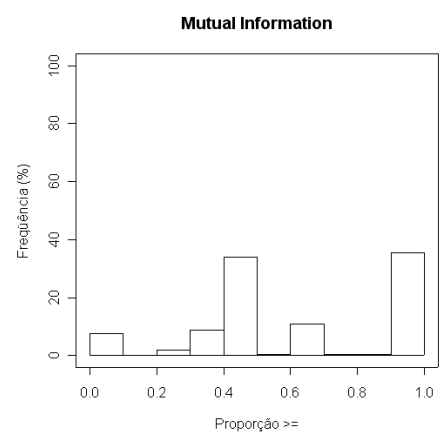

(b) rhs-sup-0-tax $01-1 \mathrm{~N}$

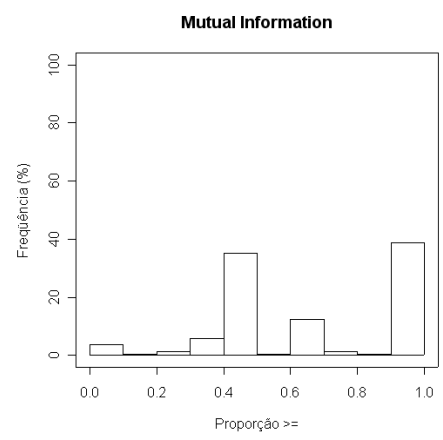

(e) rhs-sup-0-tax01-2N

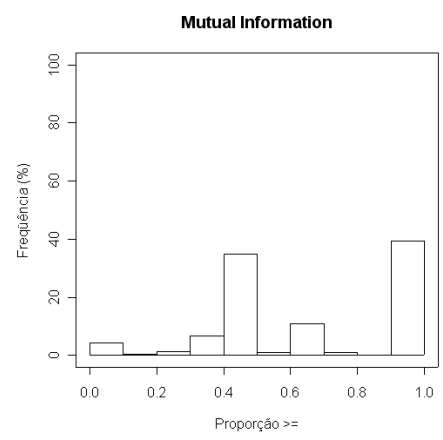

(h) rhs-sup-0-tax01-3N

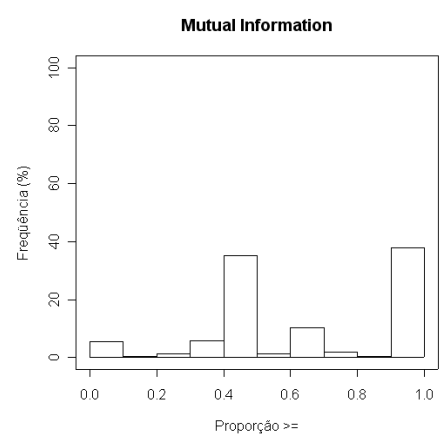

(k) rhs-sup-0-tax01-ND

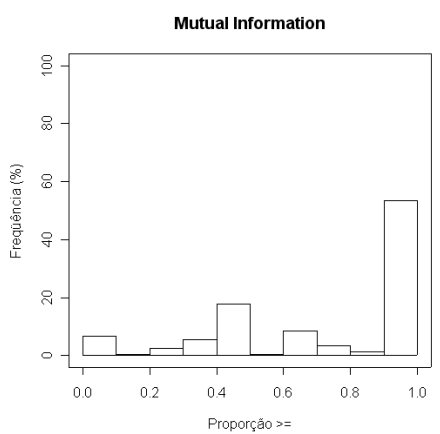

(c) lrhs-sup-0-tax01-1N

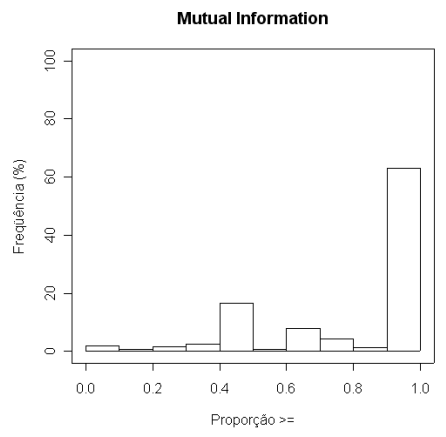

(f) lrhs-sup-0-tax01-2N

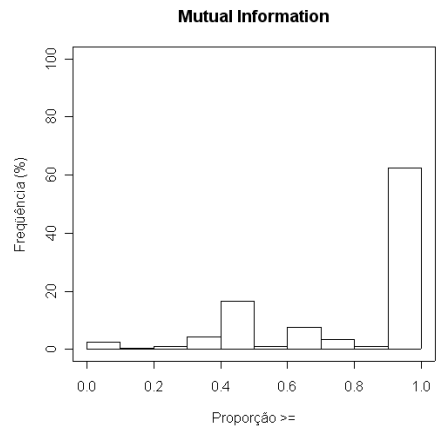

(i) lrhs-sup-0-tax01-3N

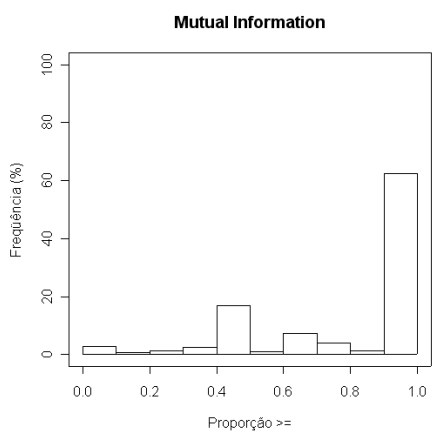

(1) lrhs-sup-0-tax01-ND

Figura I.16: Histogramas referentes a medida Mutual Information. 


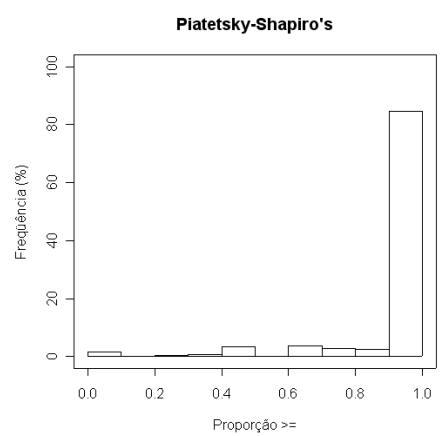

(a) lhs-sup-0-tax01-1N

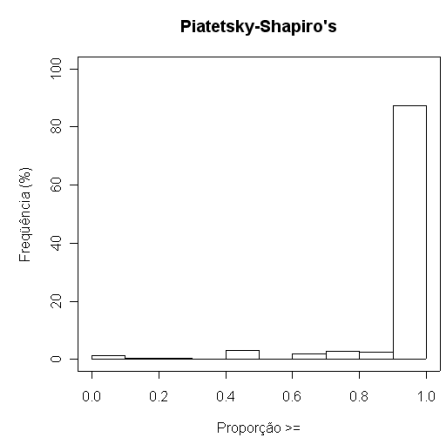

(d) lhs-sup-0-tax01-2N

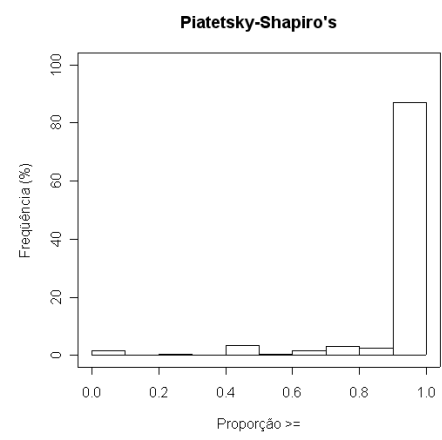

(g) lhs-sup-0-tax01-3N

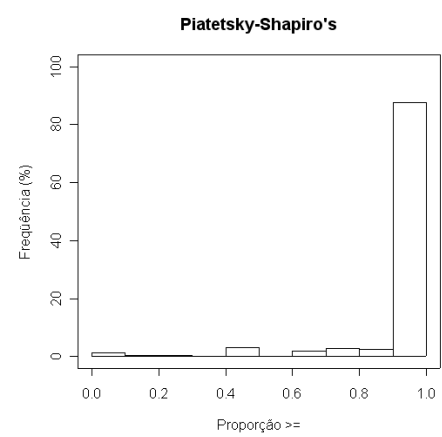

(j) lhs-sup-0-tax01-ND

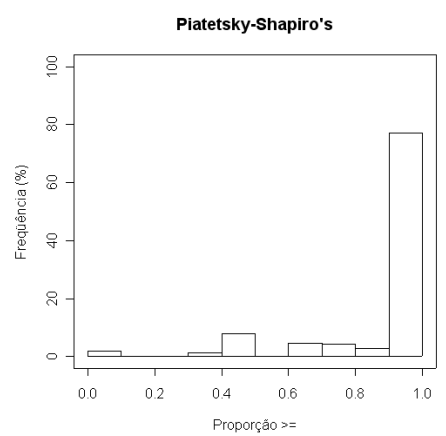

(b) rhs-sup-0-tax $01-1 \mathrm{~N}$

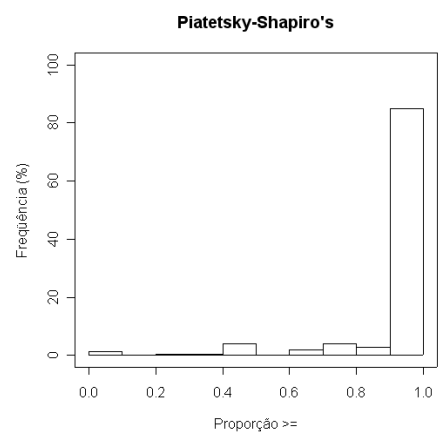

(e) rhs-sup-0-tax01-2N

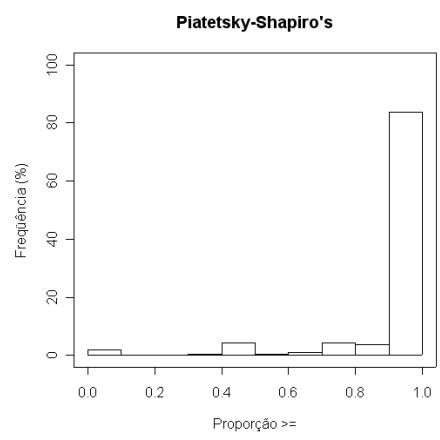

(h) rhs-sup-0-tax01-3N

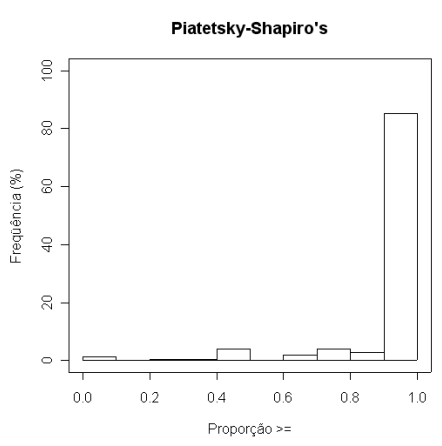

(k) rhs-sup-0-tax01-ND

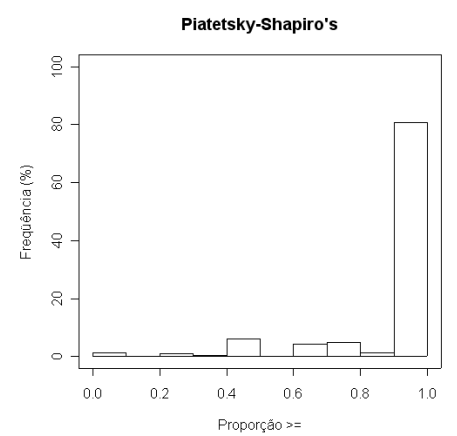

(c) lrhs-sup-0-tax01-1N

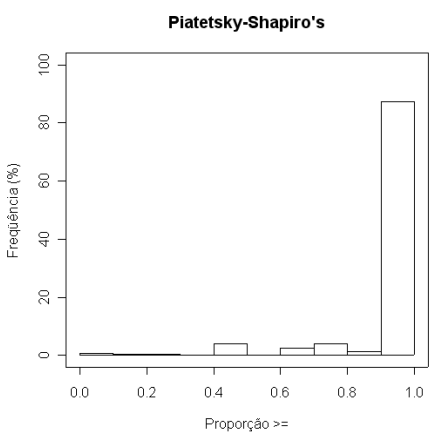

(f) lrhs-sup-0-tax01-2N

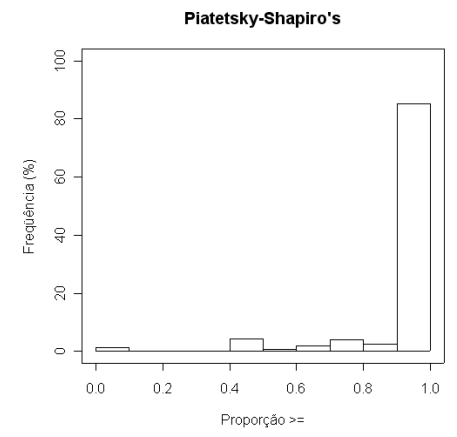

(i) lrhs-sup-0-tax01-3N

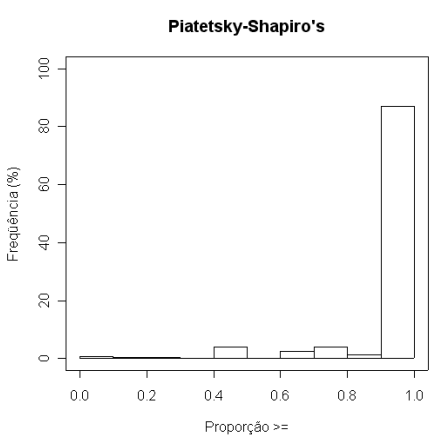

(l) lrhs-sup-0-tax01-ND

Figura I.17: Histogramas referentes a medida Piatetsky-Shapiro's. 


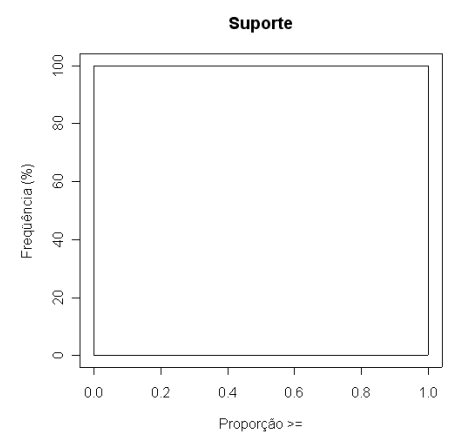

(a) lhs-sup-0-tax $01-1 \mathrm{~N}$

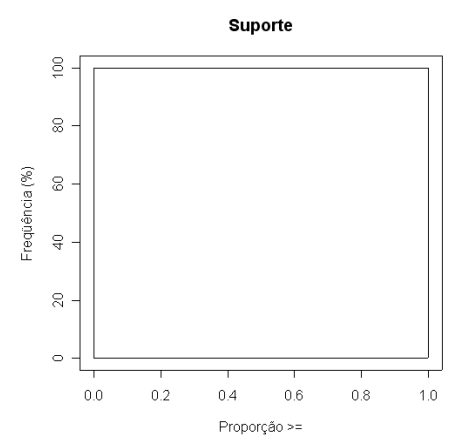

(d) lhs-sup-0-tax01-2N

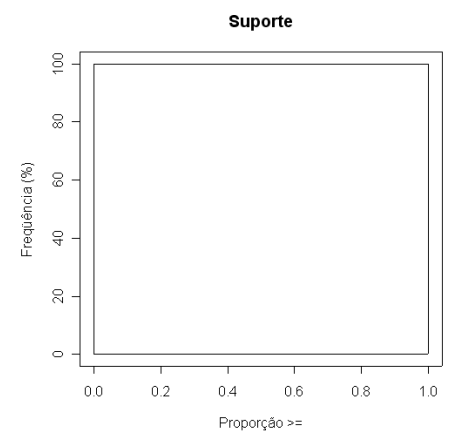

(g) lhs-sup-0-tax01-3N

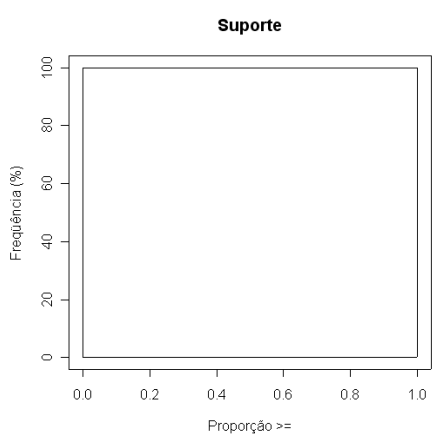

(j) lhs-sup-0-tax01-ND

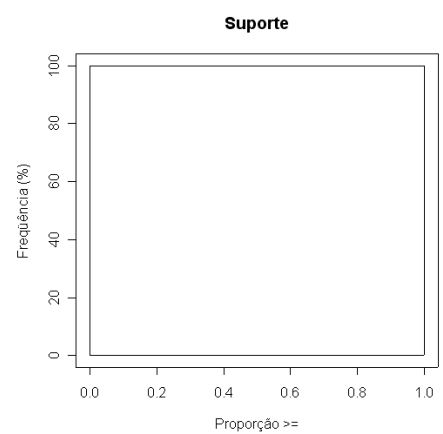

(b) rhs-sup-0-tax $01-1 \mathrm{~N}$

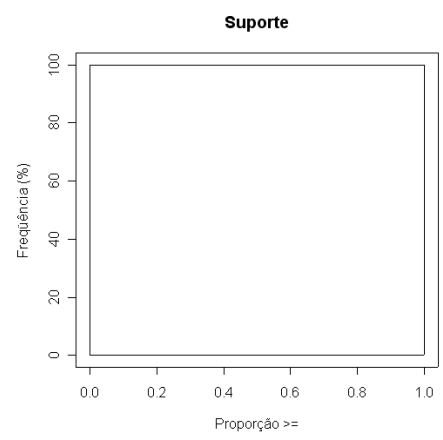

(e) rhs-sup-0-tax01-2N

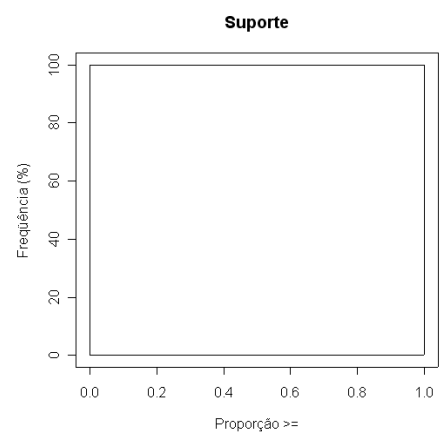

(h) rhs-sup-0-tax01-3N

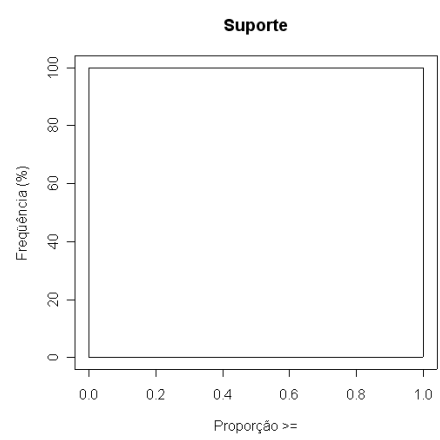

(k) rhs-sup-0-tax01-ND

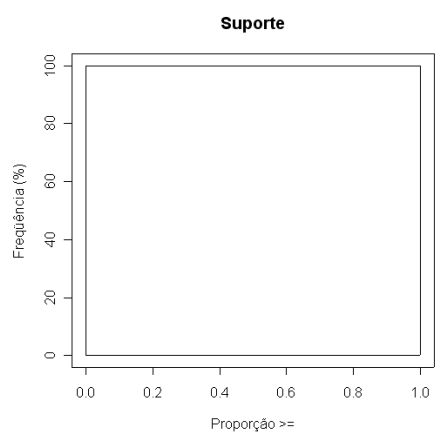

(c) lrhs-sup-0-tax $01-1 \mathrm{~N}$

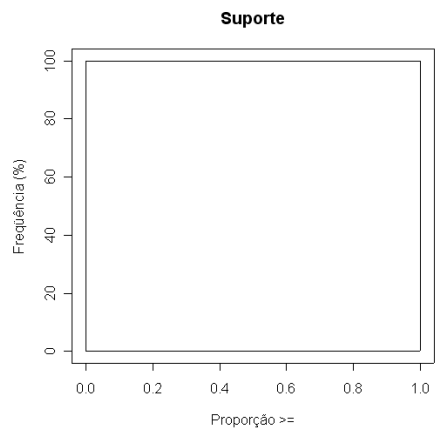

(f) lrhs-sup-0-tax01-2N

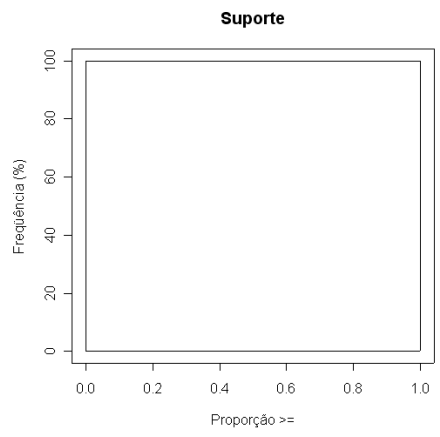

(i) lrhs-sup-0-tax01-3N

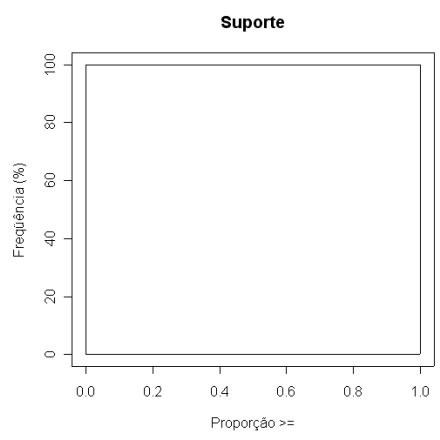

(l) lrhs-sup-0-tax01-ND

Figura I.18: Histogramas referentes a medida Suporte. 


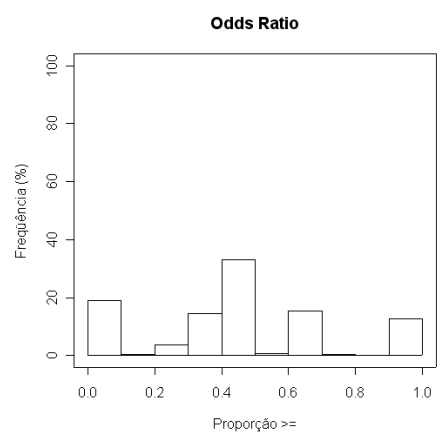

(a) lhs-sup-0-tax $01-1 \mathrm{~N}$

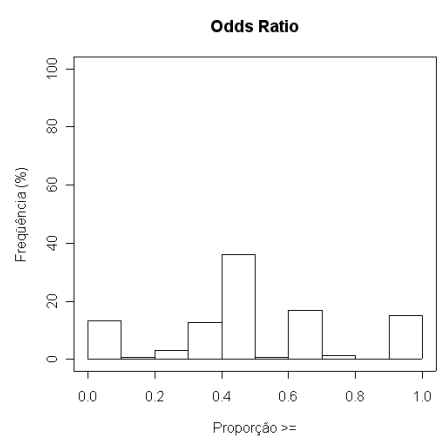

(d) lhs-sup-0-tax01-2N

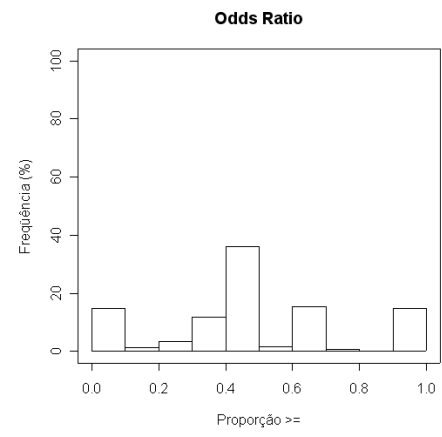

(g) lhs-sup-0-tax01-3N

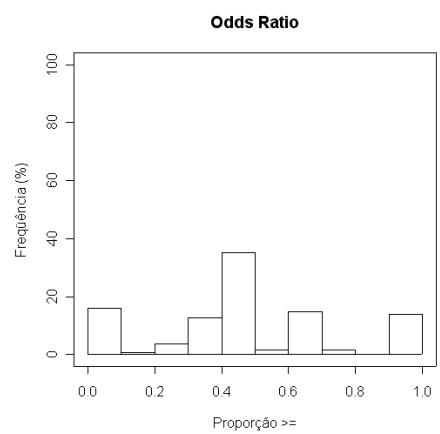

(j) lhs-sup-0-tax01-ND

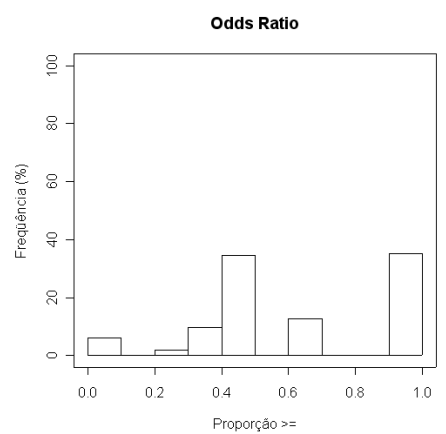

(b) rhs-sup-0-tax01-1N

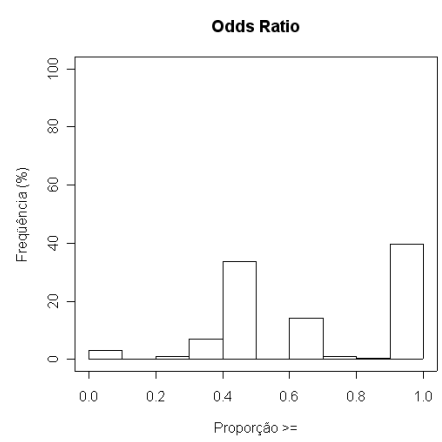

(e) rhs-sup-0-tax01-2N

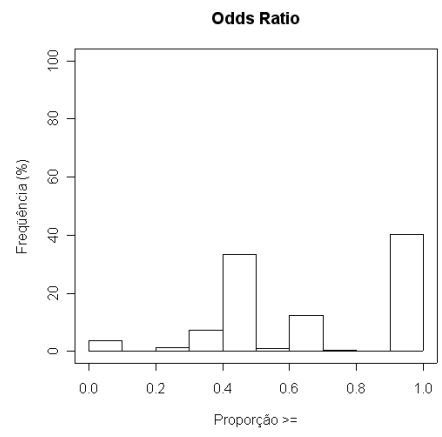

(h) rhs-sup-0-tax01-3N

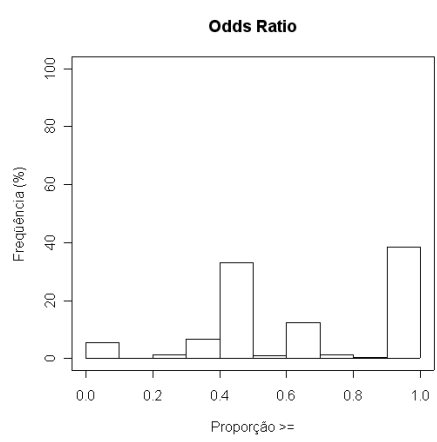

(k) rhs-sup-0-tax01-ND

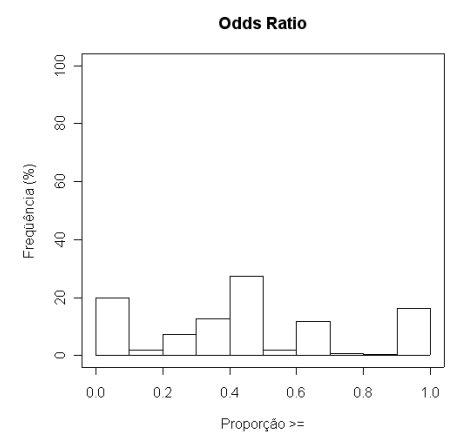

(c) lrhs-sup-0-tax01-1N

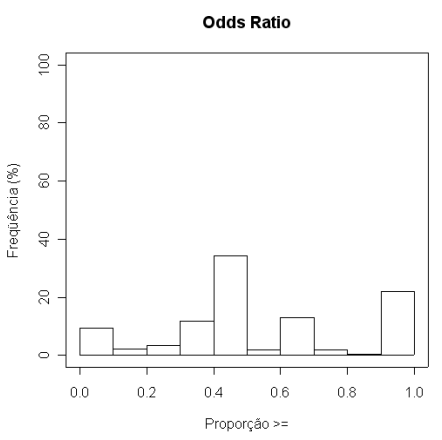

(f) lrhs-sup-0-tax01-2N

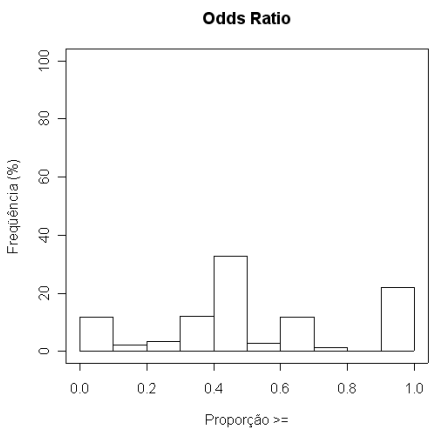

(i) lrhs-sup-0-tax01-3N

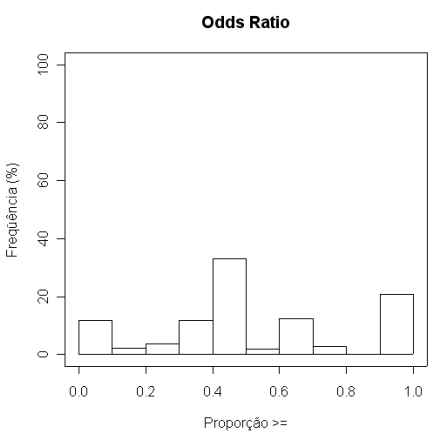

(1) lrhs-sup-0-tax01-ND

Figura I.19: Histogramas referentes a medida Odds Ratio. 


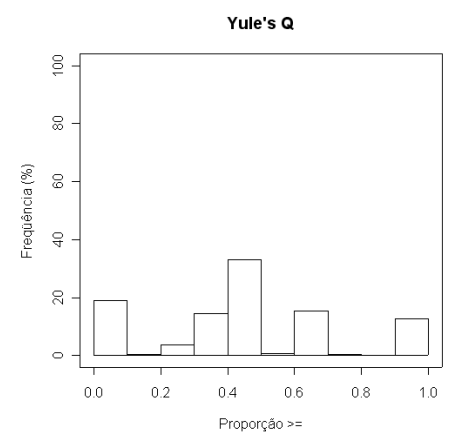

(a) lhs-sup-0-tax01-1N

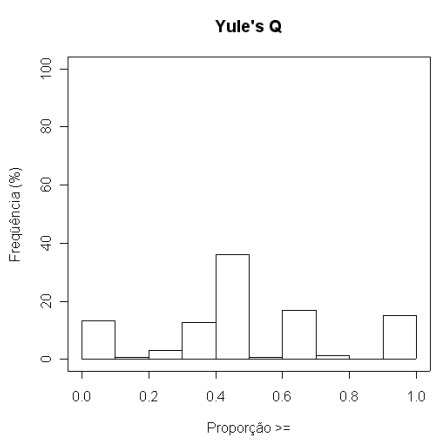

(d) lhs-sup-0-tax01-2N

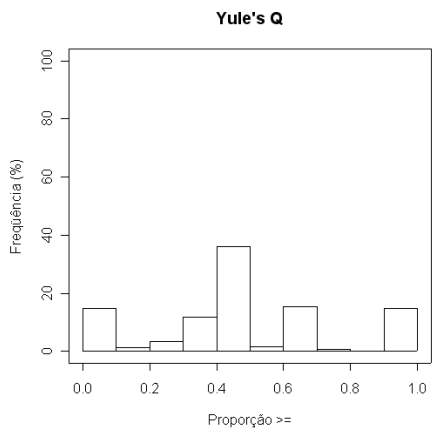

(g) lhs-sup-0-tax01-3N

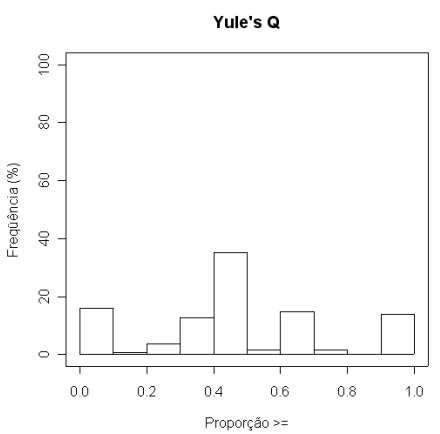

(j) lhs-sup-0-tax01-ND

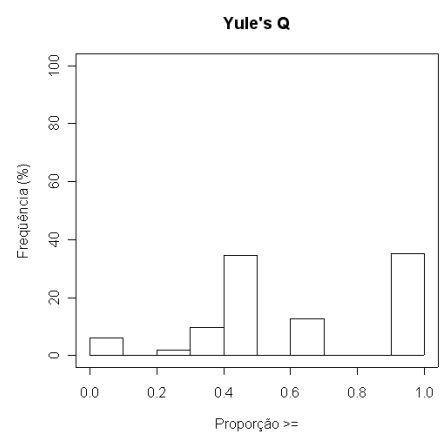

(b) rhs-sup-0-tax $01-1 \mathrm{~N}$

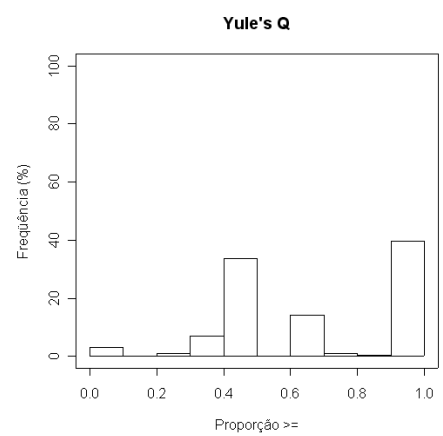

(e) rhs-sup-0-tax01-2N

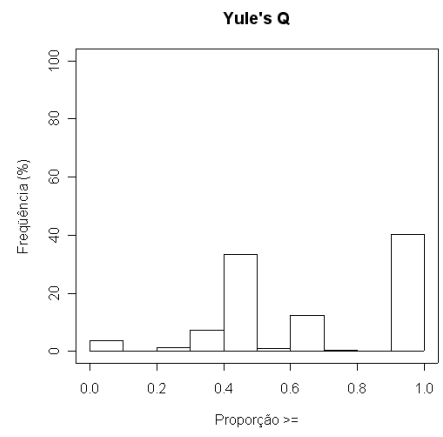

(h) rhs-sup-0-tax01-3N

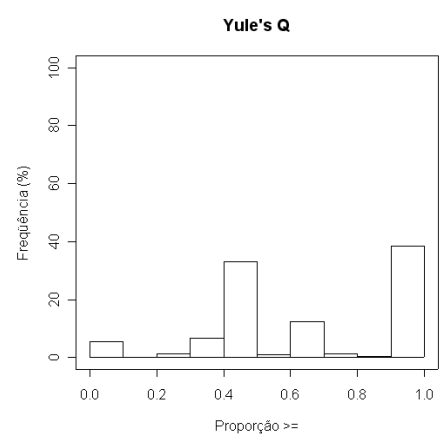

(k) rhs-sup-0-tax01-ND

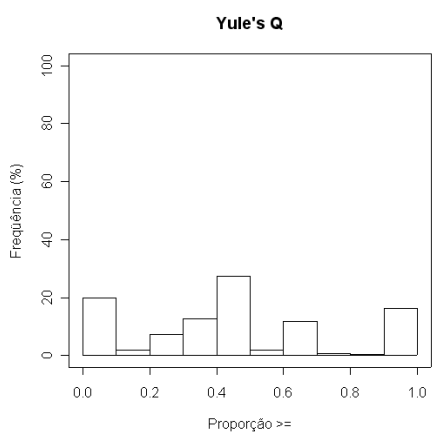

(c) lrhs-sup-0-tax01-1N

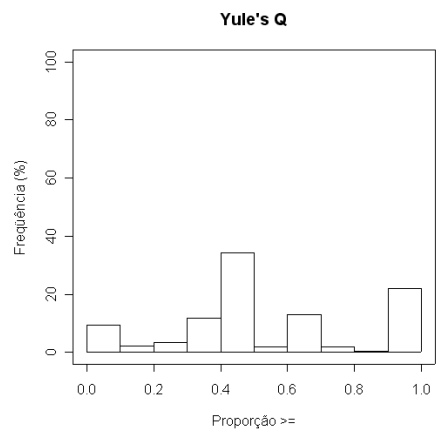

(f) lrhs-sup-0-tax01-2N

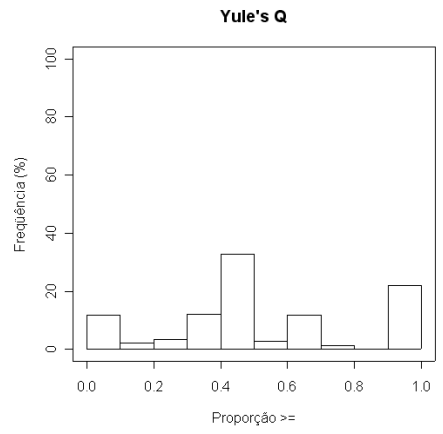

(i) lrhs-sup-0-tax01-3N

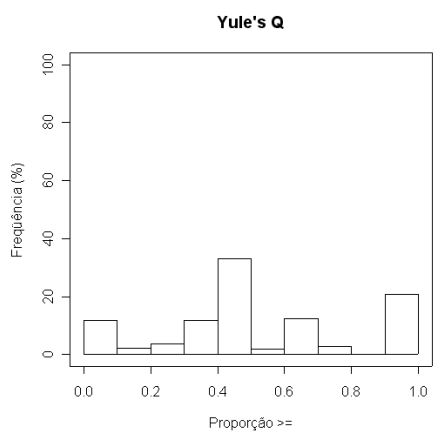

(l) lrhs-sup-0-tax01-ND

Figura I.20: Histogramas referentes a medida Yule's $Q$. 


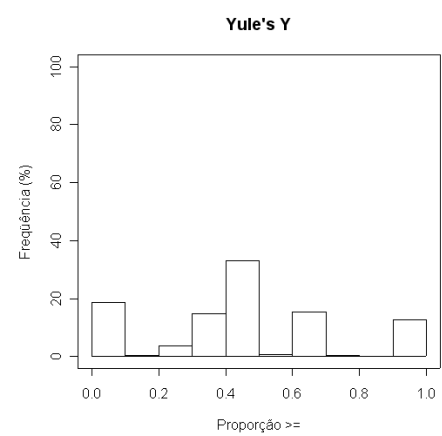

(a) lhs-sup-0-tax $01-1 \mathrm{~N}$

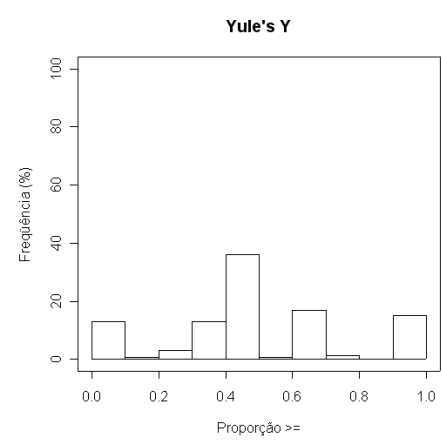

(d) lhs-sup-0-tax01-2N

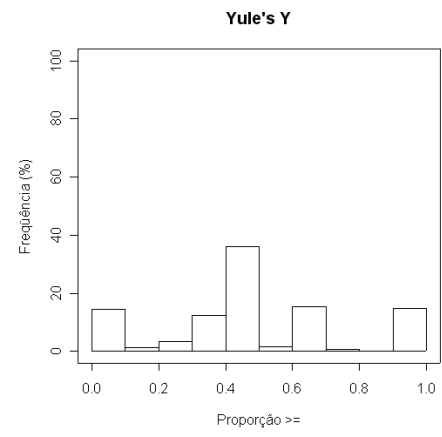

(g) lhs-sup-0-tax01-3N

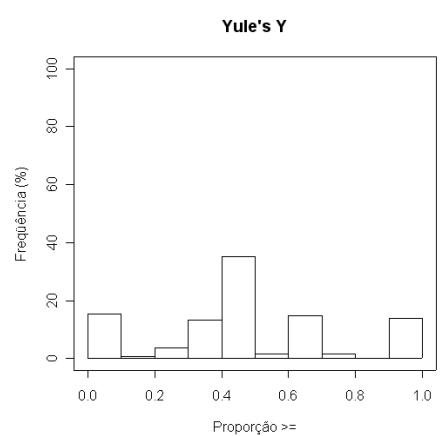

(j) lhs-sup-0-tax01-ND

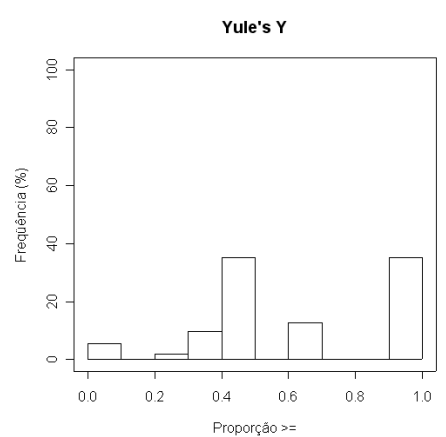

(b) rhs-sup-0-tax01-1N

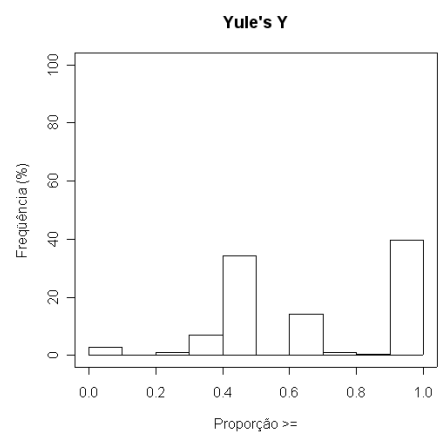

(e) rhs-sup-0-tax01-2N

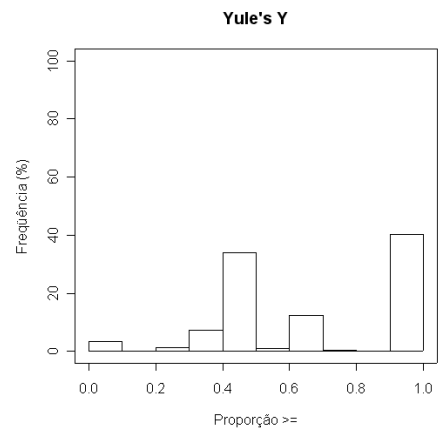

(h) rhs-sup-0-tax01-3N

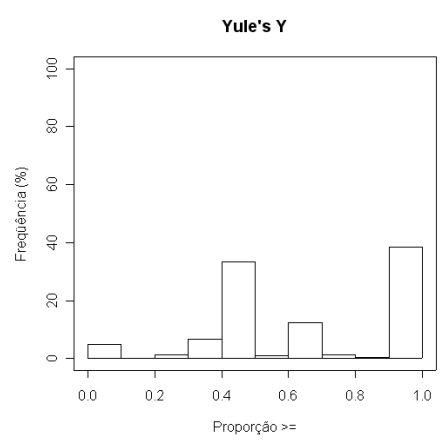

(k) rhs-sup-0-tax01-ND

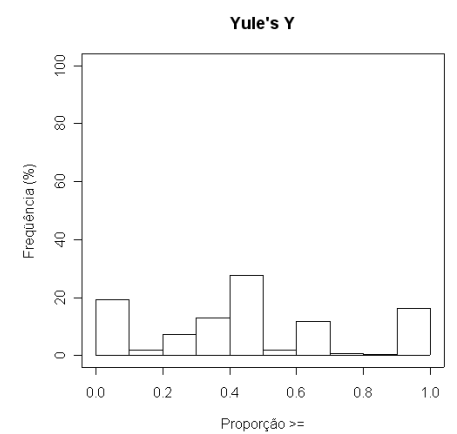

(c) lrhs-sup-0-tax01-1N

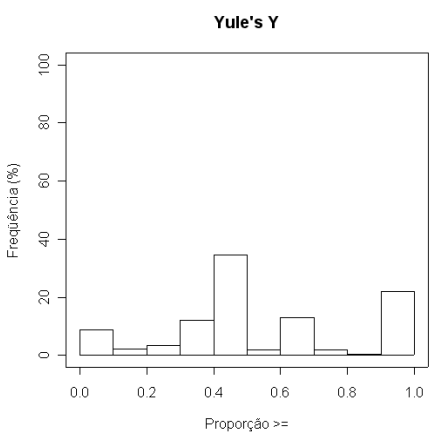

(f) lrhs-sup-0-tax01-2N

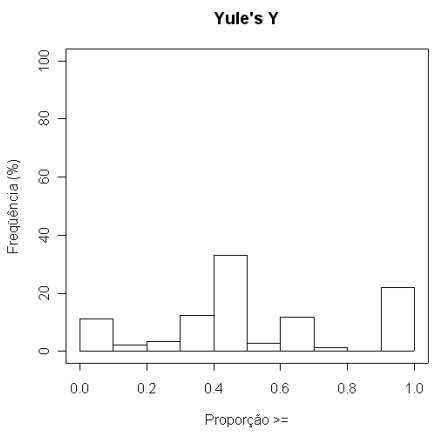

(i) lrhs-sup-0-tax01-3N

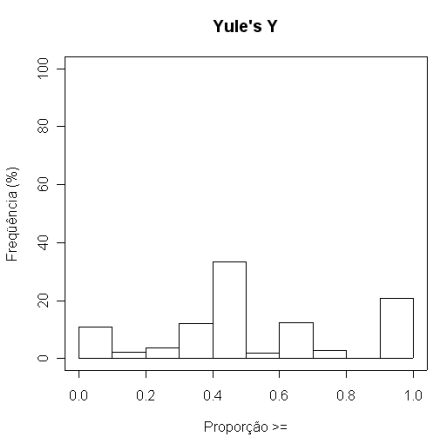

(1) lrhs-sup-0-tax01-ND

Figura I.21: Histogramas referentes a medida Yule's $Y$. 


\section{Referências Bibliográficas}

Adamo, J.-M. (2001). Data mining for association rules and sequential patterns. Springer-Verlag. 2, 14, 25, 33, 34, 36, 37, 92

Adejumo, A. O., C. Heumann, \& H. Toutenburg (2004). A review of agreement measure as a subset of association measure between raters. In Statistical Analysis of Discrete Structures - Applications in Biometrics and Econometrics, pp. 43p. The Collaborative Research Center (SFB) 386. Discussion Paper 385. Disponível em: http://www. stat. uni-muenchen.de/sfb386/papers/dp2004.html [02/03/2007]. 30

Adomavicius, G. \& A. Tuzhilin (2001). Expert-driven validation of rule-based user models in personalization applications. Data Mining and Knowledge Discovery 5(1/2), 33-58. xix, 2, 20, 22, 40, 41, 42, 43, 45, 64, 65, 77, 78, 79, 91

Aggarwal, C. C. \& P. S. Yu (1998). A new framework for itemset generation. In Symposium on Principles of Database Systems, PODS 1998, pp. 18-24. 24

Aggelis, V. (2004). Association rules model of e-banking services. Data Mining VInformation and Communication Technologies 5, 46-55. 2, 7

Agrawal, R., T. Imielinski, \& A. N. Swami (1993). Mining association rules between sets of items in large databases. In P. Buneman \& S. Jajodia (Eds.), Proceedings of the 1993 ACM SIGMOD International Conference on Management of Data, pp. 207-216. Disponível em: http://citeseer.ist.psu.edu/agrawal93mining.html [02/03/2007]. $15,16,17,18,19$

Agrawal, R. \& R. Srikant (1994). Fast algorithms for mining association rules. In J. B. Bocca, M. Jarke, \& C. Zaniolo (Eds.), Proceedings of the 20th International Conference on Very Large Data Bases, VLDB 1994, pp. 487-499. Disponível em: http: //citeseer. ist.psu.edu/agrawal94fast.html [02/03/2007]. 1, 16, 17 
An, A., S. Khan, \& X. Huang (2006). Hierarchical grouping of association rules and its application to a real-world domain. International Journal of Systems Science 37(13), 867-878. 22, 45

Apte, C., B. Liu, E. P. D. Pednault, \& P. Smyth (2002). Business applications of data mining. Communications of the ACM 45(8), 49-53. 1

Baesens, B., S. Viaene, \& J. Vanthienen (2000). Post-processing of association rules. In Proceedings of the Special Workshop on Post-processing, The 6th ACM SIGKDD International Conference on Knowledge Discovery and Data Mining, KDD 2000, pp. 2-8. 2, 20, 21

Baixeries, J., G. Casas, \& J. L. Balcázar (2000). Frequent sets, sequences, and taxonomies: New, efficient algorithmic proposals. Relatório Técnico LSI-00-78-R, Departament de LSI - Universitat Politècnica de Catalunya. Disponível em: http: //citeseer.ist.psu.edu/428618.html [02/03/2007]. 2, 37, 39

Batista, G. E. A. P. A., A. C. P. L. F. Carvalho, \& M. C. Monard (2000). Applying one-sided selection to unbalanced datasets. In Proceedings of the Mexican International Conference on Artificial Intelligence, MICAI 2000, Lecture Notes in Artificial Intelligence, pp. 315-325. Springer-Verlag. 11

Batista, G. E. A. P. A. (2003). Pré-processamento de dados em aprendizado de máquina supervisionado. Tese de Doutorado, Instituto de Ciências Matemáticas e de Computação - USP - São Carlos. 10

Berzal, F., I. Blanco, D. Sánchez, \& M.-A. Vila (2001). A new framework to assess association rules. In F. Hoffmann, D. J. Hand, N. M. Adams, D. H. Fisher, \& G. Guimarães (Eds.), Advances in Intelligent Data Analysis, 4th International Conference, IDA 2001 , Volume 2189 of Lecture Notes in Computer Science, pp. 95-104. 25, 28, 29

Besemann, C., A. Denton, A. Yekkirala, R. Hutchison, \& M. Anderson (2004). Differential association rule mining for the study of protein-protein interaction networks. In 4th Workshop on Data Mining in Bioinformatics in conjunction with The Tenth ACM SIGKDD International Conference on Knowledge Discovery and Data Mining, pp. 1-8. 7

Blanchard, J., F. Guillet, \& H. Briand (2003). Exploratory visualization for association rule rummaging. In Proceedings of the 4th International Workshop on Multimedia Data Mining MDM'03 in Conjunction with KDD'03, pp. 107-114. Disponível em: http://irweb01.polytech.univ-nantes.fr/blanchard/ blanchard2003visualization.pdf [29/04/2004]. 22 
Blanchard, J., F. Guillet, R. Gras, \& H. Briand (2005). Using information-theoretic measures to assess association rule interestingness. In Proceedings of the fifth IEEE International Conference on Data Mining, ICDM 2005, pp. 66-73. IEEE Computer Society. 29

Borlund, P. \& P. Ingwersen (1998). Measures of relative relevance and ranked half-life: Performance indicators for interactive IR. In Proceedings of the 21st Annual International ACM SIGIR Conference on Research and Development in Information Retrieval, SIGIR 1998, New York, NY, USA, pp. 324-331. ACM Press. Disponível em: http://doi .acm. org/10.1145/290941.291019[17/05/2006]. 27

Botta, M., J.-F. Boulicaut, C. Masson, \& R. Meo (2002). A comparison between query languages for the extraction of association rules. In Proceedings of the 4 th International Conference on Data Warehousing and Knowledge Discovery, DaWaK 2002, London, UK, pp. 1-10. Springer-Verlag. 20

Breiman, L. (2000). Some infinity theory for predictor ensemble. Relatório Técnico 577, University of California. Disponível em: http://www.salford-systems.com/doc/ SOME_THEORY2001.pdf [02/03/2007]. 14

Brin, S., R. Motwani, J. D. Ullman, \& S. Tsur (1997). Dynamic itemset counting and implication rules for market basket data. In J. Peckham (Ed.), Proceedings of the ACM SIGMOD International Conference on Management of Data, pp. 255-264. 17, 25

Brisson, L., M. Collard, \& N. Pasquier (2005). Improving the knowledge discovery process using ontologies. In Proceedings of the Mining Complex Data Workshop (MCD'05) in ICDM'05 Conference. 7p. 3, 43

Bruha, I. \& A. Famili (2000). Postprocessing in machine learning and data mining. ACM SIGKDD Explorations Newsletter 2(2), 110-114. Disponível em: http://doi .acm.org/ 10.1145/380995. 381059 [12/04/2004]. 14

Carvalho, D. R., A. A. Freitas, \& N. Ebecken (2005). Evaluating the correlation between objective rule interestingness measures and real human interest. In A. Jorge, L. Torgo, P. Brazdil, R. Camacho, \& J. Gama (Eds.), Proceedings of the 9th European Conference on Principles and Practice of Knowledge Discovery in Databases, PKDD 2005, Volume 3721 of Lecture Notes in Computer Science, pp. 453-461. Springer. 117, 118

Ceglar, A., J. Roddick, P. Calder, \& C. Rainsford (2005). Visualising hierarchical associations. Knowledge and Information Systems 8(3), 257-275. 22

Chakravarthy, S. \& H. Zhang (2003). Visualization of association rules over relational DBMSs. In Proceedings of the 2003 ACM symposium on Applied computing, SAC 2003, New York, NY, USA, pp. 922-926. ACM Press. 22 
Chen, S. Y. \& X. Liu (2005). Data mining from 1994 to 2004: an application-orientated review. International Journal of Business Intelligence and Data Mining 1(1), 4-21. 1

Chen, X., X. Zhou, R. Scherl, \& J. Geller (2003). Using an interest ontology for improved support in rule mining. In Y. Kambayashi, M. K. Mohania, \& W. Wöß (Eds.), 5th International Conference on Data Warehousing and Knowledge Discovery, DaWaK 2003, Volume 2737 of Lecture Notes in Computer Science, pp. 320-329. Springer-Verlag. 2,39

Domingues, M. A., A. M. Jorge, \& C. Soares (2006). Using association rules for monitoring meta-data quality in web portals. In Proceedings of the II Workshop em Algoritmos e Aplicações de Mineração de Dados (WAAMD-2006) - SBBD/SBES, pp. 105-108. 2

Domingues, M. A. \& S. O. Rezende (2005). Using taxonomies to facilitate the analysis of the association rules. In Proceedings of ECML/PKDD'05 - The Second International Workshop on Knowledge Discovery and Ontologies, KDO 2005, pp. 59-66. xix, 2, 14, $22,41,42,43,44,77,78,79,91$

Domingues, M. A. (2004). Generalização de regras de associação. Dissertação de Mestrado, Instituto de Ciências Matemáticas e de Computação - USP - São Carlos. xix, 2, 14, 22, 41, 42, 43, 44, 77, 78, 79, 92

Dong, G. \& J. Li (1998). Interestingness of discovered association rules in terms of neighborhood-based unexpectedness. In Proceedings of the 2nd Pacific-Asia Conference Knowledge Discovery and Data Mining, PAKDD 1998, Volume 1394 of Lecture Notes in Artificial Intelligence, pp. 72-86. 21

Eugenio, B. D. \& M. Glass (2004). The Kappa statistic: A second look. Computational Linguistics 30(1), 95-101. 27

Everitt, B. S. (1977). The analysis of contingency tables. Monographs on Applied Probability and Statistics. Halsted Press (John Wiley \& Sons Inc.). 27, 28

Fayyad, U. M., G. Piatetsky-Shapiro, \& P. Smyth (1996a). From data mining to knowledge discovery: An overview. In U. M. Fayyad, G. Piatetsky-Shapiro, P. Smyth, \& R. Uthurusamy (Eds.), Advances in Knowledge Discovery and Data Mining, Capítulo 1, pp. 1-34. AAAI Press. 1, 7, 8

Fayyad, U. M., G. Piatetsky-Shapiro, \& P. Smyth (1996b). Knowledge discovery and data mining: Towards a unifying framework. In Proceedings of the 2nd International Conference on Knowledge Discovery and Data Mining, KDD 1996, pp. 82-88. AAAI Press. 8 
Fayyad, U. M. (1996). Data mining and knowledge discovery: Making sense out of data. IEEE Expert-Intelligent \& Their Applications 11(5), 20-25. 8

Fisher, D. (1996). Iterative optimization and simplification of hierarchical clusterings. Journal of Artificial Intelligence Research 4, 147-180. Disponível em: http: //citeseer.ist.psu.edu/fisher95iterative.html [22/05/2006]. 26

Fonseca, B. M., P. B. Golgher, E. S. de Moura, \& N. Ziviani (2003). Using association rules to discover search engines related queries. In Proceedings of the First Conference on Latin American Web Congress - LA-WEB'03, pp. 66-71. IEEE Computer Society. 2

Freitas, A. A. (1998). On objective measures of rule surprisingness. In J. M. Zytkow \& M. Quafafou (Eds.), Principles of Data Mining and Knowledge Discovery, Volume 1510 of Lecture Notes in Artificial Intelligence, pp. 1-9. Disponível em: http://citeseer. ist.psu.edu/21646.html [14/04/2004]. 21

Fujimoto, M. L., V. O. Carvalho, \& S. O. Rezende (2007). Descrição do módulo de exploração de regras de associação generalizadas RULEE-RAG. Relatório Técnico 296, Instituto de Ciências Matemáticas e de Computação - USP - São Carlos. 80

Fule, P. \& J. F. Roddick (2004). Experiences in building a tool for navigating association rule result set. In M. Purvis (Ed.), Proceedings of the 2nd Workshop on Australasian Information Security, Data Mining and Web Intelligence, and Software Internationalization, Volume 32, pp. 103-108. Disponível em: http://delivery.acm.org/10.1145/980000/976455/p103-fule.pdf?key1=976455 \ \&key2=0508932801 \\&coll=GUIDE \\&dl=ACM \\&CFID=20319918\\&CFTOKEN=76185555 [29/04/2004]. 22

Galindo, M. G. L., P. S. S. Coelho, \& G. Lachtermacher (2002). Usando taxonomias para criar regras de associação: Aplicação em uma base de dados transacional. In $X I$ Latin-Iberian American Congress of Operations Research, CLAIO 2002, Volume 1, pp. 102-110. 2, 39

Garcia, E. (2005). C-indices and measures of associations - Understanding c-indices, association measures and co-occurrence patterns. Internet: Mi Islita.com. Disponível em: http://www.miislita.com/semantics/c-index-2.html[22/05/2006]. 27

Geng, L. \& H. J. Hamilton (2006). Interestingness measures for data mining: A survey. In ACM Computing Surveys, Volume 38. ACM Press. 23, 91

Giha, F. E., Y. P. Singh, \& H. T. Ewe (2006). Mining generalized customer profiles. In International Conference on Artificial Intelligence and Machine Learning, AIML 2006, Volume 1, pp. 141-147. 2, 39 
Glymour, C., D. Madigan, D. Pregibon, \& P. Smyth (1997). Statistical themes and lessons for data mining. Data Mining and Knowledge Discovery 1(1), 11-28. Disponível em: http://citeseer.nj.nec.com/glymour96statistical.html [12/04/2004]. 11

Goethals, B., J. V. Bussche, \& K. Vanhoof (1998). Decision support queries for the interpretation of data mining results. Manuscript. Disponível em: http://citeseer. ist.psu.edu/goethals98decision.html [29/04/2004]. 20

Gonçalves, E. C. \& A. Plastino (2004). Mining strong associations and exceptions in the STULONG data set. In Discovery Challenge. In 8th European Conference on Principles and Practice of Knowledge Discovery in Databases, PKDD 2004, pp. 44-55. Disponível em: http://lisp.vse.cz/challenge/ecmlpkdd2004/[19/05/2006]. 25

Graaf, J. M., W. A. Kosters, \& J. J. W. Witteman (2000). Interesting association rules in multiple taxonomies. In A. V. D. Bosch \& H. Weigand (Eds.), Proceedings of the 12th Belgium-Netherlands Artificial Intelligence Conference, BNAIC 2000, pp. 93-100. Disponível em: http://citeseer.nj.nec.com/degraaf00interesting.html [14/04/2004]. 92

Han, J. \& Y. Fu (1995). Discovery of multiple-level association rules from large databases. In U. Dayal, P. M. D. Gray, \& S. Nishio (Eds.), Proceedings of 21th International Conference on Very Large Data Bases, VLDB 1995, pp. 420-431. Disponível em: http://citeseer.nj.nec.com/han95discovery.html [13/07/2004]. 2, 39

Han, J. \& Y. Fu (1999). Mining multiple-level association rules in large databases. IEEE Transactions on Knowledge and Data Engineering 11(5), 798-805. 92

Hilderman, R. J. \& H. J. Hamilton (1999). Knowledge discovery and interestingness measures: A survey. Relatório Técnico Report CS 99-04, Department of Computer Science, University of Regina. Disponível em: http://citeseer.ist.psu.edu/ hilderman99knowledge.html [29/04/2004]. 21

Hilderman, R. J. \& H. J. Hamilton (2001). Evaluation of interestingness measures for ranking discovered knowledge. In Proceedings of the 5th Pacific-Asia Conference on Knowledge Discovery and Data Mining, PAKDD 2001, pp. 247-259. 10

Hilderman, R. \& H. J. Hamilton (2000). Applying objective interestingness measures in data mining systems. In D. A. Zighed, J. Komorowski, \& J. Zytkow (Eds.), Proceedings of the 4 th European Symposium on Principles of Data Mining and Knowledge Discovery, PKDD 2000, Volume 1910 of Lecture Notes in Artificial Intelligence, pp. 432-439. Springer-Verlag. 2 
Hipp, J., U. Güntzer, \& G. Nakhaeizadeh (2002). Data mining of association rules and the process of knowledge discovery in databases. In Advances in Data Mining, Volume 2394 of Lecture Notes in Artificial Intelligence, pp. 15-36. Disponível em: http: //citeseer.nj.nec.com/534971.html [12/04/2004]. 7, 15

Hipp, J., C. Mangold, U. Guntzer, \& G. Nakhaeizadeh (2002). Efficient rule retrieval and postponed restrict operations for association rule mining. In M.-S. Cheng, P. S. Yu, \& B. Liu (Eds.), 6th Pacific-Asia Conference on Knowledge Discovery and Data Mining, PAKDD 2002, Volume 2336 of Lecture Notes in Computer Science, pp. 52-65. 20, 23

Hipp, J., A. Myka, R. Wirth, \& U. Güntzer (1998). A new algorithm for faster mining of generalized association rules. In J. M. Zytkow \& M. Quafafou (Eds.), Proceedings of the 2nd European Symposium on Principles of Data Mining and Knowledge Discovery, PKDD 1998, pp. 74-82. Disponível em: http://citeseer.nj.nec.com/hipp98new. html $[13 / 07 / 2004]$. 2, 39

Houaiss, A. (2001). Dicionário eletrônico Houaiss da língua portuguesa. CD-ROM versão 1.0 para Windows. Rio de Janeiro, Objetiva Ltda. 65

Houtsma, M. \& A. Swami (1995). Set-oriented mining for association rules in relational databases. In P. S. Yu \& A. L. P. Chen (Eds.), Proceedings of the 11th International Conference on Data Engineering, pp. 25-33. 17

Hou, X., J. Gu, X. Shen, \& W. Yan (2005). Application of data mining in fault diagnosis based on ontology. In Proceedings of the Third International Conference on Information Technology and Applications, ICITA 2005, Volume 2, Washington, DC, USA, pp. 260263. IEEE Computer Society. 3, 43, 46

Huang, Y.-F. \& C.-M. Wu (2002). Mining generalized association rules using pruning techniques. In Proceedings of the 2002 IEEE International Conference on Data Mining, ICDM 2002, Washington, DC, USA, pp. 227-234. IEEE Computer Society. 35

Hussain, F., H. Liu, \& H. Lu (2000). Relative measure for mining interesting rules. In 4th European Conference on Principles and Practice of Knowledge Discovery in Databases PKDD'00 - Workshop in Knowledge Management: Theory and Applications, pp. 16p. Disponível em: http://citeseer.nj.nec.com/hussain00relative.html [18/07/2003]. 21

Hussain, F., H. Liu, E. Suzuki, \& H. Lu (2000). Exception rule mining with a relative interestingness measure. In Pacific-Asia Conference on Knowledge Discovery and Data Mining, PAKDD 2000, pp. 86-97. 21 
Huynh, X.-H., F. Guillet, \& H. Briand (2005). ARQAT: An exploratory analysis tool for interestingness measures. In Proceedings of the 11th International Symposium on Applied Stochastic Models and Data Analysis, ASMDA 2005, pp. 334-344. 21

Imieliński, T. \& A. Virmani (1998). Association rules...and what's next? - Towards second generation data mining systems. In W. Litwin, T. Morzy, \& G. Vossen (Eds.), Advances in Databases and Information Systems, Proceedings of the 2nd East European Symposium, ADBIS 1998, Volume 1475 of Lecture Notes in Computer Science, pp. 6-25. 20,45

Itskevitch, J. (2001). Automatic hierarchical e-mail classification using association rules. Dissertação de Mestrado, Simon Fraser University - Department of Computing Sciences. 26

Jaroszewicz, S. \& D. A. Simovici (2002). Pruning redundant associations rules using maximum entropy principle. In M.-S. Chen, P. S. Yu, \& B. Liu (Eds.), Advances in Knowledge Discovery and Data Mining, 6th Pacific-Asia Conference, PAKDD 2002, Volume 2336 of Lecture Notes in Artificial Intelligence, pp. 135-147. 21

Jorge, A., J. Poças, \& P. Azevedo (2002). A post-processing environment for browsing large sets of associations rules. In Proceedings of IDDM'02 Workshop on Integration Aspects of Decision Support and Data Mining, pp. 12p. Disponível em: http://www . niaad.liacc.up.pt/ amjorge/Projectos/Class/ [18/07/2003]. 21, 23

Jorge, A. (2004). Hierarchical clustering for thematic browsing and summarization of large sets of association rules. In M. W. Berry, U. Dayal, C. Kamath, \& D. Skillicorn (Eds.), Proceedings of the 4th SIAM International Conference on Data Mining SIAM’04, pp. 10p. Disponível em: http://www.niaad.liacc.up.pt/ amjorge/ Projectos/content-mgm/documents.html [29/04/2004]. 2, 20, 22

Klemettinen, M., H. Mannila, P. Ronkainen, H. Toivonen, \& A. I. Verkamo (1994). Finding interesting rules from large sets of discovered association rules. In N. R. Adam, B. K. Bhargava, \& Y. Yesha (Eds.), 3rd International Conference on Information and Knowledge Management, CIKM 1994, pp. 401-407. ACM Press. Disponível em: http: //citeseer.ist.psu.edu/klemettinen94finding.html [22/07/2004]. 23

Klemettinen, M., H. Mannila, \& I. Verkamo (1999). Association rule selection in a data mining environment. In J. M. Zytkow \& J. Rauch (Eds.), Principles of Data Mining and Knowledge Discovery, 3rd European Conference, PKDD 1999, Volume 1704 of Lecture Notes in Artificial Intelligence, pp. 372-377. 23 
Klösgen, W. (1996). Explora: A multipattern and multistrategy discovery assistant. In U. M. Fayyad, G. Piatetsky-Shapiro, P. Smyth, \& R. Uthurusamy (Eds.), Advances in Knowledge Discovery and Data Mining, Capítulo 10, pp. 249-271. AAAI Press. 30

Lavrač, N., P. Flach, \& R. Zupan (1999). Rule evaluation measures: A unifying view. In S. Dzeroski \& P. Flach (Eds.), Proceedings of the 9th International Workshop on Inductive Logic Programming, ILP 1999, Volume 1634 of Lecture Notes in Artificial Intelligence, pp. 174-185. Springer-Verlag. 14, 18, 21, 23

Lee, H. D. (2000). Seleção e construção de features relevantes para o aprendizado de máquina. Dissertação de Mestrado, Instituto de Ciências Matemáticas e de Computação - USP - São Carlos. 12

Lee, H. D. (2005). Seleção de atributos importantes para a extração de conhecimento de bases de dados. Tese de Doutorado, Instituto de Ciências Matemáticas e de Computação - USP - São Carlos. 11

Lee, S. J. \& K. Siau (2001). A review of data mining techniques. Industrial Management $\&$ Data Systems 101(1), 41-46. 1

Lent, B., A. N. Swami, \& J. Widom (1997). Clustering association rules. In Proceedings of the Thirteenth International Conference on Data Engineering, ICDE 1997, Washington, DC, USA, pp. 220-231. IEEE Computer Society. 22

Liu, B., W. Hsu, S. Chen, \& Y. Ma (2000). Analyzing the subjective interestingness of association rules. IEEE Intelligent Systems 86 their Applications 15(5), 47-55. 14, 21, 23,34

Liu, B., W. Hsu, \& Y. Ma (1999). Pruning and summarizing the discovered associations. In Proceedings of the 5th ACM SIGKDD International Conference on Knowledge Discovery and Data Mining, KDD 1999, pp. 125-134. 21

Liu, B. \& W. Hsu (1996). Post-analysis of learned rules. In Proceedings of the 13th National Conference on Artificial Intelligence, AAAI 1996, pp. 828-834. 10

Liu, B., M. Hu, \& W. Hsu (2000). Multi-level organization and summarization of the discovered rules. In Knowledge Discovery and Data Mining, SIGKDD 2000, pp. 208-217. Disponível em: http://citeseer.ist.psu.edu/liu00multilevel.html [14/04/2004]. 22,45

Lourenço, F., V. Lobo, \& F. Baçäo (2004). Binary-based similarity measures for categorical data and their application in self-organizing maps. In XI Jornadas de Classificação e Análise de Dados, JOCLAD 2004 - Lisboa/Portugal. 18p. Disponível 
em: http://www.isegi.unl.pt/ensino/docentes/fbacao/Lourenco_joclad04.pdf [02/03/2007]. 27

Lui, C.-L. \& F.-L. Chung (2000). Discovery of generalized association rules with multiple minimum supports. In Proceedings of the 4th European Conference on Principles of Data Mining and Knowledge Discovery, PKDD 2000, Volume 1910 of Lecture Notes in Artificial Intelligence, pp. 510-515. Springer-Verlag. 92

Ma, Y., B. Liu, \& C. K. Wong (2000). Web for data mining: Organizing and interpreting the discovered rules using the web. SIGKDD Explorations 2(1), 16-23. 22, 23

Ma, Y., C. K. Wong, \& B. Liu (2000). Effective browsing of the discovered association rules using the web. In ACM SIGKDD-2000 Workshop on Post-Processing in Machine Learning and Data Mining, pp. 8p. Disponível em: http://www.cs.uic.edu/ liub/ publications/papers_topics.html [02/03/2007]. 2, 22, 23

McGarry, K. (2005). A survey of interestingness measures for knowledge discovery. Knowledge Engineering Review 20(1), 39-61. 45

Melanda, E. A. \& S. O. Rezende (2003a). Pós-processamento de regras de associação com o uso de medidas objetivas. In IV Workshop on Advances $\&$ Trends in AI for Problem Solving, ATAI 2003. 14, 20, 21

Melanda, E. A. \& S. O. Rezende (2003b). Sintaxe padrão para representar regras de associação. Relatório Técnico 206, Instituto de Ciências Matemáticas e de Computação - USP - São Carlos. 17

Melanda, E. A. \& S. O. Rezende (2003c). Uso combinado de medidas objetivas como filtro de regras de associação. In Proceedings of the 4 th Congress of Logic Applied to Technology Conference, LAPTEC 2003, Volume 2, pp. 170-178. 14, 20, 21

Metwally, A., D. Agrawal, \& A. E. Abbadi (2005). Using association rules for fraud detection in web advertising networks. In Proceedings of the 31st international conference on very large data bases - VLDB'05, pp. 169-180. 2

Mishra, S. \& R. G. Knowlton (2003). Testing for input-output dependence in performance assessment models. In 10th International High-Level Radioactive Waste Management Conference, IHLRWM 2003, pp. 882-887. 29

Natarajan, R. \& B. Shekar (2005). Interestingness of association rules in data mining: Issues relevant to e-commerce. $S \bar{A} D H A N \bar{A}-$ Academy Proceedings in Engineering Sciences (The Indian Academy of Sciences) 30(Parts 2\&3), 291-310. 2, 3, 20, 45 
Nawarecki, E., M. A. Valenta, \& A. Zygmunt (2003). Mining association rules. In Artificial Intelligence Methods, AI-METH 2003, pp. 203-206. Disponível em: http: //kpkm.mt.polsl.gliwice.pl:8083/papers/41.pdf [29/04/2004]. 22

Ohsaki, M., S. Kitaguchi, K. Okamoto, H. Yokoi, \& T. Yamaguchi (2004). Evaluation of rule interestingness measures with a clinical dataset on hepatitis. In J.-F. Boulicaut, F. Esposito, F. Giannotti, \& D. Pedreschi (Eds.), Proceedings of the 8th European Conference on Principles and Practice of Knowledge Discovery in Databases, PKDD 2004, Volume 3202 of Lecture Notes in Artificial Intelligence, pp. 362-373. Springer-Verlag New York, Inc. 23

Oliveira, S., O. Zaane, \& Y. Saygin (2004). Secure association rule sharing. In H. Dai, R. Srikant, \& C. Zhang (Eds.), Proceedings of the 8th Pacific-Asia Conference, PAKDD 2004, Volume 3056 of Lecture Notes in Artificial Intelligence, pp. 74-85. Springer. 7

Omiecinski, E. R. (2003). Alternative interest measures for mining associations in databases. IEEE Transactions on Knowledge and Data Engineering 15(1), 57-69. 21

Park, J. S., M.-S. Chen, \& P. S. Yu (1997). Using a hash-based method with transaction trimming for mining association rules. IEEE Transactions on Knowledge and Data Engineering 9(5), 813-825. 17

Paula, M. F. (2003). Ambiente para exploração de regras. Dissertação de Mestrado, Instituto de Ciências Matemáticas e de Computação - USP - São Carlos. 20, 23, 79, 80

Pei, J., J. Han, \& R. Mao (2000). CLOSET: An efficient algorithm for mining frequent closed itemsets. In D. Gunopulos \& R. Rastogi (Eds.), Proceedings of ACM SIGMOD Workshop on Research Issues in Data Mining and Knowledge Discovery, pp. 21-30. Disponível em: http://citeseer.nj.nec.com/pei00closet.html [12/04/2004]. 17

Piatetsky-Shapiro, G. \& C. J. Matheus (1994). The interestingness of deviations. In Proceedings of the Knowledge Discovery in Databases, KDD 1994, pp. 23-36. Disponível em: http://citeseer.nj.nec.com/piatetsky-shapiro94interestingness.html [20/03/2003]. 10

Pohle, D.-K. C. (2003). Integrating and updating domain knowledge with data mining. In M. H. Scholl \& T. Grust (Eds.), Proceedings of the International Conference on Very Large Data Bases, VLDB 2003, PhD Workshop, Volume 76. CEUR Workshop Proceedings (CEUR-WS .org). 5p. Disponível em: CEUR-ws.org/Vol-76/pohle.pdf [23/01/2007]. 40

Pramudiono, I. \& M. Kitsuregawa (2004). FP-tax: Tree structure based generalized association rule mining. In Proceedings of the 9th ACM SIGMOD - Workshop on Re- 
search Issues in Data Mining and Knowledge Discovery, DMKD 2004, New York, NY, USA, pp. 60-63. ACM Press. 2, 39

Rajkumar, N., M. R. Karthik, \& S. N. Sivanandam (2003). Fast algorithm for mining multilevel association rules. In IEEE TENCON 2003 Conference on Convergent Technologies for the Asia-Pacific Region, Volume 2, pp. 688-692. 2, 39

Rezende, S. O., J. B. Pugliesi, E. A. Melanda, \& M. F. Paula (2003). Mineração de dados. In S. O. Rezende (Ed.), Sistemas Inteligentes: Fundamentos e Aplicações (1 ed.)., Capítulo 12, pp. 307-335. Manole. 8, 9

Rezende, S. O. (2004). De dados a conhecimento: Evolução e desafios. Tese de Livre Docência. Instituto de Ciências Matemáticas e de Computação - USP - São Carlos. 7, 15

RimRod (2002). Associative symmetry: An examination of the representation of associations in human memory. Internet. Disponível em: http://everything2.com/index. pl?node_id=1320138 [24/05/2006]. 30

Sahar, S. (2002). Exploring interestingness through clustering: A framework. In Proceedings of the 2002 IEEE International Conference on Data Mining, ICDM 2002, pp. 677-680. 22

Sahar, S. (2003). What Is Interesting: Studies on Interestingness in Knowledge Discovery. Tese de Doutorado, Tel-Aviv University - Raymond and Beverly Sackler Faculty of Exact Sciences. 23

Scheffer, T. \& S. Wrobel (2003). Finding the most interesting patterns in a database quickly by using sequential sampling. Journal of Machine Learning Research 3, 833-862. 30

Semenova, T., M. Hegland, W. Graco, \& G. Williams (2001). Effectiveness of mining association rules for identifying trends in large health databases. In F. J. Kurfess \& M. Hilario (Eds.), Workshop on Integrating Data Mining and Knowledge Management, The 2001 IEEE International Conference on Data Mining, ICDM 2001, pp. 12p.

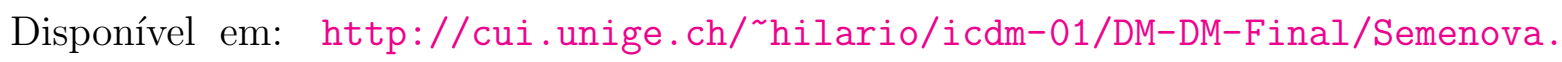
pdf $[19 / 11 / 2003] .2$

Shah, D., L. V. S. Lakshmanan, K. Ramamritham, \& S. Sudarshan (1999). Interestingness and pruning of mined patterns. In 1999 ACM SIGMOD Workshop on Research Issues in Data Mining and Knowledge Discovery, pp. 5p. 21 
Shekar, B. \& R. Natarajan (2004). A framework for evaluating knowledge-based interestingness of association rules. Fuzzy Optimization and Decision Making 3(2), 157-185. 45

Shortliffe, E. H. \& B. G. Buchanan (1990). A model of inexact reasoning in medicine. Readings in Uncertain Reasoning, 259-275. 24

Silberschatz, A. \& A. Tuzhilin (1995). On subjective measures of interestingness in knowledge discovery. Proceedings of the 1st International Conference on Knowledge Discovery and Data Mining KDD'95 1, 275-281. 21

Silberschatz, A. \& A. Tuzhilin (1996). What makes patterns interesting in knowledge discovery systems. IEEE Transactions on Knowledge and Data Engineering 8(6), 970974. 20, 21

SISA (2007). Overview of procedures: Two by two tables. Internet - Simple Interactive Statistical Analysis - SISA. Disponível em: http://home.clara.net/sisa/ [19/02/2007]. 31

Smaldon, J. \& A. A. Freitas (2006). A new version of the Ant-Miner algorithm discovering unordered rule sets. In Proceedings of the 8th Annual Conference on Genetic and Evolutionary Computation, GECCO 2006, New York, NY, USA, pp. 43-50. ACM Press. 28

Smyth, P. \& R. M. Goodman (1991). Rule induction using information theory. In G. Piatetsky-Shapiro \& W. J. Frawley (Eds.), Knowledge Discovery in Databases, pp. 159-176. 26

Srikant, R. \& R. Agrawal (1995). Mining generalized association rules. In Proceedings of the 21th International Conference on Very Large Data Bases, VLDB 1995, pp. 407-419. $2,33,35,37,39,92$

Srikant, R. \& R. Agrawal (1997). Mining generalized association rules. Future Generation Computer Systems 13(2/3), 161-180. Disponível em: http://citeseer.nj.nec.com/ srikant95mining.html [14/04/2004]. 34, 65, 92

Srikant, R. (2001). Association rules: Past, present and future. ICCS 2001 International Workshop on Concept Lattice-based theory, methods and tools for Knowledge Discovery in Databases. Invited Talk. Disponível em: http://www.almaden.ibm.com/cs/people/ srikant/talks/assoc.pdf [19/09/2003]. 34

Sriphaew, K. \& T. Theeramunkong (2004). Fast algorithms for mining generalized frequent patterns of generalized association rules. IEICE Transactions on Information $\mathcal{G}$ Systems E87-D(3), 761-770. 2, 33, 34, 40 
Tamir, R. \& Y. Singer (2006). On a confidence gain measure for association rule discovery and scoring. The VLDB Journal - The International Journal on Very Large Data Bases 15(1), 40-52. 21

Taniar, D. (2007). Research And Trends in Data Mining Technologies And Applications (Advances in Data Warehousing and Mining Series). Idea Group Publishing. 1

Tan, P.-N., V. Kumar, \& J. Srivastava (2004). Selecting the right objective measure for association analysis. Information Systems 29(4), 293-313. 21, 23, 25, 29, 103, 104, 105

Tan, P.-N. \& V. Kumar (2000). Interestingness measures for association patterns: A perspective. In 6th ACM SIGKDD International Conference on Knowledge Discovery and Data Mining, KDD 2000, pp. 9p. Disponível em: http://www.cas.mcmaster.ca/ 〜bruha/kdd2000/kddrep.html [22/07/2004]. 21, 23, 29

Tan, P.-N., M. Steinbach, \& V. Kumar (2005). Association analysis: Basic concepts and algorithms. In Introduction to Data Mining, Capítulo 6, pp. 327-414. Addison-Wesley. 27,103

Techapichetvanich, K. \& A. Datta (2005). VisAR: A new technique for visualizing mined association rules. In First International Conference on Advanced Data Mining and Applications, ADMA 2005, Volume 3584 of Lecture Notes in Artificial Intelligence, pp. 88-95. 22

Thakur, R. S., R. C. Jain, \& K. R. Pardasani (2006). Mining level-crossing association rules from large databases. Journal of Computer Science 2(1), 76-81. 2, 40

Toivonen, H., M. Klemettinen, P. Ronkainen, K. Hätönen, \& H. Mannila (1995). Pruning and grouping discovered association rules. Workshop Notes of the ECML'95 Workshop on Statistics, Machine Learning, and Knowledge Discovery in Databases, 4752, MLnet. Disponível em: http://citeseer.ist.psu.edu/toivonen95pruning.html [29/04/2004]. 21, 22

Tuzhilin, A. \& B. Liu (2002). Querying multiple sets of discovered rules. In Proceedings of the Eighth ACM SIGKDD International Conference on Knowledge Discovery and Data Mining, KDD 2002, pp. 52-60. ACM Press. 20, 45

van Rijsbergen, C. J. (1979). Automatic classification. In Information Retrieval (Second Edition ed.)., Capítulo 3. London: Butterworths. Online Version. 27

Webb, G. I. (1995). OPUS: An efficient admissible algorithm for unordered search. Journal of Artificial Intelligence Research 3, 431-465. Disponível em: http://citeseer.nj . nec.com/35589.html [12/04/2004]. 17, 18 
Weber, I. (1998). On pruning strategies for discovery of generalized and quantitative association rules. In I. L. Bing, W. Hsu, \& W. Ke (Eds.), Proceedings Knowledge Discovery and Data Mining Workshop, PRICAI 1998. 8p. Disponível em: http: //citeseer.nj.nec.com/25197.html [13/07/2004]. 2, 39

Weiss, S. M. \& N. Indurkhya (1998). Predictive data mining: A pratical guide. Morgan Kaufmann Publishers Inc. 8, 11, 12, 13

Wong, P. C., P. Whitney, \& J. Thomas (1999). Visualizing association rules for text mining. In G. Wills \& D. Keim (Eds.), Proceedings of IEEE Information Visualization, INFOVIS 1999, pp. 120-123. Disponível em: http://citeseer.ist.psu.edu/ wong99visualizing.html [22/07/2204]. 23

Yang, L. (2005). Pruning and visualizing generalized association rules in parallel coordinates. IEEE Transactions on Knowledge and Data Engineering 17(1), 60-70. 16, 22, 35,45

Yao, Y. Y. \& N. Zhong (1999). An analysis of quantitative measures associated with rules. In Proceedings of the Third Pacific-Asia Conference on Methodologies for Knowledge Discovery and Data Mining, PAKDD 1999, London, UK, pp. 479-488. Springer-Verlag. 30

Yen, S.-J. \& A. Chen (2001). A graph-based approach for discovering various types of association rules. IEEE Transactions on Knowledge and Data Engineering 13(5), 839-845. 2, 39

Yen, S.-J. (2000). Mining generalized multiple-level association rules. In Proceedings of the 4th European Conference on Principles of Data Mining and Knowledge Discovery, PKDD 2000, Volume 1910 of Lecture Notes in Artificial Intelligence, pp. 679-684. Springer-Verlag. 2, 39

Yule, G. U. (1912). On the methods of measuring association between two attributes. Journal of the Royal Statistical Society 75(6), 579-652. 30

Zaki, M. J. (2000). Generating non-redundant association rules. In Proceedings of the 6th ACM SIGKDD International Conference on Knowledge Discovery and Data Mining, KDD 2000, pp. 34-43. ACM Press. 21, 45

Zaki, M. \& C. Hsiao (2002). Charm: An efficient algorithm for closed association rule mining. In R. Grossman, J. Han, V. Kumar, H. Mannila, \& R. Motwani (Eds.), 2nd SIAM International Conference on Data Mining, pp. 17p. Disponível em: http://www. siam.org/meetings/sdm02/proceedings/sdm02-27.pdf [05/12/2002]. 17 
Zhang, C. \& S. Zhang (2002). Association rule mining: Models and algorithms, Volume 2307 of Lecture Notes in Artificial Intelligence. Springer. 16, 17

Zheng, Z., R. Kohavi, \& L. Mason (2001). Real world performance of association rule algorithms. In F. Provost \& R. Srikant (Eds.), Proceedings of the 7th ACM SIGKDD International Conference on Knowledge Discovery and Data Mining, pp. 401-406. ACM Press. Disponível em: http://doi.acm.org/10.1145/502512.502572 [12/04/2004]. 13 Zhou, H., B. Ruan, J. Zhu, Y. Zhu, \& B. Shi (2001). ARMiner: A data mining tool based on association rules. In X. S. Wang, G. Yu, \& H. Lu (Eds.), The Second International Conference on Web-Age Information Management, WAIM 2001, Volume 2118 of Lecture Notes in Computer Science, pp. 114-121. Springer-Verlag. 2, 39 